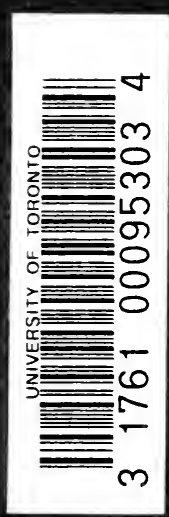




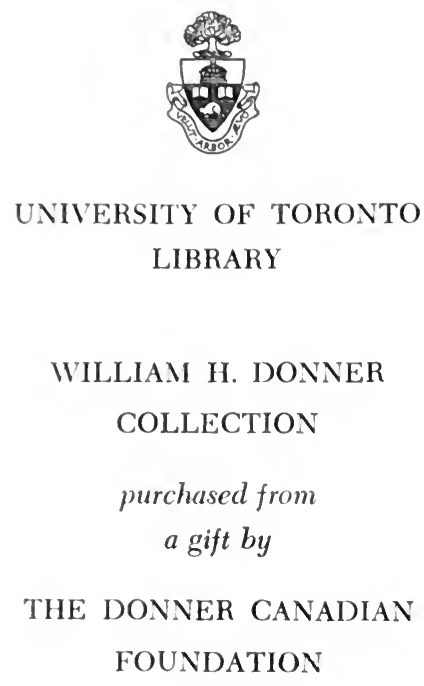




$$
\text { . }
$$


1 
Digitized by the Internet Archive in 2008 with funding from Microsoft Corporation 


\section{Die Lehre der Upanishaden}

und die Anfänge des Buddhismus 



\title{
Die Lehre der Upanishaden und \\ die Anfänge des Buddhismus
}

\author{
Von \\ Hermann Oldenberg
}

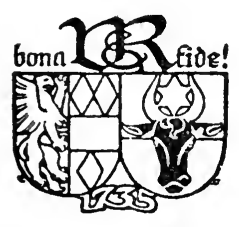

Göttingen

Vandenhoeck \& Ruprecht

1915 
Übersetzungsrecht vorbehalten.

Copyright 1915 bj Vandenhoeck \& Ruprecht, Göttingen.

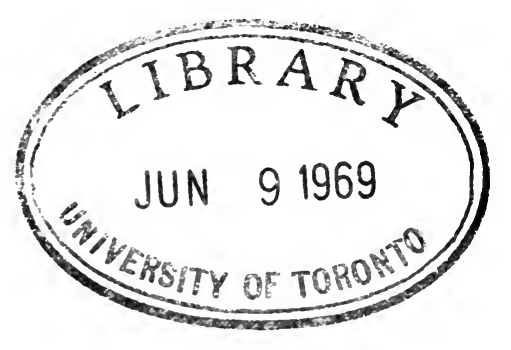

Gedrakt bei Hubert Co, G. $m$ b. H. in Göttingen. 


\section{Inhaltsverzeichnis.}

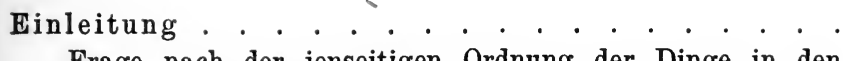

Frage nach der jenseitigen Ordnung der Dinge in den $1-35$ älteren Upanishaden, den jüngeren (Sāmkhya) und dem Buddhismus S. 1.

Land und Volk. Die Brahmanenkaste . . . . . . . . Chronologisches. Geographisches S. 3. Die Rasse. Kastenwesen S. 4. Brahmanenkaste S. 4 . Der Brahmanenschüler. Sein Verhältnis zu seinem Wissen S. 6. Des Brahmanen Wissensstolz S. 9.

Die Opferwissenschaft . . . . . . . . . . . . . .

Vorgeschichtlicher Hintergrund S. 10. Die vedischen Götter S. 12. Persönliche und unpersönliche Wesenheiten S. 13. Die Brahmaṇatexte S.15. Die Zaubermächte im Opfer S. 15. Potenzen in der Natur, in der menschlichen Persönlichkeit, im Veda S. 18. Stil des darauf gerichteten Denkens S. 20. Ordnungen unter jenen Potenzen S. 22. Tod und Jenseits

Das Jenseitsproblem; Mischung älterer und jüngerer Elemente S. 26. Der Wiedertod S. 27. Karman S. 28. Unsterblichkeit, Erlösung S. 31.

Erstes Kapitel. Die älteren Upanishaden. $36-201$

Kultische Wirkung des Gedankens, der „Verehrung“" S. 37. Henotheismus der unpersönlichen Weltmächte S. 38. Richtung des Denkens auf Einheit S. 39. Richtung der Wünsche auf Einheit S. 41. Mystik S. 43.

Das Brahman .

$10-26$

$3-10$

$26-35$

Verschiedene Namen für das Allwesen S. 44. Das Brahman, sein alter Begriff S. 45. Brahman und Kshatra S. 48. Verwandte außerindische Vorstellungen S. 49. Aufsteigen des Brahman zu höchster Geltung S. 50.

Der Ātman

Ātman und Atem S. 52. Der Ātman das Selbst S. 52. Der universelle Ātman S. 54 . 
Brahman und Ātman identifiziert

Seite

Der Prosahymnus des Sāṇ̃ilya S. 57.

Das Absolute und sein Verhältnis zur Welt

Das Problem des Einen und der Vielheit S. 59. Das Eine all belebend S. 61. Positive und negative Ausdrücke. Das „Nein Nein" S. 62. Das Eine allbelebend S. 65. Unendlich groß und onendlich klein S. 71. Der innere Lenker, Ursprung der Werte S. 74. Der.Weltschöpfer S. 78. Neben dem Einen auch der Vielheit Realität verbleibend S. 84. Identität des Einen und der Vielheit S. 86. Die Vielheit für Schein erklärt? S. 89.

Das Absolute in sich. Persönlichkeit oder Unpersönlichkeit. Das Absolute in der Welt nicht aufgehend S. 96. Unbestimmtheit der Alternative von Persönlichkeit und Unpersönlichkeit S. 100. Unpersönliche Züge S. 101. Persönliche Züge S. 103.

Seelenwanderung. Karman . . . . . . . . . . . . . 105-115

Verschiedene Formen der Seelenwanderungslehre S. 105. Das Karman, moralische Vergeltung S. 108.

Der Wert des Daseins . . . . . . . . . . . . . . 115-124

Die Welt bewertet als vom Brahman durchdrungen S. 115.

Die Welt bewertet als vom Brahman verschieden, Pessimismus S. 116. Der Tod und die andern Übel S. 117. Charakter des indischen Pessimismus S. 124.

Die Erlösung . . . . . . . . . . . . . . . . . .

Verhältnis des universellen und individuellen Selbst S. 124. Erlösung durch Wissen, nicht durch Werke S. 129. Das Absolutum wißbar? S. 131. Das Nichtbegehren S. 134. Wesen des Erlösungsvorganges S. 135. Das Erdendasein des Erlösten. Śramanatum S. 137. Anfänge des Yoga S. 141. Egoismus des Erlösungsideals S. 142. Tod des Erlösten S. 143. Bedenken gegen den Charakter der Unsterblichkeitshoffnung S. 146.

Die literarische Form der Upanishaden

Vielheit der Upanishaden. Zugehörigkeit zu den „Wald-

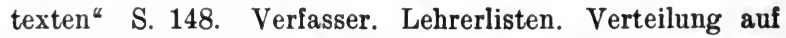
die Vedaschulen S. 149. Bestehen aus kurzen Textstücken S. 151. Größere Kompositionen S. 153. Upanishad im engeren Sinne (Text der "Verehrung") S. 155. Dialoge S. 160. Ihre äuBere Umrahmung, auftretende Personen S. 161. Hervortreten fürstlicher Persönlichkeiten? S. 166. Nichtmenschliche Wesen, S. 168. Charakteristik der auf- 
tretenden Denker S. 170. Technik des Dialogs S. 171.

Seite

Wesen dieser Prosa S. 178. Einzelne Schlagworte S. 181.

Gleichnisse S. 182. Rätsel S. 186. Verse S. 187.

Rückblick . . . . . . . . . . . . . . . . . . .

Die Upanishaden zwischen alter und neuerer Zeit stehend

S. 191. Das All-Eine und die Welt: Bedeutung ihrer Gegenüberstellung S. 192. Verbältnis zu Kant, zur christlichen Mystik S. 195. Brahmanentum und Śramanatum S. 200.

Zweites Kapitel. Die jüngeren Upanishaden und die Anfänge von Sāmkhya und Yoga . . . . . . . Die jüngeren Upanishaden S. 202. Kāțhaka Upanishad, der Naciketasdialog S. 203. Die Śvetāśvatara Up., Maitrāyaṇa Up. S. 205.

Die Anfänge des Sāmkhyasystems . . . . . . . . . . 206-258

Verhältnis zur älteren Spekulation im Allgemeinen S. 206. Der Name Sāmkhya S. 208. Kapila und andre Philosophen S. 208. Die Upanishaden' und das Epos als Quellen S. 209. Der Dualismus S. 211. Das materielle Grundprinzip (Prakṛti) S. 212. Die drei Gunas S 214. Das geistige Prinzip (Purusha) S. 223. Die Entfaltungen der Prakṛti S. 225. Purusha und Prakrti S. 233. Die Bindung des Purusha S. 238. Die Erlösung S. 243.

Rückblick und Ausblick auf die. weitere Entwicklung S. 246. Das Zustandekommen geistigen Geschehens S. 247; des Leidens S. 249. Vielheit der Purushas S. 253. Die Erlösung in der jüngeren Gestalt der Lehre; die Prakṛti ihr Wirken für den Purusha einstellend S. 256.

Der Yoga . . . . . . . . . . . . . . . . . . .

Anfänge des Yoga S. 258. Atemdisziplin, Körperhaltung, Beherrschung des Vorstellungslaufes S. 260. Die Versenkungen S. 263. Früchte des Yoga: Wunderkräfte S. 265, Erlösung S. 267. Theoretische Grundlagen, Verhältnis zum Sāmkhya S. 268. Nirvāṇa S. 270. Stellung des Yoga in der indischen Geistesentwicklung S. 272.

Ein persönlicher Gott. Die Śvetāśvatara Upanishad . . . . 273-281

Drittes Kapitel. Die Anfänge des Buddhismus. . . 282-340 Brahmanismus and Buddhismus S. 282. Geographisches Verhältnis des Buddhismus zu den Upanishaden S. 283. Chronologisches Verhältnis zu den älteren Upanishaden; geschichtliche Fortschritte S. 284. Chronologisches Ver- 
hältnis $\mathrm{zu}$ den jüngeren Upanishaden S. 288. Geistige Seite Umgebungen des Buddha, Sophistik, Skepsis S. 290. Buddha lehnt rein theoretisches Wissen ab S. 292. Einflüsse des Sāmkhya? Buddhistische Zeugnisse über dieses S. 294. Innere Zusammenhänge vorhanden? S. 296. Der buddhistische Dualismus von "Gestaltetem" und "Ungestaltetem " S. 296. Stellung zur Idee des Ātman S. 298. Herrschaft der Kausalität in der Welt S. 300. Überweltliches Sein S. 303. Das Nirvāṇa S.311. Die "Unterlagen" (upadhi) S. 312. Verhältnis von Welt und Überweltlichem S. 313. Das Sāmkhya als Vorstufe dieses buddhistischen Dualismus S. 315. Verhältnis des Buddhismus zum Yoga S. 319. Selbständige Schöpfungen des Buddhismus: auf dem Gebiet der Lehre S. 331. Auf dem Gebiet des geistlichen Lebens S. 333. Die Gestalt des Buddha S. 335.

Anmerkungen . . . . . . . . . . . . . . . . . 341-360 Register. . . . . . . . . . . . . . 361-366

Die Anmerkungen, die es wünschenswert schien dem Leser zugleich mit dem Text vorzuführen, sind unter der Seite, andre am Schluß des Bandes (S. 341 ff.) gegeben. Die ersteren sind mit ${ }^{1}$ ), ${ }^{2}$ ) usw., die letzteren mit ${ }^{1},{ }^{2}$ usw. bezeichnet.

Stellen des Mahābhārata sind nach der von Deussen ( „Vier philosophische Texte des Mah. ") angenommenen Zählweise zitiert.

In indischen Worten ist $\mathrm{c}$ wie tsch, $\mathrm{j}$ wie dsch auszusprechen. 


\section{Einleitung.}

Die Frage nach einer jenseitigen Ordnung der Dinge hinter oder über dem Diesseits, das damit so eng verbundene Problem des Todes und dessen, was nach dem Tode folgt, hat die Denker Indiens schon in sehr alter Zeit auf das ernstlichste beschäftigt. Von der Geschichte dieser Gedanken sollen hier einige Abschnitte dargestellt werden, die eine natürliche Einheit bilden.

Sie heben da an, wo das Chaos altertümlicher, großenteils aus primitiver Vergangenheit stammender Vorstellungen vom Weltdasein und Geschehen sich lichtet, um der mächtigen Idee des Brahman, des All-Einen die Herrschaft einzuräumen, und wo neben die Hoffnungen auf freudenreiches Fortleben nach dem Tode in der Gemeinschaft göttlicher Weltherren die alles überfliegende Sehnsucht tritt nach Eingehen in den stillen Frieden der Ewigkeit.

Dies Stadium der Entwicklung liegt in den älteren jener den Veden zugerechneten Texte vor, die man "Upanishaden" nennt.

Jüngere Upanishaden schließen sich an. Sie zeigen dieselben Gedanken in fortschreitender Durchbildung. Aufmerksamer werden die Fragen beachtet, die sich inbezug auf das Verhältnis des Brahman zu der dem Auge erscheinenden Welt aufdrängen. Hier begegnen wir der ältesten, vedischen Gestalt der Sāmphyyalehre. In ihr hat das philosophische Nachdenken der Inder zum ersten Mal ein System geschaffen. Dies System wurde später, als die Zeiten des vedischen Altertums längst abgelaufen waren, von der erstarkten, verfeinerten Wissenschaft Indiens, die 
wie in Pāninini's Grammatik komplizierteste Gedankenmassen scharfsinnig und kunstreich darzustellen wußte, in modernere Form gegossen. Neue Motive wurden geschickt eingewebt. So nahm die Sāmkhyalehre ihre, wie man sagen darf, klassische Gestalt an, auf die wenigstens einen Blick zu werfen wir uns nicht versagen werden.

Noch ehe sich aber in engen Kreisen philosophischer Denker die letzterwähnten Vorgänge abspielten, entwickelten sich in andrer Umgebung aus denselben Keimen Gebilde völlig andrer Art. Die Philosopheme gaben eine Grundlage ab stark genug um mächtige religiöse Schöpfungen zu tragen. Buddha erschien und brachte den von Lebensnot und Todesangst Gequälten den Trost seiner Lehre. Er verhieß Erlösung von Leiden und Tod, Eingang in das rätselhafte Jenseits des Nirvana. Es soll zu unsern Aufgaben gehören, die Lehre des ältesten Buddhismus darauf hin zu betrachten, in welchem Zusammenhang sie mit jenen ihr vorangehenden Schöpfungen des Denkens gestanden hat.

Da möge denn unsre Darstellung Halt machen. Sie will die philosophischen Systeme, die sich dann weiter in einer nunmehr zwischen festeren Ufern verlaufenden Bewegung angeschlossen haben, nicht in ihren Bereich ziehen, ebenso wenig wie die späteren Religionen Indiens, die Religionen des Vishnu oder Krishna, des Siva. Auch innerhalb der Grenzen, auf die wir uns beschränken wollen, ist es nicht die Absicht Vollständigkeit zu erstreben. Versucht werden soll vielmehr, die dialektischen Grundmotive, mit denen das alte Denken arbeitete, ihr Ineinandergreifen, ihre Entwicklung zu verstehen. Und auch, die hier herrschenden seelischen Bedürfnisse und Stimmungen nachzufühlen. Die oft bizarren, doch eigenartig ernsten Gestalten der Denker vor Augen zu stellen, die kraftbewußt und entsagungsmutig sich als Sieger gefühlt haben im Ringen darum, vom Jenseits den Schleier zu heben, den Tod zu überwinden.

Kann es gelingen, "unter Büchern und Papier", im Zimmer, in das der blasse Himmel des Nordens hineinsieht, 
Gedanken nachzudenken, die unter indischer Sonnenglut oder den Strömen indischen Regens gedacht sind, nahe den Opferplätzen der Dörfer oder in Asketenhütten unter dem weiten Laubdach mächtiger Bäume? Gedanken, deren Grundlinien sich in einer Vergangenheit herausgearbeitet haben, als von den fremdartig ungestalten Schöpfungen vorgeschichtlicher Phantasie noch so viel lebte und von bedächtig prüfender, nüichtern und klug aufbauender Wissenschaft so wenig? Schwierigkeiten, wie sie schon etwa der Erforscher Platons fühlen wird, treten hier mit ganz anderer Wucht auf. Die bis zu unserm eignen geistigen Dasein führende geschichtliche Kontinuität, welche dort die schon an sich viel geringeren Entfernungen überbrücken hilft, fehlt hier. Wie aus Erdtiefen ausgegraben stehen diese Gedanken unvermittelt vor uns, voll von Rätseln. Und plötzlich scheinen uns wiederum altvertraute Züge aus ihnen entgegenzublicken. Wir dürfen nicht versuchen, ihre Schwächen zu verbergen. Aber an manchem Punkt kann auch ein Gefühl der Ehrfurcht vor ihnen nicht schweigen.

Land und Volk. Die Brahmanenkaste.

Welches ist das Zeitalter, in dem sich die uns beschäftigenden Entwicklungen des Denkens angesponnen haben? Das läßt sich sicher nicht bestimmen, wie ja überhaupt die ältere Chronologie Indiens durchaus dunkel ist. Vermutungsweise Schätzung mag in die Zeiten um den Anfang des ersten vorchristlichen Jahrtausends führen ${ }^{1}$ ). Der geographische Schauplatz dieser Vorgänge liegt, wie sich das aus der Entstehungsgeschichte und der Ausbreitung der vedischen Kultur erklärt, ganz im nördlichen Indien: der Hauptsache nach in den reichen Ländern an den Schwesterströmen Ganges und Yamuna. Doch beginnt die Bewegung bald über den Vereinigungspunkt der beiden Ströme hinaus

1) Vgl. das Nähere unten im Abschnitt tuber den Buddhismus. 
nach Osten zu dringen. Wir dürfen uns in diesen Zeiten die höheren Klassen der bekanntlich von Iran her - vielleicht etwa ein Jahrtausend früher - eingewanderten arischen Inder wohl als noch nicht allzu tief berührt durch Rassenmischung mit den verachteten dunkeln Urbewohnern des Landes denken: noch gegenwärtig haben sich ja an vielen Orten Brahmanen von reinem oder annähernd reinem weißem Typus erhalten. So waren hinsichtlich des Rassencharakters die Brahmanen jenes Altertums ihren Verwandten wohl noch ähnlich: den iranischen Priestern, die vielleicht um dieselbe Zeit die Reform Zarathustras erlebten. Und doch hatte sich die Verschiedenheit des indischen geistigen und geistlichen Wesens rom iranischen offenbar schon damals scharf genug ausgeprägt. Die Natur, das Klima Indiens, die leichte Beherrschung der Urbevölkerung, die Abwesenheit großer geschichtlicher Kämpfe breitete um die Brahmanen eine Atmosphäre ungestörter Ruhe aus. Da gedieh der Hang zum Reflektieren, zur Pflege komplizierten Wissens, zum Spiel einer immer schrankenloser im Ungeheuren und Ungeheuerlichen sich ergehenden Phantasie. Vor allem wirkte dahin auch die Abgeschlossenheit der Kaste. Denn schon damals hatten die Ordnungen der Kaste begonnen, das Dasein Indiens zu beherrschen. Und wenn die Gedanken, von denen wir sprechen werden, auch ihrer Natur nach die Tendenz hatten, sich von Kastenschranken unabhängig zu machen, so konnte dieser freiheitliche Zug doch nicht schon von Anfang an seine Wirkung beweisen. Ihren Ausgangspunkt hatte die Bewegung, wie sich in ihr deutlich zu erkennen gibt, eben im Schoß der Brahmanenkaste - unter diesen Männern, die sich dessen bewußt waren, im Anfang der Dinge aus dem Haupt des Purusha, des tausendköpfigen, tausendfüßigen Urwesens, hervorgegangen zu sein: so trugen sie ihre geistliche Würde in sich als ein von Geburt her ihnen gehöriges Erbteil, als ein Stück ihrer innersten Natur. Mit der heiligen Schnur, dem Abzeichen der Kaste, behangen gingen sie einher, an ihrer seltsamen Haartracht - 
der rechts getragenen Haarmuschel oder den drei Haarmuscheln oder den eigenartig geordneten Haarsträhnen und ähnlichen Absonderlichkeiten - erkennbar als Glieder des einen oder anderen jener großen Brahmanengeschlechter, deren Ahnherren die Hymnen des Rigveda "geschaut" hatten. Unzweifelhaft dürfen wir uns die Angehörigen dieser Kaste schon für die Zeiten, von denen hier die Rede ist, nicht als eine in Lebensstellung und Interessen vollkommen gleichartige Masse vorstellen. Da waren in Wohlleben hausende, reiche Herren. So der Brahmane, den ein Text sagen läßt: "An Gold habe ich mein Teil, an Kühen, Rossen, Sklavinnen, an Decken und Gewändern" - oder ein andrer, zu dem man spricht: "Vieles von allerlei Art wird in deinem Hause gesehen: der rollende Maultierwagen, die Sklavin, der goldne Halsschmuck; du issest Speise und schaust, was dir lieb ist." Aber es gab auch arme Schlucker, wie jenen Ushasti, der im hagelverwüsteten Land mit seinem Weib in bitterer Not umherwandert und sich bei einem reichen Mann etwas von dem Reisschleim erbettelt, den er jenen essen sieht. Es gab Brahmanen von durchaus weltlicher Art, Hofmänner, Großgrundbesitzer. Aber doch trat unter den Angehörigen der Kaste geistliches Wesen - das haben wir allen Grund anzunehmen - immer noch stark, vielleicht überwiegend hervor: der Typus jener Brahmanen, die so dachten, wie ein alter Text es ausspricht: „Ihren Weg gehen die Wasser, geht die Sonne, geht der Mond, gehen die Sterne. Wie wenn diese Gottheiten ihren Weg nicht gingen, ihr Werk nicht täten: so ist ein Brahmane an jenem Tag, an dem er nicht seine Textlektion studiert" - der Typus der Brahmanen von altem Schrot und Korn, welche Jahrhunderte später ein buddhistischer Poet schildert:

„Die aus gelehrtem Haus stammen, verschwistert

heilger Wissenschaft" -

wie denn noch heute die Brahmanen entfernt nicht ausgestorben sind, unter denen die Traditionen altehrwürdigen Lehrens und Lernens sich unangetastet erhalten haben. 
So war denn erst recht in jenem Altertum die Bemühung um das Wissen die große Angelegenheit dieses Philosophenstandes, wie später ein Grieche die Brahmanen genannt hat. Wohl wurden unter ihnen auch die geheimen Künste ekstatischer Erregungen geübt, übernatürliche Kräfte und die Gemeinschaft von Göttern und Geistern erstrebt durch Fasten, Erhitzung und sonstige Kasteiungen. Aber all das trat zurück hinter der Beschäftigung mit der Wissenschaft des Veda und des Opfers.

Der gelehrte geistliche Herr tat sich als Lehrer auf. Das Ziel seines Ehrgeizes zeigt der Vers, den er betete:
„Wie zum Meere der Flüsse Lauf
Von Ost und West zusammenströmt, Möge der Freunde, der Schüler Schar
Mir zuströmen von Ost und West."

Im Hause eines solchen Lehrers verlebte der Brahmane seine Jugend, lange Jahre. Die Pflicht des Bettelns und harten Dienstes, der dort dem Schüler oblag, die gewollte Dürftigkeit seines äußern Daseins stand in scharfem Kontrast zur Glorie jenes geistigen Besitzes, den zu erwerben er sich allem willig unterwarf.

Damals erschien das Verhältnis des Menschen zu seinem Wissen in anderm Licht, vollzog sich darum auch der Erwerb des Wissens in sehr andrer Form, als in unsrer mit Wissen übersättigten, das Wissen sachlich und geschäftlich handhabenden Zeit. Uralte Anschauungen griffen hier ein. Wie der Name einer Wesenheit, ihr Bild oder ihr Schatten, so steht auch das Wissen von ihr zu ihr selbst in engster mystischer Beziehung. Noch in anderm Sinn als in dem unsern gilt hier das Wort, daß Wissen Macht ist: nicht, wie wir es verstehen,' indem es zu' richtigem Handeln befähigt, sondern direkt, indem es geheimnisvollen Konnex zwischen dem Wissenden und dem Gewußten herstellt ${ }^{1}$ ), etwa eine

1) Beispielsweise, wo über die Bewegung der Sonne die Lehre aufgestellt wird: "Sie (die Sonne) geht in Wahrheit nie unter", fährt der Text fort: „Nie geht unter, zu ihrer (der Sonne) Gemeinschaft und Gleich- 
unmittelbare Zaubermacht über das Objekt des Wissens in sich schließt, während andrerseits dies Objekt für unzureichendes, falsches Wissen sich am Wissenden rächen mag. Nicht jeder ist fähig, jedes Wissen aufzunehmen - es ist hier nicht an die geistige Fähigkeit des Verstehens gedacht, sondern an mystisches Ausgerüstetsein zum Beherbergen der Erkenntnis und an Geschütztheit vor den ihr innewohnenden bedenklichen Kräften. So bewegt sich Lehren und Lernen in einer sakramentalen, mit Zauber gesättigten Atmosphäre. Die Scheu vor Unheimlichem liegt in der Luft. Aber wenn es gelingt alle Gefahren zu beschwören, erlangt man dafür auch als Wissender unabsehbare Macht.

„Der Schüler geht, entflammt vom Brennholzscheite ${ }^{1}$ ),

In schwarzes Fell gehüllt, geweiht, langbärtig.

Von Meer zu Meer schweift er im $\mathrm{Nu}$, die Welten

Bedeckt er mit der Hand, enthüllt sie wieder."

Mit Zauberriten tritt er seine Lehrzeit an. Keuschheit ist strenge Pflicht - nicht sittliche Pflicht in unserm Sinn, sondern ein Element des Zaubers - für den, der sich im geweihten Zustande des „Brahmanwandels“ d. h. der Schülerschaft befindet. Mancherlei besondere Observanzen werden vor dem Lernen einzelner von eigenartigen Kräften erfüllter Texte beobachtet. Wer die Verse studieren will, die Macht über Wolken und Regen verleihen, muß schwarze Kleider tragen - der Farbe des Gewölks entsprechend - und schwarze Nahrung genießen. Wer durch einen andern Text sich in eine Art Bundesgenossenschaft mit der Sonne zu versetzen wünscht, darf nichts zwischen sich und die Sonne kommen lassen außer Bäumen und Schutzhütten. Die Kenntnis derartiger Texte und überhaupt alles Wissen, das von besonders gefährlicher Heiligkeit durchtränkt ist, wird nicht im Dorf erworben; die dabei in Aktion versetzten Mächte könnten

artigkeit, zum Wohnen in ihrer Welt gelangt, wer solches weiß." Aitareya Brāhmaṇa III, 44.

1) Das Holzscheit, das er täglich auf das Feuer seines Lehrers legt, teilt ihm selbst heilige Glut mit. 
dem menschlichen Alltagsleben Schaden zufügen. Sondern nach einer Zeit des Fastens und Schweigens geht man zum Wald hinaus, „zu einer reinen Stätte in nordöstlicher Richtung ${ }^{1}$ ), die von Osten her beleuchtet ist." Dort empfängt in dem Kreise, der durch einen Wasserguß geweiht ist, der Schüler, der die Augen schließt oder dessen Augen verbunden sind, die mit Zauberkraft gesättigte Kunde. Ein Besitz, dem er von lange her mit Erwartung und heißem Verlangen entgegengesehen hat. „Zu den Knaben sagen die Mütter, wenn sie ihnen die Brust geben: wachst heran, ihr Söhnchen, zu Leuten, die das Śakvarīgelübde zu vollbringen wissen."

Endlich ist dann für den herangewachsenen Brahmanen die Zeit gekommen das feierliche Bad zu nehmen: das wäscht die Kraft oder Substanz des „Brahmanwandels“ von ihm ab und beendet damit die Lehrzeit, so daß er nun "von Kühen oder von einem fruchttragenden Baum her" aufbrechend in das heimatliche Dorf zurückkehren kann. Ein Text zeichnet das Bild eines Schülers, der sich nach diesem Ende sehnt. "Zwölf Jahre hatte er seine (des Lehrers) Opferfeuer bedient. Der Lehrer aber ließ die andern Schüler ziehen, doch ihn ließ er nicht ziehen. Da sprach zu dem Lehrer dessen Gattin: ,Der Schüler hat sich heiß abgequält. Er hat die Feuer gut bedient. Sieh zu, daß die Feuer nicht an dir vorbei ihm die Lehre mitteilen. Teile du sie ihm mit.' Er aber, ohne sie ihm mitzuteilen, zog über Land. Da wurde der Schüler krank und wollte nicht essen" - worauf die Feuer, wie es die Frau vorhergesehen hatte, selbst ihn belehren: und nun erglänzt sein Antlitz als das eines Wissenden. Ein andres Bild eines solchen zum Abschluß der Lehrzeit gelangten Schülers. Er gehört einer Familie an, in der Niemand ungelehrt bleiben mag. Zwölfjährig ist er ausgezogen zu studieren. Vierundzwanzigjährig „kommt er

1) Der Nordosten ist glückbringend, wohl weil er die Kräfte des Ostens, also des Sonnenaufgangs, und des Nordens, dem die Sonne in der Zeit der zunehmenden Tage zustrebt, in sich vereinigt. 
wieder, nachdem er alle Veden durchstudiert hat, hochmütig, sich gelehrt dünkend, aufgeblasen"...

Wissensverlangen und Wissensstolz, wie sie in diesen Bildern brahmanischen Schülertums hervortreten, begleiten den Brahmanen dann durch sein Leben. Immer handelt es sich um die einzige Wissenschaft, die es damals in Indien gibt: um Kunde und Verständnis des Opfers und der Opfertexte. Die "Wildnisse des Opfers" reichen durch Hunderte von Tagereisen, und wer sich als Unwissender da hinein wagt, dem geht es wie dem Reisenden, den im Wald Hunger und Durst oder böse Geister angreifen. Man ist gewohnt - uns mutet das oft kleinlich und schlimmer als kleinlich an - Vorfälle des täglichen Lebens, irgend einen Erfolg, ein Mißgeschick, in Verbindung mit richtigem oder falschem Opfern zu bringen. Bhăllaveya hat zwei Verse, die einander entsprechen sollen, in verschiedenen Versmaßen statt im gleichen Maß ausgewählt. Er fällt vom Wagen und bricht sich den Arm. Er ist klug genug die Ursache des Unfalls alsbald einzusehen. Dem Yājnavalkya sagt ein priesterlicher Gegner voraus, daß wegen seiner Weise einen bestimmten Ritus auszuführen der Lebensatem ihn verlassen wird. Das war freilich einem Opferkünstler wie Yājnavalkya gegenüber wenig am Platz. „Er blickte auf seine Arme und sagte: ,Diese Arme sind altersgrau geworden. Wo ist das Wort des Brahmanen geblieben?" " Aber nicht nur in solchen Zauberwirkungen bewährt sich die Kraft des Wissens. Es handelt sich auch um Realitäten, an denen selbst der Unfrömmste nicht zweifeln kann. Dem, der im Ruf des Wissens steht, erwächst überall Ehre und Gewinn; seine Tätigkeit als Opferpriester wird ihm von reichen Opferherren verschwenderisch gelohnt. Die Rivalitäten, die da unausbleiblich entstehen, machen sich in Disputationen über Opferweisheit Luft. Die finden am liebsten vor möglichst zahlreichem Publikum statt - ohne Zeugen streiten sich Sīdras - ; oft wird da eine höchst kräftige, durchaus persönliche Sprache geführt. Das Vorspiel jener Disputationen, denen wir be- 
gegnen werden, von den Geheimnissen des all-einen Wesens. Übrigens sind es nicht allein menschliche Wissende, die mit einander streiten oder einander in den Besitz des kostbaren Wissensschatzes setzen. Wie ein im Augenblick wieder verwehender Hauch von Märchenpoesie klingt es in die Prosa der priesterlichen Pedanten hinein, wenn man liest, wie zu Keśin Dārbhya der goldne Vogel geflogen kommt. Ein gelehrter Vogel. Er sagt: „Du verstehst die Opferweihe nicht. Die verstehe ich und will sie dir erklären“...

\section{Die Opferwissenschaft.}

Wie diese Wissenden, ähnlich sieht ihr Wissen aus.

Die Wissenschaft vom Opfer, die in der Folge viele ihrer Charakterzüge auf die Lehre vom All-Einen vererbt hat, steht ihrerseits, wie schon berührt wurde, in engem $\mathrm{Zu}$ sammenhang mit dem Denken einer sehr fernen Vergangenheit.

Deren Vorstellungen von Dingen und Geschehen waren tief verschieden von dem, was dem modernen Menschen als wirklich, ja auch nur als vorstellbar erscheint. Man hat - mit einem Ausdruck, über dessen vollkommene Berechtigung ich hier nicht streite - von "prälogischer" Geistesverfassung gesprochen ${ }^{1}$ ). Natürlich soll nicht gesagt werden, daß sich die Theologie oder Metaphysik der Brahmanen selbst noch auf diesem prälogischen Niveau hält. Aber sie ist erst auf dem Wege sich von ihm zu entfernen und hat nicht in jeder ihrer Richtungen auf diesem Weg sehr weite Strecken zurückgelegt. Es gibt Stellen, wo sie nicht viel mehr tut, als jene Denkweise alter Vergangenheit auf die Materialien des Opfers, mit denen sie selbst es zu tun hat, anwenden, den primitiven Vorstellungsmassen ein etwas verändertes, etwas modernisiertes sakrifikales Gewand anziehen.

1) Ich verweise namentlich auf das geistvolle Werk von L. LéryBruhl, Les fonctions mentales dans les sociêtés inférieures. Paris 1910. 
Jene vorgeschichtliche Gedankenwelt lernen wir gegenwärtig in ihren noch heute erhaltenen Überresten immer besser kennen. Personen und Dinge - die einen von den andern mehr für uns als für die Alten unterschieden - weisen da beständig Eigenschaften auf und entfalten Wirkungen, die nur eine durchaus, anders orientierte Vorstellungsweise als die unsre ihnen beilegen kann. Soviel begreift sich ja leicht, daß man das Herz des Bären oder Raubvogels ißt, um mutig zu werden, daß man sich Gehirnsubstanz eines klugen Menschen auf die Stirn schmiert, um Klugheit zu erlangen: in jenem Herzen oder Gehirn wohnt die Wesenheit des Muts, der Klugheit; die nimmt man so in sich auf. Auch solche Zusammengehörigkeiten sind begreiflich, wie die mystische Identität, die etwa zwischen dem Schatten eines Wesens oder auch seiner Fußspur, seinem Namen und andererseits ihm selbst vorgestellt wird, so daß, wer das eine faßt, das andere hält. Oder Wirkungen wie die, daß eine vom Zauberer in der rechten Weise hergestellte Nachahmung von Regen den Regen selbst herbeiführt. Das Eine bedeutet das Andre, ist das Andre. Oft aber kann es uns nur auf weiten, ungewissen Umwegen oder überhaupt nicht gelingen, Anhaltspunkte für unser Verständnis zu finden; die verbindenden Fäden sind verborgen, zuweilen hoffnungslos versteckt. Schneiden sich die Frauen der auf der Elefantenjagd befindlichen Männer das Haar, werden den Männern die gefangenen Elefanten entkommen (Laos, Indochina). Durch ein Bild der Königin Victoria im Besitz eines Missionars wurde eine Epidemie hervorgerufen (Neuguinea) ${ }^{1}$ ). Solchem Glauben an bizarre Wesenszusammenhänge und Wirkungsweisen außerhalb alles uns Denkbaren kommt intensivste Lebendigkeit zu. Mit vollkommner Selbstverständlichkeit leuchtet es den Gläubigen ein, daß ein Ding zugleich es

1) Beruht es allein auf dem Sophisma post hoc, ergo propter hoc, daß man dem Bilde diese Wirkung zuschrieb? Lévy-Bruhl a. a. 0.74 gibt Gründe dagegen. 
selbst ist und etwas - nach unsrer Auffassung - vollkommen verschiedenes. Hier begegnet ein Stamm, dessen Angehörigen nichts gewisser ist, als daß sie Araras sind. Dort trifft man auf die Überzeugung, daß jedes Individuum gleichzeitig der und der Mann oder die und die Frau ist und der und der Vorfahr aus der fabelhaften Vergangenheit, daß es aber auch zugleich der Totem ist, die Wesenheit der Tier- oder Pflanzenart besitzt, deren Namen es trägt. Der sich selbst noch nicht in starker Individualität von seiner Umgebung sondernde Geist leiht auch den Wesen der Außenwelt keine feste und individuelle Existenz. Allgemeine, in's Unbestimmte wirkende Kräfte oder Fluida füllen das Weltdasein mit ihrer einherströmenden grotesken oder kapriziösen Bewegung, in der das eine haltlos in das andere hinüber schwankt, taumelt, zerfließt. Gewiß kein sich seiner selbst bewußter Pantheismus. Aber ein prähistorisches Vorspiel des Pantheismus ist dies in der Tat.

All das kann hier nur in der Kürze angedeutet werden, um von diesem Hintergrund der brahmanischen Opferspekulation eine Vorstellung zu geben. Nur sehr allmählich für die Zeiten, von denen wir sprechen werden, liegt es noch größtenteils in der Zukunft - zerstreuen sich jene Nebel, lernt man anstatt des imaginären Geschehens das wirkliche sehen. Fürs erste - immer noch lange vor der Entwicklung der brahmanischen Spekulation - haben inmitten jener uralten Vorstellungswelt die Gestalten großer Götter mächtige Geltung gewonnen: menschenähnliche, doch übermenschlich gewaltige Individuen. Die meisten von ihnen sind Verkörperungen von Naturmächten.

Da ist Indra - ursprünglich, scheint es, ein Gewittergott - , der trinklustige Dreinschläger und Feindebezwinger. Agni - das Feuer -, der göttliche Freund und Gast der Menschen. Varuna - in vorgeschichtlicher Zeit, wie man vermuten darf, ein Mondgott - , der Durchschauer und Bestrafer auch verborgenster Sünden. Die wirksamen Mittel, sich der Gnade dieser Götter zu versichern sind, unter ein- 
ander eng zusammengehörig, das Gebet und das Opfer, in welchem - so darf die leitende Idee wenigstens des vedischen Opfers ausgedrückt werden - der Mensch dem Gott gibt, damit dieser ihm wieder gebe, ihn schone und beschütze. Das Opfer prachtvoll und wirksam auszugestalten, kunstvolle Gebete dafür "zu "zimmern": das war das große Werk der "Rishis", der priesterlichen Poeten, die in den Anfangszeiten der indischen Geschichte auftraten. Sie lehrten, mit sinnreichen Hymnen Agni die Stätte bereiten, für Indra den berauschenden Soma pressen und seinen Sieg über den Drachen Vritra feiern, den Zorn Varunas hinwegflehen.

In diesen Göttern beginnt das zuvor im Menschenleben und darum auch im religiösen Wesen noch stark zurücktretende Element der Persönlichkeit seinen Triumph zu feiern.

Freilich keinen unbestrittenen, noch weniger einen endgiltigen Triumph.

Wenn Indra, Agni und ihresgleichen in der Tat im ältesten aller indischen Texte, den Hymnen des Rigveda, durchaus im Vordergrund stehen, so darf man nicht übersehen, daß nach dem Wesen dieser Hymnenpoesie hier von den verschiedenen Richtungen, in denen das religiöse Bedürfnis sich äußert, gerade nur diese des Sichwendens an die Gnade persönlicher Götter zur Geltung kommen kann. Aber doch schon im Rigveda selbst zeigt sich eine beginnende Neigung, die Umrisse jener göttlichen Individualitäten wieder zu verflüchtigen, in ihnen eine Umschleierung zu erkennen, die ein unpersönliches Eines umhüllt:

"Als Indra, Mitra, Varuna und Agni

Benennt man es und als den Himmelsvogel.

Das Eine, vielfach nennen es die Priester.

Agni und Yama, Mātariśvan heißt es".

Und in anderer Weise sieht man die Geltung persönlichen Wesens zurücktreten, wenn man von den Hymnen des Rigveda hinüberblickt in den Yajurveda, den Veda der Opfersprüche. Dort begegnet man beständig priesterlichem 
Tun, das innerhalb des Opfers doch von der Grundidee des Opfers unabhängig die Götter, die Bewerbung um ihre Gnade beiseite läßt und sich dem Prinzip nach vielmehr in der Sphäre vorgöttlicher Anschauungsweise hält. Wenn der Priester im Zusammenhange der Opferverrichtungen einen Feuerbrand ergreift, teilt er dem Feuer seine Wirkung zu, indem er sagt: „Vernichtet ist der böse Feind, vernichtet die Mißgunst." Wenn er auf dem Opferplatz hin oder her zu gehen hat, sagt er: „Dem weiten Luftraum wandle ich nach." Oder in anderen Situationen, an dies oder jenes Gerät, an diese oder jene Opfergabe sich wendend: "Geh zum Himmel; von dort erwecke uns Regen" - "Zwischen schiebe ich dir Himmel und Erde; zwischen schiebe ich den weiten Luftraum". Während also in den Hymnen der Priester die Hilfe der Götter anruft, zeigen ihn diese Opfersprüche fortwährend selbständig mit den Naturmächten schaltend, mit Himmel und Erde hantierend, die bösen Geister mit Feuer verjagend. Neben den großen Opfern stehen dann Massen geringerer Riten für Hochzeit, Totenbestattung, Anlässe aller Art des täglichen Lebens: beständig verfährt da der Priester, oder weist den von ihm beratenen Laien zu verfahren an, ganz in der gleichen Weise, ganz im Stil der vorgeschichtlichen Zeit. Er läßt auf einen Stein treten, wem er Festigkeit mitteilen will; er läßt Fisch essen, wer die im Fisch wohnende Schnelligkeit begehrt; er stellt ein Abbild des Regens her, damit es regne ${ }^{1}$ ). In all dem ist er schlechterdings nicht Diener der Götter; man kann ihn als Zauberer benennen.

Und diese Richtung auf den Zauber statt auf die Götterverehrung zeigt sich weiter im Erstarken, wie dann folgende

1) $\mathrm{DaB}$ da nicht nur alte Riten einfach als überkommener Besitz wiederholt werden, sondern die Motive für die Denkweise der Handelnden noch durchaus lebendig sind, kann nicht bezweifelt werden. Bedürfte es eines Beweises, würden ihn die vielen Fälle ergeben, in denen diese Motive sich in der Produktion evidenter Neubildungen fruchtbar zeigen. Ein Beispiel s. in meiner Religion des Veda S. 481 A. 1. 
Generationen von Brahmanen, welche die Opferordnungen und Gebete fertig vorfinden, an die nunmehr sich als Nächstes darbietende Aufgabe herantreten, dies alles auf ihre Weise zu erklären um ihm so in der Hand des Wissenden die volle Macht zu sichern.

Hier ist der Punkt erreicht, wo wir eben jener brahmanischen Opferwissenschaft begegnen, die als Grundlage und Nährboden der großen pantheistischen Spekulation unsere Betrachtung verlangt ${ }^{1}$ ).

Unabsehbar eintönig dehnen sich die "Brāhmaṇas" aus: die Werke, in denen die Wissenschaft vom Opfer niedergelegt ist. Da liest man, zu Hunderten und zu Tausenden, Betrachtungen wie die folgenden. Über die „Litanei der Gabeldeichsel", die beim Somaopfer für sieben Gottheiten oder Göttergruppen vorgetragen wird, heißt es:

„Den Atemkräften wahrlich gehört diese Litanei zu eigen, welche die Gabeldeichsel ist. Er trägt die Texte der sieben Gottheiten vor. Sieben wahrlich sind die Atemkräfte im Haupt. Damit setzt er die Atemkräfte in das Haupt. Was ist, sagt man, am Wohl und Wehe des Opferherrn dem Priester gelegen, der für ihn die Litaneien vorträgt? Hier kann er mit ihm machen, was er will. Wen er an seinem Ausatmen schädigen will, für den muß er den Abschnitt an Vāyu (den Windgott) verwirrt vortragen. Er muß einen Vers oder ein Versglied auslassen: dadurch wird dies (Stück der Litanei) verwirrt. Damit schädigt er jenen an seinem Ausatmen. Wen er an seinem Aus- und Einatmen

1) Es darf nicht verschwiegen werden, daß die Grenzlinie - auch die chronologische Scheidung - zwischen den Texten jener Wissenschaft und den spekulativen Upanișhaden keine vollkommen feste ist. So bleibt in Bezug auf manche Äußerung ungewiß, ob sie in die Vorgeschichte der pantheistischen Spekulation oder in diese selbst hineingehört. Im Großen und Ganzen sondern sich die beiden Perioden doch hinlänglich. DaB sie im Einzelnen oft in einander fließen, ist eben eins der Charakteristika dieses Entwicklungsvorgangs. 
schädigen will, für den muß er den Abschnitt an Indra und Vāyu verwirrt vortragen, " usw.

Eine andere Stelle betrifft eine Reihe von Opfern, die sich durch ein Jahr hindurchziehen; sie geben Anlaß vom geheimen Wesen des Jahres zu handeln, damit man als Kenner dieses Mysteriums Herr über die damit verknüpften Kräfte und Wirkungen werde: „Ein Mann wahrlich ist das Jahr. ,Mann' ist ein Ding; ,Jahr' ist ein Ding. Das aber ist dasselbe. Zwei Wesenheiten sind des Jahres Tage und Nächte; zwei sind diese Atemkräfte des Mannes (Einatmen und Ausatmen). Das aber ist dasselbe... Viersilbig ist samvatsara („Jahr"); viersilbig ist dieser yajamāna („Opferherr"). Das aber ist dasselbe ... Dreihundert und sechzig sind des Jahres Nächte; dreihundert und sechzig sind des Mannes Knochen. Das aber ist dasselbe ... So viele Schweißporen es gibt, so viele Tropfen regnet es. So sprach Vārkali, der dies wußte: Die Wolke, welche die ganze Erde beregnet, kenne ich, und dieses Regens Tropfen $\left.{ }^{1}\right) .{ }^{\text {" }}$

Mit den Göttern, an die doch Litaneien und Opfer von Haus aus gerichtet waren, hat all das wenig zu tun. Denen floß ihr Leben zu aus dem Glauben, daß sie als Herren aller Güter, alles Geschehens Glück und Leid zuteilen, wie es ihnen gefällt. Das priesterliche Selbstbewußtsein aber, das aus den Brāhmanatexten spricht, liebt es nicht, in unterwürfiger Demut aus der Hand eines Höheren zu empfangen. Und der priesterliche Wissensdrang findet keine volle Befriedigung, so lange er Halt machen muß vor dem unreduzierbaren Letzten, das ihm in jenen Götterpersönlichkeiten gegenübersteht. Im Wollen wie im Erkennen greift man selbstvertrauender, anspruchsvoller zu. Man erfaßt das Geschehen, wie es in primitivster Form schon jene vorgeschichtliche Weltauffassung getan hat, als beruhend auf dem Spiel von Kräften, die das Universum durchwalten und deren

1) Das scheint zu heißen: wer den menschlichen Körper kennt, kennt das Gesetz des Regens, den das Jahr bringt. Denn der schweiBergießende Körper ist so viel wie die regenergießende Naturmacht. 
Wirkungsweise, von fern der Naturgesetzlichkeit des modernen Weltbildes vergleichbar, der Kenner zu berechnen und wie er will zu lenken weiß. Dieser Kenner aber ist man selbst. Selbst beherrscht man den Gang der Dinge durch das zu allmächtigem Zauber umgedeutete Opfer. Hat Jemand einen Erfolg, fragt man: welchen Kunstgriff hat er beim Opfer angewandt, um das zu erreichen? Auf dem Opfer beruht Wesen, Gestalt, Geltung aller Dinge. Mit dem Baccalaureus Goethes könnte der Opferer sagen: "Die Sonne führt' ich aus dem Meer herauf" - er könnte es nicht nur sagen; er sagt es tatsächlich: „Gewiß die Sonne würde nicht aufgehen, wenn man nicht in sie diese Opferspende ergösse. Darum gießt er diese Opferspende aus." Da kann denn den Indra und Varuna nur der Schatten ihrer einstigen Größe bleiben. Auch in Indien sind es die Priester, die den Göttern die Lebenskraft verkümmert haben. Die Poesie und Andacht, von der sie in den alten Hymnen umflossen waren, ist in den Brăhmanatexten von ihnen gewichen. Wo sie hier handelnd auftreten, pflegen sie mit kleinlichen Ränken gegen einander und gegen ihre außergöttlichen Feinde anzugehen. Sie sind furchtsam, boshaft, voll niederer Begehrlichkeit. Selbstverständlich müssen sie es sich gefallen lassen, den jetzt geltenden Anschauungen entsprechend systematisiert, umgedeutet, so $\mathrm{zu}$ sagen in die Sprache der neuen Zeit übersetzt zu werden. Der Gott Brihaspati ist das Brahman, die Potenz der Heiligkeit. Vishnu ist das Opfer. In ihre Mythen werden die Vorstellungen, bei denen jetzt das Denken zu verweilen liebt, plump und gewaltsam hineingetragen. Wo die alten Hymnen mit feierlichem Schwung von jenem großen Augenblick der Entscheidung redeten, als Indra auf Vritra den Donnerkeil schleuderte, heißt es jetzt, daß Indra den Vritra durch eine Opferdarbringung erschlagen hat. Den Göttertrank Soma vom Himmel herabzuholen fliegen anstelle des alten mythischen Adlers die Metra der heiligen Hymnen in die Höhe. Absurde und stillose Vermischungen heterogener Vorstellungs- 
reihen: kein Wunder, daß so die vollkommensten mythologisch-spekulativen Mißgeburten zur Welt kommen.

Schließlich gewöhnt man sich daran, neben den alten Göttern und statt ihrer die großen Mächte der Außenwelt als "Gottheiten" (devatāh) zu benennen, die physischen und ähnlichen Wesenheiten, bald mehr phantastische Kolosse, bald mehr Fluida, in denen man jetzt die vor allem entscheidenden Faktoren des Geschehens erkennt.

$\mathrm{Da}$ ist Sonne und Mond. Die drei Welten: Erde, Luft, Himmel. Die Weltgegenden. Das Jahr und die Jahreszeiten, die Monate mit ihren Hälften des zunehmenden und abnehmenden Lichts, Tage und Nächte. Vielleicht würden wir erwarten, in dieser Reihe dem Raum und der Zeit zu begegnen. Offenbar schweben die in der Tat den alten Denkern in gewisser Weise vor, wenn sie die „Weltgegenden und das "Jahr" nennen. Im Ganzen ist man noch nicht $\mathrm{zu}$ jenen reinen Formen der Anschauung, die eben nur Formen sind, durchgedrungen. Man bleibt meist an diesen konkreteren Vorstellungen der Weltgegenden, des Jahres haften, die den lebendigen Inhalt einer Mannigfaltigkeit nit verschiedenen Kräften ausgerüsteter, im Weltleben - insonderheit im Opfer - verschieden wirkender räumlicher und zeitlicher Elemente in sich schließen ').

Eine besondere Gruppe von Wesenheiten, denen die Brāhmanatexte neben diesen "Gottheiten" eine bedeutende Rolle zuweisen, sind die Substanzen, aus denen sich das körperliche und geistige Dasein der menschlichen Persönlichkeit aufbaut. Da ist Geist, Atem und Rede, oder anstelle des Atems eine Vielheit von Atemkräften. Da ist Speise und das dem Körper angehörende Wasser, Knochen und Mark, Auge und Ohr.

1) Doch schreitet man in der Tat daneben auch schon zu der abstrakteren Vorstellung des ${ }_{n} \mathrm{~K} \bar{l}{ }^{a}{ }^{*}$ fort: das Wort bedeutet, scheint es, zunächst den rechten, für einen Zweck geeigneten Zeitpunkt, dann die-Zeit überhaupt. Vgl. auch die Anführung in Anm. 11 am Ende dieses Buchs. 
Weiter aber ist bezeichnend, wie neben diesen Sphären des Makrokosmus und Mikrokosmus als gleichberechtigt eine dritte steht: das Opfer mit dem Kreis der ihm zugehörigen einzelnen Verrichtungen und vor allem mit den heiligen Vedatexten - mit den Details ihres Wortlauts, den Versmaßen, den verschiedenen Formen künstlicher Wiederholung und Verschränkung der Versglieder beim Aufbau der Gesangliturgien, bis herab zu solchen Minutien wie dem Auftreten des und desLauts an irgend einer Stelle oder dem Wechsel der Kasusformen eines Schlagworts in den heiligen Formeln: interessante Anfänge grammatischer Beobachtung werden hier gelegentlich sichtbar. Man sieht, wie deutlich sich die Eigenart dieses priesterlichen Weltbildes ausprägt: zusammen mit Sonne und Mond, mit Atem und Geist regieren die Metra der heiligen Hymnen als Großmächte den Weltlauf. In einem Brāhmana heißt es: „dies alles, was da ist: die heiligen Hymnen, Sprüche, Lieder, Metra, Opfer, Menschen und Vieh".

Schließlich gehört, wie in dem bisher Gesagten schon gelegentlich hervortrat, in diesem Gewirr mystischer oder magischer Substanzen auch all dem eine Stelle, was uns als Eigenschaft eines Wesens oder als eine ihm innewohnende Kraft erscheint. Auch dies sind „Körper" (tanī)1: so in dem Weibe, das mit schädlichen Eigenschaften ausgestattet ist, der "gattentötende Körper", der "Körper der Sohnlosigkeit". Ähnlich ist die Kraft vorgestellt, die den Priester oder den Adligen zu dem macht, was er ist: das Brahman, das Kshatra.

Eine gewisse Fortgeschrittenheit des Denkens von den vorgeschichtlichen Gebilden zu Reinerem, Wirklicherem ist in all dem ja unverkennbar. Die Weltgegenden, das Jahr und ähnliche Mächte, ja selbst Opfer und Opferlieder als Beherrscher des Geschehens tragen in der Tat den Stempel höherer Vorstellungsweise als die Fratzengestalten der Vorzeit. Und doch, was das Denken der Brahmanen in jenen Wesen sieht, die Vorgänge, die es unter ihnen sich vollziehen läßt: all das fällt immer noch 
fortwährend in den Stil grotesker Unwirklichkeit zurück, der für die prähistorische Zeit charakteristisch ist. Nicht verwunderlich, wenn man sich vergegenwärtigt, wie ganz und gar diese Priester noch Zauberer gewesen sind. Die Versmaße sprechen und handeln. Das Jahr hat ein Verlangen. Das Opfer verwandelt sich in eine Schildkröte und redet. Viel unbestimmtes Schweben zwischen unpersönlichem und persönlichem - schattenhaft persönlichem - Dasein. Netze phantastisch willkürlicher Beziehungen umspinnen alle diese Wesenheiten, aus deren Aktion sich die Struktur des Opfers, seine Wirkung auf Weltlauf und Ich erklären soll. Sie wirken auf einander durch Berührung, durch die ihnen innewohnende Zahl, durch irgend etwas ihnen Anhängendes. Sie fürchten sich vor einander, ruhen auf einander, gehen in einander ein, sind mit einander verwoben, paaren sich mit einander. Sie erschaffen einander, indem das Eine das Andre aus sich entläßt, nehmen sich wieder in einander herein, absorbieren einander, verwehen in einander. Das Eine geht in das Andere über, wird zum Andern, ist eine Form des Andern, ist das Andre. Vor allem dies letzte: das Eine ist das Andere. Von der alten Fähigkeit der vorgeschichtlichen Zeit, als unmittelbare Gewißheit zu empfinden, daß etwas zugleich es selbst und etwas anderes ist (oben S. $11 \mathrm{f}$.), besitzen diese Theologen noch einen recht starken Rest. Das Opfer ist das Jahr. Das Opfer ist Rede. Das Opfer ist Vieh. Das Auge ist die Wahrheit. Das Versmaß Trishtubh ist Kraft. Es ist schwer, die Intensität der Gleichsetzungen, die sich in solchen Sätzen aussprechen, sicher $\mathrm{zu}$ veranschlagen. Kaum zweifelhaft scheint doch, daß verglichen mit den uns geläufigen symbolisierenden Zusammenstellungen - Halbmond und Islam, Lorbeer und Ruhm - es sich dort um eine wesentlich stärkere Empfindung wirklicher Identität handelt. Sie mag ähnlich heutzutage von dem gefühlt werden, für den das Brot des Abendmahls nicht den Leib des Herrn bedeutet, sondern sein Leib ist.

Fortwährend wechseln die Figuren, in denen sich die 
Elemente dieses Weltbildes an einander fügen. Das Einzelne schwankt und schwirrt hin und her, ist jetzt dies, jetzt jenes. Die Klammern, die alles in der gegenseitigen Lage festhalten oder vielmehr nicht festhalten, sind schwach. Mit den Beweisen dafür, daß das Eine das Andre ist - sofern überhaupt solcher Beweis versucht wird - macht man es sich bequem. „Der Feueraltar, den man geschichtet hat, ist diese Rede. Denn mit der Rede ${ }^{1}$ ) wird er geschichtet" - so schließt man ganz im Stil prähistorischer Logik. „Das Gewordene ist das Selbst. Denn gewiß ist das, was geworden ist, und gewiß ist, was das Selbst ist." Man möchte meinen, daß, wenn sich hier zwei Vorstellungen einmal in einer gewissen gegenseitigen Nähe befinden, es nicht mehr gelingen will sie auseinander zu halten. Sind bei den Betrachtungen, die man anstellt, Zahlenverhältnisse im Spiel, so huldigt man denn auch dem Prinzip, daß es auf eins oder zwei mehr oder weniger nicht ankommt, oder man gestattet sich auch einen direkten Rechenfehler. Gern hält man sich an oft recht geringfügige Wortähnlichkeiten, um auf die Identität zweier Wesenheiten oder auf mystische Kräfte in ihnen zu schließen: man bringe, um die Überzeugungskraft zu würdigen, die ein solcher Beweis besitzt, die alte Vorstellung von der mystischen Wesensgemeinschaft zwischen Namen und benannter Sache in Anschlag. indha ist indra, dhūrva $\bar{a}$ ist dūrvā. Zwar stimmt die Wortgleichheit nicht recht - um so viel besser; sie ist eben "verborgen; das Verborgene aber lieben die Götter“. So lassen Begriffe, Zahlen, Worte es sich ohne viel Widerstand gefallen, nach Belieben hin und her geschoben zu werden. Einer Wesenheit, die als wirkungsvoll erscheinen soll, gönnt man es gern, "dies Alles" zu sein: warum sollte man auch vor einer Grenze halt machen, wo man es ebenso leicht hat über die Unbegrenztheit zu verfügen? Als Parameshthin, Sohn des Weltschöpfers Prajāpati, das Neu- und Vollmondsopfer dar-

1) Unter Rezitation von Sprüchen usw. 
gebracht hatte, „kam ihm der Wunsch: ,Möge ich dies Alles sein'. Er wurde zu den Wassern. Die Wasser wahrlich sind dies Alles" - und wenige Zeilen weiter: der Atem ist dies Alles; die Rede ist dies Alles; der Genießer der Speise und die Speise selbst sind dies Alles. Ein Weltbild, in dem so alles in einander schwimmt, gibt eben die rechte Atmosphäre her, die der priesterliche Zauber braucht, um die Dinge $z u$ beschleichen, von fern her das Eine im Andern $\mathrm{zu}$ erfassen und zu bezwingen. In der Gewinnung der Erkenntnisse, durch die das erreicht wird, arbeitet und kämpft nicht der Gedanke seinen schweren Kampf, die Hindernisse zu besiegen, die ihm den Zugang zur Wesenstiefe der Dinge verwehren. Sondern es ist ähnlich wie es in der prähistorischen Zeit war: wo eine Frage auftaucht, hat man auch alsbald ohne riel Suchen die Antwort bereit. In der ruhigen Abgeschlossenheit der privilegierten Kaste, keiner andern Kritik ausgesetzt als einer, die mit genau dem gleichen Rüstzeug arbeitet, am wenigsten von Selbstkritik behelligt, läßt man nach Willkür und Behagen die Phantasie von Einfall zu Einfall ihr Spiel treiben.

Daß im Gewirr jener welterfüllenden und den Weltlauf beherrschenden Potenzen doch vor den Augen der priesterlichen Betrachter gewisse Ordnungen mit größerer oder geringerer Bestimmtheit sich feststellen, ist ja natülich. Ein sehr primitiver, auf der voryeschichtlichen Entwicklungsstufe häufiger Typus der Klassifikation ist die Einteilung von Wesenheiten aller Art entsprechend der sozialen Gruppierung der Menschen. Tiere, Pflanzen, Himmelskörper, Weltgegenden - Alles ordnet sich nach den Totemgruppen, Clans, Phratrien der menschlichen Gesellschaft. In Australien kann der Zauberer, welcher der sozialen Gruppe Mallera angehört, beim Zauber nur Gegenstände verwenden, die ebenfalls Mallera sind; stirbt er, muß das Holz des Gerüsts, auf das die Leiche gestellt wird, von einem Baum der Malleraklasse kommen." Eine deutliche Veranschaulichung davon, wie andre Wesenszüge jenes Denken verglichen mit dem unsrigen 
in Personen und Dingen sieht und wichtig genug findet, um darauf fundamentale Einteilungen und Regeln für das Handeln zu bauen. Genau dieselbe Denkweise erscheint nun auch in der brahmanischen Opferwissenschaft. Die gleichen Kasten wie unter den Menschen gibt es unter Göttern und Tieren. Und der brahmanischen Phantasie würde etwas Wesentliches fehlen, wenn diese Einteilung nicht auch die Metra der heiligen Texte, die Melodien und Anordnungsweisen der Gesanglitaneien umfaßte. Auch die Jahreszeiten, auch die Zahlen, welche für die Metra maßgebend sind, werden dem System angeschlossen. Was unter den Menschen der Brahmane ist, ist unter den Göttern Agni, unter dem Vieh der Ziegenbock, unter den Versmaßen das aus achtsilbigen Reihen gebildete: dies Alles ist unter elnander gleichen Wesens, ist Alles aus dem Haupt des Weltschöpfers hervorgegangen. Ebenso haben der Adlige, der Vaiśya, der Ś̃udra, die der Reihe nach aus Brust und Armen, aus dem Bauch, aus den Füßen des Schöpfers stammen, ihre Verwandten gleichen Ursprungs in jenen andern Daseinssphären. Auf dieser Klassification beruht es, daß der Brahmanenknabe im achten bis sechzehnten Lebensjahr die Jünglingsweihe empfangen soll, da acht die Zahl seiner Kaste ist, während für den Adligen und Vaiśya aus dem gleichen Grunde das elfte bis zweiundzwanzigste, das zwölfte bis vierundzwanzigste Jahr gilt. Ebenso legt der Brahmane die heiligen Opferfeuer im Frühling an, in der Jahreszeit seiner Kaste, der Adlige im Sommer, und so fort. Natürlich zwar kann das Alles nicht in dieser Form direkt aus höchstem Altertum stammen, denn weder die Kasten noch die für die Zahlenverhältnisse maßgebenden Versmaße - und schließlich auch nicht die Götter - sind uralt. Aber es ist kaum zweifelhaft, daß auf den Stoff, den die geschichtliche Zeit hervorgebracht hat, doch hier eine Denkgewohnheit angewandt ist, die sich in ununterbrochener Kontinuität aus fernen Tiefen vorgeschichtlicher Vergangenheit erhalten hat.

Während die eben besprochene Klassifizierung vor allem 
für die Beurteilung des Verhältnisses der Brāhmaṇaspekulation $\mathrm{zu}$ jener Vorgeschichte lehrreich ist, hat eine andre oft begegnende Einteilung des Weltgebiets direkte, erhebliche Wichtigkeit für die vor uns liegende Frage, wie sich in dieser Spekulation die Idee des All-Einen vorbereitet. Die Figuren, nach denen sich irgend welche unter den welterfüllenden Wesenheiten ordnen, werden gern als auf verschiedenen Daseinsgebieten wiederkehrend in mehreren sich gegenseitig entsprechenden Exemplaren neben einander gestellt, mit stehend wiederholten Schlagworten wie besonders häufig den folgenden: "So in Beziehung auf die Gottheiten. Nun in Beziehung auf das Selbst." Und auch oft: "Nun in Beziehung auf das Opfer": also eine Mehrheit, etwa eine Dreiheit der Erscheinungsformen - sie wurde schon oben (S. 19) berührt - , in denen, hier und dort entsprechend, dasselbe Verhältnis, derselbe Vorgang sich manifestiert ${ }^{1}$ ). Mit den „Gottheiten“, von denen da die Rede ist, pflegen in der Regel nicht Agni, Indra und ihre Genossen gemeint $\mathrm{zu}$ sein, sondern jene mehr kosmischen als mythischen Wesenheiten, die wir oben (S. 18) zur Würde von "Gottheiten" aufrücken gesehen haben. Prajāpati der Weltschöpfer bringt die drei großen rituellen Gebilde hervor, die man als die "drei Ozeane" betrachtet: die Schichtung des mystischen Feueraltars, die Gesanglitanei Mahāvrata, die Hymnenlitanei Mahaduktha. Die sind Erdwelt, Luftreich, Himmel. „So in Beziehung. auf die Gottheiten. Nun in Beziehung auf das Selbst": - eben jene drei Mysterien sind Geist, Atem, Rede. Gerade derartige von vornherein auf weltumfassende Symbolik angelegte Riten, die von raffinierteren priesterlichen Technikern neben die alten vergleichsweise naturwüchsigen Opfer gestellt sind, eignen sich be-

1) Wie diese Dreiheit als stehend aufgefabt und welche beherrschende systematische Bedeutung ihr beigelegt wurde, zeigt ein Memorialvers in einem jüngeren vedischen Ritualtext: „Was sich auf die Gottheiten bezieht, auf das Selbst, auf das Opfer: diese Dreibeit in den Sprüchen und in den Brāhmaṇas wird Wissen genannt" (Śānkhāyana Gṛhyasūtra I, 2, 5). 
sonders dazu, mit den schematischen Linien solcher Figuren überzogen zu werden. Äußerungen wie die eben angeführte mögen, ihren Einzelheiten nach betrachtet, als rein spielerisch erscheinen. Aber es zeigt sich in ihnen eine Tendenz, die für das Ganze der Gedankenentwicklung doch von Bedeutung ist. Das Gewirr der Potenzen, welche die Welt erfüllen, fängt sich für das Bewußtsein der Brahmanen selbst zu ordnen an. Große Reiche, auf die sie alle sich verteilen, sondern sich zugleich von einander ab und fallen auch wieder in mystischer Identität zusammen: hier die Außenwelt, dort die menschliche Persönlichkeit; dazu dann, dem priesterlichen Betrachter als gleichberechtigtes drittes Reich erscheinend, die Sphäre von Opfer und Veda. Prajāpati der Weltschöpfer "schaute um unter allen Wesen. Da erblickte er im dreifachen Wissen ${ }^{1}$ ) alle Wesen. Denn hier ist das Selbst aller Metra, aller Formen des Preislieds, aller Atemkräfte, aller Gottheiten". Und in die Welten ergießt dann der Schöpfer „als in den Mutterleib sein zum Samen gewordenes Selbst, bestehend aus den Metris, aus den Formen des Preislieds, aus den Atemkräften, aus den Gottheiten". So wird er zum Selbst aller Wesen, und wie er, so wird es der Opferer, in dem sich wiederholt, was dem Schöpfer widerfahren ist. „Wenn der, der also weiß, aus dieser Welt scheidet, so gelangt er zu jenem Selbst bestehend aus den Metris, aus den Formen des Preisliedes, aus den Atemkräften, aus den Gottheiten. Ein hieraus Bestehender wird er und zur Höhe steigt er empor, wer also wissend jenes (Opfer-)Werk vollzieht, oder wer dies also weiß." Man sieht in solchen Äußerungen, wie jene großen Daseinsreiche der Außenwelt (der "Gottheiten“), des persönlichen Wesens, des Opfers oder Veda zusammenfließen, wie die Mannigfaltigkeiten ihrer Inhalte sich in einem Punkt konzentrieren. Und die Schlußworte der angeführten Stelle zeigen, wie dann dieser ganze allumfassende Reichtum dazu da ist, im

1) Der Kunde der drei Veden: Rig-, Yajur- und Sāmaveda. 
Jenseits als Lohn dem zuzufallen oder vielmehr in dessen Wesen sich zu ergießen, der die Kunst kennt ihn sich anzueignen: der Opferer, der Wissende.

Damit ist nun die letzte Frage berührt, mit der sich unsre Betrachtung der indischen Opferweisheit beschäftigen muß. Was lehrt diese über Tod und Jenseits?

\section{Tod und Jenseits.}

Das Problem des Jenseits wird in den Brāhmanatexten nicht selten beruhrt, häufiger und angelegentlicher als in den alten Poesien des Rigveda. Beruht das nur darauf, daß das Gelage des Somaopfers, der Preis trinklustiger Götter, wenig Anlaß gab, von jenen düsteren Regionen zu reden? Man kann zweifeln. Glaublich ist es doch, daß sich jetzt in der Tat gesteigerte Aufmerksamkeit dorthin richtete. Mehr als vordem war man gewöhnt, wenn auch in phantastischer Weise, an Gesetze des Weltlaufs, an die Struktur der menschlichen Persönlichkeit zu denken. Das mochte dahin wirken, daß neben den Wünschen und Bedürfnissen des Heute und Morgen immer mehr auch die letzten Entscheidungen erwogen wurden, die jenseitige Zukunft des Menschendaseins. Wie kurz schien die Spanne des Erdenlebens verglichen mit jenen Ewigkeiten. "Drüben gibt es mehr Nächte", sagte man.

Die Grundlage nun der Gedanken, die sich da entwickelten, bildeten selbstverständlich die aus der Vergangenheit ererbten Vorstellungen, in denen ältere und jüngere Elemente hier wie bei andern Völkern sich übereinander geschichtet, mit einander vermischt hatten: der Glaube an gespenstisches Fortleben der Seele in größerer oder geringerer Nähe der alten Behausung, an ein Reich der "Väter", beherrscht von einem König der Toten, daneben an Aufsteigen zu Himmelshöhen, zur Gemeinschaft der Götter - Eile dörthin zu kommen hatte man nicht; das Erdenleben war ja erfreulich genug -, und an die Kehrseite solcher Himmelsseligkeit, furchtbare Strafen in Höllenfinsternissen. Neben all dem ist vielleicht 
auch diesem Zeitalter die Leugnung jeglichen Fortbestehens jenseits des Todes nicht fremd gewesen, wie später eine Upanishad sagt: Manche glauben, daß die Toten sind, Manche daß sie nicht sind. Die verschiedenen Auffassungen über das Jenseits gehen begreiflicherweise ohne den Versuch eines ernstlichen Ausgleichs ihrer Widersprüche in den Brāhmanatexten durch einander. Dort ist auch die Rede von den gequälten Toten, die aus Verwirrtheit oder zur Strafe einer Verschuldung den rechten Weg hinüber vergeblich suchen: „Mancher weiß seine Stätte nicht zu finden. Verwirrt vom Feuer (der Leichenverbrennung), betäubt vom Rauch weiß er seine Stätte nicht zu finden." Wer eines Brahmanen Blut vergießt, "soll so viele Jahre, wie das hervorspritzende Blut Staubkörnchen trifft, die Welt der Väter nicht kennen".

In diese und ähnliche ungeordnet hin und her spielende Vorstellungen fügt sich nun ein weiteres - freilich wissen wir nicht gewiß, ob ein vollkommen neues ${ }^{1}$ ) - Element ein, in eine Richtung weisend, die zu entscheidenden Umgestaltungen des Jenseitsglaubens $\mathrm{zu}$ führen bestimmt ist. Es steht nicht fest, ob die betreffende Vorstellung, die uns natürlich in priesterlicher Fassung vorliegt, in der Tat aus dem Denken brahmanischer Kreise hervorgegangen ist. Nichts scheint die Möglichkeit auszuschließen, daß es sich um einen von Haus aus populären Glauben handelt, der in der Überlieferung priesterlicheStilisierung empfangen hat. Ein Schlagwort, das in den ältesten Texten nicht begegnet, tritt jetzt auf und wird oft ausgesprochen: Wiedertod. Die „Väter", die Gestorbenen bleiben selbst sterblich. Ihnen droht im Jenseits Wiederholung des Todesgeschicks, ja vielleicht ins Unabsehbare Wiederkehr immer neuen Sterbens ${ }^{2}$ ). „Welche dies also

1) Siehe über diese Frage unten S. 29, Anm. 2.

2) Es ist, wie schon bemerkt, nicht unmöglich, dab diese Vorstellung des „Wiedertodes" in die Zeit des Rigveda oder gar weiter zurückreicht. In einer Anrufung Somas (Rigv. IX, 113) wird von den Himmelswelten gesprochen und Vers für Vers das Gebet wiederholt: „Dort mach mich 
wissen oder welche dies Werk vollbringen " - heißt es betreffs eines bestimmten Ritus und der Kunde von seinem Sinn - „die gelangen sterbend zu neuem Dasein: das Dasein, zu dem sie gelangen, ist Unsterblichkeit. Aber die, welche nicht also wissen oder welche dies Werk nicht vollbringen, gelangen sterbend zu neuem Dasein: die werden wieder und wieder seine (des Todesgottes) Speise“.

Besonders fern lag die in mancherlei Gestalten ja auch unter Naturvölkern verbreitete Vorstellung des Wiedertodes in der Tat nicht. Das Hinübergehen in das Totenreich wird im Veda bisweilen als ein Geborenwerden in diesem Reiche aufgefaßt: „wenn er stirbt und sie ihn auf den Scheiterhaufen legen: wenn er von dort aus zum Dasein gelangt, dann wird er zum drittenmal geboren " ${ }^{1}$ ). Der also Geborene ist dann in jener Welt mannigfachen Schicksalen ausgesetzt. So muß er essen und hungert, wenn er nicht zu essen hat. Warum sollte es in dieser Existenz, in die hinein man geboren wird, nicht auch ein Sterben geben?

Wie ist aber dies Wiedersterben des Gestorbenen näher zu verstehen? Verbleibt er wiedersterbend im Totenreich, so daß der Wiedertod nur eine innerhalb desselben jenseitigen Daseins sich zutragende Katastrophe ist - neues Hereinbrechen von Todesschmerzen, etwa auch sich wiederholender Verlust lieben Besitzes, Abreißen gewohnter $\mathrm{Zu}$ sammenhänge? Oder, wie der Tod von der Erdenwelt in die

unsterblich." Darin kann liegen, daB in jenen Welten auch neuer Tod drohte. In der Tat sieht die Stelle manchen späteren recht ähnlich, die in diesem Sinne von Erlangung der Unsterblichkeit in der Himmelswelt reden. Mit der Bestimmtheit wie Boyer (in seinem ausgezeichneten Aufsatz "Sur l'origine de la doctrine du Samsāra", Journal asiatique 1901, II, 466) möchte ich hier doch nicht sprechen; jener Wortlaut läBt sich m. E. auch weniger scharf deuten. Übrigens gehört das Lied zu den allerjüngsten des Rigveda: womit freilich vereinbar ist, dab der in ihm vielleicht angedeutete Glaube auch älteren Zeiten, in deren Dichtungen von Tod und Jenseits wenig die Rede ist, eigen gewesen sein kann.

1) Die erste Geburt ist die natürliche, die zweite der Erwerb der Fähigkeit zum Opfern. 
Väterwelt geführt hat, führt so der Wiedertod von der Väterwelt in andere Welten, vielleicht auch zum Erdenleben zurück $^{1}$ )? Die Quellen sind mit Äußerungen hierüber recht karg. Im Ganzen scheint die erste dieser beiden Auffassungen vorzuherrschen. „Wer ohne sich von diesem Tode befreit zu haben in jene Welt hinübergeht . . . den tötet er (nämlich der Sonnengott, der hier als Tod vorgestellt ist) in jener Welt wieder und wieder": also der Schauplatz aller Wiederholungen des Sterbens bleibt immer das Jenseits. So werden denn auch die „Väter" nicht selten als „ein für allemal weggewandt" (vom irdischen Dasein) bezeichnet. Doch findet sich daneben auch die zweite jener Auffassungen. Am klarsten an einer Stelle, die vom Ruf $s v \bar{a} h \bar{a}$ („Heil!“) am Ende der Formeln für Darbringung der Opfergaben spricht. Dieser Ruf bedeutet ein Ende. Für den Wissenden aber muß sich das Ende zum besten wenden: „Aus dem Winter wahrlich ersteht wiederauflebend der Frühling. Denn aus jenem kommt dieser wieder zum Dasein. Wieder zum Dasein wahrlich kommt in dieser Welt, wer dies also weiß." So gibt es also nach dem Tode nicht allein neues Sterben, sondern es kann auch - offenbar im Anschluß an solches Sterben - Wiederkehr zum Erdendasein geben ${ }^{2}$ ). Und

1) Man kann weiter an definitive Vernichtung im Wiedertode denken. $\mathrm{DaB}$ es im Gewirr so vieler Meinungen auch diese anderwärts nicht selten begegnende gegeben hat, ist möglich. Besondere Wahrscheinlichkeit scheint mir doch dafür kaum zu sprechen. Ließ der erste Tod unter allen Umständen ein dem Wiedertode ausgesetztes Dasein fortbestehen, warum sollte der Wiedertod, den sein Name so deutlich als gleichartige Wiederholung des ersten kennzeichnete, anders wirken? Und ausdrücklich ist von wiederholtem Wiedertod die Rede. Wenn die "Väter" "sterblich" genannt werden, brancht natürlich kein das Dasein vernichtendes Sterben gemeint $\mathrm{zu}$ sein.

2) $\mathrm{DaB}$ auch die Vorstellung von dieser Wiederkehr in der Tat viel älter ist, als es nach den Äußerungen der Texte den Anschein hat, jene vielleicht - woran Oltramare (Hist. des idées théos. I, 97) denkt - an alten Volksglauben anknüpft, ist durchaus möglich. Quellen wie der Rigveda lassen eben, wie erwähnt, inbezug auf derartige Fragen das 
wenn an einer andern Stelle neben einander von Beschützung der Väter und des Viehs vor dem Wiedertode die Rede ist, so kann das dahin gedeutet werden, daß in die große Bewegung von Sterben und Wiedergeburt neben der menschlichen Existenz auch die tierische einbegriffen ist: was dann wohl an primitive Vorstellungen vom Hineinfahren der menschlichen Seele in Tiere anknüpfen würde ${ }^{3}$. Gewiß liegt in solchen vereinzelten Äußerungen das spätere Seelenwanderungssystem noch nicht fertig vor. Aber man sieht, wie innerhalb des alten Glaubens an ein Jenseits, an Hinubergehen in die Väterwelt, ohne daß jener Glaube aufgehoben würde, neue Elemente auftreten, oder vielleicht vorhandene Elemente neues Gewicht erhalten, in denen sich die Richtung auf das spätere Dogma deutlich zu erkennen gibt.

Betreffs der Entscheidung darubber, wie sich für einen jeden der Weg von Dasein zu Dasein gestalten soll, hat, wie bekannt, die spätere Zeit aus sehr alten Vorstellungen von jenseitiger Vergeltung die Lehre vom „Karman“ entwickelt. Je nach Verdienst oder Schuld seiner Werke gelangt man $\mathrm{zu}$ höherem oder niederem, seligem oder qualvollem Dasein und verbleibt in solcher Existenz, bis das Karman ausgenossen oder abgebüßt ist. Auch dieser Gedanke oder mindestens ihm Ähnliches scheint schon jetzt berührt zu werden. So heißt es von dem, der einen gewissen Ritus kennt: „Ihm trinken Tage und Nächte in jener Welt nicht seinen dort niedergelegten Schatz aus. Dem unausgetrunkenen Schatz nach geht er hin. " Was kann der "Schatz" anders sein als der Schatz guter Werke, die drüben den Kommenden erwarten und die der Wissende dort, ungeschmälert durch feindliche Macht, ausgenießen darf?

Argumentum ex silentio nicht zu. - In der oben angeführten Stelle ist die Unebenheit leicht begreiflich, $d a B$ von der Wiederkehr als etwas Heilvollem die Rede ist, während im Allgemeinen der Wiedertod gefürchtet wird. 
Von der Gedankenbewegung, die auf die Idee eines Allwesens hinarbeitet, ist dieser ganze Vorstellungskreis offenbar zunächst unabhängig, wenn auch natürlich in der Folgezeit zwischen beidem die so leicht sich ergebenden Verbindungslinien gezogen wurden. In den Perspektiven, die sich jetzt immer sichtbarer eröffnen, überwiegt der Charakter der Düsterkeit. Unabsehbare neue Entscheidungen, neue Gefahren; über alles ergießt von vornherein das Wort "Wiedertod" seinen Schatten. Angelegentlicher, peinlicher, als wenn man sicher wäre, durch eine einmalige Entscheidung allen Ungewißheiten ein Ende zu machen, richten sich die Gedanken und Sorgen der furchtempfänglichen Seelen auf die Zukunft.

Doch wie sollte Priesterkunst nicht Rettung aus diesen Nöten finden?

Wenn für das Denken der Folgezeit das Ringen um Unsterblichkeit das beherrschende Motiv bildete: hier war ein Kampfplatz, wo man sich in leichten Erfolgen auf künftige Triumphe vorbereiten konnte. Eher als die harte Macht des irdischen Todes ließ sich ja das luftige Gebilde des "Wiedertodes" uberwinden und ließ sich durch solchen Sieg "Unsterblichkeit" erwerben, "das höchste dieser ganzen Welt". Natürlich bedeutete die Unsterblichkeit, auf die man hoffte, nicht grenzenlose Verlängerung des Erdenlebens, sondern endgiltiges Eingehen zu den Seligkeiten, die jenen Gläubigen als die begehrenswertesten vorschwebten. Für das Diesseits wünscht man langes Leben bis in hohes Alter hinein, für das Jenseits solche Unsterblichkeit. Bald ist das, was $\mathrm{zu}$ dieser verhelfen soll, irgend ein rituelles Handeln - etwa ein Zauber, der die sterblichen Wesensbestandteile mit unsterblichen umgibt und sie dadurch unsterblich macht ${ }^{5}$-; bald ist es irgendwelches Wissen aus dem Gebiet der um das Opfer gelagerten Wissenschaft. Ja die priesterlichen Ansprüche versteigen sich zu Lehren wie der, daß ein König „sein volles Leben durchlebt, vom Wieder- 
tod frei bleibt, wenn ein also wissender ${ }^{1}$ ) Brahmane Wächter seines Reiches und sein Hauspriester ist". Man kann durch richtigen Ritus und rituelles Wissen auch seine schon hingegangenen Väter vom Wiedertode befreien. Die Flachheit aller dieser Gedanken verrät sich deutlich in der Leichtigkeit und Willkür, mit der jetzt hier jetzt dort, bald für diese bald für jene Leistung, ohne eine Spur ernsthafter Motivierung, die Verheißung der Erlösung vom Wiedertode gespendet wird.

Was Wesen und Inhalt des todbefreiten Daseins anlangt, so steht begreiflicherweise die Vorstellung des Weilens in der Himmel- oder Götterwelt im Vordergrund. Im Übrigen schwanken die Äußerungen, abhängig von den Zufälligkeiten des jedesmaligen Zusammenhangs. An einer Stelle wird der Erlöste beschrieben als aus der Höhe auf die Bewegung der Tage und Nächte herabblickend „wie wer auf einem Wagen steht und von oben auf die sich drehenden Wagenräder schaut". Ein andresmal heißt es, daß, während im Tode sein Auge zur Sonne geht und andre Teile seines Wesens zum Mond, den Himmelsgegenden, dem Wind, er selbst „zu der unter diesen Gottheiten wird, die er erwählt, und die Ruhe findet“. Oder „zum Opfer werdend wird er vom Tode erlöst... Welche Darbringung er opfert, die wird in jener Welt sein Selbst. Wenn der also Wissende aus dieser Welt scheidet, dann ruft jene Darbringung hinter seinem Rücken folgend ihm zu: Komm! Hier bin ich, dein Selbst! ${ }^{8 *}$

Trotz aller der Zukunftsweiten, mit denen man da zu spielen liebt, liegt doch die innere Engheit dieser dem Priesterhirn entstiegenen Gedanken am Tage. Die Welt ist ein vergrößerter Opferplatz; im Jenseits thront der Selige, durch ein bizarres Wunder zu einem Stück Opfer geworden. Das Alles ist wie die ganze Opferwissenschaft

1) Der Kenner einer bestimmten an der betreffenden Textstelle vorgetragenen Lehre. 
der Brahmanen weihelos, trocken, kalt. Aber doch bereiten sich herannahende große Entwicklungen darin vor. Es finden sich Stellen - sie mögen den jüngeren der Brāhmanazeit zugehören - die ohne den Boden jener Wissenschaft zu verlassen, doch fast schon die Sprache der kommenden Zeit reden. Man betrachte einige solche Äußerungen ?

„Da sagt man: wer steht höher, wer dem eigenen Selbst (ātman) opfert oder wer den Göttern opfert? Wer dem Selbst opfert, soll man antworten." Den Göttern gebrachtes Opfer gleicht dem Tribut, den der gemeine Mann dem König bringt. Wer aber dem Selbst opfert, „der tut diesen sterblichen Leib, alles Übel von sich ab wie die Schlange ihre Haut von sich abtut. Aus heiligen Hymnen, Sprüchen, Liedern, Opferspenden besteht seine Wesenheit. So gelangt er zur Himmelswelt."

Nachdem das "Brahmanopfer" d. h. die täglich vorzunehmende Vedarezitation beschrieben ist - Brahman ist hier in alter Weise als die in den Vedatexten wohnende Kraft der Heiligkeit zu verstehen ${ }^{1}$ ) - wird dem, der dies Opfer mit rechtem Verständnis bringt, die Verheißung gegeben: "Wahrlich er wird vom Wiedertode erlöst; sein Selbst vereinigt sich mit dem des Brahman" ").

"So soll er wissen: alle Welten habe ich in mein Selbst (Ātman) gesetzt. In alle Welten hab ich mein Selbst gesetzt. Alle Götter ... alle Veden ... alle Atemkräfte habe ich in mein Selbst gesetzt. In alle Atemkräfte habe ich mein Selbst gesetzt. Unvergänglich wahrlich sind die Welten, unvergänglich die Götter, unvergänglich die Veden, unvergänglich die Atemkräfte, unvergänglich das All. Aus Unvergänglichem geht zu Unvergänglichem hin, den Wieder-

1) Darüber Eingehenderes im nächsten Abschnitt.

2) Wörtlich: er gelangt zur Gleichselbstigkeit (sātmatā, abgeleitet von atman) mit dem Brahman. - ̈̈hnlich wird im Kaushïtaki Brāhmaṇa "Teilhaben an der Welt des Brahman und Gemeinschaft mit ihm" verheißen - hier ohne einen Anhaltspunkt für die Auffassung von Brahman. 
tod wehrt von sich ab, alles Leben erreicht, wer dies also weiß."

Den Beschluß mache einer jener Verssprüche, die zuweilen in die Prosa der Brāhmaṇatexte eingefügt sind.

„Nur durch Wissen zu wunschloser Höhe man sich

Wohin nicht Opferlohn aufsteigt, Kasteiung ohne erheben mag,

Wissen nicht."

Hier trägt in der Rivalität von Wissen und Werken als Spendern jenseitiger Güter da, wo es sich um das höchste Gut handelt, das Wissen den Sieg davon. Man wird das begreifen. Wir kommen noch darauf zurück, wie innerhalb der Opfertheologie selbst sich ein Wissen allgemeinerer Art $\mathrm{zu}$ bilden anfing, das nicht unmittelbar mit greifbar konkreten rituellen Werken zu schaffen hatte; von den höchsten Dingen aber war gern eben in solchem freiern Zusammenhang die Rede. Auch mochte verglichen mit den handgreiflichen Realitäten des Opferwerks das Wissen als der unfaßbarere, subtilere und darum mächtigere Zauber erscheinen. Welche andere Macht sollte da für die Anschauung dieser Schulen, in denen Alles auf den Erwerb und Besitz des Wissens abzielte, höher hinaufreichen als eben das Wissen? -

In der großen Zeit der brahmanischen Spekulation, in den Upanishaden, lehrte man, daß aus dem.Elend der Seelenwanderung erlöst der Wunschlose, Wissende ist, der in seinem Selbst das all-eine Selbst, das Brahman erfaßt. Die Gedanken, die hier dargestellt wurden, bereiten das vor. In ihnen prägt sich - wenn auch unter vielerlei Verwirrtheit - der Gegensatz des immer erneuten Sterbens und der Unsterblichkeit mit wachsender Entschiedenheit aus. Der alte Gegensatz der Lebenden und der Toten hat sich abgeschwächt, indem man an Wiederkehr der Toten zum Erdenleben zu denken anfängt. Jetzt kommt es vielmehr darauf an, ob man vom Wiedertode erlöst ist oder nicht. 
Unsterblichkeit, Erlöstheit fängt an das Ziel der Ziele zu sein. Und insonderheit die zuletzt gesammelten Stellen sprechen, von der Unsterblichkeit und dem Weg dorthin redend, schon alle großen Schlagworte der Upanishaden aus: Wissen und Wunschlosigkeit, Ätman (Selbst) und Brahman. Unmerklich gleiten die Ideen der Opferwissenschaft in die der Upanishaden hinüber. Wie manche Gedanken enthalten Tiefen unausgeschöpft vom rasch verklingenden Wort, das zuerst über sie hinstreift. Hier war es nicht den Lehrern der Brāhmanazeit gegeben in diese Tiefen zu dringen. Das war allein dem Ernst und der genialen Schauenskraft vorbehalten, deren Denkmal die Upanishaden sind. 


\section{Frstes Kapitel. \\ Die älteren Upanishaden.}

Den Versuch, die Gedankengänge und Gedankenspiele der Upanishaden - zunächst der älteren ${ }^{8}$ - zu beschreiben, will ich nicht damit einleiten, daß ich vom Aussehen dieser Texte selbst spreche oder von der Frage, inwieweit ihr Inhalt ein System gebildet hat. Die Darstellungsform, welche jene Alten handhabten, das Dasein oder Fehlen zusammenhängender Ordnung in ihren Ideen wird sich mit größerer Anschaulichkeit und Bestimmtheit später besprechen lassen. Hier soll vor allem von den Ideen selbst die Rede sein.

Schon die oben gegebene Schilderung der Opferwissenschaft hat mehrfach gezeigt, wie es in ihr an Momenten nicht fehlte, die über sie selbst hinaustrieben und die Bildung jener Ideen vorbereiteten.

Bisher aber fand sich nicht Gelegenheit, einer eigenartigen Sphäre des Kultus zu gedenken - man kann sagen, $\mathrm{da} ß$ sie an der Grenze seines Reichs liegt - die offenbar für die uns beschäftigenden Entwicklungen von ganz besonderer Bedeutung gewesen ist. Neben den greifbaren Opferriten und liturgischen Prozeduren gab es schon früh gewisse Verfahrungsweisen immateriellen Charakters, welchen hervorragende Fähigkeit zu innerlicher Vertiefung eigen war. Sie stellten sich ihrer Natur nach leicht in den Dienst neu in den Gesichtskreis tretender ideellerer und darum dem Opfer oder den gewöhnlichen Formen des Zaubers schwerer zugänglicher Mächte. Dem bloßen Gedanken wurde von altersher magische Wirkung beigelegt; so schrieb man denn an 
gewissen Stellen der heiligen Handlungen bestimmte Gedanken vor, deren Kraft dem Ritus die Richtung auf ein in jenen Gedanken ausgedrücktes Ziel irgendwelcher Wünsche oder Bedürnisse verleihen sollte. Weiter ist hier eine Betätigung zu erwähnen, die sich als „Verehrung“ bezeichnen läßt. In feierlicher Haltung, bald mit bald ohne Sprüche, trat man vor die zu ehrende Wesenheit hin (upa-sthā); man setzte sich auch in ehrerbietiger Meditation zu ihr hinzu (upa-ās, upa-ni-shad: es fällt in die Augen, daß wir uns hier der Sphäre der „Upanishaden“ nähern) '). „Wenn er abends und morgens zum Opferfeuer der Darbringungen hinzutritt oder sich dazu setzt: das ist dessen Verehrung". Eine besondere, häufig begegnende Form der "Verehrung" ist die, daß man des zu verehrenden Wesens unter einer gewissen Benennung, als in der so benannten Wesenheit verkörpert, ehrfurchtsvoll gedenkt: den mystischen Feueraltar verehre man als die Rede; den Opfergesang verehre man als die Silbe Om. An die Vorschrift, die das anordnete, konnten sich dann Erläuterungen schließen, die betreffende Identifikation weiter ausspinnend oder verdeutlichend. Hier ließen sich, wie man sieht, leicht Übungen eines vergeistigteren Kultus entwickeln, die das Sichhinwenden auf erhabenste, transzendente Gegenstände der Anbetung, das Nachdenken über deren mystische Natur in sich schlossen und dafür eine feste Form schufen.

Die Richtung nun auf solche höchste Objekte wurde weiter dem Gedanken mit besonderer Kraft gegeben durch die im ganzen Kultwesen so mächtige Tendenz auf immer volltönendere Verherrlichung der Mächte, von denen man Erfüllung seiner Wünsche erwartete. Den Göttern gegenuiber zeigt sich das, wie allbekannt, sehr deutlich im Rigveda. Dort liebten die Dichter jenen zu schmeicheln, indem sie ihnen sagten, sie seien nicht allein sie selbst, sondern auch

1) Darüber mehr unten. Vgl. auch Anmerk. 97. 98 am Ende dieses Buchs. 
das, was andere Götter sind, sie trügen deren ganze Macht und Herrlichkeit in sich. „Du, o Agni, bist Varuna, wenn du geboren wirst. Du wirst zu Mitra, wenn man dich entflammt. In dir sind die Allgötter, o Sohn der Kraft. Du bist Indra für den Sterblichen, der dir dient." Und etwas wie der "Henotheismus", von dem man hier gesprochen hat, die Verehrung von Göttern, die abwechselnd als höchste, ja als einzige erschienen, konnte sich im Reich jener weltdurchströmenden Substanzen, mit denen sich die Opferwissenschaft vor allem beschäftigte, wohl noch leichter entwickeln. Denn wenn schon die Umrisse der göttlichen Persönlichkeiten nicht scharf und fest genug waren, um solches Hinauswachsen über die eigenen Grenzen, solches Durcheinanderschwimmen auszuschließen, so ist es begreiflich, daß eben dasselbe vollends von den noch unbestimmteren, fließenderen Potenzen der Opfertheologie gegolten hat. Dazu unterstützten manche positive, wenn auch noch so unvollkommene Beobachtungen die Neigung, eine einzelne Natur- oder Seelenkraft mehr oder minder entschieden in den Mittelpunkt von allem zu stellen. Das vom Wind verwehte Feuer, das von ihm ausgetrocknete Wasser schien in den Wind eingegangen. Wenn beim Schlafenden die Rede schweigt, das Auge nicht sieht, das Ohr nicht hört, aber der Atem fortatmet, so schien dieser alles andere, Rede, Gesicht, Gehör in sich aufgenommen zu haben. Es lag in der Art der indischen Phantasie, rasch bis zum Äußersten zu gehen. Wie aber konnte man das Wesen, auf das sich gerade die Aufmerksamkeit richtete, dem gegenüber sich der Drang des Verherrlichens regte, überschwänglicher ehren, als indem man es für das All erklärte? So war man denn in der Tat, wie schon oben (S. 21) erwähnt ist, fruhzeitig leicht bereit, bald der einen bald der andern unter jenen Potenzen nachzurühmen, daß sie "dies Alles" sei. Welcher Kontrast gegenüber jener alten Zeit, für die der höchste Preis des stärksten Gottes dahin ging, daß er den großen Drachen trotz seines furchtbaren Zischens, trotz Blitz und 
Donner, Nebel und Hagelwetter erschlagen habe! Jenes Kompliment freilich, das irgendwelche Wesenheit als das All benannte, war schließlich doch für das ernstliche Auftreten der Idee des All-Einen nur eine Vorbereitung; diese Idee selbst war damit noch nicht errreicht.

Auf sie drängte weiterhin vornehmlich jenes so tief dem philosophierenden Bewußtsein innewohnende Verlangen danach, in aller Vielheit der Erscheinungen die Einheit des Wesens zu erfassen. Wo sich nur der philosophische Gedanke regt, sehen wir ja dieses Grundmotiv wirken. Bald erweckt es Traumgestalten der Dichtung und Ekstase, bald die Bemühung darum, durch die zwingende Kraft von Schlußfolgerungen zu erweisen, was doch dem inneren Anschauen unbewiesen längst feststand. Möglich ist ja zwar eine Denkweise - und Züge von ihr sind auch der vielgestaltigen indischen Philosophie nicht vollkommen fremd geblieben -, welche beim Hinabsteigen zum Wesensgrund der Erscheinungen, beim Suchen, wie in Indien oft gesagt wird, nach der Essenz (rasa) und nach der Essenz der Essenz, durchaus innerhalb der Grenzen des Einzelnen verharrt, so daß das Erscheinende verstanden wird als Erscheinung eines Innern, das eben nur ihm gehört, eben nur es ist, allein aus sich selbst seine Kraft saugend. Die Weltauffassung aber, die dort heimisch zu sein pflegt, wo man den Gang der Dinge durch Zauber und dem verwandte Künste $\mathrm{zu}$ beeinflussen strebt, ist von vornherein, wie schon früher (S. 12) hervorgehoben wurde, vielmehr andrer Betrachtungsweise zugewandt. Hier herrscht ein Schauen, für das "eins in dem andern wirkt und lebt" und so denn "alles

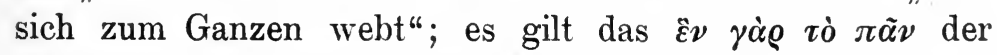
Alchymie. Und wohin dieser Glaube neigt, ebendahin neigte mit besondèrer Kraft auch die Eigenart des indischen Geistes, so daß die für jenes allerorts beobachtbare Stadium der geistigen Entwicklung charakteristische Richtung und die aus dieser besonderen Volksseele stammenden Einflüsse sich gegenseitig verstärkten. In Indien fehlte dem 
Persönlichkeitsgefühl die volle Energie; so ward auch den Objekten in ihrer Begrenztheit kein sicheres, starkes Dasein zuerkannt. Hier herrschte nicht die Übung eines Handelns, das auf die feste und spröde Einzelnatur der hart im Raum sich stoßenden Sachen trifft und um zu seinen Zielen zu gelangen deren Besonderheiten ergrüden und achten muß. Vielmehr waltete hier die Ungeduld eines Sinnens, das gar nicht schnell genug das Eine erkennen kann, „durch dessen Erkenntnis diese ganze Welt erkannt ist". So kam ja auch die Schönheit, die in der Erscheinung des Einzelnen wohnt, in der in sich selbst ruhenden Kraft und Bestimmtheit seiner Formen, der indischen Seele nur selten zum vollen Bewußtsein: die bildenden Künste Indiens legen dafür Zeugnis ab. Das Auge schloß sich den Erscheinungen und ihrer farbenreichen Besonderheit; man hing dem nach darauf $\mathrm{zu}$ lauschen, wie der Lebensstrom in ihrer dunkeln Tiefe rinnt, der eine in allem.

Schon an mancher Stelle der rigvedischen Hymnen (vgl. oben S. 13) und vollends nicht selten in den Brāhmanas, hier freilich mit der diesen Texten eignen Dürrheit und Unbeholfenheit, tritt sehr deutlich die Abneigung dagegen hervor, diese und jene Vielheit definitiv anzuerkennen. Die größere Zahl, die irgendwelchen Wesenheiten zunächst zuzukommen scheint, strebt man schrittweise auf kleinere Zahlen zu reduzieren, bis man bei der Einheit anlangt. Sākalya fragt: "Wie viele Götter gibt es, Yājnavalkya? - Dreihundert und drei, und dreitausend und drei. - Amen! antwortete jener. Wie viele Götter gibt es in Wahrheit, Yāinavalkya? - Drei und dreißig." Und so wird die Zahl weiter und weiter herabgesetzt. Es sind drei, zwei, anderthalb. Es ist einer. Der eine ist der Atem: gemeint wird sein, daß der als Allbeleber das ist, worauf aller Götter Dasein beruht. Ganz ähnlich wird an einer andern Stelle gefragt, wie viel Tage das Jahr hat, und durch Antwort um Antwort wird die Zahl vermindert, bis es zuletzt heißt: "Einen Tag" - denn das Jahr hindurch wiederholt sich 
immer gleich Tag um Tag. "Das ist die dem Jahr geweihte Verehrung (upanishad). Wer diese dem Jahr geweihte Verehrung also kennt, wird während des Jahreslaufs immer vorzuiglicher. Ihm wird Selbstheit zuteil. Er wird zum Jahr. Zum Jahr geworden geht er zu den Göttern ein." Man lasse sich durch den phantastischen Ton dieser Gedankenspiele nicht hindern, den bezeichnenden Zug wahrzunehmen, auf den es in ihnen ankommt. Der erste Eindruck, den die Dinge erwecken, ist der einer gewaltigen Vielheit. Man sieht auf diese Vielheit hin: unter den Augen des Betrachters verringert, vereinfacht sie sich. Weiter und weiter fragt man: man langt bei der Einheit an. So steht man am Ziel. Da winken die Belohnungen, welche die magische Kraft des Wissens dem Wissenden sichert. Ein leicht gewonnener Triumph. Allzu schnell und lässig hat man über die ganze Fülle dessen weggesehen, was die Vielheit zur Vielheit macht. Die Einheit zu entdecken ist so nicht schwer.

Das theoretische Interesse nun an dieser Einheit verbündete sich mit Wünschen und Bedürfnissen für das höchste Wohl des eigenen Daseins, mit Regungen träumender Sehnsucht und gebieterischen Verlangens. Erst dieser Zusammenschluß gab jenem Interesse seine ganze Wirkenskraft. Zum Streben nach Erkennen allein um des Erkennens willen ist man ja nur langsam und allmählich fortgeschritten.

Den Charakter des Wünschens, das hier die Seelen füllte, schildert ein Text sehr lebendig: „Was der Mensch nur erlangt: er strebt darüber hinaus. Erlangt er das Luftreich: er strebt darüber hinaus. Erlangte er jene (die jenseitige) Welt: er würde darüber hinausstreben." Ein Heil wollte man mit raschem Griff erfassen, das aller Gefährdung, aller Einengung entnommen ist. Dafür mußte man einen Stützpunkt in einer allumfassenden, alldurchdringenden Wesenheit gewinnen. Eine Allkraft - von allen Kräften die tiefste, verborgenste - mußte da sein, damit man selbst an deren überschwänglicher Fülle teilnehmen könne. So 
mußte sich Befreiung vom Wiedertode, Unsterblichkeit, der so viele Gedanken und Wünsche zustrebten, erreichen lassen: besser als auf den Wegen jener schwankenden Gedankenspiele, die dem Vollzieher dieses oder jenes Ritus, dem Besitzer dieses oder jenes rituellen Wissens in freigebiger Laune den Lohn der Unsterblichkeit verhießen. Hinauf zur Überhöhe des Einen, das über den Tod erhaben ist! Hinab in die Tiefen des eigenen Wesens, wo man versteckt eben jenes selbe findet, „das durch des Menschen Altern nicht altert, durch seine Tötung nicht getötet wird!“ Und nicht allein auf die Regionen jenseits des Todes blickten die Wünsche, die für das Ich Erhebung zu allbeherrschender Höhe erstrebten. Eine Upanishad sagt einmal sehr offen und bezeichnend: "Was die Fülle ist, das ist Lust. Nicht gibt es Lust an Dürttigem ... Wo man nichts andres sieht, nichts andres hört, nichts andres erkennt: das ist die Fülle. Wo man aber etwas andres sieht, etwas andres hört, etwas andres erkennt: das ist das Dürftige. Was die Fülle ist, wahrlich das ist das Unsterbliche. Was aber das Dürftige ist, das ist das Sterbliche. - Und worauf, Erhabener, gründet die Fülle sich? - Auf ihre eigne Größe, oder auch nicht auf Größe. Größe werden in dieser Welt Kühe und Rosse genannt, Elefanten und Gold, Sklaven und Gattinnen, Felder, Heimstätten. So ist es nicht gemeint, nicht gemeint sagte er - denn da gründet sich immer eins auf das andre. Sie aber (die Fülle) ist unten, ist oben, ist im Westen, im Osten, im Suiden, im Norden. Sie ist dieses Alles." Wer so sein Selbst als das All erfaßt, fährt der Text fort, „an seinem Selbst sich freuend, mit dem Selbst spielend, mit dem Selbst sich paarend, am Selbst sich ergötzend, der wird Selbstherr; frei durchwandelt er alle Welten. Die es aber anders erkennen, die sind fremder Herrschaft untertan; vergängliche Welten gehören ihnen; unfrei bewegen sie sich durch alle Welten".?

In Äußerungen wie diesen befindet man sich in naher Nähe der Sphäre, oder man ist schon in die Sphäre selbst 
eingetreten, in welcher der Genuß solcher Fülle, das Aufgehen im Allsein am tiefsten ersehnt und genossen wird: die Sphäre der Mystik.

Auch in Indien hatte sich schon von altersher das Trachten der Mystik geregt, höheres Sein in sich aufzunehmen, mit höherem Sein zu verschmelzen. Zuerst selbstverständlich in plump grotesken Formen. Der Somarausch erhob den frommen Trinker in Höhen, wo er Himmel und Erde überragte. Ein Lied des Rigveda schildert das wilde Treiben der "in Schmutz gekleideten" Heiligen, in welche „die Götter gefahren sind". Jüngere Vedatexte beschreiben die „blauschwarze Dunkelheit" und „packende Kraft" mannigfacher schamanenhafter Kasteiungen. ${ }^{10}$ Im Ganzen fand das alles dort keinen besonders günstigen Boden, wo die auf eine andre Tonart gestimmte Verehrung der persönlichen Vedagötter in voller Kraft stand; in der Somapoesie des Rigveda trat das ritualistische Element vor dem mystischen weit in den Vordergrund. Aber dann hatte die Brāhmanaspekulation ihren Zug auf das Unpersönliche eben in das rituelle Wesen hineingetragen. Das alte Opfer war nicht mehr der nüchterne Vorgang des Gebens und Nehmens von Person zu Person geblieben. Die mit ihm spielende Phantasie hatte es zu geheimnisvollen Wirkungen unpersönlicher Potenzen umgeschaffen. So waren jetzt die Bahnen dafür geebnet, daß in neuen Gestalten Mystik, die in der Sphäre des Unpersönlichen so viel leichter gedeiht, ihren Einzug halten konnte. Nunmehr stand sie natürlich auf anderm Niveau als dem jener rigvedischen Fakirs. Sie ging durch ähnliche Läuterungen hindurch, wie sie in Griechenland von der Raserei alten Bakchantentums bis zu Plotins Ekstase geführt haben. Der Mystiker der Upanishaden hatte es nicht mehr mit dem Lärm wilder, ungeberdiger Geister zu tun. Er wurde nicht von jäher Besessenheit erfaßt, erstrebte auch nicht - oder doch nur als Nebensache, den Anschauungen des Zeitalters seinen Tribut bringend - die Zauberkünste eines Wundermannes. Sondern er suchte Unsterblichkeit, 
Ewigkeit, beseligendes substantielles Einssein mit dem Jenseitigen, All-Einen. -

So wurden durch das Zusammentreffen mannigfacher Motive unter den Potenzen, denen die Opferwissenschaft Macht über die Dinge zuerkannte, Bewegungen hervorgerufen, in denen sich eine beherrschende Obergewalt uber das Gewirr erhob. Sehr viel zielbewußte Gedankenarbeit war dabei wohl auch jetzt nicht im Spiel. Es ist als hätten sich die Vorstellungen vermöge ihres eignen Schwergewichts zu der neuen Figur geordnet.

Das Brahman.

Was sollte der Name sein, der das zur Herrschaft gelangende Allwesen benannte?

Man könnte einen allgemeinsten Ausdruck erwarten, etwa wie das "Sein", das "Seiende" der Eleaten. Hatte doch schon ein rigvedisches Lied in wundervoller Frühreife der Abstraktion über den Anfang der Dinge das Wort gesprochen:

„Da war nicht Nichtsein, und da war auch Sein nicht.“ In der Tat wurde hier und da in den Upanishaden und verwandten Texten das "Seiende" als das Urwesen genannt. Oder um etwas noch Ursprünglicheres zu finden, dem selbst das Seiende entstammen konnte, ging man auf das Nichtseiende zurück, lehrte wohl auch kühnlich, daß im Anfang der Dinge das Nichtseiende war, „dieses war das Seiende." Oder dem Urwesen wurden in tastendem Hin- und Hergreifen gelegentlich Namen gegeben wie Kāla „die Zeit", ${ }^{11}$ oder mit persönlicher Wendung Prajāpati, der in den Brāhmaṇatexten geläufige Name des Weltschöpfers.

Doch weit in den Vordergrund traten vor diesen im Anfang noch konkurrierenden Benennungen und Auffassungen des höchsten Wesens zwei andre.

Man nannte es Brahman, etwa "heilige Macht." Und man nannte es Ātman „das Selbst".

Es ist bezeichnend und entspricht dem oben entwor- 
fenen Bilde des Hergangs, daß es eben nicht das "Seiende" war, sondern konkretere schon inmitten jenes welterfüllenden Gewirrs der Opfersymbolik vorhandene Potenzen, die nunmehr zur definitiven Besitznahme der höchsten Stelle aufrückten. Jene beiden allem Anschein nach etwa gleichzeitig: ein zweiter nicht weniger bezeichnender Zug. Dieselbe Tendenz des Aufruickens wirkte in verschiedenen Regionen der Vorstellungsmassen. So traten zwei einander ähnliche Versuche der Lösung desselben Problems auf. Daß dies darauf beruht, daß hier die Arbeit Vieler vorliegt, ist möglich, doch kaum gewiß. Das ungeordnete Hin- und Herwogen dieser Ideen läßt als durchaus denkbar auch erscheinen, daß denselben Geistern sich abwechselnd, wenn nicht gleichzeitig, diese und auch jene Wesenheit als das Allwesen darstellte. Anderswo wären nun vielleicht zwei Systeme einander gegenüber getreten: Brahmanlehre und Âtmanlehre. Hier aber haben sich alsbald die Träger der höchsten Würde unter einander identifiziert; ein Ein und Alles konnte es ja nur in einem Exemplar geben. Ein dritter sehr charakteristischer Zug dieser Gedankenbewegung endlich ist, daß von den zum Allwesen aufsteigenden Mächten keine dem Reich der physischen Natur angehörte ${ }^{1}$ ). Andre Geheimnisse als die der Natur schienen tiefer, entscheidender. Da war hier die zentrale Potenz des Veda, das Brahman. Dort die zentrale Potenz der Persönlichkeit, Ātman. In die Augen fällt der ich möchte sagen egozentrische Charakter dieser Vorstellungen. Die alles Dasein regierende Gewalt wurde vom brahmanischen Denker in dem gefunden, was

1) Anfänge von Erwägungen derart, wie die älteste griechische Philosophie sie anstellte, Zurückführung verschiedenster Naturwesenheiten auf dasselbe latent in ihnen enthaltene physische Element, begegnen allerdings auch in den Upanishaden (vgl. auch S. 38). So heißt es: „Wasser nur in festem Zustand ist diese Erde, die Luft, der Himmel, die Berge, die Götter und Menschen, Vieh und Vögel, Kräuter und Bäume, wilde Tiere bis zum Gewürm, Motten und Ameisen: sie sind Wasser in festem Zustand." Aber als letzten Grund des Seins, wie bei Thales, versteht der betreffende Text (Chānd. Up. VII, 10) das Wasser darum doch nicht. 
er als die geheime und furchtbare, sein eignes Inneres durchwaltende magische Macht fühlte, oder in einem universellen Selbst, das seinem eignen Selbst glich, nein sein eignes Selbst war.

Das Wort und die Vorstellung des Brahman läßt sich $\mathrm{zu}$ den ältesten Texten Indiens zurückverfolgen. Kein Zweifel, daß es in Wahrheit noch älter ist. ${ }^{1}$ )

Seine Bedeutung zu verstehen bedenke man, daß es auf dem Boden jener Weltanschauung erwachsen ist, mit der eben unsre bisherigen Darlegungen es zu tun hatten: das All durchwogt von Kräften, die bald hier oder dort ihren Sitz haben, in diesem oder jenem Menschen, Tier, Ding, Zahl, Wort wohnen oder sich verkörpern, bald frei umherschweben, sich anderswohin durch Berührung übertragen oder hinüberfliegen, offen oder versteckt, aus eigner Macht oder einem Zauber gehorchend, um die Wirkungen auszuuben, die den phantastischen Ordnungen ihrer Natur entsprechen.

In diesem Sinn war das Brahman, lange ehe die Spekulation das absolute Wesen so benannte, zugleich das Vedawort und - was für die alte Vorstellungsweise damit zusammenfällt - die dem Vedawort im Gegensatz zum profanen Wort und auch dem Kenner und Besitzer dieses Worts, dem Brahmanen im Gegensatz zum profanen Menschen innewohnende heilig-unheimliche Substanz und Kraft. Den hier eben gebrauchten Ausdruck „heilig“ darf man aber, wie kaum erinnert $\mathrm{zu}$ werden braucht, nicht in dem uns geläufigen Sinn höchster und reinster ethischer Erhabenheit verstehen. Ethische Elemente - insonderheit Elemente unsrer Ethik - sind fern zu halten. "Heilig“ ist hier das

1) Das Wort scheint mit dem irischen bricht (Zauber, Zauberspruch) verwandt. Vgl. Osthoff, Bezzenberger's Beiträge 24, $113 \mathrm{ff}$. In vorhistorischer Zeit muB es ein mit brahman eng verwandtes und gleichbedeutendes Nomen brh gegeben haben, wie aus dem Götternamen Bṛhaspati $=$ Brahmanaspati $\left({ }_{n}\right.$ Herr der brh resp. des brahman $\left.{ }^{*}\right)$ geschlossen werden kann. 
dem gewöhnlichen Dasein nicht Angehörige, ihm unvergleichlich Überlegene, in seiner eignen geheimen Art Waltende - etwas, dessen Überkraft jedes Gegners spottet, das die vorwitzige Berührung durch alltägliches Tun und Treiben, die Verletzung des Tabu furchtbar bestraft.

Die Heiligkeit des Brahman also kam zunächst in dem mit mystischer Kraft gesättigten Vedawort zur Erscheinung. Ein Brāhmanatext spricht vom "siebensilbigen Brahman", auf das die Sonne gegründet ist: eine Silbe ist rc (der heilige Hymnus); je zwei Silben sind yajus und sāman (Opferspruch und Opferlied); zwei Silben endlich sind all das brahman, das es außer jenen noch gibt - man wird an die Zauberformeln und -lieder des Atharvaveda und Ähnliches denken; auch daran, da $\beta$ der Priester, der vom Geheimsinn des Opfers redete, ein "Brahmansprecher" hieß. So war denn das Brahman soviel wie das "dreifache Wissen" die nach Hymnen, Opfersprüchen, Opferliedern gegliederte Vedakunde. „Die Rede wahrlich ist das Brahman. Dieser Rede Wahrheit ist das Brahman": man bedenke, um diese Äußerung zu würdigen, die Rolle, welche die alte Anschauung dem Wort, seinem mystischen Wesen, seiner geheimen Kraft beilegte. Unwiderstehlich, unfehlbar wirkt im Himmel und auf Erden das Brahman, der Zauberspruch oder das Zaubergebet, das der kundige Priester handhabte. Er schirrt, wie das rigvedische Lied sagt, durch sein Brahman dem Gott die langmähnigen Rosse an für die Fahrt zum Somagelage. Viśvāmitra's, des Priesters, Brahman hat das Volk der Bharatas beschützt. Durch das Brahman tötet man böse Geister und irdische Feinde. Wer die Kraft und Kunde des im Veda wohnenden Brahman erwerben, in sich ansammeln will, wen der Lehrer "in das Brahman setzt" und wer so „das strahlende Brahman in sich trägt: darin sind alle Götter verwoben“, der muß die Pflichten des "Brahmanwandels" (vgl. oben S. 7) üben. Das Gebot der Keuschheit, das für ihn gilt, hat den Sinn, daß nichts, was mit der kostbaren Brahmansubstanz gesättigt ist, aus seinem Körper entweichen 
darf. Kein Wunder, daß man diese starke Konzentration von Zauberkraft nicht aus dem Schülertum in das tägliche Leben hinübernimmt. Ein Bad schließt die Schulzeit ab. Es wurde schon bemerkt (S. 8), daß dessen ursprüngliche Bestimmung die war, wegzuwaschen, was von dem Heiligen in der veränderten, für den unmittelbaren Kontakt mit ihm nicht gerüsteten Lebenslage gefahrbringend schien.

So gab es also als Verkörperung des Brahman neben dem heiligen Wort noch ein zweites, den heiligen Menschen, der als Brahmacārin (Vollzieher des Brahmanwandels) und dann überhaupt als Brahmane eben von jener ihn erfüllenden Wesenheit den Namen hatte. Das im Brahmanen weilende Brahman hatte ein Gegenstück in der Potenz, die dem weltlichen Adel, der zweiten Kaste innewohnte, dem Kshatra. ${ }^{19}$ Brahman und Kshatra sind "die beiden Kräfte", welche die menschliche Gesellschaft beherrschen. Als die Waffen des Kshatra nannte man den rossebespannten Streitwagen, Panzer, Pfeil und Bogen; Waffen des Brahman sind die Opfergeräte. Das Bündnis jener weltlichen und dieser geistlichen Gewalt erschien auch indischen Staatskünstlern als Notwendigkeit. Man betete:

"Wo zusammen geht einträchtig des Brahman und des Kshatra Kraft:

Mög' ich die heil'ge Welt schauen, wo Agni bei den Göttern weilt."

Wobei man nicht unterließ $\mathrm{zu}$ betonen - vielleicht um so angelegentlicher, als die Wirklichkeit diesem Ideal kaum immer entsprach - daß in jenem Bund dem Brahman der Vorrang gebührt. „Wo das Kshatra dem Willen des Brahman untertan ist: das Königreich gedeiht; das ist reich an Helden; ein Held wird daselbst geboren." Wagt aber das Kshatra das Brahman zu beleidigen, so zerbricht seine irdische Gewalt elendiglich vor jener Zauberkraft, vor der Übermacht des Unsichtbaren gegenüber dem Sichtbaren, des Feinen, Tiefen gegenüber dem auf der Oberfläche Liegenden: 
„Scharfpfeilgeschoßbewehrt sind die Brahmanen.

Des Ziels gewiß sind ihres Bogens Schüsse.

Den Feind mit Grimm und mit Kasteiungsgluten

Verfolgen sie zerschmetternd aus der Ferne."

Aus all dem sieht man, wie auf dieser Entwicklungsstufe das Brahman noch ganz in der Sphäre des altertümlichen Zauberglaubens sein Wesen trieb. Unter dem indischen Inventar dieses Glaubens war ihm nah verwandt das oft mit ihm zusammen genannte Tapas (wörtlich "Hitze“, vgl. oben S. 6), das magische Fluidum der Kasteiungskraft - jener Kraft, wie sie einst der Weltschöpfer Prajāpati erworben hat: nach tausendjähriger heißer Kasteiung kamen aus seinen Poren Lichter hervor, die Sterne. Blicken wir über Indien hinaus, so begegnen wir dem Mana der Melanesier, der Kraft, „die alles bewirkt, was über die gewöhnliche menschliche Kraft hinausgeht, was außerhalb der normalen Naturvorgänge liegt. Es ist in der Atmosphäre des Lebens gegenwärtig, heftet sich an Personen und Dinge, und offenbart sich in Erfolgen, die nur seinem Wirken zugeschrieben werden können ... Zauberer, Ärzte, Wettermacher, Propheten, Zeichendeuter, Traumkünstler: sie wirken alle gleichermaßen überall in den Inseln durch diese Kraft" (Codrington). Ähnlich das Orenda der Huronen und bei andern Völkern oder Stämmen eine stattliche Reihe vergleichbarer Potenzen, denen gegenwärtig die Völkerkunde eingehende Aufmerksamkeit zuwendet. ${ }^{13}$ Man wird zwar deren Unterschied vom Brahman nicht übersehen. Das Brahman ist nach seinem ältesten uns erkennbaren Wesen keine allgemeine weltdurchwirkende übernatürliche Kraft - Namen und Vorstellung einer solchen scheint mir im Veda zu fehlen -, sondern speziell eben das heilige, zaubermächtige Vedawort und das ihm sowie seinen Inhabern innewohnende mysteriöse Fluidum. Soziale Entwicklungen haben diese besondere Potenz in ihrer eigenartigen Geltung gestaltet, und dann ist sie erst sekundär, wie wir verfolgen werden, zu universeller Bedeutung aufgestiegen. Immerhin bleibt die Gleichartigkeit 
des Brahman mit Mana, Orenda und Verwandtem groß genug, um zur Charakteristik des freilich schon durch den Veda allein deutlich indizierten geschichtlichen Niveaus beizutragen, dem die Vorstellung vom Brahman in ihrer hohen Altertümlichkeit zunächst angehört. Die Verbindungslinien, diè von da zur jüngeren Phase, zum Brahman als höchster Idee der pantheistischen Spekulation führen, durchlaufen offenbar keine sehr weiten Zeitstrecken. So ist von vornherein wahrscheinlich, daß, wenn die Bewegung zum Ziel gelangt sein wird, in der Erscheinung jener Idee Spuren kaum fehlen werden, in denen sich noch die Nachbarschaft der alten Vorstellungen deutlich verrät. -

Diese Bewegung, von der jetzt zu sprechen ist, spiegelt sich in vielen volltönigen Äußerungen der Texte $a b$, die dem Brahman erhabensté, dem höchsten Gipfel sich annähernde Dignität zuweisen. Es wäre ein müßiges Bemühen, die einzelnen Einfälle, die da auftauchen, nach dem Grad ihrer Annäherung an den letzten Höhepunkt zu ordnen. Gelänge es, bliebe immer noch ungewiß, wie weit damit auch die chronologische Ordnung des Einzelnen hergestellt wäre. Für das Verständnis des ganzen Vorgangs aber muß man sich dies gegenwärtig halten, wie grundverschieden von unserm Weltbild das Weltbild ist, in dem diese Idee des Brahman zu ihrer beherrschenden Höhe aufsteigt. Ein Bild, wie wir sahen, unter dessen Elementen, zwischen Zaubermächten aller Art, ebenso stark, vielleicht stärker als Himmel und Erde, die Opferhymnen, Opfersprüche, Opferlieder im Vordergrund stehen. Wo die Geschehnisse und Bewegungen des Weltlebens den Figuren des Opfervorgangs, der Liturgien entsprechen und durch die im Vedawort wohnende magische Kraft gelenkt werden. Das alles betrachtet mit den Augen dessen, der eben diese Kraft als von Geburt her sich selbst innewohnend fühlt. Der weiß, daß „aus dem Brahman das Kshatra gebildet ist: der Brahmane aber ist Brahman durch sein eignes Selbst." Der seine Tage damit verbringt, das Brahman immer stärker in sich an- 
zusammeln, es vorsichtig zu behüten, kunstgerecht zu betätigen.

Bald ${ }^{14}$ ist "das Brahman, das dreifache Wissen" das erste Geschöpf, welches der Weltschöpfer Prajāpati sich abmühend in heißer Kasteiung aus sich entlassen hat und das zur Grundlage dieses All geworden ist. . Bald ist jenes Geschöpf mit dem Schöpfer zusammengeflossen und man lehrt: „Prajāpati wahrlich ist das Brahman, denn von des Brahman Natur ist Prajāpati." "Das Brahman ist das Älteste (Höchste), denn es gibt nichts Älteres (Höheres) als dies. Wahrlich Ältester und Herrlichster unter den Seinen wird, wer also weiß." „Das Brahman ist unter den Göttern das Höchste ... Durch das Brahman sind Himmel und Erde aus einander gestützt." "Im dreifachen Wissen sind alle Wesen."

„Den Ric ${ }^{1}$ ) gehört des Ostens weite Gegend" -

so hebt ein Lied an, das die vier Himmelsgegenden den Veden zueignet, die Kasten aus den Veden geboren sein läßt -

"Die Alten taten kund dies Wort den Alten."

Auch Sonnenaufgang, Mittag und Untergang, sagt dasselbe Lied, werden von Rigveda, Yajurveda, Sāmaveda regiert:

"Voll der drei Veden geht den Weg die Sonne." Und weiter:

„Alle Gestaltung heißt den Ric entsprungen,

Jede Bewegung immerdar den Yajus;

Der Sāman Aussehn tragen alle Gluten:

Vom Brahman ist dies ganze All erschaffen."

Sehr deutlich zeigt sich, daß es im Grunde immer noch das alte, in den Veden offenbarte Brahman ist, das sich hier zu allschöpferischer Macht erhoben hat, zum All sich so verhält, wie seine Zweige oder Erscheinungsformen, die drei Veden, zu den einzelnen Daseinstypen oder Lebensphasen innerhalb des All. ${ }^{15}$

Und endlich war es dann in der verschwimmenden Un-

1) Den im Rigveda gesammelten heiligen Versen. 
bestimmtheit aller dieser Gedanken kaum noch ein bemerkbarer Schritt vorwärts, wenn das Wesen, welches das All geschaffen hat, nun selbst Allwesen wurde. Indem dieser Schritt geschah, lockerte sich unvermeidlich das Band zwischen dem Wort Brahman und seinem alten, beschränkten Sinn. Dafür schickte das Brahman sich an mit jener andern Idee zusammenzufließen, die gleichfalls die Kraft besaß zu allbeherrschender Geltung aufzusteigen, mit dem Ātman.

\section{Der Ātman.}

Die Grundbedeutung von Ātman ist, wie sich kaum bezweifeln läßt, „Atem"; mit diesem deutschen Wort gehört das indische etymologisch wohl zusammen. Alte Vedaverse setzen gern Ātman in Beziehung zu Vāta, dem Wind oder Windgott. Der Wind ist der Ātman Varuña's, der Ātman der Götter. Stirbt der Mensch, „soll zur Sonne sein Auge gehen, zum Winde der Ätman". Es ist ersichtlich, wie da dem Ātman die Rolle zufällt, der einem Einzelwesen zugehörige, in ihm wohnende windesgleiche Hauch zu sein. Indem nun der Hauch als Träger des Lebens erscheint und als das, worauf das Dasein der Persönlichkeit beruht, tritt bald die ursprüngliche Bedeutung von Ātman vor diesem vornehmeren, tieferen Sinn zurück. So differenzirt sich Ātman gegenüber Prāna, welches Wort mehr dazu neigt, den Atem im eigentlichen Sinn der körperlichen Funktion, oder auch im Plural eine Mehrheit solcher Funktionen, die "Atemkräfte“, zu benennen ${ }^{16}$. Verglichen mit dem Prāna oder den Prāṇas ist der Ātman bedeutender, zentraler. Er ist "der unbenannte Prāna": das Unbenannte aber gilt fur tiefer, wunderbarer als das Benannte. "In der Mitte wohnt dieser Ātman, um ihn herum die Prānas.“ „Zehn sind die Prānas im Menschen. Der Ātman ist der elfte, auf den die Prānas gegründet sind." Mit diesem Ausgehen von der Hauchvorstellung aber steht es nicht in Widerspruch, daß der Ätman auch, uraltem Seelenglauben entsprechend, als ein kleiner Mann (purusha), etwa daumengroß oder so groß 
wie ein Reiskorn, ein Gerstenkorn, im Innern des Herzens wohnt. Er ist der Herrscher über die einzelnen Organe und bedient sich ihrer für seine Zwecke. Gewiß darf schon der Periode, in der sich die Upanishadenspekulation vorbereitet, die Anschauung zugeschrieben werden, die sich ausgesprochen allerdings, soviel ich sehe, erst in einer Upanishad findet: der Sehende, Hörende, Redende ist in Wahrheit der Ātman; Auge, Ohr, Stimme sind bloßes Werkzeug. Ist im Gegensatz etwa zu den Kindern, zum Vieh, das man besitzt, die Rede von der eigenen Person, so ist das Wort dafür Ātman. Als Ausdruck für das Selbst wird Ātman geradezu Reflexivpronomen; für "er kauft sich selbst los" wird gesagt: „er kauft den Ātman los".

Ein Begriff, durchaus geschaffen, in diesen Entwicklungen des Denkens eine leitende Rolle zu spielen. Hier fand sich eine Figur eben wie man sie vorzustellen liebte: in der Tiefe einer Vielheit wohnend ein Eines, auf dem jene begründet ist, von dem sie beherrscht wird. Und dies Eine das Ich: den Punkt bezeichnend, an dem die letzten, höchsten Interessen in Frage kommen. Vom Reich des Ich aber laufen, wie schon oben (S. 24f.) berührt wurde, ganz wie von der Sphäre des Vedaworts, für das Bewußtsein dieser Zeit allerstärkste Fäden zum Universum. Wie sollten der heiß erregten Phantasie die Grenzen zwischen beidem feststehen? Das Universum flutet in das Ich hinein. Das Ich nimmt vorstellend, erkennend jenes in sich auf. Die Konfiguration der Ichwelt bildet die der großen Welt draußen ab. Wie im Körper der Atem lebt, so ist es nichts anderes als "Atem" (prāạa), was auch in der Natur blitzt, donnert, regnet:

"Wenn der Atem mit Regenguß die weite Erde

überströmt,

Dann wird alles Getier fröhlich: jetzt ward uns

Überfluß zuteil!

Gras und Kräuter regenbeströmt sprechen zum Atem allzumal:

$\mathrm{Du}$ bist's der uns verlieh Leben! Du spendetest uns süßen Duft!“ 
Wenn nun dann weiter ähnlich, wie es sich hier beim "Atem" (prāna) zeigt, das menschliche oder tierische Auge der Sonne entspricht, und mehr als das, im Tode zur Sonne hingeht, sich mit ihr in vollster Wirklichkeit zu vereinen, und wenn die andern Glieder gleichermaßen Entsprechung und Ziel in Wesenheiten des Makrokosmus besitzen, so drängte sich offenbar die Vorstellung eines ebenso dem menschlichen Ātman entsprechenden, ihm wesensgleichen universellen Selbstes geradezu unvermeidlich auf. Dies große Selbst mußte der Grund sein, auf dem das individuelle Selbst beruht, das Ziel, dem sich seine Bewegung zuwendet. Hier war das Verlangen, das eigene Ich in höchstem Sein verankert $\mathrm{zu}$ wissen, seiner Erfullung sicher.

Schon längst, in der alten Zeit des Rigveda, hatte ein Hymnendichter - damals nur in flüchtigem Gedankenspiel - die Vorstellung eines universellen Ātman vorweggenommen: „die Sonne, der Ātman des Bewegten und des Ruhenden." Jetzt konnte nicht mehr Hervorhebung einer einzelnen materiellen Wesenheit wie der Sonne das letzte Wort sein. Eine Formel entstand, welche die geläufigen Korresponsionen der vorher beschriebenen Art wie Sonne - Auge, Weltgegenden - Ohr usw. in das offenbar den Höhepunkt der ganzen Reihe bildende Schlußglied auslaufen ließ: „Der Ātman beruht in meinem Ātman" - im persönlichen der universelle: eine Beziehung vielleicht noch enger, noch einleuchtender als alle jene vorangehenden, weil hier nicht mehr zwei verschiedene Worte wie Sonne und Auge einander gegenüberstanden, sondern dasselbe Wort Ātman hüben und drüben die Vorstellung voller Identität hervorrief.

Ein gewisser Unterschied zwischen der Bewegung, in der Brahman und Ātman diese höchste Höhe erstiegen haben, scheint nicht zu verkennen. Neben der äußersten Steigerung der Vorstellung des Brahman finden sich in den Texten, wie wir sahen, mindere solche Steigerungen. Der Ātman dagegen springt, scheint es, unvermittelt von seiner 
individuellen Geltung zur allgemeinen über. Das unbestimmte Fluidum des Brahman war eben wohl leichter fähig, minder weit und tief oder auch weiter vorzudringen. Der Ātman dagegen, das Selbst, welches doch das Selbst irgend einer Wesenheit sein mußte, trug in diesem Gebundensein an ein bestimmtes Substrat, dessen Kräfte er in sich zusammenfaßte, selbst ein gewisses Bedürfnis der Bestimmtheit in sich. Man mochte neben dem Selbst der in der Erfahrung gegebenen Wesen, oder etwa mit jenem identisch, auch ein universelles Selbst denken. Auf dem Wege vom einen zum andern aber eine Zwischenstation, man weiß nicht wo, zu machen, ein Selbst vorzustellen, das mehr als das eine und doch noch nicht das andere gewesen wäre, empfand man schwerlich einen Antrieb.

\section{Brahman und Ātman identifiziert.}

So war denn Alles bereit, daß sich das große Ereignis vollziehen konnte: das Zusammenfallen der beiden Wesenheiten, die schon im Selbst des vom Brahman erfülten Brahmanen verschmolzen, nun beide zu universeller Macht aufgestiegen waren: hier der alten Zauberkraft des heiligen Worts und der heiligen Kaste, dort der Idee des Ich, des Selbst. Die Schranken fielen. Nun fuhren die Denker, wenn sie vom Allwesen unter dem einen Namen zu sprechen angefangen hatten, mit dem andern fort. Wollten sie den Ätman beschreiben, sagten sie, daß er das Brahman ist. Wurde nach dem Brahman gefragt, erklärten sie es als den Ātman: diese letztere Gedankenrichtung vielleicht vor der andern vorwiegend, denn die Vorstellung des Brahman war die dunklere, die des Ātman dem Verständnis näher. Soweit das auch hier noch überall herrschende Schwanken der Umrisse solche Unterscheidungen erlaubt, kann man vielleicht sagen, daß zu der aus Brahman und Selbst, also in gewissem Sinne über Brahman und Selbst jetzt sich aufbauenden Gestalt des Allwesens das Brahman, seiner früheren Natur entsprechend, mehr die Richtung in die Weite mitbrachte, 
das Selbst mehr die Richtung in die Tiefe. Jenes hat objektiveres Wesen; dieses ist das Subjekt. Dort eine die Dinge durch alle Fernen ubergewaltig, zauberhaft - mehr zauberhaft als königlich - regierende Kraft. Hier ein im Innersten des Daseins wohnender, eben dies Innerste seiender Wesenskern. Vom Brahman kam es dem All-Einen wie ein Hauch aus der Vorzeit, ein Anflug vom Erdgeruch des Bodens, in dem die Vorstellungen von Zaubertum und Zauberermacht erwachsen waren: dem auf jenem Boden heimischen Brahmanen keine geringe Erleichterung des Eintritts in das neue Gedankenreich. Vom Ātman kam dem Allwesen Licht und Erkennen, Verwandtschaft, nein Einssein mit dem menschlichen Ātman, der dies Ewige sucht und denkt. Der Leser der Upanishaden wird, meine ich, die Empfindung haben, daß ihren Verfassern, denen diese Doppelnatur für ihre Gedankenbewegung manche Erleichterung bot, im Ganzen wohl Âtman, verglichen mit Brahman, als der wenn auch vielleicht nur um eine Nuance adäquatere Ausdruck erschienen ist. Dringender als das Selbst hatte es Brahman nötig, dem Allwesen seinen Namen gebend Beschränkungen überwundener Denkformen von sich abzustreifen, die nur noch in einer immer leiser werdenden Erinnerung nachklangen. Schließlich kommt doch wohl im Nebeneinander der beiden Namen in gewisser Weise etwas von Emanzipation der höchsten Idee gegenüber der Vorgeschichte, aus der sie erwachsen ist, zum Ausdruck. So entschieden man jeden dieser Namen als giltigen Namen der Idee empfand, war doch keiner von ihnen der einzige Name, blieb das Höchste zu allerletzt vom einen wie vom andern Namen unabhängig. Es verhielt sich ja eben auch nicht mehr so - oder wenigstens oft verhielt es sich nicht so daß man vom Brahman oder vom Selbst im nächsten Sinn dieser Worte redete, um es dann weiter als das All-Eine zu verkünden. Sondern man sprach vom All-Einen, und indem menschliches Bedürnis für das Unbenennbare Namen suchte, nannte man es Brahman, nannte man es Ātman. - 
Eins der ältesten Zeugnisse, vielmehr wohl das älteste, für die Verschmelzung von Brahman und Ātman ist in einem Erguß philosophischer Beredsamkeit enthalten, der dem weisen Sāndilya zugeschrieben wird. Die schon von der ursprünglichen Überlieferung gegebene Anknüpfung an diesen Namen scheint bestreitbar. Doch was liegt am Namen? Der Textabschnitt findet sich, in zwei Redaktionen, in einem Brāhmaña und einer Upanishad ${ }^{12}$. Die Grenzen zwischen beiden Gattungen sind ja nicht fest. Und jene Doppelstellung stimmt dazu, daß eben hier der Punkt liegt, wo die Gedankengänge der Brāhmaṇas in die der Upanishaden übergehen. Aus der Umgebung, in welcher der Abschnitt im Brāhmana steht, hebt er sich als etwas Eigenes, neu Geartetes hervor. Mit keinem Wort wird der Riten gedacht, um die es sich dort sonst handelt. Statt der kühlen, trockenen Steifheit, der lehrhaften Pedanterie der Brāhmanadiktion herrscht hinreißender Schwung, entstammend einer selbst hingerissenen, in tiefem Schauen weilenden Seele. Die Häufung der Beiworte und Vergleiche malt wundervoll lebendig des Redenden Verlangen, mit seinen Worten dem näher, immer näher zu kommen, was ganz kein Wort ausspricht ${ }^{1}$ ). In der Fassung des Brāhmanatextes lautet die Stelle:

„Das Brahman ist das Wahre: so verehre man es. Aus Wollen nur besteht der Mensch. Welches Wollens er aus dieser Welt scheidet, solches Wollens gelangt er scheidend zu jener Welt hin. So verehre er das Selbst (ātman): Gedanke ist seine Natur, Odem sein Leib, Licht seine Gestalt, der Äther sein Selbst - das wunschgestaltete, gedankenschnelle, wahren Bedenkens, wahren Haltens, allduftreich, allsaftreich, alle Weltgegenden durchwirkend, dies All durchdringend, wortlos, achtlos. Wie ein Korn Reis oder Gerste

1) Der Übersetzer kann diese Beiworte nicht in ihrer ganzen Wucht wiedergeben. Da unsere Sprache in der Fähigkeit Zusammensetzungen zu bilden weit hinter der indischen zurücksteht, muß oft, was dort ein Wort ist, in mehrere aufgelöst und dadurch abgeschwächt werden. 
oder Hirse oder ein Hirsekern, so ist dieser Geist im Selbst darinnen, golden wie rauchlose Flamme, größer als der Himmel, größer als der Äther, größer als diese Erde, größer als alle Wesen. Dies ist des Odems Selbst; dies ist mein Selbst. $\mathrm{Zu}$ diesem Selbst werde ich von hier scheidend hingelangen. Wem solches zu eigen, wahrlich, da gibt es keinen Zweifel. Also sprach Śāṇdilya. So ist es."

Ungern schwächt man solche Worte durch Erklärungen ab. Aber die Entferntheit der Ausdrucksweise von der unsern, die Weglassung mancher $\mathrm{Z}$ wischenglieder legt doch den Versuch nah zu beschreiben, wie der Gedankengang verläuft.

Die Eingangsworte fordern in der hergebrachten Form (vgl. oben S. 37) zur "Verehrung" auf, indem sie den Ausdruck namhaft machen, unter dem diese Verehrung dem höchsten Wesen zu bringen ist. Das Brahman verehre man als das Wahre ${ }^{18}$ : diese seine Wahrheit verbürgt die Erreichung des Erfolges, zu dem dann der Weg gezeigt wird; sie schließt den Zweifel aus, den auch der Schluß des Stückes abwehrt. Das aber, wofür diese Zuversicht gilt, ist das Streben, im Jenseits sich die Stätte zu bereiten: die große Frage aller Fragen. Über ihre Lösung entscheidet das Wollen. Das Wollen führt den Sterbenden auf dem Jenseitspfad: zum rechten Ziel das rechte Wollen. Das rechte Wollen richtet sich auf das Selbst. So wird, wie im Eingang Verehrung des Brahman, jetzt Verehrung des Selbst empfohlen: zum zweitenmal das charakteristische Leitmotiv der "Verehrung“. Brahman und Selbst aber sind unzweifelhaft als identisch gedacht. Das bestätigt zum Überfluß die andre Fassung der Stelle, die gegen den Schluß des Ganzen hinter den Worten "dies ist mein Selbst" (in der Upanishad: „dies ist mein Selbst im Herzen darinnen") hinzufügt „dies ist das Brahman".

Es folgt die Verherrlichung des Selbst in seiner geistigen Lichtnatur. Mancher Zug dieses wundervollen Hymnus ist auf den Vorstellungen von der irdisch-menschlichen Selbstheit 
begründet. Aber deren Wesen ist zu allumfassender Weite, allüberragender Höhe gesteigert. Das Selbst ist so klein wie das Kleinste und doch größer als' das Größte. Das AllSelbst ist mein Selbst: damit ist meinem Selbst das Ziel gewiesen, die Stätte gesichert. Die Worte am Schluß ,zu diesem Selbst werde ich von hier scheidend hingelangen" entsprechen deutlich dem Eingang, wo es hieß, daß jeder je nach seinem Wollen "scheidend zu jener Welt hingelangt". Darin hatte die Frage gelegen: welches soll mein Wollen sein? Wohin wird es mich führen? Jetzt ist die Antwort darauf gegeben.

Einen Widerspruch möchte man darin finden, daß das eigne Selbst das höchste Selbst sein soll und es dann doch heißt „zu diesem Selbst werde ich von hier scheidend hingelangen": was eben noch Wirklichkeit und Gegenwart war, entfernt sich in die Zukunft. Die Lösung des Widerspruchs - soweit sie möglich ist - kann hier noch nicht versucht werden. Sie verlangt zusammenhängende Erwägung darüber, wie man das Verhältnis des absoluten Wesens zu der Welt, in der jenes zur Erscheinung kommt, vorgestellt, Einheit und Vielheit zu vermitteln versucht hat. Dem, der an unsrer Stelle redet, ist wohl kaum zum Bewußtsein gekommen, welche ungelösten Rätsel hier übrig blieben. Für ihn „wahrlich gibt es keinen Zweifel": es wurde schon bemerkt, daß dieser Schluß auf den Anfang, auf die Verherrlichung des Brahman als des Wahren, gegen jeden Zweifel und Fehlschlag Schützenden zurückzeigt. So liegt über allem tiefer Friede, in dem die Aengste des Suchens zur Ruhe gekommen sind - Gewißheit ewigen Seins.

Das Absolute und sein Verhältnis zur Welt.

Das Denken, aus dumpfer Phantastik in langsamem Tasten den Ausgang suchend, hatte eine Station seines Weges zurïckgelegt. Noch war das Gewirr schattenhafter Verzerrungen, durch das es sich bewegte, nicht geschwunden und sollte so bald nicht schwinden. Aber ein Licht war 
hineingefallen. Zuerst nur für Augenblicke. Erscheinend und wieder erlöschend, vielfältig getrübt. Bald bleibender. Im Gesichtsfeld war ein Gebilde andern Stils aufgetaucht als Indra und Agni oder als die Zaubermächte der Opferwissenschaft: die Idee einer alldurchdringenden, allbeherrschenden, alldurchleuchtenden Macht. Ein Zentrum, in dem die unübersehbare Vielheit der Dinge Einheit und Halt fand. Eine Stätte, an der die Welt alle ihre Güter dem Ich des Denkers überantwortete, ihren Wesenskern als dieses Ich enthüllte. Wie sollte jene Idee jetzt nicht die Gedanken übermächtig auf sich ziehen? Es galt sie an sich selbst und in ihrer Beziehung zur Erscheinungswelt durchzudenken. Die eigene Bedeutung dieser Welt trat dem gegenüber weit zurück. Sie war nur noch der Vorhang, hinter dem man zu entdecken suchte, was allein des Schauens wert war.

Das Problem, das sich hier stellte, kann nach dem augenfälligsten der Gegensätze zwischen Brahman-Ātman und Welt als das Problem des Einen und der Vielheit benannt werden: so zwar, daß das Interesse der Betrachter ganz vorwiegend auf das Eine gerichtet war. Mit jenem Gegensatz hingen dann andre zusammen oder tauchten wenigstens am Horizont auf. Solche Gegenüberstellungen entgegengesetzter oder auch in irgendwelcher Korrelativität in einander greifender Kategorienpaare beherrschen ja naturgemäß das Denken als Leitmotive häufig auf weiten Strecken seines Weges. Sie bieten ihm die Themen, in deren Durcharbeitung es fortschreitet, nicht immer ohne aus dem Hinblicken auf solche Gegensätzlichkeiten, in denen oft etwas von Feindseligkeit enthalten ist, einen Zug des Harten, Intransigenten anzunehmen. Für die Denker der Upanishaden war mit jenem Gegensatz von Vielheit und Einheit der von Leiden und von Leidüberwindung, Seligkeit verbunden. Von Sterben und Unsterblichkeit. Dessen was man hatte und dessen wonach man verlangte. Es lag nicht fern, daß die Gegenüberstellung von Vergänglichem und Unvergänglichem sich zu der von Werden und Sein, vielleicht auch von Schein 
und Wirklichkeit fortbildete. Weiter konnte das Kategorienpaar Stoff und Form oder wenigstens eine Annäherung daran leicht in diese Gedankengänge hineinspielen. Und die Auffassung des Allwesens als Ātman mußte dazu anregen, mit der Gegenüberstellung von Subjekt und Objekt zu arbeiten; die ließ sich weiter als eine Art Antagonismus des Schauenden nicht Handelnden, und des Handelnden nicht Schauenden ausmalen. Voran aber stand, aus der Vorgeschichte sich am direktesten ergebend, eben das Problem des Einen und der Vielheit - das Eine als belebende, lichtbringende Kraft im Vielen. Die Erscheinungswelt zeigt sich als Vielheit. So konnte das Eine nur hinter jener, in jener verborgen weilen. Es mußte das Umhüllte sein, jenes die Hülle.

In den Schilderungen, welche die Upanishaden von diesem Einen geben, begegnet natürlich - wie weiterhin anschaulich werden wird - recht Vieles, was nicht aus der herrschenden Grundidee hervorgegangen, sondern aus älteren Vorstellungsmassen herübergenommen und wohl oder übel den neuen Gedanken eingefügt ist. Von derartigem sehen wir für jetzt ab, um allein die Formen ins Auge zu fassen, in denen die Idee frei von solchen Störungen zur Erscheinung kommt.

Das Eine, das die Vielheit belebt: die Anblicke, die das bietet, bedeuten, wie sich erwarten läßt, zum einen Teil vorwiegend dies, daß jenes allem Leben bringt. Zum andern Teil mehr, daß es allem Leben bringt. Womit natürlich nur eine ganz unbestimmte Gliederung der tatsächlich von beiden Seiten beständig in einander fließenden Vorstellungsmassen gegeben ist. Doch dürfen wir uns immerhin für einige Schritte unsres Weges von dieser Unterscheidung leiten lassen, darauf gefaßt, andern Fragestellungen $\mathrm{zu}$ begegnen, die uns in neue Richtungen lenken.

Wir verfolgen zunächst das erste der beiden Motive.

Hier tritt nun wieder eine eigentümliche, doch im Grunde sehr begreifliche Doppeltheit der Anschauungsweise 
auf. Zunächst drückte sich die alldurchdringende, aller Wirkungen mächtige Kraft und Herrlichkeit des Brahman in Prädikaten aus, deren Leitmotiv eben das "all“ ist.

So in jenem Hymnus des Śāndilya (S. 57), wo das höchste Wesen "allduftreich" heißt, "allsaftreich, alle Weltgegenden durchwirkend, dies All durchdringend." Wenn dann weiter folgt "wortlos, achtlos", so zeigt das schon in eine zweite Richtung. Für die erste sei noch folgende Stelle angeführt: "Wahrlich dieses Selbst ist das Brahman. Aus Erkennen besteht es, aus Gedanke besteht es, aus Atem, aus Auge, aus Ohr, aus Erde, aus Wasser, aus Wind, aus Äther, aus Glut, aus Nichtglut, aus Begehr, aus Nichtbegehr, aus Zorn, aus Nichtzorn, aus Recht, aus Nichtrecht; aus allem besteht es." ${ }^{10}$ Wie hier "Glut und Nichtglut", "Zorn und Nichtzorn" in das Brahman verlegt werden, liebt man auch anderwärts dessen Allfülle und Allvermögen durch Gegensatzpaare zu charakterisieren:

„Dieses regt sich. Dies regt sich nicht.

Dieses ist fern und dies ist nah.

Drinnen in allem Sein ist es

Und außerhalb von allem ist's."

Auf der andern Seite stehen nun aber solchen Ausdrücken intensivster und extensivster Bejahung nicht weniger starke Verneinungen gegenüber: jeder Inhalt, jede Eigenschaft, die man dem Brahman zuschreiben möchte, wird ihm abgesprochen. Neben das "All"motiv stellt sich das Motiv des "Nicht", des "Un-“, neben die gleichzeitige Beilegung entgegengesetzter Prädikate deren gleichzeitige Verneinung.

Es mag sein, daß bei dieser Verschiedenheit auch das im Spiel ist, daß dort der Gedanke an das im allgestaltigen Weltleben wirkende Brahman, hier der Gedanke an das bei sich seiende, in seiner stillen Einsamkeit thronende uberwiegt. Ich glaube doch nicht, daß jene Erscheinung allein hierauf beruht. Es handelt sich wohl nicht nur um ein Hinblicken nach zwei verschiedenen Richtungen, sondern auch das in einer und derselben Richtung Gesehene ließ 
eben jene doppelte Auffassung zu. Was Bejahungen mit einer gewissen Schlichtheit aussprachen, konnte man durch Verneinungen noch voller, volltönender ausdrücken: daß das höchste Wesen unberührt ist von jeglicher Beschränkung auf einzelne Formen des Seins und Wirkens, denen andre ihm versagt bleibende gegenüber stehen würden. Um alles Sein $\mathrm{zu}$ beherrschen und in sich zu fassen, durfte das Brahman sich an kein einzelnes Sein binden. Die sich so ergebende Neigung zu negativem Ausdruck wurde weiter dadurch gesteigert, daß ja schon im Zauberwesen und seiner priesterlichen Stilisierung die Überzeugung lebendig war, daß Verborgenes wirkungsvoller, vornehmer ist als Offenbares: und was verbirgt tiefer als die Verneinung? Hier spielte ferner wohl auch die Neigung zum Paradoxen mit, die dem indischen Geist und dazu über die Erde hin allem, was sich der Mystik nähert, eigen war und ist. Dann die indische Vorliebe dafür, das Geradlinige, grobkörnig Massive abzulehnen, sich 'geschmeidig ihm zu entziehen. Aus all dem ist es begreiflich, daß Ausdrücke, welche die Allfülle des höchsten Wesens in den Schein der Leerheit kleideten, gerade in Indien besonders gern ergriffen, in kürzester, schärfster Form geprägt wurden. Auch solche Verneinungen priesen die Hoheit des Brahman, und an verständnisvoller Empfindung für diese Weise der Verherrlichung fehlte es nicht.

In der Upanishad, die vor allen andern klassisch heißen darf, in der des Bṛhadāraṇyaka, wiederholt der weise Yājñavalkya nicht weniger als viermal - zu einem Teil auch ein fünftes mal - Worte, die offenbar als vollwichtigster Ausdruck eines tiefsten Geheimnisses angesehen wurden ${ }^{20}$. „Er ist der Ātman, der da heißt: Nein, nein! Er ist ungreifbar, denn er läßt sich nicht greifen, unzerstörbar, denn er läßt sich nicht zerstören, unhaftend, denn er haftet nicht, ungebunden; er wankt nicht, er leidet keinen Schaden." Die auf den Eingangssatz folgenden Verneinungen zwar schließen nur Schwächen vom Wesen des Ātman aus. Aber 
die ersten Worte selbst verneinen jegliche Bestimmtheit überhaupt. „Denn es gibt über dem ,So ist es nicht' nichts andres Höheres", erklärt die Upanishad. Kann man kühner, größer von dem Weg reden, den hier der Gedanke wagt, ins Unbetretene, nicht zu Betretende? Es ist die Sprache auch der christlichen Mystik auf ihrer höchsten Höhe. Der „Ātman, der da heißt Nein, Nein!" - er ist der Gott, von dem Scotus Eriugena sagt: „Deus propter excellentiam non immerito Nihil vocatur", und Angelus Silesius: "Gott ist ein lauter Nichts" "21. Oder wird man einen leisesten Unterschied hier doch noch fühlen? Der alles Inhalts entleerten Verneinung haftet schließlich immer noch eine allerletzte, nicht zu tilgende Spur davon an, welches Inhalts, welcher Bejahungen sie entleert ist: hier derer der westlichen Vorstellungswelt, dort des Weltbildes der vedischen Liturgen und Opferer. Ein Geschöpf indischen Denkens zu sein hat auch das Brahman in aller Erhabenheit seines „Nein, Nein" nicht aufgehört, konnte es nicht aufhören ... An einer andern Stelle ${ }^{22}$ legt die Upanishad Yãjnavalkya die Worte in den Mund: „Es ist das, o Gārgī, was die Brahmanen das Unvergängliche nennen. Es ist nicht grob und nicht fein, nicht kurz und nicht lang, ohne Blut und ohne Fett, ohne Schatten und ohne Dunkel, ohne Wind und ohne Äther, ohne Haften, ohne Geschmack und ohne Geruch, ohne Auge und ohne Ohr, ohne Rede und ohne Denken, ohne Glut, ohne Atem, ohne Mund, ohne Maß, ohne Innen und ohne Außen -

Nichts gibt's, das von ihm wird verzehrt,

Und Niemand ist, der es verzehrt."

Ein Vers spricht vom Brahman:

„Verschieden vom Entstehn, sagt man,

Verschieden ist's vom Nichtentstehn ${ }^{1}$ ):

Also vernommen haben wir's

Von Weisen, die es uns erklärt." -

1) Etwas anders dann der nächste Vers. Er verheibt Sieg äber den Tod dem, der „Entstehung und Vergehen kennt, beides zusammen." Da 
Wenn sich nun so, sei es in der Häufung aller Attributionen, sei es in der Ablehnung jeder einzelnen, die Allheit des Brahman ausdrückt, seine Fähigkeit allem Daseienden jegliche Gestalt zu verleihen: wird sich diese Allseitigkeit, oder wenn man will diese Keinseitigkeit, auch da festhalten lassen, wo der Nachdruck darauf fällt, daß das, was das Brahman den Dingen spendet, eben Licht, Leben, Bewegung ist - wo es sich also darum handelt, ihm eine bestimmte Weise des Wirkens, unter wenigstens stillschweigender Verneinung der entgegengesetzten, zuzuschreiben?

Auf diese Frage wird später zurückzukommen sein, wenn wir von dem, was die Upanishaden über das Verhältnis des Brahman zur Welt lehren, weitere Anschauung gewonnen haben. -

Die auf dies Verhältnis bezüglichen Gedankengänge nun lassen beständig - um an die oben (S. 61) angedeutete Gliederung zurückzuerinnern - neben der allbelebenden Wesenheit des Brahman zugleich die allbelebende in die Erscheinung treten.

Ich hebe zunächst eine Stelle hervor, die in ruhig gleichmütiger Sprache ohne poetischen Schmuck und ohne Akzente innerer Beteiligung vom Verhältnis des Brahman zur Welt redet. Offenbar gehört der Text den älteren Phasen der uns beschäftigenden Spekulationen an. Er steht in einem Brāhmana ${ }^{28}$, und auch sein Anschluß an die Vorstellungen des Götterglaubens und Opferwesens - durch Weglassung dieser Elemente würden wir den echten Gharakter der Stelle fälschen - vereinigt sich gut mit der Annahme alter Herkunft.

ist an Stelle des „Nichtentstehens" das „Vergehen" getreten, an Stelle der doppelten Verneinung doppelte Bejahung. Ist der Gedanke der, daB in das allumfassende Brahman hier auch das Vergehen verlegt wird? In der Tat scheint das ,beides zusammen" darauf hinzudeuten, daß auch der vorangehende Vers die Aussage des Entstehens oder des Nichtentstehens deshalb für unzulänglich erklärt, weil das Brahman beides gleichermaßen umfabt und eben darin sich als über beides erhaben erweist.

Olden berg: Upanishaden. 
„Brahman wahrlich war dies (All) im Anfang. Das erschuf die Götter. Als es die Götter erschaffen, ließ es sie diese Welten besteigen: Agni (das Feuer) diese Welt, Vāyu (den Windgott) die Luft, Sūrya (den Sonnengott) aber den Himmel. Und die Gottheiten, die höher sind als diese, ließ es die Welten besteigen, die höher als diese sind... Das Brahman selbst aber ging zur jenseitigen Sphäre. Zur jenseitigen Sphäre gegangen, dachte es: wie kann ich wohl zurück und in diese Welten hinabgelangen? Da gelangte es durch zweierlei zurück und in sie hinab, durch Gestalt und durch Namen. Wovon nur immer es einen Namen gibt: das ist Name. Und weiter, wovon es keinen Namen gibt, was man an seiner Gestalt erkennt (und spricht) ,diese Gestalt ist es': das ist Gestalt. So weit wahrlich reicht dies (All), wie Gestalt und Name. Dies sind die beiden großen Riesenwesen des Brahman. Wer diese beiden großen Riesenwesen des Brahman kennt, wird selbst ein großes Riesenwesen. Dies sind die beiden großen Wunderwesen des Brahman. Wer diese beiden großen Wunderwesen des Brahman kennt, wird selbst ein großes Wunderwesen. Von jenen beiden ist eins das höhere, die Gestalt. Denn auch was Name ist, ist Gestalt. Wer das höhere von diesen beiden kennt, wird höher als jener, über dem er höher zu sein wünscht. Wahrlich sterblich waren die Götter im Anfang, und erst als sie es durch das Brahman erlangt hatten, waren sie unsterblich. Wenn er (der Opferpriester) dem Geist das Sprengopfer bringt ${ }^{1}$ ) - Geist wahrlich ist die Gestalt, denn durch den Geist weiß man: ,diese Gestalt ist es" - , so erlangt er dadurch die Gestalt. Und wenn er der Rede das Sprengopfer bringt - Rede wahrlich ist der Name, denn durch die Rede nennt man den Namen -, so erlangt er dadurch den Namen. Wahrlich so weit reicht dies All, wie Gestalt und Name. Das alles erlangt er. Wahrlich Allheit

1) Von den zwei das Opfer einleitenden Sprengopferspenden ist die. eine dem Geist geweiht, die andre der Rede. 
ist das Unvergängliche. So wird ihm dadurch unvergängliches gutes Werk, unvergängliche Welt zuteil."

Die Stelle zeigt das absolute Wesen einerseits für sich allein: zuerst vor der Weltschöpfung, und nach dieser wieder sich in seine ,jenseitigeSphäre" zurückziehend. Auf der andern Seite wird berichtet, wie es die natürliche Welt schafft und mit seinen Kräften in sie eingeht.

Damit ist eine gewisse Gliederung der Gedankenmassen angedeutet.

Unsere Darstellung unterliegt ja unvermeidlich auf Schritt und Tritt dem Zwang, ungeordnete, halbgeordnete Vorstellungen der Alten in selbstgewählte Ordnung zu fügen - ich spreche von Ordnen, nicht von Systematisieren -: womit in der Tat etwas Fremdes in das Gegebene hineingetragen wird. Ein Hineintragen liegt im Grunde auch schon da vor, wo ein in den Texten gelegentlich auftauchendes, dann aber wieder vergessenes Ordnungsprinzip von uns festgehalten und behandelt wird, als wäre es den Alten durchweg gegenwärtig gewesen. Solcher nun einmal unentrinnbarer Gefahren mir wohl bewußt glaube ich doch mich der alten Vorstellungswelt so eng wie eben möglich anzuschließen, wenn ich im folgenden, ähnlich wie es in der eben mitgeteilten Stelle geschieht, das Wirken des Brahman$\bar{A}$ tman in den Dingen und sein Beisichsein von einander sondere. Und zwar scheint es angemessen, wie es auch der bisher befolgten Richtung unsrer Erörterung sich leichter einfügt, zuvörderst allein beim ersteren dieser Gedankenkreise zu bleiben und den zweiten künftiger Betrachtung vorzubehalten. Zunächst trat doch wohl den alten Denkern das absolute Wesen vor allem in seinen Beziehungen zur Vielheitswelt vor Augen. An diese Erkenntnisse erst werden sich dann - soweit hier die natürlich nur ganz unbestimmte Unterscheidung eines Prius und Posterius statthaft ist die Gedanken über die Eịnsamkeit des Absoluten in seinem jenseitigen Beisichsein geschlossen haben.

Auf die Welt der Vielheit bezieht der Text, mit dem 
wir uns beschäftigen, das absolute Wesen sowohl als ihren Schöpfer wie als in sie eingehend, sie gestaltend. Auch hier steht das eine neben dem andern schwerlich in ganz gleichem Range. Die Entstehung und der Gesamteindruck dieser Gedankenmassen läßt wohl als die zunächst hervortretende Rolle des höchsten Wesens die erscheinen, daß es in den Dingen formend, belebend, lenkend weilt. Die ferne Vergangenheit der Weltschöpfung steht in zweiter Linie.

Das Brahman ist in die Dinge eingegangen mit seinen „beiden großen Riesenwesen", Gestalt und Namen. Man hat hier einen Anklang an die beiden Attribute von Spinoza's Gott gefunden, Extensio und Cogitatio. Ich meine mit Unrecht. Ein durchaus anderer und in anderm Stil geformter Gedanke liegt vor. "Namen und Gestalt" - regelmäßig in dieser Reihenfolge - bilden ein stehendes Paar; so erscheinen sie schon in der ältesten Literatur ${ }^{24}$. Kein Zweifel, daß hier dieselbe primitive Vorstellung damit verbunden ist wie im höchsten Altertum. Gleich der Gestalt eines Dinges ist auch sein Name ein reales, höchst bedeutsames Element seines Wesens. Als solches bewährt er sich beständig in der Verwendung, die er im Zauber findet. Ähnlich wie es im israelitischen Schöpfungsbericht nicht genug ist, daß die Dinge erschaffen werden, sondern sie auch ihren Namen bekommen müssen, geht darum an unsrer Stelle der Schöpfer in die Welten ein dem Ungestalteten, Unbenannten neben der Gestalt auch den Namen bringend. Im Ganzen ist deutlich, daß man hier mit Kategorien zu arbeiten versucht, die wir unsrerseits als Stoff und Form benennen würden. $\mathrm{Zu}$ der durch die Konsequenz verlangten Vorstellung freilich einer ungeformten Materie, die dann von der formenden Tätigkeit des Schöpfers erfaßt würde, ist man nicht vollständig durchgedrungen: sind doch schon, ehe das Brahman Namen und Form bringt, die Welten und die uber sie herrschenden Götter in ihrer Besonderheit da, einen Zug des Geformtseins an sich tragend. Und auch sonst bleibt die ganz im Stil des alten Zauberglaubens gehaltene Vor- 
stellung, wie hier das Brahman mit seinen zwei „Riesenwesen“, seinen zwei „Wunderwesen“ leibhaftig in die Welten hineinfährt, von abgeklärterer Handhabung der Kategorien von Stoff und Form weit entfernt.

Das in unserm Text dargestellte formende Eingehen der schöpferischen Macht in das Erschaffene nun wird in ganz ähnlicher Weise öfter besprochen. Es ist klar, daß es sich hier um eine von diesen Denkern konsequent festgehaltene, im Vordergrund ihres Weltbildes stehende Vorstellung handelt. So lesen wir, um unter den Parallelstellen nur eine hervorzuheben, daß der weise Śvetaketu seinen Sohn folgendermaßen belehrt ${ }^{25}$ :

„Seiend nur, mein Teurer, war dies (All) im Anfang, eines nur, ohne ein Zweites. Zwar sagen Einige: ,Nichtseiend nur war dies (All) im Anfang, eines nur, ohne ein Zweites;' aus diesem Nichtseienden werde das Seiende geboren. Wie aber, mein Teurer, könnte es also sein? so sprach er; wie könnte aus dem Nichtseienden das Seiende geboren werden? Seiend vielmehr nur, mein Teurer, war dies (All) -im Anfang, eines nur, ohne ein Zweites. Das dachte: Ich will vieles sein; ich will mich fortpflanzen. Da schuf es die Glut ${ }^{26}$. Die Glut dachte: Ich will vieles sein; ich will mich fortpflanzen. Da schuf sie die Wasser. Deshalb wo immer der Mensch Hitze empfindet oder schwitzt, da werden aus der Glut Wasser (von Schweiß oder Tränen) geboren. Die Wasser dachten: Wir wollen vieles sein; wir wollen juns fortpflanzen. Da schufen sie die Nahrung ${ }^{2}$. Deshalb wo immer es regnet, da entsteht reichlichste Nahrung; da wird aus den Wassern Genuß der Nahrung geboren ... Jene Gottheit (das Seiende) nun dachte: Wohlan ich will in diese drei Gottheiten (Glut, Wasser, Nahrung) mit diesem lebenden Selbst (Ātman) eingehen und Namen und Gestalt aus einander legen. Und jede von ihnen will ich dreifach machen. Da ging jene Gottheit in diese drei Gottheiten mit diesem lebenden Selbst ein und legte Namen und Gestalt aus einander. Und jede von ihnen machte sie dreifach. 
Wie nun, mein Teurer, jede dieser drei Gottheiten dreifach wird, das vernimm von mir." Es folgt eine Darlegung - der Text ist hier von Verwirrung nicht frei - wie in Feuer, Sonne, Mond, Blitz jedesmal eine rote, eine weiße, eine schwarze "Gestalt" enthalten ist: das sind die „Gestalten" der Glut bez. der Wasser, der Nahrung ${ }^{1}$ ). „,So ist . des Feuers Feuersein (dann ebenso: der Sonne Sonnesein usw.) verschwunden; es haftet allein am Wort ${ }^{28}$, ist eine Umwandlung, eine Benennung; die drei Gestalten allein, die sind das Wahre. Das haben die Alten erkannt, die großen Herren, die Hochgelehrten, die da sagten: Jetzund kann Niemand uns etwas mitteilen, das uns ein Ungehörtes, Ungedachtes, Unverstandenes wäre. Denn von diesen Wesenheiten her erkannten sie es. Was wie etwas Rotes war, das erkannten sie als Gestalt der Glut. Was wie etwas Weißes war, das erkannten sie als Gestalt der Wasser. Was wie etwas Schwarzes war, das erkannten sie als Gestalt der Nahrung. Was wie etwas Unbestimmtes war, das erkannten sie als Zusammensetzung eben jener Gottheiten $\left.{ }^{2}\right)$."

Auch in diesem etwas weiter ausgeführten Weltbilde bringt, wie man sieht, das Urwesen - hier ,das Seiende“ genannt - in der von ihm geschaffenen Welt Bestimmtheit nach "Namen und Gestalt" hervor, indem es in die Welt

1) Es ist klar, daB das nicht der vorangehenden Ankündigung entspricht, nach der vielmehr von je dreifacher Ausgestaltung von Glut, Wasser, Nahrung die Rede sein müBte. Möglich, daß eine ältere Vorlage hier verwirrt wiedergegeben ist. Doch wenn ein Redaktor Konfusion angerichtet haben soll, kann das natürlich ebenso gut dem Verfasser selbst begegnet sein. Deussen"s (Sechzig Upanishads 155) auf indischer exegetischer Tradition beruhender Versuch die Schwierigkeit fortzuerklären überzeugt nicht; die Vergleichung von $\mathrm{Ch}$. Up. VI, 4,7; う scheint mir ihn zu widerlegen.

2) An das hier Wiedergegebene schliebt sich noch eine Auseinandersetzung darüber, wie die drei „Gottheiten" in den Menschen gelangend sich jede dreifach zerlegen. So wird von der Nahrung das Gröbste zu Kot, das Mittlere zu Fleisch, das Feinste zu Geist, usw. 
eingeht „mit diesem lebenden Ātman“. Und auch hier, ganz wie an der vorher besprochenen Stelle, ist die Konsequenz nicht gezogen, daß jene Welt zuvor absolut gestaltlos gewesen sein müßte. Schon von Anfang an ist sie nach den Grundelementen von Glut, Wasser, Nahrung, oder von Rot, Weiß, Schwarz gegliedert: drei Elemente oder Konstituenten, die wir später in wichtigen Gedankengängen der Folgezeit wiederfinden werden.

Die entscheidende Grundvorstellung nun, daß das Göttliche durch alle Weltweiten allen Wesen innewohnt, wird in den Upanishaden zu zahllosen Malen in immer neuen Wendungen nachdrücklichst ausgesprochen. „Der in der Erde weilend von der Erde verschieden ist, den die Erde nicht kennt, dessen Leib die Erde ist, der die Erde innen lenkt: das ist dein Selbst, der innere Lenker, der unsterbliche“" ${ }^{28}$ : - worauf das von der Erde Gesagte vom Wasser, dem Feuer und allen Elementen wiederholt wird, von Himmel und Weltgegenden; eine andre Redaktion vergißt nicht, auch alle Veden und alle Opfer zu nennen. Weiter dann überhaupt von "allen Wesen", von den menschlichen Kräften und Sinnen, Atem, Auge, Geist. Hier zeigen sich nun freilich Abstufungen. Der Mensch, wird einmal gesagt, ist das brahmanhafteste Wesen. Kräuter und Bäume, liest man an einer andern Stelle, enthalten nur Saft. In den Tieren tritt Bewußtsein dazu, das sich doch allein auf Hunger und Durst richtet. Im Menschen aber ist der Ātman am sichtbarsten: er sieht über das Heute hinüber auf das Morgen; mit seinem sterblichen Wesen trachtet er nach Unsterblichkeit. So ist der menschliche Ātman vor allem andern der Ātman: diesen zentralen Gedanken, der die Spekulation der Upanishaden mit Leben durchströmt, können wir für jetzt nur berühren ${ }^{1}$ ).

Angelegentlich beschäftigen sich die Texte mit der Frage, wie in räumlicher Hinsicht das Darinnensein des Ātman in den Wesen vorzustellen ist. Hier zeigt sich eine Doppelt-

1) Siehe unten den Abschnitt "Die Erlösung". 
heit der Auffassung, ähnlich der oben (S. 62) besprochenen zweiseitigen Beschreibung des Ātman bald durch positive, bald durch negative Bestimmungen. Man konnte es seiner Herrlichkeit angemessen finden, ihn als allgegenwärtig vorzustellen, alle Fernen umspannend, jedes Wesen in seiner vollen Ausdehnung durchdringend. Es konnte andrerseits die Verneinung noch erhabener scheinen als solche Bejahung: im kleinsten Raum wohnend und doch von da aus alle Weiten beherrschend mußte das ewige Wesen seinen höchsten Triumph feiern. Hier tritt die eine, dort die andre Anschauung hervor. Oder man läßt auch geflissentlich beide zugleich zu Worte kommen. Beide sind wahr, und eben in ihrem Widerspruch offenbart sich die ganze Fülle des höchsten Wesens. "Er ist hier eingegangen", heißt es vom Ātman," „bis zu den Nagelspitzen, wie ein Schermesser in seinem Behälter ruht oder ein Skorpion(?) in seinem Nest." Der Ātman weilt in den Dingen wie das Salz, das im Wasser aufgelöst ist: man kann es nicht herausholen, aber überall wo man vom Wasser kostet, ist es salzig. Vom Baum ist die Rede: wo man den anschneidet, trieft er, denn er lebt. Welchen Teil von ihm das Leben verläßt, der verdorrt. „Vom lebenden Ātman durchdrungen, strotzend, freudig steht er da." Aber wiederum, im selben Abschnitt dicht daneben: in der Frucht des Baumes sind ganz kleine Kerne; spaltet man sie, sieht man gar nichts. „Aus dieser Feinheit, mein Teurer, besteht der Nyagrodhabaum, der so groß dasteht." Und mit deutlichster Hervorhebung des gewollten Widerspruchs eine andre Stelle: sie darf hier angeführt werden, obwohl sie mehr von der Größe des Ātman an sich als von der Weise seines Darinnenseins in den Dingen spricht: „Dies ist mein Ātman im Herzen darinnen, kleiner als ein Korn Reis oder Gerste oder Senf oder Hirse oder als ein Hirsekern. Dies ist mein Ātman im Herzen darinnen, größer als die Erde, größer als die Luft, größer als der Himmel, größer als diese Welten."

Man könnte geneigt sein, dieses Vereinigen der Gegen- 
sätze des räumlich Größten und Kleinsten als Suchen nach einem Ausdruck für raumloses Sein aufzufassen. Wofür sich eine Bestätigung in $\ddot{u}$ ßerungen finden ließe wie dieser: „Von Unreinheit frei, jenseits des Äthers, der ungeborne Ätman, groß, beständig“ — "Äther" (ākäśa) ist ja in gewissem Sinn ein Ausdruck für den Raum, der als erfüllt von dieser feinsten Substanz gedacht wird. Es ist doch wichtig, die in der Tat vorhandene tiefe und grundsätzliche Verschiedenheit aller dieser Vorstellungen von dem, was wir Raumlosigkeit nennen, zu beachten. Für die Denker der Upanishaden handelt es sich keineswegs um ein etwa in der Natur des Ātman liegendes Unerfaßbarsein für die Anschauungsform des Raumes, um ein Sein in einer andern Welt als der räumlichen. Daß man sich in diesem Sinn vom Gebundensein an die Raumanschauung zu befreien gewußt hätte, ist für eine so alte Stufe des Denkens kaum glaublich. Sondern was jene Denker meinten, war ein durchaus innerhalb der ihnen selbstverständlichen räumlichen Daseinsform verbleibendes souveränes Erhabensein des Ātman über alle Gefangenschaft in den Fesseln eines Hier oder Dort, der Größe oder der Kleinheit ${ }^{1}$ ). Man möchte einen Anklang an Vorstellungen finden, die in der Tat jenem Zeitalter nah genug lagen, vom Spiel übernatürlicher Zauberkräfte mit dem Raum. Der Ātman hat etwas von dem Yogin, der sich unendlich klein und unendlich groß machen kann. Und das Wohnen des höchsten Wesens „jenseits des $\bar{a} k \bar{a} \boldsymbol{s} a^{\prime}$ " bedeutet auch gewiß kein Losgelöstsein von allem räumlichen Dasein, sondern nur ein wunderbares Hinausreichen so zu sagen in einen Raum jenseits des Raumes, in Sphären unerreichbar für die Bewegung, die den uns umgebenden Raum füllt ${ }^{2}$ ).

1) Weiter, als hier ausgesprochen, geht auch die Behandlung der Raumfrage offenbar nicht, die sich in den Äußerungen über den Tod des Erlösten, zum Brahman Eingehenden findet (s. unten den Abschnitt „Die Erlösung").

2) Das hier Gesagte nähert sich den Ausführungen Deussen's, Allg. 
Doch wir sind von der Betrachtung, wie der Ätman den Dingen innewohnt, in andre Gedankengänge hinübergeglitten. Derartiges scheint kaum vermeidlich. Wir wollen ja, wie immer wieder betont werden muß, die alten Vorstellungsmassen nicht in ein ihnen fremdes System zwängen. Ihren Verkettungen suchen wir zu folgen, wie die Texte uns dazu einladen, deren Verwirrung ordnend, zu den in ihnen angefangenen Linien in ihnen selbst Fortgang und Ende suchend.

Wir kehren zum Wirken des höchsten Wesens in den Dingen zurück.

Mit seiner Eigenschaft, im kleinsten Raum weilend größte Wirkungen zu entfalten, gehören andre ähnliche Züge zusammen. Es ist das Subtilste, Ungreifbarste. Wie es unsichtbar im Innern des leer scheinenden Fruchtkerns den ganzen Baum wachsen macht, so ist es auch das Unsichtbare, das man im Körper als Wärme spürt. Es ist das, was man bei zugehaltenem Ohr als Sausen hört. Es ist die geheimnisvolle Kraft, die bewirkt, daß beim Gottesurteil der Unschuldige am glühenden Beil sich nicht verbrennt.

In solch unfaßbarer Feinheit in der Tiefe verborgen gibt das Brahman den Wesen nicht allein, wie gezeigt wurde, Namen und Gestalt. Es bewegt sie, regiert sie mehr in ruhevollem Gleichmaß, als im Sturm und Drang "wechselnden Webens, glühenden Lebens". Es ist der „innere Lenker", der in der Erde und allen Elementen darinnen ist, dessen Leib alles jenes ist. Yājñavalkya spricht

Gesch. der Philos. I, 2, 137 f., von denen es sich doch wiederum in der Überzeugung unterscheidet, daB die Gedanken der Upanishaden statt an die Kritik der reinen Vernunft vielmehr an primitive Auffassungen anzuschlieBen sind. - Eine Bestätigung meines Versuches, für die Vorstellung vom Sein ,jenseits $\operatorname{des} a k a s a^{4}$ eine gewisse Anschaulichkeit zu gewinnen, finde ich in dem, was eine jüngere Upanishad (Maitr. Up. VI, 15) über die „nichtteilbare Nichtzeit" sagt (Wortspiel: akalah „nichtteilbar", akălah „Nichtzeit"), die der mit Erschaffung der Sonne anfangenden „teilbaren", nach Jahren gegliederten Zeit vorangeht. Im strengsten Sinn zeitlos ist diese "Nichtzeit" nicht; sie geht der Zeit zeitlich voran. 
zu Gārgi ${ }^{31}:$ „Auf dieses Unvergänglichen Geheiß wahrlich, o Gārgī, stehen Sonne und Mond fest, ein jedes an seiner Statt. Auf dieses Unvergänglichen Geheiß wahrlich, o Gārgī, stehen Himmel und Erde fest, ein jedes an seiner Statt. Auf dieses Unvergänglichen Geheiß wahrlich, o Gārgī, stehen Augenblicke, Stunden, Tage, Nächte, Halbmonate, Monate, Jahreszeiten, Jahre fest, ein jedes an seiner Statt. Auf dieses Unvergänglichen Geheiß wahrlich, o Gārgī, strömen die einen Flüsse gen Osten von den weißen Bergen, die andern gen Westen und nach jeglicher Himmelsgegend. Auf dieses Unvergänglichen Geheiß wahrlich, o Gārgī, preisen die Menschen den Geber, die Götter den Opferer, nehmen die Väter beim Löffel ${ }^{1}$ ) Platz."

"Aus Furcht vor ihm die Winde wehn,
Aus Furcht vor ihm die Sonn' aufgeht;
Aus Furcht läuft seinen Weg Agni
Und Indra und der Funfte: Tod."

Wenn er nicht will, kann das Feuer den Strohhalm nicht verzehren, der Wind ihn nicht wegwehen. Er ist der Vater, der in jedem Mutterleib, in jedem Sohn, der erzeugt wird, selbst zu eines Vaters Sohn wird. Er haucht ein im Einhauch, haucht aus im Aushauch. Wenn das Auge, das Ohr sich auf die Dinge richtet, so wirkt er als der Geist (wörtlich: der Mann) in Auge und Ohr; jene „dienen nur zum Sehen, zum Hören." „Er läßt rechte Tat den tun, welchen er aus diesen Welten emporführen will. Und unrechte Tat läßt er den tun, welchen er in den Abgrund führen will." Er bringt den Wesen Wonne als aller Wonne Heimat: "von einem Teilchen dieser Wonne leben die andern Wesen." Der Gatte ist der Gattin, die Gattin dem Gatten lieb nicht um seiner selbst, um ihrer selbst willen, sondern um dessen willen, der - in unsrer Sprache ausgedrückt - der Ursprung aller Werte ist: der Ātman. In dunkel tiefsinniger Sprache sagt

1) Die Väter sind die Seelen der Verstorbenen. Der Löffel muß als bei der Totenspende gebraucht verstanden werden. Im folgenden Vers: Agni der Feuergott, Indra der Gewittergott. 
eine Dichtung ${ }^{82}$, welche vom Atem (prāṇa) die sonst dem Brahman-Ātman zukommenden Ausdrücke braucht - es ist wohl gemeint, daß das höchste Wesen nur mit einem Teil seiner selbst die Welt belebt $^{1}$ ), während der andre Teil für sich verharrt - :

„Den einen Fuß zieht nicht heraus der Schwan aufsteigend aus der Flut.

Zög er heraus den Fuß, wahrlich es gäb kein Heut, kein Morgen mehr.

Keine Nacht und kein Tag wäre; nicht schiene mehr das Morgenrot" -

ein Vers, der an jenes Wort des christlichen Mystikers erinnert: „Wäre Gott nicht in allen Dingen, so hätte die Natur weder Wirksamkeit noch Begehr."

Zuweilen meint man bei diesem belebenden und beherrschenden Darinsein des höchsten Wesens die Erinnerung an die in die Dinge hineinfahrende und sie regierende Zauberkraft des Brahman im älteren Sinn dieses Worts durchschimmern su sehen. Vor allem aber, wie das in den eben beigebrachten $\ddot{u}$ ußerungen mehrfach hervortritt und sich aus den Texten noch reichlicher belegen ließe, ist es das durch die Vorstellung des Ātman ja mit Selbstverständlichkeit angezeigte Verhältnis von Körper und Seele, das hier die Phantasie anregt. Die Frage drängt sich auf, ob man den Bewegungen, welche diese Seele dem von ihr bewohnten Riesenleib der Welt mitteilt, Rhythmus und Einheit, Plan und Ziel zugeschrieben hat. Weshalb befiehlt das "ewige Wesen, daß die einen Flüsse gen Osten, die andern gen Westen strömen? Daß Tag und Nacht wechseln und die Morgenröten aufleuchten? Wozu sieht das Göttliche im irdischen Auge, hört es im irdischen Ohr, lebt es im irdischen Leben? Wir werden weiterhin der nächst verwandten Frage begegnen: wozu hat jenes Wesen die Welt

1) So wird gleich im folgenden Vers gesagt, $\mathrm{da}$ b es mit seiner einen Hälfte die ganze Welt hervorgebracht hat. Ich verweise weiter auf den Abschnitt unten: Das Absolute in sich. 
geschaffen? - worauf ärmliche und bedeutungslose Antworten gegeben werden. Hier finden wir überhaupt keine Antwort. Das vom Ātman gelenkte Welttreiben wird als Tatsache hingenommen. Daß ein Weltzweck dadurch verwirklicht werde: dieser Gedanke trägt einen so entschiedenen Zug geschichtlicher Betrachtung in sich, daß man ihn hier anzutreffen nicht erwarten wird. -

Blicken wir zurück, so hat sich auf die Frage nach den Bestimmungen, die dem allbelebenden Wesen daraus zufließen, daß es alles belebt, die Antwort herausgestellt: es ist beseelende Kraft; es ist Licht, Erkennen, Wonne. Die Allseitigkeit seines Wesens zeigt sich also doch in gewisser Weise determiniert. Dies Licht ist nicht ebensowohl auch Finsternis, diese Wonne nicht Schmerz. Wie man die Frage nach dem Ursprung von Schmerz und Leiden behandelt hat, muß später besprochen werden. Für jetzt ist dies festzustellen, daß sich das höchste Wesen zu jenen Gegensätzen nicht neutral verhält. Es steht auf der positiven Seite $\left.{ }^{1}\right)$. -

Dem Licht, welches der Ātman ist, gehört eine nur ihm eigene Hoheit: hierfür haben die Upanishaden manches tiefe Wort gefunden. Oft brauchen sie Ausdrücke wie diesen:

"Ihm huld'gen als der Lichter Licht die Götter, als Unsterblichkeit."

In der Welt also gibt es Licht; der Âtman ist das Licht der Lichter. Ganz ähnlich, mit der gleichen Redefigur, eine zweimal wiederholte Stelle: „Seine Verehrungsform (s. oben S. 37) heißt: Das Wahre des Wahren. Die Atemkräfte wahrlich sind das Wahre. Deren Wahres ist er." Ebenso wird gesagt, daß das Brahman von dem gekannt wird,

1) Dies darf man offenbar als der Gesamtanschauung der Upanishaden entsprechend hinstellen. Aber daneben ist allerdings auch wiederum die Fernhaltung solcher Beschränkung, die Wahrung des Gleichgewichts von Positivem und Negativem zu bemerken. Man vergleiche Bṛhad Ār. Up. IV, 4, 5 (oben S. 62). 
„Der Atems Atem und des Auges Auge,

Des Ohres Ohr, des Geistes Geist verstehet."

Die Sammlung solcher Ausdrucke, die gewissermaßen durch eine Potenzierung das Brahman zu einer zweiten, höchsten Stufe von Realität und Kraft erheben, könnte noch vermehrt werden. Mir scheint hier etwas gemeint zu sein, das - unbeschadet aller Verschiedenheit, die Niemand ubersehen wird, - der Auffassung verwandt ist, welche der platonischen Ideenlehre zu Grunde liegt. Wie nach Platon das irdische, vergängliche Schöne dadurch schön ist, daß es an der ewigen Idee der Schönheit einen freilich durch fremde Beimischung beeinträchtigten Anteil hat, so ist hienieden das Licht, das Wahre der Ausfluß eines Seins, das allein im höchsten Sinn Licht und Wahres ist: zu ihm muß man aufsteigen, will man Licht und Wahrheit in absoluter Vollendung schauen.

Damit haben wir freilich schon von dem in der Welt erscheinenden Brahman in eine Sphäre hinübergegriffen, in welche dessen Betrachtung selbstverständlich fortwährend hinweist: zum Brahman in seinem Beisichsein. Hiervon weiter zu sprechen ist dies noch nicht der Ort. -

Mehrere der Stellen, mit denen wir uns beschäftigt haben (S. 66. 69), zeigten den göttlichen Beseeler der Welt zugleich als Weltschöpfer. Ihm steht als durch seine Schöpferkraft gestaltet nicht etwa ein von ihm unabhängiges, zweites Prinzip gegenüber, eine Materie, die seiner Macht ebenbürtiges, gleich ewiges Dasein entgegensetzt. Sondern er allein vollbringt beides. Er erschafft die Welt, zunächst als eine der Unbestimmtheit bloßer Materie wenigstens sich annähernde (S. 68). Dann zweitens geht er gestaltend und belebend in die Welt ein. Begreiflich, daß man beides derselben Allmacht zuschrieb. Eine nicht von Brahman erschaffene Materie annehmen hätte ja gehießen dem Einheitsstreben des Gedankens entsagen. Und was war begreiflicher, als daß man die Rolle, welche die alten Schöpfungslegenden so manchen Wesen abwechselnd zu- 
teilten - im Anfang der Dinge allein dazusein und dann die Welten zu schaffen - nunmehr in ihrem ganzen Umfang dem Brahman, dem Ātman übertrug? Aber es scheint sich fühlbar zu machen, daß die Gedankengänge, in denen sich die Idee dieses höchsten Wesens entwickelt hatte, ihrer Natur nach vielmehr darauf hinzielten, ihm belebendes und beherrschendes Innewohnen in der Welt als Erschaffen der Welt zuzuschreiben. So erklärt es sich, daß dem Problem der Schöpfung gegenüber dies Denken sich als wenig produktiv erwies und hier besonders beharrlich in überkommenen Bahnen verblieb.

Sehr deutlich zeigt sich das in der folgenden Schöpfungsgeschichte einer Upanishad ${ }^{8 \mathbf{3}}$ :

„Dies All war im Anfang allein Ātman in Gestalt eines Menschen (purusha). Er blickte um sich und sah nichts anderes als sich selbst. Da sprach er zu Anfang: ,Das bin ich.“ Daraus entstand der Name ,Ich'. Daher sagt auch jetzt, wer angerufen wird, zuerst nur: ,Ich bin es', und nennt dann den andern Namen, den er hat... Er fürchtete sich. Daher fürchtet sich, wer allein ist. Da dachte er: ,Nichts andres ist da als ich. Weshalb fürchte ich mich denn?، So verging seine Furcht. Wovor hätte er sich auch fürchten sollen? Furcht gibt es ja nur vor einem Zweiten. Aber er fühlte sich auch nicht wohl. Daher fühlt sich nicht wohl, wer allein ist. Er begehrte nach einem Zweiten. Nun war er so groß wie Weib und Mann, die sich umschlungen halten. Dieses sein Selbst ließ er in zwei Teile zerfallen. Daraus entstanden Gatte und Gattin $\left.{ }^{1}\right)$... Er begattete sich mit ihr; so wurden Menschen geboren. Da dachte sie: ,Nachdem er mich aus sich selbst erzeugt hat, wie mag er sich mit mir begatten? Wohlan! Ich will mich verbergen:" Da ward sie zur Kuh. Der andere aber ward zum Stier und begattete sich doch mit ihr; so wurde das Rindvieh

1) Wortspiel: „er lieb zerfallen" apātayat; „Gatte, Gattin“ patiḥ, patni. 
geboren." Es folgt in derselben Weise die Geburt von Pferden, Eseln und anderm Getier. „So erschuf er alles, was sich paart, bis zu den Ameisen. Da erkannte er: ,Wahrlich ich bin die Schöpfung, denn ich habe dies alles erschaffen'. Daraus entstand die Schöpfung $\left.{ }^{1}\right)$. In dieser seiner Schöpfung findet eine Stätte, wer solches weiß." Dann wird berichtet, wie der Schöpfer ,aus seinem Munde als Mutterschoß und aus seinen Händen" Feuer (Agni) hervorgehen ließ. Aus seinem Samen ließ er alles Feuchte hervorgehen: das ist Soma.

„Dies ist die Überschöpfung des Brahman. Weil es Götter schuf höher als es selbst und weil es, selbst ein Sterblicher, Unsterbliche schuf, deshalb ist es eine Überschöpfung. In dieser seiner Überschöpfung findet eine Stätte, wer solches weiß."

Offenbar hat sich hier der Ātman, um als Weltschöpfer aufzutreten, in alte, seinem wahren Wesen fremde Vorstellungskreise hineingeschoben mit einer gewissen Gewaltsamkeit, welche diesem Textstück ein so augenfälliges Gepräge der Bizarrerie verleiht. Gewiß haften auch dem echten Bild des Ātman - oder allen den echten Bildern, die uns die Texte geben - Züge genug aus der Vergangenheit an. Aber dies ungeheuerliche Zauberwesen, das zu Mann und Weib, zu Stier und Kuh, zu Esel und Eselin wird, sich vor sich versteckt, sich mit sich begattet ${ }^{2}$ ), scheint doch besonders wenig befugt, den erhabenen Namen Ātman

1) Ich übersetze durchaus wörtlich und lasse die auf der Hand liegenden Unklarheiten der Vorstellung bestehen. „So entstand der Name Schöpfung“ Deussen. „Hence he became the creation" Max Müller.

2) Deussen (Allg. Geschichte der Philos. I, 2, 179) meint, man könnte versucht sein. diesem Mythus (?) tieferen Sinn unterzulegen: „Das Männliche wäre der nach seiner Manifestation verlangende Wille, das Weibliche der Inbegriff der Formen (der platonischen Ideen), welche, obgleich aus dem Willen entsprungen, ihm doch heterogen sind, vor ihm fliehen, bis der schöpferische Wille sich ihrer bemächtigt, um in ihnen allen sein Wesen zum Ausdruck zu bringen." Lassen wir doch jene Ausgeburten der alten Brahmanenphantasie in ihrer Rohheit und ihrer Echtheit be- 
zu führen. Wie tief steht, was hier berichtet wird, unter den Gedankengängen, von denen weiterhin zu reden ist: der Âtman in seinem Reich einsam weilend, in seiner Alleinheit, seiner All-Einheit der Trennung von Subjekt und Objekt nicht unterliegend und so denn über Bewußtsein und Denken erhaben. Hier dagegen spricht der Ātman; er fürchtet $\left.\operatorname{sich}^{1}\right)$; er begehrt. Ja er ist zum Sterblichen herabgedrückt, und es ist eine "Überschöpfung", wenn er unsterbliche Götter erschafft.

Auf die Frage, wie im Gleichgewicht des höchsten Seins ein erster Antrieb zur Bewegung, zum Schaffen sich hat erheben können, wird man ja eine wirkliche Antwort von den Upanishaden so wenig erwarten, wie Sankara, Plotin, Schelling sie hat geben können. Die Bemühungen aber, die man hier auf jenes Problem gewandt hat, sind in der Tat besonders schwächlich: das Unbehagen der Einsamkeit, das den Ātman überkommt, muß hinreichen, die Weltschöpfung zu motivieren - nicht tiefer übrigens nennt eine andere Stelle (s. S. 69) ganz in der Weise der Brāhmaṇatexte, als solches Motiv den Wunsch des höchsten Wesens: „Ich will vieles sein; ich will mich fortpflanzen“, und spricht in gleichem Sinn eine jüngere Upanishad von seinem Verlangen „Wahrheit und Unwahrheit zu genießen." Es ist bezeichnend, daß eine Fortsetzung, in welcher die eben

stehen. Es handelt sich wirklich nicht um den „Willen" und platonische Ideen, sondern um Stier and Kuh, um Esel und Eselin.

1) Man möchte für möglich halten, daß dem Autor die eben berührten entgegenstehenden Gedanken nicht unbekannt waren. Es sieht fast wie eine Travestie dieser aus, wenn der sich fürchtende Ātman sich dann daran erinnert, daß er ja allein da ist, also sich gar nicht zu fürchten hat. Ist hier vielleicht eine ältere Gestalt des Schöpfungsberichts umgearbeitet, nach der das Urwesen sich in seiner Einsamkeit fürchtet und darum die Welt schafft? Wie die Erzählung jetzt dasteht, ist es doch seltsam, daß der Ātman sich erst die Furcht durch die Erwägung vertreibt, daß kein andres Wesen da ist, und dann alsbald selbst andere Wesen schafft. $\mathrm{DaB}$ er in seiner Einsamkeit "sich auch nicht wohl fühlt", soll vielleicht die Schwierigkeit so gut es eben geht überbrücken. 
mitgeteilte Erzählung weiter das Verhältnis des Ātman zu der von ihm erschaffenen Welt bespricht, unverkennbar ihrem Gedankengehalt nach auf sehr viel höherem Niveau steht: die Ätmanlehre war eben anders ausgerüstet vom Weltdasein als von der Weltschöpfung zu sprechen. -

Das Wort für ,schaffen", das in diesem Text und uberhaupt stehend gebraucht wird (sri-), enthält die Vorstellung des Loslassens, des Ergießens von etwas Festgehaltenem, Drinnenseiendem. Man wählt dies Wort gern, wenn es sich um das Entsenden eines Geschosses oder auch einer Rede handelt, um Rennpferde, die man laufen läßt, um Kühe, deren Stall geöffnet wird, um den Regen, den der Gott oder Regenzauberer aus dem Wolkenverschluß entsendet, um die Flüsse, denen Indra die Bahn öffnet, damit sie aus der Felsentiefe über das Land strömen. So ist das Schaffen als ein Hervorgehenlassen aus dem Innern des schaffenden Wesens gedacht: wobei begreiflicherweise die Frage, ob und wie das Geschaffene zuvor in diesem Innern existiert hat, unaufgeworfen bleibt. Eine Menge von Bildern und Vergleichen knüpft die Vorstellung des Schaffens an Situationen des Alltagslebens an, in denen ein Hervorgehen oder Entlassenwerden von etwas aus etwas anderm stattfindet. Die Welt geht aus dem Ātman hervor, wie die Töne aus der Trommel, die geschlagen wird, aus der Muschel, die geblasen, aus der Laute, die gespielt wird. Wie von einem Feuer Rauchwolken ausgehen, so sind des Allwesens Aushauch alle Veden, Wissenschaften, Upanishaden. Man bemerke, daß an Stellen wie dieser - in Abweichung von den oben besprochenen Schöpfungsgeschichten - das Absolute die zu erschaffenden Wesenheiten direkt aus sich hervorgehen läßt: nicht zuerst ein Substrat, das dann durch einen zweiten Akt geformt wird. Eine begreifliche Variante.

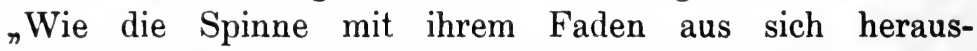
kommt ${ }^{1}$ ), wie aus dem Feuer die kleinen Funken hervor-

1) In einer jüngeren Upanishad: „Wie die Spinne (den Faden) entläBt und einzieht." 
gehen, so gehen aus diesem Ātman alle Atemkräfte hervor, alle Welten, alle Götter, alle Wesen." Auch das Sprießen der Pflanzen aus dem Erdreich, das Herauswachsen der Haare aus Haupt und Körper dient als Vergleich. Unter allen diesen Vorstellungen aber tritt am meisten begreiflicher Weise die des Gebärens hervor. Wohl mehr als ein bloßer Vergleich: das Schaffen der Wesen ist geradezu ein Gebärakt. Gemeinsam ist allen diesen Auffassungen, daß das Geschaffene als ein vom Schöpfer verschiedenes Wesen dasteht. Die Töne kommen aus der Laute, aber sind nicht die Laute. Der Faden ist nicht die Spinne, das Kind nicht die Mutter. Sehr bezeichnend ist folgende Stelle ${ }^{84}$, die man, wenn sie auch einem Brāhmana, nicht einer eigentlichen Upanishad angehört und nicht vom Âtman, sondern vom alten Weltschöpfer Prajāpati spricht, doch als klares und vollgiltiges Zeugnis darüber verwenden darf, wie über die beim Schaffen d. h. „Entlassen“ in Frage kommende Wesensidentität oder Verschiedenheit des Entlassenden und des Entlassenen gedacht wurde. Von Prajāpati heißt es, daß er ,,alle Wesen schuf, was atmet und was nicht atmet, beide Götter und Menschen. Als er nun alle Wesen geschaffen hatte, fühlte er sich erschöpft, und Furcht vor dem Tode überkam ihn. Da dachte er: ,Wie kann ich wohl alle diese Wesen wieder in mein Selbst (âtman) ergießen, wieder in mein Selbst hineintun? Wie kann es wohl geschehen, daß ich wieder das Selbst aller dieser Wesen bin?" "Worauf, nach vielem vergeblichen Bemühen, der Schöpfer dessen inne ward, daß "alle Wesen im dreifachen Wissen (Rigveda, Yajurveda, Sāmaveda) enthalten sind" ${ }^{1}$ ) Durch rituelle Zauberkünste ,ergoß er dieses dreifache Wissen in sein Selbst, tat es in sein Selbst hinein. In diesem (Tun) eben wurde er zum Selbst aller dieser Wesen“. Der Akt des „Entlassens" also - das zeigt sich hier deutlich —, den Entlasser ausleerend, verleiht dem Entlassenen eigne, jenem fremd gegenüber-

1) Man erinnere sich der oben S. 51 besprochenen Vorstellungen. 
stehende Wesenheit. Die Fremdheit kann dann vielleicht überwunden werden. Zunächst aber ist sie da. -

Die Lage des hier erreichten Standpunkts im Ganzen dieser Gedankenbewegung ist wohl erkennbar.

Alles arbeitet auf Einheit des Weltbildes hin. Das Bedürfnis nach ihr bekämpft, für jetzt immer siegreicher, den Eindruck grenzenloser Vielheit der umgebenden Welt, wie er sich dem natürlichen Bewußtsein aufdrängt.

Die älteren Zeiten, widerstandsloser diesem Eindruck hingegeben, hatten damit angefangen, die Einheit vor allem dahin $\mathrm{zu}$ verlegen, wo sich am leichtesten über freien, von der Vielheit nicht in Beschlag genommenen Raum verfügen ließ: in den Anfang der Dinge. Die Einheit des Schöpfers(Prajāpati etc.) schlang ein Band um die Vielheit des Geschaffenen. Diese Vielheit selbst, obwohl auch sie schon früh von mannigfachen der Einheit zustrebenden Strömungen bespült wurde, hielt im Ganzen doch stand, festgewurzelt in ältesten geistigen Gewöhnungen, bestätigt durch dieEindrücke jedes Augenblicks.

Nun gelingt dem Einheitsstreben der große Sieg: ein höchstes Wesen wird gedacht, das nicht allein, Prajāpatis Erbschaft übernehmend, die Vielheit schafft, sondern vor allem auch gestaltend, belebend ihr inne wohnt. Das Einheitsband, das die Dinge zusammenhält, hat sich damit gewaltig verstärkt. Aus der Vergangenheit des Weltanfangs reicht es in und durch die Gegenwart. Dem Einen allein, dem "Wahren des Wahren " ist höchster Grad der Realität vorbehalten. Das Viele, für sich nur dämmerhafter Existenz teilhaft, erhält Leben, indem jenes in ihm lebt. Es wird weiter davon zu sprechen sein, wie der Einheit im Anfang der Dinge das Eingehen zur Einheit als Ziel des Weges entspricht: so daß das Eine es ist, „aus dem diese Wesen geboren werden, durch das die geborenen leben, in das sie hinscheidend zur Ruhe eingehen ". ${ }^{85}$ Wie tief hat sich da die Bedeutung dessen, was nicht das Eine ist, gesenkt. Aber in alldem ist doch von Leugnung des Daseins der Vielheit, von Herabdruckung dieses Daseins zu bloßem Schein 
schlechterdings nicht die Rede. Alles oben Dargelegte zeigt das. Wäre die Vielheit trügerischer Schein, könnte nicht von der Weltschöpfung berichtet werden. An ihrer Stelle müßte ein Vorgang stehen, in dem jener Schein - sofern er nicht anfangslos war - sich erhoben hätte. Es könnte nicht von Eingehen des höchsten Wesens in das Erschaffene die Rede sein. Die Erde und die andern Elemente dürften nicht der Leib jenes Gottes heißen, „der in der Erde weilend von der Erde verschieden ist.... der die Erde innen lenkt" (oben S. 71). Jene kontrastierenden Vorstellungen, nach denen das Brahman bald den kleinsten Raum im Mittelpunkt der Einzelwesen bewohnt, bald diese in ihrer ganzen Ausdehnung durchdringt, wären allesamt gegenstandslos. Die Gleichnisse wie das vom Aufgelöstsein des Salzes im Salzwasser (oben S. 72) träfen vorbei. Am wenigsten dürfte man davon sprechen, daß "das Feuersein des Feuers - das Sonnesein der Sonne usw. - allein am Wort haftet, eine Umwandlung, eine Benennung ist, die drei Gestalten allein (,Glut, Wasser, Nahrung") das Wahre sind" (oben S. 70). Damit wird ja in einer Darlegung, deren Absicht gerade dies ist, der vorübergehenden Erscheinung das Wesenhafte gegenüber zu stellen, jenen Grundelementen, aus denen sich die Schöpfung aufbaut, Substanzialität zugeschrieben, die freilich dann noch ein Eingehen des Ātman erwarten muß, um fertig und lebendig im Welttreiben ihre Laufbahn anzutreten.

Kurz zusammengefaßt also ist, was gelehrt wird, dieses. Außer dem einen unvergleichlichen Wesen gibt es die Vielheit des von ihm Erschaffenen. Dieser Vielheit kommt Gestalt, Leben, Licht von dem in sie eingegangenen Einen.

Das ist der Glaube, der in den Upanishaden durch stärkste Reihen harmonierender Zeugnisse bestätigt wird: Zeugnisse, die nur zum Teil dasselbe wiederholen, zum andern Teil aber auf die gleichen Grundanschauungen von verschiedenen Seiten hinblicken, verschiedene Probleme jedesmal in deren Licht behandeln und so für ihren Erweis eine besonders stark gefestigte Evidenz ergeben. - 
Nun aber gehört zum Charakter des hier geschilderten tiefschauenden, doch der sicheren Übung selbstverständlich ermangelnden Denkens auch ein vielfältiges Schwanken der von ihm beschriebenen Linien. Als sähe man eine Landschaft durch dunsterfüllte Atmosphäre, die das Gesehene flimmern läßt. In einer Upanishad sagt das höchste Wesen: "Wahrlich ich bin die Schöpfung, denn ich habe dies alles erschaffen" (S. 80). Der Satz veranschaulicht, wie hier beständig der Gedanke schwankt. Schöpfer sein wird zum Schöpfung sein, ja ein "denn" bezeichnet das zweite als aus dem ersten folgend. Wie schon oben bemerkt: geraten zwei Vorstellungen in eine gewisse Nähe zu einander, so versagen leicht die Hemmungen, die ihren Zusammenfall hindern sollten: was dieses ist, das ist jenes.

Kann es da überraschen, daß das Eine und das Viele, eins dem andern innewohnend und es belebend, nun auch hier und da vollständig in einander umschlagen?

Zunächst wenigstens eine Annäherung hieran scheint beispielsweise vorzuliegen, wenn einmal gesagt wird ${ }^{38}$, die von Dasein zu Dasein wandernden Kreaturen gehen in das Seiende ein und kommen wieder hervor "wie wenn die Honigbienen den Honig bereiten und von mancherlei Bäumen die Säfte zusammentragen und den Saft zur Einheit werden lassen; wie dann diese Säfte nicht zu unterscheiden wissen: ich bin dieses Baumes Saft; ich bin jenes Baumes Saft" - und ein zweites Gleichnis: „Diese Ströme fließen im Osten gen Morgen, im Westen gen Abend. Von Ozean zu Ozean strömen sie; zu Ozean werden sie. Wie die dann nicht wissen: ich bin dieser Strom; ich bin jener Strom"... Hier scheint der Gedanke unverkennbar, daß das Einzelwesen, eine Zeitlang als solches in einer gewissen Trennung vom Allwesen verharrend, wie der Fluß vom Meer getrennt ist, doch, seiner Substanz nach von jenem nicht verschieden, wieder in ihm verschwindet, wie der Fluß im Meer ${ }^{1}$ ).

$\left.{ }^{1}\right)$ Der Text selbst allerdings spricht den durch die Gleichnisse veranschaulichten Gedanken dahin aus, daß die Kreaturen, in das Seiende 
Entschiedener noch scheint sich die Identität des Einen und der Vielheit an andern Stellen auszusprechen. „Dieses, obwohl es eine Dreiheit ist (es hatte gehießen: Eine Dreiheit wahrlich ist dies [All], Name, Gestalt, Tun), ist Eins, nämlich dieser Ātman. Und er, obwohl er Eins ist, ist diese Dreiheit." Vielleicht möchte man bemerken, daß es sich bei der Dreiheit nicht um die Mehrheit der Weltwesen handelt, sondern um eine Mehrheit der Wirkungsweisen des Ātman. Aber nun sehe man die folgenden Äußerungen: „Dies ist das Brahman, dies das Kshatra, dies die Welten, dies die Götter, dies die Wesen, dies das All, was dieser Ātman ist." „Brahman wahrlich war dies (All) im Anfang. Dies wußte allein sich selbst (ātmānam): ,Ich bin das Brahman'. Dadurch wurde es zu diesem All." - Nachdem vom Eingehen des Ātman in die nach "Namen und Gestalt" entfaltete Welt die Rede gewesen ist („,bis zu den Nagelspitzen, wie ein Schermesser in seinem Behälter ruht" usw., oben S. 72), fährt der Text fort: „Den sieht man nicht, denn er ist zerteilt. Atmet er, heißt er Atem. Redet er, Rede. Sieht er, Auge. Hört er, Ohr. Denkt er, Geist. ${ }^{87}$ Das sind nur Namen für seine Tätigkeiten. Wer davon nur ein Einzelnes verehrt ${ }^{1}$ ), der versteht es nicht. Denn zerteilt ist er durch all dies Einzelne. Als den Ātman allein soll man ihn verehren, denn darin werden alle jene (Wesenheiten) eins." Die oben hervorgehobene Unbestimmtheit der Vorstellung

eingehend und wieder aus ihm hervorkommend, kein Bewußtsein von jenem Eingehen und Hervorkommen haben. Ist nicht doch - vielleicht neben jenem Sinn - der oben bezeichnete deutlich aus den Gleichnissen herauszulesen? Man vergleiche, wie in der Praśna Up. VI, $\check{j}$ das Gleichnis von den Flüssen und dem Ozean für das Verschwimmen von „Namen und Gestalt" im unsterblichen Purusha gebraucht wird (vgl. auch Mundaka Up. III, 2, 8 sowie das einigermaßen ähnliche buddhistische Gleichnis in meinem „Buddha" 6. Aufl., 215). Wie leicht in der Behandlung eines Gleichnisses im Text Verschiebungen eintreten konnten, zeigt die Gegenüberstellung von Brih. Är. Up. II, 4, 12 und IV, $5,13$.

1) Zur hier auftretenden Vorstellung des „Verehrens" vgl. oben S. 37 und unten (s. Register). 
oder wenigstens des Ausdrucks verrät sich hier deutlich. Zuerst ist der Ātman, der vorherrschenden Auffassung entsprechend, in die Welt der Vielheit eingegangen. Darin würde liegen, daß er dem Auge etwa, wie anderwärts in der Tat öfter gesagt wird, als "der Mann (purusha) im Auge" innewohnt. Statt dessen ist er hier das Auge, das Ohr selbst. Um zu handeln ist er nicht in das Organ eingegangen, sondern selbst das Organ geworden, das die betreffende Handlung vollzieht. Ist das nur ein abgekürzter oder flüchtiger Ausdruck für die Vorstellung, daß er die lebendige, jenem Organ innewohnende Kraft ist? Unmöglich für die einzelne Stelle das mit Sicherheit zu entscheiden. Im Ganzen aber ist so viel doch wahrscheinlich, daß in der Tat ein gelegentliches Hinüberspielen stattfindet von der überwiegenden Vorstellung, daß der Ātman der Vielheit als das allein Lebendige, Wertvolle innewohnt, zu der Vorstellung, daß er diese Vielheit ist. Die Nuance, die das Eine vom Andern trennt, ist zu gering, als daß sie hier mit Bestimmtheit hätte festgehalten werden können. ${ }^{88} \mathrm{Um}$ so mehr, als ja ohnehin von den Zeiten der Opferwissenschaft her die Neigung, irgend eine Wesenheit kurzweg das All sein zu lassen, den brahmanischen Denkern im Blut lag.

Mit dem Schritt aber, den man hier tat, oder besser mit dem Gleiten, in das man verfiel, war die Geltung des Einen wieder um eine Stufe gesteigert. In der Vielheit war jetzt nichts mehr, das nicht das Eine ist. Man hat, mir scheint zutreffend, an Spinoza's Lehre von den Modi erinnert $^{89}$, wonach die endlichen Dinge Affektionen, Zustände der einen unendlichen Substanz sind. Es ist klar, daß wie Spinoza so auch hier die Upanishaden der Vielheitswelt die Realität schlechterdings nicht abstreiten. Kein Irrtum des Betrachters wird behauptet, dem das Eine fälschlich als in viele Zustände eingegangen erschiene. Sondern daß jenes in diese Zustände eingegangen, ist Wahrheit, und Irrtum wäre es nur, wollte man denen einzeln eine auf sich beruhende Substanzialität zuerkennen. So fährt die oben 
(S. 87) angeführte Stelle von der Identität der "Dreiheit" und des Âtman fort: „Dasselbige ist das Unsterbliche verhüllt durch das Wahre. Der Atem ${ }^{1}$ ) wahrlich ist das Unsterbliche, Namen und Gestalt das Wahre. Durch diese ist jener Atem verhüllt." Und eine andre Stelle, vom Ātman sprechend: „Seine Verehrung (upanishad) lautet: ,das Wahre des Wahren." Wahrlich die Atemkräfte sind das Wahre. Deren Wahres ist er. "40 Womit die Vielheit, die das Eine umgibt, deutlich nicht als Trugbild bezeichnet ist, sondern als Wahrheit. Als eine Wahrheit, die gemessen an der absoluten Höhe, am Wahren des Wahren, eine Stufe niedriger steht, so zu sagen ein Sein zweiter Ordnung darstellt ${ }^{2}$ ). Aber sie ist doch Wahrheit. -

Nunmehr ist schließlich zu fragen, ob in der großen Bewegung des Gedankens, in welcher die Vielheit vor der Einheit zurückweicht, schon jetzt auch der letzte Schritt geschehen ist. Ob der Punkt erreicht ist, der in den eben betrachteten Äußerungen noch nicht erreicht war: die Vielheit wird für Schein erklärt; Wahrheit ist allein die Einheit.

In späteren Zeitaltern haben, wie bekannt, Vertreter der Vedāntaphilosophie, die sich auf den Upanishaden aufbaut und deren Inhalt systematisiert, in ihnen eben diese Lehre gefunden und sie sich selbst zu eigen gemacht. Jahrhunderte vor dem großen Śankara gab schon die Māndụukyakārikā des Gauḍapāda jenes berühmte, oft wiederholte Gleichnis: wie im Dunkeln der Strick für eine Schlange gehalten wird, so ergeht es mit dem göttlichen Einen. Statt seiner erscheint grenzenlose Vielheit:

„Das ist des Gottes Trugzauber, durch den er selber sich betört" -

die "Māya $\bar{a} "$, jene zauberhafte Vorspiegelung, die den leeren Schein des Weltdaseins erweckt. Bis wahre Erkenntnis den

1) Steht "Atem" (prāna) hier im Sinne von Ātman, welche Bezeichnung kurz vorher gebraucht war?

$\left.{ }^{2}\right)$ "Realty presents itself as a thing of degrees", sagt treffend im Hinblick auf diese Gedankengänge Griswold (Brahman S. 50). 
Trug vernichtet, die scheinbare Vielheit vor dem ewigen Einen in ihr Nichts versinkt.

Daß schon jenes Altertum, mit dem wir uns hier beschäftigen, zu solch äußerster Zuspitzung der Ātmanlehre gelangt sei, ist mir durchaus unwahrscheinlich."

So viel zunächst, meine ich, ist klar, daß in jedem Fall die herrschende Ansicht der Upanishaden eine andre ist. Die Weltwirklichkeit wird gelten gelassen. Das höchste Wesen hat die Welt geschaffen. Es ist in die geschaffene Welt eingegangen. Außer ihm und seiner Seligkeit - hiervon ist weiterhin $\mathrm{zu}$ sprechen - herrscht wirkliches, nicht geträumtes Leiden. Von dem gibt es wirkliche Erlösung, nicht bloßes Aufwachen aus einem beängstigenden Traum. Das Nichtwissen, das die wahre Erkenntnis verdunkelt, besteht darin, daß der A tman und seine weltheherrschende Macht ungekannt bleibt. Nicht darin, daß man die Welt, welche unwirklich wäre, vermöge der Māyā für wirklich hält.

Höchstens so viel könnte in Frage kommen, ob doch unter den Massen auftauchender und wieder verschwindender Gedanken und Einfälle, von denen die Upanishaden voll sind, ganz gelegentlich auch solche erscheinen, in denen die Māyālehre vorweggenommen wird. Aber auch hieran zweifle ich. Die Äußerungen der Texte ${ }^{1}$ ), auf die man sich da berufen hat, scheinen mir zum großen Teil andre Deutung zu verlangen. Ein Rest bleibt, der andre Deutung wenigstens zuläßt, ja sie empfiehlt.

Ich gebe einige Beispiele.

Uns werden weiterhin Betrachtungen der Upanishaden beschäftigen, die es mit dem Beisichsein des Ātman in seinem eignen Reich, entfernt von der geschaffenen Welt, zu tun haben: mit jenem höchsten Sein, in dem sich für das Selbst des Erlösten seine Identität mit dem All-einen vollendet oder

1) Natürlich scheiden für diese Erwägungen - woran zu erinnern vielleicht nicht überflüssig ist - Zeugnisse jüngerer Upanishaden aus. So der berühmte, später zu besprechende Vers der Śvetāśvatara Upanishad:

„Ein Zauberspiel ist die Natur; der Zaubrer ist der höchste Gott." 
bestätigt. Dort ist der Gegensatz von Subjekt und Objekt geschwunden, also auch alle Wahrnehmung, alles Bewußtsein, das diesen Gegensatz voraussetzt. Jene klassische Stelle einer Upanishad spricht davon ${ }^{42}$ : "Wo eine Zweiheit gleichsam ist, da sieht Einer den Andern, da riecht Einer den Andern, da hört Einer den Andern, da spricht Einer zum Andern, da denkt Einer den Andern, da erkennt Einer den Andern. Wo einem aber alles nur das eigene Selbst (ătmā) geworden ist, wodurch und wen sollte er da riechen, wodurch und wen sollte er da sehen, wodurch und wen sollte er da hören, wodurch und zu wem sollte er da sprechen, wodurch und wen sollte er da denken, wodurch und wen sollte er da erkennen? Durch den er dies alles erkennt, wodurch sollte er den erkennen? Den Erkenner, wodurch denn sollte er ihn erkennen?"

Diese Sätze gehören jenem Gespräch des Yājñavalkya und seiner Gattin Maitreyī an, das man wohl einen Höhepunkt der Upanishaden nennen darf. Maitreyī sehnt sich nach der Gewißheit der Unsterblichkeit. Er erschreckt sie: "Kein Bewußtsein ist nach dem Tode." Und er erklärt: da wo allein der Ātman ist, kann es kein Sehen, kein Denken, das ja an eine Zweiheit gebunden ist, geben. Wird damit nun, die Welt der Vielheit geleugnet, zu bloßem Schein herabgesetzt? Offenbar ganz und gar nicht. Dem Verfasser des Gesprächs konnte es nicht in den Sinn kommen $\mathrm{zu}$ bestreiten, daß wir hienieden sehen, hören, denken, also in einer Welt der Vielheit leben. Wenn der Tod aber den Vollendeten in jenes Reich hinüberführt, in das die Vielheit sich nicht erstreckt ${ }^{43}$, wo der Ātman allein bei sich selbst ist, dann, und erst dann hat alles Sehen und Denken sein Ende gefunden. Yājnavalkya sagt nicht: das Bewußtsein und die von ihm unzertrennliche Vielheit ist Täuschung. Er sagt: „kein Bewußtsein ist nach dem Tode."

Ganz ähnlich, ja teilweise mit denselben Worten wird an einer andern Stelle ${ }^{44}$ das irdische Vorspiel der jenseitigen Vollendung beschrieben: der Tiefschlaf, in dem der Geist 
kein Bewußtsein eines Draußen und Drinnen hat, wo „der Vater nicht Vater, die Mutter nicht Mutter ist . . . denn dann hat er alle Qualen des Herzens überwunden." „Wenn er dann nicht sieht", heißt es, "so ist er sehend, obwohl er nicht sieht. Denn die Sehkraft kann dem Seher nicht verloren gehen, da sie unvergänglich ist. Aber es ist kein Zweites, von ihm Verschiedenes, das er sehen könnte ... Wo ein Andres gleichsam ist, da kann Einer das Andre sehen, Einer das Andre riechen ... Einer das Andre erkennen." Auch dies ist deutlichermaßen entsprechend wie vorher zu verstehen. Der Tiefschlaf führt in ein Reich, dem die Vielheit fern ist. "Dieses ist die Brahmanwelt", sagt der Text ausdrücklich. Die Vielheit aber, in der sich das wache Dasein bewegt, wird darum nicht geleugnet. Dieselbe Erörterung, die sich hier mit dem Schlaf beschäftigt, wendet sich dann dem Tode zu. Der Nichtverlangende, Erlöste erreicht sterbend die höchste WVelt. In diesem Zusammenhang folgen Verse, deren Eingang uns schon in anderm Zusammenhang beschäftigt hat:

„Wer Atems Atem und des Auges Auge,

Des Ohres Ohr, des Geistes Geist verstehet,

Der kennt das uranfänglich alte Brahman,

Das nur der Geist erschauen mag,

Das frei von aller Vielheit ist.

Des Todes Tod $^{1}$ ) ist dessen Teil,

Der hier Vielheit zu sehen meint.

Als Einheit nur erschaue man

Das unvergänglich Ewige."

Auch hier, meine ich, wird keineswegs der Welt der Vielheit das Dasein - wir dürfen im Sinn des oben (S. 89) Bemerkten sagen, ein Dasein zweiten Ranges - abge-

$\left.{ }^{1}\right)$ „Des Todes Tod“ ist Steigerung von „Tod“, ähnlich wie vorher „des Atems Atem" usw. Wegen dieser Parallelität ziehe ich die obige Übersetzung der an sich möglichen Auffassung ,Tod auf Tod erlangt er" vor. 
sprochen. Würde es sonst in derselben Versreihe, zwei Verse vorher, vom Ātman heißen:

„Drauf die fünffache Wesenschar

Samt dem Äther begründet ist" - ?

In den obigen Versen aber ist deutlich vom Brahman die Rede, wie es in seiner eignen Welt thront, wohin dem Erlösten der Ausweg sich auftut. Dort Vielheit zu erkennen: das ist es, wovor gewarnt wird.

Ebenso deutlich scheint mir, daß mit den andern Stellen, die als Zeugnisse für die alleinige Realität des Einen angeführt werden, in der Tat die Anerkennung der Weltwirklichkeit durchaus vereinbar ist oder durch jene Stellen geradezu gefordert wird. Wir begegneten oben (S. 82) dem Vergleich: wie Funken aus dem Feuer sprühen, gehen aus dem Ätman alle Wesen hervor. An einer andern Stelle ${ }^{45}$ : "Wie in der Nabe und im Radkranz alle Speichen befestigt sind, also sind in diesem Ātman alle Wesen, alle Götter, alle Welten, alle Atemkräfte, alle diese Selbste (Ātman) befestigt." Zeugen solche Äußerungen, wie man befremdenderweise behauptet hat, für die alleinige Realität des Ātman? Stellen sie nicht vielmehr die Wirklichkeit der Vielheitswelt ausdrücklich fest $\left.^{1}\right)$ ? Sind die sprühenden Funken nicht real wie das Feuer? Die Speichen wie Nabe und Radkranz? Wem das Hervorgehen einer Vielheit aus dem Einen, das Befestigtsein einer Vielheit am Halt- und Mittelpunkt, den das Eine bietet, als Trugbild der Māyā erschienen wäre: hätte der nicht anders gesprochen? „Den Ātman wahrlich", sagt Yājnavalkya in jenem oben erwähnten Gespräch, ,soll man sehen, hören, denken, sich in ihn vertiefen, o Maitreyī. Durch das Sehen, Hören, Denken, Erkennen des Ātman wahrlich wird alles dies (Dasein) gewußt." Schließt das Leùgnung der Welt in sich? Besteht es nicht zu recht,

1) Ebenso die Worte, die der letztangeführten Stelle vorangehen: „Wahrlich dieser Ātman ist aller Wesen Oberherr, aller Wesen König. Man sollte das Folgende nicht ohne Rücksicht auf das Vorhergehende betrachten. 
auch wenn die Welt, wie in Spinoza's Lehre von den Modis Gottes (vgl. oben S. 88), als eine Vielheit von Zuständen des Ātman umfassend angesehen wird? Oder gleichermaßen wenn, der vorherrschenden Auffassung der Upanishaden entsprechend, der Ātman gedacht wird als der Mannigfaltigkeit des von ihm Erschaffenen innewohnend und sie belebend? Das Wissen von dem in der Welt allein Lebendigen, Schöpferischen, Wertvollen konnte doch wohl den Denkern der Upanishaden als einem Wissen von der Welt gleich erscheinen: hieran Anstoß nehmen hieße jenen eine Fähigkeit zum Festhalten von Subtilitäten und eine Geneigtheit zum Festhalten rein theoretischer Subtilitäten zuschreiben, die ihnen in der Tat sehr fremd war. Wäre nicht vielmehr jene Gleichsetzung der Erkenntnis des Ātman und der Erkenntnis der Welt geradezu irreführend im Munde eines Denkers, der die Existenz der Welt leugnete?

$\mathrm{Da} \beta$ in der ungeheuren Masse dunkler oder vieldeutiger Äußerungen der Upanishaden, in der Rätselsprache ihrer Verse, welche oft mystische Geheimnisse mehr zu verhüllen als zu entschleiern lieben, nie der Gedanke an die Täuschung der Māyā vorgeschwebt habe, ist natürlich nicht positiv erweisbar. In der Tat hatte man Regionen des Denkens erreicht, von denen der Weg zur Leugnung der Welt nicht mehr sehr weit war. An Mut auch Äußerstes zu wagen fehlte es nicht. Wie früh da zuerst ein Vorläufer seine Kraft in jenem letzten Schritt versucht haben mag? Wir müßten eine bestimmter redende Überlieferung besitzen, um das vollkommen sicher zu wissen.

Sollten aber in der Tat vorauseilende Ahnungen die Auflösung der Welt in Trug der Māyā schon jetzt vorweggenommen haben, so würden immer noch die Gedankenkreise der Upanishaden ein sehr andres Aussehen behalten, als sie in einer scharfsinnigen, von starker persönlicher Überzeugung getragenen Darstellung eines neueren Forschers ${ }^{40}$ zeigen. Nach ihm sollen diese Texte, je älter sie sind, um so schroffer und nachdrücklicher den illusorischen Charakter 
der empirischen Realität hervorheben. Und wenn dann doch diese Realität anerkannt wird oder zu werden scheint, so soll das auf Akkommodationen beruhen an das aus der Vergangenheit Überkommene und an die dem Menschen von Natur eigene Anschauung der Welt, wie diese in ihrer räumlichen, zeitlichen, kausalen Ordnung sich mit nie ganz zu überwindender Macht dem Bewußtsein darstellt.

Es wurde im Obigen versucht zu zeigen, wie wenig jene besonders nachdrücklich den älteren Upanishaden zugeschriebene Betonung des illusorischen Charakters der Welt mit dem wirklichen Textbestand im Einklang steht. Ich möchte hinzufügen, daß auch die innere Wahrscheinlichkeit in andre Richtung weist. Und zwar in eben jene, die auch durch die Prüfung der Quellentexte empfohlen wird. Die Upanishaden schließen sich ja in vollständigster Kontinuität, wie literaturgeschichtlich so auch in der Entwicklung der Ideen, an die Brāhmanas. Das Brahman, der Ātman der Upanishaden geht aus dem Brahman, dem Ātman der Brāhmanatexte hervor. Jene Potenz lebt in den Dingen so wie diese Potenzen in ihnen lebten: nur gewaltiger, alleinkräftig, zu höchstem Herrschertum aufgestiegen. Die Vorstellung vom Wirken innewohnender Substanzen oder Kräfte, insonderheit vom Wirken des Selbst in allen Lebensäußerungen der Person beherrscht die Brāhmanaspekulation und setzt sich ganz ebenso in den Gedanken der Upanishaden über den A tman fort: immer das Walten einer Kraft in einer von ihr regierten Wesenheit, wobei betreffs der realen Existenz der letzteren von Zweifel nicht die Rede ist. So erscheint die Spekulation der Upanishaden in der realistischen Auffassung, die im Obigen vertreten wurde, als fest verknüpft mit der Denkweise des unmittelbar vorangehenden Zeitalters und darin so zu sagen verankert. Wäre die ursprüngliche, reine Doktrin der Upanishaden die Māyālehre, so müßten wir zwischen die beiden eben genannten Phasen des Denkens eine Wendung zum extremen Idealismus dieser Lehre in die Mitte schieben und dann weiter eine davon wiederum 
abfallende Akkommodation an Fremdes dort annehmen, wo evidentermaßen in der Tat einfache, geradlinige Weiterentwicklung aus dem vorangehenden Stadium vorliegt. Die Nichtrealität der Welt als älteste und reinste Upanishadenlehre steht, meine ich, ungefähr mit jenem Urmonotheismus auf einer Linie, den manche Religionshistoriker in den Anfang der Dinge zu verlegen beliebt haben. Wie dort religiöse, so hat hier philosophische Voreingenommenheit das Urteil getruibt.

Das Absolute in sich. Persönlichkeit oder Unpersönlichkeit.

Wird das höchste Wesen darin, daß es die Dinge beseelt und lenkt, restlos aufgehen?

Längst war man gewohnt, an die Spitze des Weltdaseins Mächte zu stellen, die selbst über die Welt hinausreichten, anderswo zu Hause waren als in der Welt, älter oder größer waren als die Welt. In primitiver Form galt das schon von den alten Göttern. Wenn Gott Indra unter den Menschen sein Wesen trieb, sagte der vedische Dichter zu ihm: „Du hast Soma getrunken. Jetzt fahre heim, Indra. Eine schöne Gattin, herrlichen Besitz hast du in deinem Hause." Prajāpati, der dann die Rolle des Schöpfers übernahm, war allein da, ehe er die Welt schuf. Der Purusha des rigvedischen Hymnus (X, 90), der zur Welt wurde, ging in dieser doch nicht mit seinem vollen Wesen auf. Ein Teil von ihm, ja der größere Teil führte eignes Dasein:

,So groß ist er, und größer noch als dieses ist der Purusha: Ein Teil sind alle Wesen; drei Teil' unsterblich im Himmel sind."

Zwingende Notwendigkeit es ebenso anzusehen hätte für die Spekulation der Upanishaden zwar an 'sich nicht bestanden. Von der Betrachtung der Welt ausgehend konnte sie sich daran genügen lassen, die höchste Macht allein als in dieser wirkend aufzufassen. Aber es war doch natürlich, daf man jene gewohnte Vorstellung, sie unver- 
gleichlich vertiefend, auch auf die neuen Gedankenkreise übertrug. Es wäre ja seltsam gewesen, hätte man dem Absoluten eben nur so viel Spielraum gegönnt wie für seine Funktionen innerhalb der Welt nötig war. Ihm, dem von allem Weltdasein fundamental verschiedenen, gebührte jenseitige Einsamkeit, damit es dort ähnlich den platonischen Ideen in seiner eignen, vollen und reinen Glorie leuchtete. Und noch ein besonderer Antrieb war wirksam, dem Denken diese Richtung zu geben. Das Verlangen dem vom Tod beherrschten Dasein zu entrinnen wies auf ein todbefreites Jenseits hin: wie hätte da die Idee des höchsten Seienden, die gewiß wesentlich eben unter dem Einfluß solches Verlangens gebildet war, nicht die Gestalt annehmen sollen, die diesem das klarste und vollste Genüge tat? So war es natürlich, und schon das früher Besprochene weist darauf an manchen Stellen hin, daß auch Brahman-Ātman, die Welt schaffend, in die Welt eingehend, ähnlich wie jene seine mythischen Vorgänger als über die Welt hinausreichend vorgestellt wurde. Von den beiden Wesenheiten, die dem Höchsten den Namen gaben, hatte das Brahman von Haus aus sein eignes Dasein, die Dinge beherrschend, aber sich in den Dingen nicht erschöpfend. In der ursprünglichen Natur des Ätman ließe sich zwar eher - doch auch hier nicht mit zwingender Notwendigkeit - eine Beschränkung finden auf die Daseinssphäre des Wesens, dessen A tman jener ist. Aber es ist begreiflich, daß der Ātman, mit Brahman zur Gestalt des Absoluten zusammenfließend, an solcher Begrenzung nicht hielt.

In den Texten verschwimmt nun begreiflicherweise oft der Gedanke an das in den Dingen und an das in sich selbst seiende Absolutum. Daß aber eine Unterscheidung der beiden Situationen nicht außerhalb des Gesichtskreises lag, tritt doch deutlich hervor.

Die oben (S. 66) mitgeteilte Kosmogonie hob damit an, daß das Brahman im Anfang allein war. Als es die Welten geschaffen, „ging es selbst zur jenseitigen Sphäre“. 
$\mathrm{Da} \beta$ es von dort wiederum in das Diesseits mit seinen „beiden großen Kiesenwesen" Gestalt und Namen hinabsteigt das Ungeformte $\mathrm{zu}$ formen, besagte schwerlich, daß es darum auf sein eigenes Dasein in jener ,jenseitigen Sphäre" verzichtet hätte. In demselben Sinn ist wohl auch der oben (S. 76) angeführte Vers vom Schwan zu verstehen, der Untergang über die Welt brächte, zöge er seinen einen Fuß aus der Flut heraus: den andern Fuß, wird man ergänzen, hat er nicht in die Flut getaucht - die Gottheit bleibt mit einem Teil ihres Wesens der Welt fern. Hierher könnte es möglicherweise weiter gehören, daß eine der ältesten Upanishaden sagt ${ }^{47}$ : "Zwei Gestalten des Brahman wahrlich gibt es: die körperhafte und unkörperhafte, die sterbliche und unsterbliche, die stehende und gehende, das Seiende und das Jene ${ }^{1}$ )." Freilich wird dann, mit befremdender Verflachung des Gedankens, das Unkörperhafte, Unsterbliche usw. als Wind und Luftraum, das Körperhafte als alles andre gedeutet. Man möchte meinen - wenn das auch natürlich nicht beweisbar ist - , daß sich da eine verfehlte Erklärung nachträglich eingedrängt hat, ursprünglich aber es abgesehen war auf die Gegenüberstellung der Verwirklichung des Absoluten in der Welt und seines Verharrens in reinemBeisichsein. Dafür spricht, daß eine jüngere Upanishad die ganz ähnliche Gegenüberstellung zweier Daseinsformén des höchsten Wesens ausdrücklich in eben diesem Sinn deutet: „Er (der Ātman) begehrte: möge ich vieles sein, möge ich mich fortpflanzen. Er übte Kasteiung. Als er Kasteiung geübt hatte, schuf er alles dieses, was da ist. Als er das geschaffen hatte, ging er in eben dasselbe ein. Als er darin eingegangen war, war er das Seiende und das Jene ${ }^{2}$, Ausgesprochenes und Unausgesprochenes, Wohn-

1) Ein unübersetzbares Wortspiel. sat ("Seiendes") und tyam ("Jenes", falsche Form dem Wortspiel zu Liebe für die richtige tyat gesetzt) ergeben zusammen satyam („das Wahre"). Deussen übersetzt "Seiendes und Jenseitiges". Vielleicht hat in der Tat ein Gedanke an derartiges vorgeschwebt. Dem Wortsinn nach aber ist tya nicht njenseitig*.

2) Siehe die vorige Anmerkung. 
stätte und Nichtwohnstätte, Erkenntnis und Nichterkenntnis, Wahres und Unrechtes ${ }^{1}$ ). "Während also das höchste Wesen in seiner „ausgesprochenen" Gestalt in der Welt weilt, in die es eingegangen ist, verharrt es außerhalb dieser ${ }^{2}$ ) in seiner "unausgesprochenen" Seinsform. Das Brahman ist Weltseele, aber es ist nicht nur Weltseele. Ein Gedanke von entscheidender Bedeutung. Wenn Gott Indra von der Erde zu seiner himmlischen Wohnung zurückkehrt, liegt darin noch nicht viel von Vorstellungen der Jenseitigkeit. Anders wenn ein Wesen wie das Brahman über die Welt hinausreicht. Da eröffnet sich der Ausblick auf ein Sein, auf ein Ziel fundamental verschieden von dieser Welt, grenzenlos wichtiger und höher als sie. Das hienieden vor sich gehende Wirken des Höchsten erscheint als nebensächlich. Welt und Brahman ordnen sich im größten Zusammenhang alles Seins erst dann an ihre rechte Stelle, wenn jenseits der vom Brahman durchwobenen Welt das überragende, ungeheure Geheimnis des überweltlichen Brahman erscheint - nein kaum erscheint. Und, sollte man dann freilich vielleicht noch hinzufügen, wenn dem Denker auch dies letzteste gelingt, die Einheit zu erfassen, in der beide Gestalten des Brahman mit einander verbunden sind. Deutet auf einen solchen Gedanken nicht die folgende Stelle hin? "Der Name dieses Brahman wahrlich ist satyam [das Wahre]. Das sind drei Silben: sa-ti-yam. sat [das Seiende] ist das Unsterbliche. $t i$ ist das Sterbliche. Mit dem yam regiert.

1) „Realität und Nichtrealität" Deussen. Wir dürfen, meine ich, das deutlich dastehende "Unrechte" (oder "Unwahre") nicht verflüchtigen. Das Absolutum in die Welt eingehend hat die mit diesem Wort bezeichnete Gestalt angenommen. Ein Zeugnis für die Māyālehre (oben S. 89) wird man darin natürlich nicht finden. Zur Wahl des betreffenden Ausdrucks trug offenbar bei, daß man einmal im Zuge war Gegensatzpaare einander gegenüberzustellen.

2) $\mathrm{DaB}$ für dies AuBerhalb sich dann auch so materielle Ausdrücke finden, wie „Wohnen in der Sonne" (Taitt. Up. II, 8; III, 10), entspricht ganz der Weise der Upanishaden. 
(yam-, yacchati) es beides. Weil es damit beides regiert, darum heißt es yam."

Beziehung zwischen der Welt und der überweltlichen Seite des Brahman zeigt sich zunächst in der Betrachtung des Weltursprungs. Das Brahman entläßt die Welt aus seiner eignen unergründlichen Wesenstiefe - aus Vollem Volles, wird einmal gesagt, wo dann das Volle voll übrig bleibt. Es ist die „jenseitige Sphäre" seines Beisichseins, aus der das ewige Wesen in die Welt eingeht. Sodann aber tritt, wie schon beruihrt wurde, sehr viel ernstlicher das Denken beschäftigend und über die letzten Hoffnungen des Denkers selbst entscheidend, jene Beziehung zwischen Diesseits und Jenseits bei den Betrachtungen über das Hingehen des Vollendeten in das jenseitige Reich hervor. Doch davon kann erst später die Rede sein.

Hier ist noch eine Frage zu stellen, die erst jetzt, auf Grundlage der zuletzt betrachteten Gedankengänge erwogen werden kann.

Ist das All-Eine persönlich oder unpersönlich vorgestellt?

Eine Alternative, die wir unsrerseits an die Anschauungen der Alten heranbringen; in der Sprache der Upanishaden sie auszudrücken wäre schwer. Oben wurde bemerkt, daß die Opfertheologie der Brāhmanas in ihrer Betrachtung der Mächte, auf deren Spiel und Bewegung für sie der Weltlauf beruhte, die Grenze zwischen persönlichem und unpersönlichem Dasein verschwimmen ließ. So ist auch in viel späterem Stadium, in buddhistischer Zeit, Māra der Böse bald eine satanhafte Persönlichkeit, bald erweitert sich seine Gestalt, um die ganzen Weiten der leidbeherrschten Welt in sich aufzunehmen ${ }^{48}$. Die Poesie der Bhagavadgitā läßt beständig hier die Gottnatur sich zur persönlichen Erscheinung Krishna's verdichten, dort Krishna zum neutralen Allwesen zerfließen. So kann es nicht Wunder nehmen, wenn auch in den Upanishaden von einer feste Linien 
ziehenden Behandlung des hier berührten Problems nicht viel zu finden ist. Wir müssen Bruchstücke zusammenlesen, Linien aneinander passen, unter denen manche nur ganz unbestimmt sich abzeichnen, die einen den andern durchaus zuwiderlaufen.

Von jenen beiden Wesenheiten, die dem All-Einen der Upanishaden den Namen geben, trägt das Brahman, wie schon das neutrale Wort erkennen läßt, vielmehr die Natur eines unpersönlichen Fluidums als einer Persönlichkeit an sich, wie denn auch vom neutralen "Seienden" (sat) gesprochen und gesagt wird: „Das (tat) bist du." Das Brahman ist ja im Gegensatz zu seinem Vorgänger in der höchsten Würde, Prajāpati, nicht aus dem Kreis der alten Götter, sondern aus dem der welterfüllenden Potenzen herausgewachsen. Das ist ebenso das zweite jener beiden Wesen, der Ātman, der doch einen persönlichen Zug an sich trägt. Man möchte sagen, er ist keine Person, aber er ist das Prinzip der Persönlichkeit. Einer Person ähnlicher ist der Purusha („Mann“): eine Bezeichnung, die hier und da als ungefähres Aequivalent von Ātman erscheint - wovon eingehender $\mathrm{zu}$ sprechen ist, wenn uns die große Rolle beschäftigen wird, zu der späterhin der Purusha bestimmt war. Der Ātman aber, die einige Kraft persönlichen Lebens, muß doch - wenigstens sofern die volle Konsequenz des Gedankens entscheidet -, das Reich der Vielheit beschreiten, damit sich manifestieren könne, was wir Persönlichkeit nennen. Sofern er als der Eine in seines eignen Reiches Einsamkeit weilt, sieht dieser Seher nicht, erkennt der Erkenner nicht; dem Subjekt fehlt das Objekt, dessen Gegenüberstehen erst ein Sehen, ein Erkennen wirklich werden ließe $\left.{ }^{1}\right)$. Es ist bemerkenswert, in welch eigenartigem Re-

1) Man hat diese vornehmlich im Dialog des Yājñavalkya und der Maitreyī (oben S.91) entwickelte Gedankenreihe so ausgedrückt, daß das Absolutum „über den Gegensatz von Subjekt und Objekt erhaben“, „weder Subjekt noch Objekt" sei (Simmel, Hauptprobleme der Philosophie 95). Es wäre so $z u$ sagen eine symmetrische Figur da; das Absolutum hätte 
sultat man sich hier verfängt. Das Sehen oder Erkennen wird keineswegs mißachtet, vielmehr so hoch bewertet, daß das absolute Wesen der Seher, der Erkenner, "nichts als Erkennen" ") sein soll. Und doch, wo dieser Seher, dieser Erkenner in seiner höchsten Glorie und Vollendung weilt, ist für Sehen und Erkennen kein Raum. Solch unpersönlichem Zustand des nichterkennenden Erkenners wird höchste Wonne zugeschrieben; und so scheint sich jene Lehre ${ }^{49}$ vorzubereiten, welche die eben bezeichnete Inkongruenz beseitigt: man geht darüber hinaus, das Allwesen "nichts als Erkennen" sein zu lassen; hinter dem „aus Erkenntnis bestehenden A tman" erscheint der ",aus Wonne bestehende" als das Letzte, Tiefste.

Es ist wohl unverkennbar, daß in all dem eine Richtung auf das Unpersönliche vorherrscht. Der Willensmensch, der Handelnde wird den Weltherrscher als höchsten Wollenden, Handelnden vorstellen. Aber wie wir schon sahen, der Vorfahr des Denkers der Upanishaden, der priesterliche Zauberer, der den Weltlauf in seiner Weise verstehen und beeinflussen will, neigt von alter Zeit her dazu unpersönlichen Mächten die Herrschaft anzuvertrauen. Und ebendahin neigt der Beschauliche, der Mystiker. Er gibt sich dem Wogen unumgrenzter, zerfließender Visionen hin. „Das Feuer", sagt ein solcher moderner indischer Mystiker, indem er an das Verhältnis von Gott und Welt denkt, ,hat selbst keine bestimmte Gestalt, aber in der gluhenden Asche nimmt es Gestalten an". Der wahre Schauende der Upanishaden sieht nicht die Asche; er sieht das Feuer - den gestaltlosen Gott. Oder vielmehr er sieht ihn nicht, als Sehender dem

zu beiden Polen die gleiche Lage. Ich kann mir diese Formulierung nicht aneignen. Wenigstens für die Anschauungsweise, die in jenem Dialog ihren vollendetsten Ausdruck findet, ist der Ātman Subjekt, allein Subjekt. Und in seinem Beisichsein hat er kein Objekt. So daB dort freilich das Subjekt sich als solches in Ermangelung des Objekts nicht betätigt.

1) Ganz wörtlich: nur ein Klumpen von Erkennen. 
Gesehenen gegenüberstehend. Sondern er fließt in ihn hinein. Nicht wachendes Sehen, der traumlose Schlaf, so hoch in den Upanishaden gepriesen, bringt des Rätsels Lösung, hebt das Ich zur jenseitigen Höhe des Sehers, der nicht sieht.

Begreiflich nun aber, daß die alten Denker oft tief unter dieser Höhe Halt gemacht, an sehr viel diesseitigeren, konkreteren Vorstellungen sich haben genugen lassen. Schon oben (S. 81) wurde auf den Kontrast hingewiesen, in dem jener gestaltlosen Idee die durchaus persönliche Figur des höchsten Wesens in den Schöpfungsgeschichten gegenübersteht: da denkt der Ātman, er begehrt, er fürchtet sich. Es war ja auch in der Tat schwer, anders als auf diesem oder einem ähnlichen Wege aus dem leeren Schweigen des überweltlichen, unpersönlichen oder wenn man will überpersönlichen Seins den Weg ins Weltleben hinein zu finden. Noch fühlbarer ist das Hinübergeraten der Phantasie zum Persönlichen in den Bildern, die eine allerdings nicht zu den ältesten gehörende Upanishad ${ }^{\text {s0 }}$ davon entwirft, wie der Erlöste zum Jenseits des Brahman hingelangt. Eben in dem höchsten Reich, aus dessen objektloser All-Einheit jene Rede Yājnavalkya's bewußtes Dasein des Subjekts ausschloß, läßt die Upanishad das Brahman, das dort zunächst mit diesem seinem neutralen Namen genannt ist, den Erlösten empfangen, indem es dann alsbald in die Gestalt des maskulinischen Brahman hinüberschlüpft und das ganze Kostüm eines persönlichen Gottes anlegt. Ein Gott zwar nicht mehr gleich den Göttern des alten Vedaglaubens. Er hat, dem Vorstellungsstil dieses Zeitalters entsprechend, ein weichlicheres, sultanhaftes Aussehen angenommen. Wir werden weiter unten ${ }^{1}$ ) der Schilderung begegnen, wie er über Hunderte von himmlischen Nymphen als Dienerinnen gebietend in der Pracht seines Palastes thront. Da redet der Erlöste ihn an: „Eines jeglichen Wesens Selbst (ātman) bist du. Was

1) S. den Abschnitt über die Erlösung. 
du bist, das bin ich." Der Gott erwidert: „Was bin ich denn?" Und der Erlöste antwortet: „Das Wahre ... dieses All bist du ..."Wirre Sprünge der Phantasie zwischen der Erinnerung an unpersönliche Abstraktionen und der Neigung zu bunten Bildern barocken persönlichen Lebens.

Und so wechseln denn beständig, wenn vom höchsten Wesen gesprochen wird, die Züge der einen und der andern Art. Wie Salz im Salzwasser ruht das Seiende in allen Dingen. Es ist jenes Feine, das beim Gottesurteil den Unschuldigen vor der Feuersglut bewahrt. Es ist das, was man im Körper als Wärme spürt. Was man, wenn man sich die Ohren zuhält, als Sausen hört. Aber dann auf der andern Seite: nicht nur in individuelles menschliches oder menschenähnliches Dasein inmitten der Vielheitswelt eingehend lebt der Ātman persönliches Leben, sondern auch als Herrscher über die ganze Weltbewegung entfaltet er ein Wirken, das anders als persönlich vorzustellen schwer ist. Wie von etwas Unpersönlichem spricht Yãjnavalkya zuerst, wenn er das Brahman das Unvergängliche nennt, nicht grob noch fein, ohne Innen, ohne Außen ${ }^{51}$. Aber werden dann in dies neutral scheinende Wesen nicht Hoheitsrechte der Persönlichkeit verlegt, wenn es weiter heißt, daß auf sein Gebot Himmel und Erde fest steht, auf sein Gebot der Zeitlauf sich in seiner Bahn hält, auf sein Gebot die Flüsse von den weißen Bergen herabströmen? Wenn an einer andern Stelle der Ātman „Herrscher über Alles, Oberherr uber Alles" genannt wird? Wenn - in einer jüngeren Upanishad - gesagt wird, daß er "Hüter der Welt" ist, daß er die Menschen gute oder böse Tat tun läßt, je nachdem er sie empor oder abwärts führen will? Ist es zu viel behauptet, daß da die schwankende Gestalt des höchsten Wesens durchaus die Züge eines persönlichen Gottes zeigt? Freilich bleibt immer fühlbar, daß hier nicht die volle Kraft eingesetzt ist, eine Persönlichkeit im großen Stil zu gestalten. Wie verschieden ist doch dieser Gott vom Gott des Alten Testaments! Er lenkt nicht mit übergewaltiger 
Hand die Völker und ihre Geschichte auf ein großes Ziel hin: doch wo war auch auf dem Boden, dem die Upanishaden entstammen, der Flügelschlag der Geschichte zu spüren? Für persönliche Nähe, für den Verkehr im Gebet, im Austausch der Liebe zwischen Gott und Mensch ist diese göttliche Persönlichkeit unzugänglich. Das ist es ja eben auch nicht, wonach diese Denker fragen, denen die Botschaft vom Gottsein ihres eignen Selbst für jedes andere Verlangen überreichen Ersatz bietet!

\section{Seelenwanderung. Karman.}

Oben (S. 26 ff.) wurde dargestellt, wie sich in den Brāhmanatexten der Übergang vom Jenseitsglauben des ältesten Indien zur Seelenwanderungslehre in seinem Beginn zeigt. Diese Entwicklung ist in der Periode, mit der wir uns hier beschäftigen, wesentlich weiter fortgeschritten, wenn auch im Einzelnen bisweilen zweifelhaft bleibt, wie viel von den anscheinenden Veränderungen eben nur darauf beruht, daß jetzt die Texte öfter und eingehender von diesen Vorstellungskreisen sprechen.

Kein besserer Boden als der Indiens für jene Phantasien, welche Existenz auf Existenz in so leichtem Fluß in einander hinübergleiten lassen, jede eine rasch verrauschende Welle im Meer unermeßlichen Lebens.

Von voller Ausgestaltung ist die Seelenwanderungsdoktrin doch auch jetzt noch weit entfernt. Wandlungen, die so tief zu den Fundamenten des Glaubens hinabreichen und deren Konsequenzen sich allseitig so weit erstrecken, konnten ja nicht innerhalb kurzer Zeiträume zu ihrem letzten Ziel gelangen. Auch nahm wohl der betrachtende Geist vor der zuströmenden Masse der Bilder, in denen sich das Wandern der Seele durch die Jenseitswelten darstellte, naturgemäß mannigfachere Standpunkte ein, betätigte vielleicht auch an mancher Stelle geringere Entschlossenheit und Energie des Vorstellens, als gegenüber der Einheit des ewigen Seins. 
Wo die Upanishaden von der Seelenwanderung reden, sieht man, wie im vorangehenden Zeitalter, Reste - oft recht erhebliche - des alten Volksglaubens, Ansätze neuer Gedanken, vor allem Fluten von Einfällen und Phantasien durch einander wogen in den weiten Räumen des Weltbildes, die das alles aufzunehmen so leicht bereit sind: ein Gemisch, das zu einer sich vergleichsweise fest behauptenden Form nur sehr allmählich gelangt.

Bald stellt man sich die Seele des Hinscheidenden als unmittelbar in ein neues Dasein übergehend vor, "wie eine Raupe, wenn sie zum Ende eines Grashalms gelangt ist, in eine neue Bahn eingehend sich in sich selbst zusammenzieht", oder "wie eine Weberin von einem künstlichen Gewebe den Stoff nimmt und daraus ein anderes, neues schöneres Gebilde bereitet: so läßt dieser Ātman diesen Leib fallen und in Bewußtlosigkeit versinken, und bereitet sich ein anderes, neues, schöneres Gebilde von der Natur der Väter oder der Gandharven (himmlischer Halbgötter) oder der Götter oder des Prajāpati oder des Brahman ${ }^{1}$ ) oder von sonstigen Wesen" "s?.

Anderswo - weit abweichend von den im Übrigen herrschenden Vorstellungen - läßt man die sterbenden Kreaturen in das Allwesen eingehen und dann zu neuem Dasein wiederum aus ihm hervorkommen ${ }^{88}$. Oder die Seele muß, ehe sie zu dieser Welt zurückkehrt, zuvörderst durch ferne Regionen reisen. Der "Götterweg“" ${ }^{4}$ führt zu lichten Höhen, von denen es keine Rückkehr gibt: von diesem Wege wird später die Rede sein. Auf dem "Väterweg" andrerseits geht die Seele durch Rauch und Nacht; sie gelangt zu den Zeiten des abnehmenden Mondes, der abnehmenden Tage, die den Toten geweiht sind; von alters-

1) Brahmán (masc.) scheint gemeint, die persönliche Gestalt, zu der man das Bráhman (neutr.) verdichtete. - Offenbar sind zu den glücklichen Wiedergeburten, die hier anfgezählt werden, auch niedere, leidenvolle hinzuzudenken. Der Verfasser der Stelle hob nur die Wanderungen der Guten hervor. 
her fand ja die Phantasie in Vorstellungen wie des Hingelangens zum Jahr oder ähnlichen Wesenheiten keine Schwierigkeit. Auch die "Väterwelt" wird von diesen Wanderungen der Seele berührt; die Stätten, die nach dem alten Glauben die hingeschiedenen Väter für ewige oder doch für unbestimmte Zukunft aufgenommen hatten, sind jetzt ihrer Reiseroute als einzelne Station eingeordnet. Weiter geht die Fahrt zum Mond, der in diesen Phantasiespielen besonders beliebt ist. Es scheint, daß schon alter Volksglaube ihn zu einem Aufenthalt der Hingeschiedenen gemacht hatte. Ferner sah man in seinem Abnehmen und Zunehmen ein Ausgetrunkenwerden durch die Götter oder durch Götter und Manen, und neues Sichfüllen mit himmlischem Göttertrank. Das alles wird durch einander gewirrt, und so heißt es jetzt, daß die Seelen, ,wenn sie zum Mond gelangt sind, zu Nahrung werden. Die genießen dort, wie man den Soma genießt - ,Schwill an! Schwinde hin!" - so genießen die Götter sie dort. Wenn das an ihnen vorüber gegangen ist, so gehen sie zu diesem Äther hier, vom Äther zum Wind, vom Wind zum Regen, vom Regen zur Erde. Zur Erde gelangt, werden sie zu Nahrung. Dann werden sie wieder im Mannfeuer geopfert; darauf werden sie im Weibfeuer geboren ${ }^{1}$ ). So erheben sie sich zu den Welten und durchlaufen von neuem denselben Kreislauf.“

1) Der Mensch ist nämlich nach demselben Text durch eine fünffache "Opferung" entstanden. Die Götter haben zuerst in der Himmelswelt als ihrem Opferfeuer den „Glauben" geopfert; daraus entstand der Soma. Diesen opferten sie in Parjanya (dem Regengott) als ihrem Opferfener; so entstand Regen. Den opferten sie in der Erdwelt; so entstand Nahrung. Die opferten sie im Mann; so entstand der Same; diesen im Weib, so entstand der vom Weibe geborene Mensch. Auf der für die priesterliche Färbung dieser Phantasmen charakteristischen Auffassung der betreffenden Wanderungen und Wandlungen als einer Reihe von Opfern beruht an unsrer Stelle das "Mannfeuer" und "Weibfeuer". Aus demselben Zusammenhang erklärt sich auch das "wieder" des obigen Textes; das Wesen langt wieder beim Stadium der menschlichen Existenz 
Aus all diesem Schwanken, diesen Vermischungen von Älterem und Jüngerem scheinen doch in unverkennbarer Deutlichkeit Fortschritte hervorzutreten, in denen gewisse Elemente des ganzen Vorstellungskreises sich klären und an Intensität gewinnen.

Zunächst gilt das vom Glauben an die Wiederkehr der Hingegangenen zum Erdendasein. Während in der Brāhmanazeit gegenüber dem Herrschen der Vorstellung von dem im Jenseits drohenden "Wiedertod" als deren Kehrseite der Gedanke an jene Rückkehr sich nur leise und vereinzelt ankündigt, ist dieser jetzt deutlich in den Vordergrund getreten. Selbstverständlich zwar ist man immer noch weit entfernt von den Phantasiespielen, die später der Buddhismus betrieben hat - dem Zurückverfolgen einer Daseinsverkettung durch jene unübersehbaren Mengen früherer Existenzen, wie sie in den "Jatakas“" ") beschrieben werden. Überhaupt scheint man sich in den Upanishaden vielmehr mit dem Gedanken an kommende Daseinsformen, als mit den Wanderungen der Vergangenheit zu beschäftigen ${ }^{\circ 6}$. Aber die Gedankenbahn, die in gerader linie auch zu jenen Vorstellungen führt, ist doch einmal beschritten, und man kann nicht anders als weiter und weiter auf ihr vorwärts gehen.

Ein zweites Element des Seelenwanderungsglaubens, das sich ebenfalls jetzt zwar nicht neu bildet, aber weiterentwickelt und verstärkt, ist die Lehre von der Vergeltung guter und böser Werke als der Macht, welche der wandernden Seele den Weg durch hohe und niedere Existenzen vorzeichnet.

an. Von der Opferung der Nabrung im Mannfeuer und dann im Weibfeuer spricht in deutlicherer Form ein Paralleltext: sind die Seelen als Regen zur Erde herabgefallen und dort als Reis nnd Gerste, Kräuter und Bäume, Sesam und Bohnen wiedergeboren, so ibt sie der Mann; sie werden zu seinem Samen und als solcher von ihm ergossen.

1) Den „Geschichten von den (früheren) Geburten" des Wesens, das er Buddhaschaft entgegengeht. 
„,Yājñavalkya!' fragt ein Mitunterredner den Weisen : ,Wenn nach dem Tode dieses Menschen zum Feuer seine Rede eingeht, zum Wind sein Atem, sein Auge zur Sonne, sein Geist zum Mond, zu den Himmelsgegenden sein $\mathrm{Ohr}$, zur Erde sein Leib, zum Äther sein Ātman ${ }^{1}$ ), zu den Kräutern sein Körperhaar, zu den Bäumen sein Haupthaar, in den Wassern sein Blut und sein Samen ihre Stätte finden: wo bleibt dann der Mensch selbst?، ,Gib deine Hand her, Freund Ārtabhāga. Davon müssen nur wir beide wissen; diese Leute dürfen es nicht hören.' Da gingen die beiden hinaus und redeten mit einander. Und was sie da redeten: von der Tat (oder dem Werk: karman) redeten sie. Und was sie priesen: die Tat priesen sie. Wahrlich gut wird er durch gute Tat, böse durch böse ${ }^{2}$."

Wie an dieser Stelle der Begriff des "Karman" in besonders feierlicher Form eingeführt wird, ist es als hätte der Verfasser des Dialogs ein Bewußtsein davon gehabt, daß er hier einen zu wahrhaft unabsehbarer Wirkung berufenen Gedanken ausspricht. Freilich verhält es sich nicht ganz so, wie der Ton jener Äußerung Yājnavalkyas vermuten ließe: daß dieses nur Auserwählten zugängliche Mysterium etwas durchaus Neues, eben Entdecktes sei. Abgesehen davon, daß das Bewußtsein vom Fortschreiten menschlichen Wissens durch das Denkern zuteil werdende Sichenthüllen neuer Einsichten diesem Zeitalter an und für sich fremd scheint, wäre

1) Dem Standpunkt nach, den dieser Dialog im Übrigen einnimmt, befremdet es, dem Atman als einem einzelnen, mit andern koordinierten Teil des menschlichen Wesens zu begegnen. Offenbar liegt nachlässiger Ausdruck vor, begreiflich in einer Zeit, wo die Terminologie noch schwankt. Deussen findet hier eine "der buddhistischen verwandte Anschanung, wonach nur das Werk, nicht der A tman fortbesteht". So viel kann ich in der Stelle nicht sehen. Gesagt wird nicht, daB das Werk allein bestehen bleibt, sondern dab das Werk darüber entscheidet. wo und wie der Mensch bestehen bleibt (vgl. freilich Ait. ÂA. II, 1, 3: mir scheint diese vage Stelle kein Gewicht zu beanspruchen).

2) Er gelangt zu glücklichem oder unglücklichem Dasein je nach seinen Taten. 
ein solcher Anspruch der Lehre vom Karman zu weit gehend. Dahin aber wird der geschichtliche Betrachter allerdings diesen Anspruch umformen dürfen, da $\beta$ in der Zeit jenes Dialogs die Vorstellung von der über den Tod hinaus die Existenz bestimmenden Macht der Taten im Bewußtsein zunächst wohl enger Kreise zuerst als fundamental erfaßt ist, daß man zur Klärung, zur ernstlichen Durcharbeitung dieser Lehre damals - wie auch das neu aufkommende Schlagwort Karman andeutet - einen wesentlichen Schritt vorwärts getan hat.

In die Lehre vom Karman läuft auch eine Stelle aus ${ }^{5 ?}$, die zunächt statt des Karman das Begehren des Menschen als das entscheidende nennt: in Wahrheit besagt aber das eine so viel wie das andre. "Hier spricht man nun: ,Begehren (käma) ist es, woraus dieser Mensch besteht'. Wie aber sein Begehren ist, so ist sein Wollen. Wie sein Wollen ist, solche Tat tut er. Welche Tat er tut, zu solchem Dasein gelangt er."

Ein weiteres altes Zeugnis für die Karmanlehre steht iu Verbindung mit den oben (S. 107) besprochenen Auseinandersetzungen über die Rückkehr der Seelen zur Erde im Regen und über die Metamorphosen, in denen sie dann durch Pflanzen, durch den männlichen und weiblichen Körper hindurchgehen. Worauf beruht es, daß da die eine Seele in erwünschte, die andre in ungünstige Bahn hineingerät? Der Text sagt: „Deren Wandel nun hier erfreulich ist, denen wird zuteil, daß sie in einen erfreulichen Mutterschoß eingehen: in einen Brahmanenschoß oder Kshatriyaschoß oder Vaiśyaschoß. Aber deren Wandel hier stinkend ist, denen wird zuteil, daß sie in einen stinkenden Mutterschoß eingehen: in einen Hundeschoß oder Schweineschoß oder

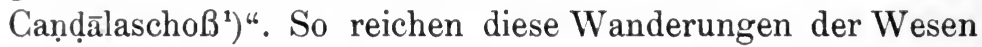
auch durch das Tierreich oder wenigstens durch Teile des Tierreichs: denn weder den Götterweg noch den Väterweg

1) Die Candālas sind eine besonders verachtete Kaste. 
(S. 106) geht das niedrigste Getier, „diese kleinen immerfort wiederkehrenden Wesen, für die es heißt: werde geboren und stirb". Woran dann, vom Vorhergehenden sich scharf abhebend, ein Verszitat geschlossen wird: Golddiebe und Branntweintrinker, Verletzer der Ehe des Lehrers und Brahmanenmörder - diese vier, und fünftens wer mit ihnen umgeht, „fallen", d. h. sie kommen in die Hölle. Es ist bezeichnend, wie hier der alte, immer fortbestehende Glaube an Vergeltung durch Höllenstrafen und die jungen Vorstellungen von der Wirkung des Karman auf einander treffen. Späterer Zeit blieb die Aufgabe, beides so gut es anging zu vereinen; die hier besprochene Stelle zeigt anschaulich, wie für jetzt eins neben dem andern unvermittelt dasteht.

Noch ist unter den Zeugnissen, die uiber die Karmanlehre dieses Zeitalters wichtige Auskunft geben, vor allem eins übrig. Jene Stelle (oben S. 106), die beschreibt, wie die Seele gleich einer von Halm zu Halm kriechenden Raupe in die Welten der Manen, Gandharven, Götter hinübergeht, fügt den Vers hinzu :

„Wenn er zum Ende der Taten gelangt ist, die er hier getan, Kehrt er aus jener Welt wieder in diese Welt zu neuer Tat.“

Die Größe der Belohnung muß irgendwie dem Verdienst entsprechen. Vielleicht schon früh wurden jene kleinlichen Rechenexempel aufgestellt, wie sich das tugendliche oder lasterhafte Tun nach einem pedantischen Tarif auf den Täter zurückwendet. Ein solcher Tarif mochte mit dem Effekt starker Steigerungen und Vervielfachungen arbeiten: er schloß doch gewisse gesetzmäßige Begrenzungen des zu Genießenden, des zu Erduldenden in sich. Wenn das Dasein, das Lohn oder Strafe enthält, die entsprechende Zeit angedauert hat, ist das Karman so zu sagen verbraucht, und es ist nötig neues Karman zu erwerben ${ }^{58}$. Wie wäre auch die Bewegung der wandernden Seelen aufrecht zu erhalten, wenn nicht immer wieder ein solcher frischer Anstoß erfolgte? Wobei sich denn ungezwungen, wie in dem eben angeführten Vers, eine Unterscheidung einstellt zwischen 
solchen Daseinsformen, in denen Karman erzeugt, und solchen, in denen es aufgezehrt wird.

Hier schlöße sich die Frage an, ob das zur Hervorbringung von frischem Karman in ein Dasein eintretende Wesen damit einen vollkommenen Neuanfang macht, in seinem Tun frei ist, oder ob eine aus der Vergangenheit übrig bleibende Nötigung es zwingt, für die Zukunft sich durch sein Karman eine bestimmte Bahn und keine andre vorzuzeichnen, so daß das Subjekt - etwa bis zum Erwerb der Erlösung - ununterbrochen im Bann derselben unentrinnbaren Notwendigkeit verbleibt ${ }^{59}$. Doch hierauf scheint sich das Nachdenken im Altertum noch nicht gerichtet zu haben. -

Dies sind die Anfänge der Lehre vom Karman, die sich dann als ein Hauptelement indischer Weltanschauung durch alle Zeiten erhalten hat. Auf sie blickt der alte Buddhist hin, wenn er das Karman seinen Besitz und sein Erbteil nennt, den Mutterleib, aus dem er geboren, das Geschlecht, dem er verwandt ist. Der Macht des Karman, sagt ein buddhistischer Vers, entrirnt man nicht im Luftreich noch in des Meeres Mitte, nicht wenn man in Bergeshöhlen hinabdringt. Und in späterer Zeit weist ein kaschmirischer Geschichtsschreiber im Bewußtsein der Unmöglichkeit, den Lauf der Dinge aus sichtbaren Ursachen zu erklären, auf das Geheimnis des Karman hin:

„Was Traum und Gaukelkunst niemals gestalten könnte, [sprüht hervor, Rätselhaften Geschehns Wunder, aus bunter Tiefe alter Tat."

Wie wir die Karmanlehre in den Upanishaden finden, wird sie durchaus von der dort wie schon in den Brāhmanas so starken Tendenz beherrscht, die Lenkung des Geschehens nicht göttlicher Macht, Gnade, Willkür, sondern unpersönlichen Ordnungen zu übertragen ${ }^{\circ 0}$. Der Intellekt verlangt das Walten fester Gesetze zu erkennen. So wirkt das Karman vermöge einer Art mechanischer Notwendigkeit. Ohne Dazwischentreten eines belohnenden oder strafenden Gottes bringt die Tat direkt ihre Folgen hervor. Die Vorstellungen 
darüber, wie sich das vollzieht, stehen im Grunde ganz auf dem Niveau des in diesem Zeitalter noch höchst lebendigen Zauberglaubens, mit dem sich die ungehindert alle Weiten von Wirklichkeit und Unwirklichkeit durchstreifende Phantasie verbündet hat. Die Entscheidung aber darüber, welches die Folgen jeder Tat sein sollen, fällt dem sittlichen Gerechtigkeitsbedürfnis anheim. Begreiflichem Entwicklungsgang folgend hat sich der priesterlich-ritualistische Zug der Brăhmanatheologie, die speziell dem Tun und Wissen des Opferers ihre Verheißungen gewährte, sehr merklich zu Gunsten weiterer und freierer, das Moralische voranstellender Betrachtungsweise abgeschwächt. Zwar macht sich die alte Gewöhnung und die Atmosphäre der Kaste immer noch in gelegentlichem Wiederauftauchen jener priesterlichen Gedankenrichtung geltend. Aber im Ganzen ist es doch jetzt nicht mehr die große Hauptsache für das Menschenleben, daß Ziegenböcke und Rauschtrank dem Gott richtig bereitet und die Priester reich honoriert werden. Sondern rechtes, reines Handeln beansprucht seine Vergeltung: die verlangt man, da sie in diesem Leben so oft ausbleibt, in andern Existenzen gewährleistet zu sehen.

Wie in dem moralisch-magischen Mechanismus, den man also als die Geschicke der Wesen beherrschend sich vorstellt, so tritt auch in den von ihm regierten Wesen selbst das persönliche Moment bemerkenswert in den Hintergrund. Dem Karman entsprechend geht die Persönlichkeit glatt und widerstandlos in neue Formen andrer Persönlichkeiten ein; sie bewegt sich auch durch Zustände der Entpersönlichung hindurch, von den Göttern verzehrt, zu Regen, zu Pflanzennahrung werdend. Ähnlich wie im ökonomischen Verkehr Werte aller Art ihre Besonderheit abstreifen und sich in bloße Geldwerte übersetzen, steht man hier dem nicht ganz fern, daß sich der lebendige Persönlichkeitswert in eine Art moralischen Geldwert, eine Summe von günstigem oder ungünstigem Karman übersetzt: wo denn die Konsequenz nicht fern liegt, bei der man dann in der Tat angelangt ist ${ }^{61}$, 
daß dieser Geldwert auch vom einen auf den andern übertragen werden kann.

Soweit die Spärlichkeit der Zeugnisse ein Urteil erlaubt, ist der Karmanlehre der Upanishaden der große Zug noch durchaus fremd, der die vom Karman beherrschten Wanderungen der Seele als ein sinnvolles Ganzes, etwa als schrittweise einem höchsten Ziel zustrebenden Läuterungsprozeß erscheinen läßt. Man erinnere sich der grandiosen Vorstellungen der Buddhisten vom Fortschreiten ihres Meisters durch zahllose Äonen zur Buddhaschaft, oder des Worts der Bhagavadgitā vom Yogin:

„In vielfält'ger Geburt reifend geht er endlich den höchsten Gang. "

Das sind Produkte einer vertiefenden Durcharbeitung des Seelenwanderungs- und Karmanglaubens, von denen man begreift, daß sie seinen Anfangsstadien noch fern liegen.

Zu der im Zentrum der Upanishadenspekulation stehenden Idee des Brahman hat man die Lehre vom Karman kaum in tiefere Beziehung zu bringen gewußt. Wo des Brahman Herrlichkeit allein waltet - wir müssen darauf noch zurückkommen - dahin reicht die Macht des Karman nicht. Aber doch auch im Diesseits soll ja das Brahman alles Geschehen lenken: auf sein Geheiß gehen Tage und Jahre ihren Gang, fließen die Ströme von den Schneebergen hernieder. So müßte, scheint es, vor allem das Gesetz des Karman sich aus dem Brahman herleiten, eine Manifestation seiner weltbeherrschenden Kraft sein. Es scheint nicht, daß die alten Denker an das Problem in diesem Sinn ernstlich herangetreten sind ${ }^{1}$ ): eine Lücke, die natürlich nichts andres ist, als eine Konsequenz jener fundamentalen, unvermeidlichen

1) Denn es ist doch kaum ein wirklicher Lösungsversuch dieses Problems, wenn das höchste Wesen zur Macht des Karman durch die gelegentlich auftretende Vorstellung in Beziehung gesetzt wird, dab jenes den Menschen gute oder böse Tat tun läßt, je nachdem es ihn segnen oder demütigen will (s. oben S. 75): so daB Gott das Gewollte auf dem Umweg über das Karman verwirklicht. 
Schwäche der Brahmanlehre: der Unmöglichkeit, in der Vollendung des ewig Einen den Ausgangspunkt zu finden, von dem zur Unruhe der Vielheitswelt ein Weg führt. Je entschiedener das Karman den Lauf des Geschehens beherrscht, um so viel weniger bedarf man dazu des Brahman; und so wird hier der Keim späterer Entwicklungen sichtbar, in denen das Absolutum, aller Macht des Handelns entkleidet, abseits vom Welttreiben und vom Wirken der darin herrschenden Ordnungen die stumme Rolle eines bloßen Zuschauers übernommen hat.

Die Lehre vom Karman liegt auf einer breiten Bahn menschlicher Gedankenentwicklung. Auch die griechische Spekulation hat sie gestreift, freilich eben nur gestreift. Bezeichnend für Indien ist nicht sowohl diese Lehre an sich, als vielmehr die herrschende Macht, zu der sie dort aufstieg, die Phantasie in rastlose Bewegung setzend, die furchtsamen Seelen ängstigend, das Leben mit Gebundenheit durch dunkle Übermacht belastend, mit den Folgen unergründlicher alter Schuld. Man kann die Wirkungen der Karmanlehre denen der Kaste vergleichen. Es war das Verhängnis dieses schwächlichen Volksgeistes, durch die Gedanken, die er dachte, wie durch die Institutionen, die er schuf, sich in Unfreiheit $\mathrm{zu}$ verstricken.

\section{Der Wert des Daseins.}

Immer zusammenhängendere, größere Linien fingen an in dem Weltbild hervorzutreten, welches das älter werdende Denken zeichnete. Da mußte auch die Wertung des Daseins als eines Ganzen immer ernstlicher erwogen werden, in immer bestimmterem Ausdruck sich festigen.

Die Zurückführung, die man vollzogen hatte, der welterfüllenden Vielheit auf die Einheit des Brahman-Ātman beeinflußte jene Wertung natürlich auf das stärkste, bestimmte sie vielleicht. Da aber standen zwei Wege offen. Der Nachdruck konnte darauf gelegt werden, daß die Welt vom Brahman durchdrungen ist: dann mußte auch sie an den 
höchsten Werten, die in diesem wohnen, teilnehmen. Oder das Gewicht lag darauf, daß die Vielheit, zwar aus dem Einen stammend, doch, wie auch immer, einen Abfall von der Einheit, einen Gegensatz zu ihr bedeutet: dann war kaum zu vermeiden, daß sich dieser Gegensatz auch in negativer Bewertung des Weltdaseins ausdrückte.

Ansätze dazu, dem Problem die erste dieser Lösungen zu geben, fehlen nicht ganz. So lehrte man, daß von der im Brahman wohnenden höchsten Wonne etwas sich der Welt mitteilt, die andern Wesen ,von einem Teilchen dieser Wonne leben" (S. 75). Und mit der Pedanterie, die in den Upanishaden wieder und wieder den Schwung der Gedanken lähmt, berechnete man zahlenmäßig die Intensität der hüben und drüben herrschenden Wonne. In der Menschenwelt gehört die höchste Wonne dem, ,der unter den Menschen erfolgreich und glücklich ist, Herr über die andern, an allen menschlichen Genüssen der reichste". Von dieser menschlichen Wonne das hundertfache bildet eine Wonneeinheit in ider Welt der Väter (Manen): und so steigt die Reihe durch Verhundertfachungen immer höher, bis mit dem sechsten Schritt, jenseits der Wonne von Prajāpati's Welt, die Wonne der Brahmanwelt erreicht wird. ${ }^{62}$ Zwischen dem Daseinswert des Menschenlebens und der Brahmanwelt also kein Gegensatz, nur eine Abstufung, stark genug, doch immerhin mäßig gegenüber den ausschweifenden Zahlen, in denen spätere Zeitalter den Kontrast zwischen alltäglichem Dasein und höheren Ordnungen auszudrücken pflegten.

Solche Auffassungen aber treten weit zurück hinter der andern, pessimistischen Lơsung des großen Wertproblems. Von der alten unbefangenen Einschätzung menschlichen Glückes und Leidens, die im Ganzen in das Gebet der vedischen Sänger um ein langes Leben von hundert Herbsten ausklingt, schlägt die stark überwiegende Strömung wenn nicht der populären so doch der philosophischen Lebensbetrachtung Indiens die zweite der vorhin bezeichneten Richtungen ein. Sie bewegt sich auf den Punkt hin, an 
dem später der Buddhismus steht: die Lehre, die an die Spitze ihrer Glaubensartikel den Satz vom Leiden alles Daseins stellt und $\mathrm{zu}$ den freudesuchenden Menschen spricht:

„Mögt ihr lachen, der Lust pflegen, wenn immerdar die Flammen lohn?

Von Finsternis umhüllt seid ihr. Wollt ihr nicht trachten nach dem Licht?"

Die Upanishaden sind noch nicht bis $\mathrm{zu}$ dieser leidenschaftlichen Ablehnung von Welt und Leben gelangt. Aber auf dem Weg dahin sind sie begriffen.

Mit vollkommener Bestimmtheit lassen sich die Momente natürlich kaum erkennen, die auf diesen Weg drängten. Mir scheinen die Texte die Vermutung zu unterstützen, daß den erheblichsten Einfluß dabei der Gedanke an den Tod gehabt hat.

Während in den Liedern des Rigveda für den glücklich Lebenden der Tod in kaum absehbarer Ferne lag, ist er, wie wir sahen, schon in der Brāhmanazeit der Vorstellung sehr viel näher gerückt. Im Glauben an den Wiedertod (S. $27 \mathrm{f}$.) hat sich seine Macht unabsehbar gesteigert. Wie die Seelenwanderungslehre in ihrer Entwicklung fortschreitet, wird immer mehr der Gedanke man möchte sagen an unvergängliche Vergänglichkeit betont. Man weiß, mit welchem Gewicht diese Sorgen später in altbuddhistischer Zeit die Seelen bedrückten. Für die Buddhisten war alle Weltlust und überhaupt alles Weltdasein verkörpert in ,Māra dem Bösen": Māra aber bedeutet ,Tod". Als Buddha sich anschickt die Predigt zu halten, die ihm die ersten Jünger gewinnen soll, stehen an der Spitze die Worte: „Tut euer Ohr auf, ihr Mönche. Die Unsterblichkeit ${ }^{1}$ ) ist gefunden." Und von den beiden Jünglingen, die dann die Vornehmsten unter den Gläubigen geworden sind, wird berichtet, daß ehe sie noch Buddha begegnet waren, ,sie die Abrede getroffen hatten: wer zuerst die Unsterblichkeit findet, soll es

1) So wörtlich. Freier: die Erlösung vom Tode. 
dem andern sagen." Wie hier an Hauptstellen der buddhistischen heiligen Geschichte die Frage nach Tod und Unsterblichkeit als entscheidend hervortritt, ganz so finden wir es schon in der Upanishad in jenem wundervollen, zweimal dort wiederholten Gespräch ${ }^{1}$ ) des Weisen, der von seinem Hause geht um als Einsiedler zu leben, mit seiner heiligen Wissens kundigen Gattin. ${ }^{68}$ „Maitreyī! sprach Yājñavalkya. Ich will nun von dieser Stätte hinausziehen. Wohlan! so will ich Teilung halten zwischen dir und der Kātyāyanī $\bar{q}^{\text {) }}$ dort. Da sprach Maitreyĩ: Wenn mir nun, Erhabener, diese. ganze Erde mit all ihren Schätzen gehörte, würde ich dadurch unsterblich sein? Nein, antwortete Yājñavalkya, dein Leben würde sein wie das der Reichen; auf Unsterblichkeit aber geben Schätze keine Hoffnung. Da sprach Maitreyĩ: Wodurch ich nicht unsterblich werde, was soll mir das? Was du weißt, Erhabener, das sage mir." Und Yājnavalkya redet ihr vom Âtman: in dessen All-Einheit möge man eingehn, jenseits von der Welt des Bewußtseins, das eine $Z$ weiheit des Sehenden und Gesehenen, des Erkenners und Erkannten einschließt: „das ist die Bedeutung der Unsterblichkeit.“

So stellen sich auf der einen Seite das dringendste Verlangen der vom Tod geängsteten Seele und andrerseits die höchste Idee, zu der das Denken sich - wohl nicht zum wenigsten eben unter dem Antrieb jenes Verlangens erhebt, auf einander gewissermaßen als Frage und Antwort ein. Vielleicht wächst der Vorstellung des Todes eben durch diese Gegenüberstellung noch gesteigerte Bedeutung zu, wird er als das Leiden aller Leiden um so intensiver empfunden, weil er das Leiden ist, für das es allein in der höchsten Höhe Hilfe gibt. Den Ausdruck, den schon die frühere Zeit geprägt hatte, ,das Übel, der Tod“"8), wieder-

1) Dasselbe Gespräch, von dem oben S. 91 die Rede war.

2) Seiner zweiten Gattin.

3) Was hier „das Übel" übersetzt ist, ist dasselbe Wort, das in dem buddhistischen Ausdruck ,Māra der Böse" (oben S. 117) als „der Böse* wiederkehrt. 
holt man jetzt besonders häufig. Man sagt „Möge mich nicht das Übel, der Tod erreichen": der Tod ist eben das Übel schlechthin. Man betet ${ }^{64}$ : „Aus dem Nichtseienden führe mich zum Seienden. Aus dem Dunkel führe mich zum Licht. Aus dem Tode führe mich zur Unsterblichkeit" - und man erklärt: das Nichtseiende, das Dunkel ist der Tod; das Seiende, das Licht ist die Unsterblichkeit. So bedürfen und erhalten in jenem Gebet die ersten beiden Sätze eine Deutung: die Benennungen des Nichtseienden, des Dunkels weisen auf die Vorstellung des Todes. Aber ,wenn es heißt: aus dem Tode führe mich zur Unsterblichkeit, so ist darin nichts Verborgenes".

Nach alledem ist es, meine ich, wohl glaublich, daß für die Denker der Upanishaden, geneigt wie sie waren mit großen Verallgemeinerungen, schroffen Gegensätzen zu arbeiten, eben der Gedanke an den Tod es vor allem gewesen ist, der für die Bewertung dieser Welt deren Gegensatz zum Ātman den Ausschlag geben ließ, nicht ihr Durchdrungensein durch den Ātman. So entfaltet denn nun das Motiv dieses Gegensatzes seine typischen, so vielfach in der Geschichte des menschlichen Denkens wiederkehrenden Wirkungen. Während auf den Ätman alle Prädikate von Licht, Herrlichkeit, Seligkeit gehäuft werden, fällt auf alles, was nicht Ātman ist, ein schnell sich verdichtender Schatten.

Ja mehr als ein Schatten, der nur von außen kommt. Untrennbar haftet der düstere Zug dem innersten Wesen aller dieser Existenz an.

Jetzt heißt es nicht nur ${ }^{65}$ : „Diese Welt ist ganz vom Tode erfaßt, ganz in der Gewalt des Todes"; „diese ganze Welt ist des Todes Speise" - wo Welt und Tod immer noch einander als zwei Wesenheiten gegenüberstehen. Sondern der Tod ist, wie später für die Buddhisten, der eigentliche Kern des Weltdaseins selbst: „diese Welt, die Gestalten des Todes."

Und an die Seite des Todes stellen sich weiter alle andern ihm verwandten Übel. Es wird von Alter und Tod 
gesprochen, oder von Alter, Tod, Schmerz, Hunger und Durst - man denke an indische Hungersnöte, Durst in indischer Sonnenglut. Oder es wird gesagt: Hunger und Durst, Schmerz, Wahn, Alter, Tod; und ein Vers stellt dem All-Einen die Welt des Leidens mit den Worten gegenüber:

„Nicht schaut der Schauende den Tod,

Nicht Krankheit oder Kümmernis.

Das All erschaut der Schauende;

Das All allfältig er erlangt."

Es sind kurze, schlichte Fassungen, in denen da ausgesprochen wird, was man als die Leiden des Daseins erkennt. Man hat noch nicht angefangen, wie später der Buddhismus und schon eine jüngere Upanishad, in langen, mit Pathos gesättigten Ergüssen sich über die einzelnen Situationen des Lebens zu verbreiten und ihren Leidensgehalt in ausführlichen Schilderungen ans Licht zu stellen. Wenn aber der Buddhismus in der lapidaren Fassung seines Credo, der "vier heiligen Wahrheiten“, vom Daseinsleid redet und dessen Grundformen benennt, bereitet sich in den eben berührten Äußerungen der Upanishaden doch schon deutlich vor, was dort der erste jener vier Sätze sagt: „Geburt ist Leiden, Alter ist Leiden, Krankheit ist Leiden, Tod ist Leiden, mit Unliebem vereint sein ist Leiden, von Liebem getrennt sein ist Leiden, nicht erlangen, was man begehrt, ist Leiden $\left.{ }^{1}\right)$."

Und auch darin gehen schon die alten Upanishaden dem Buddhismus voran, daß sie - natürlich gleichfalls nur mit kurzen Worten - die negative Beurteilung der Daseinswerte auch auf das zu erstrecken anfangen, was dem alltäglichen Bewußtsein als Glück erscheint, worin die nervöse

1) Nicht unähnlich bei den Jainas, Uttarādhyayana XIX, 15 (SBE. XLV, 90). - Man beachte die Übereinstimmung, wenn sie auch leicht auf blobem Zufall beruhen kann, der letzten Worte der buddhistischen Formel mit einer Stelle der Chāndogya Upanishad (VIII, 3,2), wo von der Unbefriedigung des Weltdaseins die Rede ist: „und was man sonst nicht erlangt, das man begehrt ${ }^{4}$. 
Phantasie dieser Denker aber wie in allem, was nicht der $\bar{A}$ tman ist, einen Zug von Hinfälligkeit, Hohlheit, Tod zu entdecken weiß. „Wahrlich wer ohne dieses Unvergängliche zu kennen, o Gārgī, in dieser Welt Opfergüisse und Opferspenden bringt und Kasteiung übt viele tausend Jahre lang, für den ist das (der Lohn für sein Tun) nur endlich ${ }^{66}$." „Wie hienieden die durch Arbeit gewonnene Stätte schwindet, ebenso schwindet auch in jener Welt die durch gute Werke gewonnene Stätte. Darum die von hinnen scheiden ohne den Âtman und jene wahren Wünsche gefunden zu haben, denen ist in allen Welten unfreie Bewegung verhängt. Aber die von hinnen scheiden nachdem sie den Ätman gefunden haben und jene wahren Wünsche, denen ist in allen Welten freie Bewegung gewährt." Also auch dem Dasein, zu dem gute Werke führen, haftet Vergänglichkeit, Unfreiheit an. So steht es mit aller körperlichen Existenz: „Sterblich wahrlich ist dieser Körper, vom Tode erfaßt. Er ist dieses unsterblichen, körperlosen Selbst (ātman) Wohnstätte. Der Bekörperte wird von Lust und Schmerz (wörtlich: von Liebem und Unliebem) erfaßt. Wahrlich für den, der bekörpert ist, gibt es keine Abwehr von Lust und Schmerz. Wer aber körperlos ist, den berührt Lust und Schmerz nicht." Klingt hier nicht durch, daß wie der Schmerz so auch die Lust, die im Reich der Körperlichkeit wohnt, abgewehrt werden muß und unwürd̄ig ist, in die Welt der körperlosen Vollendung einzugehen? Hierher gehört weiter eine schon in anderm Zusammenhang ${ }^{67}$ berührte Stelle, die noch bestimmter spricht. Wahre Lust ist allein in der Fülle: da wo man nichts andres sieht und hört. Solche Fülle ist das Unsterbliche; dürftig ist das Sterbliche. Was man in dieser Welt preist, der Besitz von Kühen und Rossen, Gold, Weibern, Feldern, ist keine Fülle, „denn da gründet sich immer eins auf das andre". Am kürzesten, in schneidendster Sprache urteilt eine Stelle, die in den Reden des Yājnavalkya (Ḅ̣had Āranyaka Upanishad) dreimal wiederholt wird. Nachdem von der Erhabenheit des all-einen Wesens ge- 
sprochen ist, heißt es: "Was von ihm verschieden, ist leidvoll." Und bald spricht eine jüngere Upanishad direkt das Wort "Weltleiden" aus: von dem ist der Ātman unberührt, wie die Sonne, das Weltauge, unberührt bleibt von den Krankheiten des menschlichen Auges.

Seinen Anfang muß dies Weltleiden - das liegt in der Konsequenz der gesamten Vorstellungsmasse - damit genommen haben, daß der Ātman es erwählte, in jenes von ihm Verschiedene, die Welt der Körperlichkeit, mit seinem eignen Wesen einzugehen. Wir werden sehen, daß andrerseits die Aufhebung dẹs Leidens in nachdrücklichster Sprache als bedingt durch das Erwachen des Ātman zur Erkenntnis seiner selbst beschrieben wird: was offenbar als Kehrseite verlangt, daß des Leidens Ursprung mit etwas wie einem Vergessen seines eignen Wesens und seiner Hoheit zusammenhängt, das dem Âtman bei jenem Eingehen in die Welt der Dinge widerfahren sein muß. In den Berichten über die Weltschöpfung sind wir der Erzählung davon begegnet, wie das höchste Eine sich in seiner Einsamkeit nicht wohl fühlte, wie es eine Vielheit zu sein begehrte und darum die Welt erschuf (S. 69). Jetzt sehen wir, daß dieser Vorgang konsequenterweise als ein unsagbar schweres metaphysisches Unglück, bestimmter könnte man sagen, als eine metaphysische Schuld hätte erscheinen müssen. Wir haben doch die bemerkenswerte Tatsache festzustellen, daß aus dem Zeitalter, von dem hier die Rede ist, Äußerungen solches Inhalts nicht vorliegen. Ist das Zufall? Oder hat man, damals wenigstens, jene Anklage gegen das All-Eine, die uns so schwer vermeidbar scheint, der Konsequenz zum Trotz in der Tat nicht zu erheben gewagt?

In das Sichabwenden des Geistes von der Welt, das aus den von uns betrachteten Gedankengängen überall hervorblickt, wird doch ein fremder Zug hineingetragen, wenn man daraus ein Grauen herauszufühlen meint vor der unauflöslichen Irrationalität des Verhängnisses, daß es eine Welt gibt - vor dieser harten Tatsache des Seins, die sich 
jedem vernunftmäßigen Erweis ihrer Notwendigkeit unerbittlich verschließt ${ }^{68}$. In Wahrheit hat, scheint mir, der Erkenntnisdrang jener Alten die Frage überhaupt noch kaum gestreift, ob in diesem Sinn das Denken des Seins Herr werden kann, und wie man es ertragen will, wenn das nicht gelingt. Warum es undenkbar ist, daß das Brahman nicht sei? Oder daß die Welt nicht sei? Keine Spur der ersten Frage. Kaum wirkliche Spuren der zweiten. Denn Einfälle wie jener, daß das höchste Wesen sich einsam fühlte und darum die Welt geschaffen hat, verraten ja kein Bewußtsein von der Tiefe des Problems; sie gleichen den bequemen Antworten, mit denen man vorwitzige Fragen von Kindern abspeist.

Nicht vor der Tatsache also, daß die Welt ist, empfindet man jene bis in die letzte Lebenstiefe reichende Erschuitterung, sondern davor, daß alles, was die Welt in sich schließt, vergänglich, dem Leiden und Tod verfallen ist. Aus diesem Bewußtsein heraus tritt hier der seelische Zwiespalt in die Erscheinung, der unter den Signaturen höheren religiösen Lebens so selten fehlt. Die ungebrochene Einheit des Daseins, in der man einst so unbefangen und selbstgewiß den Kleinkampf gegen das einzelne Übel, um das einzelne Gut gekämpft hatte, ist dahin. In andrer geschichtlicher Umgebung, in Bereichen starken Gottesglaubens, versteht man das Leiden, von dem man sich bedrückt fühlt, als Folge der eignen ethischen Unzulänglichkeit gegenüber den Forderungen Gottes, als der Sünde Sold. Hier dagegen erscheint es vielmehr als Folge der metaphysischen Unzulänglichkeit des Weltdaseins gegenüber dem jenseitigen Ideal. So äußert sich die innere Entzweiung hier nicht als Zerknirschtheit des zerrissenen Gewissens, sondern als Drang des Sichlosreißens aus der Unbefriedigung der Welt, von den Gütern, an die sich einst das Herz mit allen Fasern geklammert hatte. Es gibt nur ein Gut, und das steht jenen Scheingütern in unversöhnlichem Antagonismus gegenüber. Es liegt im Jenseits. 
Die Weise, wie sich in den Geistern der indischen Denker und Asketen der ungeheure Umschwung vollzieht, ist höchst bezeichnend. Früh wird hier die Stelle erreicht, an der die Wendung eintritt. Der größte Teil der Geschichte des indischen Volkes, soweit es da Geschichte gegeben hat, liegt noch in der Zukunft. Man lebt in Gedeihen und Wohlsein. Es sind nicht Leidgequälte, die hier vom Weltleiden reden. Es sind phantasiegewandte Denker. In der Richtung aber, die ihr Denken einschlägt und festhält, scheint sich ein Ermüden der aus nördlicheren Wohnsitzen stammenden Rasse kundzugeben, das nach den frisch bewegten Zeiten des Rigveda im heißen Lande einsetzt körperliche Dispositionen, die Lebensmut und Genußfreudigkeit schwächen, die ängstliches Haften der Phantasie an jeder Sorge, jedem düstern Gedanken befördern. Hinaus aus Bewegung und Lärm des Arbeitens, des Geschehens! Hin zum sichern Hafen der ewigen Ruhe! Die äußeren Verhältnisse schaffen eine Atmosphäre, in welcher das von solchen Stimmungen beherrschte Denken ungehindert seinen Weg bis zu letzten Extremen verfolgen und das ganze Innendasein mit sich reißen kann ohne starkem Widerstand anderer, in das reale Leben verflochtener und dort Befriedigung findender Seelenkräfte $\mathrm{zu}$ begegnen. In der Gedankenwelt tritt die Vorstellung jenseitigen Seins beherrschend in den Vordergrund. Seiner Erhebung in höchste, überselige Höhe entspricht die unbedingte Ablehnung des Diesseits. Doch für den, der $\mathrm{zu}$ dieser Ablehnung siegreich durchgedrungen ist, verliert sie den Charakter schmerzlicher Resignation. Denn den Ausgang aus dem Weltleiden in die Herrlichkeit jener Überwelt sich zu eröffnen fühlt er sich nicht $\mathrm{zu}$ schwach und $\mathrm{zu}$ gering.

Die Erlösung.

Der Angelpunkt der Erlösungshoffnung liegt - soviel ist nach all dem klar - im Verhältnis des Ich zum Brahman, zum All. Es muß noch eingehender als 
bisher betrachtet werden, wie dies Verhältnis gedacht wurde.

Nur ein zaghafter Ausdruck hierfür ist es, wenn das Selbst einmal „die Wegspur alles dieses (Daseins) " genannt wird, „denn durch jenes kennt man all dies (Dasein) ${ }^{469}$. In Wahrheit sieht man in ihm unvergleichlich viel mehr als nur eine Wegspur. Es ist nichts Geringeres als das Allumfassende, Allbeherrschende selbst. Jenes Wort des Śanndilya (oben S. 58) spricht es aus, was man die Grundlehre der Upanishaden nennen kann: das alldurchdringende Selbst, größer als der Himmel, ist mein Selbst. In der Chāndogya Upanishad heißt es: "Wahrlich so groß wie dieser (Welt-) raum, so groß ist dieser Raum im Innern des Herzens.

Beide, Erd' und Himmel zumal drinnen in ihm beschlossen sind, Beide Feuers und Windes Gott, beide die Sonn' und auch

[der Mond -

Blitz und Sterne, und was einem hier gehört und was einem nicht gehört: alles das ist darinnen beschlossen". Yājnavalkya sagt: „Der Raum hier inwendig im Herzen, darin liegt er, der Gebieter des All, der Herrscher des All, der Oberherr über das All." Und derselbe Lehrer gibt auf die zweimal wiederholte Frage nach dem "offenbaren, nicht verborgenen Brahman, dem Atman, der in allem darinnen ist" zweimal dieselbe Antwort: „Es ist dein Âtman, der in allem darinnen ist". Tat tvam asi "das bist du", sagt der Vater zum Sohn. Gewiß nicht nüchterne Erwägung, daß das höchste Wesen, welches alles ist, darum unter anderm auch mein und dein Ich sein muß. Vielmehr die triumphierende Gewißheit der Mystik, im Ich das All zu erfassen, das All zu sein.

Solcher aus dem Vollen schöpfenden Seligkeit mußte jedes Abschwächen der Gleichung des Tat und des tvam durch kühle Analyse fern liegen. Nicht ein Teil der Wesensfülle des Brahman, der von andern Teilen gesondert wäre, sondern das ganze Brahman mußte es sein, was dem Schauenden aus der eignen Herzenstiefe entgegenleuchtet. Gab es da- 
gegen Bedenken? Aber dazu war man ja noch viel zu sehr von den Anschauungen des alten Zauberglaubens durchdrungen. Unendlich groß und zugleich unendlich klein zu sein, dieses und zugleich etwas andres zu sein machte da den Wesen keine Schwierigkeit. So konnten die Widersprüche zwischen der Allfülle des universellen, der Begrenztheit des persönlichen Ātman nicht stören. Vorhanden freilich waren sie, und es ließ sich kaum von diesen Dingen reden ohne daß man irgendwie an sie stieß: nur daß der Stoß eben nicht gefühlt wurde. Schon in jener selben Rede des Sāñạilya hieß es, wie wir schon früher sahen: „Dies ist mein Selbst. $\mathrm{Zu}$ diesem Selbst werde ich von hier scheidend hingelangen" (S. 58) - als ob das Selbst, um bei sich selbst anzulangen, sich auf die Wanderschaft zu begeben oder die Zukunft abzuwarten nötig hätte. Darf hier auch die Äußerung einer Upanishad herangezogen werden, die nicht $\mathrm{zu}$ den ältesten gehört, so ist an die schon erwähnte (S. 103f.) Beschreibung zu erinnern, welche die Kaushītaki Upanishad vom Weg des Hingeschiedenen zur höchsten Höhe der Brahmanwelt gibt. Droben thront Brahman - die maskulinische Personifikation des neutralen Brahman -; der fragt ihn: "Wer bist du?" Und die wandernde Seele antwortet: „Was du bist, das bin ich": also zugleich Identität und ein Gegenüberstehen des Fragers und des Antwortenden, des in der Höhe Herrschenden und des Ankömmlings von unten.

So bereitet sich - vermutlich den brahmanischen Denkern unbewußt - neben der in der Sphäre zauberhafter Mystik sich realisierenden schlechthinnigen Gleichsetzung von Weltātman und menschlichem Atman eine davon abweichende Auffassung vor. Schwächerwerden des Zauberglaubens, wachsendes Bedürnis nach anschaulicher, widerspruchsloser Geordnetheit des Weltbildes befördert diese Entwicklung. Man schickt sich an, dem Welt-Ich, damit es $\mathrm{zu}$ den vielen menschlichen Ichheiten werde, etwas wie eine Teilung seiner selbst zuzumuten, die Abzweigung eines ge- 
wissen Maßes seiner Substanz hierhin und dorthin, um hier und dort die Individuen $\mathrm{zu}$ beseelen.

Auf eine solche Vorstellung führen mit größerer oder geringerer Bestimmtheit mehrere der Gleichnisse, an denen die Texte so reich sind ${ }^{70}$. Die Kreaturen gehen in das Seiende ein, wie der Saft von mancherlei Bäumen im Honig zusammenfließt. Sie sind die Fluisse; das Seiende ist der Ozean (s. oben S. 86). Das Seiende wohnt ihnen inne wie das Salz dem Salzwasser: man kann kaum an dem Gedanken vorübergehen, daß es verschiedene Teilchen der ganzen Salzmasse sind, die diesen und jenen Wassertropfen salzig machen. Der Ātman läßt alle Wesen aus sich hervorgehen wie die Spinne ihren Faden, wie das Feuer die Funken. Ist das so gemeint, daß das materielle Dasein der Wesen zwar ein vielfältiges ist, aber die Einheit des sie alle beseelenden Ātman unbeeinträchtigt bleibt? Es darf doch wohl verstanden werden, daß auch das, was in den vielen Seelenfunken als feuergleiche Kraft lebt, zwar alles seelisches Feuer und insofern dasselbe ist, daß aber doch hier und dort verschiedene Teile der einen mächtigen Feuersubstanz wirken ${ }^{1}$ ). Der Gedanke an Teile des Atman ist offenbar den Alten nicht ohne weiteres als unannehmbar erschienen ${ }^{2}$ ). Das zeigt jene Stelle (S. 87), die vom Ātman in seinem Verhältnis zu Auge, Ohr usw. sagt: „Zerteilt ${ }^{8}$ ) ist er durch all dies Einzelne": wie hier die verschiedenen Funktionen, so kann doch wohl auch die Verschiedenheit der

1) Eine der beiden Rezensionen, in denen dieser Text vorliegt (Śatapatha Br. XIV, כ, 1, 23), sagt beim Gleichnis von der Spinne und dem Faden, vom Feuer und den Funken geradezu: „ebenso gehen aus diesem Atman alle Atemkräfte, alle Welten, alle Götter, alle Wesen, alle jene Átmans hervor." So wird die Vielheit, die im Gleichnis durch die Vielheit der Funken abgebildet ist, ausdrücklich auch auf die Ātmans bezogen.

2) Anders freilich Śankara: „,Ein Teil' heißt ,gleichsam ein Teil'. Denn einen Teil im eigentlichen Sinn kann es bei einem Wesen, das keine Glieder hat, nicht geben."

s) Wörtlich: "nicht ganz". 
empirischen Subjekte, denen der Ātman innewohnt, eine gewisse Teilung bedingen.

Sollten alle diese Aussprüche noch Zweifel übrig lassen, so ist die folgende Stelle aus Yājnavalkya's Rede über Tod und Erlösung wohl unzweideutig. Es wird zuerst gesagt, daß der Ātman (= Brahman) „aus Begehr, aus Nichtbegehr, aus Zorn, aus Nichtzorn, aus Recht, aus Nichtrecht, aus allem besteht" (S. 62). Dann fährt der Text fort: „Wenn es da nun heißt, aus diesem bestehend, aus jenem bestehend': wie er gehandelt, wie er gewandelt, so wird er ${ }^{1}$ ). Wer Gutes getan, wird ein gutes Wesen. Wer Böses getan, wird ein böses Wesen." Es scheint unvermeidlich, dem zu entnehmen, daß im universellen Ātman alle Gegensätze - wir dürfen wohl ausmalend hinzufügen, im Indifferenzzustand - vereint sind. Im individuellen Ätman erscheint oder überwiegt die eine Seite jedes Gegensatzes: daher die Verschiedenheit der individuellen Charaktere, Lebensführungen, Seelenwanderungsläufe. Es ist klar, daß diese Vorstellung mit der absoluten Gleichsetzung des universellen und individuellen $\bar{A}$ tman unvereinbar ist. Der letztere muß als ein Ausfluß des ersten gedacht werden. Als ein Teil von ihm, der so oder auch anders gestaltet sein kann. Nicht als er selbst in seiner vollen Majestät. Bekanntlich zieht später das Sāṃkhyasystem ") aus der verschiedenen Verteilung von Geburt und Tod unter den Wesen, aus dem Überwiegen hier des Sattva, dort des Rajas, dort des Tamas ${ }^{8}$ ) den Schluß auf die Vielheit der Ātmans. Das bereitet sich jetzt vor. Zwar davon ist man weit entfernt, die individuellen Ichheiten in der absoluten Trennung neben einander zu stellen, wie im Sāṃkhya geschieht. Aber gemeinsamem Quell entstammend haben sie sich von da, jede in

1) D. h. er gelangt zu einer entsprechenden Wiedergeburt. - Ganz dieser Stelle ähnlich: oben S. 109.

9) Ich spreche hier von dessen klassischer Gestalt.

s) Die drei "Guna" oder Konstituenten: das Leichte, Helle - das Bewegte, Schmerzliche - das Starre, Finstere. 
ihrer eignen Richtung, ein Stück Weges für eine Zeitlang entfernt.

Doch gleichviel nun, ob vermöge eines mystischen Wunders derselbe eine Âtman in diese leidvolle Welt verflochten ist und doch zugleich ungeteilt und frei in seinem eignen Reiche weilt, oder ob er vielmehr aus seiner Freiheit heraus Teile seiner selbst in die Welt entsandt hat: in jedem Fall muß das Ziel des Abtuns von Leiden und Tod so viel bedeuten wie die Aufhebung der Verbindung mit der Welt.

Was kann diese Aufhebung herbeiführen?

Von den Zeiten der Brāhmanas her kommen vor allem zwei Mächte in Frage. Werke, insonderheit rituelle Werke. Andrerseits das Wissen.

Es ließe sich drittens an die Zauberkraft von Kasteiungen denken. Das Treiben derer, „die im Wald der Kasteiung und dem Glauben Ehre erweisen", war ja diesem Zeitalter nicht fremd. Aber auf der einen Seite hängt die Geltung der Kasteiungen, mindestens zum großen Teil, eben damit zusammen, daß sie auf übernatürliche Weise Wissen erzeugen ${ }^{21}$. Sodann scheint es doch, daß eigentliche Kasteiungen in jener Sphäre der Opfertheologie, aus der die Gedanken der Upanishaden hervorgegangen sind, eine erheblichere Rolle nicht gespielt haben. Von den immerhin verwandten Versenkungen nach Art der späteren Yogapraxis wird weiterhin die Rede sein: daß davon Anfänge - aber offenbar eben nur Anfänge - in das uns beschäftigende Zeitalter zurückreichen, ist in der Tat nicht unwahrscheinlich $^{72}$.

In der Rivalität nun aber von Wissen und Werken hatte sich schon früh (vgl. S. 34) die Tendenz gezeigt, dem Wissen den Vorrang einzuräumen. Schwankungen zwar blieben immer noch übrig. Denen mehr und mehr ein Ende zu machen war offenbar eben jetzt die Zeit gekommen. Jetzt hatte neben die alten Ziele religiösen Strebens die $\bar{A}$ tmanspekulation ein neues, schlechthin unvergleichliches 
gestellt. $\mathrm{Zu}$ guten Werken sollte und mußte der Weg Allen offen stehen. Dies neue Ziel dagegen zu begreifen und $\mathrm{zu}$ erstreben war nur eigenartigem, in die Tiefe dringendem Wissen Weniger möglich. Von selbst fügten sich da die Gedankenlinien zu einer klaren Figur. Die Werke fanden nach der Ordnung der Karmanlehre in den Freuden und Schrecken des Seelenwanderungslaufes ihren allverständlichen, unter den Nichtwissenden allbegehrten Lohn oder ihre Strafe. Jenen geheimnisvollen letzten Preis aber behielten die Wissenden mit noch anderer Emphase, mit tieferer Motivierung als sie den hundert Verheißungen der Brāhmanatexte für „den, der solches weiß", beigewohnt hatte, sich selbst vor. Wem konnte der Zugang zum Brahman mit so vollem Recht gebühren wie denen, welche die dem Brahman vor allem verwandte Kunst zur Vollendung brachten, die des Wissens vom Verborgenen? In denen der Ātman sich selbst in seinem Versteck wiederfand, während die Andern "über den vergrabenen Goldschatz, unkundig der Stelle, beständig hingehn ohne ihn zu finden"?

$\mathrm{Da} \beta$ doch auch jetzt noch die Klarheit, auf die alles hindrängte, über die Abgrenzung der Sphären von Werk und Wissen, nicht mit einem Schlage absolut vollkommen war, ist begreiflich. So wird in den Schlußsätzen der Chāndogya Upanishad gesagt, zur Brahmanwelt gehe ein, wer nach der Ordnung seine Schülerzeit verbracht, als Hausvater den Veda weiter studiert, fromme Söhne und Schüler aufgezogen, alle seine Organe im Ātman zur Ruhe gebracht und zeitlebens keinem Wesen ein Leid zugefügt habe. Aber trotz solcher gelegentlicher Äußerungen steht im Ganzen die prinzipielle Sonderung der beiden Daseinsrichtungen fest: weltliches Glück durch Werke, Erlösung im Brahman allein durch das Wissen.

"Wahrlich, o Gārgī", sagt Yājnavalkya ${ }^{78}$, "wer ohne jenes Unvergängliche zu kennen in dieser Welt Gußspenden ergießt, opfert, sich kasteit viele tausend Jahre lang: das bringt ihm nur endlichen Lohn." 
Vom Wissenden aber andrerseits heißt es:

„Wem der Âtman ist kund worden, wer ihn erkannt hat: ,ich bin er',

Was suchend mag, wonach trachtend er nachkranken der Leiblichkeit?

Wer fand den Âtman, wer zu ihm erwachte, ${ }^{1}$ )

Der in der Leibverkittung Abgrund hauset:

Der ist Allschöpfer, denn das All erschafft er.

Die Welt gehört ihm, der er selbst die Welt ist."

Der Schüler spricht zum Lehrer: „Von Männern deinesgleichen, Erhabener, habe ich gehört: ,Wer den Ātman weiß, dringt über allen Schmerz hinüber.' Ich leide Schmerz, Erhabener: so wolle du mich zum Ufer jenseits des Schmerzes hinüberführen." "Da durch das Wissen vom Brahman die Menschen zum All zu werden gedenken, was hat das Brahman gewußt, woher es zum All wurde? Wahrlich dies (Seiende) war im Anfang Brahman. Das wußte allein sich selbst: ich bin das Brahman. Daher wurde es zum All ${ }^{2}$ ). Und wer immer von den Göttern (zu dieser Erkenntnis) erwachte ${ }^{8}$ ), auch der wurde dazu; ebenso von den Rishis ${ }^{4}$ ), ebenso vön den Menschen. Dies hat der Rishi Vāmadeva gesehen, der sein Lied anhob:

,Ich ward zu Manu, und zur Sonne ward $\left.i \mathrm{ch}^{5}\right)^{6}$.

So auch jetzt: wer dies weiß ,Ich bin das Brahman', der wird dies All. Und selbst die Götter haben des nicht Macht, daß er es nicht werde. Denn deren Selbst (ātman) ist er." -

Hier erhebt sich nun freilich eine Schwierigkeit. Neben der Forderung der Upanishaden das höchste Seiende zu

1) Man bemerke das hier gebrauchte Wort pratibuddhah („er ist erwacht"): ein Vorklang buddhistischer Redeweise. Vgl. meinen „Buddha“ (6. Aufl.), S. 56.

2) Der unbeholfenen Darstellung wird man nicht nachrechnen, da hier das Brahman dem Wortlaut nach als zum All werdend erscheint, während es in Wahrheit von Ewigkeit her das All ist.

8) pratyabudhyata. Man vgl. Anm. 1.

4) Den alten Weisen und Verfassern der Vedalieder.

5) Ein Vers des Rigveda. 
wissen erscheint dort wiederholt und höchst nachdrücklich die These von dessen Unerkennbarkeit ${ }^{44}$. "Nicht kannst du den Seher des Sehens sehn. Nicht kannst du den Hörer des Hörens hören. Nicht kannst du den Denker des Denkens denken. Nicht kannst du den Erkenner des Erkennens erkennen." „Wahrlich dies Unvergängliche, o Gārgī, ist das ungesehene Sehende, das ungehörte Hörende, das ungedachte Denkende, das unerkannte Erkennende." „Durch den er dies alles erkennt, wodurch sollte er den erkennen ... den Erkenner - wodurch denn sollte er den erkennen?" Es mag etwa der Gedanke, daß das Auge sich nicht selbst sieht, vorgeschwebt und diese - an sich schwerlich zwingende ${ }^{1}$ ) - Konsequenz herbeigeführt haben: ein den Ātman erfassendes Erkennen wäre ein Sichselbsterkennen dieses alleinigen Erkenners und ist darum ausgeschlossen. Liegt nun im Nebeneinanderstehen der Forderung solches Erkennens und der Behauptung seiner Unmöglichkeit ein Widerspruch? Vielfach mögen diese Gedanken so gestaltet gewesen sein, da $\beta$ der in der Tat vorhanden war. Zwei von verschiedenen Punkten ausgehende Gedankenreihen kollidierten, wie das für junges Denken, ungeübt darin, prüfend nach allen Seiten zu sehen, oft kaum vermeidbar ist. Doch scheint auch eine Lösung des Widerspruchs vorgeschwebt $\mathrm{zu}$ haben. Es ist bemerkenswert, wie dicht bei einander die beiden unvereinbar scheinenden Vorstellungen zum Ausdruck gelangen. Den oben angeführten Worten Yājnavalkya's an Gārgī geht im selben Abschnitt desselben Dialogs unmittelbar der Satz voraus: „Wahrlich wer ohne dies Unvergängliche zu wissen, o Gārgī, aus dieser Welt scheidet, der ist elend. Wer aber dies Unvergängliche wissend, o Gārgī, aus dieser Welt scheidet, der ist ein Brahmane." Können wir annehmen, daß dieser so unendlich oft in den Upanishaden erscheinende, sie geradezu beherrschende Gedanke für den Verfasser der Stelle, schon

2) So bemerke man die eben angeführte Stelle vom Brahman, das nallein sich selbst wuBte*. 
als er zum nächsten Satz kam, in Nichts zerflossen war? Gab es kein Wissen vom Ätman, was anders wäre ihm als der Weg der Erlösung erschienen? So halte ich für das Glaublichere, daß jenes unentbehrliche Wissen vom Ātman und diese unmögliche Erkenntnis des Ātman eben von einander unterschieden sind. Unerreichbar eine Erkenntnis seiner, wie im Alltagsdasein das erkennende Subjekt sie von dem ihm gegenüberstehenden Objekt erwirbt. Unaufgebbar aber das Trachten nach Durchleuchtung des Innern durch die unmittelbare Gewißheit des Tat tvam asi. Nach jener mystischen Steigerung des Bewußtseins, wo wir - um den Gedanken der Upanishaden mit Worten Schelling's wiederzugeben - „uns aus dem Wechsel der Zeit in unser innerstes, von allem, was von außenher hinzukam, entkleidetes Selbst zurückziehen und da unter der Form der Unwandelbarkeit das Ewige anschauen." Jüngere Upanishaden scheinen zu bestätigen, daß die alten Texte in eben diesem Sinne zu verstehen sind. Sie sagen vom Atman ${ }^{75}$ :

„Unerkannt vom Erkennenden, erkannt von dem, der nicht erkennt" -

„Nicht durch Reden wird er erreicht, nicht durch Denken, durch's Auge nicht.

,Er ist' spricht man. Wie sonst würd' er als nur durch dieses Wort erfaßt?"

Die eigenste Sprache dieser Mystik wie aller Mystik ist Schweigen. Es wird eine jüngere Upanishad sein - uns liegt sie nicht vor -, der die von Sankara ${ }^{76}$ überlieferte Äußerung des weisen Bāhva entnommen ist. Jemand bat diesen: "Lehre mich das Brahman, Erhabener!" $\operatorname{Er}$ aber schwieg. Der andre bat zum zweiten und drittenmal. Da sprach er: „Ich lehre es dich ja, du aber merkst es nicht. Dieser Âtman ist stille." Nicht das Schweigen des Nichtwissens, sondern des Wissens jenseits vom Wissen, der höchsten Fülle des Schauens und inneren Erlebens.

Das alles deutet in eine Richtung, die in Indien bald mit Entschiedenheit von der asketischen Mystik des Yoga 
beschritten wurde ${ }^{27}$. Wie man dort das Erkennen des Unerkennbaren zu verwirklichen gestrebt hat, wird uns weiterhin beschäftigen müssen. -

Wir kehren von dieser Abschweifung zur Frage zurück, worin die Upanishaden die erlösende, zum Brahman führende Macht gesehen haben.

Die erste Antwort lautete: im Wissen. Es ist doch im Grunde nur ein Unterschied der Formulierung, wenn statt des Wissens auch das Nichtbegehren genannt wird.

Der Gedankengang, der zu dieser Fassung der Lehre geführt hat, scheint zu Tage zu liegen.

Im Reich der Endlichkeit, der Seelenwanderung herrscht die Wirkung der Taten. Die beruhen auf des Täters Begehren. Schon oben (S. 110) wurde die Äußerung aus Yājnavalkya's großer Rede von Schlaf und Tod erwähnt: „Hier spricht man nun: ,Begehren (käma) ist es, woraus dieser Mensch besteht. Wie aber sein Begehren ist, so ist sein Wollen. Wie sein Wollen ist, solche Tat tut er. Welche Tat er tut, zu solchem Dasein gelangt er." Werden also die Schicksale der Seelenwanderung durch das Begehren bestimmt, so entstand unvermeidlich die Frage: welche Gestalt des Begehrens ist es, die zur höchsten jenseitigen Höhe, zum Brahman führt? Worauf die Antwort nur sein konnte: das Aufhören alles Begehrens - des Begehrens, das sich nicht auf das eine letzte Ziel richtet. An der eben angeführten Stelle heißt es, nachdem von der Seelenwanderung die Rede war, dann weiter ${ }^{78}$ : "So der Begehrende. Nun der Nichtbegehrende. Wer ohne Begehren ist, von Begehren frei, erfüllten Begehrens, nach dem Selbst (ätman) begehrend: dessen Atemkräfte ziehen nicht aus ${ }^{1}$ ). Brahman ist er und zum Brahman geht er hin." Im Freisein von Begehren, wie es hier verstanden wird, liegt wohl zugleich Verschmähen des Begehrens und Gesättigtsein: nicht das satte Besitzen dessen, was die Welt begehrt, aber

2) Sie gehen nicht, wie beim Tode des Unerlösten, in neues Dasein hinüber. 
der Besitz des Einen, der über jene Wünsche himmelhoch hinaushebt.

Kein Zweifel aber, daß wenn hier die Yājnavalkyarede ihre beiden Abschnitte vom Tode des Unerlosten und des Erlösten durch die Stichworte „der Begehrende - der Nichtbegehrende" charakterisiert, der Sache nach dieser Gegensatz mit dem des Nichtwissens und Wissens zusammenfällt. Wissen ist eben Nichtbegehren; genauer: Wissen ist die Ursache, Aufhören des Begehrens die Folge. Wir begegneten schon (S. 131) dem Vers vom Erkenner des Ātman - dem, der vom Âtman weiß: ,ich bin er —, wo es heißt „Was suchend mag, wonach trachtend er nachkranken der Leiblichkeit?"

Für diese Auffassung des Verhältnisses der beiden Formulierungen - die Erlösung abhängig vom Wissen, vom Nichtbegehren - gibt sicherste Bestätigung die Weise, wie dieselbe Doppeltheit bei den Buddhisten wiederkehrt. Die populärere Fassung ihrer Glaubensregel, die Formel der ,heiligen Wahrheiten“, nennt als Grund des Weltleidens den „Durst", das Verlangen nach endlichem Glück. Die philosophische Fassung andrerseits, die „Kausalitätsformel", führt die lange Kette der Ursachen und Wirkungen, die in ,Alter und Tod, Schmerz und Klagen, Leid, Kümmernis und Verzweiflung" auslaufen, auf das "Nichtwissen" als tiefste Ursache der Ursachen zurück. Aber diese Formel schaltet die Kategorie des „Durstes" darum nicht aus. Sondern der "Durst" ist eins der Mittelglieder, durch die an das Nichtwissen das Leiden sich kettet. Man sieht, wie zu diesen verschiedenen Formen des buddhistischen Dogma vor alters in den Upanishaden der Grund gelegt, mehr als nur der Grund gelegt ist. -

Von der Erlösung durch Erkennen des Ātman ist behauptet worden ${ }^{79}$, sie bedeute nicht ein Werden $\mathrm{zu}$ etwas, das vorher nicht war, sondern nur Innewerdung von etwas bis dahin Verborgenem. Wir alle - so will man die Upanishadenlehre auffassen - sind schon erlöst, aber diese 
Wahrheit ist von Unwahrheit umhüllt. Die Erkenntnis: ,Ich bin Brahman' zieht den Schleier fort; nun leuchtet uns entgegen, was doch an sich von Ewigkeit zu Ewigkeit war und ist.

Wir begegnen hier wieder der bedenklichen Übertragung jüngerer indischer Anschauungen - zugleich etwa auch eigner des modernen Denkers - auf das Altertum. Ganz im eben bezeichneten Sinn lehrt später der vedantistische Philosoph Gaudapāda, daß die Seelen zur erlösenden Erkenntnis ,als von Anfang an erwachte und erlöste erwachen". Das ist nichts anderes als eine Konsequenz der Grundanschauung, daß neben dem allein seienden Ātman die Vielheitswelt nur vermöge der Täuschung der Māyā erscheint: wo dann natürlich das Verflochtensein des Ich in Welt und Weltleiden und entsprechend seine Erlösung daraus gleichfalls nur scheinbar sein kann. Oben wurde versucht (S. 89f.), die Māyālehre als den alten Upanishaden fremd oder mindestens durch sie schlechterdings nicht gewährleistet $z u$ erweisen. Damit steht im Einklang, daß auch für die Scheinnatur des Erlösungsvorgangs in der Tat das Zeugnis dieser Texte versagt ${ }^{80}$. Durchweg wird in ihnen das Leiden, das überwunden werden soll, als ein wirklich vorhandenes besprochen, durchweg ebenso dessen Überwindung als ein wirkliches Geschehen, nicht als die Hinwegräumung bloßen Scheines. Die gegebenen Ausführungen enthalten hinreichende Zeugnisse dafür, die als irgendwie minderwertig, etwa als Akkommodation an das populäre Bewußtsein beiseite zu schieben wir schlechterdings keinen Grund haben. Wie kann man es auch geschichtlich und psychologisch glaublich finden, daß diese grandiose Entwicklung mächtigen Erlösungsstrebens von Anfang an damit begonnen habe woran selbst die Lehre Buddhas soviel später nicht gedacht hat - das Leiden samt dem Vorgang der Erlösung für nichts als Schein zu erklären? -

Da das Leiden als auf der Verbindung des Ātman mit der Körperlichkeit beruhend aufgefaßt wird, das Wissen 
aber die erlösende Macht vorstellt, könnte man die Konsequenz erwarten, daß im Augenblick der Wissenserlangung jene Verbindung sich alsbald lösen, der Wissende hinscheiden werde. Begreiflicherweise wurde diese Konsequenz in der Tat nicht gezogen. Die Überzeugung stand fest, daß es unter den Lebenden Wissende gibt. Als ein solcher fühlte man wohl sich selbst. Die Unebenheit des Gedankenlaufs, die hier entstand, mag in alter Zeit unbemerkt geblieben sein. Später liebte man, wie bekannt, sich hier mit dem Gleichnis von der Töpferscheibe zu helfen, die sich eine Zeitlang weiter dreht, wenn auch der Topf fertig ist.

Vom Erdendasein dessen, der weiß ,ich bin das Brahman", zeichnete man ein Bild, über dem stiller, leuchtender Friede lag. Ob die Wirklichkeit überall diesem Bild entsprochen hat, daran erwecken die Upanishaden selbst mit der Schilderung der in ihren Dialogen auftretenden Personen ${ }^{1}$ ) manchen Zweifel. Was ist auch natürlicher, als daß da Disharmonien blieben, daß die Hoheit des Denkens leicht nur sozusagen in einem abgeschlossenen Bezirk des Innern die Herrschaft ergriff und daneben liegende Sphären unberührt ließ? Dem Ideal als solchem bleibt darum doch seine Bedeutung. Der Wissende, heißt. es ${ }^{81}$, ist „ruhevoll, bezähmt, abgewandt, geduldig, gesammelt .. frei von Unreinheit, frei von Zweifel". „Ihm geht die Sonne nicht auf noch unter; immerdar ist es für ihn Tag." „Hat er diesen Damm überschritten, wird er der Blinde sehend, der Verwundete heil, der Kranke gesund."

Besonders nachdrücklich, wie das der Bedeutung der Lehre vom Karman entsprach, betonte man die Unberührbarkeit des Weisen für die Wirkung guter wie böser Taten: seine Vollendung verlangt vou diesen weder Hilfe noch hat sie Störung von ihnen zu fürchten. „Wie am Blatt der Lotosblüte das Wasser nicht haftet, so haftet böse Tat nicht Abschnitt.

1) Ich verweise auf die Besprechung der Dialoge im nächsten 
an dem, der also weiß." Neben der psychologisch-realistischen Auffassung, daß der Weise, von Begehren frei, hinfort keine Taten mehr tun wird, stand vielleicht die man kann sagen mystisch-zauberhafte, daß wie die vergangene Tat so auch die künftige, die etwa noch getan werden möchte, durch des Wissens Kraft vernichtet wird.

Vor der Konsequenz, daß das äußere Dasein des also von der Welt Gelösten nicht bleiben kann wie es war, scheut man nicht zurück. Dem Tod zu entrinnen flieht man aus dem toderfüllten Leben. Durch dies Leben ist man sein Stück Weges gegangen. Man hat darauf gehört, was ,die göttliche Stimme, der Donner" sagt: $d a d a d a$, das ist: dāmyata „bezwingt euch", datta ,gebt", dayadhvam „,seid gütig“. Man hat dies Gebot, mehr sanfter Milde als kraftvollen Handelns ${ }^{82}$, befolgt. Den Veda hat man studiert und ist über den Veda hinausgekommen. Den beschränkten Stolz des Schriftgelehrten hat die Mahnung gedämpft:

„Nicht simn' er über viel Worte, ermüdend nur der

Rede Kraft - “"

dem Ziel ist fern, wer nur ,Spruchkenner, nicht Ātmankenner" ist. So hat man ,die Gelehrsamkeit abgetan und getrachtet wie ein Kind zu werden". Auch geopfert hat man und hat den begrenzten Wert der Opfer durchschaut: nicht zur Freude der Götter, die ungern einen Spender von Opferspeise und Somatrank verlieren. „Wer einen andern Gott ${ }^{1}$ ) verehrt und denkt: ,Ein andrer ist er, ein andrer bin ich', der versteht es nicht. Er ist wie ein Tier, das den Göttern gehört. Fürwahr so wie viele Tiere dem Menschen Nahrung schaffen, so schafft jeglicher Mann den Göttern Nahrung. Wird jemandem auch nur ein Tier fortgenommen, ist es ihm unangenehm, und nun gar wenn viele. Darum ist es den Göttern nicht angenehm, daß die Menschen das wissen." Doch die Götter haben sich in den Verlust fugen müssen; das Wissen, das über die Verehrung fremder Mächte

1) Als den im eigenen Ich offenbarten Ātman. 
hinausführt, hat man errungen. Wenn nun so die überkommenen Formen religiösen Tuns sich entwertet haben, wenn Sollen und Handeln aus dem Leben verschwunden ist, was bleibt dann übrig? Ein Wort Yājnavalkyas spricht es schlicht und groß aus: „Der über Hunger und Durst, Schmerz und Wahn, Alter und Tod hinausgeht: wahrlich ihn den Ātman wissend erheben sich die Brahmanen vom Trachten nach Söhnen und vom Trachten nach Habe und vom Trachten nach Welten, und als Bettler ziehen sie einher $\left.{ }^{1}\right)^{\prime}$ - als Bettler, wie von altersher die Brahmanenschüler bettelten: das ehrenreiche Kennzeichen dessen, der um geistlicher Ziele willen von irdischem Besitz und Erwerb losgelöst ist.

So war jetzt über die Stellung des Wissenden zur Welt die Entscheidung gefallen, wie sie in Indien nicht anders fallen konnte, wie sie für Buddha und bis auf den heutigen Tag dort gegolten hat und gilt. Der Stand der Śramana, der „sich Abmühenden" war ins Dasein getreten: jener $\Sigma \alpha \varrho \mu \tilde{\alpha} v \alpha \iota$ oder $\Sigma \alpha \mu \alpha v \alpha i ̃ o$ (so nach der volksdialektischen Form Samaña), die später von den griechischen Berichterstattern den Brahmanen als eine zweite Klasse der „Philosophen" an die Seite gestellt wurden ${ }^{88}$. Noch war dieser neue Stand selbstverständlich ein ganz unfertiges Gebilde. Gewiß war man weit davon entfernt, daß nun jeder Erkenner des Brahman ein Śramaṇa geworden wäre. Am wenigsten war an feste Einordnung des Śramanatums in den normalen Lebensgang, den die Sitte vorschrieb, zu denken. Aber das Ideal des Śramana war doch aufgestellt und hatte angefangen in die Wirklichkeit einzutreten. Bald

1) Eine Parallelstelle sagt: ,ziehen die Hinausziehenden hinaus" (pravrājinah ... pravrajanti). Wieder ein im Buddhismus technisch gewordener Ausdruck. Dort wird stehend der Übergang aus dem häuslichen Leben in das heimatlose Asketentum so bezeichnet; s. meinen „Buddha“, 6. Aufl, S. 394. Schon die Upanishad läbt Yājñavalkya sein Gespräch mit Maitreyī halten ,in der Absicht hinauszuziehen" (pravrajishyan). 
bevölkerten sich die indischen Wälder mit solchen Asketen: wir sehen ihr Bild, freilich eine Reihe von Jahrhunderten später, auf den alten buddhistischen Skulpturen, wie sie langbärtig mit den mächtigen um den Kopf gewundenen Haarflechten vor ihren blätterbedeckten Hütten sitzen. Einsiedler hielten sich an den Furten der Flüsse auf oder in verlassenen Häusern; sie zogen auf den Landstraßen in endlosen Wanderungen von Ort zu Ort - nicht unvermischt mit unechten Elementen, mit Narren und Marktschreiern -, diese Männer und bald auch Frauen, die den tiefen Trunk aus dem Quell der Jenseitshoffnungen getan hatten, denen es auf dem Gesicht geschrieben stand, daß alle Wirklichkeit, in der die Andern lebten, für sie verblaßt war vor der allein vollwertigen Wirklichkeit ihres Denkens und Schauens.

Gleichviel ob der Sramana einen letzten Rest des alten Opferkultus noch festhält oder nicht, sein eigentlicher Kult und der Inhalt seines Lebens ist jene sinnende „Verehrung“ (upāsana, upanishad) des Allwesens, das in ihm wohnt, das er ist. Sie mag dem amor intellectualis Spinozas verglichen werden mit seinem still das Grenzenlose durchschwebenden Frieden. Der rechte Sramaṇa gehört zu denen, ,die unter den Menschen Großheit erlangen: die haben die Gabe des Sinnens als ihr Teil erhalten" - anders als die Kleinen, die Streitsüchtigen und Afterredner. ${ }^{84}$ „Es sinnt gleichsam die Erde. Es sinnt die Luft. Es sinnt der Himmel. Es sinnen die Wasser. Es sinnen die Berge. Es sinnen gleichsam Götter und Menschen." Mit diesem Sinnen aller Wesen strömt das erhabenste Sinnen des Gotterkennenden zusammen. Näher als in der Begrenztheit und Gebundenheit des wachen Daseins fühlt er sich dem All-Einen in der Freiheit des traumerfüllten Schlafs, wo nicht die fremde Welt draußen den Geist einéngt, sondern er sich selbst seine Welt schafft - „denn er ist der Schöpfer". Und noch näher als im Traum kommt er dem Ziel in der Versunkenheit des tiefsten Schlafs, wo man ,kein Begehren fühlt, 
keinen Traum schaut", sondern schläft „wie ein Kind oder ein großer König oder ein großer Brahmane in überschwänglicher Wonne" und "wie von einem geliebten Weib umschlungen ... nichts draußen weiß und nichts drinnen. Das ist die Wesensform, wo das Begehren erfüllt ist, wo man das Selbst begehrt, wo man ohne Begehren ist, dem Leid entnommen. Da ist der Vater nicht Vater, die Mutter nicht Mutter, die Welten nicht Welten, die Götter nicht Götter ... denn dann hat er alles Leid seines Herzens überwunden."

Wenn nun das Hinschwinden des persönlichen Lebens im tiefsten Schlaf so hoch gefeiert wird, scheint es - mit voller Gewißheit läßt sich hier freilich nicht sprechen -, daß noch ein andres Genießen, wovon jenes gewissermaßen ein Vorspiel ist, schon den Asketen dieser Zeiten zuteil zu werden wenigstens anfing. Ich denke an jene physiologisch oder auch pathologisch bestimmt charakterisierten, ihrer Natur nach jedesmal zeitlich eng begrenzten Zustände ekstatischen Schauens, die später in Indien den Adepten des Yoga und ebenso außerindischen Mystikern so unvergleichliche Seligkeiten gewährt haben. Das ganze Milieu der älteren Upanishaden und speziell die Ausdrucksweise einzelner an Yogaartiges anklingender Stellen ${ }^{85}$ läßt es wohl für möglich halten, daß derartige Ekstasen schon diesem Zeitalter bekannt gewesen sind, wenn auch solche Verbreitung und systematische Planmäßigkeit wie im vollentwickelten Yoga ihnen jetzt offenbar noch nicht zukam. Und so mögen wir uns wohl ein zwar nur blasses Bild davon machen, welche Erscheinungen, welche mächtigen, wenn auch von fratzenhafter Beimischung nicht freien inneren Erlebnisse damals vielleicht manchem der Asketen zuteil wurden, die im Brahman Versenkung erstrebten.

Starr sitzt der Meditierende da. Regelmäßigkeit des Ein- und Ausatmens hat durch seinen Körper Ruhe verbreitet. Wo noch ein Gedanke auf das von ihm verlassene, ferne Diesseits zurückfällt, erscheinen ihm wie in einem 
Nebel Welten über Welten, Existenzen über Existenzen, ein unabsehbarer Dschungel - Leben und Sterben, Menschen, Götter, Vedén, Opfer: alle die Rauchwolken, die aus dem Feuer des Allwesens hervorwirbeln. Er aber dämmt die Gestaltenfülle zurück. Sein Ziel liegt im Reich des Gestaltlosen. Zuerst sind es doch noch sichtbare Erscheinungen, in denen sich das über alle Sichtbarkeit Erhabene ankündigt. Der „Mann, der im rechten Auge wohnt", ist die Essenz des Nichtgestalteten - da blitzen die Visionen auf: „wie ein mit Safran gefärbtes Gewand, wie ein weißes Schaffell, wie ein Coccinellenkäfer, eine Feuerflamme, eine weiße Lotosblume, ein plötzlicher Blitz." Und andre Reste bestimmten, kaum noch bestimmten Vorstellens bleiben der Phantasie als Stützpunkte. Er mag das höchste Sein als Erkenntnis verehren, als Wahrheit, als Liebes, als Wonne. Oder als ,.jene Sonne: wie die geboren ward, erhob sich hinter ihr her Lärm und Jauchzen, und alle Wesen und alle Wünsche." Oder im heiligen Wort Om, im Summen des Ohrs, in der Körperwärme, im Saft, der den Baum belebt, mag der Versenkte die Gegenwart des Höchsten hören, fühlen. Aber auch solcher letzte Rest von Bestimmtheit verschwimmt, versinkt. Und der schauende Geist selbst versinkt. Nicht das Ich lebt mehr; es lebt in ihm, das Seiende, in keine Form eingeschlossene, das "Nein, nein". Ohne Hülle steht es vor dem Blick - vielmehr das blickende Auge selbst, das Innerste der Seele ist zusammengeflossen mit seiner Unendlichkeit. Tat tvam asi. -

Freilich war der Weise, wie er in den Upanishaden erscheint, wenig darum bemüht, dies Tat tvam asi, in dem er sich selbst beseligt fühlte, auch auf den Mitmenschen anzuwenden. Die Pflichten und Tugenden des weltlichen Lebens lagen weit hinter ihm. Die Mahnung, ,alle Wesen in seinem eignen Selbst anzuschauen und sein Selbst in allen Wesen“, klang nur flüchtig an sein Ohr. „Das bist du" bedeutete ihm vor allem ,Das bin ich". „Nicht um des Gatten willen ist der Gatte lieb. Um des Selbstes willen 
ist der Gatte lieb." Treffend ist bemerkt worden, daß bei aller Entferntheit dieses Asketentums vom alten Opferwesen doch die dort unter den Opferern herrschende Stimmung eifersüchtiger Rivalität sich hier unverändert erhalten hat. ${ }^{\mathbf{8}}$ Es klingt, als fürchtete man selbst dadurch ärmer zu werden, daß man mit den Schätzen der eignen Erkenntnis den Andern reich macht: „Dieses Brahman soll der Vater dem ältesten Sohn kund tun oder einem vertrauten Schüler: keinem andern, wer er auch sei. Und gäbe man ihm diese wasserumschlossene Erde voll Reichtum: jenes ist mehr als dies; das soll er bedenken." Welcher Weg von hier bis dahin, wo Buddha sprach: „Aufgetan ist das Tor der Unsterblichkeit denen, die Ohren haben." Aber wen wollte es verwundern, daß da, wo sich solche neue Weiten auftaten wie in den Upanishaden, auch ein Rest von Engheit zurückblieb, dessen Überwindung der Zukunft anheimfiel? -

Auf dies dem Sinnen und der Versenkung geweihte Asketenleben folgt das Sterben dessen, der die Unsterblichkeit erreicht hat.

Hier wie überall in den Upanishaden haben selbstverständlich unter den Ideen, die der eignen Gedankenrichtung dieser Zeit angehörten, auch unklare Beimischungen altgewohnter Vorstellungen sich erhalten. Wir sahen schon (S. 103), wie das Brahman, in das der Erlöste eingeht, die Leistung vollbrachte, indem es das Brahman blieb, doch zugleich die Gestalt eines persönlichen Gottes anzunehmen, zu dessen Herrlichkeit jener hingelangt: welcher Gott freilich nicht mehr Yama oder Varuna hieß, sondern eben Brahman. Auf dem Weg zu ihm kommen der wandernden Seele fünfhundert himmlische Nymphen entgegen: hundert bringen Früchte, hundert bringen Augensalbe, hundert Kränze, hundert Gewänder, hundert wohlriechendes Pulver. So geht es zu Brahmans Stadt und Palast. Da sitzt er auf seinem Thron, und es entspinnt sich zwischen ihm und der Seele ein Gespräch, in dem sich diese natülich, durch die Upanishad ausgeruistet, als vollendet sattelfest in allen Ge- 
heimnissen erweist $\left.{ }^{1}\right)$. Eine andere Stelle ${ }^{87}$ malt die Freiheit, die dem Wissenden im Jenseits gehört, dahin aus, daß ihm nach seinem Belieben nicht nur „die Welt der Väter" oder „der Mütter" zuteil wird, sondern auch „die Welt der Wohlgerüche und Kränze“, „des Essens und Trinkens“, „,des Gesanges und Saitenspiels", „der Weiber": so konnte es auf der Jenseitshöhe auch recht irdisch aussehen.

Von diesen hybriden Vorstellungen wenden wir uns zur reinen, folgerichtigen Upanishadenlehre. Die liegt an jener teilweise schon angeführten Stelle der Yãjnavalkyarede vom Schlaf und Tod vor (vgl. S. 134). „Nun der Nichtbegehrende. Wer ohne Begehren ist ... nach dem Ātman begehrend: dessen Atemkräfte ziehen nicht aus $\left.{ }^{2}\right)$. Brahman ist er und zum Brahman geht er hin ... Wie eine Schlangenhaut tot, abgeworfen auf einem Ameisenhaufen liegt, so liegt dieser Körper da. Aber dieser unkörperliche, unsterbliche Odem ist nur Brahman, nur Licht $\left.{ }^{3}\right)$."

Es scheint, daß trotz des Ausdrucks ,zum Brahman geht er hin" nicht an einen Weg in höchste Fernen gedacht ist, sondern eher an ein eben hier sich vollziehendes Aufgehen im allgegenwärtigen absoluten Sein. So sagt auch ein an derselben Stelle angeführter Vers:

„Der Sterbliche wird unsterblich, hier gelangt er zum Brahman hin."

Wie ja gleichfalls im Zustand des Tiefschlafs (s. oben S. $140 \mathrm{f}$.), dem vorübergehenden Abbild der Vereinigung mit dem Brahman, das Selbst sich nicht nach außen entfernt, sondern ins Innerste seiner körperlichen Behausung sich zurückzieht. In der Tat scheint es, daß das ,hier" des eben mitgeteilten Verses genau zu nehmen und in diesem Sinn

1) Einzelheiten der Stelle (aus der Kaushītaki Upanishad) wurden schon oben a. a. 0 . berührt.

$\left.{ }^{2}\right)$ "Hier eben ziehen sie sich zusammen", fügt eine andre Fassung des Textes hinzu.

3) "Aber dieses gebeinlose, unkörperliche, erkenntnishafte Selbst (atman) ist nur Brahman, nur Welt", heibt es in der zweiten Fassung. 
zu verstehen ist. Dann würde die Freiheit und Reife in der Behandlung der Raumanschauung, die das eigne, welterhabene Reich des Brahman auch ohne äußerliche Erhebung in höchste Höhe als hier und überall gegenwärtig vorzustellen weiß, schon bis auf diese Stelle zurückreichen. Freilich würde in bezug hierauf, wie so oft in den Upanishaden, die Anschauung schwanken. Auf die oben wiedergegebenen Prosasätze (,ist nur Brahman, nur Licht") folgen alsbald recht upanishadenhaft nach dem Großen kleinliche Phantasterei - Verse über den Weg, auf dem sich das Weiße und das Dunkelblaue befindet, das Braune, Grüne, Rote. Das sind die Adern voll bunter Flüssigkeit, die vom Herzen ausgehen, in die Sonnenstrahlen verlaufen, und so zusammen mit diesen Herz und Sonne verbinden, „wie eine große Straße sich erstreckt und nach beiden Dörfern verläuft, nach diesem und nach jenem." ${ }^{88}$ Das, wird in der Yājñavalkyarede gesagt, ist der Weg,

„Auf dem die Weisen gehn, die Brahmankenner

Von hier empor zum Himmel, die Erlösten" -

deutlichermaßen dieselbe Auffassung, die in den Upanishaden oft auftritt, und über welche diese ältere Zeit schwerlich anders als höchstens in einzelnen Momenten hinausgekommen ist: aus dem vom Brahman durchwalteten Dasein hienieden geht der „Götterweg“ des Erlösten aufwärts über die Sonne ${ }^{1}$ ) - diese Weltpforte, „Eingang für die Wissenden, Verschlossenheit für die Nichtwissenden" - zu einer in aller räumlichen Konkretheit $\mathrm{zu}$ verstehenden Höhe, wo das Brahman in seinem Beisichsein weilt. Wenn es dann anderwärts von den Erlösten heißt: „In jenen Brahmanwelten bewohnen sie die höchsten Fernen; für sie gibt es keine Wiederkehr", so scheint das auf ein Erhaltenbleiben individuellen Daseins auch in jenen Höhen zu deuten. Die reinste, vollkommenste Gestalt der Upanishadenlehre aber ist das

1) Hier kann an die oben (S. 99 Anm. 2) berührte Vorstellung erinnert werden, nach der das Brahman in der Sonne selbst wohnt.

oldenberg: Upanishaden. 
selbstverständlich nicht. Yājnavalkya sagt zu Maitreyĩ: „Kein Bewußtsein gibt es nach dem Tode." Der Ätman, aus der Körperlichkeit zu sich selbst, in sein eignes Reich zuruckkehrend, geht in jene absolute Einheit, jene bewußtlose Seligkeit ein, deren Vorspiel auf Erden der tiefste Schlaf ist. ${ }^{88}$

Haben alle, denen dies Bild der Unsterblichkeit vor Augen gestellt wurde, daran volles Genüge gefunden?

Die Erzählung von Indra's Schülerschaft bei Prajāpati ${ }^{90}$ kann Zweifel daran erwecken.

Prajāpati beschreibt dem Gott die höchste Seligkeit eben in jener Gestalt des traumlosen Schlafs: „,Wenn man im Schlaf mit seinem ganzen Dasein zur Ruhe gekommen ist und keinen Traum schaut: das ist der Ātman' - so sprach er - ,das ist die Unsterblichkeit, die Freiheit von Furcht, das ist das Brahman'. Er aber (Indra) ging zufriedenen Herzens von dannen. Doch ehe er noch bei den Göttern angelangt war, kam ihm dieser Gedanke und flößte ihm Furcht ein: ,Auf die Weise kennt einer doch gar nicht mehr sich selbst, daß er das ist, und kennt auch nicht die andern Wesen. Er ist hin und verschwunden. Darin kann ich kein Glück sehen'. So kehrt Indra zu Prajāpati zurück und klagt ihm seinen Zweifel. Der antwortet: "Allerdings steht es so mit ihm (dem Ātman), o Maghavan ${ }^{1}$ ). Aber ich will ihn dir noch weiter erklären. Anderswo als in ihm (liegt die Lösung) nicht. Verweile weitere fünf Jahre (als Schüler)."

Und was sagt nun nach Ablauf dieser Jahre der göttliche Lehrer, das Bedenken seines Hörers zu beschwichtigen? Der Text läßt uns hier unbefriedigt. Man hat den Eindruck, daß der Verfasser, der bis dahin den Faden gluicklich festzuhalten wußte, jetzt kurz vor dem Ende zusammenbricht. Statt vom traumlosen Schlaf zu etwas letztem, erhabenstem aufzusteigen, steigt er, scheint es, $z u$ einer

1) „Gabenspender" - Beiname Indra's. 
niederen Stufe herab. Zwar spricht er zuerst von körperlosem Eingehen in das höchste Licht. Aber dann beschreibt er dies wiederum als einen Zustand, in dem „der höchste Geist" lacht und spielt und sich an Weibern erfreut und an den Leib, den er verlassen hat, nicht zurückdenkt. Soll man dies auf eine von Halluzinationen erfüllte Ekstase deuten ${ }^{1}$ )? In jedem Fall ist die Stelle vor allem für die Verwirrung bezeichnend, die so oft in den Upanishaden herrscht; für unser Wissen davon, wie man sich mit den nachdenklichen Betrachtungen Indra's abgefunden hat, ist sie wertlos.

Daß man in der Tat schließlich doch der Unbefriedigtheit jener Betrachtungen die Herrschaft nicht eingeräumt hat, zeigt die Geschichte. Von den alten Upanishaden an durch lange Zukunft hat das brahmanische Denken - und wir werden sehen, daß dasselbe im Grunde auch vom buddhistischen gilt - als höchstes Ziel das selige Aufgehen im Unendlichen festgehalten. Das sei hier zum Schluß noch einmal mit den Worten einer Upanishad ${ }^{91}$ ausgesprochen:

„Wie Ströme, von Gestalt und Namen lassend, Im Ozean eingehn zu ihrer Ruhe, So geht der Weise, von Gestalt und Namen Erlöst, zum göttlich überhöchsten Geist hin."

1) Nicht auf gewöhnliche Träume. Von denen war in einem vorangehenden Abschnitt die Rede. 


\section{Die literarische Form der Upanishaden.}

Neben der Lehre der Upanishaden zieht auch die Darstellung unsre Aufmerksamkeit auf sich. Ein eigenartiges Gemisch von Kunstlosigkeit und Kunst, hilflosem Gestammel und Inspiration des Genius.

Es gab von vornherein eine Anzahl verschiedener Upanishaden: nicht etwa nur verschiedene Redaktionen einer Upanishad. Das lag in den Existenzbedingungen der vedischen Literatur. In diesem schriftlosen Zeitalter konnte ja kein Text bestehen ohne eine Schule, die ihn von Generation zu Generation mündlich überlieferte. Die Anlehnung aber der Upanishadenspekulation an die Gedankengänge der Brāhmanatexte, aus denen jene hervorging und an die sie sich von ihnen losstrebend doch immer noch mit tausend Fäden knüpfte, machte es selbstverständlich, daß die Organisation eben der Brāhmanaschulen auch die Überlieferung der Upanishaden übernehmen mußte. So fügten sich diese vermöge ihrer Vorgeschichte von Anfang an in die Trennung der drei Veden und ihrer einzelnen großen Schulen ein, was sich dann allerdings immer entschiedener als ihren eignen Daseinstendenzen widerstrebend erwies. Sie bildeten Anhänge an die Brāhmaṇas oder geradezu Teile der Brāhmanas: speziell der Brāhmaṇapartien, die wegen ihrer hohen Heiligkeit oder zauberhaften Gefährlichkeit nicht im Dorf, sondern draußen in der Wildnis vorgetragen und den Āranyakas oder "Waldtexten" zugerechnet wurden ${ }^{* 2}$. Den Wald also oder das öde Land außerhalb des Dorfs haben wir uns als die Szenerie dieses Überlieferungsbetriebes vorzustellen. Dort wurden Auserwählten der Schüler, die im 
Dorf Ordnungen und versteckte Bedeutung von Feuer- und Somaopfer gelernt hatten, nach vorangehendem Fasten und Schweigen neben Geheimnissen wie denen eines besonders mächtigen Regenzaubers und Sonnenzaubers auch die Lehren vom All-Einen und von der Erlösung mitgeteilt: Mysterien, deren gegenseitige Distanz offenbar noch nicht allgemein gefühlt wurde. Und wenn immerhin solche Zauberkunde höheren Stils mit den Offenbarungen vom Ätman ein gewisses Umgebensein vom Schauer des Übergroßen gemein haben mochte, so ist weiter auch gegen niedrigen und allerniedrigsten Zauber eine Grenze nicht gezogen worden. In den Upanishaden selbst werden Rezepte von allerlei Künsten mitgeteilt, deren Anspruch auf Zulassung in so vornehme Umgebung offenbar allein auf ihrer geheimen Natur beruhte. Da handelte es sich um den Rührtrank, durch den man "Größe" erlangt, um Liebeszauber, um Zauber gegen den Buhlen der Frau oder für die Geburt eines Sohnes. Es ist nicht viel derartiges, was in die Upanishaden Eingang gefunden hat. Aber daß solche Abschnitte uiberhaupt in ihnen vorkommen, daß die Umgrenzung des Inhalts eine so unvichere ist, gehört zu ihrem Bilde.

Mit den Namen bestimmter Verfasser wissen wir die Entstehung der Upanishaden nicht zu verknüpfen. Die Schulhäupter, auf die man die verschiedenen Zweige der Vedakunde zurückfuhrte, konnten natürlich als Urheber der den betreffenden Schulen zugehörigen Upanishaden sogut wie der Brāhmanas angesehen werden. Doch das war selbstverständlich eine Fiktion. Die Namen ferner der teilweise mit jenen Schulhäuptern identischen Denker, die in den Dialogen der Upanishaden selbst als Lehrer von den letzten Geheimnissen auftreten, verdienen schwerlich mehr Glauben. Es sind im Ganzen eben die Namen, die auch in den Diskussionen der Brāhmanatexte über das Opfer eine Rolle spielen. Daß die unbefangen gläubige Tradition diese Männer darum auch die Lehre vom Brahman verkünden läßt, ist begreiflich; daß sie das wirklich getan haben, kann bei der 
andern Geistesrichtung, die in dieser Lehre herrscht, und bei deren allem Anschein nach im Ganzen wesentlich jüngerer Entstehung kaum möglich scheinen.

Noch ist hier zu erwähnen, daß sich für mehrere vedische Texte, darunter auch für die größte der Upanishaden bez. ihre einzelnen Hauptbestandteile, lange Listen erhalten haben, in denen die Kunde des betreffenden Textes von der Gegenwart der Redaktoren aufwärts Lehrer für Lehrer zurückverfolgt wird ${ }^{93}$. In solchen Listen läßt sich bisweilen das Aufsteigen zunächst zu den Gegenden der vorher erwähnten Schulhäupter und sonstigen Autoritäten der Brāhmanatexte verfolgen; dann weiter zu den sagenhaften Verfassern der vedischen Hymnen und Ahnherrn der großen Brahmanengeschlechter; schließlich durch immer erhabenere Urwesen etwa zum Sonnengott oder dem durch sich selbst seienden Brahman. Daß die unteren Teile dieser Reihen Wahrheit enthalten, ist durchaus glaublich. In einem oder zwei Fällen scheint sich überzeugend der Punkt zu markieren, an dem mehrere zuerst nebeneinander herlaufende Überlieferungsströme im selben Bett zusammengeflossen sind. Und auch dies ist sehr wohl denkbar, daß die authentischen Namen von Verfassern größerer oder kleinerer Upanishadstücke inmitten dieser Namenreihen Platz gefunden haben. Aber herauserkennen können wir sie nicht. Könnten wir es, würden solche nackte Namen uns auch schließlich wenig sagen. Und so müssen wir uns mit der freilich farblosen Vorstellung begnuigen, daß hier und dort im Schoß der vedischen Schulen, in der Bewegung der langsam weiterfließenden Gedankenmassen diese Texte - meist, wie wir sogleich sehen werden, in ziemlich kleinen Stücken - von verschiedenen Autoren verfaßt worden sind, deren Persönlichkeit im Dunkel bleibt. Literarisches Eigentumsrecht, Autoreneitelkeit war jenen Kreisen ja fremd. Sie meinten nur eine von andern empfangene ewige Erkenntnis weiter zu geben: ährlich wie in der Folgezeit der buddhistische Mönch, welcher Lehrreden oder Poesien verfaßte, das Bewußt- 
sein hatte, nur das auszusprechen, was Buddha und unzählbare Buddhas vergangener Ewigkeiten ausgesprochen hatten. Bald ließen sich in den Upanishaden flache, wirre Schwätzer und Pedanten hören, bald auch - der seltenere Fall Denker, denen es gegeben war, für mächtige Gedanken und Ahnungen das von der Bewegung ihres Innern durchwogte tiefe Wort zu finden. Selbstverständlich haben hier so wenig wie früher bei der Sammlung der Vedahymnen oder später bei der Redaktion der buddhistischen heiligen Texte sichtende Hände kritischer Beurteiler Weizen und Spreu gesondert. Dem Betrachter liegt es ob, nicht für den Weizen allein, auch nicht für die Spreu allein ein Auge zu haben, sondern den Vorgang, der beides mit einander vermischt hat, zu verstehen, so weit hier eben geschichtliches Verstehen erreichbar ist.

Auf die verschiedenen Veden und Vedaschulen verteilt sich der Bestand der Upanishaden recht ungleich. Am meisten tritt der weiße Yajurveda hervor, ebenso nach dem Umfang wie nach der inneren Bedeutung, zum großen Teil wohl auch nach dem Alter seiner Upanishad (Bṛhad Āranyaka Upanishad). Ihm zunächst steht der Sāmaveda (Chāndogya Upanishad). Nicht selten hat Beeinflussung der Schulen durcheinander stattgefunden, Austausch bedeutender und wirkungsvoller Stücke. So ist gelegentlich, was nach den hier immer noch oft durchscheinenden Gesichtspunkten der Priester- und Opfertechnik dem einen Veda zugehören sollte und offenbar ursprünglich in der Tat ihm zugehört hat, nachträglich entsprechend dem Vorwalten eines von jenen Gesichtspunkten unabhängigen Interesses in einen andern Veda hineingeraten ${ }^{94}$ : bezeichnend für den Punkt, an dem hier die Entwicklung steht, dem Opfer- und liturgischen Wesen noch nah und zugleich doch von ihm sich loslösend oder losgelöst.

Es wurde schon erwähnt, daß sich die Upanishaden aus einzelnen kürzeren oder längeren - meist nicht sehr langen - Textstücken zusammensetzen. Die stehen, größten- 
teils vollkommen ungeordnet, selbständig neben einander. Zusammen bilden sie die Upanishad. Oder es sind zuerst kleinere Sammlungen, ursprünglichere Upanishaden, aus ihnen hergestellt und die dann zum Ganzen der uns vorliegenden Upanishad vereinigt worden. Selbst in der Sphäre einer unvergleichlich höheren Gedankenkunst und literarischen Technik dachten ja Xenophon und Platon nicht daran, ein nach einheitlichem Plan aufgebautes System sokratischer oder platonischer Philosophie vorzutragen, sondern sie brachten in kurzeren Einzeldarstellungen die sokratische, platonische wissenschaftliche Denkweise jetzt in der Anwendung auf dieses, jetzt auf jenes Problem zur Anschauung. Ähnlich ist es hier geschehen; im ganzen ähnlich auch noch Jahrhunderte später in der schriftstellerischen Produktion der alten Buddhisten. Zwar schon in der Brāhmanazeit hatte der festgeordnete Verlauf des einzelnen Opfers, die von selbst sich fügende Gruppierung der verschiedenen Opfer, um deren Beschreibung und Deutung es sich damals handelte, zur Entstehung großer, in gewissem Sinn förmliche Systeme bildender literarischer Komplexe geführt. Aber die Gedankenmassen, die man in den Upanishaden vorzutragen hatte, stellten sich nicht mit solcher Selbstverständlichkeit wie die Bestandteile jener Opferkunde in Reih und Glied. So wurde - wie es übrigens auch in den Brāhmanatexten neben den großen systematischen Ausführungen geschehen war - ein Problem nach dem andern, oder dasselbe Problem immer wieder auf Grund der hier herrschenden, vergleichsweise feststehenden Fundamentalanschauungen besprochen, oder auch bald diese bald jene zerstreuten Einfälle, Gedanken- und Wortspiele wurden vorgetragen. Auf das eine hinblickend hatte man noch nicht gelernt das andre nicht unterdessen aus dem Gesicht $z u$ verlieren und vollends den Zusammenhang des einen mit dem andern sich klar zu machen oder gar ein Ganzes anzuschauen, das jenes alles als seine Teile in sich faßte. Im Großen hielten wohl in der Tat die einigermaßen gleich bleibenden Grund- 
tendenzen des Denkens das einzelne so weit zusammen, daß wir unsrerseits ein leidlich in sich ubereinstimmendes Gesamtbild der hier herrschenden Weltanschauung zusammenfügen können und müssen. Aber als ein solches Ganzes und in der Geordnetheit, die wir diesem Bilde unvermeidlich mitteilen, ist es natürlich im Geiste keines jener Alten je tatsächlich vorhanden gewesen: welchem Satz freilich wohl als seine Kehrseite der andre an die Seite zu stellen sein wird, daß auch die Zerfahrenheit, das Hin und Her der Upanishadtexte doch den wahren geistigen Besitz ihrer Verfasser nicht vollkommen widerspiegelt: neben dem Ausgesprochenen wird ja beständig Unausgesprochenes dagewesen sein, mit jenem zusammen, wenn auch gewiß unklar genug, immerhin in der Richtung auf ein Ganzes weisend. In allem Einzelnen nun erscheinen natürlich fortwährend Widersprüche über Widersprüche. Wie sollte es anders sein? Neben einander oder sich gegenüber standen die verschiedenen Schulen und innerhalb jeder Schule die einzelnen Denker oder auch Gedankenlosen: selbst bei diesen esoterischen Spekulationen Mitarbeiter in solchen Massen, wie sie im literarischen Betrieb Indiens nun einmal überall und unvermeidlich auftreten. Und unter diesen Massen wurde jeder einzelne fortwährend von verschiedenen Motiven, wechselnden Launen hin und her bewegt. Jetzt trieb ihn die Konsequenz des Gedankens vorwärts; jetzt zogen ihn Erinnerungen an Altes, Veraltetes zurück. Da konnte sich der Gesamtlauf der Gedankenarbeit unmöglich so zu sagen als eindimensionale Linie darstellen. Er mußte vielmehr einem bald breiten, bald sich verengenden, windungsreichen, nach rechts und links sich verästelnden, Seen bildenden Strom gleichen, der langsam und über mannigfache Hemmungen hinüber fließt: vorwärts seinem Ziele zu strömt er schließlich doch.

Ein Fortschreiten über die erwähnte Form kurzer für sich stehender Einzelstücke ist in den Upanishaden wenigstens in den Anfängen sichtbar. Von solchem Fortschritt 
wird bei der Beschreibung der Dialoge, die hier eine so bedeutende Rolle spielen, bald eingehender die Rede sein. Auf ein Beispiel - das hervortretendste, das die älteren Upanishaden bieten - des planmäßigen Zusammenschlusses kleinerer Einheiten zu einem bedeutenden Ganzen sei doch schon jetzt hingewiesen: auf die glänzenden Reden des Yājnavalkya, die in schrittweiser Annäherung den Hörer zum Verständnis des höchsten Zieles, des Aufgehens im ewigen Ātman, hinführen ${ }^{95}$. Vom alltäglichen Zustand das wachen Daseins hebt die Reihe der Bilder an, die Yājnavalkya zeichnet. Schon in dies Dasein hinein scheint das höchste Licht: das Licht des Selbst (Ātman), das dem Menschen leuchtet, auch wenn Sonne und Mond untergegangen, das Feuer erloschen, jedes Wort verstummt ist. Und nun verfolgt Yājnavalkya's Rede von Stufe zu Stufe das fortschreitende Sichbefreien des Selbst von den Hemmungen, denen es in jenem Dasein unterliegt. Schritt für Schritt treibt der Hörer den Redenden weiter, indem er immer von neuem das Verlangen erhebt, nicht Halt zu machen vor dem Ende, vor der Erlösung. Nach dem Wachen folgt der Schlaf, wo das Selbst träumend sich seine eigne Welt schafft. Nach dem traumerfüllten Schlaf der traumlose - wie angelegentlich und fein beschäftigt man sich hier mit dem Schlaf, legt ihn in zwei Typen von vollkommen verschiedener Natur auseinander! Dann wendet sich die Rede dem Tode zu. Aber der Tod des Unerlösten ist noch nicht die Befreiung; er ist Übergang der wandernden Seele in neues Dasein. So folgt endlich das Letzte, Höchste, der Tod des Wunschlosen, Erlösten: „Brahman ist er; zum Brahman geht er hin." Und hier zu ihrem Ziel gelangt nimmt die Rede poetische Gestalt an; sie wird zu einem Hymnus auf die Herrlichkeit des ewigen Einen. Wer mit der buddhistischen Literatur vertraut ist, mag sich durch diesen Upanishadenabschnitt wohl an jene Predigt Buddhas erinnern lassen, die in ähnlicher Stufenfolge - dem Fortschritt der literarischen und philosophischen Entwicklung 
entsprechend in noch größer angelegtem, kunstvollerem Aufbau - die Segnungen darstellt, die das Erlösungsstreben des Asketen belohnen ${ }^{96}$. Von den Ehrungen und Bevorzugungen, deren er sich im täglichen Leben erfreut, schreitet die Rede fort zu immer höherem innerem Gewinn, bis endlich nach dem Hindurchgehen durch alle Stufen der Ekstasen und Erleuchtungen die höchste Erkenntnis, die volle Befreiung aufstrahlt: "vernichtet ist die Wiedergeburt, vollendet der heilige Wandel, getan das Werk; keine Rückkehr gibt es mehr zum Diesseits". Es ist bezeichnend, wie in der Upanishad und in dieser buddhistischen Predigt die Gleichartigkeit des Ideals gleichen Aufbau der Rede herbeiführt. In der Upanishad der zukunftsreiche Anfang, im buddhistischen Sütra ein Höhepunkt derselben großen Bewegung des Denkens, derselben Form der Verkündigung.

Von besonderen, eigenartig ausgeprägten Typen der philosophierenden Darstellung innerhalb der Upanishaden sind zuvörderst jene Upanishaden im engeren Sinne des Worts hervorzuheben, die der ganzen Textgruppe den Namen gegeben haben ${ }^{97}$. Schon in anderm Zusamenhang (oben S. 37) berührten wir diese Erörterungen darüber, unter welcher Benennung man die "Verehrung" (upanishad) eines besonders hohen Verehrungsobjekts, dessen ehrfurchtsvolles Fixieren durch den Gedanken, vollziehen soll. Die Entwicklung dieser "Verehrungs"texte läßt sich, wie es scheint, ziemlich deutlich verfolgen. Ihre Anfänge haben es noch nicht mit dem all-einen Wesen zu tun. Sie reichen in ein früheres Stadium zurück, wurzeln noch in der Ritualtheologie. Da gibt es schon "Upanishaden", denen besondere Ehren zuerkannt werden, mit denen sich zu beschäftigen man nicht müde wird: „in dieser Upanishad“, heißt es einmal - d. h. im Überdenken dieser Upanishad - „hütete Tārukshya ein Jahr lang die Kühe". Von solchen "geheimen Anweisungen", nämlich über besondere Formulierungen der Verehrung, wird gesagt, daß sie „der Lebenssaft des Lebenssaftes" sind: „denn die Veden sind Lebenssaft; deren 
Lebenssaft sind jene. Sie sind das Ambrosia des Ambrosia. Denn die Veden sind ambrosisch; deren Ambrosia sind sie". Ich wähle zur Veranschaulichung eine solche noch auf dem älteren, ritualistischen Standpunkt stehende Erörterung gleich im Eingang der großen Chāndogya Upanishad. „Om - als diese Silbe soll man den Udgitha verehren ${ }^{98}$, denn mit dem Om (anfangend) singt man ihn", lauten die ersten Worte. Der Udgitha ist der Hauptteil, der Höhepunkt des Sāman, des liturgischen Liedes. Den leitet die heilige Silbe Om ("Amen") ein; sie sammelt so zu sagen seine Kraft in sich. So weist diese Form und Formel des "Verehrens" den Sänger auf den konzentriertesten Gehalt seines liturgischen Tuns hin. Und damit zugleich, wie das der indischpriesterlichen Denkweise entspricht, auf Weiteres, Allgemeineres. An die eben mitgeteilten Eingangsworte der Upanishad schließen sich die Sätze: „Die Erläuterung davon ist die folgende. Dieser Wesen Lebenssaft ist die Erde. Der Erde Lebenssaft die Wasser. Der Wasser Lebenssaft die Pflanzen. Der Pflanzen Lebenssaft der Mensch ${ }^{1}$ ). Des Menschen Lebenssaft die Rede. Der Rede Lebenssaft die Ric (Vers des Rigveda). Der Ric Lebenssaft das Sāman (liturgisches Lied). Des Sāman Lebenssaft der Udgitha. Dies ist von den Lebenssäften der saftkräftigste, höchste, oberste $^{2}$ ), achte, was der Udgitha ist." Jene "Verehrung" bedeutet also, daß der Gehalt des Seienden in einem letzten Lebenssaft aller Lebenssäfte gesammelt ist, dessen Wirkungs-

1) Denn die dem Wasser innewohnende Kraft setzt sich in die Pflanzen um, die erwachsen, wo es Wasser gibt. Die kräftigsten Bestandteile der Pflanzen verwandeln sich als Nahrung in den menschlichen Körper.

2) Deussen ubersetzt „transscendent". Ebenso - doch das Wort des Originals ist dort ein andres - Bṛhad Āraṇyaka Up. III, 4, 1 ,das immanente, nicht transscendente Brahman"; in Wahrheit steht wörtlich da: „was vor Augen, dem Auge nicht verborgen das Brahman ist." Man sollte sich versagen, in den schlichten alten Text durch willkürliche Einführung von Schlagworten der modernen Philosophie fremde Gedankengänge hineinspielen zu lassen. 
kraft der Wissende sich durch sein Wissen und Verehren aneignet. "Was man mit Wissen tut, mit Glauben, mit der Upanishad $^{1}$ " - schließt der in Rede stehende Abschnitt — „das ist kräftiger. Dies ist die Erklärung eben jener Silbe (des Om)."

Im selben Text folgen dann noch sehr viel weiter ausgesponnene Erörterungen über die ,Verehrung“. Erläuterungen werden gegeben, die bald "in bezug auf das Selbst", bald „in bezug auf die Gottheit" (vgl. oben S. 24) die Verehrungsform deuten. Dort ist es Hauch, Auge, Rede, kurz der ganze Kreis der auf die Persönlichkeit bezüglichen Kräfte und Funktionen, mit dem es diese Formeln und Erklärungen zu tun haben; hier sind es die kosmischen "Gottheiten" wie Erde, Luft, Himmel, Sonne, Mond. Geschichten, diese „Verehrungen" betreffend werden erzählt. Die Götter haben den Udgitha verehrt, und je nachdem sie das falsch oder richtig machten, sind sie im Kampf gegen die bösen Dämonen unterlegen oder haben sie gesiegt. Brahmanen unterreden sich über den Udgītha, über seine Zusammenhänge mit dem Weltganzen, und dem „der ihn (den Udgitha) also wissend verehrt", wird für diese und jene Welt hohes Heil verheißen. Fortwährend, in der Form ganzer Tabellen, wiederholt sich die Vorschrift: „man soll das und das so und so verehren“; dazu Verheißungen bald für den, der also wissend verehrt, bald auch kurzweg - gemeint ist offenbar dasselbe - für den, der das und das weiß. Zu diesen Vorschriften über Verehrung oder das ihm wesensgleiche Wissen gehören dann Observanzen: wer die und die Auffassungsform des liturgischen Mysteriums wählt, muß - wie es scheint, einem aus primitiver Vorkultur stammenden Schema entsprechend - in seinem Tun und noch häufiger in seinem Lassen irgend eine Besonderheit, ein Tabu beobachten, worin sich seine Ergebenheit gegen die verehrte Wesenheit kundgibt. Wer

1) Deutlich greift hier Upanishad ("Verehrung“) auf das im Eingang stehende upāsita ( man soll verehren") zurück. 
seine Meditation auf das Sāman als in das Feuer verwoben, oder als in die Begattung verwoben, oder als in die Körperteile verwoben richtet, darf dem entsprechend nicht gegen das Feuer hin den Mund spülen oder ausspeien, darf sich keinem Weibe entziehen, darf ein Jahr lang kein Mark essen oder überhaupt kein Mark essen.

Man sieht, wie da recht buntscheckige Darlegungen sich doch zu einer gewissen Einheit zusammenschließen. Anweisungen über Ausdruck und Symbolik, die für die Verehrung maßgebend sein sollen, spekulativ-phantastische Erklärungen dazu, endlich mancherlei Diskussionen, Geschichten, Verheißungen, Verhaltungsmaßregeln: alles findet seinen Mittelpunkt, sein Leitmotiv in der immer wiederkehrenden Vorstellung der Verehrung.

Eben hier, bezeichnet durch dies Schlagwort "Verehrung“ (Upanishad), liegt der Punkt oder ein wichtigster der Punkte, wo sich an die Literatur der alten rituell-liturgischen Symbolik die neu entstehende der Ātmanspekulation angesetzt hat ${ }^{99}$. Die gab ja von den Bahnen, auf denen der Kultus sich bewegte, die einst meistbetretene, die des Opfers, auf, um die der Verehrung zu beschreiten: der Verehrung, welche der letzten Essenz alles Seins gewidmet ist.

Beständig nimmt in dieser Literatur die zentrale Frage - was das all-eine Wesen ist und wie das Denken ihm nah kommt - die Gestalt eines Forschens nach der Verehrungsform jenes Wesens an. Wie wir es eben von der Verehrung des Udgitha sahen, so wird jetzt die des Brahman gesucht. „Für den wahrlich", heißt es, "geht die Sonne nicht auf noch unter, immerdar ist für ihn Tag, der also diese Upanishad (.Verehrung") des Brahman kennt"100. Ein Kreis schriftgelehrter Brahmanen wirft die Frage auf: "Was ist der Âtman? was das Brahman?" Sie gehen zu einem Kenner: der studiert den Ätman; er soll ihn ihnen erklären. Dieser Wissende nun fragt sie, einen nach dem andern: In welcher Gestalt verehrst du (upāsse) den Ātman? Sie antworten: als den Himmel - als die Sonne - als den 
Wind, und Ähnliches. Worauf er sie anweist, wie man in Wahrheit den Âtman verehrt (upāste). Wer ihn allein als Atem, als Rede, Auge, Ohr, Geist verehrt, wird an einer andern Stelle gesagt, „der versteht es nicht. Denn zerteilt ist er durch all dies Einzelne. Als den Ātman allein soll man ihn verehren, denn darin werden alle jene (Wesenheiten) eins ... Wer einen andern Gott verehrt und denkt: ,Ein andrer ist er, ein andrer bin ich', der versteht es nicht" (vgl. oben S. 138). Weiter in anderm Zusammenhang wird erzählt, wie König Janaka dem weisen Yājnavalkya die Erklärungen berichtet, die früher von ihm befragte Lehrer ihm über das Brahman gegeben haben: das Brahman sei die Rede; es sei das Leben, und Ähnliches. In jeder dieser Erklärungen ist ein Stüick Wahrheit enthalten : den verläßt die Rede nicht, den verläßt das Leben nicht, "wer also wissend dies verehrt (upāste)". „So hast du denn, großer König“, fährt nun Yājnavalkya fort, "wie man um eine weite Reise zu tun sich einen Wagen oder ein Schiff verschafft, also deine Seele mit diesen Verehrungen (upanishad) ausgerüstet" - worauf der Weise seinerseits das Letzte, Höchste, was jenem zur Erkenntnis des Ātman noch fehlt, ihm überliefert.

Man sieht — und weiter ausgedehnteZusammenstellungen, als ich sie hier vorlegen mag, würden immer wieder dasselbe ergeben -, wie die Upanishadtexte ganz und gar durchzogen sind von Erörterungen über das rechte Schlagwort für die Verehrung des höchsten Wesens, von Ablehnungen oder bedingter Anerkennung verfehlter oder unvollkommener Ausdrücke, von Darstellungen schrittweisen Sichannäherns an die rechte Fassung. Die Verehrung jenes Wesens kennen wird dem gleichgesetzt seinen Namen zu kennen. "Seine Upanishad ist: das Wahre des Wahren", heißt es, und ganz ebenso: "Sein Name ist: das Wahre des Wahren" - der Name aber ist ja ein mystisches Äquivalent des Wesens selbst, das er benennt. So kommt es denn auch, wie schon berührt wurde, für die Texte auf 
ein und dasselbe heraus, das Absolute als das und das zu wissen, und es als das und das zu verehren ${ }^{101}$. Es handelt sich ja nicht um ein Wissen, das nur kaltes, ehrfurchtloses Begreifen wäre. Und auch nicht, kann man hinzusetzen, um ein Wissen von Begriffen, die durch Definitionen umschrieben in klarer, objektiver Bestimmtheit vor dem Geist des Wissenden ständen. Die Kunst des Definierens besitzt man nicht. Sie hätte auch kein leichtes Spiel gegenüber diesen Wesenheiten, die so gar nicht nur sind, was sie sind, sondern die über alle Begrenzungen im Zauberflug wegschweben. Da bieten sich denn Wendungen wie die Verehrungsformeln zur rechten Zeit dar, ihren schwimmenden Schein und den Schauer anbetender Versenkung durch die Seelen zu ergießen: „das Nein, Nein“, „das Wahre des Wahren“, oder Rätselworte von gewollter Dunkelheit: „als jalān verehre er es friedevoll“. Die Bedeutung, die solchen „Upanishaden" für das Ganze der nach ihnen benannten Texte zukommt, läßt sich danach wohl begreifen.

Besonders stark tritt weiter unter den Elementen, aus denen sich die Upanishaden aufbauen, der Dialog hervor. Ein indisches Gegenstück zum platonischen Dialog, in ähnlicher Distanz wie die Bharhutskulpturen von denen des Parthenon.

Kleine Gespräche zwischen Opferkundigen über rituelle Probleme sind schon in den Brāhmanatexten nicht selten. An die knüpft der Gebrauch der Dialogform in den Upanishaden an. Aber hier erscheinen die Dialoge viel häufiger, in bedeutenderem Umfang und mit entsprechend größerem innerem Gewicht.

Das ist wohl verständlich.

Die alte Opferweisheit hielt sich im ganzen inmitten eines Kreises gleichmäßig Wissender. Das höhere Wissen vom Brahman dagegen war der Besitz Einzelner, Erwählter. Die teilten es wiederum Einzelnen, Erwählten mit: ein Vorgang, dem der Charakter eines ausnahmsweise bedeutenden Ereignisses zukam. Keine große Hoffnung, jenes Wissen 
auf anderem Wege zu erlangen: so etwa mochte es dem Sokratesschüler undenkbar scheinen, außer durch die Berührung mit dem unvergleichlichen Meister zu höherem geistigem Leben erweckt zu werden. In einer Upanishad spricht der Schüler zum Lehrer ${ }^{102}$ : „Von Männern deinesgleichen, Erhabener, habe ich sagen hören, daß das vom Lehrer empfangene Wissen am besten zum Ziel führt." An einer anderen Stelle findet sich dafür das Gleichnis von dem mit verbundenen Augen in die Irre Geführten. Die Binde wird ihm abgenommen, und er läßt sich den Weg in die Heimat sagen: so weiß auch ,wer einen Lehrer gefunden", da $\beta$ er zum Erlösungsziel gelangen wird. Begreiflich also, daß sich die Vorstellung dieses Wissens von Anfang an mit dem konkreten Bilde erhabener Wissender und ihres Lehrens eng verknüpft hat.

Die äußere Umrahmung der Erzählungen von solchen Mitteilungen, die Schilderung der Personen, der zu Grunde liegenden Situation ist stets sehr einfach. Die Männer, die hier mit einander reden, sind selbstverständlich überwiegend Brahmanen. Aus deren Dasein liefern die Texte eine Reihe von Bildern. Knappe, unbeholfene Zeichnungen. Aber in ihnen weht die Luft, die jene Alten atmeten. Und uns treten bald ehrwürdig, bald bizarr, die Schattenbilder ihrer selbst entgegen, der brahmanischen Denker - derer, die sich in geheimnistuerischen Wortschwall hüllten, und auch jener, die das Mysterium des Brahman entdeckt, in seinem Anschauen den Frieden gefunden haben.

Bald trägt sich der Vorgang im Brahmanenhaus zu: im Dorf, denn von städtischem Leben ist noch kaum etwas vorhanden. In der Nähe denken wir uns die Opferstellen und die Weiden mit den großen Kuhherden, dem Glück und Stolz ihrer Besitzer.

Eine der einfachen Scenen, die sich da abspielen ${ }^{108}$. Mehrere geistliche Herren kommen zusammen, alle „reich an Gut und an Gelehrsamkeit". Sie forschen gemeinsam: "Was ist der Ātman? Was das Brahman?" Sie gehen

oldenberg: Upanishaden. 
miteinander zu einem vermeintlichen Sachkenner; der aber fühlt sich seines Wissens nicht sicher und schickt sie weiter zu einem Andern - merkwürdigerweise zu einem König, bei dem sie dann ihr Ziel erreichen. Auf diese Rolle, die bisweilen einem König zugeteilt ist, kommen wir später zurück.

Ein andres kleines Bild. Zwei Brahmanen speisen zusammen. Ein bettelnder Schüler tritt an sie heran. Man gibt ihm nichts. Er weiß ein sinnreiches Rätsel aufzugeben. „Reicht ihm zu essen", heißt es nun.

Ein Jüngling, ,Wahrlieb" mit Namen, meldet sich bei einem Lehrer, um als sein Schüler einzutreten. Der fragt ihn, aus welcher Familie er ist. Meine Mutter hat mir gesagt, sie ist in ihrer Jugend viel herumgekommen; wer mein Vater ist, weiß sie nicht. So ehrlich, entgegnet der Lehrer, spricht nur ein Brahmane. Hole das Brennholz; du sollst mein Schüler sein.

Der Sohn des Brahmanen kommt gelaufen. Jemand hat ihm Fragen gestellt, die er nicht beantworten kann. Weiß der Vater die Antwort? Nein - ,soweit solltest du mich kennen, mein Lieber! Alles, was ich selbst weiß, das habe ich dir auch gesagt." Und der Vater geht zu jenem Frager und meldet sich ihm als sein Schüler an.

Der Sohn, 24 Jahre alt, ist von der Lehrzeit zum Vaterhause zurückgekehrt, wissensstolz, aufgeblasen. Aber das kostbarste Wissen besitzt er nicht. Der Vater spricht ihm von dem Einen Seienden: Es ist der Vater und der Sohn, zwischen denen jenes Wort gefallen ist: Tat tvam asi, "Das bist Du, o Svetaketu".

Gatte und Gattin reden miteinander. Yājnavalkya, im Begriff als Einsiedler die Welt zu verlassen, will Teilung halten zwischen seinen beiden Frauen: Maitreȳi, „die die Rede vom Brahman kennt", und Kätyāyañ̄, „die nur weiß, was die Weiber wissen". Wir haben schon beschrieben (S. 118), wie Maitreyĩ, irdischen Besitz verschmähend, zu wissen verlangt, wie es mit der Unsterblichkeit im Jenseits steht. „Lieb bist du mir wahrlich und hast das Liebe 
noch gemehrt", spricht der Gatte. „Wohlan! Ich will ès dir jetzt erklären. Du aber bedenke wohl, was ich dir sage." Und so heben jene tiefsinnigen Reden des Yājnavalkya an. "Also sprach Yājñavalkya und zog seines Weges."

Oft hat der Wissende es mit einem reichen Weltmann, insonderheit mit dem König zu tun. Diesen kleinen heerdenreichen Despoten zeichnen die Upanishaden so, wie der brahmanische Philosoph ihn sich träumt: von unbegrenzter Geflissentlichkeit und Demut gegenüber den geistlichen Berühmtheiten und von ebenso unbeschränkter Gebelust. Daß in Wahrheit das Dasein der brahmanischen Herren von königlicher Gnade und Laune durchaus abhängig ist, bleibt trotz jener Idealisierungen doch fühlbar.

Da ist jener Notleider, der Brahmane Ushasti (oben S. 5), dem es gelungen ist, sich eine Portion Reisschleim zu erbetteln. Am nächsten Morgen steht er auf und sagt zu seiner Frau: „Hätte ich jetzt nur zu essen, wollte ich auch schon zu Besitz kommen." Zum Glück hat ihm die Frau vom vorigen Tage her etwas verwahrt: „Da ist ja noch Reisschleim, Mann!“ Er ißt und geht hin, wo der König eben ein Opfer darbringen läßt. Die Sänger, welche die Litanei anstimmen sollen, sitzen schon an ihrem Platz. Er setzt sich ohne weiteres zu ihnen und redet sie mehr deutlich als höflich an: Euer Kopf muß euch zerspringen, wenn ihr, ohne die und die geheime Kunde zu besitzen, singen werdet. "Da standen jene davon ab und saßen stumm da." Der König aber weiß den erhabenen Gast gebührend zu schätzen. Er stellt ihn alsbald bei seinem Opfer an. Wobei jener nicht versäumt, sich so viel Lohn auszubedingen, wie alle anderen Priester zusammen bekommen. Und nun, auf deren bescheidentliche Bitte, belehrt Ushasti sie über jenes Geheimnis, mit dem er ihnen vorher so kräftig aufgetrumpft hat.

Das seltsamste Bild vom Verkehr des Weisen und des Reichen gibt die Geschichte von Raikva: uns möchte als Zerrbild erscheinen, worin in Wahrheit ein echtes Stück altindischer Wirklichkeit enthalten ist. Die Gänse, die nachts vorüber- 
fliegen, haben den Ruhm Raikva's gesungen. Wer ist Raikva? Man sucht ihn vergebens. Endlich findet man ihn, ,wo man einen Brahmanen suchen muß" - er sitzt unter einem Karren und schabt sich den Aussatz. Nun zieht der reiche Jānaśruti zu ihm hinaus und bringt als Geschenk sechshundert Kühe, Goldschmuck, einen Wagen mit Maultieren : „Lehre mich, welche Gottheit du verehrst"wir erkennen das stehende Leitmotiv der Upanishaden(S.155ff.), die Frage nach der darzubringenden Verehrung. Doch so billig ist der Weise nicht zu haben. „Hihihi, du Sūdra! Behalte das alles für dich, samt den Kühen!" Nun holt Jānaśruti statt der sechshundert Kühe tausend, dazu seine Tochter; die bietet er ihm samt dem Dorf, in dem der Weise sitzt. „Da richtete (Raikva) ihr (der Tochter) Antlitz in die Höhe und sprach: ,Hahaha, all die (Kühe), du Śūdra! Mit diesem Antlitz allein hättest du mich zum Sprechen gebracht!" " und er teilt ihm die Kunde mit, die jener begehrt.

Unter den Königen ist Janaka, der Beherrscher der Videhas, der größte Gabenspender. Wo ein Fürst besondere Gebelust zeigt, kommen die Leute gelaufen und rufen: „Ein Janaka! Ein Janaka!“ Mit diesem freigebigsten und frömmsten König gehört eng zusammen der Weiseste der Weisen: jener Yājnavalkya, von dessen Gespräch mit seiner Gattin die Rede war. Der König sitzt da, um Audienz zu erteilen. Da erscheint der Brahmane. „Yãjñavalkya! Weshalb bist du hergekommen?. Trägst du nach Kühen Verlangen oder nach subtilen Gesprächen?" „Nach beidem, großer König." Im Laufe einer solchen Unterredung sagt Janaka einmal über das andere: „Ich schenke dir tausend Kühe mit einem Stier wie ein Elefant." Yājnavalkya erwiedert: „Mein Vater hat gemeint, ehe man den andern belehrt hat, soll man nichts annehmen." So geht das Gespräch weiter. Zum Schluß sagt der König: „Friede sei mit dir, Yājnavalkya, der du, Erhabener, uns den Frieden verkündest. Verehrung sei dir! Da nimm die Videhas und nimm mich selbst hin!" 
Einmal hat Janaka ein Opfer mit reichem Opferlohn veranstaltet $^{104}$. „Daselbst hatten sich Brahmanen von den Kur u und Pañcāla ${ }^{1}$ ) versammelt. Da begehrte Janaka, der Videha, zu erkennen, wer von diesen Brahmanen wohl der gelehrteste wäre. Und er nahm tausend Kühe, und an den Hörnern einer jeden waren zehn Pādas (Gold) befestigt. Und er sprach zu ihnen: ,Erhabene Brahmanen! Wer von euch der größte Brahmane ist, treibe diese Kühe heim!' Die Brahmanen aber wagten das nicht." Worauf Yājnavalkya die Kühe durch seinen Schüler heimtreiben läßt. Zornig fragt man ihn: Du bist also der größte Brahmane? Er antwortete: „Wir beugen uns vor dem größten Brahmanen. Aber auf diese Kühe haben wir Lust" - nicht ohne Feinheit lehnt er scheinbar ab, den stolzen Anspruch zu erheben, und macht ihn doch in der Tat sehr deutlich geltend. So entbrennt nun das Kampfspiel der Reden. Neun Gegner treten mit ihren Fragen gegen Yājñavalkya auf, um einer nach dem andern zu unterliegen; in Reihe und Glied mit den brahmanischen Kämpen auch zwei Brahmanenfrauen. Eine von diesen Frauen ist es, die besonders temperamentvoll ihren Angriff eröffnet, im voraus dem Gegner zu Gemüte führt, welch schweren Stand er haben wird: „Wie der Sohn eines Gewaltigen vom Kāśi- oder Videhaland seinen abgespannten Bogen spannt und zwei feindedurchbohrendePfeile in der Hand sich aufmacht, so habe ich mich gegen dich mit-zwei Fragen aufgemacht. Die löse du mir." Doch wie alle anderen wird auch diese streitbare Philosophin zum Schweigen gebracht und sagt zu ihren Genossen: „Erhabene Brahmanen! Seid froh, wenn ihr von ihm damit loskommt, daß ihr ihm eure Huldigung bringt. Besiegen aber im geistlichen Redestreit wird ihn von euch keiner!“

1) Zwei Volksstämme des nordwestlichen Indiens (Gegend von Delhi), während die von Janaka beherrschten Videhas weiter südöstlich, am Ganges abwärts (Gegend nördlich von Patna) wohnen. Bei den Kuru und Pañcāla ist die Heimat der brahmanischen Opferwissenschaft, die sich von da $z u$ den Videhas verbreitet hat. 
Der noch übrige letzte der neun Kämpen läßt sich nicht warnen. Selbstverständlich unterliegt auch er. „Dich also haben diese Brahmanen sich dazu genommen, die Kohlen für sie zu löschen", sagt Yãjñavalkya verächtlich. Und seines Gegners Kopf zerspringt: das gebührende Schicksal dessen, der die Prüfung nicht besteht. „Und Diebe raubten seine Gebeine, indem sie sie für etwas anderes hielten." -

Hier und da ist in den Upanishaden die Rolle zwischen Brahmanen und König vertauscht. Einem solchen Fall sind wir schon begegnet (S. 162). Ein zweiter ist der folgende ${ }^{105}$. Der Brahmane Gārgya hat vergeblich versucht, dem König Ajātaśatru von Kāśi (Benares) das Brahman zu erklären. $\mathrm{Er}$ muß beschämt stillschweigen. „Ajātaśatru aber sprach: ,Bist du am Ende?، ,Ich bin am Ende." ,Das reicht nicht hin, (das Brahman) zu erkennen.‘ Da sprach Gārgya: ,Ich will dein Schüler werden.' Ajātaśatru aber antwortete: ,Das ist ja gegen alle Ordnung, daß ein Brahmane eines Kshatriya Schüler wird, damit ihm der das Brahman erklärt. Doch unterweisen will ich dich." Und was der Brahmane nicht gekonnt hat, gelingt dem König.

Man hat mit Stellen wie dieser die Auffassung zu begründen gesucht, daß im Gegensatz zur alten Opfertheologie der Brahmanen die Lehre vom All-Einen als Schöpfung des fürstlichen Standes anzusehen sei. „Der Kriegerkaste“, sagt ein herrorragender Forscher ${ }^{106}$, ,gebührt der Ruhm, in richtiger Erkenntnis des gedankenlosen Opferwesens und seiner albernen Symbolik, durch Erschließung einer neuen Ideenwelt den großen Umschwung in dem geistigen Leben Altindiens bewirkt zu haben." Mir scheint dies weit úber das Ziel hinaus zu treffen. Den Zeugnissen, die Kshatriyas im Gegensatz zu Brahmanen als Kenner höchster Geheimnisse verherrlichen, steht die große Úberzahl andrer entgegen, die eben jenes Wissen vielmehr Brahmanen zuschreiben: wie beispielsweise jene Stelle über die Weltentsagung der Erkennenden (S. 139) davon spricht, daß Brahmanen das Trachten nach Söhnen und nach Habe aufgebend als Bettler einherziehen. 
Schwerlich ist dieser so begreifliche Sachverhalt durch die Erwägung zu entwerten, daß die Redaktion der Texte auf Brahmanen zurückgeht, und daß darum wenige diesen ungünstige Zeugnisse schwerer wiegen als viele günstige. Man erinnere sich, wie schrittweise und durchaus unmerklich die Spekulationen der Brahmanlehre aus denen der Opfersymbolik, also aus Gedankenkreisen offenbar priesterlicher Natur, sich entwickelt haben. Wie es das Brahman als die dem Vedawort und Brahmanenstand innewohnende Potenz war, das zum Brahman als dem Absolutum aufgestiegen ist. So beantwortet sich die Frage wohl von selbst, ob vornehmlich Brahmanen oder Kshatriyas das Allwesen in der Gestalt des Brahman erfaßt haben.

Das aber scheint doch richtig, daß Anfänge einer Anteilnahme des weltlichen Standes an dieser geistigen Bewegung in Zeugnissen wie den erwähnten eine Spur hinterlassen haben ${ }^{1}$ ). Ihrer ganzen Natur nach mußte ja diese Bewegung je länger je mehr die auf dem Zauberglauben alter Zeiten beruhende Ausnahmestellung des Brahmanenstandes zurückdrängen. Wie konnten vor der Überhoheit des All-Einen, vor der Wucht des Erlösungsproblems sich auf die Dauer die Unterschiede behaupten derer, die aus dem Kopf und die aus den Armen des Purusha entsprungen waren, der zum Somatrank Befähigten und der Nichtbefähigten? Weltlichem Adel hat später Buddha und sein Zeitgenosse Nātaputta, der Begründer der Jainagemeinde, angehört $\left.{ }^{2}\right)$. Die beherrschende Stellung solcher Männer in der religiösen Bewegung bereitet sich hier vor. Aber einstweilen nur in vereinzelten Ansätzen: wofür vielleicht auch

1) Die ersten Anfänge eines Eindringens von Adligen in priesterliches Wissen brauchen das nicht gewesen zu sein. Man sehe etwa, wie im Śatapatha Brāhmana (XI, 6, 2) ein König - allerdings ist es Janaka als tiefster Kenner den Geheimsinn des Agnihotra (Feueropfers) dem Yājñavalkya erklärt.

2) Soll man in diesem Zusammenhang drittens (mit Garbe) den Namen Krischna's nennen? Ich habe Bedenken. 
geltend gemacht werden kann, daß, so viel ich sehe, die Texte nie fürstliche Persönlichkeiten die spekulativen Probleme unter sich erörtern lassen, wie doch wohl erwartet werden dürfte, wenn es sich hier in der Tat um Schöpfungen des Kshatriyastandes handelte. Vielmehr sind es beständig Brahmanen, die von den Kshatriyas belehrt werden. Und fast immer wird dabei die Abnormität ausdrücklich hervorgehoben ${ }^{1}$ ). Damit wird die Leistung der Adligen zu gleicher Zeit anerkannt und so zu sagen als merkwürdige Ausnahme charakterisiert, welche die Regel bestätigt. Biş diese Ausnahme selbst Regel geworden ist, mußten noch Jahrhunderte vergehen.

Der geistigen Atmosphäre, die sich in den Upanishaden darstellt, würde etwas von voller Echtheit fehlen, wären dort die Dialoge allein in der Welt irdischer Wirklichkeit eingeschlossen, unter Brahmanen und Brahmanenfrauen, Schülern und Fürsten. Für die Denker dieser Zeiten so gut wie für die Massen fließt Irdisches und Überirdisches, Natur und Zauberwelt ununterscheidbar in einander. So schlägt denn hier, wie früher in den Brāhmanatexten (S. 10), das heilige Wissen auch in andern Geistern als menschlichen seinen Sitz auf. Unter den Lehrern von den höchsten Geheimnissen erscheint kein Geringerer als Prajāpati, der Herr. der Geschöpfe. Indra von den Göttern, Virocana von

1) So auch in dem S.167 A. 1 erwähnten Gespräch über das Agnihotra, wo Yājñavalkya den Gedanken an eine Disputation der Brahmanen mit dem König zurückweist: "Wir sind ja doch Brahmanen, und er ist von königlichem Stande. Besiegen wir jenen, wen können wir sagen, daB wir besiegt haben? Besiegt er aber uns, wird man zu uns sagen: Da hat ein königlicher Mann die Brahmanen besiegt." Der Abschnitt schlieBt sehr charakteristisch damit, daß Yājñavalkya dem Janaka zum Dank für die empfangenen Lehren einen Wunsch bewilligt. Der König wünscht sich, nach Belieben eine Frage an jenen tun zu dürfen. „Von da an war Janaka ein Brahmane." Also derselbe Autor, der hier den Brahmanen durch den König belehrt werden läßt, weist die Rolle des eigentlichen Beantworters von Fragen schlieblich doch dem Brahmanen zu und läbt den König, der ihm darin Konkurrenz zu machen verstanden hat, eben dadurch sich zur Brahmanenwürde erheben. 
den Dämonen ist sein Schüler. ${ }^{107}$ Freilich gelingt dem Upanishadenverfasser nicht, oder vielmehr er versucht überhaupt nicht, was kein griechischer Autor sich leicht hätte entgehen lassen: der Verlegung der Szene in so erhabene Umgebung entsprechende Wirkungen abzugewinnen, die Götter in einer Tonart reden und Dinge sagen zu lassen, die sich eben nur für Götter schicken. In der Tat verläuft alles ganz in irdischem Geleise: etwa wie es außerhalb des Gesichtskreises der älteren indischen Plastik lag, Göttergestalten in ihrer Göttlichkeit über die menschlichen hervorzuheben. Prajāpati ist nichts als ein gewöhnlicher Brahmane und Lehrer; Indra ist der verständige Schüler, Virocana der törichte. Man sieht das planlose Hinundhergreifen dieser Verfasser nach Gestalten, an die sie die neuen Gedanken heften können. Hier verfallen sie auf die alten Götter, und nun werden die in der Atmosphäre der Brahmanenschule - eine seltsame Travestie - zum Schulmeister, zum Schüler. Anderswo fällt die Rolle des Wissenden dem Geist (Gandharva) zu, der in einem besessenen Weibe wohnt; er spricht mit den geistlichen Wanderern, die dahin kommen, wo die Besessene ist. Wieder in einem andern Abschnitt sind Tiere die Spender der Offenbarung. Den Brahmanenschüler, der die Herde seines Lehrers treulich hütet, bis die vierhundert Rinder sich auf tausend vermehrt haben, redet ein Stier an und erklärt ihm ein Viertel des Brahman: "das Feuer wird dir ein weiteres Viertel kund tun" - und nach dem Feuer die Gans, nach der Gans der Vogel Madgu. Mit so wenigen Strichen des Bild gezeichnet ist, man sieht die Szene vor sich, beim Schein des indischen Abendrots, nahe den Wassern der Yamunā oder des Ganges, zwischen Feldern und Dschungel. "Als es Tag geworden war, trieb er die Kühe weiter. Wo sie gegen Abend hinkamen, legte er Feuer an, pferchte die Kühe ein, legte ein Holzscheit auf und setzte sich westlich vom Feuer nieder, das Antlitz gegen Osten gekehrt. Da kam die Gans auf ihn zugeflogen" und hinterher: „Da kam der Vogel Madgu auf ihn zuge- 
flogen und sprach zu ihm -." Vielleicht Umformung eines alten Märchens, in dem die Tiere zum Knaben von ganz andern Dingen redeten, wie sich's für ein Märchen schickt ${ }^{1}$ )? Was nun aber diese seltsamen Lehrer sagen, ist wieder nichts andres, nicht unmittelbarer, tiefer, wilder, als die alltägliche Weisheit der Brahmanenschulen. -

Blicken wir von diesen Märchenbildern noch einmal auf die menschlichen Figuren der Upanishaddialoge zurück.

Die Männer, die zuerst hinter der phantastischen Wirrheit ihres Weltbildes das Ewige, Eine erkannt haben, treten im Einklang mit der geschichtlichen Wirklichkeit hier noch durchaus in der Vielheit auf. Erst spätere Zeiten konnten solche Einzelgestalten eines Unvergleichlichen schaffen wie des Buddha: so wie in anderm Lande auf die Menge der großen und kleinen Propheten der eine Gottessohn gefolgt ist. Vielleicht doch ein erster Anfang der Entwicklung zu solcher Unvergleichlichkeit: Yājnavalkya, der schlechthin Wissende, Überlegene.

Im Ganzen sind es keine Idealgestalten, diese Denker der Upanishaden. Die menschlichen Schwächen, mit denen der Drang nach Wissen und Erlösung sicher bei recht vielen - hier wie anderwärts - widerspruchsvoll vermischt blieb, sind unbefangen, man kann sagen ahnungslos mit verzeichnet. Sogar der Anflug von Schmutz, der zu indischem Asketentum zu gehören pflegt, ist nicht vergessen. Eine große Rolle spielt, unverändert aus der Vorzeit uberkommen, die eifrige Liebhaberei für die Sportsleistungen geistlicher Turniere, für möglichst effektvolles Dartun davon, daß man weiß, was alle andern nicht wissen. Jenes Wort einer Upanishad, daß streitsüchtig die kleinen Leute sind,

1) Man kann etwa vergleichen, wie der alte Mythus von der Herabholung des Soma durch den Adler in den Brähmañatexten zu der ebenso beliebten wie absurden Geschichte von seiner Herabholung durch das Versmaß Gāyatrī umgeformt ist (vgl. oben S. 17). - Hier sei noch auf die Erzählung mehrerer Upanishaden hingewiesen vom Streit der Sinnesorgane über den Vorrang: gewiß auch Bearbeitung eines Märchens. 
während den Großen die Gabe des Sinnens zuteil geworden ist, beherzigt man recht unvollkommen. Man ist Virtuos und will als solcher anerkannt werden. Dem minderwertigen Rivalen mag es übel gehen. Ihm begegnet die unverfälschte derbe Ironie, Grobheit, Haß der guten alten Zeit. Nicht genug, daß ihm ,der Kopf zerspringt": Räuber müssen seine Gebeine stehlen (S. 166) - diese Unglücksmenschen glaubten etwas Besseres erwischt zu haben! Der Sieger aber nimmt befriedigt neben der Ehre auch die Kühe mit den goldbehängten Hörnern entgegen. Und sollte ein weiser Mann für solchen Besitz unempfänglich sein, bleibt die Chance, daß er für ein schönes Mädchen mehr Verständnis hat. So fehlt in der Tat häufig recht viel daran, daß die neuen hohen Ideale vom ganzen Menschen Besitz ergriffen hätten. Aber dann doch wieder: das Verlangen nach Erkenntnis der großen Geheimnisse, wie echt, mit wie überzeugender Kraft spricht es sich an so mancher Stelle aus! Wie heben sich von der Äußerlichkeit jener Redekämpfe die Gespräche zwischen Vater und Sohn, zwischen Gatten und Gattin, zwischen dem Weisen und seinem fürstlichen Jünger ab! Das Gesicht dessen, der das Brahman kennt, erglänzt. Der Greis ordnet sein Haus und zieht heimatlos von dannen. Welches Bewußtsein davon, daß hier ein Gut in Frage kommt, das seines Gleichen nicht hat! -

Nach der Umrahmung der Dialoge, den auftretenden Personen, ihren Stimmungen, lernen wir weiter, von außen nach innen fortschreitend, die Kunst oder den Mangel an der Kunst kennen, die sich dieses Apparats bedient, um die Gedanken und Gedankengänge entstehen, sich entwickeln zu lassen.

Hier sei vorangeschickt, daß zum Charakter der dialogischen Prozedur, deren Mechanismus wir zu betrachten haben, dies gehört, daß sie in gewisser Weise zugleich die Eigenschaften eines Zaubervorganges an sich trägt.

Rechtshistoriker haben bemerkt, daß auf niederer Kulturstufe das Prozeßverfahren eine Art Zauber ist. Die Grammatiker des Zeitalters, mit dem wir uns hier beschäftigen - 
schon jetzt wurden ja grammatische Forschungen eifrig betrieben - vermischten ihre Beobachtungen uiber Laute und lautliche Vorgänge mit Mystik und Zauber ${ }^{108}$; wer die Vokale und die Verschlußlaute richtig aussprach, verlieh damit Indra Kraft und schützte sich selbst gegen den Todesgott. So wohnt ein deutlicher Anflug von Zauberhaftem auch den Disputationen der Upanishaden bei. Die dialektischen Erfolge und Mißerfolge haben ihre magischen Wirkungen. Die Verwandten dessen, der sich in einen solchen Streit einläßt, vergießen Tränen und denken an ihn wie an einen Toten ${ }^{109}$. Denn Verwünschungen, die der Sieger über den Unterliegenden ausspricht, erfüllen sich - kein Wunder, daß die Brahmanen "der früheren Zeiten“ gern ein Stück Gold zu sich steckten, um nötigenfalls den Gegner hinsichtlich solcher Verwünschung milde zu stimmen. Man droht einander zauberhafte Schädigung durch die gefährlichen mystischen Mächte an, von denen eben im Dialog die Rede ist. Die sind selbst zugegen und lauern darauf, zum Verderben des Unkundigen oder Vorwitzigen einzugreifen. Wer statt zur Verehrung des Ātman selbst sich zu der andrer Wesenheiten bekennt, die in Wahrheit nur des Átman Auge oder Atem sind, der muß sich vom Gegner sagen lassen, daß er sein eignes Auge, seinen eignen Atem in Gefahr bringt: „Blind wärst du geworden, der Atem wäre von dir gewichen, wenn du nicht zu mir gekommen wärest (die wahre Verehrung zu lernen)". Wer mit seinen Fragen nicht an der rechten Stelle Halt macht, verfällt dem Verderben, durch das ewige Ordnung sich an solchem Übergriff rächt. Fragen darf man allein, wie die niederen Welten in immer höhere Welten „eingewoben und verwoben " sind - bis zu den Brahmanwelten. „Worin nun aber sind die Brahmanwelten eingewoben und verwoben?، Da antwortete er: ,Gārgī! Überfrage nicht, daß dein Kopf nicht zerspringe. Eine unüberfraghare Gottheit überfragst du. Gārgì! Ửberfrage nicht!' Da schwieg Gārgī, des Vacaknu Tochter, still“" 110 . 
$\mathrm{Zu}$ dieser Zaubersphäre, in der die Dialektik arbeitet, paßt ganz das Bild ihrer eigentlich dialektischen Qualitäten.

Natürlich in schärfstem Kontrast erscheint auf der einen Seite die Hauptperson, der Wissende - vielmehr ein Wissender als ein Denker -, auf der andern Seite der Nichtwissende oder die Nichtwissenden, Fragenden - mögen sie nun in ehrlicher Wißbegierde oder in aggressiver Absicht fragen -, oder auch die vermeintlich Wissenden, deren Nichtwissen entlarvt wird.

Der Vorgang nun, der Wissen erzeugt, falsches Wissen zu nichte macht, ist meist über das Stadium primitiver Unentwickeltheit noch wenig fortgeschritten. Vom literarischen Abbild dieses Vorgangs in den Upanishaden gilt das ohne Zweifel vor allem deshalb, weil es von ihm selbst in Leben und Wirklichkeit jenes Zeitalters gegolten haben wird.

Zwischen Nichtwissen und Wissen liegt hier kein schrittweises, innerem Gesetz folgendes Aufsteigen, sondern ein Sprung. Der Nichtwissende wird vom Andern nicht angeregt, in seinem eigenen Bewußtsein und im Anschauen der Dinge die Spuren aufzusuchen, die zum Wissen führen. Das Wissen wird ihm fertig in den Schoß geworfen ${ }^{1}$ ). Der vermeintlich Wissende spricht eine Meinung aus, die schwerlich Jemand im Ernst hätte hegen können; sie ist eben nur Sprungbrett für den Dialog. Er wird vom Gegner, dessen Überlegenheit sich für den gläubigen Hörer von selbst versteht, mit einer orakelhaften Äußerung übertrumpft. Da muß er denn stillschweigen oder sich als Schüler des Siegers erklären, sofern der Ausgang nicht noch deutlicher markiert wird, dem Überwundenen der Kopf zerspringt. Wie schwer sich in der Tat die Vorstellungsmassen, mit denen man zu schaffen hat, einer fester und feiner zugreifenden Behandlung fügen würden, ist klar; schon oben (S. 160) wurde dies bei der Besprechung der so vagen "Verehrungsformeln"

1) Von einem Fall, der mir als Ausnahme erscheint, ist in Anm. ${ }^{111}$ (am Ende dieses Buchs) gesprochen. 
angedeutet. Allzu viel ist eben noch übrig vom alten Spuk der aufsteigenden, verschwindenden, fortwährend sich wandelnden, in jedem Lufthauch flatternden Phantasmen. Von jener Weise die Natur anzusehen, wo man am menschlichen Herzen die fünf Götterhöhlungen wahrnimmt, im Sonnenball den goldnen Mann, goldhaarig, goldbärtig, bis zur Nagelspitze ganz Gold. Wie sollte es da von Beweisführungen mehr geben, als - ganz wie in der Brāhmanazeit - Anfänge ${ }^{111}$, Bruchstiicke, vor allem Surrogate: Gleichnisse, phantastische Betrachtung irgendwelcher Eigentümlichkeiten von Worten, z. B. ihrer Silbenzahl, oder Spiel mit Wortanklängen. Die wirklichen Beweise liegen hier nicht in dem, was als Beweis vorgetragen wird, sondern in der instinktiven inneren Gewißheit, die im Hintergrund steht, mächtig aber dumpf, zu Tiefem und Flachstem gleich bereitwillig Ja sagend.

Als oben (S. 153f.) vom Bestehen der Upanishaden aus kleinen meist regellos aneinander gereihten Textstücken die Rede war, fand sich schon Gelegenheit $\mathrm{zu}$ bemerken woran hier bei Betrachtung der Struktur der Dialoge zurückzuerinnern ist -, daß Ansätze zu planmäßigem Aufbau der Gedankengänge immerhin doch nicht fehlen. Es wurde auf jene Rede des Yãjñavalkya hingewiesen, die nach dem wachen Zustand des Menschen den Traumschlaf, den Tiefschlaf, den Tod des Unerlösten bespricht, um endlich ihr Ziel zu erreichen, das Eingehen des Erlösten ins Brahman: zugleich ein stufenweises Fortschreiten und ein Arbeiten mit dem doppelten Kontrast von Traumschlaf und Tiefschlaf, unerlöstem und erlöstem Sterben. Anderwärts bietet sich als Gerüst für den Aufbau der Gedankenmasse, nicht ohne ein gewisses Geschick verwandt, die Aufeinanderfolge mehrerer etwa in einem Wettstreit des Wissens konkurrierender Unterredner dar. Oder auch ein Bericht des Fragers an den Wissenden darüber, was ihm vorher von andern, vermeintlich Wissenden, gesagt ist, wodurch dann die Belehrung vonseiten des wirklich Wissenden vorbereitet wird: 
ein Darstellungsschema, das schon hier ganz ähnlich wie später bei den Buddhisten begegnet.

König Aśvapati ${ }^{112}$ fragt jeden der sechs Schriftgelehrten, die zu ihm gekommen sind: "Als was verehrst du den Ātman?" Der Eine antwortet: als den Himmel! Die Andern: als die Sonne - den Wind - die Erde, und Ähnliches. Dem, der den Himmel genannt hat, erwidert der König, daß der Himmel doch nur das Haupt des Ātman ist. Die Sonne: nur sein Auge. Wind, Erde: nur Odem, Füße. So wird der Schluß vorbereitet: man soll den Ātman nicht als etwas Draußenstehendes, von sich Gesondertes verehren, sondern als das Zentrum von allem, als das eigne Selbst.

Ähnlich im großen Redestreit Yājnavalkya's mit den neun Gegnern. ${ }^{1.18}$ Der Lehre vom Brahman, auf die das Ganze hinzielt, wird ein Fundament von Gedanken geringeren Ranges untergebaut. Man fängt von Verhältnissen des Opfers und ihrer geheimen Bedeutung an. Der sich als Meister des höchsten Wissens bewähren wird, zeigt hier seine Herrschaft auch über dessen niedere Gestalten. Da handelt es sich um die Verse, die der Hotarpriester vorträgt, und um die Opferspenden dargebracht vom Adhvaryu, um Wind und Mond, um Einhauch und Aushauch. Der kundige Hörer fühlt wohl, daß das alles nur Vorspiel ist. Bald kommt man dem Ziel näher. Tod, Jenseits wird berührt und die Macht des Karman. Wo sind des Parikshit Nachkommen hingegangen? Auch jetzt noch wirrt sich Großes und Kleines durcheinander: Gott Indra als Falk, der Wind als die Besonderung und als die Vereintheit, die Abwehr des Wiedertodes. Da blitzt die Frage aller Fragen auf: "Das Brahman, das offenbare, nicht verborgene, den Ātman, der in allem darinnen ist: den erkläre mir!“ Und im Munde des folgenden Unterredners Wort für Wort dieselbe Frage: „Das Brahman eben, das offenbare, nicht verborgene, den Ātman, der in allem darinnen ist, den erkläre mir." Wie könnte der ganze Nachdruck, der auf dieser Frage liegt, stärker fühlbar gemacht werden als durch solche 
Wiederholung? Und nun steigt von den verschiedensten Ausgangspunkten die Gedankenbewegung immer zum selben Gipfel auf. Sie steigt zum Brahman auf von den irdischen und himmlischen Welten; jede davon ist einer höheren Welt "eingewoben und verwoben": bis zu den Brahmanwelten. Zum Brahman wird aufgestiegen von den Elementen und kosmischen Wesenheiten, Erde, Wasser, Wind, Sonne; in allem wohnt herrschend das Eine: „das ist dein Ātman, der innere Lenker, der Unsterbliche." Es wird aufgestiegen von den Göttern; deren Vielheit führt auf den einen Gott hin: „der ist das Brahman, das ,Jene': so nennt man ihn." Dazwischen dann immer noch Verwirrung über Verwirrung - durch einander Unsterblichkeit, Weiber, Wahrheit, Himmelsgegenden. Aber das alles überklingt doch mächtig der eine Ton. Wieder und wieder dieselben Worte vom Atman als dem alleinigen Heil: "was von ihm verschieden, ist leidvoll." Und endlich - der Dialog hat sich von Prosa zu poetischer Form erhoben - gipfelt das Ganze in Yājñavalkya's Schlußworten. Sie zeigen in Hymnenton die Vision des All-Einen, von unbestimmtem Lichtglanz umschwommen:

„Erkennen, Wonne das Brahman ist,
Spende, des Gebers höchstes Ziel,
Des Feststehenden, Wissenden."

Gewiß ist das nicht voll entwickelte Kunst der Komposition, kein Ineinanderaufgehen von Form und Inhalt in innerer Notwendigkeit. Wer würde dem hier zu begegnen erwarten? Aber Plan und Wollen fehlt doch nicht ganz, die wenn auch nur stückweise Betätigung einer Energie, welche das Bedeutsame, Entscheidende über das nur Vorbereitende hinaushebt.

Daß die Wirkung dieses Aufbaus, wie überhaupt des Upanishadenstils, auf die alten Hörer von der Wirkung auf uns durchaus unterschieden werden muß, ist selbstverständlich. Uns erscheint alles, was die früheren Abschnitte des eben besprochenen Dialogs füllt und wovon Ausläufer auch in seine Hauptpartien hineinreichen, als Flugsand, als Wort- 
geklingel. In uns entsteht unvermeidlich die Empfindung, die jeder Leser der Upanishaden allzu gut kennt: die schwere Beeinträchtigung großer Eindrücke durch solchen Wust des Absurden. Aber wir dürfen doch, meine ich, nicht daran zweifeln, daß dem Inder auch diese Phantasmen, so lange eben jedes von ihnen vor seinem leicht beweglichen Geist stand, bedeutend und eindrucksvoll genug erschienen sind. $\mathrm{Daß}$ die acht Greifer von den acht Übergreifern gefesselt werden, daß man durch die drei beim Opfer vorgetragenen Verse alles, was Odem hat, gewinnt: dies war den Alten - wenn auch vielleicht jedesmal nur für einen Augenblick in der Tat ein Aufschluß über Ordnung und Zusammenhang des Daseins, über das Treiben großer Weltmächte, samt wertvollem Unterricht darüber, wie man selbst zu diesem Treiben Stellung zu nehmen hat.

Die bunte und oft so widersinnig scheinende Mischung derartiger Einfälle mit den Ideen vom All-Einen spiegelt den Werdegang des indischen Denkens in seiner von den entsprechenden westlichen Entwicklungen tief verschiedenen Eigenart recht deutlich ab. Aus dem wirren, viele Denkgewohnheiten uralten Zauberglaubens in sich bewahrenden Weltbild der Brāhmaṇazeit war die große Neubildung der Brahmanspekulation als höchst frühreife Frucht hervorgewachsen. Damit war in jenes Weltbild wohl ein neuer beherrschender Faktor hineingesetzt worden, aber eine durchgreifende reinigende Umformung des Bildes, der ganzen Weise, in der es aufgefaßt und wiedergegeben wurde, hatte darum keineswegs stattgefunden. Auch jetzt noch dachte man auf weite Strecken hin den Weltlauf nicht anders als im alten Zauberstil oder im Stil der Opfersymbolik. Und von diesen unteren Regionen her mischte sich unvermeidlich die Armseligkeit und Willkürlichkeit der sie bevölkernden Gebilde in die neuen hohen Gedankenkreise und darum auch in deren Darstellung hinein. Man meint den Upanishaden die Nähe des Fastens und aller der Riten anzufühlen, durch welche die geistlichen Männer, die hier redeten, sich zu oldenberg: Upanishaden. 
heiligem Tun zu bereiten gewohnt waren. Sie fragten wenig nach den Ordnungen der Natur oder nach den Wirklichkeiten, die sich im Schicksal der Menschenwelt kundgeben. Sie kamen vom Opferplatz, aus dem Dunstkreis des Feueropfers, des Somaopfers.

Alles, was hier beschrieben wurde, ist weit überwiegend in Prosa verfaßt. Das verstand sich von selbst. Der Zweck war ja Belehrung, und die natürliche Form für das Belehren war die prosaische. Vor den Upanishaden.die großen Brāhmanas waren Prosatexte. Nicht anders hat später, nach der Zeit der älteren Upanishaden, die Buddhistengemeinde ebenso den kurz pointierten Fundamentalsätzen ihrer Weltbetrachtung, den vier "heiligen Wahrheiten", wie der ganzen Masse der ausführlichen Lehrreden vom Weltleiden und von der Erlösung prosaische Form gegeben. Wie hätten die Upanishaden, durchaus auf der Entwicklungslinie zwischen diesen beiden Textgruppen stehend, eine andere Form haben sollen, als die jenen gemeinsame?

Die Prosa der Upanishaden ist selbstverständlich nicht die lebendige Prosa wirklicher, gesprochener Rede mit ihrem Wechsel von Licht und Schatten, mit Sprung und Willkür, bewegt von den Impulsen des Augenblicks. Sie ist vielmehr die feierlich gemessene Prosa der Brāhmanatexte, aus denen die Upanishaden ja herausgewachsen sind. Abgesehen von den kurzen Sätzchen ritueller. Formeln ist das die einzige literarisch fixierte Prosa, die man in dieser Zeit kennt. Denn Prosa der politischen oder gerichtlichen Rede ist in Indien nicht vorhanden, und die erzählende Prosa hat man literarisch durchzubilden noch nicht versucht ${ }^{1}$ ). Unbeeinflußt also von anders gearteter, leichterer Sprachkunst formt jene Prosa ihre nach der Schnur gebauten Sätze, ähnlich

1) Die kunstmäBige - oder vielmehr eben nur teilweise kunstmäBige - Erzählung bestand aus Prosa mit eingelegten Versen. Feststehenden Wortlaut aber hatten nur die Verse. Die prosaische Umhüllung gab jeder Erzähler improvisierend mit seinen eigenen Worten. 
den hieratischen Gebilden archaischer Plastik, oft nicht unkompliziert, aber immer geradlinig, steif. Jeder wiederholt eins der wenigen vorhandenen Konstruktionsschemata, häufig dieselben Worte kaum variiert, so wie jene plastischen Figuren gern in langen Reihen erscheinen, einander ununterscheidbar gleich. Man möchte sagen, daß sich auch hier wieder etwas von jener Sinnesart fühlbar macht, für welche Sprechen das Ausüben eines Zaubers einschließt über das, wovon man spricht. Der Zauber hat seine bestimmte notwendige Form: so hat hier der sprachliche Ausdruck eines Gedankens von Natur seine ihm gebührende Gestalt. Diese Gestalt gilt es wiedergeben, nicht nach eigner Willkür sie modeln. Nirgends also Abkürzungen, Fortlassung von Wiederholungen, die dem heutigen Leser unnütz, ja störende tote Belastung scheinen. Wiederholt sich doch auch in der Außenwelt dasselbe Geschehen, ohne sich morgen darum kürzer zu fassen, weil es gestern und heute schon dagewesen ist. Gern häuft man synonyme Ausdrücke. Jeder von ihnen hat das gleiche Recht wie der andre, gehört zu werden; fehlte einer, wäre man nicht gewiß, vollständig gesagt zu haben, was gesagt werden muß. Beeiltsein gibt es hier für Redende und Hörende nicht, keine Ungeduld, diese unerbittliche Langsamkeit des Fortschreitens anzutreiben. In den Brahmanenschulen und Waldhuitten hat man unbegrenzte Zeit.

$\mathrm{Zu}$ all dem kommt dann noch der Einfluß, den das Fehlen des Schriftgebrauchs übt. Wer schreibt, wer liest, wird leichten Herzens niederschreiben und lesen, auch was nach Inhalt und Form rein individuelles Gepräge, ephemere Bedeutung hat. Im schriftlosen Zeitalter aber heißt einen Text verfassen so viel wie den Anspruch erheben, daß der durch alle Zukunft auswendig gewußt und von einem Wissenden nach dem andern, in feierlich stilisierter Betonungsweise, rezitiert werde. Da findet Zufälliges, Persönliches nicht leicht Eingang. Von selbst stellt sich eine Regelmäßigkeit ein, die dieser Prosa Halt gibt, dem Gedächtnis 
des Lernenden ähnlich zu Hilfe kommt, wie bei Versen das Versmaß.

Man sehe beispielsweise, wie die Upanishad den Gedanken ausdrückt, daß Wahrnehmung da unmöglich ist, wo es keine Zweiheit von Subjekt und Objekt gibt ${ }^{114}$ :

„Wenn er dann nicht sieht, so ist er in Wahrheit ein Sehender und sieht doch dann nicht. Denn für den Seher gibt es keine Unterdrückung des Sehens wegen dessen Unvergänglichkeit. Aber es gibt nicht das Zweite, Andre, von ihm Verschiedene, das er sehen könnte.

.Wenn er dann nicht riecht, so ist er in Wahrheit ein Riechender und riecht doch dann nicht. Denn für den Riecher gibt es keine Unterdrückung des Riechens wegen dessen Unvergänglichkeit. Aber es gibt nicht das Zweite, Andre, von ihm Verschiedene, das er riechen könnte.

"Wenn er dann nicht schmeckt, so ist er in Wahrheit ein Schmeckender und schmeckt doch dann nicht. Denn für den Schmecker gibt es keine Unterdrückung des Schmeckens wegen dessen Unvergänglichkeit. Aber es gibt nicht das Zweite, Andre, von ihm verschiedene, das er schmecken könnte". . .

Die Reihe dieser Wiederholungen ist noch nicht fertig. Was vom Sehen, Riechen, Schmecken gesagt ist, wird weiter, jedesmal in genau derselben Ausführlichkeit, vom Reden, vom Hören, vom Denken, vom Berühren, vom Erkennen wiederholt: woran sich dann endlich die Zusammenfassung schließt:

"Wo ein Andres gleichsam wäre, da würde Einer das Andre sehen, würde Einer das Andre riechen, Einer das Andre schmecken, Einer das Andre reden, Einer das Andre hören, Einer das Andre denken, Einer das Andre berühren, Einer das Andre erkennen"115.

Man wird in einem Stück wie diesem doch nicht allein die Weitläufigkeit wahrnehmen, sondern auch bemerkenswerte Anfänge eines Könnens, das hier und da selbst minder einfache Figuren des Gedankens richtig aufzuzeichnen rer- 
steht. Ausdrücke, die etwa unserm „an sich" oder unserm Gegensatz des Potentiellen und Aktuellen entsprächen, besitzt man nicht. Aber sind hier nicht doch treffende Worte gefunden für den Zustand des Sehers, des Hörers, der an sich Seher und Hörer ist, dessen Sehen und Hören aber in Ermangelung eines Objekts nicht zur Aktualität gelangt?

Wenn auch, wie bemerkt, die technische Behandlung der Prosa in den Upanishaden im wesentlichen genau dieselbe ist, wie in den Brāhmanas, so reißen doch hier bisweilen die Vorstellungen, um die es sich handelt, mit ihrer so viel stärkeren Wucht die Sprache zu Leistungen fort, die in den trockenen Darlegungen der alten Opferkunst nicht ihres gleichen haben. Man denke etwa an jene dem Śandịilya zugeschriebene Rede vom höchstenSelbst (oben S. 57): wo kennen die Texte der Opfertheologie ein solches Sichaufschwingen der Prosa zur Höhe eines Hymnus, wie er dort seinen Strom geistdurchwogter Beiworte um die Majestät des Ātman ergießt? Dieser Fähigkeit, die Fülle des Seins in der Fülle der Sprache abzubilden, steht auf der andern Seite auch das Vermögen gegenüber, für Höchstes kürzesten Ausdruck zu prägen. Nicht selten gerät man auf diesem Wege in Dunkelheiten wie in jener Benennung des Allwesens - welches auch der Sinn dieses Rätsel- oder Zauberworts sein mag - als jalän ${ }^{116}$. Aber dann wiederum ist der Wurf gelungen, ist es der Ergriffenheit des Geistes aufgeleuchtet, das treffende, entscheidende Wort, das in wenigen Lauten die ganze Tiefe des Mysteriums offenbart. So wenn überkühn die Verneinung als Ausdruck für das Freisein von den Schranken jeglicher Bestimmtheit ergriffen und das Allwesen genannt wird "Nein, nein". Oder wenn drei kürzeste Worte, jedes für sich genommen farblos, in wundervoller Schlichtheit und Größe jenes selbe Wesen im eignen Ich erkennen lehren: Tat tram asi "Das bist Du“. Wie das "Nein, nein" oft im alten Text wiederholt wird, wie in jenem Gespräch zwischen Vater und Sohn die Rede des Vaters immer wieder in das unvergleichlich eindring- 
liche „Das bist Du, o Śvetaketu“ ausläuft, meint man zu empfinden, daß schon die Verfasser der Upanishaden selbst sich der Vollkraft solcher Worte bewußt waren, die in der Tat dazu bestimmt gewesen sind, von jenem Altertum an durch Jahrtausende unverwelklich lebendig zu bleiben.

Über welche Mittel verfügten nun die Upanishadverfasser, die Eintönigkeit ihrer Darstellung zu unterbrechen und zu schmücken?

An erster Stelle ist hier von den Gleichnissen zu sprechen. Die konnten den Upanishaden so wenig fehlen, wie sie irgend einer der ihnen verwandten Literaturmassen ${ }^{1}$ ) gefehlt haben. Gewiß dienten sie der Verkündigung vom All-Einen nicht allein als Schmuck, sondern sie hatten auch die Bestimmung, die Überzeugungskraft der Rede zu verstärken, das der Wahrnehmung Entzogene anschaulich zu machen. Hier und da lag in ihnen wohl auch, dürfen wir hinzufügen, eine Anregung für die Verfasser selbst, die dazu beitrug, deren Gedanken über den durch das Gleichnis verdeutlichten Gegenstand zu befruchten und zu dirigieren. Besonders an Höhepunkten der Darstellung, wo alles daran lag, der Phantasie des Hörers den Einblick in die jenseitige Ordnung der Dinge zu eröffnen, ließ man die Gleichnisse gern in ganzen Reihen, kürzeren oder längeren, auf einander folgen. Vom menschlichen Geist, der bald im Reich des Wachens, bald in dem des Schlafs weilt und dann jenseits des Traumschlafs in die Tiefen der Traumlosigkeit hinabtauchend einen Vorschmack rom Frieden des All-Einen genießt, sprechen die Gleichnisse ${ }^{117}$ :

"Wie sich ein großer Fisch an beiden Ufern entlang bewegt, am östlichen und am westlichen, ebenso bewegt sich dieser Geist an jenen beiden Stätten entlang, an der

1) Unter denen sei hier die kanonische Literatur der Buddhisten hervorgehoben. Ich glaube mir Dank bei manchen zu verdienen, wenn ich inbezug auf diese den inhaltvollen, schönen Aufsatz von Mrs. Rhys Davids erwähne: Buddhist Parables and Similes (The Open Court, Chicago, Sept. 1908). 
Stätte des Traumes und der Stätte des Wachens. Wie hier im Luftreich ein Falk oder ein Adler von seinem Flug ermüdet die Flügel zusammenschlägt und sich zur Rast duckt, ebenso eilt dieser Geist zu jener Stätte hin, wo er schlafend keinen Wunsch fühlt, keinen Traum schaut."

Das Hervorgehen alles Daseins und alles Wissens aus der Wesenstiefe des All-Einen beschreiben Gleichnisse, zuerst dreimal in archaischer Steifheit dasselbe Motiv kaum variierend, dann zu Neuem fortschreitend:

„Wie, wenn eine Trommel geschlagen wird, man nicht die Töne draußen greifen kann: greift man aber die Trommel oder den Trommelschläger, so hat man auch den Ton gegriffen -

"Wie wenn eine Muschel geblasen wird, man nicht die Töne draußen greifen kann: greift man aber die Muschel oder den Muschelbläser, so hat man auch den Ton gegriffen -

"Wie wenn eine Laute gespielt wird, man nicht die Töne draußen greifen kann: greift man aber die Laute oder den Lautenspieler, so hat man auch den Ton gegriffen ${ }^{1}$ ) -

1) Man wird dies dreifache Gleichnis zunächst gewiß dahin verstehen, daß das Allwesen dem Instrument verglichen wird, welches die Töne hervorbringt, die Welt der Kreaturen aber den Tönen. Dazu paBt auch das nächste Gleichnis vom Feuer und Rauch. Das dann folgende Gleichnis indessen (s. oben im Text) vom Salz und Wasser kann auf eine andre Auffassung des ersten dreifachen Gleichnisses deuten. Das Salz, das man für sich allein nicht herausschöpfen kann, das vielmehr an die andre, greifbare Wesenheit (das Wasser) gebunden ist, entspricht ja dem Allwesen, das Wasser den konkreten Dingen. Wären danach nicht auch die Töne, die an sich selbst nicht festgehalten werden können, vielmehr als das Allwesen zu verstehen, die greifbare Trommel, Muschel, Laute aber als die Kreaturen? Ich halte nicht für unmöglich, daß in der Tat eine Vermischung verschiedener Auffassungen vorliegt. Je nachdem an das Verhältnis des Hervorbringenden und Hervorgebrachten oder an das des Greifbaren und Ungreifbaren gedacht wird, ordnet sich die Entsprechung zwischen der dargestellten Sache (Weltgrund und Welt) und dem sie darstellenden Bilde (Instrument und Töne) bald auf die eine bald auf die andre Weise. 
„Wie von einem Feuer, auf das feuchtes Holz gelegt ist, nach allen Seiten Rauchwolken ausgehen: so wahrlich ist dieses großen Wesens Aushauch der Rigveda, der Yajurveda, der Sāmaveda, die Atharvan- und Angiraslieder, die Erzählungen, Geschichten der Vorzeit, Wissenschaften, Upanishaden ${ }^{1}$ ), Verse, Lehrsätze, die andre Erklärung und die Erklärung. Das alles ist sein Aushauch."

Und weiter im selben Abschnitt kurz darauf, ebenfalls uiber das Verhältnis von Weltgrund und Welt:

"Wie ein Salzklumpen, den man in Wasser geworfen hat, im Wasser zergeht und man ihn nicht herausnehmen kann, wo man aber schöpft, da ist es salzig: so wahrlich verhält es sich mit diesem großen Wesen, dem endlosen, grenzenlosen, das nichts als eine Erkenntnismasse ist: aus diesen Wesen erhebt es sich und mit ihnen verschwindet es wiederum ${ }^{2}$ ).

Eigentliche Erzählungen, die sich zu einer wenn auch mäßigen Länge ausdehnen, wie in den buddhistischen Texten oder dem Neuen Testament, finden sich unter den Gleichnissen der Upanishaden kaum. Den literarischen Gewohnheiten dieses Alterturns war es offenbar noch fremd, ein bloßes Gleichnis zu solcher Dimension und solcher Selbständigkeit anwachsen $\mathrm{zu}$ lassen ${ }^{3}$ ). Auch der Inhalt, auf

1) Vermutlich sind hier die Belehrungen über die Verehrungsform des höchsten Wesens (S.158) gemeint, die unsern Texten den Namen gegeben haben, nicht diese Texte selbst.

2) An einer andern Stelle (Chānd. Up. VI, 13) wird dies selbe Gleichnis zu einer förmlichen Aufführung umgeformt. Der Lehrer läßt den Schüler ein Stück Salz in Wasser legen und am nächsten Tage damit wiederkommen. "Gib mir das Salz." Es ist nicht da. "Schıürfe von dem Wasser." Es ist salzig. „Obwohl Es (das Ewige) hier ist, nimmst du es doch nicht wahr, mein Teurer. Aber es ist hier." Ähnliche Inszenierung von Gleichnissen findet sich bei den Buddhisten.

3) Einer kurzen Erzählung immerhin nahe kommt das Gleichnis von dem Mann, der aus seiner Heimat fortgeführt ist und sich dann dorthin zurückfindet (Chānd. Up. VI, 14, vgl. oben S. 161). Doch beachte mán, $\mathrm{daB}$ nicht direkt erzählend gesagt wird: „Einstmals geschah es, daß man einen Mann mit verbundenen Augen aus dem Lande der Gandhāra her- 
dessen Verdeutlichung es abgesehen war, begünstigte das nicht. Es handelte sich ja um tiefe aber sehr einfache Erkenntnisse und um ein ebenso einfaches Verhalten hier der Erkennenden dort der Nichterkennenden. Dem entspricht es, daß diesen Gleichnissen meist alle dramatische Aktion fremd ist, das Aufeinandertreffen von Willen und Willen, von Wirkung und Gegenwirkung. Vielmehr pflegt allbekanntes Verhalten von Naturwesenheiten besprochen zu werden, Gewohnheiten der Tiere, einfachste menschliche Erlebnisse. So schlichten Bildern fehlt es doch nicht an Eindringlichkeit und auch nicht an Weihe. Können Verhältnisse und Vorgänge der geistigen Welt, des geistlichen Lebens dem Verstehen und Empfinden wirksamer nah gebracht werden als durch die Gleichnisse, an die hier kurz erinnert werden möge? Vom Einssein aller Dinge im Brahman das Gleichnis von den Strömen, die gen Morgen oder gen Abend fließen und alle zu lauter Ozean werden. Vom Darinnensein des Einen in aller Vielheit jenes Gleichnis von dem im Wasser aufgelösten Salz, das sich nicht herausschöpfen läßt und durch das doch jeder Tropfen salzig ist. Vom Versinken des Geistes in traumlosen Schlaf der Vergleich mit dem, der von einem geliebten Weibe umschlungen kein Bewußtsein hat von dem, was draußen und was drinnen ist. Vom Hinwegsehen des Alltagsmenschen über das Brahman, vom Sichhinfinden des Lernenden, Strebenden zum Brahman die Gleichnisse hier von dem verborgenen Gold-

führte usw., sondern mit Bewahrung der vergleichenden Form: „Wie man einen Mann ... herführen möchte ${ }^{*}$ usw. In den folgenden Abschnitten allerdings ohne ein "Wie": „Um einen kranken Mann sitzen seine Verwandten herum" usw., und: "Einen Mann an den Händen gefesselt führen sie heran" usw. Doch das sind nicht eigentlich Gleichnisse, sondern in den betreffenden Situationen wird ohne jeden Vergleich das Wirken des All-Einen direkt aufgewiesen (verfehlt ist Deussen's Versuch, Sechzig Upan. 159, im Einklang mit Śankara den Passus vom gefesselten Dieb zu einem Gleichnis umzudeuten). Wenn bei diesen Abschnitten und bei den ihnen benachbarten Gleichnissen derselbe stehende Schlubsatz wiederholt wird, wird eben Ungleichartiges als gleichartig behandelt. 
schatz, über den der Nichtwissende achtlos immer wieder hingeht, dort von dem Mann, den man mit verbundenen Augen in die Irre geführt hat: und nun wird ihm die Binde abgenommen, und von Dorf zu Dorf fragt er sich nach der Heimat zurück. Vom Nichthaften böser Tat am Wissenden, Erlösten das später so oft wiederholte Gleichnis vom Wasser, das an der Lotosbluite nicht haftet. Diese Gleichnisse beanspruchen nicht poetisch zu sein, sondern nur das Verborgene, Geistige durch Naheliegendes und Natürliches zu verdeutlichen. Aber ungesucht weht hier oft doch auch ein Hauch der Poesie hinein, wenn der Gedanke hin und her spielt zwischen den beiden Vorstellungen, die so leicht und vollkommen in einander aufgehn: wenn von hüben diese Bilder aus Natur und Menschenleben auf die Geheimnisse des Jenseits hinzeigen, und wenn von drüben das Unerfaßbare sich herabneigt, um das Gewand des Sichtbaren anlegend selbst sichtbar zu werden.

Der Form des Gleichnisses steht die des Rätsels nah. Schon die alte Vedapoesie, die hierin offenbar eine aus noch fernerer Vorzeit stammende Neigung bewahrt, liebte es Rätsel aufzugeben und zu raten ${ }^{118}$. Begreiflicherweise zeigt sich auch in den Upanishaden, der in ihnen herrschenden Weltanschauung und Sinnesart entsprechend, fortwährend das Gefallen an rätselhaft dunklem Ausdruck und an der Treffsicherheit des Klugen, der das Geheimnis durchschaut. Prajāpati ${ }^{119}$ belehrt seine Nachkommen, die Götter, Menschen, Dämonen. $\mathrm{Zu}$ jeder der drei Wesensklassen spricht er die eine Silbe, die auch im Donner zu hören ist: $d a$. „Habt ihr es verstanden?" "Wir haben es verstanden" - und in der Tat haben richtig die einen verstanden dämyata, die andern datta, die dritten dayadhvam (s. oben S. 138). Eigentliche Rätsel sind doch in den Upanishaden auffälligerweise ganz selten. Eins der wenigen, die sich dort finden, ist folgendes: "Wer das junge Tier kennt samt seiner Wohnstatt, samt seiner Bedachung, samt dem Pfosten, samt dem Strick: der wehrt die sieben Hasser, die feindlichen Vettern 
ab." Das zu raten - es gerade so zu raten, wie der Aufgebende verlangte - wäre gewiß selbst den alten indischen Kennern nicht leicht gewesen, und auf wirkliches Raten war es denn auch wohl kaum abgesehen. Die Upanishad selbst gibt die Lösung: „Fürwahr dies ist das junge Tier: dieser Odem in der Mitte. Dies ist seine Wohnstatt (hier wies man, scheint es, auf den Körper). Dies ist seine Bedachung (man wies auf den Kopf)“, usw.

Von sehr viel größerer Bedeutung als diese Weise, Spielereien des Gedankens spielerisch in Szene zu setzen, ist das letzte hier zu beschreibende Mittel, das den Upanishadverfassern zu Gebote stand, in die Eintönigkeit ihrer Prosa erhöhtes Leben und Schönheit zu ergießen: die Einfügung von Versen.

Schon die ältere Zeit kannte nicht allein in der kunstmäßigen Erzählung den Wechsel von Prosa und Versen. Auch die lehrhafte Prosa pflegte hier und da ihren Schritt für einen Augenblick anzuhalten, um einem Vers Raum zu lassen ${ }^{120}$. Der faßte bald das Dargelegte für das Gedächtnis als versus memorialis zusammen oder er bestätigte dessen Wahrheit, hob seine Bedeutung und Merkwürdigkeit in pointiertem Ausdruck hervor. Zuweilen griff man da nach altvorhandenen Versen etwa des Rigveda. Anderwärts scheint es, daß diese Verse neu gedichtet sind, eben um an der betreffenden Stelle angeführt zu werden.

In gleicher Weise nun verfuhren die Upanishaden. Zuweilen gaben sie auch statt eingeschobener Verse versifizierte Einleitungen einer folgenden Darstellung: in Versform wurde das Thema vorangestellt, das man dann in prosaischer Erläuterung jener Verse ausführte. In die Sphäre wirklicher Poesie erhob sich all das kaum; meist blieb es, wie so Vieles in den Upanishaden, in zuweilen recht übler Pedanterie befangen ${ }^{1}$ ).

1) Man sehe die Verse von Chānd. Up. VII, 26, 2 über den Schauenden, dessen beschränktes Dasein sich zu vielfältiger Fülle erweitert:

„Er ist einfach und ist dreifach, und fünffach ist er ebenfalls, Siebenfach ist er, dazu neunfach, und auch als elffach kennt man ihn. Einhundert zehn und eins ferner, und zwanzig Tausende an Zahl." 
Mit solchen an sich unerheblichen Anfängen aber hatte man einen Weg betreten, der weiter führte. Der Einzelvers oder die kleine Versgruppe konnte zu längeren Versreihen anwachsen, denen auf diese Weise gewichtigere Geltung zuteil wurde. Vor allem aber konnte das Sichregen der Phantasie stärker und freier werden. Bilder konnten die Schlichtheit der Gedankengänge schmücken. Das durch die neu sich auftuende Ideenwelt wachgerufene Fühlen konnte seinen Ausdruck suchen.

In dieser weiter und höher sich entwickelnden Gestalt erscheinen Verse innerhalb der ältesten Gruppe der Upanishaden freilich noch selten. Eine einzige, die Iśā Upanishad, besteht fast ganz aus Versen: einer kurzen Versreihe, doch eben durch das Fallenlassen der Prosa wichtig für die Entwicklungsgeschichte der Upanishadform. Im übrigen findet sich in den alten Upanishaden eine äußerlich und innerlich bedeutende Versmasse eigentlich nur an einer Stelle ${ }^{121}$ : in jener Rede des Yājnavalkya, die von der Schilderung des wachen Daseins durch die Zwischenzustände von Traumschlaf und Tiefschlaf zum Tod und dem Eingehen in das Brahman fortschreitet (S. 154). Zuerst setzen die Verse dort ein, wo vom Traumschlaf die Rede ist. "Da sind", heißt es in der Prosa über die Schöpferkraft des Geistes im Traum, "nicht Wagen, nicht Gespanne, nicht Wege. Sondern Wagen, Gespanne, Wege schafft er sich. Da sind nicht Wonnen, Freuden, Lüste. Sondern Wonnen, Freuden, Lüste schafft er sich. Da sind nicht Seen, Lotosteiche, Flüsse. Sondern Seen, Lotosteiche, Fluisse schafft er sich. Denn er ist der Schöpfer." „Darüber", wird dann fortgefahren, "gibt es diese Verse":

„Das, was des Leibes ist, zur Ruhe bettend Blickt er, der Wache, auf der Sinne Schlummer, Tränkt sich in Glanz und kehrt zur Heimat wieder, Der Schwan, der einsame, der Geist, der goldne." 
„Das niedre Nest behütet ihm der Odem $^{1}$ );

Er, der Unsterbliche, entfliegt dem Neste.

In freier Lust schweift er umher unsterblich

Der Schwan, der einsame, der Geist der goldne."

„In Traumeswelten auf und nieder schweifend

Erschafft der Gott sich vielerlei Gestalten.

Jetzt scheint mit Frau'n er Liebesspiel zu treiben,

Jetzt lacht er, Schreckensvolles jetzt erblickt er."

„Seinen Lustgarten ${ }^{2}$ ) nur sieht man;

Niemand vermag ihn selbst zu sehn."

Am reichsten aber mit Versen geschmückt ist der Abschnitt derselben Rede vom Erlösten und vom Brahman. Da heißt es zuerst:

„Wenn sich, was ihm das Herz füllte, alles Wünschen

Geht der Sterbliche unsterblich in das Brahman hat abgelöst, hienieden ein."

Bald folgt dann eine Reihe von vierzehn Versen in wechselnden Versmaßen, jenes selbe Thema ausführend und den verherrlichend, der das Wissen von diesen Geheimnissen besitzt. Einiges davon ist uns schon früher begegnet ${ }^{3}$ ). Da heißt es noch:

„Dieweil wir hier sind, wird dies Wissen unser.

Hat man es nicht erkannt, folgt schweres Unheil.

Unsterblich werden sie, die dies erkennen.

Die Andern gehen ein ins Reich des Leidens."

„Unterhalb seiner Höh durchkreist die Zeit mit Jahr und Tag die Bahn.

Ihm huld'gen als der Lichter Licht die Götter, als Unsterblichkeit.“

Gegen Schluß des Ganzen noch ein einzelner Vers:

1) Im Leib des Schlafenden, den der Geist verlassen hat, ist Atem und Leben zurückgeblieben.

2) Der Leib ist gemeint.

$\left.{ }^{3}\right)$ Siehe S. 77f. 92. 131. 
„Dies ist die ew'ge Größe des Brahmanen.

Sie wächst noch schwindet nicht durch Frucht der

Man suche ihre Spur. An ihrem Finder

Werke.

Kann keines bösen Werks Befleckung haften."

So hält hier die Poesie des Brahman, der weltabgewandten Hingabe an ein Jenseitiges, ihren Einzug. Man will nicht lehrhaften Gehalt vortragen. Die Glückseligkeit des Besitzes, der dem Erkennenden, tief Ergriffenen zu teil geworden ist, kann nicht schweigen. Sie breitet triumphierend ihr eignes Bild und des Brahman Herrlichkeit aus; sie redet vom Elend der Andern, dem sie selbst entronnen ist. Von Ordnung und Aufbau ist wenig vorhanden. Wiederholungen sind häufig. Die Sprache ist schlicht, an Schmuck nicht reich. Hier und da erscheint doch ein schwungvolleres Wort, ein schöner bildlicher Ausdruck - der Geist als der einsame Schwan -, eine eindringliche Häufung von Beiworten, wie wenn vom höchsten Wesen gesagt wird:

„Staubfrei, jenseits des Raumes, fest, ungeboren das große Selbst."

Vorstufen dieser Poesie reichen bis zum Rigveda zurück. Sie selbst bereitet ihrerseits den Dichtungen der jüngeren Upanishaden, dann des Buddhismus, des Jainatums den Weg. Hält man sie etwa mit Texten wie dem Dhammapada oder dem Suttanipāta der Buddhisten zusammen, so kommt diesen, wie sich von selbst versteht, in der Entfaltung von Form und Inhalt, im Reichtum der Erfahrungen über das Hinund Herwogen des Seelenlebens, in der eindringlichen Kraft der Beredsamkeit der höhere Rang zu. Aber neben der Blüte werden wir auch die Knospe nicht gering achten. Das gilt von dieser Poesie, wie es von den alten Upanishaden überhaupt gilt. 


\section{Rückblick.}

Wir blicken auf die dargestellten Gedankenmassen zurück, um kurz und schärfer als es der obigen notwendig an vielen Einzelheiten haftenden Besprechung möglich war, einige der herrschenden Grundzüge hervorzuheben. Und wir versuchen für das Ganze den Platz zu bestimmen, den es in weiteren Zusammenhängen einnimmt.

In ferner Vergangenheit hatte sich der Zauberer zum Priester entwickelt. So fängt in der Zeit der Upanishaden der Zauberer-Priester an, Philosoph zu werden. Phantastisches Nachdenken von Technikern des Opfers schlägt eine Richtung ein, in welcher sich deren wirre und dumpfe geistige Bedürfnisse immer mehr läutern. Man sucht nach der ein en beherrschenden Macht alles Daseins, dessen ein er Wurzel. Durch solche Erkenntnis zum Mittelpunkt hin vorgedrungen wird man mit einem Schlage den ganzen Umkreis bemeistern.

Die Weise der Gedankenführung ist auf der einen Seite noch im alten Zaubertum befangen, wo "Neun ist Eins, und Zehn ist keins." Aber hier und dort beginnt sich aus dem Wirrwarr die Kraft und Kunst philosophischen Denkens zu erheben: Bewußtsein kann es nur geben, wo die Zweiheit des Sehers und des Gesehenen, des Erkenners und des Erkannten da ist; im Reich des All-Einen aber wen sollte der Erkenner erkennen? Da blickt aus den Worten Seher, Hörer, Erkenner, aus den Worten Gesehenes, Gehörtes, Erkanntes der Gegensatz von Subjekt und Objekt hervor und schickt sich an, die Fülle seines philosophischen Inhalts zu ent- 
falten. Ähnliches Sichaufhellen des Horizonts, Herrortauchen der Philosophie aus priesterlichen und Zaubersphären hätte sich im Abendland vielleicht im Bereich des Druidenwesens ereignet, wenn dieses, nicht gestört und zerstört von fremder Übermacht, dazu gelangt wäre das entsprechende Entwicklungsstadium zu durchleben.

So steht das all-eine Wesen der Upanishaden am Berührungspunkt zweier geistiger Welten. Hier unbezwingbare groteske Phantasie, dort Abstraktion, die sich von jener $\mathrm{zu}$ befreien trachtet: sie haben ihre Fäden durch einander geschlungen. Die Abstraktion, alles Sichtbare und Erkennbare, jede Begrenzung und Bestimmtheit mit leidenschaftlicher Energie abtuend, heftet dem höchsten Wesen ihr „Nein, nein" an; sie versenkt es in gestaltlose Unermeßlichkeit, wie unendlich weit jenseits der kunstverwandten Gestaltenfülle von Platons Ideenreich! Aber wenn jenes "Nein, nein" die Tafel rein gewischt zu haben scheint, sind nicht doch Spuren und Schatten alter Bilder darauf zurückgeblieben, die zu neuen Formen, zu neuer Unförmlichkeit wiederzubeleben die Phantasie geschäftig ist? Da erhalten sich am Übersein Züge, die von der Opferweisheit herkommen. Jenes verkörpert sich in der Silbe Om. Es schickt sich an, von den bizarren und gewalttätigen Künsten des Yoga sich in Beschlag nehmen zu lassen, dieser unentwirrbaren Mischung von Philosophie und Zauber. Es verwandelt sich in den Gott Brahman und geht in dieser Gestalt den Zeiten entgegen, wo es vier Gesichter haben und aus der Lotosblume entspringen wird. Der indische Geist besaß das Geheimnis, die erhabene Leerheit des reinen Gedankens und die Buntheit solcher Bilder zugleich auf dem Gesichtsfeld erscheinen zu lassen.

Die Konzeption des all-einen Wesens nun stellte zuerst, oder doch zuerst mit voller Entschiedenheit, der diesseitigen Welt ein Jenseits gegenüber. Das Jenseits des alten Vedaglaubens war nicht mehr gewesen als eine Verlängerung des Diesseits durch weitere, erfreulichere oder qualvolle 
Regionen. Das Brahman selbst hatte seine Laufbahn angetreten als eine diesseitige Potenz unter andern gleichartigen, dem Kshatra (S. 48) zwar überlegen, aber doch mit ihm in fester Korrelation stehend. Das wurde jetzt anders. Die eine große Macht, die alle Wirksamkeiten im Diesseits allein an sich zog und in sich vereinte, erwies sich in der Fülle und Art ihres Seins als etwas toto genere Einziges: und als solches fing sie nun an, bei sich selbst seiend auch, ja vor allem, unvergleichlich viel bedeutender als das Darinnensein im Diesseits, ihr Dasein jenseits der Welt zu führen. Jene alte, vom rigvedischen Dichter leicht hingeworfene und vielleicht bald fast vergessene Wendung von dem einen Viertel des Höchsten, das alle diese Wesen ist, und andrerseits seinen drei Vierteln, die unsterblich im Himmel sind, empfing jetzt vollen, vertieften Inhalt. Verschwunden aber, in bloßen Trug und Schein aufgelöst war das vierte Viertel, um den Ausdruck des alten Poeten festzuhalten, keineswegs. Dem Jenseits gegenüber behielt auch das Diesseits seine Wirklichkeit, dem Einen gegenüber die Vielheit. Spricht man kurzweg vom "All-Einen" der Upanishaden, darf man nicht vergessen, daß dieses genau genommen - wenigstens für die in den Upanishaden weit vorherrschende Auffassung (vgl. S. 84 f.) - nicht das einzige Seiende ist, sondern nur in allem Sein das einzige Beherrschende, Feststehende, Wertvolle. Die Vielheitswelt blieb immer noch das "Wahre", wenn auch „des Wahren Wahres" zu sein nur dem Einen vorbehalten war. Für jetzt hatte sich das Denken der Betrachtung und Durcharbeitung des Vielen !noch nicht so weit zugewandt, daß dies in dem anschaulichen Kontrast, wie später die Sāṃkhyalehre ihn herausarbeitete, dem Einen als gewaltiger, ja fast ebenburtiger Antagonist hätte entgegentreten können. Aber - unbeschadet dessen, daß der Ursprung der Vielheitswelt auf einen Schöpferakt des Einen im Anfang der Dinge zurückgeführt wurde - die Gegenüberstellung beider Reiche, beider Seinsformen, des einen positiven Werts und der old e n b erg: Upanishaden. 
vielen negativen, war doch an sich schon jetzt durchaus: vorhanden und trug die Kraft in sich, immer entschiedenerdie Herrschaft über das Denken an sich zu ziehen. Jeglicher Gegensatz innerhalb der Vielheitswelt, wie der von Glück und Leid, verblaßte vor der allem, dem vergänglichen Glück wie dem Leid, gemeinsamen Gegenüberstellung gegen das: unvergängliche Eine. Alle Ziele erschienen wertlos neben dem einen Ziel der Erlösung.

Es wurde eben schon berührt, wie nach gewissen Seiten der große Gegensatz, auf den hier Alles hinauslief, noch weitere, der Zukunft vorbehaltene Durcharbeitung verlangte. Hier sei ferner auf Folgendes hingewiesen. Aus jener Gegenüberstellung von Seher, Hörer, Erkenner und Gesehenem, Gehörtem, Erkanntem, also mit einem Wort des erkennenden Subjekts und des Erkenntsnisobjekts, hatte man, wie. wir sahen, schon jetzt die Folgerung gezogen, daß das Subjekt des Erkennens nicht dessen Objekt werden könne, derErkenner selbst unerkennbar sei. Da lag es nicht fern, das. Subjekt nun auch weiter von allen den Bewegungen, die sich in der Welt der Objekte vollziehen und für diese Welt charakteristisch sind, loszulösen, die Kraft des Wirkens, Handelns dem Erkenner abzusprechen. Eben dahin drängte die Beschäftigung mit einer andern Gegenüberstellung, die dem Denken offenbar vorschwebte, aber doch erst auf dem Wege dahin war, sich in voller Bestimmtheit durchzusetzen: von Werden und Sein. Selbstverständlich konnte die Diesseitswelt nur auf der Seite des Werdens stehen, während das Absolute 'schon als der sichere Hafen für die Flucht vor dem Tode, für das Ruhebedürfnis in den Mühsalen der Seelenwanderung zur Seite des Seins hinneigte. Gewiß wäre es den Denkern der Upanishaden nicht in den Sinn gekommen, in jene höchsten Regionen, wo es keine Zweiheit und darum auch kein Bewußtsein gibt, irgend welcher Bewegung des Werdens, Geschehens, Handelns Eintritt zu verstatten. Im Diesseits aber ließen sie das Absolute, seiner Vorgeschichte entsprechend, als Schöpfer und Regierer 
handelnde Allmacht betätigen. So blieb hier eine Verflechtung des Seienden ins;Werden übrig, deren Beseitigung, je schärfer der Gegensatz von Werden und Sein sich zuspitzte, um so dringender gefordert scheinen mußte. Ob und wie diese Aufgabe gelöst worden ist, wird später zu betrachten sein. -

Man hat die Upanishadenlehre in die nächste Nähe von Kant und Schopenhauer gestellt.

Ich möchte, was darüber zu sagen scheint, an eine Bemerkung anknüpfen, die neuerdings von philosophischer Seite (Simmel) gemacht worden ist ${ }^{\mathbf{1 2 2}}$ : wobei sich zugleich Gelegenheit finden wird, die im Eingang dieses Abschnitts hervorgehobenen Motive der Upanishadspekulation weiter zu präzisieren. Zwei prinzipielle Versuche seien geschehen, das zu vollbringen, worauf das philosophische Denken als solches eingestellt ist, die Ganzheit des Seins zu ergreifen, eine Verständlichkeit dafür zu schaffen, daß der denkende Geist von dieser Ganzheit berührt ist und auf sie antwortet: der eine der Weg der Mystik, der andre der Kants. Die Mystik etwa Meister Eckharts sammelt die Ganzheit der Welt in einen Punkt: Gott, der "weder dies noch das" ist, sondern alles „ein und einfältig in sich selber." Dies Eine aber ist nichts andres als das Innerste unsrer eignen Seele, deren letzter, einfacher Lebenspunkt, das „Fünkchen“, mit Gott eins und nicht nur vereint. "Mein Auge und Gottes Auge ist ein Auge und ein Gesicht." In jenen Grund der eignen Seele uns versenkend gelangen wir zum Grund alles Seins, erleben wir unmittelbar dieses als Ganzes.

In andrer Richtung verläuft der Weg Kants. Hier ist das Grundmotiv, daß im Erkenntnisprozeß der Weltinhalt in die Formen eingeht, die der erkennende Geist in eigner Aktivität jenem aufprägt. So wird die Unerschöpflichkeit der Welt im Geist gesammelt; das Chaos, vom Geist die Form empfangend, wird zu dem, was wir Natur nennen, jenem Zusammenhang, in dem alle Mannigfaltigkeiten sich zu einer durch Gesetze zusammengehaltenen Einheit ordnen. 
In diesem Sinne schreibt der Verstand der Natur ihre Gesetze vor, bringt die Natur so überhaupt erst zustande: die Natur d. h. das Weltdasein, sofern es in unserm Bewußtsein ist und in ihm sich $\mathrm{zu}$ einem Ganzen formt - denn von den Dingen, außer insoweit sie unser Bewußtseinsinhalt sind, können wir überhaupt nicht sprechen.

Also um die Gegensätzlichkeit der mystischen Lösung des Weltproblems und der Kants kurz zusammenzufassen: dort unmittelbare Durchdringung von Seele und Welt; hier das Bewußtsein 'das Weltmaterial zur Welt formend. Das Ganze der Welt wird ergriffen in seiner Reduktion dort auf die formlose Substanz, hier auf die inhaltlose Form.

Meint man die Upanishadgedanken in der Nachbarschaft Kants zu finden, so hat man, scheint mir, für diese Ortsbestimmung von jenen beiden Polen den falschen gewählt.

Soviel ist zunächst klar, daß es den Upanishaden durchaus fern liegt, die erkenntnistheoretischen Probleme, an denen bei Kant Alles hängt, aufzuwerfen oder gar in den Vordergrund $\mathrm{zu}$ stellen, auf Unterscheidung dessen hinzuarbeiten, was in unserm Weltbild von den Dingen kommt und was von dem sie auffassenden Erkenntnisorgan. Wie wären auch solche Fragestellungen hier zu erwarten? Es war ja das einzig Natürliche, daß jugendliches Anschauen und Denken zuvörderst durch lange Zeiten geradeaus und unbefangen in das Weltdasein hinaus, in das Seelenleben hinein blickte, ehe es anfing, den Vorgang dieses seines eignen Wirkens - anders als etwa in elementarster Weise zu analysieren, den Apparat zu untersuchen, durch den man die Dinge und sich selbst sieht: wo dann erst der Gedanke entstehen konnte, daß wesentlichste Züge des erscheinenden Bildes auf die Konstruktion dieses Apparats zurückzuführen sein möchten. Und auch abgesehen von jeder näheren Analyse des Erkenntnisvermögens, schon diese allgemeine Erwägung den Upanishaden zuzuschreiben erscheint mir als Mißverständnis, die Welt existiere für mich nur, sofern sie 
in meinem Bewußtsein vorhanden ist, so daß sie nur Erscheinung im Sinn Kants ist. ${ }^{123}$ Ein Gedanke so durchaus im Stil einer andern Welt, eines andern Zeitalters gedacht, wie etwa gegenüber der naturwüchsigen und phantastischen Betrachtung des Sternenhimmels im Veda die Ideen von Kopernikus und Kepler. Wo fände sich in den Upanishaden die Spur des Überspringens so weiter Fernen der Geistesgeschichte? Man weist vor allem auf jenes Wort Yājnavalkyas an Maitreyī hin: nicht um des Gatten willen ist der Gatte lieb, sondern um des Selbstes (ātman) willen - Söhne, Besitz, Welten, Götter, das All ist nicht um seinetwillen lieb, sondern um des Selbstes willen. Heißt das aber wirklich, wie man gewollt hat, daß das Selbst als das Subjekt des Erkennens Träger dieser ganzen Welt ist, die ihre Realität nur durch jenes hat, ohne jenes nichts ist? Nein, vom Erkenntnisvorgang, von der Realität der Welt, von Beziehung dieser Realität zu jenem Vorgang ist in Yājnavalkyas Worten ja überhaupt nicht die Rede. Gefragt wird nicht, wodurch und inwiefern Welten und Götter sind, sondern um wessen willen sie uns lieb sind. Wir lieben, sagt Yājnavalkya, in Wahrheit allein unser Selbst; alle andre Liebe fließt aus dieser Liebe und dient ihr: wobei das in der Tat deutlich genug ausgesprochene Bekenntnis zur Selbstliebe ${ }^{124}$ doch wohl aufgefaßt werden darf als vertieft durch den mitklingenden Gedanken, daß das eigne Selbst das Allselbst ist. Dann fährt Yājnavalkya freilich fort, vom Lieben des Selbst zum Denken des Selbst übergehend: „Das Selbst wahrlich soll man sehen, hören, denken, sich darin vertiefen, o Maitreyĩ. Durch das Sehen, Hören, Denken, Erkennen des Selbst wahrlich wird alles dies (Dasein) gewußt." Doch auch in diesen Sätzen wäre es Willkür, einen Anklang an Kant zu finden. Wir haben uns schon oben mit der Stelle beschäftigt (S. 93). Im Selbst, will der Weise sagen, liegen alle Werte; aus dem Selbst stammt alle Lebensfülle; so ist denn in der Erkenntnis des Selbst alle Erkenntnis beschlossen: ein Gedanke so zu sagen in einer andern Ebene. 
liegend als die Problemstellungen der Erkenntnistheorie, als die Kritik der reinen Vernunft.

So weit nun nach alldem die Weise Kant'scher Reflexion, die „ihren Angelpunkt im Formbegriff hat" (Simmel), von der Formlosigkeit dieses altindischen Weltbildes entfernt ist, so allernächst berührt sich das letztere mit jener zweiten Grundrichtung des Philosophierens: mit der Mystik, in deren Wesen es liegt, über der Versenkung in die formlose Substanz sich des Hinblickens auf die Form der Erscheinungen zu entschlagen.

Wie bei Eckhart, so ruht in den Upanishaden alles Betrachten und Empfinden des Weltdaseins auf dem einen mächtigen Fundament: auf dem Sichzusammenschließen jeglicher Existenz in der Einheit des göttlichen Wesens - in jener Allheit, die Eckhart "weder dies noch das", "Nichts" nennt, Yājnavalkya das „Nein, nein". Und weiter: wie Eckharts „ungeschaffenes Licht in der Seele“, das „Fünkchen", so wohnt der Ātman der Upanishaden der Seele als innerster Mittelpunkt inne, in dem sich das Allwesen unmittelbar offenbart, der das Allwesen ist. Jener Satz des christlichen Mystikers, daß mein Auge Gottes Auge und Gesicht ist, oder daß die Seele und Gott nur eine Seligkeit, nur ein Reich ist, könnte einer Upanishad angehören.

Unbeschadet aller selbstverständlichen Verschiedenheit in Farbe und Linienführung sind es also die Gedankengebilde der großen christlichen Mystiker vielmehr als Kants Vernunftkritik, denen die Upanishaden nächst verwandt sind. In der antiken Welt, kann man hinzufügen, ist es vornehmlich Plotin; im Islam ist es der Sufismus. Zwischen allen diesen Formen der Mystik und den Upanishaden drängen sich, wohin man nur sieht, die weitgehenden, tiefgreifenden Parallelen auf. Und wenn Schopenhauer den Gleichklang reines eignen Denkens mit dem der alten indischen Meister so nachdrücklich und voll Ergriffenheit betont hat, spricht aus ihm weniger der Jünger Kants, als der von einem Zug der Mystik Berủhrte. ${ }^{195}$ 
Damit sind wir denn auf das Motiv geführt worden, das in den Upanishaden dem Hinstreben des philosophischen Intellekts zur Einheit alles Seins die besondere Färbung gibt: die Sehnsucht der Mystik nach dem Ineinanderaufgehen des eigenen Ich und des Allseins jenseits von Vergänglichkeit und Tod. Diese Sehnsucht ergießt in die Gedankenarbeit der Upanishaden Leben, gibt ihr Flügel, so wie andrerseits die Spekulation jenem wortlosen Drang und Genießen Worte darbietet sein unaussprechliches Geheimnis zu offenbaren.

Der brahmanisch-priesterlichen Herkunft dieser Mystik entspricht ihr intellektualistischer Charakter, die starke Betonung des Wissens. Ebenso die selbstbewußte Weise, wie neben der Sehnsucht nach Aufgehen des Ich in der Gottheit die Gewißheit ihres Innewohnens im Ich beständig zur Geltung gelangt. Weiter, damit eng zusammenhängend, die Überzeugung, daß zum Erreichen des Ziels, zum Sieg über Leiden und Tod nur die - freilich der Mithilfe eines Wissenden bedürftige - eigne Geisteskraft führt.

Es ist hier nicht zu untersuchen, wieweit diese Züge, welche das indische, älteste Exemplar höherer Mystik bezeichnen - neben ihnen wäre noch die ausgesprochen pessimistische Beurteilung der Diesseitswelt hervorzuheben - auch anderwärts wiederkehren. In keinem Fall können sie die wesentliche Gleichheit aller Exemplare unter einander irgend verdecken. Die über die Erde reichende Identität des räumlich und zeitlich Entfernten, die den Betrachter niedrigster religiöser Gebilde so oft erstaunen macht, kehrt auf andrer Stufe hier noch einmal wieder. Denn eben hier fallen die Zufälligkeiten, die endlosen Möglichkeiten fort, die Verflechtungen in tausend wechselnde Beziehungen des Lebens, die das religiöse Wesen sonst durch so unberechenbar verzweigte Entwicklungsbahnen hindurchführen. Die Verschiedenheit der menschlichen Sprachen macht hier dem einen Schweigen Platz, das, wenn es doch von seinem inneren Glück reden muß, nur nach wenigen fast unvermeid- 
lichen Worten zu greifen weiß, das eigne Einssein mit dem einen Seienden zu feiern. Es ist, als ob der Grund und Boden, auf dem die Ströme der religiösen und philosophischen Entwicklung rinnen, so gebildet wäre, daß von allen Seiten die Wasser eben hier in einem Bett zusammenfließen müssen.

Das „Brahman“, das im Gedankenreich zur Herrschaft. gelangt, trägt zunächst selbst noch, wie sein Name anzeigt, den Zug des Brahmanentums, des Kastengeistes an sich. Aber in seinem Wesen liegt es schließlich doch, an der Zerstörung dieser Schranken zu arbeiten, vorwärts zu weisen dahin, wo der Buddhismus stehen wird. Wie die Spekulation über dem alten Weltbild eine neue allüberragende Stufe des Seins aufbaut, baut sich im sozialen Dasein der Upanishadenzeit abseits von den Kasten der Weltmenschen der Stand der Śramana als ein anders und höher gearteter auf. Neben ihm erscheinen auch die Brahmanen als gleich den übrigen Kasten ins Weltleben verflochten. Vergleicht man den Śramanastand mit der Brahmanenkaste, so fällt der geschichtliche Fortschritt sehr deutlich in die Augen. Das Wesen des Brahmanen beruht, man kann sagen, auf Zaubereigenschaften. Das Śramanatum beruht auf Wissen und mystischem Schauen, oder wenigstens auf dem Streben danach: wobei der Zusammenhang mit Zaubertum wohl, wie begreiflich, nicht auf einen Schlag gelöst, aber doch gelockert ist. Der Brahmane wird als solcher geboren, als Glied einer der Familien, in denen das Brahmanentum erblich und auf die es beschränkt ist. Śramana dagegen wird man als Individuum, durch eignen, persönlichen Entschluß. So ist der Weg vom Brahmanen zum Śramana ein Fortschreiten von alter Gebundenheit zur Freiheit.

$\mathrm{Zu}$ einer Freiheit zwar, die für jetzt nur Auserwählten zugute kommt. Der Zugang zu den Geheimnissen ist schwer. Die eifersüchtigen Hüter der Mysterien gewähren Wenigen ihre Hilfe. Wem solche Gunst nicht vergönnt wird oder 
wer nicht die Kraft besitzt, das Dargebotene sich anzueignen, vollends aber die große Masse, die nichtgeistlichen Menschen, finden das Heiligtum auch jetzt wie in der alten Ordnung der Dinge verschlossen. Hier wirkt ja nicht göttliche Gnade, die sich auch des Geringen und Hilflosen erbarmen mag, sondern das eigene Wissen. Ja die Ausschließung wird eine noch strengere als zuvor. Die Zaubereigenschaft des Brahmanen ließ sich auch für den nutzbar machen, der sie nicht selbst besaß; er brauchte nur ihren Besitzer zu bezahlen. Eben die innerlichere Auffassung der neuen Zeit dagegen bringt es mit sich, daß Wissen und Vertiefung des Śramana allein ihm selbst das Heil bringen kann. Nur eine zufällige Nebenwirkung ist es, wenn das Dasein solcher Geheiligter auch dem Draußenstehenden ermöglicht, durch Gaben und Dienste, jenen dargebracht, niederen Preis, den Lohn guter Werke zu erwerben: ein in den alten Quellen wenig hervortretendes Anhängsel der Erlösungslehre, das man später mit bezeichnender, in mancher Hinsicht bedenklicher Vorliebe kultiviert hat. Der Frieden und die Glorie des Brahman selbst aber leuchtet in das Leben des Alltagsmenschen nicht hinein. Wohl ist alles Weltdasein vom Brahman durchdrungen. Aber eben aus dessen Verflechtung mit der Welt ist ja gerade das Leiden erwachsen, vor dem man flieht. Ein Teilhaben am Reich des Ewigen gibt es nur, wo jedes Lebensbedürfnis verschwunden ist außer dem einen der Aufhebung dieses Lebens. Das Bewußtsein hiervon, in den Zeiten der alten Upanishaden heranreifend, befestigt sich immer mehr, wie nun neue Generationen an die Gedankenarbeit herantreten, um unfertige Fragestellungen und Fragebeantwortungen fortzubilden, Widersprüche auszugleichen, das Zerstreute in festem Zusammenhang zu vereinigen. 


\section{Zweites Kapitel.}

\section{Die jüngeren Upanishaden und die Anfänge von Sāmkhya und Yoga.}

Auf die alte Schicht der Upanishaden, mit der wir uns beschäftigt haben, folgt eine zweite. Wie es der fortschreitenden Entwicklung entspricht, heben sich diese Texte im ganzen in stärker ausgeprägter Eigenart von einander ab. Gewisse gemeinsame Züge ihres literarischen Charakters sind doch sichtbar. Der Anschluß an den Typus, den wir in der älteren Textgruppe kennen lernten, tritt sehr deutlich hervor, doch zugleich auch ebenso deutlich ein allmähliches Anderswerden. Von der Weise der alten Brāhmanatexte löst sich die Darstellungsform immer mehr ab. Die Gewöhnung wächst, verhältnismäßig größere Kompositionen zu schaffen, die der Erörterung eines bestimmten Problems gewidmet sind und dementsprechend von einer gewissen Einheit beherrscht werden. Der Inhalt dieser Texte setzt, wie die folgende Darstellung ergeben wird, ein Überschauen weiterer Zusammenhänge voraus, die Fähigkeit des Gedankens, vielerlei Fäden festzuhalten und auseinander zu halten. Trotzdem entfernen sich diese Upanishaden von ihren Vorgängerinnen nicht sehr weit in der unermuddichen Neigung zu Wiederholungen, zu beständigem Behaupten, während wenig bewiesen wird, zu sprunghafter Abgerissenheit, unvermitteltem Wechseln des Tons. Auch jetzt versteht sich das Bedurfnis von selbst, den Gedankeninhalt nicht, oder nicht allein, in nackter Abstraktheit zu geben. Man will die Schönheiten, Erhabenheiten, Schrecken, die in 
den Erkenntnissen wohnen, zur Geltung bringen, Bilder schaffen, Hoffnung und Furcht reden lassen, den ganzen Menschen ergreifen und umwandeln. Diese Tendenzen finden in der wachsenden Unabhängigkeit vom Brāhmaṇastil freiere Bahn. So tritt vor der Prosa die Poesie vielfach stärker hervor als in der vorangehenden Zeit. Statt der kurzen philosophischen Hymnen der Veden, der von Prosa umgebenen Versreihen, die wir an einigen Stellen der alten Upanishaden auftauchen sahen, erscheinen mehrfach ganze Lehrgedichte ${ }^{126}$. Da sind die Verse oft nachlässig gebaut. Aber wenigstens in einem Text wie der Käthaka Upanishad zeugt manches unvergeßbare Wort, manche tiefgründige Vergleichung davon, wie die Sprache, die hier geführt wird, aus dem Innersten kommt.

Unter den einzelnen Upanishaden dieser Gruppe, die spezielle Hervorhebung und Charakteristik verlangen, ist die älteste und zugleich zweifellos bedeutendste die eben erwähnte Kățhaka Upanishad. Ein Anhauch von vedischer Denk- und Redeweise ist in ihr deutlich fühlbar ${ }^{127}$. Die Upanishad ist auf einer Brāhmanastelle aufgebaut, welche die kunstgerechte, höchsten jenseitigen Lohn bringende Schichtung eines Feueraltars lehrt. Der Eingang dieser Stelle, in gewöhnlicher Brāhmanaprosa verfaßt, ist nahezu gleichlautend in die Upanishad als deren Eingang übernommen: „Uśant, des Vājaśravas Sohn, gab seine ganze Habe $^{1}$ ) hin. Er hatte einen Sohn mit Namen Naciketas. In diesem, der noch Knabe war, erwachte bei der Einherführung der Opfergaben Glauben ${ }^{2}$ ). Er sprach: ,Vater, wem wirst du mich geben?' (Und so sprach er) zum zweiten, zum drittenmal. Jener antwortete ihm (von Zorn) ergriffen: ,Dem 'Tode gebe ich dich'." Beide Texte erzählen

1) Als Opferlohn für die Priester.

2) Die Gaben an die beim Opfer tätigen Priester bestehen in Kühen. Der "Glaube" ist die in Freigebigkeit sich betätigende Zuversicht zur heiligen Kraft der Priester und ihres Opferns (Zeitschr. der Deutschen Morg. Ges. 50, 448). 
dann vom Hinabstieg des Knaben zum Totenreich, wo ihm der Todesgott drei Wünsche gewährt. Wie ist aber die Kahlheit des Brāhmana in der Upanishad umgestaltet und vertieft! Statt dürrer Ritenkunde ein ergreifendes Bild unbezwingbaren Verlangens, das in des Knaben Seele wohnt, nach tiefstem, todbefreiendem Wissen. Von jenen ersten Prosasätzen gleitet die Upanishad alsbald zu poetischer Form hinüber. Der entscheidende unter den drei Wünschen ist der dritte, größte. Der Knabe spricht zum Gott:

„In Zweifel ist gehüllt der Toten Schicksal:

Sie sind, spricht dieser. Sie sind nicht, spricht jener. Das will ich wissen. Das sollst du mich lehren.

Dies ist der dritte Wunsch, den ich erwähle."

Der Tod weigert sich zu enthüllen, wonach selbst die Götter vergebens geforscht haben. Doch Naciketas läßt sich nicht abweisen:

„Kein andrer ist, der es wie du mir künde,

Kein andrer Wunsch, den ich für diesen wähle."

Nun bietet ihm der Gott alle Genüsse der Welt, Reichtümer, langes Leben. Naciketas besteht unentwegt:

„Kein Reichtum mag dem Menschen Gnüge geben:

Was soll uns Habe, wenn wir dich erblickten?

Wir werden leben, so lang du gebietest,

Doch jener Wunsch allein ist's, den ich wähle.

Alter- und todbefreites Sein erkennend

Der Alternde, der Sterbliche hier unten:

Möcht er, auf buntes Glück und Lust und Wonne

Hinschauend sich wohl langes Lebens freuen?"

Man kann vielleicht die Situation jenes älteren Dialogs (oben S. 154) vergleichen, wo Yājnavalkya seinem königlichen Hörer das letzte Wort uber das Geheimnis der $\mathrm{Er}_{-}$ lösung auszusprechen zögert. "Von nun an rede nur, was zur Erlösung dient", sagt der König immer wieder. Aber statt der hieratischen Starrheit jenes Textes, welches Leben und welche Größe - eine Vorahnung buddhistischer Größe - 
Im Bilde des Naciketas, der ohne Besinnen Glück und Glanz fahren läßt, um das eine höchste Gut, das Wissen, das über Alter und Tod hinausführt, dem Gott abzuringen. Endlich ist dessen Sträuben besiegt:

„Dein ist dies Wissen. Fest hast du beharret.

Mög Frager ich gleich dir, o Jüngling, finden."

Und nun geht der Dialog in ein Lehrgedicht über. Der Todesgott spricht vom ewigen Seher, der körperlos in den Körpern, beharrend im Nichtbeharrenden weilt, im eignen Innern erschaubar:

"Wer das gesehn, kommt aus des Todes Rachen los." -

Ein andres Lehrgedicht ist die Śvetāśvatara Upanishad. Auch mit ihr werden wir uns eingehend zu beschäftigen haben, mit der Schönheit und der Verwirrtheit ihrer Verherrlichung des persönlichen Gottes ${ }^{\mathbf{1 2}}$.

An dritter und letzter Stelle ist der offenbar weitaus jünste der hier in Betracht kommenden Texte hervorzuheben, die Maitrāyana Upanishad. In ihr überwiegt Prosa, die vielfach nach der Weise der alten Brāhmanas und Upanishaden zu reden versucht, aber doch den starken Abstand von jenen fortwährend verrät. Grundbestandteil ist ein Dialog, genauer zwei ineinander geschachtelte Dialoge. Die Personen, die da auftreten, sind in sehr anderm Stil gezeichnet als in den alten Upanishaden die Lehrer mit ihren herdenhütenden Schülern oder die Brahmanen, die vor dem König um den Preis von Kühen und Gold disputieren. König Bṛhadratha „ergab sich, da er diesen Leib als vergänglich erkannte, der Entsagung und zog in den Wald hinaus. Dort vollbrachte er höchste Kasteiung. In die Sonne blickend stand er mit emporgestreckten Armen da. Als tausend (Jahre) vergangen waren, nahte sich dem Asketen, rauchlosem Feuer gleich, wie von versengender Glut erfüllt, ein Ātmankenner, der erhabene Śākāyanya." Das sind Gestalten, die mit dem Altertum der Vedazeit kaum mehr Zusammenhang haben. Sie gehören dem in- 
dischen Mittelalter an. In vollem Einklang damit stehen die stilistischen Eigentümlichkeiten dieser Upanishad. Sie deuten, scheint mir, unverkennbar in jüngere Zeit als die frühbuddhistische. Die endlosen Aufzählungen - so der vielen mächtigen Könige, die alle aus dieser Welt haben scheiden müssen, oder der Laster, die aus den "Guṇa's", den Konstituenten des Naturdaseins, stammen - gehen durchaus über die Dimensionen hinaus, innerhalb deren sich die älteren buddhistischen Texte zu halten pflegen. Ebenso die überlange Reihe von Vergleichungen, welche das Elend des im Welttreiben gefangenen Geistes schildern (s. unten), oder die maßlose Ausdehnung mancher Wortzusammensetzungen: lauter Charakteristika jüngern Stils, die in ihrer Gesamtheit und gegenseitigen Übereinstimmung wohl nicht irre führen können.

Ziehen wir, was den Inhalt anlangt, die Zusätze mit in Betracht, die an den ursprünglichen Kern dieser Upanishad herangetreten sind und vielfach gerade das Wichtigste enthalten, so ergibt sich ein überaus buntscheckiges und verwirrtes Durcheinander von alten Opfervorstellungen, ritueller Symbolik und von verhältnismäßig jungen Philosophemen. Viele umfängliche Zitate - auch sie ein Kennzeichen der späten Zeit - geben Proben verlorener philosophischer Texte, die auf wichtige, uns jetzt nur unvollkommen erkennbare Vorgänge in der Geschichte der Spekulation Licht werfen würden.

Mit diesen Vorgängen müssen wir uns jetzt beschäftigen. Sie sind das Bedeutsamste, wovon die hier aufgeführten Upanishaden berichten oder worüber sie wenigstens Andeutungen geben.

\section{Die Anfänge des Sāmkhyasystems.}

Ein ähnlicher Fortschritt, wie in der literarischen Form der jüngeren Upanishaden, zeigt sich dort im Stil des Denkens. Der Rest von Zaubervorstellungen und phantastischen Ungeheuerlichkeiten, in die man sich immer noch 
verirrt, ¡nimmt ab. So häufig und stark die Vertrautheit auch dieser Denker mit Opfer und Vedawort hervortritt, ihre eigenen Gedanken entfernen sich in ihrem wesentlichen Gehalt von da mehr und mehr ${ }^{1}$ ). Dafür wird immer ernstlicher und konsequenter versucht, psychologische Tatsachen im Gesichtsfeld festzuhalten und zu analysieren. Man ordnet, schafft in manchen Punkten neu eine Terminologie, die dem Denken Halt gibt. Deutlich ausgeprägte Anfänge von Systembildung werden sichtbar. Die im Großen wirkende schöpferische Genialität des vorangehenden Zeitalters zwar hat nachgelassen. Wie hätte auch die Bewegung alsbald in gleicher Macht von Höhepunkt zu Höhepunkt fortschreiten können ohne Ruhepause, ohne daß der in kühnstem Wurf errungene Gewinn durch stille Arbeit angeeignet, durchgebildet, geklärt wäre? Man mag es Epigonenarbeit nennen, was jetzt zu leisten war. Die zu diesem Werk Berufenen aber haben nicht versagt. Sie sind auf den Bahnen, die sie eröffnet fanden, vorwärts gegangen. Nicht immer mit sicheren Schritten, doch gedankenreich, Klarheit erstrebend: so haben sie die Spekulation den Stellen nähergeführt, wo von neuem große Gebilde entstehen konnten, entstanden sind.

Jene scharfe Zeichnung des Entwicklungsganges, die man in der Geschichte der griechischen Philosophie vor sich sieht, das plastische Sichabheben der Denkergestalten und Gedankensysteme von einander fehlt auch jetzt. Schwerflußig bewegt sich der Strom vorwärts; nur leise lassen sich die Änderungen wahrnehmen, die in seiner Richtung eintreten. So grenzt sich auch das Milieu, in dem vornehmlich die Weiterbildung der alten Gedanken sichtbar wird, nur unvollkommen gegen seine Umgebungen ab. Aber bis auf einen gewissen Grad ist es doch in seiner Besonderheit

1) In dieser Weise läßt sich, meine ich, die Stellung der alten Sāṃkhyalehre - dab es sich hier um diese handelt, wird sich alsbald zeigen zum Veda beschreiben. Daß das Sāṃkhya von Haus aus „unbrahmanisch" gewesen und erst später mehr oder minder brahmanisiert worden sei, scheint mir unzutreffend. 
erkennbar. Es wird durch das Schlagwort Sāmkhya bezeichnet. Schon jetzt entwickelt sich eine diesen Namen tragende Vorstufe des späteren klassischen Sāṃkhyasystems.

Sāṃkhya bedeutet das von der Zahl Beherrschte, nach der Zahl Bestimmte. ${ }^{\mathbf{1 8 9}}$ Nicht darum zwar handelt es sich hier, etwa im Sinn pythagoreischer Lehre in die Zahl die letzte Wahrheit, das metaphysische Wesen der Dinge zu verlegen. Die Rolle der Zahl ist eine äußerlichere. Man trägt Sorge, die Kategorien, mit denen man arbeitet, in festen Reihen aufzuzählen, bestimmt $\mathrm{zu}$ wissen, aus wie vielen Gliedern, nicht mehr und nicht weniger, jede Reihe besteht ${ }^{1}$ ). Diese speziell indische Neigung zum Aufzählen, der Gedankenarbeit Bestimmtheit verleihend und sie $\mathrm{zu}$ vollständigem Überblicken des Stoffs treibend, verbunden freilich mit der Gefahr, daß durch Aufzählungen die Probleme allzu schnell für erleđigt gehalten werden, setzt zwar nicht erst hier ein. Aber sie erscheint hier bemerkbar intensiver als zuvor, um dann in der indischen Wissenschaft lebendig zu bleiben: bis zu jenen Zeiten, wo die Poetik achtzig Arten des übertragenen Ausdrucks, die Liebeswissenschaft gar dreihundertvierundachtzig Typen der Liebhaberinnen in wohlgeordnetem Aufbau den lernbeflissenen Schülern vorführte.

Die Namen der Denker, denen man die neue Philosophie zuschrieb, erwecken dadurch Vertrauen, daß wenigstens in der besseren Überlieferung statt der Opfertheologen der alten Upanishaden andre. Persönlichkeiten erscheinen. ${ }^{\mathbf{1 3 0}}$ An der Spitze Kapila; er hat immer als Begründer der Sāṃkhyalehre gegolten. Eine aller Wahrscheinlichkeit nach reale, doch für uns im Nebel der Legende sich vollständig

1) Das Interesse an derartigen Zählungen veranschaulicht etwa ein Vers der Śvetāśvatara Upanishad (I, 4), wo die Erscheinungswelt beschrieben wird als ein Rad "mit einem Radkranz, dreifach, sechzehnendig, mit einem halben Hundert Speichen, zwanzig Gegenspeichen, sechs Achtheiten, mit einem allgestaltigen Seil, auf drei Pfade sich verteilend, erfallt von einem zweibedingten Wahn". Ähnliche Zahlen gehen auch durch den nächsten Vers. 
verlierende Figur: die älteste Stelle, die ihn erwähnt, vermeldet, daß kein Geringerer als Brahman

„In seinem Geist den urerzeugten Weisen

Kapila trug und den Gebornen schaute" ${ }^{131}$.

Neben ihm hebt sich, in nicht gleich alter, aber doch auch unverkennbar guter Tradition, der Philosoph Pañcaśikha (der "fünfhaarsträhnige") hervor. Später ist dann allerdings unter den Namen der Alten, die man mit Sāmkhyalehren in Verbindung brachte, starke Verwirrung eingerissen. Wie einst im Bṛhad Āranyaka der Opfertheologe Yājñavalkya zum Verkünder der Lehre von Ātman geworden war, ganz so läßt das große Epos denselben berühmten Mann nunmehr die leitende Philosophie dieser Zeit, das Sāṃkhya vortragen. Leider steht es mit solcher Fiktion offenbar auch auf einer Linie, wenn das große Epos unter alten Sāṃkhya- oder Yogalehrern einen Asita Devala nennt. Man könnte einen Augenblick versucht sein, sich hier über einen chronologischen Hinweis zu freuen, der an das Zeitalter des Buddha denken ließe. Denn Asita Devala wird in der buddhistischen Legende der Seher genannt, der als Greis das Buddhakind besucht und seine Herrlichkeit vorherverkündet. Doch wird diese scheinbare Brücke zwischen Erinnerungen der Sāmahyaschule und des Buddhismus durch nähere Prüfung zerstört ${ }^{132}$.

Auf uns sind die Erinnerungen über Anfänge und ältere Gestalt des Sāṃkhya in einer Form gelangt, die für unsre Kenntnis der Einzelheiten und vollends für das Verständnis der treibenden Motive nicht gerade günstig ist. Einen Text aus alter Zeit, der das System solches vortrüge, besitzen wir nicht. Was wir haben, sind zunächst in mehreren Upanishaden - namentlich in den drei eben (S. 203ff.) besprochenen - einzelne Partien, in denen die Ausdrucksweise des Sāṃkhya, daneben und eng damit verbunden die des Yoga charakteristisch, wenn auch kaum ohne Beimischung von Andersgeartetem, zu Tage tritt $\left.{ }^{1}\right) . \quad \mathrm{Da}$ in

1) Weitaus die ergiebigste ist unter den drei Upanishaden die Maitr. Up. - leider eben auch die weitaus jüngste.

Oldenberg: Upanishaden. 
den ältesten Upanishaden derartiges wenigstens für das Sāṃkhya fehlt, darf unbedenklich dahin gedeutet werden, daß damals dies System noch nicht existierte: womit die innere Konsequenz der Entwicklung in unbedingt überzeugendem Einklang steht. Danach läßt sich annehmen, daß die erwähnten jüngeren Upanishaden, insonderheit die älteste von ihnen - die Kāthaka Up. - ziemlich nah an die Entstehungszeit des Sāmkhya heranreichen. Was sie aber von diesem System enthalten, sind Fragmente, zum Teil in dunkler, vielfach verwirrter Sprache. Verständlich werden die vielfach nur, indem man das sogleich zu erwähnende epische und das spätere Sāṃkhya zur Deutung heranzieht: womit man natürlich auf Schritt und Tritt der Gefahr verfällt, ältere und jüngere Gestalten dieser Vorstellungen $\mathrm{zu}$ vermischen.

Ein im Vergleich mit den Upanishadzeugnissen offenbar, wie das auch dem Alter der Texte entspricht, weiter fortgeschrittenes Stadium in der Entwicklung des Sāṃkhya - richtiger ein Durcheinander mehrerer solcher Stadien kommt dann im großen Epos, dem Mahābhārata, zur Erscheinung: verhältnismäßig knapp in der vielgefeierten Episode Bhagavadgîtā; umfänglicher, mit endlosenWiederholungen in der Masse von Dialogen, dieim Abschnitt Mokshadharma („Erlösungslehre", in Buch XII) über einander gehäuft sind ${ }^{13 *}$. Da pflegt dann eine „alte Geschichte" nach der andern berichtet $\mathrm{zu}$ werden von Unterredungen, in denen irgend ein Weiser, gleichviel aus welchem Zeitalter, vor einem gegen chronologische Bedenken ebenso gefeiten Fürsten die letzten Geheimnisse des Seins ausbreitet, in der glatten, abgenutzten Sprache, welche der poetischen Massenproduktion dieser jüngeren Mahābhāratapartien eigen ist. Die Offenbarung, die jener Beste der Weisen da dem Erdbeschützer, Männerherrn, Männerstier, Manntiger mitteilt, wird jvon diesem andachtsvoll angehört, und nachdem er das heilsame Wort vernommen, wird er von der gebührenden Freude erfüllt. $\mathrm{Da} \beta$ in Dialogen, die in so banalem Glanz prunken, der 
philosophische Gedanke meist sehr viel weniger glänzend zum Ausdruck kommt, kann nicht Wunder nehmen. Hier haben vielfach Verfasser das Wort, die von den $\mathrm{zu}$ besprechenden Gedanken nur aus der Ferne gehört haben. Sie werfen mit den Schlagworten, die da zu ihnen gedrungen sind, sorglos und wichtigtuerisch um sich. An den eigentlichen Pointen der Gedankenentwicklung liegt ihnen weniger als am imposanten Eindruck jener Schlagworte, an rhetorisch wirksamen Tiraden. Krasse Widersprüche bereiten ihnen keinen Schmerz. Trotz aller solcher Schwächen aber darf die Bedeutung dieser Quelle für die Geschichte des Sāṃkhya nicht unterschätzt werden. Sie trägt, wenn auch in ihrer eignen Weise, im.Ganzen doch Gedanken vor, die älter sind als sie selbst. Das Skelett, das die spärlichen Andeutungen, die kurzen Schlagworte der Upanishaden uns vor Augen stellen, umkleidet sie mit Fleisch und Blut und läßt so, vielfach wertlose, zerflatternde Bilder darbietend, doch oft den echten, alten Organismus erkennen. So wird es denn möglich, ja es ist in mancher Hinsicht schon jetzt erreicht ${ }^{134}$, ein vorklassisches Sāṃkhya, zwar natürlich nicht überall mit voller Bestimmtheit, zu erkennen, das nach oben an die große Âtmanspekulation der älteren Upanishaden anschließend zunächst in den jüngeren dieser Texte, dann entwickelter im Epos auftritt und dazu beigetragen hat, daß die Gedankengänge des Buddhismus die Gestalt haben annehmen können, in der ihnen so unabsehbare Wirkungen beschieden gewesen sind.

Wie schon der Ātmanlehre des Bṛhad Āranyaka, der Chāndogya Upanishad im Grunde ein dualistischer Zug beiwohnte, ist oben gezeigt worden. Daß man die volle, enthusiastische Aufmerksamkeit und Verehrung nur der einen der beiden Seiten zuwandte, verschleierte diesen Dualismus, aber beseitigte ihn natürlich nicht. Ungetrübte Einheit des Átman wohnt allein im Jenseits. Im Diesseits ist er in ein von ihm verschiedenes Dasein eingegangen, der Unsterbliche in eine Welt des Leidens und Todes. Daß man dies Tod- 
beherrschte als $\mathrm{zu}$ allerletzt selbst vom Ātman geschaffen ansah, änderte doch nichts daran, daß in der Welt, in der wir leben, das Eine dem Andern in Wesen und Wert feindlich gegenübersteht.

So war der für das Sāmkhya so charakteristische Dualismus in der Tat keineswegs eine Neuschöpfung. Die Leistung jenes Systems war es vielmehr nur, den vorgefundenen Dualismus durchzudenken und weiterzubilden. Vor allem auf der Seite des Nicht-Ātman. War für die Alten, wie natürlich, zunächst aller Nachdruck darauf gefallen, daß die Vielheit des Weltdaseins von dem Einen her Licht empfängt, konnte man sich auf die Dauer nicht der Pflicht entziehen, die in den älteren Upanishaden hintan gestellt war, auch die Kehrseite dieses Gedankens ernstlich durchzuarbeiten: daß von dem Einen her eine Vielheit Licht empfängt. Auch in dieser Richtung galt es die Vollständigkeit des Weltbildes zu erstreben, an deren Erreichbarkeit das jugendliche Denken so gern glaubt. Überdies mußte sich ja, wie neben dem Hinblicken auf das Brahman die Betonung des Weltleidens, der Zerrissenheit des Daseins anwuchs, die Aufmerksamkeit immer entschiedener darauf richten, daß das so dringend geforderte Erlösungsstreben offenbar nicht allein im Reich des Ātman vor sich geht, sondern daß ein wie auch immer beschaffenes Tun oder Geschehen in der Sphäre des Nicht-Ich - etwa wie der Yoga es vorschrieb - einzugreifen hat. Auch von dieser Seite her erwies sich als nötig, die Struktur der irdischen Sphäre sorgfältiger $\mathrm{zu}$ ergründen.

Die Antwort nun, die das Sāṃkhya auf die Frage nach dem Nicht-Ich gab, stellte sich zugleich in einer Vorstellung dar und in einem System dreier Vorstellungen; dann weiter in einer längeren Vorstellungsreihe, die uns erst später zu beschäftigen hat.

Man schuf die Lehre von dem einen Grundprinzip der materiellen Welt. Hinausgehend über jene alten Gedankenspiele, die auf ein Letztes, Bestimmungsloses hinstrebend 
doch Reste schattenhafter Bestimmtheit abzutun nicht imstande gewesen waren (oben S. 68.71), gelangte man jetzt bis zum Ziel, zu dem durchaus Bestimmungslosen. Dieses wird in der wohl ältesten auf uns gekommenen Erwähnung Avyaktam (neutr.) "das Unentfaltete" genannt: ein Name, der deutlich hinweist auf die Aufgabe dieses Prinzips das „Entfaltete" aus sich hervorzubringen. Bald treten dann in der Überlieferung - wir wissen nicht ob in Wahrheit gleich alt mit jenem Namen - die beiden Bezeichnungen Pradhānam (neutr.) "Hauptwesen" und Prakṛti (fem.) "Grundwesenheit" hinzu: die letztere in der Gegenüberstellung zum geistigen Prinzip, dem hier meist Purusha (wörtlich „Mann") genannten Ätman, durch ihr Geschlecht die Vorstellung des Gebärens, der Mütterlichkeit anregend. Daß diese "Grundwesenheit" von Hause aus neben dem Geistprinzip als gleich ewig und unerschaffen gestanden haben müsse, braucht, scheint mir, in der eben genannten Bezeichnung nicht zu liegen. Sie erklärt sich hinreichend aus dem Verhältnis der Prakṛti zu der von ihr hervorgebrachten Welt. Für die Anfänge des Sāmkhya ist die Frage nach Erschaffenheit oder Unerschaffenheit der Prakrti durch den Âtman-Purusha nicht sicher zu beantworten. Im Epos finden sich Schwankungen, aus denen vielleicht die Spur eines ältesten Glaubens an Erschaffenheit herausgelesen werden darf ${ }^{1}$ ). In jedem Fall aber konnte die Aufstellung und Benennung eines einheitlichen Prinzips der Vielheitswelt - vermutlich nach dem Vorbild des einen Ātman kaum anders als in der Richtung wirken, daß dies Naturprinzip, wenn nicht von Anfang an, so doch im Lauf der Entwicklung, dem geistigen Prinzip als ein gleich absolutes, ewiges, als ein gewaltiger Antagonist gegenübertrat.

Mit der Einführung des Avyaktam, der Prakrti war ein großer Schritt vorwärts geschehen. Die Vielheit des

1) Während das unten (S. 215) erwähnte Wortspiel, die Benennung der Prakrti als "Ziege" (zugleich „die Ungeborene") in die entgegengesetzte Richtung führt. 
Weltdaseins bot sich nunmehr, zu einer bestimmt ausgeprägten Einheit zusammengefaßt, der analysierenden Betrachtung leichter und einladender dar, als in der unsicher fluktuierenden Vorstellungssphäre der früheren Zeit. Und die alte, nur halb klare Gegenüberstellung von Einheit und Vielheit hatte jetzt veränderte Gestalt angenommen. Fortan handelte es sich um die reine Einheit und um eine andre, die ein Moment der Vielheit in sich trägt, sich zur Vielheit entfaltet.

Es ist ein bezeichnendes Schauspiel, wie das Denken in das Avyaktam alsbald - vielleicht schon vom ersten Augenblick an - das Vielheitsmotiv in Gestalt der drei "Guṇa" oder Konstituenten hineinspielen ließ: gleichsam, wie das Wort andeutet, der drei Fäden ${ }^{135}$, die zum Avyaktam als zu einem Seil vereinigt sind. Sie heißen Sattva, Rajas, Tamas und bedeuten der Reihe nach das Leichte, Freudige, sodann das Bewegte, Schmerzliche, endlich das Finstere, Dumpfe, Starre.

Wurde Kapila oder wer sonst dieser Lehre Gestalt gegeben hat, durch die Zahl drei als die erste Vielheitszahl angezogen, die jenseits vom engen Bezirk des Dual in die Unbegrenztheiten des Plural führt? Anknüpfungspunkte in älteren Vorstellungskreisen und Phantasiespielen, welche auf die Dreizahl hinwiesen und eben diesen Aufbau der Dreiheit vorbereiteten, hat die Lehre von den Guna in jedem Fall vorgefunden. Ich glaube, daß dahin schon jene Dreiteilung der verschiedensten Daseinsgebiete gehört, die entsprechend den drei Kasten des arischen Gemeinwesens bei Göttern wie bei den Versmaßen der Vedalieder, bei Jahreszeiten wie bei Zahlen jedesmal einen ersten, so zu sagen brahmanenhaften Typus, dann einen der kriegerischen Kraftäußerung, zuletzt einen der untertanenhaften Gewöhnlichkeit unterscheidet (vgl. oben S. 23). Weiter läßt sich an die drei Welten denken - Himmel, Luftraum, Erde deren mittlere dem mittleren Guṇa (Rajas) den Namen gegeben hat. Auch auf jenen Bericht von der Weltschöpfung 
(S. 69f.) ist hier zu verweisen, wo dem einen Ātman die materielle Welt als aus den drei Grundelementen von Glut, Wasser, Nahrung, oder aus dem Roten, Weißen, Schwarzen gebildet gegenübersteht: sodaß Sonne und Mond, Feuer und Blitz sich jedesmal aus roter Gestalt der Glut, weißer des Wassers, schwarzer der Nahrung zusammensetzen und Sonne oder Mond als bloßes Wort vor dem in Wahrheit Seienden, jenen drei Gestalten, verschwindet. Die mehrfach begegnende Zuteilung der Farben weiß, rot, schwarz an die drei Guṇas läßt über den hier obwaltenden Zusammenhang kaum Zweifel. Längst hat man weiter jenen Vers des Atharvaveda $(\mathrm{X}, 8,43)$ bemerkt, der direkt die „drei Guṇas" nennt. Von ihnen - vielleicht indem sie, wie das Wort Guña nahe legt, etwa als zu einer Hülle sich verwebend gedacht werden - ist "die Lotosblume mit den neun Toren" bedeckt, darin das Seelenwesen wohnt: der Leib ${ }^{1}$ ), der als aufgebaut aus den drei Grundelementen der eben erwähnten Schöpfungsgeschichte betrachtet werden mochte, oder gar aus den drei Guñas selbst, die dann im Sāṃkhya festgehalten sind. Nicht mehr den Vorstufen dieser Sāṃkhyalehre ist es zuzurechnen, sondern sie selbst liegt in vollkommner Deutlichkeit vor ${ }^{188}$, wenn ein Vers der Śvetāśvatara Upanishad

"die eine rot und weiß und schwarze Ziege"

nennt, welche viele Junge wirft: der eine Bock bespringt sie mit Lust; der andre verläßt sie, die er genossen. Das Wort "Ziege" bedeutet zugleich "die Ungeborene"; "Bock" "den Ungeborenen“. Die Ziege ist die Prakrti; ihre drei Farben - dieselben wie in jener Schöpfungsgeschichte sind die Gunas. Der Bock ist der Geist, der von der Verbindung mit der Natur ungelöste und der göttliche oder gelöste.

Genau gibt die Gunatrias keines der Vorbilder wieder, die hier im Spiel scheinen, und sie kann sie nicht genau

1) Seine neun Tore sind die beiden Augen, Ohren, Naslöcher, der Mund, die Öffnungen für Harn und Exkremente. 
wiedergeben. Die drẹ Typen der Götter, die drei oberen Kasten halten sich durchweg in der Sphäre des mehr oder minder Edien, Anzuerkennenden, während die Guṇas das Reich des Verwerflichen mit umfassen. So können unter ihren Farben nur zwei Farben jener Kasten wiederkehren: das Weiß des Brahmanen und das Rot des Kshatriya für Sattva und Rajas. Statt des dem Vaiśya gehörenden Gelb muß für den dritten Guña das Schwarz des Sūdra eintreten ${ }^{187}$. Ähnlich, während von den drei Welten die mittlere ihre Benennung für das Gunasystem beisteuerte, schien der erste und dritte der Weltnamen nicht verwendbar. Auch unter einander stehen die Bezeichnungen der Gunas nicht in vollem, glattem Einklang. In der Mitte Rajas: das Luftreich mit seinen trüben Dünsten. Dann Tamas: die Finsternis. Entsprechend würde man als ersten Guṇa am natürlichsten Jyotis "Licht" erwarten. Ist dieser Ausdruck deshalb vermieden, weil das Licht jenseits von jener Dreiheit dem über die Natur erhabenen Geist (Purusha) zu gehören schien? Man wählte statt dessen, offenbar mit ziemlich willkürlichem Griff, die Benennung Sattva „Realität“ speziell auf gefestigte, Andres überragende Realität deutend.

$\mathrm{Da} \beta$ in all dem, unbeschadet der Anlehnung an Älteres, schließlich doch im Grunde die individuelle Konzeption eines einzelnen Denkers vorliegt, ist evident. Ihm erschienen wie in greifbarer Gestalt diese drei Grundtypen des Daseins. Verglichen etwa mit jener alten auf Götterreiche und Vedametrik hinblickenden Kastenteilung des Universums (S. 23) wie viel freier waren sie doch gedacht, wie viel klarer bildeten sie das Weltleben $a b$ !

Die Frage nach Wesen oder Physiognomie der einzelnen Gunas wird schon von einer jener Upanishaden, welche die ältesten Zeugnisse über das Sāṃkhya enthalten, wenigstens für das zweite und dritte Glied des Trias durch eine Aufzählung dahin gehöriger Affekte und Zustände beantwortet. Als aus dem Rajas stammend werden Regungen wie Liebe und $\mathrm{Ha}$ hervorgehoben, Mißgunst, Sucht zu schaden, 
Wankelmut, Zerstreutheit, Streben die Oberhand zu behalten, Haß wider unangenehme Eindrücke, Haften an Angenehmem. Von des Tamas Natur ist Verwirrung, Furcht, Schlaf, Unbesonnenheit, Altersschwäche, Schmerz, Hunger, Durst, Zorn, Unwissenheit, Neid, ungleiches Wesen gegen den Einen und Andern ${ }^{138}$. Scharf ist die Grenze zwischen den beidenGebieten nicht gezogen. Warum stehen beispielsweise Haß und Zorn, oder Mißgunst und Neid auf verschiedenen Seiten? Im Ganzen hebt sich doch der Unterschied schon jetzt hervor, den die Folgezeit dann bestimmter herausgearbeitet hat: was dem Rajas angehört, ist das Erregte, Leidenschaftliche; dem Tamas, das Stumpfe, Leblose. Auch auf Seiten des Rajas überwiegt der Charakter des Ungünstigen und Verhängnisvollen. Dies dominiert mithin auf zweien der drei Gebiete: im Einklang mit dem Grundton des Pessimismus, der hier immer lauter wird. Das Bild des in jener Beschreibung fehlenden ersten Guna, des Sattva, fügen dann die epischen Texte hinzu. Da ist die Rede von Wonne, Freude, Helligkeit, Reinheit, Gesundheit, von Geduld, Festigkeit, Wahrheit, von Bedachtsein aufs Heil der Andern und Mitleid mit allen Wesen: kurz von jeglichem Guten, sofern es außerhalb der Sphäre des Ewigen, rein Geistigen, in der Bewegtheit des Weltlebens zur Erscheinung kommt. In der Unterscheidung dieser drei Reiche tritt der Gedanke an das physische Dasein, auf das die Namen des zweiten und dritten Guṇa hinweisen, doch wenig hervor; das Psychische, Ethische ist es vor allem, dessen Grundgestalten auseinander zu legen diese Lehre mit großem Wurf versucht.

Blicken wir von den einzelnen Gunas noch einmal auf ihre Bedeutung im Ganzen zurück. Sind sie Kräfte oder Eigenschaften des "Unentfalteten"? Sind sie vielmehr Substanzen? Die klassische Sāmkhyaliteratur betont sehr entschieden und ausdrücklich die letztere Auffassung. Entsprechend redet sie vom Unentfalteten als „der Summe der Guṇas"; sie vergleicht das Verhältnis jenes Prinzips zu den 
Guṇas dem des Waldes und der Bäume. Der Ausdruck "Guna" selbst, auf die Fäden gegenüber dem aus ihnen gedrehten Seil hinweisend, dazu Äußerungen der Upanishaden, die den Gunas offenbar selbsteignes Dasein und Erleben zuschreiben, bestätigen diese Auffassung auch für die alte Zeit. Man wird doch, vermute ich, im Sinn des früheren Sāṃkhya diese Substanzialität der Guṇas nicht sehr weit von der Vorstellung von Kräften oder Eigenschaften abzurïcken haben. Es gehört ja zum Charakter des altertümlichen Denkens, daß eine klare Scheidung von Substanzen, Kräften, Eigenschaften noch nicht durchgeführt ist. ${ }^{139}$ Die Kraft, die einem Wesen innewohnt, ist selbst ein Wesen, das in jenes leibhaftig hinein- oder aus ihm herausfährt, wie vielleicht das Gebot des Zauberers es hierhin und dorthin lenkt. Daß die alte Sāmkhyalehre mit solchem Zauberglauben auf einer Linie steht, soll natürlich nicht behauptet werden. Aber sie ist von ihm doch auch noch nicht überall durch unübersteigbare Schranken getrennt. So wird man sich die Guṇas des älteren Sāṃkhya, in unvermeidlich unbestimmtem Bilde, etwa dahin verdeutlichen dürfen, daß man in ihnen Substanzen sieht - es ginge einen Schritt zu weit, von nebelhaften, so zu sagen unpersönlichen Persönlichkeiten zu sprechen -: Substanzen, deren Wesen eben darin liegt, daß sie bestimmte Grundformen des Wirkens ausüben, ja da $\beta$ sie dies Wirken geradezu sind.

Schwierigkeiten und Unklarheiten bleiben nun aber begreiflicherweise vor allem in der Frage nach dem Verhältnis der Gunas zum „Unentfalteten“. Die Vorstellung von den Fäden und dem Seil ebenso wie jenes spätere Bild von Bäumen und Wald könnte zu bedeuten scheinen, daß vielmehr in den Gunas als im Unentfalteten das letzte Prinzip der Erscheinungswelt zu finden sei: zuerst müssen ja die Fäden da sein, soll ein Seil aus ihnen gemacht werden. In der Tat hat man doch vielmehr den Anspruch des Unentfalteten, Letztes und Höchstes zu sein, gelten gelassen; 
zu ihm, nicht zu den Guṇas, hat man die Aufzählung der Weltwesenheiten - denen natürlich der außerweltliche Purusha nicht angehört - als zum Schlußpunkt hingeleitet. Die Gunas wurden schon in einer der Upanishaden ,der Prakṛti gehörend“, ja später geradezu ,aus der Prakṛti geboren" genannt, nicht aber die Prakṛti ,den Gunas gehörend", oder ,,aus den Gunas geboren“. Das Verlangen zur Quelle des Seins aufzusteigen schien doch vollständiger befriedigt, wenn man beim Einen, als wenn man bei den Dreien angelangt war. So stellen die Gunas zwar einen der Phantasie unzweifelhaft willkommenen Übergang vom Einen zur grenzenlosen Vielheit dar, aber sie enthalten keine ernstliche Antwort auf die Frage, wie die Einheit und Sichselbstgleichheit des Unentfalteten über ihre eigne farblose Indifferenz und tote Ruhe hat hinauskommen können, um Buntheit und Widerstreit des Daseins aus sich zu gebären. Die in dieser Frage liegende Schwierigkeit ist in ihrer vollen uns unüberwindlich scheinenden Macht den Urhebern der Sāmkhyalehre wohl kaum zum Bewußtsein gekommen. Soweit sie sich mit diesem Problem ïberhaupt beschäftigten, werden sie um irgend einen zu Werden und Vielheit führenden Drang innerhalb des Unentfalteten, um eine woher auch immer kommende Störung seines Gleichgewichts schwerlich verlegen gewesen sein ${ }^{1}$ ). Für sie stand hinsichtlich der Guṇas 'gewiß weniger jene Frage im Vordergrund, als vielmehr die für das menschliche Heilsstreben gewichtigere, wie die überall erscheinenden Nuancierungen der Glückseligkeitswerte, der ethischen Werte, sich untereinander ordnen und welche Elemente es enthält, dies unendlich mannigfaltige Spiel der Mischungen von innerer Helle und Dunkel, von freiem Glück, Kampfbewegtheit, Starrheit. Wie aber zu allerletzt die Probleme, die hier in Bezug auf das Eins und die Drei blieben, eine wirkliche Lösung ge-

1) Das klassische Sāṃkhya ließ bekanntlich diesen Antrieb von den (hier pluralisch vorgestellten) Purushas kommen. Garbe, S. Phil. 222f.; Oltramare I, $263 \mathrm{ff}$. Ist ein Vorspiel dieser Lehre in Maitr. Up. V, 2 zu finden? 
funden haben, danach haben wir nicht zu suchen. Sie wurden eben nicht gelöst. Sondern an dieser Stelle mündete die Vorstellungsreihe, worein allein sie münden konnte, in unaufgehelltes Dunkel.

Wir werden uns später mit der Aufzählung der „entfalteten" Wesenheiten beschäftigen, in der man das Hervorgehen der Welt aus dem „Unentfalteten" darstellte. Schon hier aber muß davon gesprochen werden, daß in jener Aufzählung neben Vernunft, Ichprinzip, Elementen usw. nicht auch die Gunas auftreten. Man hat geurteilt, daß ihr Erscheinen dort konsequenterweise zu erwarten wäre. Doch seien im historischen Verlauf dieser Systembildung die Aufzählung der aus der Prakṛti sich entfaltenden Wesenheiten und andrerseits die Lehre von den Gunas in gegenseitiger Unabhängigkeit ausgebildet worden. So habe man die Gunas in jene Aufzählung nicht aufgenommen: die Liste sei eben schon abgeschlossen gewesen ${ }^{140}$. An dieser Auffassung des Hergangs ist so viel richtig, daß, wie wir sahen, die Gunadoktrin ihre selbständige, der Aufstellung jener Liste fern liegende Vorgeschichte gehabt hat. Es läßt sich hinzufügen, daß in dem offenbar ältesten vom Sāmkhya berührten Text, der Kāṭhaka Upanishad, die Guṇas nicht erwähnt. werden ${ }^{1}$ ). So kann hier in der Tat die Spur eines Sāṃkhya vorliegen, welches jene so charakteristische Lehre sich noch nicht zu eigen gemacht hat, wenn auch bei der

1) Oder läßt sich doch dort eine Spur der Gunalehre darin finden," daB 6, 7 (im später zugefügten Teil der Upanishad) für "Vernunft" (buddhi) der Ausdruck sattva gebraucht wird? Wenn im SchluBvers der Upanishad gesagt wird, Naciketas sei "frei von Rajas" geworden, möchte ich das für keine solche Spur halten; vgl. Bṛh. Ār. Upan. IV, 4, 23. Übrigens dürfte für "frei von Rajas" (virajah) vielmehr "frei von Alter" (vijarah) anzunehmen sein (schon M. Müller denkt hieran), wie das daneben stehende „frei vom Tod" (vimrtyuh) wahrscheinlich macht. $\mathrm{DaB}$ andererseits die Spur einer alten Gestalt der Sāmkhyalehre ohne Gunas in dem bekannten poetischen Bericht des Aśvaghosha über die Doktrin von Buddha's Lehrer. Arāda Kālāma vorliege, muß ich, wie hier nicht näher ausgeführt werden kann, durchaus bezweifeln. 
Kürze und dem fragmentarischen Charakter des in jener Upanishad Gesagten ein Schluß aus ihrem bloßen Schweigen höchst unsicher bleibt. Andererseits aberist zu bemerken, daß in einer Zeit, als das Sāṃkhya zweifellos mit den Gunas zu arbeiten gewohnt war, seine Liste der Weltwesenheiten doch noch keineswegs unabänderlich festgestanden hat: wir kommen hierauf weiterhin zurück. Wenn man also im Übrigen die Trias in jene Liste aufzunehmen Veranlassung gefühlt hätte, wäre die Möglichkeit hierzu wohl dagewesen. Lag solche Veranlassung aber in der Tat vor? Aus den Unklarheiten der Gunalehre, auf die hingewiesen worden ist, hebt sich doch mit unverkennbarer Entschiedenheit der Gedanke hervor, daß die Gunas nicht im selben Sinn Produkte des Unentfalteten sind, wie etwa Vernunft oder Elemente. Sie haben andern, fundamentaleren Charakter. Wenn sie allerdings - nicht in den ältesten Quellen - aus der Prakṛti geboren heißen, sind sie ja doch wiederum die Fäden, aus denen das Seil Prakṛti besteht. In jenem Bild von der dreifarbigen Ziege sind die aus dem Unentfalteten hervorgehenden Entfaltungen die Jungen, die das Muttertier wirft; die Guṇas sind die Farben der Ziege selbst. Die Welt wird schon in einer der uns hier beschäftigenden Upanishaden ${ }^{141}$ "das Dreigunahafte" (trigunam) genannt; sie beruht auf der "Umwandlung (der Prakriti) nach der Verschiedenheit der drei Gunas". Das Epos lehrt, daß die Gunas überall untrennbar vereint sind, hier der eine dem andern überlegen, dort ihm gehorchend, sie alle, ihrerseits unoffenbar, hier so dort so, in jeglichem Erscheinenden auftretend. Beständig also stellen sich die Gunas als den einzelren Entfaltungen der Prakṛti prinzipiell so zu sagen übergeordnet dar; sie verkörpern allgemeine Grundrichtungen, nach denen jedes Dasein sich aufbaut. Es wird danach, meine ich, auch wenn den Feststellern der Evolutionenliste der Gedanke an die Gunas vollkommen gegenwärtig war, als vielleicht nicht zwingend motiviert, aber doch immerhin als gewichtig motiviert erscheinen, daß man jene in die Liste nicht aufgenommen hat. 
In der Phantasie der alten Sāṃkhyaautoren stehen die Gunas oft stärker im Vordergrund als das Unentfaltete. In ihnen drückt sich die Farbigkeit, die Unruhe, das ganze dem Welttreiben innewohnende überwiegend schmerzliche Pathos aus, von dem die inhaltleere Vorstellung des Unentfalteten nichts empfinden läßt. Das Zusammenspiel oder der Streit der beiden gewaltigen Mächte Natur und Geist - das große Thema des Sāp̣khya - gewinnt an anschaulichem Leben, leidenschaftlicher Bewegtheit, indem man dem Geist nicht das Unentfaltete gegenübertreten läßt, sondern die Guṇas.

Es kann nicht Wunder nehmen, daß die Guṇavorstellung, diese so wohlgelungene Schöpfung des Sāṃkhya, dann weit über dessen Reich hinaus gewirkt hat. In buddhistischen Kreisen später liebte man es zwar nicht davon Notiz zu nehmen, vermutlich weil die Gunas in metaphysische Auffassungen hineingehörten, die man ablehnte. Aber auf den verschiedensten andern Gebieten, in der Poesie, bis in die populäre Vorstellungswelt hinein zeigt sich die Gewöhnung der indischen Phantasie, in allem Dasein und Geschehen beständig diese drei Grundcharaktere wiederzufinden. In manchen Bereichen der späteren Philosophie Indiens freilich hat sich die Vorliebe für die Gunas nicht erhalten. Die Klarheit und Schärfe, zu der sich die Analyse der Wirklichkeit dort erhob, mochte in jenen Vorstellungen doch noch einen zu starken mystischen Beigeschmack finden, eine gewisse der Abstraktion widerstrebende phantastische Körperlichkeit. Deutlich gibt sich hier die Zwischenstellung des Sāṃkhya zwischen Veda und Neuzeit zu erkennen. Dürfte diese Stellung nach griechischen Maßstäben bemessen werden, möchte man das Sāmkhya - wenigstens seine hier in Rede stehende ältere Gestalt - auf ähnlicher Stufe finden wie vielleicht die pythagoreische Philosophie, während es kaum zuviel gesagt ist, daß in den späteren indischen Systemen etwas von der Weise des Aristoteles sich spüren läßt. -

Das Tun der Gunas nun entfaltet sich durchaus in 
ihrer Gegensätzlichkeit zum geistigen Prinzip, sowie das Bild des Geistes vom Sāṃkhya ganz auf den gleichen Gegensatz hin gestaltet ist, aus ihm allein verstanden werden kann. Daher muß jetzt zunächst von der andern Seite des Dualismus die Rede sein.

Das geistige Prinzip erscheint in dieser Lehre zuweilen unter den alten Benennungen Brahman oder Ātman. Doch die überwiegende, so zu sagen technische Bezeichnung ist jetzt vielmehr Purusha, der Grundbedeutung nach "der Mann".

Auch in älteren Texten wie dem Bṛhad Āraṇyaka begegnet man oft diesem Wort. Vielfach wird es dort von lebendig mächtigen Wesenheiten gebraucht, die in etwas anderm darin sind, in ihm wirken; eine dem entsprechende phantastische Etymologie wird gegeben, puriśaya "Burgbewohner" (wörtlich: "in der Burg liegend"). So spricht man vom Purusha, der in der Sonne ist, der im Monde ist, in Äther und Wind, im Feuer und den Wassern. Auch der große, im All lebende Geist, der höchste Ātman, heißt schon in Texten dieser Gruppe Purusha. Wenn ein Schöpfungsbericht des Bṛhad Āranyaka im Anfang der Dinge den "Ātman in Purushagestalt" dasein läßt, so wird hier noch die konkrete Vorstellung "Mann" vorherrschen. Aber zur vollen Geistigkeit und reinen Gestaltlosigkeit des Ātman im höchsten Sinn dieses Worts ist der Purusha erhoben, wenn ihm des Ātman so gern gebrauchter mystischer Name „Nein, nein" (s. oben S. 63f.) oder die Bezeichnung „das Wahre des Wahren" beigelegt wird. Und deutlichst tritt die Identität des Purusha mit dem Ātman hervor - dem absoluten, der doch nichts andres ist als mein und dein Ātman -, wenn beispielsweise im Hinblick auf den Zustand des Schlafes vom "höchsten Purusha" gesprochen wird, der aus dem Leibe sich erhebend die Traumwelt durchstreift: eben derselbe, heißt es, ist im Auge der "Purusha des Auges", der wahre Sehende, dem das Auge nur als Werkzeug dient; beim Riechen, Reden, Hören ist er „der Atman“; nur sein Werkzeug ist 
Nase, Stimme, Ohr. Die Belege dafür ließen sich leicht vervielfältigen, daß die alten Upanishaden den Purusha als Synonymum von Ātman verwenden. Ohne daß eine scharfe Scheidung im Gebrauch beider Worte behauptet werden könnte, läßt sich vielleicht doch eine Nuance beobachten. Beim „Ātman" wird uberwiegend an ein Lebens- und Lichtprinzip gedacht auf das festeste mit der Wesenheit verwoben, deren Âtman er ist, ja vielmehr eben diese Wesenheit seiend. Der „Purusha“ wohnt gleichfalls gern, wie erwähnt, einer andern Wesenheit inne, so daß er doch auch leicht dazu neigt, diese Behausung verlassend oder überhaupt einer Behausung entbehrend eignes Dasein zu führen, indem er, wie der Name besagt, als "Mann" auf sich selbst gestellt ist, gewissermaßen volle, runde Gestalt besitzt. Es ist bezeichnend, daß der Sprachgebrauch gern mit ätman den Genetiv verbindet, um auszudrücken, wessen Ātman gemeint ist, mit purusha dagegen den Lokativ, um zu sagen, worin dieser Purusha wohnt. Ich möchte danach vermuten, daß die Bevorzugung der Bezeichnung Purusha für das geistige Prinzip im Sāṃkya mit der in diesem System obwaltenden stärkeren Absonderung und Gegenüberstellung des Geistes gegen die Natur zusammenhängt. Seine Rolle als Beseeler und Beherrscher der Natur tritt eben noch entschiedener als früher zurück gegenüber dem Gedanken, daß er von Haus aus jenseits der Natur steht und in diese seine Freiheit heimkehren $m u \beta^{1}$ ). Wie ubrigens die alten Upanishaden neben "Ātman" auch "Purusha" sagen, hat sich gleichermaßen in der Sprache des Sāmkhya neben "Purusha" auch "Ātman" gehalten. Und in aller Ausdrücklichkeit bezeugt es das Epos ${ }^{142}$ :

$$
\text { "Jeglicher Wesenheit Ātman - im Sāṃkhya heißt er }
$$

1) Es scheint mir das hier Gesagte zu bestätigen, daB in der technischen Sprache des alten Sāmkhya der an sich dem Welttreiben ferne Purusha eben da, wo er als Beseeler des Individuums auftritt, „der grobe Ātman" genannt wird. Näheres darüber unten. 
So steht es denn über jedem Zweifel fest, daß der Purusha der jüngeren Lehre durchaus dem Ātman der älteren entspricht, daß er dessen Erbteil, freilich, wie wir sehen werden, nicht ungeschmälert übernommen hat.

Von der allüberragenden Höhe, in welcher der Purusha thront, spricht einer der ältesten unter jenen Upanishadenversen, die Sāmkhyaideen enthalten. Durch die Reihe der abgeleiteten Wesenheiten, insonderheit der psychischen, zu immer höheren Prinzipien aufsteigend - vom Verstand (manas) zur Vernunft (buddhi) und zum "großen Ätman“ (mit dessen Bedeutung wir uns noch beschäftigen müssen) - gelangt der Dichter endlich zum Gipfel, man kann sagen zu einem Doppelgipfel. Höher als der "Große" steht das Unentfaltete, höher als das Unentfaltete der Purusha: „Über'm Purusha nichts Höhres; er ist das Ziel, der höchste Gang.

Nicht zeigt in allem Sein weilend er,der verborg'ne Ätman, sich, Doch durch tiefster Vernunft Feinheit erschaun ihn die, die Feinstes schaun."

Diese Höhe aber enthebt den Purusha nicht dem feindlichen Gegensatz zu der Macht, der zwar hier der Platz unter ihm angewiesen wird, die aber in Wahrheit immer entschiedener sich so wie er selbst als ein Letztes, Absolutes herausstellt: die schaffende Natur, das Unentfaltete, die Gunas. Es wurde schon darauf hingewiesen, wie das Denken, hinausstrebend über die Unbestimmtheiten, an denen sich die frühere Zeit hatte genügen lassen, diesen Gegensatz immer zielbewußter herausarbeitet. Die schärfer, energischer aufgefaßte Prakṛti entwickelt eine Macht, mit der sie dem Purusha erfolgreich das Gleichgewicht hält, ja eine Zeitlang ihn $\mathrm{zu}$ überwältigen imstande ist.

Und so durchläuft denn das welterfüllende Geschehen, von dem die Philosophie berichtet, seine Bahn: die Leidverstricktheit und Leidbefreiung des Purusha.

Die Prakrti, das Unentfaltete entfaltet sich. Die eine dreifarbige Ziege (S. 215) wirft ihre vielen Jungen. 
Das epische und klassische Sāṃkhya stellt die Reihe dieser Entfaltungen in der Liste der Prinzipien (tattva) dar, die so zu sagen das Rückgrat der Sāmkhyadoktrin bildet. Wie überall in diesem „auf der Zahl beruhenden" (sāmkhya) System, wird die Zahl der Prinzipien sorgfältig vermerkt. Zusammen mit dem Unentfalteten selbst sind es vier und zwanzig. Als fünf und zwanzigster steht daneben, von jener Entfaltungsreihe gesondert, der Purusha.

Wir überblicken in der Kürze die Liste der Tattva in ihrer klassischen Gestalt, die in den meisten Punkten auch zum Epos stimmt.

Am nächsten dem Unentfalteten, als erste und höchste Entfaltungen, erscheinen geistige Wesenheiten - geistig, soweit auf dieser dem Purusha gegenüberstehenden Seite von Geistigkeit gesprochen werden kann. $\mathrm{Zu}$ oberst die Vernunft (buddhi), die auch "das Große, der Große" (mahat, mahān) genannt wird. Aus ihr geht das Ichprinzip (ahamkāra) hervor. Aus diesem der Verstand (manas) ${ }^{1}$ ) oder innere Sinn. Neben dem Verstand entstehen aus dem Ichprinzip die zehn äußeren Sinne oder Organe: die fünf Wahrnehmungsorgane (Gesicht, Gehör, Geruch, Geschmack, Gefühl) und die fünf Tatorgane (Reden, Greifen, Gehen, Entleeren, Zeugen). Ebenfalls aus dem Ichprinzip entstehen die fünf feinstofflichen Elemente (tanmātra): die Grundstoffe von Schall, Gefühl, Farbe, Geschmack, Geruch. Aus diesen endlich, ihnen entsprechend - das nähere Wesen dieser Entsprechung verfolgen wir nicht - die fünf groben Elemente: Äther, Luft, Feuer, Wasser, Erde ${ }^{2}$ ).

1) Man wolle in den Übersetzungen "Vernunft" und "Verstand" nicht mehr sehen, als den Ausdruck des Bedürfnisses, die einzelnen indischen Schlagworte durch deutsche wiederzugeben. Ahamkara scheint mir wörtlich nicht "der Ichmacher" zu sein, sondern „das Ichmachen * d. h. das Ichsagen und Betätigen der Ichheit, ähnlich wie man beim Opfer vom svāhākāra spricht, dem Opferwort svāha, eigentlich dem "Svāhāmachen", oder in der Grammatik vom akâra, dem Laut $a$, eig. dem „a-Machen“. Ähnlich Deussen, Allg. Gesch. der Phil. I, 3, 56.

2) Hier weicht das epische Schema vom klassischen ab. Es stellt 
Zu dieser Reihe der Tattva sollen Erläuterungen im Einzelnen hier nicht gegeben werden. Sie ist nur mitgeteilt als Anhalt für die Frage nach Vorhandensein und Aussehen einer eben solchen Reihe im ältesten uns erreichbaren Sāṃkhya, dem der Upanishaden. Denn wenn wir uns dort zunächst mit zerstreuten, fragmentarischen Äußerungen begnügen müssen, ist natürlich zu prüfen, ob diese Einzelheiten nicht in der Tat zu einem System ähnlich dem späteren zusammengehören und so ein Leben in sich tragen, das zu entdecken uns eben nur die Vergleichung jenes Systems möglich macht.

Nun werden in den Sāṃkyapartien der Upanishaden fortwährend Begriffe der klassischen Tattvareihe mit Namen genannt, bald einzeln, bald in Gruppierungen, die sich mit denen der späteren Doktrin genau oder annähernd decken; dazu andre Termini, wie die Gunas, aus der nächsten Nachbarschaft eben dieses Vorstellungskreises. Danach ist zunächst soviel höchst wahrscheinlich, daß auch in diesem ältesten Sāṃkhya eine, wie der schon damals geläufige Name des Systems besagt, zahlenmäßig bestimmte, mindestens im ganzen mit der späteren identische Aufzählung von Grundkategorien vorhanden war. Und weiter, da diese Aufzählung ganz so wie später, vom Purusha abgesehen, im „Unentfalteten" gipfelt, wird sich schwer bezweifeln lassen - schon oben wurde dies gelegentlich stillschweigend vorausgesetzt daß die für die jüngere Reihe maßgebende Absicht, die Ordnung des Sichentfaltens der Wesenheiten vom Urgrunde aus zu beschreiben, auch bereits im Sāmkhya der Upanishaden obgewaltet hat.

unter den letzterwähnten zweimal fünf Wesenheiten die Gruppe von Äther usw. voran; dann folgt die andre Fünfheit in Gestalt der fünf Sinnesobjekte: Schall usw. Vgl. namentlich O. Strauß, zur Geschichte des Sāmkhya, Wiener Zeitschr. f. d. Kunde des Morg. XXVII, 257 ff. - Kann Kãțh. Up. 3, 10 als Zeugnis für eine alte, freilich befremdende, Gestalt der Reihe verwertet werden, wo die Sinnesobjekte zwischen Verstand (manas) und Sinnen standen? 
Unbedenklich dürfen wir annehmen, daß schon dies alte Sāṃkya aus dem Unentfalteten das Welttreiben in der Weise hervorgehen ließ, daß die Prakrrti, wie das Epos ${ }^{143}$ sich ausdrückt, ihre Gunas spielend in hundertfacher und tausendfacher Vervielfältigung umwandelt,

„Wie man aus einem Licht tausend Lichter zum Flammenglanz erweckt."

Es entspricht vollständig dem Ton, in dem die Upanishaden von den Guṇas zu reden gewohnt sind, und darf gewiß in ihren Vorstellungskreis zurückverlegt werden, wenn das Epos - fast mit denselben Worten auch der Haupttext des klassischen Sāmkhya - beschreibt, wie jene drei Faktoren des Weltdaseins ihr gemeinsames Werk tun:

„Einer dem andern sich paarend, dieser auf jenen stützend sich,

Aus einander Bestand schöpfend, einer dem andern folgend nach,

In einander verschränkt weilend" -

das Vielheitsmotiv und das Motiv des Werdens, der Bewegung in ihrer natürlichen Verbundenheit, die in der Geschichte des Denkens so oft hervortritt...

Welches sind nun in der Weltentfaltung des ältesten Sāṃkhya die dem Unentfalteten nächst benachbarten, zuvörderst entstandenen Wesenheiten? Nach der Kāṭhaka Upanishad („höher als der. Verstand steht die Vernunft, höher als die Vernunft der große Âtman, höher als der Große das Unentfaltete") wird man annehmen, daß vom Unentfalteten aus absteigend der Reihe nach der "Große Âtman", die Vernunft (buddhi), der Verstand (manas) erschienen.

Die ungefähre Übereinstimmung im ganzen, freilich auch im Einzelnen der Unterschied von der entsprechenden Partie der späteren Prinzipienreihe fällt in die Augen. Dort ist der "Große" mit der Vernunft identisch. Und zwischen Vernunft und Verstand kommt das Ichprinzip hinzu. 
Die erste dieser Abweichungen erklärt sich wohl leicht. Die Texte machen wahrscheinlich, daß die Vorstellung des "Großen Ātman" eine Wandlung erlitten hat, die mit einschneidenden Entwicklungen dieses ganzen Gedankenkreises zusammenhängen wird. Ursprünglich ist offenbar der "Große Ātman" überhaupt nicht, was er später ist: die erste und oberste unter den Entfaltungen der Prakrti. Schon der Name Ātman stellt ihn vielmehr auf die andre Seite des allbeherrschenden Dualismus. Und die Überlieferung deutet in der gleichen Richtung. Die Kāthaka Upanishad, unmittelbar nach der eben mitgeteilten Erwähnung des Großen $\bar{A}$ tman in der Stufenfolge der Wesenheiten, sagt über den Purusha in einem Vers, der uns schon früher (S. 225) begegnet ist:

„Nicht zeigt in allem Sein weilend er, der verborg'ne Ātman sich";

es liegt sehr nah, den Ātman hier dem dicht vorher genannten Großen Ātman gleichzusetzen und $\mathrm{zu}$ verstehen, daß der Purusha, sofern er aus seinem Beisichsein in fremde Wesenheit eingegangen ist und in dieser verborgen weilt, eben den Namen "Großer Âtman" führt ${ }^{144}$. Dies bestätigt sich wohl auch dadurch, daß noch ein zweiter auf das Schlagwort Ātman gestellter Begriff auftritt, der allem Anschein nach gleichfalls ursprünglich den Purusha in seiner Individualisierung, seinem Innewohnen in den empirischen Einzelwesen bezeichnet und mithin in diesem Stadium seiner Entwicklung wohl eben nur eine Variante des Großen Ātman ist: der Bhūtātman, wörtlich „Elementen-Ātman“, d. h. der Ātman, welcher in dem aus den Elementen gebildeten Leibe wohnt; sein Wesen als Ausfluß des universellen Purusha tritt an mehreren Stellen deutlich hervor ${ }^{\mathbf{1 4 5}}$. Schließlich reicht die Erinnerung daran, daß der Große Átman aus dem Purusha stammt, genauer daß er der Purusha in seiner Individualisierung ist, mehrfach noch bis in das Epos hinein ${ }^{146}$. 
Vermutlich machte sich dann später, im Zusammenhang mit der zunehmenden Vertiefung der Kluft zwischen Purusha und Prakṛti, der Wunsch geltend, in der großen Kate'gorienreihe zwischen der Prakriti und den sich aus ihr entfaltenden Wesen nicht so zu sagen einen Fremdkörper bestehen zu lassen, sondern der Prakṛti die alleinige Herrschaft über die ganze Reihe zuzuweisen, ausgenommen nur den Purusha, für den es sich zu schicken schien, daß er ohne jeden Anhang in stolzer Einsamkeit verblieb. Soweit damit vielleicht über das Schicksal des Großen Ātman noch nicht definitiv entschieden war, mußte ein weiterer Anstoß in gleicher Richtung dadurch gegeben werden, daß dann der universale Purusha, wie später zu zeigen ist, in die zahllosen Einzelpurushas zerfiel und diese übernahmen, was von der einst dem Großen Ātman zugeschriebenen Funktion etwa noch übrig war. Damit hatte dieser Ātman, seinem alten Sinn nach verstanden, jede Existenzberechtigung verloren. So kam es, daß er zu den Evolutionen der Prakṛti hinübergeschoben wurde ${ }^{14}$. Dort brachte man ihn unter, so gut man eben konnte. Er trat in die zwar schon besetzte oberste, seinem angestammten Platz benachbarte Stelle der Evolutionenordnung ein und wurde für identisch mit deren Inhaberin, der "Vernunft", erklärt: so daß sich die frühere Folge Mahān Ātmā und Buddhi nun zu dem einen Glied Mahān oder Buddhi zusammenzog. Das Auffallende dieser Doppelbenennung verbindet sich mit den ausdrücklichen Zeugnissen für die alte Unterschiedenheit der beiden Glieder, um die Verschiebung, die hier eingetreten ist, anzuzeigen.

Schwieriger als über diese Vorgänge ist das Urteil uber die zweite der beiden oben erwähnten Abweichungen zwischen der Aufzählung der höheren Prinzipien in der Kāthaka Upanishad und im späteren Sāṃkhya. Bezeugt die Upanishad eine ursprüngliche Gestalt des Systems, in der das Ichprinzip noch fehlte? Oder war dieses von jeher vorhanden, und beruht es nur auf der besonderen Intention der betreffenden Stelle, daß es dort unerwähnt blieb? Tat- 
sache ist, daß auch das Epos, für das jenes Prinzip doch unzweifelhaft feststand, in speziellen Zusammenhängen es häufig übergangen hat. In jedem Fall wird von den in Betracht kommenden Upanishaden, außer eben nur der Kāthaka Upanishad, die spätere Dreiheit dieser obersten Entfaltungen - Vernunft, Verstand, Ichprinzip - wiederholt bezeugt, mehrfach in der Form, daß die Funktionen, die man diesen Mächten stehend jetzt so wie im klassischen Sāṃkhya beilegte, dreigliedrig aufgeführt wurden: Bedenken als Funktion des Verstandes, Entschließen als die der Vernunft, Fürsichwollen als die des Ichprinzips ${ }^{1}$ ). Doch ist insofern wohl ein Unterschied zwischen der älteren und jüngeren Fassung dieser Lehre zu statuieren, als dem Ichprinzip anfangs, wie es scheint, hinter Vernunft und Verstand die dritte Stelle angewiesen wurde, vielleicht um jenes als das Gröbere, Materiellere, vom übersinnlichen Ursprung weiter Entfernte zu kennzeichnen. Später gab man ihm unter Umstellung mit dem Verstand den zweiten Platz: vermutlich in dem Wunsch, den Verstand (den „inneren Sinn") und die dann folgenden „äußeren Sinne“, deren Zentralorgan jener ist, in ununterbrochenen Zusammenhang zu setzen, sowie den Verstand als aus dem Ichprinzip stammend und von dessen Natur berührt zu charakterisieren. Eine an sich vielleicht unerhebliche Änderung. Sie verdient doch Beachtung als eins der Anzeichen für das Hindurchgehen dieser Gedanken durch eine von den Upanishaden bezeugte vorklassische Gestalt, ehe die klassische erreicht wurde.

An die hier besprochenen Anfangsglieder der Reihe schließt sich nun die Fortsetzung offenbar im wesentlichen ganz wie in der späteren Zeit. Die Sinne oder Organe wurden eben schon berührt; wir wissen, daß sie so wie später in die beiden Gruppen der Wahrnehmungs- und Tatorgane (vgl. oben S. 226) zerfielen. Es folgen endlich die

1) Auch hier können nur annähernde Übersetzungen versucht werden (vgl. S. 226 Anm. 1); von eingehenderer Diskussion der betreffenden Begriffe sehe ich ab. 
Elemente, die ebenfalls wie in klassischer Zeit einerseits als fünf Feinstoffe (tanmātra), andrerseits als ebenso viele grobstoffliche Elemente (mahābhūta) auftraten ${ }^{148}$.

Man sieht, daß aus diesem ganzen Bilde des Weltwerdens die Fabelungetüme der alten Kosmogonien, die mit einander sich paarenden Tiere samt aller Staffage ähnlichen Schlages verschwunden sind. Ebenso die auf Veda und Opfer bezüglichen Vorstellungen; die Atmosphäre, in der Brahman als ein adäquatester Name für den Weltgrund hatte gewählt werden können, ist verflogen. Was jetzt das Gesichtsfeld füllt, sind Produkte einer freilich vielfach noch unklaren psychologischen und physikalischen Analyse. Sie schillern zwischen kosmischer Weite und Beschränkung auf die Sphäre des Individuums hin und her, wie eine solche Vermengung von Makrokosmus und Mikrokosmus ja auch in diesem Stadium der Spekulation fortwährend begegnet ${ }^{148}$. Geordnet ist die Reihe der Wesenheiten absteigend vom Feineren, Höheren zum Tieferstehenden, grob Materiellen, anders als in so vielen Kosmogonien, deren Weg sich von niedrigen Anfängen zu immer vollkommeneren Gebilden erhebt ${ }^{150}$. Da der Ausgangspunkt hier die in höchster Subtilität vorgestellte Prakṛti war, lag es nah jene Richtung innezuhalten. So kam die Bewertung zum Ausdruck, die man der Weltschöpfung zuteil werden ließ: ein immer tieferes Herabsinken vom Gipfel. Und zugleich wurde es möglich, dieser Bewegung der Evolution eine umgekehrte der Involution gegenüberzustellen. Man malte aus, wie der geistlich Strebende es erreicht, Schritt für Schritt das Niedere zur Absorption im Höheren zu bringen und so gleichsam den Weltprozeß rückgängig machend sich der Erlösung zu nähern ${ }^{1}$ ):

1) Es ist vermutet worden, daB das eigentliche Motiv für die Aufstellung der Stufen der Evolution eben in den Vorstellungen von der Involution gelegen habe, in welcher die Wesen beim Sterben, Tiefschlaf, Yoga zum Brahman eingehen. Obwohl die Ausführungen Deussen's (Allg. Gesch. der Phil. I, 2, 224f.; vgl. auch Oltramare I, 238) hierüber nicht beweisend sind, ist das doch möglich. Bedenken erregt mir indessen, dab 
ein individueller Vorgang, dem ähnlich vielleicht schon früh auch ein kosmischer vorgestellt wurde, die stetig sich wiederholende Ruickkehr der Entfaltungen zum Unentfalteten im gesetzmäßigen Kommen und Gehen der Weltperioden.

All diesem Wogen und Wallen nun, dem Werden und Vergehen, dem unabsehbar mannigfachen Spiel der Gunas steht der Purusha gegenüber, wie das seiner Herkunft aus der alten Ātmanspekulation entspricht, als der Eine Gunalose: „rein, lauter, leer, friedevoll, odemlos, selbstlos, endlos, unvergänglich, fest, ewig, ungeboren, frei weilt er in seiner eignen Majestät" ${ }^{151}$. Doch trotzdem vollzieht sich nun zwischen Überweltlichem und Welt das schmerzenreiche Geschehen, dessen Dunkel zu durchleuchten und aus dem hinauszuführen die Leidbefreierin Erkenntnis berufen ist.

Man hat vom Dualismus des Sāṃkhya Antwort auf die Frage verlangt, wie jene zwei bis in die Wurzeln verschiedenen Prinzipien, Purusha und Prakrti, denn dazu kommen sich im unendlichen Raum und in der unendlichen Zeit zu finden und zu ergreifen (Deussen). Spricht sich darin ein gewisses Befremden daruber aus, daß die beiden Wesen sich nicht so zu sagen im Leeren verirrt haben ohne einander überhaupt zu begegnen? Vermutlich ließ das ursprüngliche Sāmkhya, wie an manchen Stellen das Epos, im Einklang mit Vorstellungen der alten Upanishaden den $\mathrm{Pu}-$ rusha Schöpfer der Prakṛti sein ${ }^{1}$ ). Ohne daß dadurch, wie

eben die wichtigsten, obersten Evolutionen des Sāṃkhya im Yoga nicht wiederkehren. Wäre bei der eben bezeichneten Auffassung nicht vollere Übereinstimmung des Sāṃkhya mit der Doktrin zu erwarten, die vor allen der Sitz der Lehre von den Involutionen ist? Ich verweise auf die Bemerkungen über das Verhältnis von Sāmphyya und Yoga unten im Abschnitt über den letzteren.

1) Oder die Figur ließ sich so zeichnen, wie an einer Stelle des Epos (XII, 217, 6) geschieht: „beide, das Unentfaltete und der Purusha, und was vom Unentfalteten und dem Purusha verschieden und noch größer ist als sie". Doch dieser Aufbau eines Absolutesten über den beiden Absoluten, das diese unter sich so zu sagen zusammenschliebt, ist offenbar eine spätere, für die Gesamtbewegung des Denkens folgenlose Ausschmückung. 
schon bemerkt, dem aktuellen Antagonismus beider Prinzipien irgend die Spitze abgebrochen wurde, konnte darin doch eine Erklärung dafür liegen, daß jene in gewisser Weise auf einander angewiesen sind, daß sie nicht einfach so zu sagen an einander haben vorbeitreffen können. Wurde solches Vorbeitreffen nicht auch schon durch die Allgegenwärtigkeit ausgeschlossen, die man irgendwie - mit welchen Nuancierungen auch immer - beiden Wesen beigelegt haben wird? Aber schließlich braucht ja nach solchen Motivierungen uberhaupt garnicht gefragt zu werden. Wie im Märchen oder Traum, was sich begegnen soll, unfehlbar sich begegnet, so war es doch selbstverständlich, daß auch die philosophierende Phantasie die Wesenheiten, welche dazu ausersehen waren, zusammen das universelle Drama aufzuführen, sich nicht in der Unendlichkeit verlieren ließ, ohne daß die eine die andre gefunden hätte.

Ernstlicher und schwieriger gestaltet sich freilich die vorher bezeichnete Frage, versteht man sie dahin, warum Purusha und Prakṛti nicht die unheilvolle Verbindung mit einander haben vermeiden können, auf der das tragische Verhängnis des Weltleidens beruht. Wie in der Erlösung sich die Sonderung der beiden als möglich erweist, konnten sie nicht, mußten sie nicht ihrer Natur nach in solcher gegenseitigen Zurückhaltung von vornherein verharren? Wenn ein Text, der uns bald wieder begegnen wird, erzählt, daß das höchste Wesen, „da es seinen Zweck noch nicht erreicht fand, gedachte: Ich will die Dinge genießen " ${ }^{152}$, so ist damit wohl nicht viel gesagt. Doch ob nun für das Unerklärbare eine Erklärung gegeben wird oder nicht, die Verbindung der beiden Wesen mußte ja unvermeidlich stattfinden: sonst würden sich alle diese Gedankenmassen in Nichts auflösen. Und doch will man auch wiederum das Postulat der Unberührtheit des Purusha nicht preisgeben. Vom Gedankenbau, den man auffuhrt, wird eben auf der einen Seite verlangt, daß er die leidenvolle Wirklichkeit erkläre. Andrerseits aber, daß er auf das leidenlose Ideal als den im Wesen 
der Dinge eigentlich angelegten Zustand hinauslaufe. Man fühlt den Widerspruch, in den man da gerät, als ein zum tiefen Sinn des Seins gehörendes Element. Gleichnisse müssen das annehmbar machen:

"Das eine Feuer, in die Welt eingehend

Schmiegt jeder Form sich an und bleibt doch draußen.

So schmiegt das eine inn're Selbst der Wesen

Jeglicher Form sich an und bleibt doch draußen.

Die Luft, die eine, in die Welt eingehend

Schmiegt jeder Form sich an und bleibt doch draußen.

So schmiegt das eine inn're Selbst der Wesen

Jeglicher Form sich an und bleibt doch draußen.

Allauge Sonne leidet nicht Befleckung

Von ird'scher Augen äußeren Gebrechen.

So wird das eine inn're Selbst der Wesen

,Vom Weltleid nicht befleckt. Es bleibet draußen."

Der Konflikt zwischen Drinnen- und Draußensein, Berührung und Unberührtheit, über den hier leicht hinweggeglitten wird, ist selbstverständlich so nicht gelöst. Er wird sich von neuem geltend machen. In der Bemühung um ihn wird das Denken auf seinem Wege fortschreiten. -

Das Aufeinanderwirken von Purusha und Prakṛti zeigt deutlich - die Alten selbst freilich scheinen das nicht ausdrücklich so formuliert zu haben - eine Doppelgestalt. Der Purusha spielt der Welt gegenüber die aktive Rolle. Er beseelt, beherrscht, genießt sie. Und wiederum ist er der passive. Er gerät durch sie in Gebundenheit und Leiden. Es ist klar, wie diese Zweiseitigkeit sich aus den Grundgedanken der alten Upanishaden ergibt. Hier der weltbeherrschende absolute Ätman. Dort der das Weltleiden erduldende individuelle Âtman. Beide identisch: tat tvam asi.

Die Vorstellungen vom belebenden, regierenden Darinsein des Purusha in der Natur, im Menschen scheinen zunächst den alten Auffassungen noch nah zu stehen. Er, 
der Herr des Vergangenen und Künftigen, weilt unsichtbar als das Selbst in allen Wesen, kleiner als klein, größer als groß, „als Zwerg mitten darin sitzend ${ }^{\text {158, }}$ daumengroß im Herzen, "in den Leibern der Leiblose,
standfest im Unbeständigen."

Auf ihm beruht das physische Leben. Durch ihn sieht man die Gestalten, hört man die Töne, erkennt man. Er ist der Wagenfahrer, dessen Wagen der Leib ist: „aus der Prakrti besteht seine Peitsche; unter ihrem Antrieb tummelt er (der Wagen), dieser Leib, sich umher, wie die Töpferscheibe vom Töpfer gedreht wird." Aus dem Purusha geht die Sonne auf, in ihm geht sie unter. Auf ihn wiederholt man kaum verändert einen Vers, den ein älterer Poet vom Ātman gedichtet hatte (vgl. S. 75):

"Aus Furcht vor ihm erglüht Agni, Aus Furcht vor ihm die Sonne gluht, Aus Furcht läuft seinen Weg Indra, Und Vāyu und der Fünfte: Tod".

Es ist schwer, in solch allbeherrschenden Wirkungen, die vom Purusha ausgehen, nicht ein Tun zu erkennen, dessen Täter gleich dem Ātman der alten Upanishaden er ist. In gewissem Sinn ist das zutreffend, doch auch wieder nicht vollkommen zutreffend. Die Quellen erlauben uns nicht sicher zu beurteilen, welche Stellung das Sāmkhya in seinen ersten Anfängen hier eingenommen hat. Aber immerhin schon früh werden in bezug auf die Anerkennung des Purusha als eines Handelnden Vorbehalte gemacht. „Standortlos hat er im Nichtseienden, der Täter als ein Nichttäter seinen Stand... wie ein Zuschauer steht er da"154. Das Tun hat die Prakṛti, haben die Guṇas übernommen. Vom Purusha empfängt dies Tun Licht und Gesetz. Er ist, wie zuweilen gesagt wird, nicht Täter sondern Tunmacher: ein deutlicher Versuch, eine gewisse Aktivität ihm nicht zu nehmen und sie ihm doch auch wieder nicht direkt zuzu- 
schreiben. Wenn er an der eben angeführten Stelle Täter und Nichttäter zugleich genannt wird, erinnert das an jene Verse, die ihn drinnen in der Welt wohnen und doch draußen verbleiben lassen.

Er ist weiter der "Genießer" der Prakṛti und ihrer Tätigkeit. Im Ton altertümlich konkreter Erzählweise wird davon gesprochen. In die Höhle des Herzens eingegangen naus diesem Herzinnern heraus fand er, daß er seinen Zweck noch nicht erreicht hatte, und gedachte: ,Ich will die Dinge genießen' (wörtl.: essen). Da bohrte er diese Öffnungen (der fünf Sinne), trat heraus und genoß (wörtl.: aß) vermittelst der fünf Zügel die Objekte $\left.{ }^{1}\right)^{\text {“. }}$. Ein andresmal heißt es: „Der Purusha, der Betrachter, der im materiellen Prinzip (Pradhāna) darinnen weilt, ist auch der Genießer, der die von der Prakṛti kommende Speise genießt. Seine Speise nämlich ist dieser Elementen-Ātman ${ }^{2}$ ); dessen Schöpfer ist das materielle Prinzip. Deshalb ist das Dreigunahafte das zu Genießende. Genießer aber ist der Purusha, der darinnen weilt." "Genießen" läßt die indische Ausdrucksweise den König sein Land und dessen Einkünfte. Der König, der Adlige ist „der Esser"; der gemeine Mann „die Speise", "der Gegessene". Überhaupt zieht sich durch die alte Ritualliteratur die Gegenüberstellung von „Esser“ und "Speise", und der Wunsch selbst Esser zu sein. Wie ist nun im Fall des Purusha die Art dieses Essens oder Genießens gedacht, nach dem jener ein mit seiner allgesättigten Majestät so wenig harmonierendes Bedürfnis empfindet? Es ist doch wohl ein Schauen gemeint und ein Empfinden der Gefühle, die das Weltdasein erregt, von wo $\mathrm{zu}$ einem allzu tiefen Erfülltwerden, einem Geblendetwerden durch solche Eindrücke kein weiter Schritt ist:

1) Gemeint ist: indem er die Objekte mit den Zügeln an sich heranzog.

2) Vgl. oben S. 229. Der Elementen-Ātman (bhütätman) ist hier nicht mehr, was er m. E. ursprünglich ist, der Purusha in seiner Individualisierung, sondern dessen Gegenbild auf der materiellen Seite. Vgl. Anm. 145 am Ende des Bandes. 
„Die man Lust, Leid, Verwirrung ${ }^{1}$ ) nennt, "Sie wird zur Nahrung, diese Welt".

Deutlich klingt hier der Gedanke an, daß das Genügen, welches die Welt dem Purusha bietet, seine Kehrseite hat. Der Genießer ist in die passive Rolle geraten.

„Jener Feine fürwahr, der Ungreifbare, Unsichtbare, den man Purusha nennt: er kehrt unbewußt mit einem Teil von sich hienieden ein, so wie eines Schlafenden Erwachen unbewußt erfolgt. Was aber jener Teil von ihm ist, das ist der rein Geistige, der in jedem Menschen ist, der Kenner des Gefildes, welcher Bedenken, Entschließen, Fürsichwollen (S. 231) als Merkmal an sich trägt . . . durch ihn, den geistigen, wird dieser Leib als ein geisterfüllter hingestellt, und er ist es auch, der ihn zur Bewegung antreibt"158. So weit könnte der Purusha noch Herr der Situation scheinen. Aber der Merkmallose hat sich „Bedenken, Entschließen, Fürsichwollen“ als „Merkmal“ (linga) angeheftet. Das heißt, er ist mit den Trägern dieser drei Funktionen - Vernunft, Verstand, Ichprinzip: den obersten Entwicklungen der Prakṛti oder der Guṇas - eine Verbindung eingegangen, so daß er nunmehr in individuellen Erscheinungsformen auftritt, von denen jede vermöge jenes Merkmalkomplexes von jeder andern unterschieden ist. Mehrfach ist von dem hier beschriebenen dreifachen Linga die Rede. Und es begegnet auch schon die weiter ausgeführte Vorstellung des Linga, die dann im jüngeren Sāmkhya eine so wichtige Rolle spielt: „das vom ,Großen“ anfangende bis zu den „Besonderheiten“ (viśesha) reichende Linga“, der „feine Leib", wie er später genannt wird, bestehend aus den Produkten der Prakṛti vom obersten, dem "Großen", bis zu den feinen Elementen, also mit Ausschluß der groben Elemente - das materielle Gegenbild des Purusha, das bleibende Substrat der individuellen Existenz, welches sich im Lauf der Seelenwanderung mit wechselnden groben

$\left.{ }^{1}\right)$ Diese Dreiheit entspricht den drei Gunas. 
Körpern bekleidet, wie ein Schauspieler immer andre Rollen spielt.

Indem der Purusha sich das Linga angeheftet hat, ist er in die Tiefe gebannt. Die vorher angeführte Stelle, die das dreiteilige Linga erwähnt, läuft in den Schluß aus: "sich verbergend in dem Gewebe, das aus den Gunas gewebt ist, so steht er da". Mit einem Bild, das an die Wortbedeutung der Gunas als der zu einem Seil vereinigten Fäden erinnert, beschreibt es später das Epos:

„Wie mit dreifachem Zeugstreifen als Turban man das Haupt umhüllt, So in Sattva, Rajas, Tamas hüllt der Bekörperte sich ein." Den Freien, Höchsten trifft Gebundenheit. Die Upanishad sagt: „Denn der aus jeglichem Begehren bestehende Purusha, der Entschließen, Bedenken, Fürsichwollen als Merkmal (linga) trägt, ist gebunden. Der, mit dem es sich entgegengesetzt verhält, ist frei . . . Von den Strömen der Guṇas fortgerissen und beschmutzt, schwankend, unstet, beraubt, begehrlich, zerfahren, dem Fürsichwollen verfallen, ,das bin ich, dies ist mein' - also wähnend bindet er sich selbst durch sich selbst wie der Vogel durch das Netz. Darum ist der Purusha, der Entschließen, Bedenken, Fürsichwollen als Merkmal trägt, gebunden. Der, mit dem es sich entgegengesetzt verhält, ist frei". An einer andern Stelle wird

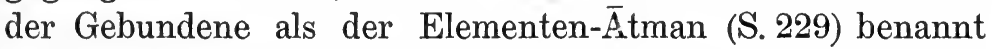
und dem Gedanken die Wendung gegeben, daß dieser vom Purusha selbst vermittelst der Gunas mißhandelt wird: so daß das Leiden, welches die Emanation des höchsten Wesens trifft, zuletzt durch dies Wesen selbst veranlaßt ist. „Von ${ }^{1}$ ) den auf die Tat folgenden Früchten überwältigt, geht er (der Elementen-Ātman) in guten oder schlechten Mutterschoß ein. So führt sein Weg abwärts und aufwärts. Von

1) Voran geht ein mit dem oben wiedergegebenen gleichlautender Passus: „Von den Strömen der Gunas ... durch das Netz" - hier auf den Elementen-Ätman bezogen. Von den beiden teilweise identischen Stellen ist diese offenbar die ältere. 
den Gegensätzen ') überwältigt irrt er umher ... . Wie ein Eisenklumpen vom Feuer überwältigt, von den Werkleuten gehämmert, mannigfache Gestalten annimmt, ebenso wahrlich nimmt jener Elementen-Ātman, vom inneren Purusha üherwältigt, von den Guṇas gehämmert, mannigfache Gestalten an. . : . Doch gleichwie, wenn man einen Eisenklumpen hämmert, nicht das Feuer überwältigt wird, so wird auch nicht jener Purusha überwältigt. Überwältigt wird dieser Elementen-Ātman wegen seiner Verflochtenheit (mit der materiellen Welt). “

Ein Vorgang also von höchster Gewaltsamkeit, dessen Folgen ins Unabsehbare reichen. Die Tiefe des Leidens, dem der Überwältigte verfällt, von den alten Upanishaden nur in einfachen, kurzen Worten ausgedrückt, wird jetzt zum Gegenstand wortreicher, in Schrecklichkeiten schwelgender Rhetorik. Die Maitrāyaṇa Upanishad ${ }^{158}$ entnimmt einem andern, ihr vorliegenden Text eine ganze Kaskade von Vergleichen: "Wie die Wogen großer Ströme lassen sich die Taten, die er zuvor getan, nicht rückwärts wenden. Wie gegen die Flutwelle des Ozeans, gibt es gegen das Herannahen des Todes keine Abwehr. Wie ein Lahmer ist er, strickgefesselt durch die Früchte seiner guten und bösen Taten. Wie im Gefängnis ist er freiheitsberaubt. Wie einen, der vor Yama (dem Totenrichter) steht, umgibt ihn viele Furcht. Wie Rauschtrank so berauscht ihn der Trank der Verblendung. Wie von böser Macht besessen wird er umgetrieben. Wie einer großen Schlange Biß, so hat ihn der $\mathrm{Bi} \beta$ der Sinnenwelt getroffen. Wie tiefe Finsternis, so ist er blind von Leidenschaft. Wie Gaukelwerk so besteht er in Zaubertrug. Wie ein Traum ist er voll Täuschung. Wie des Bananenbaumes Inneres ist er marklos. Wie ein Schauspieler wechselt er sein Kostüm Augenblick für Augenblick.

1) Wie gut und schlecht, abwärts und aufwärts. Solche Gegensätze treten ja gern für die Vorstellung hervor, die sich auf die Bewegung des zwischen jenen hin und her spielenden Werdens und Vergehens richtet. 
Wie eine bemalte Wand ist er von trügerischer Schönheit. Und man sagt:

Es dringt Gehörs-,Gefühls-Wesen wesenlos auf den Menschen ein,

Daran der Element-Ātman haftend der höchsten Welt vergißt." .

An einer andern Stelle derselben Upanishad klagt der König, der sein Reich verlassen hat und im Walde Kasteiungen übt, dem Weisen, der ihm dort begegnet, zu dessen Füßen sein Haupt neigend, das Daseinsleid der Vergänglichkeit. Der Leib ist aus niederen, ekelerregenden Bestandteilen aufgebaut; er wird von Lust und Zorn betroffen, von Hunger und Durst, Alter und Tod, vom Fernsein dessen, was man sich wünscht, und Nahesein dessen, was man sich nicht wünscht - fast wörtlich stimmen die Ausdrücke hier mit denen überein, die vermutlich schon früher den Buddhistenmönchen in ihrem feierlichen Credo geläufig waren ${ }^{1}$ ): - , was soll man da der Lust pflegen? Und wir sehen, daß diese ganze Welt vergänglich ist wie die Bremsen, Mücken und anderes solches Getier, wie Kräuter und Bäume, die wachsen und hinwelken. Doch was rede ich von diesen? Da sind andere, größere; mächtige bogenbewehrte Helden, manche von ihnen Weltbeherrscher, wie Sudyumna, Bhūridyumna, Indradyumna . . . Die haben alle vor den Augen der Ihrigen ihre große Herrlichkeit verlassen müssen und sind aus dieser Welt in jene hingegangen ... Doch was rede ich von diesen? Da gibt es andres: die großen Ozeane vertrocknen, die Berge stürzen ein, der Polarstern wankt von seinem Ort, die Windseile (welche die Sterne festhalten) reißen, die Erde versinkt, die Götter verschwinden von ihrer Stelle. In einem Weltlauf wie diesem, was soll man der Lust pflegen? Wo wir auch den, der sich der Lust ersättigt hat, immer von neuem hierher wiederkehren sehen? So errette

1) Vgl. oben S. 120 mit A. 1; siehe auch die Stellen des Epos, die Deussen Allg. Gesch. d. Philos. I, 3, 20 beibringt. 
du mich! Wie dem Frosch in einem finstern Brunnen, so ist mir in diesem Weltlauf!"

Hier und da, wenn auch selten, klingt in diesen Texten der Gedanke an, daß es sich bei der Weltverstrickung des Purusha um ein Betörtwerden, um Erliegen unter einer Versuchung handelt. Es ist ja „Lust, Leid, Verwirrung“ (S. 238), was die Welt ihm als Nahrung bietet. Man kann auch an die Worte denken, mit denen in der Kăthaka Upanishad der Todesgott seine Belehrung eröffnet, daß ein andres das Bessere ist, ein andres das Liebere: sein Ziel verfehlt, wer nach dem Lieberen trachtet. Ist dem Purusha nicht eben das widerfahren? Ist nicht die Prakrti eine große kosmische Versucherin? Wir greifen auf das Epos über. Dort findet sich ein Abschnitt, in den philosophischen Partien des großen Gedichts wohl einer der Höhepunkte: der Monolog des in das Reich der Natur verschlagenen, von deren Zauber lange betörten, im Saṃsāra umherirrenden Geistes, der zur Erkenntnis seines Elendes, zur Sehnsucht nach seiner wahren Heimat erwacht. Da heißt es:

„Weh über mich den Unweisen, der ich, verstrickt in blindem Wahn, In Person für Person einging, daseinsversunken nach wie vor.

Jener Ew'ge allein ist mir verwandt, bei ihm nur kann ich sein,

Ihm gleich und mit ihm eins werdend. Wie er ist, also bin auch ich...

Nicht mehr jener fortan nah' ich, wenn ich, der Wandellose, auch

Mich lange durch die Trugkünste der Wandelreichen täuschen ließ.

Und doch, nicht ihre Schuld war es; der Schuld'ge bin allein ich selbst, Der, ohne hinzuschaun, blindlings zu ihr trat und mich an sie hing."

Wie geht nun die Lösung dieser unseligen Verbindung vor sich, die Befreiung des verstrickten Selbst? 
Sucht man nach der Lehre des ältesten Sāṃkhya hierüber in den Upanishaden, so stößt man auf eine eigenartige Schwierigkeit. Von jener Frage wird dort ganz überwiegend in Ausdrücken vielmehr des Yoga als des Sāmkhya gesprochen.

Mit dem Yoga, welcher durch kunstvoll und planmäßig hervorgerufene Versenkungen die Erlösung erstrebt, und mit seinem Verhältnis zum Sāṃkhya werden wir uns alsbald eingehender beschäftigen. Wenn vielleicht nicht als gewiß, so wird sich doch als wohl wahrscheinlich herausstellen, daß nicht, wie man nach jenen Upanishaden annehmen könnte, von Anfang an der Yoga mit dem Sāṃkhya als integrierender Bestandteil zusammengehört hat, als der praktische Teil mit dem theoretischen. Sondern es scheint sich von Haus aus um zwei Doktrinen zu handeln. Allerdings neigten die zur Verschmelzung. Dem Sāmkhya lag es nah, eine ihm adaptierte Form des Yoga in seine Lehre von der Erlösung hereinzunehmen; dem Yoga erwiesen sich die Begriffssysteme des Sāṃkhya als geeignet, der Unaussprechlichkeit seiner nebelhaften Vorstellungswelt etwas von lehrhafter Klarheit und Aussprechbarkeit mitzuteilen. Ziehen wir aber die Entwicklungslinie in Betracht, auf der das ursprüngliche Sāmkhya liegt — zwischen den alten Upanishaden auf der einen Seite, dem epischen und klassischen Sāṃkhya auf der andern -, werden wir doch wahrscheinlich finden, daß innerhalb seiner Erlösungslehre das Yogahafte eben nur ein Element neben andern Elementen dargestellt hat: so daß die hier aufgeworfene Frage nach der betreffenden Sāmkhyadoktrin als einer im Yoga nicht einfach aufgehenden zu Recht bestehen bleibt.

Nun läßt sich zwar nicht in Abrede stellen, daß manche selbst nicht direkt ausgeprägten Yogacharakter zeigende Äußerung unsrer Quellen, an die wir uns gern beim Suchen nach der speziellen Sāmkhyalehre halten würden, doch mit Yogahaftem so eng verbunden auftritt, daß gegen ihre Verwertung für das Sāṃkhya, als vom Yoga unterschieden, 
Bedenken bestehen. Immerhin scheinen uns die Texte doch zur Beantwortung unsrer Frage wenigstens einige Beiträge $\mathrm{zu}$ liefern, für deren Prüfung der eben berührte Gesichtspunkt, die Lage des alten Sāmkhya zwischen uns bekannten älteren und jüngeren Entwicklungsphasen, nützlichen Anhalt bietet.

Da steht nun selbstverstăndlich, wie entsprechend schon für die ältere Spekulation, im Vordergrund die Überzeugung, daß es das Wissen vom Purusha ist, das über die Erlösung entscheidet. In der Śvetāśvatara Upanishad heißt es im Hinblick auf das mit "Gott" identifizierte Allwesen, das dort gelehrt wird (s. unten):

„Wer ihn erkennt, zerreißt des Todes Fesseln"...

"Unsterblich werden die, die solches wissen."

So konnte nun freilich auch ein Yogin sprechen, und es ist sogar wahrscheinlich, daß hier in der Tat ein Yogin spricht: für ihn waren die Konzentrationen und Ekstasen des Yoga eben der Weg zu jener höchsten Erkenntnis. Die Besonderheit des Sāmphya aber lag wohl darin, daß neben solchen Übungen, deren Bedeutung man nicht leugnete, das Gewicht doch, so wie wir es im klassischen Sāṃkhya finden, auf die reine Gedankenarbeit gelegt wurde, auf das Wissen von den Prinzipien des Seins und Geschehens und von ihrem gegenseitigen Sichverhalten. „Das Brahman ist', so sprach ein des Brahmanwissens Kundiger. ,Dies ist das Tor des Brahman', so sagt hiervon, wer durch Askese sich vom Bösen befreit hat. ,Om! Die Majestät des Brahman!' so sagt hiervon, wer wohlangespannt (su-yuktah) unermüdlich nachdenkt. Deshalb wird durch Wissen, durch Askese, durch Nachdenken das Brahman erfaßt" "15?. Es liegt ja auf der Hand, daß die Arbeit der Spekulation, aus der die Sāṃkyalehre hervorgegangen ist, ohne die Überzeugung von der hohen Bedeutung des verstandesmäßigen Erkennens für den Erwerb der Erlösung nicht getan worden wäre. Freilich kann es nun auch nicht überraschen, daneben wiederum Stimmen zu hören, die sehr andres sagen: 
„Durch Unterweisung ist Er nicht erlangbar, Durch Geisteskraft, durch viel gelehrtes Wissen. Nur wen Er selbst_erwählt, mag ihn erlangen;

Ihm offenbart der Ātman sich leibhaftig."

Man wird diese deutliche Verkündigung der Gnadenwahl nicht durch die Überlegung abschwächen, daß der Begnadende und der Begnadete ja in Wahrheit derselbe ist. Im Grunde kann man in diesem Vers wohl Yogafärbung erkennen. Er weist den Yoga nicht wie das Wissen zurück ${ }^{2}$ ). Ähnlich wie dem sich kasteienden Asketen gnädig die Gottheit erscheint, erwählt der Ātman gnädig den - so darf man wohl verstehen -, der in der rechten Sammlung und Anspannung ihn in sich selbst zu schauen strebt.

Sofern aber doch die Forderung des Wissens erhoben wird, arbeitet sich immer bestimmter der Zug heraus, daß es sich dabei um ein Unterscheiden handelt. Die alte Auffassung, daß es gilt das Verborgene zu finden, gestaltet sich dahin aus, daß es nötig ist, Verwechslung des täuschend Ähnlichen zu überwinden. Dem Nichtwissenden versteckt sich der Purusha unter den geistig scheinenden Schöpfungen der Prakrrti. Es kommt darauf an, ihn von diesen zu unterscheiden. Oder, wie man noch besser sagen kann, es kommt darauf an, daß er sich von ihnen unterscheide. Die Stelle einer Upanishad ist angeführt worden (S. 239), wo es heißt, daß der Purusha sich gebunden hat, indem er vom Naturdasein sagt: „Das bin ich; dies ist mein." Dem entsprechend erfolgt die Lösung, indem er sich von dem unterscheidet, was ihm fälschlich als sein Ich erschien. Häufig und nachdrücklich spricht hiervon das Epos. Purusha und Prakrti sind verschieden wie der Fisch und das Wasser, in dem er schwimmt, wie die Fliege und der Udumbarabaum, auf dem sie sitzt. Der Purusha erwacht zum Wissen: „ein andrer bin ich, eine andre ist sie"; so erlangt er die Reinheit. Das Wissen von dieser Fremdheit ist zugleich - uns mag das

1) In der Richtung auf den Yoga deutet, scheint mir, auch der nächste Vers (Kāțh. Up. 2,24), der dadurch das hier Gesagte bestätigt. 
ein etwas rascher Schritt scheinen - ein Abtun des Fremden. „Deshalb", heißt es an der eben berührten Upanishadstelle, „verharre er ohne Entschließen, ohne Bedenken, ohne Fürsichwollen. Das ist der Erlösung Kennzeichen. Das ist hier die Wegspur, die zum Brahman führt. Das ist hier das Auftun der Pforte. Dadurch wird man dieser Finsternis jenseitiges Ufer erreichen."

Wir blicken auf die Grundzüge dieser Gedankengänge zurück, die in so mancher Hinsicht zwischen alter und neuerer Zeit in der Mitte stehen. Vorwärts drängende Tendenzen zeigen sich. Sie führen zu späteren, schon jetzt präformierten Entwicklungen hinüber. Auch auf diese einen Blick wenigstens zu werfen wird am Platz sein. Das Ende, bei dem eine Bewegung anlangt, hilft jene selbst verstehen.

Die aus der älteren Zeit überkommene Scheidung zwischen den beiden ungeheuren Mächten und Reichen von Welt und Überwelt wird begreiflicherweise immer schroffer, je mehr das Denken sich mit ihr beschäftigt. Die Prädikate und Funktionen, die jeder der zwei Grundwesenheiten zukommen, werden ihr in immer wachsender Steigerung zugesprochen, immer restloser der andern abgesprochen. Was das Eine ist, ist das Andre nicht. Der alte Ätman, in sich selbst ein Prinzip unwandelbaren Seins, war doch zugleich, in einem gewissen Kontrast damit, der Bewirker aller Bewegung des Weltlebens gewesen; die erschaffene Welt war damals allzu wenig vom Denken bearbeitet, allzu tief in den Hintergrund geschoben, als daß sie diese Funktion hätte übernehmen können. Das ist jetzt anders geworden. Jener Kontrast scheint nicht länger ertragbar. Und jetzt hat neben dem Purusha das zweite Prinzip eine Kraft gewonnen, die es fähig macht, als Repräsentant von Werden und Bewegung dem seienden Purusha an die Seite zu treten.

Wenn wir auf die Gegenüberstellung von Purusha und Prakṛti, wie sie sich hier entwickelt, die Schlagworte Sein 
und Werden anwenden, halten wir uns nicht vollkommen in den Grenzen dessen, was die ältesten Sāmkhyaquellen wörtlich aussprechen ${ }^{1}$ ), aber wir treffen durchaus deren Sinn. Der Purusha, um todentnommen zu sein, ist seiner wahren Natur nach notwendig ein Seiender. Im Bild der Prakṛti, der Gunas steht das Werden im Vordergrund, das sich dem indischen Pessimismus vor allem vonseiten der Unbeständigkeit, der Wandelbarkeit zeigt.

So hat sich denn, einer Gedankenbahn folgend, auf welche die Ātmanidee zu führen begonnen, aber eben nur begonnen hatte, das Geistige mit dem Sein identifiziert, das Ungeistige mit Werden und Geschehen.

Hier erhebt sich die Frage: wo bleibt bei solcher Gestaltung der Gegensätze Raum für geistiges Geschehen?

Schon in der Maitrāyana Upanishad zeigt sich die Arbeit an diesem Problem. Man ist sich klar darüber, daß die Bewegungen des Denkens und Wollens, eben weil sie Bewegungen sind und weil in ihrem Auf- und Abströmen, in ihrer Helligkeit und ihrem Dunkel das Spiel der Gunas sich manifestiert, insofern zunächst auf die Seite des Ungeistigen gehören. So ist es denn ein schon in jener Upanishad bezeugter, an sich vermutlich weit älterer Satz des Sāṃkhya, daß Vernunft, Verstand, Ichprinzip und damit die Funktionen des Entschließens, Bedenkens, Fürsichwollens aus der Prakrti stammen. Daß ihnen dann aber geistige Bedeutung zuteil wird, davon scheint die Upanishad mit dem Ausdruck zu sprechen, daß sie "Speise" sind: „deren Genießer ist der Guṇalose (d. h. der Purusha); in seiner Genießerschaft erweist sich seine Geistigkeit" ${ }^{158}$. Offenbar liegt da schon der Hauptsache nach, wenn nicht sogar fertig und vollständig, die spätere Sāṃkhyalehre vor: die an sich rein materiellen Vorgänge von Wollen und Denken werden rom Licht des Purusha durchstrahlt und scheinen

1) Ich möchte es nicht als vollgiltige Nennung dieser Schlagworte ansehen, wenn z. B. in Kāthh. Up. 4, 2 vom vergeblichen Suchen „des Festen im Nichtfesten" gesprochen wird. Der Ausdruck ist allzu vag. 
dadurch aus ihrer wahren Sphäre hinaus in's Geistige erhoben zu werden - bis der Purusha, der Fremdheit dieses Fremden inne werdend und freilich eben in solcher Zurückweisung des Denkens selbst einen Denkakt vollbringend, von all dem sagen wird: "Dies ist nicht Ich".

Schwerlich hätte eine auf die Dinge selbst hinblickende Spekulation aus ihnen den Antrieb geschöpft zu diesem Auseinanderschneiden der geistigen Bewegung hier in die Bewegung, dort in den Geist, hier alles geistigen Inhalts, dort eines Geistes, dem jener Inhalt fremd gegenübersteht. Die denkende Bearbeitung der Wirklichkeit aber hat sich hier sehr unverkennbar schon zur Bearbeitung der Gedanken über die Wirklichkeit ausgewachsen. $\mathrm{Da}$ wird man von Konsequenz zu Konsequenz gedrängt. Gleichviel ob wir unsrerseits mit jeder einzelnen von ihnen uns befreunden: der ganze Vorgang zeigt auf das deutlichste eine Erstarkung des Denkens an, die wachsende Fähigkeit und das Bedürfnis, immer weiter hinaus die Linien $\mathrm{zu}$ verlängern, die man einmal gezogen hat.

Ebenso nun wie dem Purusha nicht mehr die Bewegung des Gedankenlaufs, der Willensvorgänge inne wohnen kann, steht es inbezug auf Handeln, auf Leiden.

Die ältere Auffassung des Sāmkhya hatte noch mit einer gewissen Unbefangenheit den Purusha ins Weltleben hinabsteigen lassen. Dort herrschte und wirkte er; dort litt er auch, indem die Bewegung, in die er mitten hinein geraten war, ihn fortriß, die Wellen über ihm zusammenschlugen. Dabei konnte es nicht bleiben. Immer schroffer wurde er ja als der Unbewegte der Weltbewegung gegenübergestellt. Daß nur er geistig ist, akzentuierte sich dahin, daß er nur geistig ist. So mußte der einst Allgewaltige sein Eingreifen in die materielle Welt aufgeben. Er wurde zum bloßen Zuschauer ${ }^{1}$ ), mit dem Gleichnis des

1) Warum nur schaut dieser Zuschaner zu? Hat er ein Interesse daran? Aus seiner Beaufsichtigung handelnde Einwirkung hervorgehen zu lassen hat er ja nicht die Kraft. 
spätern Sāṃkhya zum Lahmen neben der kraftvoll sich bewegenden, aber blinden Prakrti. Seine Vornehmheit verurteilte ihn zur Passivität. Um ihn gegen Vergänglichkeit und Tod abzuschließen hob man ihn aus dem Leben heraus: Leben ist ja Tod. In all dem liegt es, daß die beiden Antagonisten Prakṛti und Purusha jetzt unmöglich mehr in der Unmittelbarkeit, wie man das einst vorgestellt hatte, so zu sagen handgemein werden konnten. Die Aktion, die so heftig aussah, mußte sich vor der tiefer eindringenden Betrachtung schließlich in bloßen Schein auflösen.

Was wurde nun bei dieser Konstellation des Gedankens aus der Tatsache des Leidens? Des Leidens Ursache, die Vergänglichkeit, war allein in die Prakṛti verlegt, die Fähigkeit Leiden zu fühlen, allein in den Purusha: der Schnitt zwischen beiden, zerschnitt er nicht unvermeidlich die Möglichkeit, das Leiden $\mathrm{zu}$ verstehen?

Hier sehen wir nun zunächst soviel, daß man schon früh die Konsequenz, die sich aufdrängte, erkannt hat: der leidvoll Gebundene ist in Wahrheit gar nicht der Purusha. Das Leiden - als rein materieller Vorgang, bei dem die Frage für jetzt noch offen bleibt, wie er zum. Bewußtsein gelangen kann - trifft nur das Gegenbild des Purusha in der Sphäre der Prakṛti (S. 238). Nicht ihn selbst.

Die erste Äußerung, die derartiges anzeigt, findet sich schon in der Maitrāyana Upanishad ${ }^{159}$ : "Hier sagen einige: es ist der Guna, welcher vermöge der Differenzierung der Prakṛti in die Selbstbindung des Entschließens verfällt ${ }^{1}$ ); und indem das Gebrechen des Entschließens verschwindet, tritt Erlösung ein." Der Verfasser selbst zwar weist diese Lehre zurück; er hält daran fest, daß nicht der Guna d. h. die Naturwesenheit gebunden und erlöst wird, sondern der Purusha. Aber was man hier noch ablehnt, setzt sich dann durch. Die natürliche Auffassung wird ja dabei auf den

1) Man erinnert sich, daß „Entschließen" die charakteristische Funktion der "Vernunft" ist, des höchsten Komponenten des materiellen Gegenbildes des Geistes. Vgl, oben S. 231. 
Kopf gestellt, aber die Konsequenz der einmal eingeschlagenen Gedankenrichtung führt in der Tat dahin. Das Epos beschreibt den Purusha als

„Anfangslos, grenzenlos, endlos, alles schauend, von Schmerzen frei."

Und in der klassischen Zeit sagt die Kārikā, ganz im Sinn jener von der Upanishad zurückgewiesenen Lehre:

„So wird denn nicht erlöst, es wird nicht gebunden

Der Purusha, und er ist es nicht, der wandert.

Die Wandrerin, die Gebund'ne, die Erlöste

Ist die Prakṛti, die bald hier bald dort sich festhält" -

wo dann freilich daneben immer noch Äußerungen übrig bleiben, die unbekümmert um alle Subtilitäten die alte, natürliche Richtung festhalten, den Purusha erlöst werden lassen: wie die Milch der Kuh, obschon unbewußt, sich für die Ernährung des Kalbes regt, so regt sich die Prakrti um der Erlösung des Purusha willen; wie die Menschen ihr Werk tun ihre Wünsche zu befriedigen, so tut die Natur ihr Werk für des Purusha Erlösung.

Hält man sich aber an die andre, fortgeschrittenere Auffassung, so ist es sehr deutlich, wie hier die Befreiung, die man für den Purusha erstrebte, so intensiv ausgefallen war, so fest sich in dessen innerstem Wesen verankert hatte, daß sich nun eben nicht mehr begreifen ließ, wie er je hatte gebunden sein können. Die Absicht des Denkens war das gewiß nicht gewesen.

Jetzt aber blieb natürlich die Frage, wie bei der Ungeistigkeit der Prakṛti das in der Tat doch ebenso unwidersprechlich vorhandene wie für das System unentbehrliche bewußte Fühlen des Leidens zustande kommt.

Hatte man es unvermeidlich gefunden, bei der Konstruktion des objektiven Leidensvorgangs den Purusha auszuschalten, so konnte man hier, wo es sich um die subjektive Seite eben dieses Vorgangs handelte, ihn, das alleinige Subjekt, nicht entbehren. 
Der Ausweg, den man aus der Schwierigkeit fand, ist angezeigt durch das, was oben (S. 247f.) über die Konstruktion des bewußten Denkens und Wollens bemerkt wurde. Ein Lavieren zwischen Wirklichkeit und Schein. Eben genug Wirklichkeit, um der Tatsache des Leidens als eines bewußt gefühlten die unvermeidliche Anerkennung zuzuwenden - oder soll man sagen zu erschleichen? Und genug von bloßem Schein, um den Unerklärlichkeiten zu entgehen, die angesichts der Prinzipien des Systems der Annahme vollwirklichen Leidens anhafteten. Kompromisse, Weiterschieben der Schwierigkeiten von einem Punkt zum andern: das gehört zur Signatur dieser Spekulationen. Von dem Aussehen, das man ihnen hat zuschreiben wollen, des Hervorgetauchtseins gleichsam aus dem Nichts, des Fertigseins auf einen Schlag, sind sie in der Tat recht weit entfernt.

Durch die nun einmal als Tatsache hingenommene „Verbindung" mit dem Purusha, so lehrt die Kārikā, wird das ungeistige Linga ${ }^{1}$ ) "gleichsam geistig“. Und der untätige Purusha - in Wahrheit tätig sind ja allein die Gunas wird "gleichsam ein Täter"; man könnte hinzufügen, gleichsam ein Leidender.

Ein solches "gleichsam" muß die Kluft überbrücken, das Unmögliche möglich machen, das rein objektive, unbewußte Leiden, das sich im Ungeistigen vollzieht, in das Reich des Bewußtseins hinüberspielen. Ein zwar nicht in der Kārikā selbst, aber später häufig begegnendes Gleichnis veranschaulicht, wie es gemeint ist: jenes objektive Leiden, das den Schöpfungen der Prakṛti innewohnt, überträgt sich scheinbar auf den Purusha, wie sich im reinen Krystall die ihm nah gebrachte rote Blüte abspiegelt und jener dadurch rot erscheint. Oder ein andres Gleichnis:

„Wie im Schwanken des Seespiegels der Mond schwankend dem Blick erscheint,

So der Seher, das Selbst scheinbar nimmt an des Nichtselbst Eigenschaft."

1) Das materielle Gegenbild des Purusha; vgl. S. 238. 
Es ist bezeichnend, welche große Rolle hier vielfach den Gleichnissen zufällt. Sie sind geschickt und scharfsinnig ersonnen. An die schlichte Tiefe der alten Upanishadgleichnisse reichen diese des jüngeren Sāmkhya doch nicht heran. Es wohnt zu viel Klugheit in ihnen. Indem sie in die Gedankenentwicklung ihre gefälligen Bilder hineinspielen lassen, führen sie die Phantasie unvermerkt über bedenkliche Stellen fort ${ }^{1}$ ). Im vorliegenden Fall wird man sich vielleicht zunächst sagen, daß doch nur einem Dritten der Krystall rot, der Mond schwankend erscheint: dem Beschauer von Krystall und Blume, von Mond und See. Wo ist ein solcher Beschauer von Purusha und Prakṛti? Und wäre er da und entstände jener Schein für ihn, was täte das dem Purusha, der Prakrti? Man kann entgegenhalten, daß in einer bestimmten Hinsicht das Gleichnis eben hinkt: der Krystall ist ungeistig, der Purusha aber geistig, so daß der falsche Schein, der beim Krystall nur den Dritten täuscht, hier ihn selbst täuschen kann. Möglich, daß der Schöpfer jenes Gleichnisses in der Tat so antworten würde. Aber bleibt es nicht auch so trotz aller Gleichnisse nach wie vor unverständlich, daß in Ihn, der dem Geschehen so ganz und gar entnommen ist, auch nur ein Widerschein von Geschehen und Leiden - also in gewisser Weise doch eben auch ein Geschehen - Eingang findet und Leiden zu erzeugen die Kraft hat, in sein reines Licht die Trübung. solches Wahns?

Wir werden auf die Frage zurückkommen, wie nun, indem die Realität des Leidens sozusagen in eine Komödie der Irrungen verflüchtigt ward, das Bild der Erlösung von diesem Leiden sich gestaltet hat. Vorher aber ist es nötig noch einer andern tief eingreifenden Neuerung zu gedenken, die

1) So auch das berühmte Gleichnis (oben S. 249) vom Lahmen (Purusha) and Blinden (Prakrti), die zusammen den Weg machen. Der Blinde kann sich durch den Sehenden dirigieren lassen, aber wie kann das die Prakriti? Der Lahme kann dirigieren, aber wie kanu das der Purusha? 
besonders wesentlich dazu beigetragen hat, die ursprüngliche Sāṃkhyalehre in ihren klassischen Typus überzuführen.

Aus alter Vergangenheit hatte der Purusha es ererbt, über der Vielheit des Welttreibens als der Eine zu stehen. Die Zeit kam, wo die faszinierende Kraft des Einheitsmotivs sich zu verbrauchen anfing. Einst hatte die allumfassende, allbeherrschende Übergröße des Einen dasein müssen, damit man bei ihr Rettung aus dem Getriebe der Vielheit finden könne. Jetzt, wo die Sonderung des Geistigen von der Vergänglichkeit immer strenger durchgeführt wurde, taten sich auch andre Möglichkeiten für die Erreichung des Heils auf. So konnten Bedenken gegen die Einheitslehre, über welche der Schwung der alten Pfadfinder hinweggeeilt war, bemerkt werden und ihr Gewicht ausüben.

Der Purusha des älteren Sāmkhya, von den Gebilden der Natur seinem Wesen nach gesondert und doch dieser Sonderung zum Trotz hier und dort mit diesen, mit jenen in leidvolle Verbindung sich verlierend, kehrte jetzt hier, jetzt dort zu sich selbst zurück. So verteilte Er, der der Eine sein sollte, sich über zahllose Laufbahnen. Zum entscheidendsten aller Dilemmas, dem von Gebundenheit und Erlösung, verhielt er sich hier so, dort anders. Lassen sich Erlöstheit und Unerlöstheit so vereinen? Schon die Maitrāyana Upanishad (II, 5) sprach davon, ja die Vorstellung läßt sich offenbar in weit ältere Zeit zurückverfolgen (S. 127), daß der Ewige da jedesmal nur mit einem Teil seines Wesens im Spiel sei. War das nicht ein Notbehelf, über den hinaus man weiter getrieben wurde? Die Teilung war doch offenbar veranlaßt durch die Natur mit ihrer endlosen Mannigfaltigkeit. Machte die schärfere Trennung der beiden Prinzipien es nicht immer schwerer, jener eine solche Wirkung auf den Purusha zuzuschreiben? Gerieten die Teile des einen Purusha einmal so weit auseinander, warum da nicht lieber viele Purushas annehmen?

Es ist begreiflich, daß solche oder ähnliche Erwägungen beitrugen, den Standpunkt der schlichten Erfahrung wieder 
zu Ehren zu bringen, das Bewußtsein der Vielheit der Geister, das vor dem Überschwang der all-einheitstrunkenen Mystik lange verstummt war. So sehen wir denn im Epos ${ }^{160}$ die Frage auftauchen: gibt es viele Purushas oder gibt es nur einen? Hier wurde noch geantwortet, daß der eine Purusha der Ursprung der vielen ist, daß in ihn, den guṇalosen, jene, wenn sie gunalos geworden sind, eingehen. Ein Ausweg, der zu vermitteln suchte und doch nicht auf die Dauer vermitteln konnte. Derselbe Abschnitt des Mahābhārata bezeugt, daß die Gedankenbewegung schon damals uiber diese Beantwortung der Frage hinaus einen entscheidenden Schritt weiter getan hatte. Zum Fürsten spricht der Weise:

„Sāṃkhya und Yoga lehrt Vielheit der Purushas in

Daß nur ein Purusha da sei, das leugnen sie, dieser Welt.

o Kurusproß."

Damit ist denn der Standpunkt des klassischen Sāṃkhya erreicht.

In dessen leitendem Text, der Kārikā, hat man vielleicht mit Recht noch die Spur davon finden wollen, daß es eine Neuerung ist - in der Tat eine fundamentale Neuerung -, die sich hier vollzogen hat. Beständig spricht die Kārikā im Singular von „dem Purusha;" daß an eine Vielheit gedacht wird, läßt sich dem Wortlaut der meisten Sätze nicht entnehmen. Ein Festhalten altgewohnten Ausdrucks, das freilich auch durch die Konfiguration des Gedankens erleichtert wird. In der Vielheit der qualitätfreien Purushas, dieser individualitätslosen Individuen, herrscht trotz des verschiedenen Verhaltens der sie umspielenden Prakṛti doch eine solche Einerleiheit, dals "der Purusha" sehr wohl als vollgiltiger Vertreter aller Purushas erscheinen $\operatorname{kann}^{101}$.

Ausgesprochen wird in der Kārikā die Lehre von der Vielheit der Purushas, die in der Tat dem Verfasser ohne Frage durchweg gegenwärtig ist, vor allem an einer Stelle. 
In der dunkel gedrängten Redeweise dieses Textes sang man den Vers:

„Aus der Geburt, des Todes und der Organe

Verteilung, auch aus dem nicht gleichzeit'gen Wirken

Wird erschlossen der Geister Vielheit,

Ferner aus des Dreigunahaften Gegensatze."

Was offenbar bedeutet: stände allen Körpern ein und derselbe Geist gegenüber, so wäre unverständlich, daß Geburt und Tod, d. h. Verbindung des Geistes mit einem neuen Körper und Trennung solcher Verbindung, nicht überall zugleich eintritt, sowie daß dem Geist hier diese dort jene materiellen Organe gehören. Auch bliebe unbegreiflich, daß nicht alle Wesen gleichzeitig sich bewegen oder ruhen. Endlich führt zum selben Ergebnis auch der Gegensatz des Purusha und der dreigunahaften Natur: diese besteht nur in einem Exemplar; so muß jener als ihr entgegengesetzt in vielen Exemplaren vorhanden sein. Das letzte Argument ist ja handgreifliche Künstelei, bezeichnend nur dafür, wie gewiß man sich fühlte, in jeder Beziehung die beiden Prinzipien im Gegensatz zu einander anzutreffen. Die ersten Beweisgründe dagegen zeigen vermutlich in der Tat die ungefähre Richtung an, in der das Denken dahin gelangt ist, die Einheit des Purusha zu zerstören. Wie hat sich doch seit der Zeit der alten Upanishaden die Stimmung geändert! Dort hing jeder Gedanke daran, wie das Selbst über alle Schranken hinweg sich in die Unendlichkeit taucht und sie durchströmt, sich von ihr durchströmen läßt: „Das bist du!“ Hier ist bedächtige Kritik an der Arbeit. Sie kann über die Getrenntheit des Ich und des Du nicht hinwegsehen, und so erkennt sie sie denn gelassen an. Hüben die Natur, drüben individuelle Seelen: das ist nunmehr das Einzige, womit das Denken es zu tun hat. Die Allseele mit ihren grenzenlosen Weiten ist verschwunden. Das Universum ist entgöttert. -

Wir müssen schließlich, wie schon oben bemerkt wurde, noch einen Blick darauf werfen, wie sich bei der veränderten Auffassung des Leidens - und, muß nunmehr hinzugefügt 
werden, bei der eben beschriebenen Umformung der Lehre vom Purusha - das Bild der erreichten Erlösung gestaltet hat.

Die Erkenntnis der Unterscheidung von Purusha und Prakṛti ist gewonnen. Dem Spiel der Reflexe zwischen beiden ist damit ein Ende gemacht. Was wird nun aus Purusha und Prakriti?

Im Hinblick auf das Dogma von der Vielheit der Purushas kann die Frage selbstverständlich nur dies bedeuten: was wird aus dem einen Purusha, für den die Erlösung gewonnen ist, und aus der Prakrti, sofern sie eben diesem Purusha gegenüberstand?

Der Purusha, daran ist kein Zweifel, geht in den Frieden seines Beisichseins ein, fortan unberührt vom flackernden Schein des Geschehens, der Vergänglichkeit. Das über alles bewußte Dasein erhabene Sein des Âtman in seinem eigenen Reich, wie einst die Rede des Yājnavalkya es lehrte, kehrt hier wieder, nur daß es nicht mehr das Allwesen ist, sondern der einzelne Geist, der sich als transzendenter Anachoret in sich selbst zurückgezogen hat. Wir begegnen dem Vers eines jüngeren Poeten ${ }^{\mathbf{1 6 2}}$ :

"Wenn auf des Spiegels Fläche sich kein Berg, Kein Tal, kein Wesen widerspiegelt, so verharrt Die Spiegelkraft allein im eignen Sein.

Dem gleicht, wenn der Erscheinungen Gewirr, Wenn Ich und Du und Welt verschwunden ist, Die Einsamkeit des Sehers, der nichts sieht."

Und die Prakṛti? Man sollte erwarten, daß sie im Dunkel ihrer Ungeistigkeit ins Unabsehbare die nunmehr unschädliche Bewegung fortsetzen wird, die vollziehen zu müssen in ihrem Wesen liegt.

Das Sāmkhya hat diese Konsequenz nicht gezogen.

In das Bild vom Nebeneinanderstehen und Widerstreit der Welt und des Überweltlichen war nämlich ein kleinlicher Zug geraten, in der Sāṃkhya Kārika fortwährend hervortretend, der dazu beitrug, das einst groß Gedachte ins 
Zierliche herabzuziehen. Die Konsequenzen dieses Zuges machen sich hier fühlbar.

Die alte Überzeugung, daß die höchste Macht und Herrschaft dem Ātman gehört, hatte sich, dem Geschmack späterer Zeit entsprechend, in Vorstellungen umgesetzt, die aus dem Purusha einen sultanhaft untätigen Gebieter machten, aus der Prakṛti eine unermüdlich eifrige, nie an sich denkende Dienerin. Um des Purusha, um jedes einzelnen Purusha willen - als die zu Erlösenden sind hier diese gedacht (vgl. S. 249) - vollbringt sie die Arbeit ihrer Entfaltung, läßt sie jedes Linga (S. 238) wie einen Schauspieler seine wechselnden Rollen übernehmen, „zum fremden Zweck, als obs zum eignen Zweck geschähe",

„Hilfe leistend auf mannigfache Weise

Sie die hilfreiche ihm dem nichthilfreichen."

So müht sie sich ab, daß das Endziel des Weltgangs erreicht werde, daß die erlösende Unterscheidung entstehe, die den Purusha zur Reinheit seines absoluten Seins gelangen läßt. Die Frage liegt freilich nah, wozu dann vorher eben dieser Weltgang seit anfanglosen Ewigkeiten dahin hat wirken müssen, dem Purusha den allerschlechtesten Dienst zu leisten, ihn in jener unheilvollen Verbindung festzuhalten, die dann so mühevoll gelöst wird. Die Verbindung der beiden findet statt, heißt es einmal in der Kārikā, die Schöpfung entsteht, damit sich die Erkenntnis, die Sonderung von Purusha und Prakṛti erreichen lasse: mit andern Worten, das Unglück geschieht im Interesse des Verunglückenden, damit diesem dann herausgeholfen werde ...

Aus solchen Vorstellungen nun erklärt sich das Bild, das man sich vom Verhalten der Prakrti nach Erreichung des Zieles machte. Wieder beschreiben es Gleichnisse:

„Wenn der zuschauenden Schar sich die Tänzerin Hat gezeigt, so macht sie dem Tanz ein Ende.

So die Natur, wenn sie dem Geist ihr Wesen

Offenbart hat, tritt sie zurück und verschwindet" und weiter:

Oldenberg: Upanishaden. 
"Nirgends gibt's ein Wesen so zart empfindlich

Wie die Prakrti; dies ist meine Meinung.

Wenn sie merkt: "er hat mich gesehn",

Zeigt sie des Purusha Blicken sich nicht wieder."

In der Tat für die Blinde, Ungeistige viel Feingefühl, so wie es vorher viel Zielstrebigkeit derselben Ungeistigen gewesen war, daß sie ihre Arbeit in den Dienst des Purusha zu stellen und sie seinem Zweck anzupassen gewußt hatte.

Wo ist aber in alldem der bittere Ernst und die Not des Weltleidens geblieben? Die Bajadere, die den zuschauenden Despoten unterhält, das schamhaft vor den Blicken des Mannes sich zurückziehende Weib: in der graziösen Pikanterie solcher Gleichnisse zeigt sich, wie diesem Denken die rechte, volle Wucht verloren gegangen ist. Künstlich, subtil, elegant, und doch wieder achtlos gegenuber starken Unklarheiten und Widersprüchen -- so hat man jetzt die Gedankenmassen aufgebaut, umgebaut.

Die Tragödie aber hat dabei manches von einem Ballett angenommen.

\section{Der Yoga.}

An der Seite der Sāmkhyalehre, ihr nah verbunden, erscheint in der Literatur der Yoga. Er sucht für die Gedankengänge der Spekulation Verwirklichung in Übungen einer körperlichen und seelischen Disziplin, die mystische Zustände methodisch herbeiführt.

Schon oben (S. 141 f.) haben wir den Yoga berührt. Spuren von ihm scheinen sich bereits in den älteren Upanishaden $\mathrm{zu}$ finden ${ }^{108}$. Ja ein kosmogonischer Mythus schon des Rigveda gibt einem dort auftretenden Urwesen einen Namen, der auf eine in der Yogatechnik begegnende Körperhaltung des Asketen hinweist, das Sitzen mit untergeschlagenen Beinen, die Fußsohlen nach oben gekehrt ${ }^{164}$ : doch das ist offenbar kein Beweis für die innerlich unmögliche Annahme, daß es wirklichen Yoga schon in rigvedischer Zeit gegeben 
habe, sondern nur dafür, was ohnehin selbstverständlich ist, daß zwischen Yoga und primitivem Kasteiungswesen der Vergangenheit Zusammenhang besteht.

In voller Existenz erscheint der Yoga erst in jenen selben Upanishaden, die auch über das Sāmkhya zuerst berichten. Sie tragen den Inhalt beider Lehren in Verbindung mit einander vor. Es ist bezeichnend, daß eine dieser Upanishaden eben da, wo man in ihr die älteste Erwähnung des Namens Sāṃkhya findet, in engstem Zusammenhang damit auch den Yoga nennt - gleichfalls einer der frühesten Belege für den Namen dieses Systems: Gott wird dort als die „durch Sāṃkhya und Yoga erkennbare Ursache" der Welt bezeichnet ${ }^{185}$. Ebenso nah verbunden zeigen sich Sāmkhya und Yoga dann in den epischen Quellen und endlich in der Literatur, welche die klassische Gestalt beider Systeme darstellt: von diesem auch für die Vorgeschichte des Buddhismus wichtigen Verhältnis wird noch eingehender die Rede sein.

Wie aus der Situation, zu welcher die oben beschriebenen Bewegungen des Denkens geführt hatten, der Yoga hervorgegangen ist, begreift sich. Dem religiösen Erkennen und Handeln waren neue größte Aufgaben gestellt. Es konnte nicht genügen die jenseitige Welt, die man entdeckt hatte, nur von fern zu denken, gleichsam die Formeln auszurechnen, die ihr Wesen ausdrückten. Schauen mußte man das Unanschaubare, überselig es genießen, von allen irdischen Hemmnissen gelöst in seiner Fülle, seiner Leere Stand fassen. Da bedurfte es stärkerer, konzentrierterer Bemühungen, als das heimatlose Bettlerleben der alten Upanishaden sie in sich schloß. Die dunkeln Kräfte boten ihre Hilfe an, die von altersher vollste, wirklichste Gewißheit der Beherrschung übernatürlicher Visionen, übernatürlicher Wirkungen, des Verkehrs mit übernatürlichen Wesenheiten verbürgten: die Zauberkräfte der Kasteiung (Tapas). Wie man durch Tapas die Götter in sich fühlte, ähnlich mußte es mit dem jenseitigen, absoluten Selbst ge- 
lingen. Allzu nah, als daß man diesen Weg nicht hätte einschlagen sollen, stand dem Denker der Upanishaden auch jetzt noch nicht der Priester allein, sondern auch der Zauberer. Allzu dicht lag unter den Höhen der Spekulation das ungeklärte Bild einer Welt, in der natürliches und magisches Geschehen wirr und düster durcheinander wogte. Tatsächliche Errungenschaften, die auf dem Gebiet der Selbsthypnose gelangen, griffen entscheidend ein: zwischen der Vertiefung in die fließenden Traumgebilde der Brahmanspekulation und hypnotischen Zuständen konnte der Weg ja nicht weit sein. Und so sublimierte sich das Tapas, wörtlich "Erhitzung“, den neuen Problemen sich anpassend, zum Yoga, der Wortbedeutung nach „Anspannung". Für den Sinn des Wortes ist bezeichnend, daß eine der ältesten Upanishadstellen über den Yoga ${ }^{100}$ durch eine Reihe von Vedaversen eingeleitet wird, die alle mit einer Form des Verbs „anspannen“ (yuj-) anfangen und Anspannung des Geistes zu frommem Tun vom "Gott Antreiber" (Savitar) erbitten. Diese Kunst der inneren Anspannung stellte sich auf das Ziel ein, dem auch die alten Kasteiungsubungen im Grunde verwandt waren: auf die Loslösung des Geistes von dieser Welt.

Die älteren Upanishaden hatten solche Loslösung vor allem im traumlosen Schlaf verwirklicht gefunden. Jetzt suchte man weniger Alltägliches, Kunstvolleres, das glänzendere seelische Reichtümer spenden konnte. Über den drei Zuständen von Wachen, Träumen, traumlosem Schlaf "den Vierten".

Die Bemühung darum setzte auf körperlichem Gebiet vor allem beim Atem ein, den es zu beherrschen galt, auf seelischem beim Vorstellungslauf, den man zu beschwichtigen, zu unterdrücken suchte:

„Des Atems und Verstands Einheit und der Sinnesorgane auch,

Jeglichen Zustands Abstreifung: dies ist es, was man Yoga nennt." 167 
Die große Rolle, die hier der Disziplin des Atems zukam, scheint sich, wie gewöhnlich in derartigen Fällen, aus dem Zusammentreffen verschiedener Motive zu erklären ${ }^{168}$. Ein erheblicher Teil der körperlichen Bewegungen, die Unruhe und Verflochtensein in das materielle Weltleben bedeuten, ließ sich ohne weiteres ausschalten. Von dem, was übrig blieb, war die Atmung das erheblichste, zentralste. Von altersher galt der Atem als Sitz des Lebens. Im Zusammenhang damit sind die Brāhmaṇatexte voll von Riten und recht wirren Theorien, die es mit dem Atem und dem komplizierten System der verschiedenen ihm beigelegten Formen. zu tun haben. Diese populären oder sakrifikalzauberhaften Anschauungen hatten sich dann zu metaphysischen Gedankenspielen über den Atem als Prinzip des Weltlebens erweitert. Es kam hinzu, daß die alte rituelle Sitte Anhalten des Atems als Sicherung gegen Gefährdung durch schädliche Mächte kannte, die in der Nähe ihr Wesen trieben. Es galt ferner als hitzeerzeugend, stellte sich als eine Form der Kasteiung (Tapas, eigentlich Erhitzung) dar. So verband sich auf mannigfache Weise damit die Vorstellung von Reinigung und Sühnung. Vielleicht schon früh glaubte man ferner, nicht ganz ohne Grund, an $\mathrm{Zu}$ sammenhang zwischen dem Tempo der Atmung und dem des Vorstellungslaufes. Endlich ist offenbar auch die durch unzureichende Atmung bewirkbare, bis zur Hypnose gehende Verdüsterung der Gehirntätigkeit, im Sinn der Asketen Erhebung des Geistes in höhere Sphäre, beobachtet worden. So ist begreiflich, daß der Yogin (Ausüber des Yoga) in der Verminderung und absolut strengen Regularisierung des Atmens ein kräftigstes Mittel sah, die Intensität des eignen Daseins in der Diesseitswelt herabzusetzen und inmitten ihrer trüben Bewegung eine klare Stille zu schaffen, in der sich der Ausblick auf das Jenseits, der Weg dorthin auftat.

Wir wissen es nicht positiv, dürfen aber vermuten, daß schon in seiner Anfangszeit der Yoga unnützes Sichquälen 
und insonderheit schwächendes Fasten widerriet: die Kost soll mäßig und einfach, aber ausreichend sein. Offenbar ging das Bestreben dahin, für die schwere Arbeit, die man vor sich hatte, die Kräfte zu schonen, lähmendes Mißbehagen fernzuhalten. Überhaupt wurde diesem Zweck entsprechend ein Lebenswandel zur Pflicht gemacht, der in Tun und Lassen auf Vermeidung aller Leidenschaft und Befleckung, auf Ruhe, Reinheit, Erhebung hinarbeitete.

So setzte sich denn der Yogin zu seinem mystischen Tun nieder, in einer Umgebung, wie die Śvetāśvatara Upanishad ${ }^{169}$ sie beschreibt:

"An ebnem, reinem Ort den Yoga übe man.

Dort sei kein Kies, Sand, Feuer, Stimmgetön, kein Teich ${ }^{1}$ ).

Nichts tue weh dem Auge. Angenehm dem Geist,

An Höhlen reich, an Windesschutz die Stätte sei.“

Im Lauf der Zeit entwickelte sich die umständliche Lehre von den zahlreichen Haltungen des Sitzenden - dem Lotossitz, dem svastika-(Hakenkreuz-) Sitz usw. In einer solchen Haltung saß man da. Man preßte die Zungenspitze gegen den Gaumen. Bald wird auch des Fixierens der Nasenspitze gedacht; die hypnosigene Wirkung solches Starrens, der Konvergenz der Blicklinien ist ja bekannt. Man ubte die Kontrole und Herabsetzung des Atems, ferner die Zurückziehung der Sinne von den Objekten: denn nach auswärts hat der Schöpfer die Öffnungen des Körpers aufgetan, und so sieht man von Natur nach außen; der Weise aber blickt nach innen, dort Unsterblichkeit zu finden; er meidet die Beruhrung mit den Sinnesobjekten, wie der Enthaltsame $n$ in menschenleerem Hause die zu ihm eingehenden verliebten Weiber nicht berührt". Von besonderer Wichtigkeit war die Fixierung des unruhig fluktuierenden Denkorgans 'auf einen Punkt; man hält dies Organ fest, sagt das Epos, wie einen Fisch, den man töten will. Gern richtete man die Meditation auf das mystische Wort Om,

1) Um üble Dünste, Moskitos und dgl. fern zu halten? 
dessen eine Silbe als Essenz der Essenzen alle Kräfte der Heiligkeit in sich faßt. Naciketas wird vom Todesgott belehrt:

„Das Wort, das alle Veden zu dir sprechen,

Das dir erklingt aus jeglicher Kasteiung,

$\mathrm{Zu}$ dem des Heil'gen frommer Wandel hinstrebt,

Das kurze Wort, ich will es dir verkünden:

$\mathrm{Om}$, so heißt es ......

Dies Wort, der beste Halt ist es;

Dies Wort, es ist der höchste Halt.

Die solchen Halt erkannt haben,

Werden erhöht in Brahman's Welt."

Und eine andre Upanishad sagt: "Wie eine Spinne an ihrem Faden emporklimmt und ins Freie gelangt, wahrlich so gelangt jener Meditierende am Wort Om emporklimmend zur Freiheit."

Bezeichnend ebenso für den letzten leisen Zusammenhang dieser Gedankenströmungen mit dem alten Opferkult, wie zugleich für das Sichauflösen dieses Zusammenhangs. Das heilige Wort des Yoga ist das "Ja“ oder "Amen“ der Opferlitaneien. Aber die bunten Welten von Veda und Opfer sind jetzt verschwunden im Abgrund der einen Silbe ... .

Häufig ist von den Versenkungen des Yogin in Ausdrücken der Sāṃkhyalehre die Rede. Die niederen Seelenvermögen soll man schrittweise in die höheren eingehen lassen und sie so zur Ruhe bringen. Man soll, heißt es an einer der ältesten hier einschlagenden Upanishadstellen, Rede und Verstand (manas) im Erkenntnisselbst (d. h. der Vernunft, buddhi) hemmen; dieses im "Großen Selbst" (s. oben S. 229f.); dies endlich im "Ruheselbst".0

Anderwärts - wir müssen unvermeidlich Angaben verschiedener Texte mit einander kombinieren - werden Betrachtungen erwähnt, das Denkorgan beruhigend und die erhabenere Versenkung vorbereitend, welche durch die Schlagworte „Freundschaft" (mit allen Wesen), "Mitleid", "Fröhlichkeit" und "Gleichmut" charakterisiert sind. Die 
älteren Yogaquellen nennen sie nicht, aber die Übereinstimmung mit asketischen Übungen des Buddhismus sichert ihr Alter und verleiht ihnen Bedeutung für die Forschung.

Als Vorläufer des entscheidenden Erfolges werden Erscheinungen aufgeführt, wie eine Upanishad sie beschreibt:

"Nebel und Rauch, Sonne und Feuer, Winde,

"Leuchtkäfer, Blitze, Bergkrystall und Mondglanz".. ${ }^{171}$

Zentrale Stellung nun in der Theorie der Versenkungen nimmt die Lehre ein zuerst von vier schrittweise aufsteigenden Stufen der "bewußten" Konzentration, dann von der "unbewußten", die sich über jener als Gipfel erhebt. Die ältesten Quellen zwar sprechen hiervon nicht. Bei ihrem fragmentarischen Charakter kann man doch nicht schließen, daß die betreffenden Vorstellungen damals noch gefehlt haben, und auch hier treten wichtige buddhistische Zeugnisse, auf die wir später zurückkommen, für das hohe Alter jener Lehre mindestens ihren Grundzuigen nach ein. Das klassische Yogasystem charakterisiert diese Versenkungen der Reihe nach dahin, daß in ihnen das auf gröbere, dann nur das auf feine Objekte gerichtete Nachdenken übrig bleibt, weiter das Wonnegefühl, endlich allein noch das Gefühl des Ichseins: ist auch dies verschwunden, so ist die höchste, "unbewußte Konzentration" erreicht.

Wie nun aber auch im Einzelnen solche scholastische Distinktionen gestaltet sind, aus allen Äußerungen derer, die diese gewi $\beta$ im Wesentlichen auf Selbsthypnose zurückzuführenden Zustände durchlebt haben, spricht mit überzeugender Kraft die Erinnerung an namenloses, durch und durch dringendes Glück. Von dem, der die Höhe erreicht hat, ist alle Erdenschwere gewichen. Alle Schranken sind gefallen. In der Tiefe des eignen Selbst ist er ihm erschienen,

"Der schwer zu schaun ist, im Verborgnen weilend,

Der in der Höhle wohnt, der Gott, der alte."

Und es ist nicht beim bloßen Schauen geblieben. Das Schauen hat sich in Einssein mit dem Geschauten ver- 
wandelt. Über unermeßlichen Ätherweiten, in Leerheit voller als alle Fülle schwebt der Geist. Er ist ganz Frieden, tiefer, leuchtender Frieden. So brennt an windstillem Ort - immer wieder kehren die indischen Dichter zu diesem Vergleich zurück - ein Licht, unbewegt, die Flamme emporstrebend. Können solche Bilder es den Ungeweihten ahnen lassen? Worte erklären es ihm nicht. Eine Upanishad sagt:

„Die Seele, durch Versenkung reingewaschen

Von Flecken, in den Ātman eingegangen:

Welch Glück ihr wird, das sagen keine Worte.

Im eignen Innern muß man's selbst erfahren." -

Wie stellen sich nun die Früchte dar, die dies Tun und Erleben dem also Begnadeten bringt?

Hier vermischen sich, wie begreiflich, ältere und jüngere Vorstellungsrichtungen, durchaus niedere, ja für unser Gefühl ins Burleske verfallende Strebungen mit höheren.

Auf niederer Stufe wird dem Yogin bequeme, störungsfreie Frische des Befindens, der körperlichen Funktionen in Aussicht gestellt.

„Gesundheit, Leichtigkeit, Begierdenfreiheit,

Klares Gesicht und angenehme Rede,

Guter Geruch, Urins und Kotes Knappheit:

Dies kennt man als die erste Frucht des Yoga."

Weiter - die alten Texte schweigen davon, aber die Vorstellungen sind zweifellos alt - erwirbt der Yogin Wunderkräfte, wie die Fähigkeit, sich klein und unsichtbar zu machen oder sich ins Unendliche zu vergrößern, den eignen Körper zu vervielfältigen, seiner früheren Geburten sich zu erinnern und andre Fertigkeiten dieses Schlages mehr ${ }^{1}$ ).

1) Der Glaube der alten Zauberwissenschaft, daß Wissen von einem Objekt Macht über dies Objekt verleiht (oben S. 6), ist hier noch vollkommen lebendig. Der Yogin, der die beherrschende Kraft seiner Versenkung beispielsweise auf die eigne Körperform richtet, erwirbt dadurch die Fähigkeit, sich unsichtbar zu machen. Richtet er sie auf die Wesenheit der fünf Elemente, erlangt er Herrschaft über diese u. dgl. mehr. Yogasūtra III, 21. 44. 
Mit diesen fiktiven Vorzügen hat sich ubrigens an einer Stelle Andres, Wirkliches vermischt. Früh - wir wissen leider nicht, wie früh - ist es indischer Findigkeit gelungen, neben der Selbsthypnose auch die auf Andre gerichtete Hypnose zu entdecken. Sie wurde als „Eingehen des Geistes in den Leib eines Andern" natürlich unter die Wunderkräfte des Yogin aufgenommen. Das große Epos erzählt mehrere Geschichten, bei denen es sich offenbar um Hypnotisierung handelt. So schützte der Brahmanenschüler Vipula durch Hypnose die Gattin seines verreisten Lehrers gegen die Galanterien des Gottes Indra. ${ }^{128} \mathrm{Er}$ setzte sich zu ihr und

"Mit ihrer Augen Strahl einend die Strahlen seines Augenpaars

Also in ihren Leib drang er, wie in den Raum des Windes Wehn."

Der Gott tritt herein und sieht neben der schönen Frau sitzend den Hypnotiseur - vielmehr dessen Körper,

„Gemaltem Bilde gleich scheinend, bewegungslos, das Auge starr."

Die Frau will vor dem Gast aufstehen, aber alle ihre Sinne und Kräfte sind "mit des Yoga Fesseln" gebunden. Sie will reden: ihre Sprache ist "von ihr weg gewandt". Endlich bringt sie ein gleichgiltiges Wort hervor, nicht in der schlichten Redeweise der Frauen, sondern in vornehmem Sanskrit, wie der Beschwörer es sprechen würde. Der läßt sie los, wie die Gefahr vorüber ist, und "geht wieder ein in den eignen Leib".

Mit der beherrschenden Gedankenrichtung des Yoga haben diese wirklichen oder erdichteten Kräfte des Yogin im Grunde nichts zu schaffen. Gelingt es ihm, sein Ich von der Welt loszulösen, so ist nicht abzusehen, inwiefern dadurch innerhalb dieser Welt das Spiel der Kausalitäten seiner Allmacht unterworfen werden soll ${ }^{1}$ ), und ebenso wenig,

1) Die Berufung darauf, daß der Yogin vermöge des Yoga direkt 
welches Interesse er, der Weltentnommene, seinerseits an solcher Allmacht hat. Es ist klar und auch vollkommen begreiflich, daß hier eben Reste unüberwundener primitiver Vorstellungen hineinspielen. In der Tat legt denn auch der wahre Yogin auf seinen Besitz jener Vorzüge keinen Wert. Wert hat für ihn nur das letzte Ziel.

Dies Ziel ist die Erlösung. Man stellt sich die nicht als in unabsehbarer Ferne liegend vor. Die Macht des Yoga führt rasch vorwärts. Eine Upanishad sagt, daß kraftvollem Streben eine Zeit von sechs Monaten genügt ${ }^{1}$ ). Wenn das materielle Dasein des Yogin zu tiefer Ruhe gekommen ist, wenn „die Funktionen des Seelenorgans untergegangen sind und so dies Organ an seiner Ursprungsstätte zur Ruhe geht, wie ein Feuer brennholzlos an seiner Ursprungsstätte zur Ruhe geht" ${ }^{178}$, wenn die Wogen der Vergänglichkeit nicht mehr über das ewige Selbst hinspülen, sondern dessen Licht aus unbewegter Stille hervorleuchtet, dann vollendet sich die Trennung des zuvor Untrennbaren. Die Kățaka Upanishad sagt, mit einem Gleichnis, welches dann im Epos wiederkehrt und auch den Buddhisten bekannt ist, daß man das innere Selbst aus dem Leibe heraus zieht "wie den Halm aus dem Schilf". "Wenn er", heißt es in einer andern Upanishad, „durch sein Selbst das Selbst, feiner als Feines, glänzend, nach Hinschwinden des Manas (S. 226) erschaut, dann wird er, durch sein Selbst das Selbst schauend, entselbstigt. Aus der Entselbstigung folgt, daß er als über alle Zählbarkeit erhaben, als ursprungslos zu denken ist. Dies ist das Wesen der Erlösung; solches ist das höchste Geheimnis." "Aus der Entselbstigung folgt, daß er nicht an Freude noch Leid teil hat; er erlangt die Absolutheit." „Sie

„mit dem materiellen Grundprinzip und darum mit allem Raum, aller Zeit usw. in Verbindung steht" (Aniruddha zu Sāmkhya S. I, 91), scheint mir das Bedenken nicht wegzuräumen.

1) Sollte dabei nicht stillschweigend vorausgesetzt sein, was man später sicher vorausgesetzt hätte: $\mathrm{daB}$ solcher Erfolg durch gewaltigste Verdienste in früheren Existenzen vorbereitet sein muß? 
(die Weisen) sind im höchsten, wortlosen, unoffenbaren Brahman zur Ruhe gegangen. Dort sind sie frei von individuellen Eigenschaften, von individuellen Unterschieden, wie mannigfache Blumensäfte, die alle zu Honig geworden sind."

Die theoretischen Vorstellungen, die mit den Anweisungen $\mathrm{zu}$ solchem Tun, mit den Verheißungen solches Lohnes verknüpft sind, brauchen an sich kaum besonders scharf und fein entwickelt gewesen zu sein. Hat man dem Yoga eine starke Hervorhebung der Kausalitätsvorstellung zugeschrieben, ein Operieren mit einer langen Verkettung von Ursachen und Wirkungen, die der Yogin beherrscht und dadurch das Geschehen zum Erlösungsziel hinlenkt ${ }^{174}$, so halte ich für möglich, daß man sich da, insonderheit sofern es sich um den älteren Yoga handelt, von der Neigung zur Anähnlichung an den Buddhismus zu weit hat fuhren lassen. Mir scheint, die theoretischen Auffassungen, die man im Yoga findet oder vermuten möchte, können nur zum Teil als wirkliche Grundlage dieser Asketenpraxis gelten. Zum andern Teil sind sie vielmehr nachträgliche Zutaten, die von den geschickten Händen der indischen Denker freigebig und wechselnd dem Yoga angeheftet worden sind. Unzweifelhaft haben in bezug auf diese Begründungen oder Ausschmückungen mannigfache Strömungen neben einander bestanden, die uns in der unzureichenden Überlieferung sehr ungleichmäßig erkennbar werden. So ruht unser Urteil hierüber, insonderheit über den Zusammenhang des Yoga mit dem Sāṃkhya, auf schmaleren Grundlagen, als wir wünschen möchten.

An der wichtigsten Tatsache kann natürlich kein $\mathrm{Z}$ weifel sein: der Yoga hat zur Basis den Glauben an ein absolutes Wesen, welches mit unserm Selbst identisch ist und aus der Verflechtung in Welt und Weltleiden gelöst werden soll. Weiter wurde schon bemerkt (S. 259), daß in den Upanishaden der Yoga durchaus in der Nähe des Sāṃkhya steht, welcher eben diese Fundamentalanschauung in bestimmter 
Formulierung zum Ausdruck bringt. Die ältesten irgendwie erheblichen Äußerungen der Upanishaden über Yogapraxis bewegen sich ganz in der Terminologie des Sāmkhya. Oder auch, in umgekehrter Richtung betrachtet, die ältesten Zeugnisse über Sāṃkhya stehen durchweg in enger Verbindung mit Mitteilungen über Yoga. Man kann bei dieser Sachlage, bei dieser Gemeinsamkeit des Auftretens in der ältesten Überlieferung, in der Tat die Möglichkeit nicht für ausgeschlossen halten, daß Sāmkhya und Yoga anfangs eine Einheit gebildet haben. Das Sāmkhya kann von Anfang an in einen praktischen Teil, den man Yoga nannte, verlaufen sein. Und das Bedürfnis die dort gelehrte Praxis zu fundamentieren, kann - neben den aus der vorangehenden Spekulation hervorwachsenden Motiven - für die Analyse des psychischen Apparats im theoretischen Teil wirksamen Antrieb geboten haben. Nun aber zeigt sich doch neben dem Ineinanderverlaufen beider Doktrinen, wie es m. E. in der Kāṭaka und Śvetāśvatara Upanishad anzuerkennen ist, auch eine Sonderung, von der ich deutliche Spuren schon in der Maitrāyana Upanishad wahrzunehmen glaube, und die sich dann in der jüngeren Überlieferung weiter akzentuiert. Hat sich diese Sonderung gebildet, indem sich die Hälften des alten Ganzen verselbständigten und stellenweise divergierende Züge annahmen? Oder ich halte dies für wahrscheinlicher - ist das Ursprüngliche vielmehr eben die Gesondertheit, und liegen in jenen beiden Upanishaden Vermischungen, Adaptierungen des Yoga an die Auffassungen des Sāṃkhya vor? ${ }^{175}$ Tatsache ist, daß die Yogasūtras, der Grundtext des klassischen Yoga, in mancher Hinsicht recht fühlbar von den Formulierungen des Sāmkhya abweichen; und wo sie sich zu speziellen Sāṃkhyadoktrinen bekennen, kann es sich vielfach um mehr oder minder auf der Oberfläche liegende Neuerungen handeln. $\mathrm{Da} \beta$ aber die eigentlichen Grundlagen der von den Yogasūtras vorgetragenen Lehre aus recht alter Zeit stammen, wird durch ihre Beruihrungen mit dem, was die altbuddhisti- 
sche Literatur vermeldet ${ }^{176}$, sicher erwiesen. Das Epos hebt zwar wiederholt die Übereinstimmung von Sāṃkhya und Yoga hervor, ihre Kraft, zum gleichen Ziel zu führen, hier durch Erkenntnis, dort durch asketisches Tun. Die Geflissentlichkeit, mit der das betont wird, kann doch wohl darauf hindeuten, daß man sich in Wahrheit jener Übereinstimmung nicht sehr sicher fühlte und nur eben Interesse daran nahm, so löblich strebende Denker und Fromme nicht in Widerstreit mit einander erscheinen zu lassen. Das beiderseitige System ist verschieden, sagt das Epos doch einmal in der Tat ganz offenherzig. Als einen Unterschied nennt schon diese Quelle, was als solcher auch in der klassischen Gestalt der Systeme hervortritt: daß der Yoga, nicht aber das Sāṃkhya, sich zum Glauben an einen Gott bekenne. Wir müssen auf die Rolle, welche die Gottesvorstellung hier gespielt hat, demnächst eingehender zurückkommen. Hier sei noch dies hervorgehoben, daß nach dem allerdings nicht völlig bestimmten Eindruck, den die vorklassischen Texte ergeben, der Yoga länger und getreuer als das Sāṃkhya unter den Bezeichnungen für das absolute Wesen den Namen Brahman festgehalten zu haben scheint. Und mit Brahman assoziiert sich, wie in diesem Zusammenhang gleichfalls berührt werden möge, ein Ausdruck für die Erlösung, der vielleicht auch mehr der Redeweise des älteren Yoga als der des Sāṃkhya angehört hat: Nirvāṇa, d. h. „Erlöschen“, wörtlich "Verwehen". Dies Wort, im späteren Sāṃkhya und Yoga unbeliebt, begegnet im Epos, vielleicht nicht zufällig, besonders gern an Stellen, die mit dem Yoga zu tun haben. ${ }^{177}$ Von solchen epischen Äußerungen führe ich hier einen Vers der Bhagavad Gìtā an:

„Wer in sich Freud' und Glück findet, wer Licht findet im eignen Selbst,

Der Yogin geht, Brahman werdend, im Brahman zum Nirvāṇa ein."

Dazu ein Vers einer jüngeren (Kshurikā-)Upanishad: 
"Wie das Licht, das gebrannt, schwindet in des Erlöschens (nirvāna) Augenblick,

Also, der seines Werks Früchte verbrannt, der Yogin schwindet hin."

Bekanntlich zeigt die buddhistische Literatur wie die der Jainas, daß um die Zeit von 500 vor Chr. unter den Asketensekten der Gedanke und das Wort Nirvāna weit verbreitet und höchst bedeutungsvoll gewesen ist $\left.{ }^{1}\right)$. Haben diese Sekten es eben vom Yoga übernommen? ${ }^{178}$ Die vielen sonstigen Entlehnungen dorther unterstützen diese Vermutung, und sie wird in Anbetracht der Lückenhaftigkeit unsrer Quellen dadurch nicht ausgeschlossen, daß die Texte, die den Ausdruck Nirvāna im Zusammenhang mit Yogavorstellungen gebrauchen, hinter den buddhistischen an Alter erheblich zurückstehen. Doch ist uns ja von den religiösen und philosophischen Entwicklungen etwa des 6. Jahrhunderts so Vieles vollkommen unbekannt, daß neben dem Yoga andre uns unerfindliche Stellen genug übrig bleiben, an denen jenes so mächtig in neuer wie in alter Zeit die erlösungsdurstigen Seelen erfassende Wort geschaffen sein kann.

Wir kehren von dieser Abschweifung zur Frage nach dem Verhältnis von Yoga und Sāṃkhya zurück, um das wahrscheinliche Ergebnis kurz zu formulieren. Auf Grundanschauungen der Upanishadenspekulation mehr oder minder ähnlich denen des - vielleicht etwas jüngeren? - Sāṃkhya beruhend und diese Anschauungen in asketische Praxis übersetzend ist der Yoga doch früh, ja wahrscheinlich von Anfang an, in seiner Ausdrucksweise und wohl vielfach auch im Inhalt seiner Theorie eigene Wege gegangen. Natürlich haben ihn dabei bald Einfluisse des so nah benachbarten und so stark die Geister beherrschenden Sāmkhya intensiv

1) So sprechen die Jainas vom Stifter ihrer Gemeinde als dem Höchsten unter denen, die das Nirvāna gelehrt haben (Sacred Books of the East XLV, 290). Es schien also ganz allgemein und selbstrerständlich im Wesen eines solchen Meisters zu liegen, Lehrer vom Nirvāṇa zu sein. 
berührt: vermutlich in verschiedener Weise und mit verschiedener Kraft auf den mannigfachen Linien seiner offenbar vielverzweigten Entwicklung, und schwerlich auf einmal so zu sagen eine Katastrophe herbeiführend, sondern allmählich und in wiederholten Ansätzen seine Vorstellungswelt durchdringend. Gerade an vielen Stellen der klassischen wissenschaftlichen Literatur, auf die wir vorzugsweise angewiesen sind, mögen sich diese Einflüsse stärker hervorheben, als vielleicht für manche unserer Kenntnis ferner liegende Gebiete zutreffen würde. -

Mystisches Schauen Gottes und Einswerden mit Gott oder dem Absolutum ist, wie bekannt, nicht nur von Yogins, nicht nur in Indien, erfahren und auch bewußt erstrebt worden. Indisch aber ist zunächst die auf besonderer physischer Disposition beruhende mächtige Verbreitung, in der diese Erlebnisse hier auftreten. Indisch ist, daß des Geistes Wehen oder vielmehr Verwehen hier schulmäßig in den Paragraphen von Lehrtexten mit ihren Einteilungen und Untereinteilungen aufgefangen wurde, etwa wie von den indischen Erotikern alle Ekstasen des Liebesgenusses. Indische Kunst und Geschmeidigkeit erwies sich in der Vollendung, mit welcher die Strebenden es hier durch fortgesetzte Übung, in unerhörter körperlicher und seelischer Anspannung erreichten, diese Seelenzustände der Theorie entsprechend tatsächlich als Virtuosen zu beherrschen, sich von ihnen kunstgerecht durchdringen zu lassen, wie - nach einem Vergleich der Buddhisten - ein geschickter Barbier den Schaum so bereitet, daß er ganz und gar von Fettigkeit durchdrungen ist. Wo ergriffen diese mystischen Gewalten so übermächtig wie in Indien Besitz von den Seelen? Der Yoga riß seine Jünger aus der Welt heraus. Er schien sie in die Höhe des absoluten Seins zu erheben, die Einheit mit ihm für ihr traumversenktes und doch zugleich unbeschreiblich waches Bewußtsein zu verwirklichen, die Seligkeiten des Trunkes aus metaphysischen Quellen ihnen zu spenden, nach denen das Verlangen nirgend so heiß gewesen ist wie unter Indern. 
Fortan war hier höheres religiöses Wesen ohne einen Beisatz von Yoga schwer denkbar. Unter den Helden und den Idealen, von denen der indische Volksgeist weiß, ist der Yogin, sind die Ideale des Yoga zu einer höchsten, vielleicht zu der höchsten Stelle aufgestiegen.

\section{Ein persönlicher Gott. Die Śvetásatara Upanishad.}

Die Anfangsverse der im Obigen öfter als Quelle für Sāṃkhya- und Yogalehren benutzten Śvetāśvatara Upanishad geben uns eine Vorstellung von der Fülle der Fragen, der miteinander kämpfenden Meinungen, die in der Entstehungszeit jenes Textes auf die suchenden Geister eindrangen. Was ist des Daseins Grund? heißt es dort. Woher stammen wir? Von wem geleitet bewegen wir uns umher zwischen Lust und Leid? Ist Zeit oder Natur der Urgrund, Notwendigkeit oder Zufall, Elemente oder Geist? Die Weisen, in Betrachtung sich versenkend, antwortet der Text, sahen Gottes Selbstkraft, verhüllt von den eignen Gunas: Er ist es, der als der Eine allen jenen Mächten vorsteht.

Die Schlagworte, die hier begegnen, finden sich ganz ähnlich bei den Jainas und im Epos wieder ${ }^{179}$. Bereits in der altbuddhistischen Literatur sehen wir dieselben Fragen sich anspinnen. Dort wird auch schon eben der Antwort gedacht, welche die Upanishad gibt: der Verkündigung eines weltbeherrschenden Gottes. Zwar dürfen wir die Śvetāśvatara Upanishad, die unter den mit ihr näher zusammengehörigen Texten den Gottesglauben fast allein, in jedem Fall weitaus am nachdrücklichsten vertritt, schwerlich für vorbuddhistisch halten. Der Sache nach ist die von ihr vorgetragene Lehre doch älter als der Buddhismus. So können wir die Upanishad als Quelle für eine der Gedankenrichtungen verwenden, die in Buddhas Zeit wirksam gewesen sind.

Die Vorstellung eines allbeherrschenden Gottes, der seinem Wesen nach von den Götterscharen des alten oldenberg: Upanishaden. 
Glaubens völlig verschieden ist - der eben nicht èin Gott ist, sondern Gott -, tritt, wie bekannt, sporadisch schon in sehr alter Zeit auf. Ein berühmtes Lied des Rigvedá fragt:

„Der uns das Lebẻn gibt, der uns die Kraft gibt; Des Machtgebot die Götter all gehorchen, Des Schatten die Unsterblichkeit, der Tod ist:

Wer ist der Gott, daß wir ihm opfern mögen? . . .

Der groß die Wasserfluten uberschaute,

Die krafterfüllten, die das Opfer zeugen,

Er, der allein Gott unter allen Göttern:

Wer ist der Gott, daß wir ihm opfern mögen?"“

Wir gehen über diese Anfänge monotheistischen Glaubens, auch über die in den Brāhmanatexten auftretende Gestalt des Weltschöpfers (wörtlich: „Herrn der Geschöpfe“"); Prajāpati weg. Ebenso erinnern wir nur kurz an das, was. oben (S. 103f.) über das zuweilen bemerkbare Erscheinen persönlicher Züge am Brahman-Ātman der alten Upanishaden ausgeführt ist. An dieser Stelle haben wir uns mit der besonderen Konstellation zu beschäftigen, unter der die Vorstellung des einen Gottes in der Svetāśvatara Upanishad erscheint.

Natürlich durchaus nicht allein hier, aber doch innerhalb unsres Untersuchungsgebietes hier am sichtbarsten hat sich bei der Berührung von Spekulation und Gottesglauben Ähnliches zugetragen, wie es etwa der Sprachforscher bei Berührungen verschiedener Sprachen beobachtet. Da entstehen Mischsprachen, oder die eine Sprache paßt sich im Mund der anders Redenden deren Sprachgewohnheiten an und erleidet dadurch tiefgehende Veränderungen. So ging das Selbstvertrauen derer, die durch eignes Wissen, eigne Kraft den Weg durch das Labyrinth von Welt und Weltleiden zu finden sich getrauten, Mischungen ein mit der Denkweise jener, die hilfsbedürftig sich an göttliche Gnade klammerten. Wie hätte auch in Leben und Wirklichkeit beides in der Sonderung verharren können, in welche die theoretische Betrachtung es stellen mag? 
Einen besonders günstigen Boden für solche Mischungen bot, scheint es, der Yoga, der ja eben in der Śvetāśvatara Upanishad stark in den Vordergrund tritt.

Im Yoga war die Stimme prüfenden, Widersprüche ablehnenden Betrachtens am wenigsten, vorhanden. Die mächtigen Ströme, welche die Seele des Yogin durchflossen, strebten andern Zielen zu als der klaren Konsequenz des Geđankens. Der Yoga lehrte einerseits die eignen Kräfte auf das stärkste anspannen. Zugleich aber ließ er auf der andern Seite den Strebenden tief die ubergroße Schwierigkeit seines Unterfangens empfinden, das sicherlich manchem über die eigne Kraft hoffnungslos hinauszugehen schien. Der Yogin, sagt das Epos wiederholt, gleicht dem Mann, der mit einem vollen Ölgefä $\beta$ in der Hand eine Treppe hinaufsteigt, von Bewaffneten mit Schwertern bedroht. Er aber achtet unentwegt nur auf sein Gefäß und gelangt hinauf, ohne einen Tropfen zu verschütten. Wo es so Schweres zu leisten galt, lag es nah, sich nach einem Helfer umzusehn, die Götternähe, von der die Atmosphäre des alten Kasteiungswesens erfüllt war, nicht zu verscherzen. Doch war es naturlich, daß sich die Erscheinung des Göttlichen der hier wehenden reineren Luft anpaßte. Von selbst ergab sich Anknüpfung an die eben berührten Anfänge monotheistischer Denkweise. Ein Gott mußte es sein, mythologische Fratzengebilde abstreifend, als İ́vara („Herrscher“) in Sein und Handeln reine, große Gedanken der Allmacht und Gnade verkörpernd. Freilich - das nimmt nicht Wunder - konnte dieser Gott sich dann doch auch wieder in das alte, spukerfüllte Dunkel tauchen. Er konnte die Namen Śiva, Vishnu annehmen, die Träger wilder, wollüstiger, grotesker Vorstellungen ... .

Die Śvetāśvatara Upanishad ist unter den an Verwirrung oft so reichen Upanishaden eine der verwirrtesten. Eben jenes ihre letzten Grundlagen berührende Aufeinandertreffen heterogener Gedankenmassen trägt bei, das zu erklären. Hierin - und es darf hinzugefügt werden, stellenweise auch 
in hoher poetischer Schönheit - ist diese Upanishad die rechte Vorläuferin des Textes, der in einem späteren Zeitalter der Vermischung von Spekulation und Gottesglauben für Indien den klassischen Ausdruck geschaffen hat: der Bhagavad Gìtā.

In die alte Gegenüberstellung des Jenseitigen, Absoluten und der Diesseitswelt, zwischen denen der erlösungsuchende individuelle Geist gewissermaßen in der Mitte schwebt, kann ein persönlicher Gott offenbar auf zwei Weisen eintreten: woneben dann drittens die Vermischung der beiden Betrachtungsarten steht. Entweder Gott wird als ein zu den alten hinzukommendes Element eingefügt, sodaß dem Absoluten jetzt nicht mehr allein der individuelle Geist und die Welt gegenuibersteht, sondern Gott, individueller Geist und Welt. Oder Gott dringt eine Stufe tiefer in das System ein. Er schlüpft in das Gewand des absoluten Wesens selbst, zieht dessen Attribute und Funktionen an sich, wird zu ihm. Im ersten Falle muß sich die Zufügung darin zu erkennen geben, daß so zu sagen ein Auswuchs den natürlichen Verlauf der Linien stört. Im zweiten Fall darin, daß, was eine Wesenheit sein soll, zwischen zwei verschiedenen Gestalten hin und her schwankt. Je bestimmtere Sprache ein Text führt, um so schärfer wird sich fühlbar machen, daß die Ideen auf ein Prokrustesbett gestreckt sind. In der Śvetāśvatara Upanishad freilich, die abwechselnd zur einen und dann wieder zur andern der bezeichneten beiden Auffassungsweisen neigt, breitet sich über alles ein Nebel allgemeiner Unklarheit, der den einzelnen Widersprüchen manches von ihrer Härte nimmt.

An vielen Stellen läßt die Upanishad Gott, Einzelgeist, Welt als vom absoluten Brahman gleichermaßen umfaßt nebeneinanderstehen. Sie spricht von einer Dreiheit: den beiden Ungebornen (zugleich im Wortspiel: "den beiden Ziegenböcken“, vgl. S. 215), dem Wissenden und dem Nichtwissenden, dem Herrn (ìsa) und dem Nichtherrn, dazu drittens der einen Ungebornen (im Wortspiel: „Ziege"), 
"die bestimmt ist dem Genießer Genuß zu bieten". Oder auch von dem Genießer, dem zu Genießenden, dem Antreiber. Das Brahman ist diese Dreiheit, oder auch die Dreiheit ist im Brahman. Von den drei Wesen ist das Paar des Wissenden und Nichtwissenden, des Herrn und Nichtherrn, des Antreibers und des Genießers Gott und der individuelle Geist. Das Dritte oder vielmehr die Dritte ist die Natur, die sich dem Geist je nach seinen Werken, nach Verdienst und Schuld zum Genuß darbietet, während Gott, die Weltbewegung antreibend und lenkend, selbst dem entnommen ist, an jenem Genießen teilzuhaben. So stehen Einzelgeist und Gott hier nebeneinander, wie es jener alte, tiefsinnige, von der Upanishad wiederholte Rigvedavers ausspricht:

"Zwei Vögel weiß ich, Freunde und Genossen.

Sie nisten beide auf demselben Baume.

Der eine ißt vom Baum die süße Beere.

Der andre Vogel schaut und schaut und ißt nicht."

Gott verhält sich zum Geist als der "Andre“, dessen die Upanishad auch in ihrem nächsten Vers gedenkt:

„Haftend der Geist am allbewohnten Baume

Ist schmerzgequält, betört von der Nichtherrin ${ }^{1}$ ).

Schaut er den Herrn, den Andern, den erwählten

In seiner Größe, weichen alle Schmerzen."

Wenn aber der Einzelgeist und der "Andre" als „Freunde und Genossen" einander gleichartig scheinen und beide wie zwei Vögel auf demselben Baum wohnen, wie kommt es, worauf beruht es, daß dann doch zwischen ihnen die Abgrundtiefe liegt, die Gott vom leidenden Geiste trennt? Oder wenn das Brahman über Welt und Geist in seiner ewigen Majestät thront, woher und wozu dann neben diesem Höchsten noch ein zweites Höchstes, Gott? Welche abnorme Figur das Denken hier beschreibt, allein geschichtlich verstehbar aus dem Zusammenfluß getrennter Gedanken-

1) Der von allen bewohnte Baum und zugleich die Nichtherrin ist die Natur. 
strömungen, das läßt selbst die vage Sprache dieser Dichtung fuhlen. Schärfer, ungemildert tritt es im Haupttext des klassischen Yoga hervor, wo Gott beschrieben wird als ein „besonderer Geist", der — im Gegensatz zu den übrigen - von weltlicher Unreinheit, den Werken und ihrer Frucht unberührt ist. Eine armselige Figur, dieser „besondere Geist", zu dem Gott da zusammengeschrumpft ist. Und furr eine Lehre, die in aller Weltbewegung nur Leiden sieht, schwer begreiflich die Sonderstellung dieses einen, einzigen Wesens, das nicht gleich den erlösten Geistern der Welt entnommen und doch auch nicht gleich den unerlösten yom Weltleiden berührt ist.

In unsrer Upanishad nun freilich wohnt der Gottesvorstellung ein sehr viel größeres Gewicht bei als in dem klassischen Text. Hier macht sich noch die Kraft fühlbar, mit der diese Vorstellung erobernd in das System der Spekulation hat eindringen können. Bald spricht die Upanishad von ihr - ob ganz ohne Bewußtsein der inneren Diskrepanz? - in Ausdrücken des alten Vedaglaubens. Gott wird Rudra genannt, der Bergbewohner, der Pfeilschütz, und wird in dieser Gestalt mit Worten des Rigveda angerufen, er möge nicht des Beters Nachkommen und nicht sein Leben noch seine Rinder und Rosse schädigen. Bald treten an Stelle des alten Gottesnamens jüngere; es wird von Hara gesprochen, von Śiva, dem in jeglichem Wesen verborgenen. Freilich läßt der Dichter - vielleicht kein Zufall - das Gewirr konkreter Bilder draußen, die mit dem wilden Namen Siva verknüpft sind. Was bei dem vedischen Rudra anging, mochte ihm hier nicht angänglich scheinen. Bald endlich und vor allem nimmt Gott die Züge an, die dem Brahman oder dem Purusha des alten Sāmkhya eigen waren. Und damit nun kommen wir zur zweiten jener beiden oben beschriebenen Situierungen, in denen sich diese Vorstellungen zueinander ordnen. Gott nimmt seinen Platz nicht mehr unterhalb des absoluten Wesens ein. Dies Nebeneinander zweier Spitzen des Daseins, einer höchsten 
und einer minderen, mochte als sinnlos erscheinen. So schiebt sich Gott an die Stelle des Absoluten selbst, fließt mit ihm zusammen. Das Brahman wird Gott genannt; von Gott wird gesagt, was auch vom Brahman gesagt wird. Die alte Forderung, das Brahman in sich zu erkennen, tritt nunmehr in der Gestalt auf, man solle Gott in sich erkennen: der "Andre“, wie er eben noch hieß, hat jetzt im Innersten des eigenen Ich seine Wohnung aufgeschlagen. Beständig gleitet man zwischen Unterordnung Gottes unter das Absolute und andrerseits der Identifikation beider hin und her. Von der einzelnen Stelle ist es oft unmöglich zu entscheiden, ob sie auf dieser oder jener Auffassung beruht. Ja, derselbe Vers vermischt beides. Nachdem Gott als Rudra verherrlicht ist unter häufiger, an die jetzt beliebte Benennung Gottes als des "Herrschers" anklingender Hervorhebung davon, daß er "mit seinen Herrscherkräften herrscht" (iśata iśanībhih), wird fortgefahren:

"Höher noch steht das höchste, große Brahman,

In allen Wesen, Schar für Schar, verborgen.

Die diesen Herrscher (ìsa), diesen Allumfasser,

Den Einen kennen, werden frei vom Tode" -

mit dem Brahman also, das soeben über dem Herrscher Rudra in höchster Höhe stand, hat sich alsbald der "Herrscher" selbst identifiziert.

Im Einzelnen gestaltet sich dies Hin- und Herschwanken höchst mannigfaltig. Im Ganzen überwiegt doch wohl die Bedeutung der Gottesvorstellung die des absoluten Weltgrundes. Gottes Majestät ist es, die das Brahmanrad des All sich drehen läßt. Gott ist gemeint, wenn gesagt wird, daß ein Zauberer (māyin) dies All erschafft, in dem der "Andre", die Seele, durch Zauber (māya) gefangen ist:

„Das Zauberspiel ist die Natur (prakrti); der Zaubrer ist der höchste Gott ${ }^{1}$ )."

1) Die Gedankenrichtung in dieser vielbesprochenen Zeile geht nicht eigentlich dahin, dab die Natur als Zauberspiel, Gott als Zauberer hingestellt werden soll. Sondern in umgekehrter Richtung: vorher war vom 
Hier tritt das Wort, das spätere indische Denker so oft ausgesprochen haben, in philosophischem Zusammenhang zuerst auf: Māyā. Die Vorstellung, daß die Welt nur trügerischer Schein ist, verbindet sich damit jetzt offenbar noch nicht. Was der Zauberer schafft, ist für den Augenblick wirklich da. Doch freilich hat es kein volles, tiefgewurzeltes Recht auf Dasein. Fremder Wille schaltet spielend mit ihm. Der große Wollende aber, dessen Riesenspielzeug die Natur ist, er ist kein Andrer als Gott. Gott lenkt die Bewegungen der Guṇas. Er läßt die Keime heranreifen, wirkt Wanderung der Seelen und Erlösung. Zu ihm nimmt der nach Heil Verlangende seine Zuflucht. Er wird dem Yogin durch das mystische Wort Om offenbar. Da geht es, wie wenn aus den beiden Reibhölzern Feuer gerieben wird:

„Er schaut, zum untern Holz machend den Leib, das Om zum obern Holz,

Durch der Versenkung Quirldrehung verborgnem Feuer gleich den Gott."

Den Gott also schauen, den Gott erkennen: das ist das Ziel, an dem der Preis der Erlösung winkt.

„Der Ewige den Ew'gen, Geist den Geistern,

Den Vielen teilt er Woune $\mathrm{zu}$, der Eine.

Der Gott, zu dem Sāmkhya und Yoga hinführt:

Wer ihn den Urgrund kennt, wird frei von Banden ${ }^{180 . " ~}$

Keine andere Hoffnung als diese. Ein Ende des Leidens ohne daß man Gott kennt, wird es erst geben, wenn die Menschen sich in den Ätherraum wie in ein Fell wickeln werden.

So mächtig die Gottesvorstellung in all dem ist, man wird kaum verkennen, daß sie in ihrem Zusammenfließen mit den Abstraktionen der Spekulation von ihrer höchsten Wärme, dem vollsten persönlichen Leben etwas eingebußt hat. Doch höre man, was der Schlußvers der Upanishad sagt:

Zauberspiel und dem gewaltigen Zauberer die Rede gewesen, und nun wird erläutert: mit jenem ist die Natur gemeint, mit diesem aber Gott.

- Ich verdanke den Hinweis hierauf Dr. Johnson, Benares. 
„In wem mächtig zu Gott Liebe (bhakti) und Liebe auch zum Lehrer weilt,

Dem dargelegt, dem Großgeist'gen, strahlt diese Lehr' in hellem Glanz."

Man fühlt hier zwar die vedische Schulluft; die Liebe zu Gott ist ein Stück Lehrpensum, das nach Anleitung des nicht minder geliebten Lehrers geübt wird. Aber auch so bleibt es doch bedeutsam, wie wir hier, ähnlich wie vorher die Māyā, so jetzt die Bhakti („Liebe“) in ihre große Laufbahn eintreten sehen. Wieder, wenn auch diesmal nur durch ein einziges Wort, erweist sich die Śvetāśvatara Upanishad als die Vorläuferin der Bhagavad Gìtā, die in so mächtigen Tönen die Bhakti verherrlicht. „Wer mich liebt, der wird nicht verloren", sagt dort Krishna, der menschgewordene Gott.

Es wurde schon bemerkt, daß inmitten der Gedankenkreise der indischen Spekulation der Glaube an einen persönlichen Gott besonders vom Yoga, der am wenigsten eigne, strenge Denkarbeit treibenden Lehre, gefördert worden ist. Gehörte zum Yoga dieser Glaube von Anfang an als wesentliches Element? Waren Sāmkhya und Yoga stets und ihrer Natur nach so unterschieden, wie das Epos sie unterscheidet und wie sie auch in ihrer klassischen Gestalt unterschieden sind: als atheistisches und als gottgläubiges System? Man darf zweifeln. Die Praxis des Yoga setzt offenbar der innerén Konsequenz nach die Gottesvorstellung keineswegs mit Notwendigkeit voraus. Und es wäre wohl gewagt, etwa der Kāthaka Upanishad, in der so viel ältester Yoga zur Erscheinung kommt, trotz einzelner zum Gottesglauben neigender Äußerungen, geradezu diesen Glauben zuzuschreiben. Den anschaulichsten Beweis aber dafür, daß ein von Yogaelementen stark durchsetztes System den Gottesglauben doch mit aller Entschiedenheit ablehnen konnte, liefert die Lehre, von der wir jetzt zum Schluß sprechen müssen: die Lehre des Buddha. 


\section{Drittes Kapitel.}

\section{Die Anfänge des Buddhismus.}

Wir haben den Grundzügen nach die Entwicklung der Sāṃkhyalehre yon ihren altertümlichen Anfängen, ihrem Hervorgehen aus der vedischen Brahmanspekulation, bis zur fertigen, klassischen Reife und Glätte verfolgt. Wir haben weiter die damit parallele Herausbildung mystisch-asketischer Übungen im Yoga kennen gelernt.

Nun muß gefragt werden, $a b$, wie und wo von diesen Linien die Gedankengänge des Buddhismus abzweigen.

Dieselbe Frage wäre für den Glauben der Jaịnas zu stellen, der zweiten, in vieler Hinsicht der buddhistischen so eng verwandten Asketengemeinde, die von etwa demselben Zeitalter bis in die Gegenwart fortlebt. Doch scheint mir die Literatur der Jainas noch nicht hinreichend durchforscht, die komplizierte Häufung älterer und jüngerer Schichten in ihr noch nicht sicher genug analysiert, daß ich gegenwärtig an dies Problem heranzutreten wagen könnte. ${ }^{181}$ So beschränke ich mich für jetzt auf den Buddhismus.

Zwischen den Überlieferungsmassen nun, mit denen wir bisher arbeiteten, und den buddhistischen reißt die Kontinuität in so vieler Hinsicht ab, daß für unsre Untersuchungen daraus recht erhebliche Nachteile erwachsen. Die altbuddhistische Literatur, der altjainistischen eng verwandt und benachbart, bewegt sich der brahmanischen gegenüber - wenigstens zunächst muß es so scheinen - im wesentlichen auf getrenntem Boden. 
Schon die Sprache kennzeichnet den Gegensatz. Auf brahmanischer Seite die Vedasprache, im Lauf der Zeit sich modernisierend und schließlich immer mehr zum Typus des kunstmäßigen klassischen Sanskrit hinübergleitend. Auf buddhistischer Seite - ebenso auf jainistischer - Volks: dialekte. Im Dialekt des Magadhalandes (des südlichen Bihar) waren die heiligen Texte des Buddhismus ursprünglich verfaßt. Im Palidialekt (Vorstufe des Marāthī?) ist uns ihre älteste Gestalt erhalten. „Ich ordne an", soll der Meister gesagt haben, „daß ein jeder in seiner Sprache des Buddha Wort lerne." Zurückweisung also von Exklusivität und Altertümelei, Richtung auf die Gegenwart.

Auch die geographischen Umgebungen, inmitten deren sich die altbuddhistische Literatur entwickelt hat, scheinen diese von der Hauptmasse der Upanishaden und den philossophischen Urkunden des Epos zu trennen. Die alten Heimatstätten des brahmanischen Denkens lagen westlich, genauer nordwestlich, vom Zusammenfluß der beiden mächtigẹn Ströme Ganges und Jumna. Ein Brāhmanatext hat die Erinnerung daran erhalten, daß in alter Zeit Brahmanen nicht weit über diesen Punkt hinaus in die östlichen Lande zu gehen pflegten. Auf der andern Seite macht es die buddhistische Literatur in den Beschreibungen, die sie von den Wanderungen des Buddha und seiner Jünger gibt, deutlich fühlbar, daß damals den buddhistischen Asketen, die im Osten sich fortwährend durch weite Entfernungen hin und her zu bewegen gewohnt waren, jener Westen im ganzen ein fremdes Land blieb. Freilich haben Einflüsse der brahmanischen Spekulation natürlich doch schon früh wenigstens in Ausläufern auch den Osten berührt: das zeigen die Upanishadberichte über Yãjnavalkya und Janaka, den König der Videha (etwa in Tirhut). Und vollends in der buddhistischen Literatur erscheinen die östlichen Lande in der Tat als voll von Brahmanen, die auf Schritt und Tritt den Weg des Buddha freundlich oder feindlich kreuzen, und von denen selbstverständlich manche neben ihren Kastenansprüchen, 
ihren Veden und Opfern auch den Spekulationen der Upanishaden im Osten eine Stätte bereitet haben werden ${ }^{\mathbf{1 8 2}}$. Die Texte, in denen sich die ältere Geschichte des Sāmkhya verfolgen läßt, enthalten von Zeugnissen über die geographische Lokalisierung dieses Systems leider nichts oder nur Wertloses: wozu ich den Namensanklang zwischen dem Philosophen Kapila und Kapilavatthu, dem Geburtsort des Buddha, rechne. Immerhin macht die ganze Sachlage es doch wohl wahrscheinlich, daß vielmehr die alte Heimat und die Mittelpunkte brahmanischen Wesens die Entstehung und Entwicklung des Sāṃkhya gesehen haben, als das östliche Neuland. Allzu gern pflegt der moderne, europäische Betrachter die Weiten des vedischen oder des buddhistischen Indien als Einheit aufzufassen, und in der Tat wird es uns durch die Überlieferung meistens nicht gerade erleichtert, das Einzelne innerhalb dieses großen Rahmens an seinen Platz zu stellen und vollends die individuellen unterscheidenden Züge zu entdecken, die dem hierhin und dorthin gehörenden Kulturbesitz je nach seiner Heimat selbstverständlich zugekommen sein müssen. Um so notwendiger ist es, wenn auch nur in unsicherer Vermutung, auf die Distanzen hinzuweisen, welche die Glieder der hier betrachteten Entwicklungen schon rein räumlich von einander getrennt zu haben scheinen: und wie viel andres hing wohl mit der räumlichen Entfernung zusammen!

Nach den geographischen Beziehungen fassen wir die entsprechenden chronologischen der beiden Literaturen ins Auge und im Zusammenhang damit uberhaupt die großen Veränderungen im allgemeinen Zustand der Kultur und insbesondere im Stil des religiösen und philosophischen Denkens.

Soviel stellt sich da nun mit unbedingter Sicherheit heraus, daß verglichen mit der älteren Schicht der Upanishaden auch die ersten Anfänge der buddhistischen Literatur das Spätere, ja das erheblich Spätere sind.

Dies zeigt sich in der Sprache und Metrik, in der sehr viel weiter fortgeschrittenen Fähigkeit der Buddhisten, größere 
Gedankenmassen lehrhaft zu entfalten, in der Behandlung des Dialogs. ${ }^{183}$ Es zeigt sich vor allem im ganzen Inhalt dieser Literaturen, im Bilde der Welt und des Lebens, insonderheit des geistlichen Lebens, das in ihnen zur Erscheinung kommt.

Natürlich können hier nur einige charakteristische Züge hervorgehoben werden.

Das Dasein der alten Denker, wie es die Upanishaden schildern, bewegt sich allein im Dorf. Man hört von herdenzüchtenden Brahmanen und ihren Schülern, die des Lehrers Kühe auf die Weide und wieder heim treiben. Von städtischer Entwicklung ist schwerlich mehr als ein Anfang vorhanden. In der Zeit des alten Buddhismus bildet eine Anzahl bedeutender Städte den Mittelpunkt des öffentlichen und geistigen Lebens, des Kulturfortschritts. In den viel komplizierteren Erzählungen, denen man hier begegnet, ist häufig von großen Kaufleuten und hochentwickeltem Handel die Rede, von Volksgedränge, von eleganten und berühmten Kurtisanen; aus dem Tor bewegt sich der Zug der Elefanten, auf denen der König und sein Gefolge zu den Lustgärten hinausreiten.

In diesem städtischen Leben finden geistige Bewegungen eine andre Resonanz als zuvor. Was fruher Geheimlehre und ein streng gehüteter Besitz weniger war, daran beanspruchen jetzt viele teilzunehmen, und die Wissenden erkennen dies Verlangen an, ja sie erwecken und befördern es selbst in warmherzigem Entgegenkommen. In den alten Upanishaden erscheinen nur in knappster Zeichnung, noch keinen festen Umriß aufweisend, die ersten Gestalten derer, die um des Jenseits willen allen diesseitigen Gütern entsagen und „hinausziehen" (S. 139). Die altbuddhistischen Texte wissen von Massen über Massen solcher Entsagender. Sie bilden Ordensgemeinschaften verschiedenster Art; diese haben sich ihre Satzungen geschaffen, in denen die Fragen des Gemeindelebens und der Gemeindedisziplin eingehend geregelt sind. Für jenes „Hinausziehen" selbst hat der Buddhismus ein festes Ritual aufgestellt. Ein viel detaillierteres für einen zweiten 
geistlichen Rechtsakt, der den „hinausgezogenen“ Asketen zum vollberechtigten Mitglied der Mönchsgemeinde macht.

Solchem Fortschritt der geistlichen Institutionen entspricht der Fortschritt in der Gestaltung der religiösen Vorstellungswelt.

Zwei Hauptrichtungen dieses Fortschritts treten hervor.

Auf der einen Seite wird das Unfertige, Unbestimmte, Fließende vom Denken und der Phantasie in sichere Umrisse gefaßt, folgerichtig entwickelt und systematisiert, die angefangenen Linien immer weiter verlängert. So hat beispielsweise die Idee des Brahman in den alten Upanishaden soeben erst ihre beherrschende Stellung gewonnen; sie ist noch weit davon entfernt, zu fester Gestalt gelangt zu sein. Im Buddhismus hat sie sich längst weiter zum Gott Brahman hypostasiert, und die Gestalt dieses Gottes hat bereits ein Stück Geschichte durchlaufen. In den Ujpaníshaden werden die Grundlagen des Seelenwanderungsglaubens, der Karmanlehre gelegt. Für den Buddhismus ist das alles längst feststehender Besitz, vielseitig durchgearbeitet, von der Phantasie ins Grenzenlose erweitert, mit dem Schmuck zahlloser Geschichten beladen und überladen. In den Upanishaden tritt einfach und schlicht der Gedanke auf, daß das Erkennen, das Erwachen (budh-) vom Weltleiden erlöst. Der Buddhismus besitzt das Dogma von den "Erwachten" (buddha). Von ihrer gesetzmäßigen Wiederkehr in unermeßlicher Reihe an bestimmten Stellen der Aeonen. Von den schweren Kämpfen, die ihrem Sieg vorangehen, und den Verdiensten, die sie in unabsehbaren Seelenwanderungsfernen haben ansammeln müssen. Von den verschiedenen Graden der Wesen, die auf dem Wege zur Erkenntnis und Sündlosigkeit weiter oder weniger weit vorgedrungen sind.

Neben dieser Tendenz des Ausgestaltens, in mancher Hinsicht zu ihr in einem gewissen Widerspruch, doch in einem sehr begreiflichen Widerspruch stehend, kommt dann andrerseits ebenso ausgesprochen die Richtung auf Kritik zur Erscheinung, auf das Hinwegtun althergebrachter Vor- 
urteile und Willkürlichkeiten, auf das Betrachten der Dinge selbst unbeirrt durch ein Hineinspielen fremdartiger Phantasmen. Für Viele unter den religiös Strebenden - so für die Buddhisten selbst - ist es um die Autorität der Veden geschehen. Jene Alten, welche die Vedaweisheit überliefert haben, sind wie eine Kette von Blinden; „wer vorne ist, sieht nichts; wer in der Mitte ist, sieht nichts; wer hinten ist; sieht nichts. "184 Man spottet darüber, wie diese Brahmanen Verschuldungen mit Wasser von sich abzuwaschen meinèn: Hülfe das Wasser, „so müßten ja alle Frösche und Schildkröten in den Himmel kommen, die Wasserschlangen und Krokodile und was sonst in den Wassern lebt". Und die Brahmanen selbst - worauf gründet sich denn ihr Anspruch etwas Besonderes zu sein? Auf ihre Geburt? Aber von Géburt haben sie ja denselben Körper wie alle andern. Nur die Taten, die man tut, weisen dem Menschen seinen Rang an, nicht die Geburt. Wir werden bald den Diskussionen begegnen, von denen die Umgebungen des Buddha wiederhallten, über Wirklichkeit oder Unwirklichkeit jenseitigèn Lohnes, jenseitiger Bestrafung der Taten, über das Vorhandensein einer sittlichen Weltordnung: da entwickelte sich eine vom Buddhismus zwar bekämpfte Skepsis, die sehr viel weiter gehend als die eben berührten Äußerungen ihnen doch verwandt war in der Anerkennung allein des Handgreiflichen oder verstandesmäßig Faßbaren, in der Ablehnung eines hinter den Dingen verborgenen Mysteriums. Als ein in gleicher Richtung liegender wesentlichster Zug der buddhistischen Weltanschauung selbst aber hebt sich die feste Überzeugung vom gesetzmäßigen Kausalzusammenhang hervor, der alles Geschehen beherrscht. Es ist wahr, aus dem Horizont der alten Buddhisten sind darum doch Vorstellungen sehr andrer Art keineswegs verschwunden: der Glaube an mancherlei Mirakel, an boshafte und freche Spukgeister, an Schlangen in menschlicher Gestalt und an wieviel andre Wesen und Geschehnisse ähnlichen Schlages, von denen in allem Ernst gesprochen wird - an Humor da zu denken ist 
durchaus nicht am Platze. Aber bald hier bald dort fährt doch in diese Nebel frischer Lufthauch des Denkens hinein, klarbewußte Erforschung der Wirklichkeit. Man vergleiche, welche Sprache die alten Upanishaden und die Reden des Buddha über Wesen und Funktion der menschlichen Sinnesorgane führen. ${ }^{1}$ ) „Des Opfergesanges Hauptteil ist das Auge." „Was dies Auge ist, das ist jene Sonne; das ist der Adhvaryupriester." „Die Himmelsgegenden sind das Ohr." So die Upanishaden. Der buddhistische Denker dagegen, der sich mit dem Auge und seiner Tätigkeit beschäftigt, läßt Sonne und Priester beiseite. Er spricht eben nur vom Auge und den sichtbaren Objekten, von visuellem Erkennen, von der Berührung des Auges mit den Objekten, von der aus dieser Berührung entstehenden Empfindung, sei es Freude, sei es Leid, sei es nicht Leid noch Freude - einer Empfindung, die sich so aus der Berührung entwickelt, „,wie durch die Reibung und das Zusammenbringen zweier Hölzer Wärme entsteht und Feuer erzeugt wird ..."

Am chronologischen Resultat von all dem kann kein Zweifel sein. Verglichen mit Bṛhad Āranyaka oder Chāndogya Upanishad ist die buddhistische Literatur die jüngere. Und zwar ist es undenkbar, daß sie an jene Vorgänger unmittelbar anschließt. Eine Entwicklung muß in der Mitte liegen, die es unmöglich ist sich als kurz vorzustellen. Sie verlangt Jahrhunderte ${ }^{\mathbf{1 8 5}}$.

Leider aber geraten wir nun auf schwankenderen Boden, wenn nach dem zeitlichen Verhältnis der jüngeren, Sāṃkhyalehren enthaltenden Upanishaden zur Literatur der Buddhisten gefragt wird. Über so starke Altersunterschiede wie die eben besprochenen läßt sich natürlich mit anderer Sicherheit urteilen als uber die geringen. So viel halte ich doch für unzweifelhaft, daß die Kăthaka Upanishad mindestens ihre erste Hälfte - vorbuddhistischer Zeit

$\left.{ }^{1}\right)$ In solcher Vergleichung ist mir Mrs. Rhys Davids vorangegangen. Vgl. die treffenden Bemerkungen in ihrem Buch „Buddhism, a study of the Buddhist Norm" $61 \mathrm{f}$. 
angehört. Ich verweise auf das oben (S. 203) über diese Upanishad Gesagte. Es stimmt gut dazu - wenn es auch für sich allein nicht beweisend wäre -, daß die im buddhistischen Vorstellungskreise so festgewurzelte, phantasiereich ausgestaltete Figur Māra's, des Versuchers zur Weltlust, der zuletzt mit dem Todesgott identisch ist, sich im Mrtyu („Tod") dieser Upanishad unverkennbar im Entstehen zeigt. Zweifeln kann man über das zeitliche Verhältnis der Śvetāśvatara Upanishad zum Buddhismus. Ich möchte eher dazu neigen, sie späterer Zeit als die altbuddhistische Literatur zuzuschreiben, und wesentlich entschiedener urteile ich ebenso über die Maitrāyana Upanishad (vgl. S. 205f). Daß vollends die epischen Zeugnisse über das Sāṃkhya ihrer Abfassung nach - wenn auch darum nicht ohne weiteres hinsichtlich ihres Inhalts - nachbuddhistisch sind, unterliegt keinem Zweifel.

Was der Erforscher dieser Gedankenentwicklungen besonders lebhaft vermißt, wäre als ein Sichzusammenordnen der brahmanischen und buddhistischen Traditionen - zugleich mit den letzteren auch der jainistischen - in einem gemeinsamen Rahmen zu beschreiben, als Vorhandensein einer Kontinuität datierbarer Verbindungsglieder, deren Lage im Verhältnis zur einen wie zur andern Seite feststände: Besitzstücke der Überlieferung, wie sie etwa da, wo es sich um das Hervorwachsen des Christentums aus dem Judentum und um sein Berührtwerden durch griechische Einflüsse handelt, der Forschung reichlichst zu Gebote stehen und ihr dort eine uns hoffnungslos versagte Sicherheit verleihen. Wo der Buddhismus in die Erscheinung tritt, hebt sich unvermittelt gleichsam ein Vorhang an einer Stelle, die früher außerhalb des Gesichtskreises lag. Gewiß steht dieses Auseinanderfallen der Überlieferungsmassen nicht außer Beziehung zum Fehlen des Schriftgebrauchs. Geht eine Schule, eine Gemeinde des damaligen Indien unter, so verschwindet auch ihre Literatur, für deren Existenz die unentbehrlichen lebendigen Träger eben nicht mehr da sind. Alle neben- 
sächliche, gelegentliche literarische Produktion und damit die Bewahrung von Zwischengliedern zwischen den Traditionen hier dieser, dort jener Schule ist von vornherein ausgeschlossen. Man braucht doch nur auf die Übereinstimmung mancher dogmatisch wichtiger Ausdrücke zwischen Brahmanentum und Buddhismus (vgl. z. B. S. 131 A. 1) oder auf die Identität ganzer Verse in den beiden Literaturen hinzusehen, um auf den ersten Blick zu erkennen, daß vielfache und starke verbindende Fäden da in der Tat gelaufen sein müssen. Aber welches eigentlich die genauere Gestalt der Figur war, in der sich der Zusammenhang des Buddhismus mit den brahmanischen Lehren darzustellen hätte, an welchem Punkt sich die beiden Entwicklungslinien von einander scheiden: davon spricht uns keine direkte Überlieferung; das kann die Forschung nur aus inneren Gründen - man muß fürchten, unsicher und unbestimmt - ermitteln.

Die Umgebungen, inmitten derer Buddha lebte und die Grundlinien seiner Weltanschauung feststellte, waren vom Treiben verschiedenster philosophischer und pseudophilosophischer Richtungen erfüllt, von ernster Gedankenarbeit wie vom Geräusch leerer und allerleerster, ruhmoder gewinnsüchtiger Spiegelfechterei. Die Texte der Buddhisten und Jainas ergeben ein überaus lebendiges Bild. Es war ein Zustand wie ihn die rasch arbeitende Gewandtheit des indischen Geistes unvermeidlich herbeiführen mußte. Selbstkräftiges, selbstbewußtes Denken hatte seine ersten Erfolge erkämpft: damit waren die Wege geöffnet, auf denen nun der Gedanke sich leicht in allen Gangarten mit Behagen kreuz und quer tummeln, die Schar der Dialektiker von System zu System schweifen konnte, wie ein altbuddhistischer Vers es spottend beschreibt:

„Jetzt hier sich haltend, jetzt dorthin greifend,

Dem Affen gleich, der von Ast zu Ast schlüpft."

Mehr als einmal ist diese indische Sophistik, wie man sie nennen kann, neuerdings beschrieben worden. Dem großen Problem der Erlösung traten da andre Fragen an die Seite, 
die weniger auf der Sorge um das höchste Heil als auf dem natürlichen Wissensdrang beruhten, der keine Ruhe findet, bis er voll Vertrauen auf das eigne Können zu den letzten Grenzen oder Grenzenlosigkeiten des Weltbildes vorgedrungen ist. Man philosophierte über Ewigkeit oder Vergänglichkeit der Welt und des Ich, über Endlichkeit und Unendlichkeit der Welt. Die alte Frage nach Dasein oder Nichtdasein einer Seele, nach ihrer Fortdauer oder ihrem Untergang jenseits des Todes wurde immer von neuem umstritten. Man versagte sich nichts von den Genüssen des Zweifels. Gibt es ein Jenseits, eine Seelenwanderung? Oder sind, wenn die Träger den Toten zum Verbrennungsplatz gebracht haben, die bleichen Gebeine das Einzige, das übrig bleibt? Gibt es jenseitigen Lohn der Taten? Gibt es Freiheit, gut 'oder schlecht zu handeln? Oder werden die Wesen allein durch den Zwang von Schicksal, Fügung, Natur willenlos ihren Weg entlang geschleift? Gibt es Wahrheit? Oder ist Alles gleich wahr, gleich unwahr? Virtuosen der Disputierkunst ließen sich öffentlich hören. Nicht auf die Sache kam es an, sondern auf das Wort, auf den Sieg im Redeturnier. Man übte sich dem Gegner Fallen zu stellen, selbst aalglatt seinen verfänglichen Fragen, dem Verdruß und der Beschämung des Überwundenen zu entschlüpfen.

Wie zu diesem Milieu Buddha sich verhielt, davon geben unsre Quellen uns anschaulichste Kunde. So karg sie in Aufschlüssen über die Vorgeschichte des buddhistischen Denkens sind, so reich und lebendig ist ja ihr Zeugnis überall, wo es gilt, die eigne Seelenverfassung des alten Buddhismus - oft dürfen wir kühnlich sagen des Buddha selbst - zu schildern.

Von Zweifeln am Dasein jenseits des Todes, an Recht und Kraft der Grundordnungen sittlichen Lebens ließ man sich nicht berühren. Hier machte für das buddhistische Bewußtsein die Rationalisierung des Weltbildes, von der wir gesprochen haben, Halt. Im Streit mit Skeptikern und Materialisten, die jene Grundlagen antasteten, begnügte man 
sich deren Argumente dialektisch zu zerstören. Im Übrigen berief man sich auf die Intuitionen, die dem über das Jenseits hinblickenden Auge heiliger Asketen zuteil werden; den Gegner verglich man dem Blindgeborenen, der nicht an das Dasein von Formen und Farben glauben will, nicht an die Sterne noch Mond und Sonne ${ }^{186}$. Hier erkannte man den Punkt, an dem sich die Geister scheiden. Wer den sittlichen Wert des Handelns in Frage stellte, von dem wandte man sich in Zorn und Verachtung ab. „Wie von allen gewebten Gewändern, die es gibt, ein hären Gewand das schlechteste heißt - ein hären Gewand ist in der Kälte kalt, in der Hitze heiß, von schmutziger Farbe, schlecht riechend, rauh anzufühlen - so heißt unter allen Lehren der andern Asketen und Brahmanen des Makkhali Lehre die schlechteste. Makkhali der Tor lehrt also, meint also: es gibt kein Handeln, es gibt keine Tat, es gibt keine Kraft" so setzt er sich in Widerspruch mit den Buddhas der Vergangenheit und der Zukunft und mit ihm selbst, dem Buddha der Gegenwart, die alle einstimmig die Lehre von der Wirkenskraft und Freiheit des Handelns verkünden.

Kaum weniger entschieden aber, als die Zurückweisung solcher die sittlichen Fundamente angreifender Meinungen war die Abneigung des alten Buddhismus gegen alles philosophische Theoretisieren um der bloßen Theorie willen. In bitterer Seelennot hatte Buddha den langen, harten Kampf um den Ausweg aus dem Leiden der todzerrissenen Welt gekämpft. Konnte er es gelten lassen, daß man das Trachten nach dem Einem, das not ist, mit unnuitzem Ballast beschwerte? Dem tiefen Eindruck davon, in welchen äußeren und inneren Unfrieden man sich in jenem "Dickicht der Meinungen, dem Bühnenspiel der Meinungen, dem Krampf der Meinungen" verstrickte, konnte er sich unmöglich verschließen. Undenkbar, daß er angesichts des Treibens der zeitgenössischen Dialektiker eine Stimmung in sich hätte walten lassen ähnlich der heiteren Toleranz Mephistos gegenüber dem "Most, der sich ganz absurd geberdet". Selbst 
wo die schlimmsten Auswüchse jenes Sophistentums vermieden wurden, immer mußte ihm doch der Drang des Erkennenwollens um seiner selbst willen als ein Hemmnis erscheinen. Die darin sich verwickelnden Asketen und Brahmanen „wurden nicht erlöst von der Macht Māra's". Der rechte Jünger "haftet auch am Erkennen nicht".

Es scheint, daß etwas von verwandten Stimmungen auch der Zwillingssekte des Buddhismus, dem Jainatum, nicht fremd gewesen ist. ${ }^{187}$ Mit ganz besonderer Kraft aber tritt in den Äußerungen der Buddhisten diese Reaktion gegen die von allen Seiten sie umgebenden Strömungen der Dialektik hervor. Auf der einen Seite sah Buddha jene höchste Schätzung des Wissens, des allmächtigen, weltbeherrschenden, vor Augen und fühlte unzweifelhaft in sich selbst einen starken Zug dorthin: die Schätzung, wie sie in alter Zeit unter den Brahmanen, den gebornen Wissern, fest begründet war, und wie deren Nachfahren sie geläuterter, doch nicht minder stark überkommen hatten. Auf der andern Seite hatte er in der Sophistik und Skepsis seines eignen Zeitalters das leichtherzige Spiel mit dem Wissen, das geringschätzige Wegwerfen alles Vertrauens auf die Möglichkeit des Wissens kennen gelernt. Nicht als theoretischer Denker, sondern als ein großer Erzieher der Menschheit ging er selbst seinen Weg zwischen Wissen und Nichtwissen, Nichtwissenwollen, hinblickend allein auf das eine höchste Ziel der Erlösung. Felsenfeste Gewißheit der Erreichbarkeit des Wissens, das zu diesem Ziel führt. Zugleich aber, jener Skepsis ähnlich scheinend und doch in Wahrheit von ihr so verschieden, den Geist durch das Abwerfen toten Gewichts zu leichter Freiheit hebend, die $\mathrm{Zu}-$ rückweisung alles Wissens, das "keinen Gewinn bringt, nicht den Wandel in Heiligkeit fördert, nicht zur Abkehr vom Irdischen, zum Untergang aller Lust, zum Aufhören des Vergänglichen, zum Frieden, zur Erkenntnis, zur Erleuchtung, zum Nirvāṇa führt". ${ }^{188}$ Wer solch leerem Wissen nachstrebt, wird jenem törichten Verwundeten verglichen: 
der will sich nicht vom Arzt behandeln lassen, bis er den Namen des Verwunders kennt und weiß, ob der lang oder klein oder mittelgroß ist, und wie die Waffe aussieht, mit der er ihn getroffen hat - dieser Tor wird an seiner Wunde sterben. „Deshalb“, sagt Buddha zu einem Mönch, der mit seinen Fragen über die Grenze hinaus geht, "was von mir nicht offenbart ist, das laß unoffenbart bleiben, und was offenbart ist, das laß offenbart sein." Und ein andresmal weist er den Frager in seine Schranken zurück: "Mit deinen Gedanken, die unter der Herrschaft des Begehrens stehen, meinst du, du könnest des Meisters Lehre überholen."

Bei der Prüfung des geschichtlichen Verhältnisses von Buddhismus und Sāṃkhya muß beständig diese Selbstbeschränkung des buddhistischen Denkens im Gegensatz zu jenem System, für das es keine ungelösten Fragen gibt, in Anschlag gebracht werden. Direkte Übereinstimmungen können sich so von vornherein nur auf einem Teil des von der Sāṃkhyaspekulation beschriebenen Weges finden. Bei den Problemen, die der Buddhismus weggeschnitten hat, kann höchstens die Lage des Schnittes oder vielleicht ein etwaiges Mißlingen des vollständigen Abschneidens auf das Sāṃkya hindeuten.

Soviel zunächst scheint nun klar, daß Beeinflussung des Buddhismus durch das Sāṃkhya, wenn sie überhaupt stattgefunden hat, kaum als unmittelbare Abhängigkeit zu denken sein kann.

Unter den Äußerungen der Buddhisten über zeitgenössische Philosopheme begegnen allerdings neben vielen andern auch solche, die sich auf Sāmkhyalehren zu beziehen scheinen. ${ }^{18 \theta}$ So ist von Philosophen die Rede, die durch Nachdenken und Schlußfolgerungen zu der Ansicht gelangt sind: „Ewig ist Selbst (attā = skt. ātman) und Welt, nichts Neues hervorbringend, auf dem Berggipfel stehend ${ }^{1}$ ),

1) Gemeint ist wohl: an Stellen stehend, wo jede Bewegung und Annäherung des einen an das andere ausgeschlossen ist. 
pfeilergleich feststehend. Die Lebewesen zwar durchlaufen ihre Wanderungen; sie scheiden hin und werden wiedergeboren. Doch immer und ewig bleibt das Sein." Und etwas später im selben Text: „Was da Auge genannt wird und Ohr und Nase und Zunge und Körper: dieses Selbst ist unbeständig, vergänglich, nicht "ewig, dem Wechsel untertan. Was aber Seele genannt wird oder Verstand oder Erkennen: dieses Selbst ist beständig, unvergänglich, ewig, keinem Wechsel untertan; immer und ewig wird es sich gleich bleiben." Der Sāṃkhyadualismus des ewigen Geistes und der ewigen Natur scheint in der ersten dieser Stellen unverkennbar. Das Bild vom "Stehen auf dem Berggipfel" ist im epischen wie im klassischen Sāṃkhya beliebt. Dort wird es freilich nicht auf beide absolute Wesenheiten angewandt, sondern allein auf den Purusha, um dessen unbewegtes Verharren der Weltbewegung gegenüberzustellen: so scheint auf buddhistischer Seite eine Ungenauigkeit vorzuliegen, wie sie dort in Bezug auf Lehren und sonstige Verhältnisse fremder Glaubensrichtungen häufig begegnet. Die zweite Stelle sodann hat es doch wohl mit der vom Sāmkhya gelehrten Unterschiedenheit zwischen dem Geist und den in Wahrheit materiellen Substanzen zu tun, die den täuschenden Schein der Geistigkeit tragen (oben S. 247). Genau ist der Bericht auch hier nicht. Denn nicht allein die fünf Sinne, sondern auch die Gruppe, zu welcher der Verstand gehört, stehen für das Sāmkhya auf Seiten der materiellen Natur.

Wenn nun diese Stellen in der Tat wahrscheinlich machen, daß zu den hier redenden buddhistischen Autoren auch Formeln der Sāmkhyaphilosophie irgendwie gedrungen sind, so hat doch offenbar in dem ganzen philosophischen Treiben, das den entstehenden Buddhismus umgab, das Sāṃkhya - ich meine dieses selbst, nicht indirekt von ihm ausgehende Einwirkungen - eine irgend erhebliche Rolle nicht gespielt. ${ }^{180}$ Der Name Sāṃkhya kommt in den altbuddhistischen Texten nicht vor. Auch die Terminologie der buddhistischen 
Dogmatik entfernt sich von der speziellen Ausdrucksweise des Sāṃkhya - anders als vom Yoga - in den meisten Punkten so weit, wie das bei der Gleichartigkeit der behandelten Probleme und in Anbetracht davon, daß auf beiden Seiten zeitlich benachbarte indische Denker reden, überhaupt möglich ist. Der Versuch, den man gemacht hat, die fundamentale Kategorienreihe des Sāṃkhya im Buddhismus bis ins Einzelne identisch wiederzufinden ${ }^{191}$, konnte denn auch nicht. gelingen; er beruht auf unrichtiger Schätzung ich möchte sagen der Luftperspektive, in der sich die Distanz beider Doktrinen kundgibt.

Natürlich aber steht nun dies Fehlen oder Zurücktreten direkter Berührungen der Möglichkeit nicht im Wege, daß doch aus der Ferne, durch unbekannte Mittelglieder, die leitenden Ideen des Sāmkhya Einfluß auf das buddhistische Denken geubt haben.

Betrachtungen, die jetzt vorzulegen sind, deuten darauf hin, daß in der Tat solche Beeinflussung in tiefgehender Weise stattgefunden hat. ${ }^{198}$ Die Fäden vom Sāṃkhya zum Buddhismus überspannen weite Zwischenräume. Aber sie halten fest.

Von allem weltlichen oder überweltlichen Sein, das man mit dem Denken erfassen oder uberhaupt irgendwie in Betracht ziehen kann, verlangt der Buddhismus den Ausweis über seine Zugehörigkeit zu einem von zwei Reichen: des vergänglichen "Gestalteten" (samkhata), des unvergänglichen "Ungestalteten“. ${ }^{198}$ "Entstehung zeigt sich; Vergehen zeigt sich; während des Bestehens zeigt sich Veränderung. Dies sind die drei Gestaltungskennzeichen des Gestalteten. Keine Entstehung zeigt sich; kein Vergehen zeigt sich; keine Veränderung des Bestehenden zeigt sich. Dies sind die drei Nichtgestaltungskennzeichen des Ungestalteten." „Es gibt, ihr Jünger, ein Ungeborenes, Ungewordenes, Ungemachtes, Ungestaltetes. Gäbe es nicht, ihr Jünger, dies Ungeborene, Ungewordene, Ungemachte, Ungestaltete, würde es für das Geborene, Gewordene, Gemachte, Gestaltete keinen 
Ausweg geben." Möglich, daß dem Denken zugänglich allein das "Gestaltete" ist. Das nimmt jenem Gegensatz doch nicht die allbeherrschende Bedeutung. Denn auch so wird dies „Gestaltete“, Vergängliche doch immer, ausgesprochenermaßen oder stillschweigend, am Maßstab der Unvergänglichkeit bemessen und auf diese Weise als dem Gericht verfallend erkannt: auch wenn ein bleibendes Sein, das solcher Beurteilung standhielte, den Wegen des Denkens nirgénds begegnen mag.

Es ist unmittelbar evident, daß die tiefsten Wurzeln dieses fundamentalen Gegensatzes in der alten Brahmanspekulation liegen: in ihrer Gegenüberstellung des ewigen Einen und der von Tod und Vergänglichkeit beherrschten Vielheitswelt. Von jenem Altertum an nahm nun einmal dieser Vorstellungskreis samt dem zu ihm gehörenden Ideal der Erlösung in den Geistern indischer Denker die erste Stelle ein, zwang innere Notwendigkeit sie, alle Dinge und Probleme zuvörderst unter dem damit bezeichneten Gesichtswinkel zu betrachten. Ist nun die Auffassung jenes Grundmotivs von seinem ältesten Ausgangspunkt aus durch die Phase des Sāmkhya hindurchgegangen, ehe die buddhistische Gestalt erreicht wurde? Damit wir hierüber urteilen können, muß zuvörderst diese letztere noch näher beschrieben werden.

Auf der einen Seite das Reich der Vergänglichkeit. Es heißt die "Welt" (loka) oder die "Ordnungen" (dhammā), die "Gestaltungen" (samkhāāa). Kein Sein, sondern beständiges Entstehen und Vergehen. Der Gegensatz von Sein und Werden, welcher der brahmanischen Spekulation vorschwebte, doch in der älteren Zeit, wenigstens in den uns erhaltenen Texten, nicht zu vollkommen scharfer Formulierung gelangt ist, wird hier in höchster Klarheit herausgearbeitet. "An eine Zweiheit, o Kaccāna, pflegt diese Welt sich zu halten, an das, Es ist' und an das ,Es ist nicht'. Wer aber, o Kaccāna, in Wahrheit und Weisheit es anschaut, wie die Dinge in der Welt entstehen, für den gibt es kein ,Es ist nicht' in dieser Welt. Wer, o Kac- 
cāna, in Wahrheit und Weisheit es anschaut, wie die Dinge in der Welt vergehen, für den gibt es kein ,Es ist' in dieser Welt." Aus solcher Ableugung eines ,Es ist' hienieden und seiner festen Ruhe spricht die indische Gequältheit durch den Unbestand des Weltdaseins. Sie hat immer unwiderstehlicher vom ganzen Menschen Besitz genommen, läßt ihm alles, alles als „unbeständig, leidenvoll, dem Wechsel unterworfen" erscheinen. Werden ist der Untergang von immer neuem Gewordenem in immer neuem Tod:

"Alle Gestaltung, ach, wechselnd dem Entstehn, dem

Was geboren, muß hinschwinden" -

Vergehn gehört.

Ein wogender Ozean, ein flackerndes Flammenmeer.

Vergebliche Hoffnung, daß der dem körperlichen Leben versagte Halt wenigstens im Reich der seelischen Vorgänge anzutreffen sei. „Es wäre immer noch besser, ihr Jünger, wenn ein Weltkind, das die Lehre nicht vernommen hat, diesen aus den vier Elementen gebildeten Körper für das Selbst hielte als die Seele. Und warum das? Der aus den vier Elementen gebildete Körper, ihr Jünger, erscheint ein Jahr lang als bestehend oder zwei Jahre lang . . . oder er erscheint hundert Jahre lang und mehr als bestehend. Was aber, ihr Jünger, Seele genannt wird oder Verstand oder Erkennen, das entsteht und vergeht immer wechselnd Tag und Nacht. Wie ein Affe, ihr Jünger, in einem Walde, einem Gehölz umherstreift, einen Ast ergreift und den fahren läßt und einen andern ergreift, so entsteht und vergeht, ihr Jünger, das was Seele genannt wird oder Verstand oder Erkennen, immer wechselnd Tag und Nacht." Mit dem anschaulichen Bilde eines späteren buddhistischen Schriftstellers: "Wie das Wagenrad im Rollen immer nur auf einem Punkt des Reifens rollt und im Ruhen nur auf einem Punkt ruht: ebenso währt eines lebenden Wesens Dasein nur so lange ein Gedanke dauert. Ist der Gedanke vergangen, so heißt es, daß das Wesen vergangen ist." Ein bleibendes Selbst - jener Ātman, der für das Denken 
der alten Zeit die Gewißheit aller Gewißheiten war - ist in diesem Treiben nicht zu finden. "Wenn nun, ihr Jünger", sagt Buddha, „ein Selbst (attā = skt. àtman) und etwas dem Selbst Zugehöriges (attaniya) sich in Wahrheit und Gewißheit nicht erfassen läßt, ist dann nicht, ihr Jünger, der Glaube, der da sagt: ,dies ist die Welt und ist das Selbst: dies werde ich sterbend werden, fest, beständig, ewig, unwandelbar; so werde ich in Ewigkeit bestehen ${ }^{1}$ ) ist das nicht bloße leere Torheit?" "Wie sollte es nicht, Herr, bloße leere Torheit sein ?" ${ }^{104}$

Wir begegnen hier der vielbesprochenen, mit modernen Anschauungen so überraschend zusammentreffenden Lehre des Buddhismus, die es ablehnt, von einem substanziellen Seelenwesen zu sprechen, und in deren Gesichtsfeld allein der Fluß seelischen Geschehens erscheint - wo es kein cogito gibt, sondern nur ein cogitatur. Man hat diese Auffassung, buchstäblich richtig und doch, scheint mir, einen falschen Ton anschlagend, als Bekämpfung - eventuell als Überwindung - des "Animismus" gefeiert, indem man eine Bezeichnung, die den Seelenglauben tiefer Kulturstufen zu charakterisieren pflegt, auf Überzeugungen ausdehnte, wie Platon und Leibniz sie gehegt haben. Die hier in Rede stehende buddhistische Lehre nun wird man, meine ich, keineswegs als das Ergebnis einer überlegen vordringenden, die Tatsachen der Psychologie genial durchleuchtenden Analyse anzusehen haben. Es handelt sich um nicht mehr und nicht weniger als um die unvermeidliche Konsequenz der allgemeinen Grundanschauung von der alleinigen Geltung des Werdens, nicht des Seins, in dieser Welt. Nur wurde eben auf psychischem Gebiet diese Anschauung begreiflicherweise besonders stark betont, weil für das allbeherrschende Erlösungsproblem natürlich in erster Linie seelische Faktoren in Frage kamen und weil das Bedürfnis, entgegenstehende Meinungen abzuwehren, hier vorzugsweise dringend war.

1) Haben wir hier nicht alte Upanishadenlehre, genauer deren oben S. 86 ff. beschriebenen Typus? 
Der schreckensvolle Eindruck dieser Flüchtigkeit des Weltdaseins findet aber sein Widerspiel und seine Ergänzung in der Erkenntnis, daß dies Dasein, wenn auch wertlos, gliucklos, doch nicht ordnungslos ist. Jede Bewegung jeder Welle im Meer des Geschehens gehorcht festem Gesetz. Auf ein solches Gesetz weist schon die Bezeichnung der einherfließenden Ströme als Dhammā „Ordnungen" hin. Ebenso, wenn man vom "Unbeständigen, Gestalteten, in Abhängigkeit (von etwas anderm) Entstandenen" spricht: dem "Unbeständigen" ist es also wesentlich, in solcher "Abhängigkeit", wir würden sagen unter dem Kausalitätsgesetz zu stehen.

In diesem Sinn gewöhnt man sich zu fragen „was zur Grundlage habend, woraus entstehend, woraus geboren, woraus entspringend" jede einzelne Erscheinung ist. ${ }^{103}$ Man argumentiert: Wenn dies ist, ist auch jenes; wenn dies entsteht, entsteht auch jenes; wenn dies nicht ist, ist auch jenes nicht; wenn dies vergeht, vergeht auch jenes." Bei der Bekehrung des vornehmsten aller Jünger wird diesem, so erzählt man, der wesentlichste Gehalt der Lehre in dem dann zu unzähligen Malen als kürzestes Glaubensbekenntnis des Buddhismus wiederholten Satz mitgeteilt: „Welche Ordnungen (dhamma $)$ aus einer Ursache fließen, deren Ursache lehrt der Vollendete, und welches ihre Aufhebung ist: dies ist die Lehre des großen Śramana." Ein denkwürdiger Schritt vorwärts in der Erschließung des Chaos der Erscheinungen für die Durchleuchtung, das Ordnen und Begreifen des Denkens.

Wie in der Vorstellung vom Fluß des Geschehens das Elend des Sichversenktfuhlens in das Weltleiden zum Ausdruck kommt, so eröffnet sich in der Überzeugung von dem in fester Bahn diesen Fluß lenkenden Naturgesetz dem Wissenden die Hoffnung "mit Macht den Strom abzuschneiden", vom Leiden sich zu erlösen. Eine Erlösung beruhend auf mühevollem Durchforschen der Wirklichkeit mit ihrer Verkettung der Ursachen und Wirkungen, und 
auf entschlossen sicherm Eingreifen an dem so ermittelten rechten Punkt, in der Gewißheit, daß nun die ganze lange Kette der Kausalitäten nicht anders können wird, als schnell oder langsam zum gewollten Ergebnis und zu keinem andern hin abrollen. Wird man sich das Glück dieser Gewißheit durch die Erwägung trüben, daß ja auch darüber, ob jenes Eingreifen stattfinden wird oder nicht, unabänderliche Notwendigkeit entscheidet, die vielleicht die Rettung ausschließen mag? In der Bahn der Lehre, die man so energisch zurückwies - daß der Mensch willenlos durch Geschick und Natur seinen Weg geführt wird (S. 291) - , bewegte man sich ja im Glauben an die allbeherrschende Kausalität im Grunde selbst. Begreiflich doch, daß man jene Konsequenz nicht vollzogen, den religiösen Gedanken nicht in solche Selbstvernichtung hineingeführt hat. ${ }^{1}$ )

Den naturnotwendigen Verlauf des Stromes, den es zu hemmen gilt, beschreibt die zwölfgliedrige Formel vom „Kausalnexus des Entstehens,“ die „tiefe, von tiefem Glanz". Es ist hier nicht der Ort, auf ihre oft besprochenen Einzelheiten, die schwierigen Fragen, die es da zu lösen gibt, von neuem einzugehen. ") Das Ganze kann man die Formel

1) Ich kann mir nicht versagen, die folgenden treffenden Worte L. de la Vallée Poussin's (Journal asiatique 1903, II, 447) über die buddhistische Auffassung von Freiheit und Gebundenheit hierherzusetzen: „Il est certain que l'acte présent est nécessité par l'acte antérieur; mais il est non moins certain que l'acte présent détermine notre destinée: la conscience religieuse n'accepte, ne retient de ces deux propositions jumelles que celle qui est utile à la vie morale et religieuse; elle n'a cure des subtilités dialectiques."

${ }^{2}$ Ich verweise auf meinen „Buddha", 6. Aufl., 252 ff. und die dort angeführte Literatur. Den Wortlaut der Formel hierher zu setzen scheint doch am Platz: „Aus dem Nichtwissen entstehen die Gestaltungen (samkhäră). Aus den Gestaltungen entsteht Erkennen". Dann ebenso weiter der Reihe nach: „Name und Körperlichkeit ... die sechs Gebiete (der Sinne und ihrer Objekte) ... Berührung (zwischen Sinnen und Objekten) ... Empfindung ... Durst ... Ergreifen (der Existenz) ... Werden ... Geburt ... Alter und Tod, Schmerz und Klagen, Leid, Kümmernis, Verzweiflung. Dieses ist die Entstehung des ganzen Reiches 
des Weltlaufs nennen - "Welt" verstanden in jenem Sinn, in dem Buddha sagt: „Ich kenne kein Ende des Leidens, wenn man nicht der Welt Ende erreicht hat. Aber ich verkündige euch, daß in diesem beseelten Leibe, der nur klaftergroß ist, die Welt wohnt und die Entstehung der Welt und die Aufhebung der Welt und der Weg zur Aufhebung der Welt." "Welt" also ist das Leiden, außer welchem eben nichts in der Welt für den Erlösungsuchenden etwas zu bedeuten hat. Und so muß die Formel, die diese Welt beschreibt, in der Tat sehr verschieden sein von der Reihe der vierundzwanzig Prinzipien im Sāṃkhya. Nicht wie dort Entwicklung der Natur aus dem Naturgrund, von den feinsten Substanzen bis zum grob Materiellen - Gebilde an sich unempfindlich für Freude und Leid und vom Leiden erst durch die Beziehung zum draußenstehenden Purusha berührt. Sondern hier zielt alles direkt auf das Leiden, nur auf das Leiden ab. Hauptinhalt der Reihe seelische Vorgänge Vorgänge natürlich, nicht Substanzen. An der Spitze die tiefste Wurzel des Leidens, das verhängnisvolle "Nichtwissen" dann Geschehnisse wie Berührung von Sinnesorganen und Objekten, daraus entstehende Empfindung, begehrender Durst, Ergreifen des Daseins; zum Schluß das Ergebnis: „Alter und Tod, Schmerz und Klagen, Leid, Kümmernis, Verzweiflung" - und von da aus wieder neues Durchlaufen des Leidens." Eine zweite Hälfte der Formel besagt dann entsprechend, wie durch Aufhebung des Nichtwissens der Reihe nach alles daraus Entstandene aufgehoben wird: „Dieses ist die Aufhebung des ganzen Reiches des Leidens." - Daß das Glied "Geburt" nicht am Anfang der Formel steht, sondern hinter einer Reihe anderer Glieder, die offenbar die Existenz eines längst geborenen Wesens voraussetzen, erklärt sich daraus, daB die Formel, wie nicht bezweifelt werden kann, über mehrere Geburten hinüberreicht. Im Lauf des Samsūra ist die Geburt eben kein Neuanfang, sondern ein Glied der Kette unter andern Gliedern. Sehr deutlich sieht man das in der kurzen Kausalitätsformel - vermutlich der hier vorliegenden nachgebildet - der Nyāyaphilosophie. Diese Formel steigt von den Wirkungen zu den Ursachen in folgender Fassung auf: Leiden. Geburt. Handeln. Fehler. Falsche Erkenntnis. Also auch hier die Geburt eine Folge älteren Verfehlens. 
der ganzen Reihe. Nirgends ein Absolutes, sondern allein Verkettung des Geschehens. Das eine aus dem andern mit ehernem Zwang folgend; dafür aber auch des einen Aufhebung mit unfehlbarer tröstlicher Gewißheit das andere aufhebend. Die ganze Reihe ruht in voller Autonomie auf sich selbst, bedarf keines Antriebes, keiner Leitung durch ein außer ihr Stehendes.

Erkennt das buddhistische Denken ein solches Draußenstehendes, ein Jenseitiges, Unbedingtes, Ewiges an? Eine zweite Seite des allumfassenden Gegensatzes?

Wir begegneten Äußerungen, die diese Frage zu bejahen schienen (S. 296). Sie sind sehr allgemein gehalten. Sobald nach bestimmterer Antwort gesucht wird, zeigt sich, daß wir eben hier vor jener Grenze stehen, um deren Innehaltung der Buddhismus so ernstlich, so ängstlich bemüht ist: die Grenze zwischen dem Wissen, das für die Erlösung unentbehrlich ist, und dem überflüssigen, ja störenden.

Die ältere Zeit hatte ihre volle Kraft und Begeisterung daran gesetzt, auf das jenseitige Ziel hinzublicken. Von der kühn erfaßten Vorstellung dieses Ziels war Alles beherrscht. Jetzt war man enthaltsamer, kühler, umsichtiger geworden. Auch hatten sich die Eindrücke des Weltleidens verschärft und vertieft. So fiel jetzt der Nachdruck nicht mehr auf das Wohin, sondern auf das Woher: hinaus aus diesem Leiden! Um das Leiden verschwinden $\mathrm{zu}$ machen, erkennt man es, wie wir sahen, mit einer fast naturwissenschaftlichen Folgerichtigkeit, in der sich der Fortschritt des Denkens gegenüber der älteren Zeit klar ausprägt, als notwendig und als genügend, den Mechanismus der leidenschaffenden Kausalität zu durchschauen. Ein Wissen also, das sich ganz und gar im Reich des Bedingten, Diesseitigen hält. Auch in Bezug auf dies Reich lassen sich Fragen stellen, die von der allein gebotenen Richtung abliegen und darum Tadel verdienen. Vor allem aber wehe dem Vorwitz, der den Tummelplatz eitler, um Ergründung des Unbedingten, Überweltlichen bemühter Dialektik beschreitet! 
Doch nun gibt sich alsbald in verschiedensten Formen $\mathrm{zu}$ erkennen - und dies ist für unsre Fragestellungen wichtig —, daß der Buddhismus nicht einfach das Gebäude seiner Lehre bis zu jener Grenzlinie hin aufgeführt und an ihr Halt gemacht hat. Der Hergang war ein andrer. Buddha hat älteren, von ihm vorgefundenen Anbau jenseits der Grenze weggeschnitten, indem er allein das diesseits Liegende beibehielt und nach seinen eignen Tendenzen gestaltete.

$\mathrm{Zu}$ den Tatsachen, die hierauf hindeuten, läßt sich in gewisser Weise schon der Bericht über jene fremden Meinungen rechnen, die das "Selbst" und die "Welt" in mächtiger Dualität einander entgegenstellen (S. 294). Schon hierin liegt ein freilich unbestimmtes Anzeichen für die Wahrscheinlichkeit, daß auch die buddhistische Lehre, die sich allein mit der "Welt" zu beschäftigen scheint, auf einer Vorgeschichte beruht, welche von derselben Gegenüberstellung beherrscht war. Weiter spricht hierfür die beständige Polemik gegen das Zuvielbehaupten. Die ebenso beständige Zurückweisung des Zuvielfragens. All das kennzeichnet eine Atmosphäre des Denkens, in der eben die verpönten Probleme auf der Tagesordnung standen. Es wäre befremdend, sollte ihre Abweisung durch den Buddhismus nicht auf einen älteren Zustand hindeuten, in dem man sie nicht abwies.

Doch nicht allein in solcher Polemik gegen Fremdes gibt sich der Hergang zu erkennen, dem wir hier nachforschen. Tiefere Spuren hat er in den eignen Gedankengebäuden des Buddhismus selbst zurückgelassen.

Befreiung vom Leiden läßt sich denken als Aufhebung des leidenschaffenden Vorgangs oder als Sichzurückziehen des Leidenden von der Berührung mit diesem Vorgang. Das Sāṃkhya schlug den zweiten Weg ein, indem es den Geist sich von der Natur abwenden und in die Reinheit seines Beisichseins eingehen ließ. Der Buddhismus lehnte es ab vom reinen Geist zu sprechen. So ergab sich für 
ihn konsequent die Wahl des ersten jener beiden Wege: das allein im Reich der Natur entstehende Leiden wird innerhalb der Natur vernichtet.

Diese Auffassung kommt in der Tat in der Kausalitätsformel zum Ausdruck. Auch das Credo der "vier heiligen Wahrheiten", das zwar eine ausdrückliche Entscheidung darüber nicht in sich schließt, vermeidet doch Alles, was dem widerspräche.

Nun aber betrachte man etwa folgende zwei Reden des Buddha, die zu den beruhmtesten gehören und deren Inhalt in den heiligen Texten vielfach wiederkehrt. ${ }^{106}$

Nachdem Buddha durch seine erste Predigt, die von Benares, sich die ersten fünf Jünger gewonnen hat, führt er diese zur Heiligkeit und Erlösung durch eine zweite Rede "von den Kennzeichen der Nicht-Selbstheit (des NichtIch)". Er zeigt von jedem der Elemente, aus denen sich das leiblich-geistige Dasein des Menschen aufbaut - Körperlichkeit, Empfindungen, Vorstellungen, Gestaltungen ${ }^{1}$ ), Erkennen -, daß dieses nicht das Selbst $(a t t \bar{a}=\bar{a} t m a n)$ ist. Sonst wäre es nicht der Krankheit unterworfen, und man müßte darüber gebieten können: so soll es sein, so soll es nicht sein. In Wahrheit aber sind alle diese Elemente unbeständig, Leiden, dem Wechsel unterworfen, und man erkennt: das ist nicht mein, das bin nicht ich, das ist nicht mein Selbst. „Wer es also ansieht, ihr Jünger, ein kundiger, edler Hörer des Worts, wendet sich ab von der Körperlichkeit, wendet sich ab von Empfindung, Vorstellung, Gestaltungen, Erkennen. Indem er sich davon abwendet, wird er frei von Begehren. Durch des Begehrens Aufhören gewinnt er die Erlösung. Im Erlösten entsteht das Wissen von seiner Erlösung: vernichtet ist die Wiedergeburt, vollendet der heilige Wandel, erfüllt die Pflicht; keine Rückkehr gibt es mehr zu dieser Welt, also erkennt er."

1) Dies sind die aus der Vergangenheit stammenden Tendenzen, deren Wirkung das künftige Dasein gestaltet.

oldenberg: Upanishaden. 
Ganz ähnlich die „Rede von den Flammen", die Buddha ebenfalls in der Anfangszeit seines Wirkens auf dem Berge von Gayā vor tausend von. ihm bekehrten brahmanischen Asketen gehalten haben soll - wie man später erzählte, im Angesicht eines Waldbrandes, der auf einem benachbarten Berg wütete. "Alles, ihr Jünger, steht in Flammen“, beginnt die Rede. Das Auge, seine Objekte, die Seelenvorgänge, die auf der Berührung von beidem beruhen: all das durchwogen die Flammen von Begierde, Haß, Verblendung, von Geburt, Alter, Tod und Schmerzen. Wie die Sphäre des Auges, so die des Ohres und aller andern Sinne. Wer dies erkennt, dem erwächst dieselbe Frucht, von der die vorige Rede sprach. Dort die fünf Gruppen der Elemente, die das menschliche Dasein ausmachen, hier die Sinne mit ihren Objekten und den zugehörigen Seelenvorgängen: von all dem wendet sich "ein kundiger, edler Hörer des Worts" ab - wörtlich stimmen die Reden in der Beschreibung dieser Abwendung überein -, und er gewinnt die Erlösung.

Liegt hier nicht offenbar, abweichend von der Kausalitätsformel, unter den beiden oben (S. 304) unterschiedenen Typen der Leidbefreiung derjenige vor, der vielmehr Entfernung vom Quell des Leidens, als Vernichtung dieses Quells bedeutet? Kommt nicht die Vorstellung eines der Vergänglichkeit und ihrem Flammenmeer seinem Wesen nach fremden ewigen Subjekts deutlich zur Erscheinung? Es ist kein Tor, sondern der Wissende, der beschrieben wird als die Betrachtung anstellend, daß das Vergängliche nicht das Selbst sein kann: so macht er sich von jenem frei. Kann solcher Kampf und Sieg, allein von den Wellen eben jenes unbeständigen Stromes psychischer Ereignisse gekämpft und gewonnen werden? Lassen sich alle Elemente, die in dieser Beschreibung des Freiwerdens eine Rolle spielen, als im unfreien Lauf jener Vorgänge vollständig enthalten denken? Wie käme die Vergänglichkeit dazu, ihrer eignen vergänglichen Natur inne werdend zu sich selbst zu 
sagen: "das bin ich nicht", und sich von sich selbst abzuwenden? Hier spricht offenbar vielmehr ein Andrer. Ein Selbst, welches das ihm Fremde als solches an seiner Vergänglichkeit erkennt, seinerseits also in diese Vergänglichkeit nicht hineingehört. Die beiden Reden schildern, wie es die Erlösung und das Wissen von der Erlösung gewinnt: als erlöstes muß es doch jener Vergänglichkeit entronnen sein, und so ist es undenkbar - was zugleich auch zu dem ihm zugeschriebenen Bewußtsein seiner Erlöstheit im Widerspruch stände - daß es im Nichts untergetaucht wäre. ${ }^{197}$

Gewiß zeigt sich dieser Angehörige eines ewigen Reichs hier in recht schattenhafter Beleuchtung. Während die Predigten das Diesseits und seine Leiden beredt schildern, erklären sie sich nicht darüber, wer jener ist. Sie lassen nur so zu sagen ein Drama sich abspielen, das unverständlich bleibt, so lange man ihn, wie auch immer sein Wesen zu denken ist, nicht als Mitspieler annimmt.

Als Schluß aus dieser offenbaren Überschreitung der vom buddhistischen Denken sonst innegehaltenen Grenzen ergibt sich in Bezug auf die Entstehung seiner Lehre offenbar eben die vorher schon ausgesprochene Auffassung: hinter der Ablehnung des Fragens nach Jenseitigem, Unvergänglichem erscheint deutlich als geschichtliche Vorstufe ein dualistisches System, das der vergänglichen Natur den unvergänglichen Ātman gegenüberstellte. Diesen Âtman $(a t t \bar{a})$ bemühte sich der Buddhismus aus seinen Betrachtungen auszuschalten. Aber, begreiflich genug, seine Dialektik arbeitete dabei nicht mit vollkommner Sicherheit. Vermied sie, das verfängliche Schlagwort geradezu auszusprechen, so fuhr doch die Idee des ewigen Selbst fort, unausgesprochen, unvertreibbar aus den Ritzen der Argumentation hervorzublicken. So zeigt sich ein Zwiespalt zwischen der Stellungnahme, zu der man sich entschlossen hatte, und vorgefundenen Anschauungen der Spekulation, mit denen, wie sich uns immer deutlicher herausstellen wird, auch unbestimmt 
zum Ausdruck gelangende eigne Überzeugungen im Einklang standen - Überzeugungen, die von der Negativität jener Stellungnahme bemerkbar nach der positiven Seite hin abwichen. Dieser Zwiespalt machte sich schon den Alten selbst an einem Punkt fühlbar, der dem eben betrachteten auf das engste benachbart ist, fast könnte man sagen mit ihm zusammenfällt: in dem Widerspruch zwischen der Behandlung des Ātmanproblems und der Karmanlehre. „Ist die Körperlichkeit nicht das Selbst, sind Empfindungen, Vorstellungen, Gestaltungen, Erkennen nicht das Selbst, welches Selbst soll dann durch die Werke, die doch das Nicht-Selbst tut, berührt werden?" so fragt ein Mönch und zieht sich dadurch jenen Verweis zu: mit seinem unreinen Sinn suche er des Meisters Lehre zu überholen. ${ }^{108}$ Wir werden über seine Verfehlung milde urteilen. Vor dem Widerspruch, in den die Richtungsänderung des Denkens hineinführte, hatte er nur eben nicht die Augen geschlossen.

Alle diese Gedankengänge oder Zweifel betrafen das Selbst in seiner Beziehung zur Welt. Eine ähnliche, vielleicht noch schärfer ausgeprägte Figur ergibt sich aus der nämlichen Kollision altvorliegender, tiefem Gemütsbedürnis entgegenkommender Lehrmeinungen und andrerseits des Verzichtes auf solches Wissen da, wo es sich um das erlöste und so denn aus der Welt ausgeschiedene Selbst handelt.

Ist der Vollendete (tathägata) jenseits des Todes? Ist der Vollendete jenseits des Todes nicht? Die Nonne Khemā, vom König Pasenadi gefragt, verneint das eine wie das andre. ${ }^{198}$ Sie lehnt ebenso den Versuch ab, das Verhältnis des Vollendeten zu Sein und Nichtsein anders und komplizierter als durch einfache Bejahung oder Verneinung zu bestimmen: daß jener sei und zugleich nicht sei, oder daß er weder sei noch nicht sei. So scheint man bei einem Vacuum, absolutem Versagen alles positiven wie alles negativen Vorstellens angelangt. Ist damit nun das Gespräch von König und Nonne zu Ende? Noch nicht ganz. Der 
König fragt in einer Verwunderung, die wir vielleicht begreifen werden, nach dem Grunde dieser Ergebnislosigkeit. Den Sand am Ganges, erwidert die Nonne, kann niemand zählen oder das Wasser im Ozean messen. Der Ozean ist tief, unermeßlich, unergründlich. So auch der Vollendete. Sein Wesen läßt sich nicht mit dem Maß der Körperlichkeit oder der Gefühle oder der andern Elemente irdischen Daseins bestimmen. Man kann von ihm nicht sagen, daß er jenseits des Todes ist oder nicht ist, oder wie man auch die Prädikate von Sein und Nichtsein wenden und kombinieren mag.

Eine bedeutsame Schwankung gegenüber jenem Verzicht auf das Wissen vom Ewigen als unnütz für die Erlösung. Wie natürlich, daß man für jetzt noch nicht versteht, ohne solche Schwankungen seinen Standpunkt unverrückbar festzuhalten. An die Stelle des Nichtwissens, weil wir Überflüssiges nicht wissen sollen, schiebt sich das Nichtwissen, weil wir das Allzutiefe nicht wissen können. Die Ausdrücke Sein und Nichtsein, an die wir gebunden sind, gleiten von dem ab, was über alles Sein und Nichtsein erhaben ist. Und in kurzen, schlichten Worten erklingt es wie ein Hymnus auf dies Mysterium, auf die „Tiefe, Unermeßlichkeit, Unergründlichkeit" jenes Seins, das doch nicht Sein heißen kann. Ein buddhistischer Poet sagt:

„Den, der zur Ruhe ging, kein Maß ermißt ihn. Von ihm zu sprechen gibt es keine Worte.

Verweht ist, was das Denken könnt' erfassen.

So ist der Rede jeder Pfad verschlossen."

Dies Unausdenkbare, Unsagbare erlebt der Heilige, der nur äußerlich noch mit dem Nichtich seines gleichgiltigen Körpers der Welt angehört. Und vielleicht mochten ekstatische Visionen, die sich über die Sphären der „Raumunendlichkeit" oder der "Nichtirgendetwasheit" zum letzten Gipfel erhoben, dem Entrückten dort das Unaussprechliche leibhaftig in seiner vollen Glorie offenbaren. 
Eine geistvolle Forscherin hat den buddhistischen Heiligen, der sich am höchsten Ziel weiß und nun gleichmütig dem Ende seines Erdenlebens, dem Jenseitsrätsel, entgegenblickt, einem Wanderer verglichen, der nach schweren Mühen und Gefahren zur Heimat gelangt ist; dessen freut er sich für heute, was immer auch das Morgen ihm bieten oder von ihm fordern wird. Und soll doch gefragt werden so sagt man uns weiter -, wie sich das Geheimnis dieses kommenden Tages dem buddhistischen Glauben im letzten Grunde darstellen mochte, so tritt uns hier vielleicht ein alter Versuch entgegen, einen Ausdruck für jenes Naturgesetz zu finden: die höchsten, vollkommensten Entwicklungen, wie die des Genies, arbeiten nicht darauf hin, sich fortzupflanzen, sondern ihre Blüte $\mathrm{zu}$ entfalten und dann zu sterben $\left.{ }^{1}\right)$.

Ist es hier wirklich gelungen, den Nachhall der Gedanken und Stimmungen ungetrübt aufzufangen, die vor Jahrtausenden jene ewigkeitsdurstigen Seelen erfüllten? Mir scheinen die alten Zeugnisse, insonderheit die, denen wir soeben begegnet sind, andre Deutung zu verlangen.

Nicht für heute allein fühlt sich der Heilige am Ziel. Er läßt keinen morgenden Tag für sich selbst sorgen. Nein, jenseits von allem Wechsel des Heute und Morgen weiß er sich. Gleichgiltig wann der leibliche Tod kommt; er trifft nur fremde Gebilde des Naturlaufs. Die Tragödie der Vergänglichkeit, in die Hohes und Geringes ohne Unterschied verflochten ist, spielt doch nur in dieser Welt. Der Vollendete gleicht nicht der Blume, die blüht und dann verwelkt. Es gehört nicht zu seiner Vornehmheit, das Siegel des Todes an sich zu tragen. Er weilt in jenseitiger, todentnommener Ordnung der Dinge. Doch deren Mysterium auszusprechen ist keinem menschlichen Wort gegeben.

Bedeutet nun die Vorstellung des Buddhismus von

1) Ich spreche hier von ÄuBerungen in dem schönen und tiefen Buch von Mrs. Rhys Davids, Buddhism, a study of the Buddhist Norm (S. 187. 171). 
diesem Jenseits eine Verabsolutierung individuellen Seins wie im späteren Sāṃkhya (oben S. 253 f.), oder schwebt ein universelles absolutes Sein vor, in dem das Geheimnis der Vollendung verwirklicht ist? Aus der Weise, wie der Buddhismus diesen Kreis von Problemen behandelt oder vielmehr ihn zu behandeln ablehnt, folgt, daß die Vorstellungen, nach denen hier gefragt wird, sich uns nur durch eine Nebelhülle abzeichnen können. Aber die Spuren, die erkennbar scheinen, deuten doch wohl vielmehr darauf, daß ein über die Grenzen des Individuums unendlich hinausreichendes universelles Sein vorgeschwebt hat. Ein Absolutes, selbstverständlich nicht als Weltgrund: schon weil man ja keinen Antrieb fühlte nach einem Weltgrunde offen oder versteckt $\mathrm{zu}$ fragen. Aber ein Absolutes als letztes, höchstes Ziel. Gleich dem Brahman, welches das „Nein Nein" hieß, benennt man es mit Verneinungen. Es ist „weder Kommen noch Gehen noch Stehen, weder Sterben noch Geburt. Ohne Grundlage, ohne Fortgang, ohne Halt ist es." Es ist "das Ungeborene, Ungewordene, Ungemachte, Ungestaltete." Wo das Ziel so durchaus jenseits menschlichen Erkennens liegt, ist es begreiflich, daß die Sprache es liebte, in der Bildung des Schlagworts, das hier die Vorstellung stützen konnte, sich nicht an jenes Ziel selbst $\mathrm{zu}$ halten, sondern vielmehr an den Vorgang des Hinausgehens aus der Welt zu ihm hin. Anders als für die Lehren, die vom Brahman, vom Purusha sprechen konnten, steht darum für den Buddhismus eine Benennung jenes Hinausgehens im Vordergrund: das Wort, das uns schon als Besitztum des Yoga begegnet ist, "Verwehen" - Nirvāna. Und wo dann doch von dem Ziel selbst die Rede ist, wird mit Vorliebe dem Wort Nirväna die Rolle übertragen, auch jenes zu bezeichnen. "In das Nirvāṇa", heißt es, "senkt sich der heilige Wandel hinein. Das Nirvāṇa ist sein Ziel. Das Nirvāna ist sein Ende." Und ein Dichter sagt:

"Wo's kein Etwas, kein Festhalten gibt, die Insel, die einzige, Sie heißt mit Namen Nirvāṇa, die Alter-Tod-entnommene." 
So redet die Dogmatik vom "Nirvāṇaelement" (nibbānadhātu); daneben, mit ähnlicher Hypostasierung des Vorgangs, der aus der Welt ins Jenseits hinüberführt, vom „Element der Aufhebung" (nirodhadhātu); man spricht vom "Verwehen in dem restlosen Nirvānaelement", als wäre von einem Ort die Rede. ${ }^{200}$ Unter den Wesenheiten der diesseitigen Welt läßt sich nach einem späteren Text (Milindapanha) namentlich der Äther - das Wort bezeichnet zugleich den Raum dem Nirvāna vergleichen. Beide sind von den Bewegungen des Entstehens und Vergehens unberührt, durch nichts zu hemmen und unendlich.

In diesem Zusammenhang möge insonderheit noch ein charakteristisches, für die Geschichte der Lehre wichtiges Element dieser Terminologie erwähnt werden: das Wort upadhi, wörtlich "Unterlage" oder "Unterlegung".. ${ }^{201}$ Es ist das Gegenteil von Nirvāṇa. Das volle Nirvāṇa ist das, „bei dem kein Rest von upādi (upadhi) da ist". ${ }^{208}$ "Trennung von den upadhi wird das Unsterbliche, das Nirvāṇa genannt." Inmitten der buddhistischen Terminologie macht upadhi den Eindruck von etwas Fremdem. Es ist kein lebendig funktionierendes Glied der dogmatischen Maschinerie. Man versteht nicht, in welchem Sinn hier von "Unterlagen" die Rede ist. So hat man es in diesem Wort offenbar mit etwas von außen Aufgenommenem, eben nur Beibehaltenem zu tun. Nun wird im klassischen Sāṃkhya und im Vedānta der Terminus upādhi, an dessen wesentlicher Identität mit upadhi kein Zweifel ist, von den „Unterlegungen" gebraucht, durch die das Jenseitige - Purusha oder Brahman - zum empirischen, dieser Welt angehörigen Wesen zu werden scheint: das Jenseitige erhält so zu sagen eine materielle Unterlage und erscheint dadurch materialisiert. Ähnlich spricht man davon, daß aus dem unendlichen Äther = Raum endliche Raumgebilde abgegrenzt werden, indem jener mit den körperlichen Objekten als upädhi's in Verbindung tritt. In all dem ist die Vorstellung von upädhi vollkommen klar. So ist nicht zweifelhaft, daß sie auf den Buddhismus aus 
derartiger älterer Umgebung übergegangen ist: dort muß von einem Wesen die Rede gewesen sein, welchem die upa $\bar{d} h i$ 's "untergelegt" wurden: offenbar einem Jenseitigen, Absoluten, für dessen Herabziehung ins Diesseits man sich jenes im Buddhismus verwischt erscheinenden Ausdrucks bediente.

In verschiedensten Weisen haben wir so aus dem Schleier, mit dem die Buddhalehre die Vorstellung eines Jenseitigen nur halb verhüllte, Bruchstücke von Umrissen sich herausheben gesehen. Meist sind es stehengebliebene Reste aus älteren Gedankenkreisen, so daß von ihnen Licht auf die Vorgeschichte des Buddhismus fällt. An mancher Stelle tritt dabei der alte Gedankeninhalt noch so deutlich hervor, daß Erhaltung auf buddhistischem Boden kaum denkbar schiene, wäre nicht auch hier, trotz alles pflichtmäßigen Strebens nach Ausschaltung der transzendenten Probleme, doch im letzten Grunde dasselbe Verlangen wie bei den älteren Denkern nach einem ewigen Jenseits lebendig gewesen.

Die Frage, wie der Buddhismus das Verhältnis dieses Ewigen zum Diesseits gedacht oder vielmehr in unbestimmtem Gedankenbild vorgestellt hat, ist schon gestreift worden. Es wurde bemerkt, daß das "Ungestaltete" nicht gleich dem Brahman als Weltgrund gelten konnte. Es stellte auch nicht gleich der platonischen Idee die Norm für die Gestaltungen der Welt dar. Die Erscheinungswelt ruht in sich, gehorcht ihren eigenen Gesetzen. Auch auf eine letzte, höchste, Diesseits und Jenseits in sich zusammenfassende Einheit, in welcher dann erst die Vorstellung des All voll verwirklicht gewesen wäre, konnte das Denken sich hier nicht richten: ein allzu weiter Schritt in die Regionen, in denen für die Erlösung kein Gewinn zu hoffen schien. Immerhin war unvermeidlich, daß man, wenn auch kaum in konsequentem Zusammenhang, der Erscheinungswelt doch eine Stellungnahme zum jenseitigen Ideal beilegte. Hier trat nun eine wohl begreifliche Antinomie auf. Einerseits 
fiel der Welt die Rolle zu, jeglicher auf das Ideal sich richtenden Bewegung feindlich $\mathrm{zu}$ widerstreben. In diesem Sinn wird aller Weltinhalt mit Māra, dem bösen Feinde, identifiziert. „Wo es ein Auge gibt und Gestalten, ein Ohr und Töne, wo es Denken gibt und Gedanken: da ist Māra, da ist Leiden, da ist Welt." Auf der andern Seite aber streben aus der Welt Erlösungsdurstige dem Heil zu. Diese Bewegung vollzieht sich innerhalb der Welt, wird von deren Gesetzen beherrscht. Da lag denn der Welt naturgemäß die Pflicht ob, die Träger jener Bewegung zu ehren, zu fördern. Es verstand sich für die religiöse Phantasie von selbst, daß Erscheinung und Tun dieser Heroen, ihre alluiberragende Bedeutung vom Mechanismus des Weltlaufs durch Wunderzeichen gefeiert werden mußte. Den Körper des Buddha stattet die Natur mit allen Zeichen höchster Herrlichkeit aus. Erscheinungen himmlischen Lichtglanzes, überirdisches Getön, Erdbeben begleiten die großen Ereignisse seines Lebens. Daß er durch zahllose Aeonen um die Buddhaschaft gerungen und es vermocht hat seinem Ziel immer näher zu kommen, ist durch das weltbeherrschende Gesetz des Karman bedingt, das hier in den Dienst weltverneinenden Erlösungsstrebens getreten ist. So haben auch die, die als Jünger eines Buddha an dessen Erleuchtung teilnehmen, durch das Karman die Schicksalsgunst oder vielmehr den Anspruch darauf erlangt, dem Erdenweg jenes Erhabenen zu begegnen. Darin, daß so das Weltleben dem Buddhismus als fähig erscheint, das vollendete Dasein Heiliger hervorzubringen, hat man einen gewissen Optimismus des Werturteils über die Welt gefunden. ${ }^{203}$ Das ist nicht ganz unrichtig. Nur übersehe man nicht, daß jenes Heiligentum für den Buddhismus keineswegs höchste Vollendung, feinste Blüte des Weltlebens bedeutet, sondern dessen Aufhebung. Jene optimistische Ansicht der Welt reduziert sich also darauf, daß die Welt, die höchst pessimistisch betrachtete, doch unter gewissen Voraussetzungen die Flucht aus ihrem eigenen Kerker ermöglicht, ja sie durch ihre Ge- 
setzmäßigkeit herbeiführen hilft. Um zusammenzufassen: es wäre viel $\mathrm{zu}$ viel gesagt, $\mathrm{da} \beta$ die Weltbewegung im Großen und in ihrer Ganzheit dem Jenseitsreich verbündet oder dienstbar ist. Es sind einzelne Aspekte, einzelne zerstreute Zuige, von denen in diesem Sinn gesprochen werden kann. Wieder wird fühlbar, was beständig hervortritt, daß der Buddhismus das Verhältnis der beiden Daseinsordnungen in vollem Zusammenhang durchdenken nicht gekonnt und vor allem nicht gewollt hat.

Hier halten wir inne. Die Stelle ist erreicht, zu der oben (S. 297) aufgeworfenen Frage zurückzukehren. Wenn ein Grundzug der buddhistischen Weltanschauung die zuletzt auf die alten Upanishaden zurückgehende Gegenüberstellung des Ewigen und Vergänglichen ist, tritt im Buddhismus Beeinflussung durch die spezielle im $S \bar{a}$ ṃkhya vollzogene Weiterentwicklung jenes Dualismus zu Tage?

Es müßten seltsame Zufälle im Spiel sein, wenn der Eindruck täuschte, daß diese Frage zu bejahen ist.

Betrachten wir zunächst das vergängliche Dasein, das Naturreich.

Diesem erkennt der Buddhismus, wie schon bemerkt wurde, volle Autonomie zu. Seine Bewegungen regieren sich selbst nach eignem Gesetz. Auch der Strom der geistig scheinenden Vorgänge gehört in Wahrheit dem Naturlauf an. Ist diese Weiterbildung der alten Upanishadenlehre innerhalb des Buddhismus oder auf einer uns unbekannten Vorstufe des Buddhismus selbständig vollzogen worden? Aber wir sehen sie ja im Sāmkhya genau mit dem eben bezeichneten Ergebnis sich vor unseren Augen vollziehen. ${ }^{1}$ )

1) Bei der eben berührten, in die Augen fallenden Übereinstimmung zwischen Buddhismus und Sāmkhya betreffs der Einbeziehung der psychischen Vorgänge in den Naturlauf ist nur ein Unterschied nicht zu übersehen. Auf der Seite des Sāmkhya sind jene an sich rein materielle Vorgänge; sie werden zu Bewußtseinsvorgängen erst, indem von der Seele her Licht auf sie fällt (Garbe Sāmkhya-Phil. 313). Die Licht 
So ist es die natürliche Annahme, daß sie von hier auf den Buddhismus übergegangen ist. Doch betont dieser energischer als das Sāmkhya die unweigerliche, gesetzmäßige Notwendigkeit, die den Bewegungen des Naturreichs innewohnt. Gehört das Verdienst dieses großen Fortschritts ihm selbst? Oder einer jener Zwischenstufen zwischen Sāmkhya und Buddhismus, deren Annahme schwer zu entbehren scheint? Etwa dem Yoga? Mit Sicherheit wird sich diese Frage, sofern nicht weitere Durchforschung vielleicht der Jainaquellen hier neue Aufschlüsse geben sollte, wohl nicht beantworten lassen.

In den Einzelheiten zwar gehen die Bilder des Naturlaufs im Buddhismus und Sāṃkhya weit auseinander, entsprechend der geschichtlichen Distanz beider Systeme. Wie durchaus verschieden die große Prinzipienreihe des Sāmkhya und die buddhistische Kausalitätsformel konstruiert ist, wurde schon erwähnt. Dabei ubrigens, daß der Buddhismus überhaupt eine solche Reihe aufgebaut hat, kann natürlich doch eine schließlich auf das Sāmkhya zurückgehende Anregung im Spiel sein. An eine fundamentale Differenz, die ebenfalls schon berührt wurde, sei hier nochmals erinnert. Das der erscheinenden Natur zu Grunde liegende, selbst nicht erscheinende Absolutum des Sāmkhya, die Prakṛti, ist aus der buddhistischen Lehre verschwunden. Sehr begreiflich. Hier liebte man es ja nicht, jenseits der Betrachtung des Erscheinungslaufes sich in Theoretisieren über letzte metaphysische Grundlagen zu ergehen. Und der Zug ewigen, substanziellen Bestehens, der dem Bild der Prakṛti beiwohnt, lief dem buddhistischen Interesse daran zuwider, in der Natur vor allem den Wirbel substanzlosen Entstehens und Vergehens aufzuzeigen. Mit dem Fehlen der Prakṛti wird dann wohl auch das der Guṇas zusammenhängen, die ja mit jener aufs innigste verwoben sind ${ }^{\mathbf{2 0 4}}$. Vielleicht wirkte

werfende Seele feblt dem Buddhismus: so muß hier der psychische Charakter den in Rede stehenden Vorgängen schon an sich, als Naturvorgängen, zukommen. 
mit, daß speziell dem ersten der drei Gunas, dem Sattva, ein relativ so günstiger, freundlicher Charakter zukam, daß die buddhistische Tendenz, die ganze Natur als durch und durch leidenvoll abzulehnen, durch die Gunalehre hätte beeinträchtigt werden können.

Nun zur andern Seite des Dualismus. Das Verschwinden des Ātman für den Buddhaglauben im Mysterium jener Region, nach welcher man nicht fragen soll, bereitet sich offenbar im Sāmkhya vor. Indem dort die Natur Herrin ihres eignen Reiches wird, entäußert sich ja das Selbst seiner königlichen Gewalt; es beschränkt sich auf die Rolle des draußenstehenden, nicht handelnden Zuschauers. Und wo in der buddhistischen Lehre doch der Ätman, den man positiv nicht verkünden will, als Besitzstück einer geschichtlich zu Grunde liegenden Doktrin durchscheint, zeigt sich wieder das charakteristische Aussehen des Sāmkhya. Es handelt sich ja für den Buddhismus nicht um Spuren eines Ātman, dessen Rolle es wäre, in der Natur mit souveräner Macht zu walten oder gar, wozu das Absolutum der alten Spekulation bisweilen neigt, selbst die Natur zu sein. Sondern von der Natur läßt ihn der Buddhismus sagen: „Das ist nicht mein. Das bin ich nicht. Das ist nicht mein Selbst" - fast wortgetreu ${ }^{\mathbf{3 0 5}}$ gleich der ebenfalls in dreigliedriger Formel niedergelegten Erkenntnis, die dem Purusha des Sāmkhya zuteil wird: "Ich bin nicht. Nichts ist mein. Dies ist nicht Ich". So stellt sich für den Buddhismus, wenigstens in dieser mit großem Nachdruck von ihm ausgesprochenen Formulierung, die erlösende Erkenntnis dar als das Durchschauen einer vorher verborgen gewesenen Unterscheidung: ganz im Sinn des Sāṃkhya, wo auch Unterscheidung (viveka), und zwar eben dieselbe Unterscheidung, zur Befreiung vom Weltleiden führt, und nur insofern vom Sāmpkhya abweichend, als das von der Welt sich unterscheidende Selbst in der buddhistischen Lehre vom Nebel des Geheimnisses, des Nichtoffenbartseins durch Buddha verhüllt wird. Wenn dann 
aber doch von einer gewissen Beziehung zwischen Ewigem und Vergänglichem die Rede sein muß, so bedient sich, wie wir schon erwähnten, das Sāmkhya jenes in diesem System vollkommen verständlichen Wortes upādhi "Unterlage", das der Buddhismus (upadhi) gleichfalls als Bezeichnung des die Erlösung ausschließenden Vergänglichen aufgenommen hat: nur daß auf buddhistischer Seite - bezeichnend für das Entlehntsein dieses Ausdrucks aus fremder Quelle - durchaus im Dunkeln bleibt, was für einer Wesenheit denn diese "Unterlage" untergelegt ist.

So haben wir alles Recht, die Lehre, die hinter fundamentalen Vorstellungen des Buddhismus, wohl nicht als nächster, aber doch als entfernterer Hintergrund, zum Vorschein kommt, Sāṃkhya zu nennen. Freilich ist es nicht klassisches Sāṃkhya; es ist offenbar erst auf dem Wege, den definitiven Typus anzunehmen. Dafür ist zwar nicht entscheidend, daß wir diesen Typus nur in fraglos nachbuddhistischer Gestalt kennen: vor allem in der modern eleganten Darstellung der Sāṃkhya Kārikā. Hier kommt es ja aber nicht auf die Texte und ihr höheres oder geringeres Alter an, sondern auf die Lehren. Und da scheint mir nun zur Charakteristik des Sāṃkhya, das den Buddhismus beeinflußt hat, zuvörderst dies beizutragen, daß für den letzteren das Ewige, Absolute - soweit dessen oben besprochene Verschleierung von ihm zu reden erlaubt - noch nicht wie im klassischen Sāmkhya in die Vielheit individueller Seelen zerfallen ist. Im Diesseits zwar spielt selbstverständlich, wenn nicht in der buddhistischen Lehre selbst, so doch hinter ihr und durch sie hindurch sichtbar, das individuelle Selbst einer jeden Person seine Rolle. Aber in dem Jenseits, zu dem das "Verwehen" des Nirvāna führt, herrscht die eine Unermeßlichkeit des „Ungeborenen, Ungewordenen, Ungemachten, Ungestalteten “. Ein zweiter Punkt, an dem der Buddhismus von einer bedeutsamen Neuerung des klassischen Sāmkhya unberührt scheint, ist der folgende. Dies System, indem es alles Fühlen, alles Leiden unter die Vorgänge der 
materiellen Welt rechnete, hat die schließlich unvermeidliche Folgerung gezogen, daß es in Wahrheit gar nicht der Purusha ist, der gebunden oder erlöst wird (S. 249). Gebunden und erlöst wird vielmehr die Prakṛti. Wie sich die dem Buddhismus zu Grunde liegende Form des Sāṃkhya zu diesem Problem gestellt hat, ist zwar mit vollkommener Bestimmtheit begreiflicherweise nicht zu sagen. Doch wird man aus der ganzen Haltung der buddhistischen Texte den Eindruck empfangen, daß die natürliche, zunächst sich darbietende Vorstellung in jenem Sāmkhya durch die dialektische Konsequenz noch nicht zerstört war: es ist das Selbst, das gebunden ist und durch Leiden getroffen wird. Durch wirkliches, echtes Leiden. Nicht nur durch einen Widerschein, den das Spiel eines künstlichen Mechanismus von der Natur her auf das Selbst fallen läßt. Um den Standpunkt des alten Sāṃkhya wird es sich handeln, wie ihn die Maitrāyaṇa Upanishad (VI,30) definiert: „Es ist der Purusha, der gebunden ist, indem er Entschließen, Bedenken, Fürsichwollen als Linga (vgl. S. 238) besitzt, und der, wenn das Gegenteil gilt, gelöst ist $\left.{ }^{1}\right)$."

Von den Zusammenhängen des Sāṃkhya mit dem Buddhismus gehen wir nun zu denen des Yoga über. Daß solche in großer Stärke bestanden haben, ist längst erkannt. ${ }^{206}$

1) Die theoretische Konstruktion des Buddhismus ist hier freilich nicht klar, und sie kann es nicht sein, da gerade das von der buddhistischen Spekulation für unberührbar erklärte Gebiet in Frage kommt. Aus Äußerungen wie der S. 305 wiedergegebenen Rede könnte man allerdings herauslesen, da $B$ eben nur das Nichtselbst leidet, so da $B$ allein vermöge eines Irrtums das Leiden jenem Rätselhaften zugeschrieben werden kann, das wie ein Selbst durch jene Rede durchscheint und doch nicht „Selbst" heißen darf. Die Prämissen, von denen aus das Sāṃkhya schlieblich zur Konsequenz des auf bloßen Reflexen beruhenden Leidens gelangt ist, kehren hier in der Tat wieder. Für den Buddhismus aber wäre ein Verfolgen des Problems soviel gewesen wie ein Sichverlieren in unnützer Dialektik. Und die Weise, wie er vom Leiden spricht, klingt durchaus danach, daß er an solche Verflüchtigung nicht gedacht hat. 
Man ist sogar soweit gegangen, den Buddhismus gerade$\mathrm{zu}$ als einen Zweig des Yoga aufzufassen ${ }^{\mathbf{3 0} \text {. }}$

Mit scheint damit $\mathrm{zu}$ viel gesagt.

Eine vollkommen bestimmte Formel, nach der man suchen möchte, für das Verhältnis von Erkennen und yogaartiger Versenkung im buddhistischen Erlösungsstreben läßt sich wohl kaum finden. Hier haben offenbar geschichtliche Verhältnisse eine Figur hervorgebracht, die auf reine Konsequenz des Gedankens nicht zurückzuführen ist.

So viel zunächst steht außer Zweifel, daß planmäßig herbeigeführte Versenkungen im Leben vieler Jünger und, darf man höchst wahrscheinlich hinzufügen, des Meisters selbst eine bedeutende Rolle gespielt haben ${ }^{208}$. Durch Versenkung, sagt ein oft wiederholter Satz der Texte, wird der Geist „gesammelt, gereinigt, geläutert, gelöst von Befleckung, gelöst von allem Verderben, geschmeidig und zum Werk geschickt, fest und ohne Wanken." In der vierten, höchsten Stufe der Versenkung wird man des Verkehrs mit den Geistern höherer Welten teilhaftig. Es ist eine - wenn der Ausdruck statthaft scheint - in der Erkenntnistheorie dieses Zeitalters wohl allgemein verbreitete Anschauung, daß zu höherem Wissen zwei Wege führen. Entweder hat „ein Śramana oder Brahmane durch heißes Streben, durch Anstrengung, Bemühung, Wachsamkeit, rechtes Aufmerken des Geistes eine so gestaltete Konzentration (samādhi) seines Innern erreicht", daß ihm die betreffende Erkenntnis zuteil wird. Oder anderseits hat er sich „dem Nachdenken und Prüfen hingegeben", und bei ihm stellt sich „durch Nachdenken gewonnen, von Prüfen durchzogen“, jene Erkenntnis ein. Die höchste Erkenntniserlangung, von welcher der buddhistische Glaube weiß, die den Buddha zum Buddha gemacht hat, soll durch ekstatische Versenkung erreicht worden sein. Nachdem der auf die Buddhaschaft Hinstrebende die Vergeblichkeit der von ihm geübten Selbstpeinigungen durchschaut hatte, führte ihn die Erinnerung an einen im Jugendalter erlebten Versenkungs- 
zustand (jhāna = skt. dhyāna) auf diesen Weg; so sind ihm in jener Nacht unter dem Baum an der Nerañjarā die vier heiligen Wahrheiten offenbar geworden. Und aus ebensolcher Versenkung läßt der Bericht über sein Ende ihn unter den Zwillingsbäumen an der Hirañnavatī zum Nirvāna eingehen. So zeigen ihn die Texte denn auch nicht selten zwischen dem einen und dem andern dieser allerfeierlichsten Zeitpunkte in ähnlichen Zuständen. Er bringt die Regenzeit in der trefflichen und freudenreichen, das Böse vertreibenden Übung der "Wachsamkeit auf Einatmen und Ausatmen" zu: man erinnert sich an das Gewicht, das im Yoga auf die Atemdisziplin fällt. Oder er sitzt, wie die buddhistische Plastik ihn so oft darstellt, in der Berghöhle, und der Götterkönig, der ihn besuchen will, sagt: „Schwer zugänglich sind Vollendete für unsereinen, wenn sie in Versenkung eingegangen sind und in Versenkung verharren." Was aber von Buddha selbst gilt, gilt von vielen der Mönche überhaupt. Die poetischen Selbstbekenntnisse und Erinnerungen (Theragāthā), die einer Anzahl heiliger Jünger zugeschrieben werden, gedenken oft der Versenkungen, die diese durchlebt haben. Da wird die Einsamkeit gepriesen, in die man sich zurückzieht, „wie der geflügelte Vogel, wenn die Regen kommen", Berghöhlen und Wald, wo Pfauenruf und der Schrei der Elefanten ertönt: die Stätten tiefsten Glückes für den nach heiliger Schauung trachtenden Mönch,

„Der an Baumeswurzeln ins Dickicht taucht hinab, Der in Herzenstiefe Nirvāna senkt hinein."

Man sollte im Bilde des Buddhismus nie diesen Zug übersehen: aus dem Durchdenken dessen, was zur Erlösung führt, war man gewohnt - waren Viele gewohnt - immer wieder in die mystischen Unergründlichkeiten des vom Yoga dargebotenen Erlebens hinabzutauchen. Dem Zug dahin konnte die Kraft nicht dadurch gebrochen werden, daß der Gedanke an das Selbst, entscheidend für den Yogin, vom Buddhismus abgewiesen wurde. Die Loslösung von der Welt des Nicht-Selbst stand ja hier als ein ebenso ernstes 
und erhabenes Ziel da wie im Yoga. Und wenn es auch nicht das Selbst hieß, das der Versenkte in sich schaute: jene Losgelöstheit mochte darum doch nicht minder als von der Glorie und Seligkeit des jenseitigen Überseins erfüllt empfunden werden, das Worte nicht aussprechen konnten, nicht auszusprechen brauchten.

Die yogaartigen Übungen, die eine so bedeutsame Rolle im geistlichen Leben und Streben spielten, wurden vom Buddhismus denn auch in der Theorie dieses Strebens natürlich nicht übergangen. Der Heilsweg, so lehrte man, verläuft durch drei Stationen: Rechtschaffenheit, Konzentration - wohin auch die Versenkungen gehören - und Weisheit d. h. Erkenntnis. Eins bedingt und fördert das andre. Keine Versenkung (jhāna), wird im Dhammapada gesagt, ohne Weisheit; keine Weisheit ohne Versenkung: in wem Versenkung und Weisheit wohnt, der ist dem Nirvāna nahe.

Man darf doch, scheint mir, einen solchen Sinnspruch nicht allzu wörtlich verstehen, nicht die völlige Gleichwertigkeit von Versenkung und Erkennen aus ihm herauslesen. Einzelne, ja viele mochten den Weg der Versenkungen beschreiten. Als allgemeine Regel für eine große Gemeinde war das selbst in Indien nicht denkbar. Gewiß soll die Bedeutung der Yogaübungen für den Buddhismus hier nicht verkleinert werden. Aber es ist doch unleugbar, daß ganz andrer Nachdruck durchweg in den Texten auf die Probleme des Erkennens fällt, auf das was als letzte, höchste unter jenen drei Stationen "Weisheit" heißt. Der Vorstellungskreis, der die Versenkungen betrifft, pflegt mit wenigen festen Formeln erledigt zu werden. Auf die Gegenstände des Erkennens richtet sich fast die Gesamtheit der Sūtratexte: wenn man es in brahmanische Ausdrucksweise übertragen dürfte, auf die Fragen des Sāṃkhya, nicht des Yoga. Das „Nichtwissen “ ist das Grundübel ${ }^{1}$ ). Buddha sagt: „Wegen

$\left.{ }^{1}\right)$ Ich übersehe nicht, daß das einer Formel eben des Yoga entspricht; darauf ist weiter unten (S. $328 \mathrm{f}$.) zurückzukommen. 
Nichterkennens, Nichtdurchdringens der vier heiligen Wahrheiten, ihr Jünger, mußten wir, ihr und ich, den langen Weg (des Samsāra) durchlaufen und durchirren." So ist es die Erkenntnis, die das Leiden an seiner Wurzel trifft. Von den beiden großen Formeln, die der maßgebendste Ausdruck dieser Erkenntnis sind, gedenken die eben erwähnten vier heiligen Wahrheiten der Versenkungen nur in zwei Ausdrücken des vierten Satzes, indem unter den Gliedern des achtteiligen "Weges zur Aufhebung des Leidens" "rechtes Gedenken, rechte Konzentration" genannt wird; die andre Formel, die des Kausalitätsnexus, stellt in derVerkettung ihrer zwölf Glieder, von der ersten Ursache, dem Nichtwissen, bis zur letzten Wirkung, dem Leiden und Sterben, die Entstehung und entsprechend die Aufhebung des Weltleidens dar ohne das Gebiet der Versenkungen irgend zu berühren. Auch an die oben (S. 305f.) wiedergegebenen Predigten darf hier erinnert werden. Wer erkennt, daß aller Inhalt dieser Welt vergänglich, leidenvoll, nicht das Selbst ist, oder wer erkennt, daß jenes alles von den Flammen des Leidens verzehrt wird, wendet sich davon ab und wird erlöst: wieder eine Beschreibung des Erlösungsvorgangs, die es allein mit Erkenntnis, nicht mit Versenkung zu tun hat ${ }^{209}$. Zwar glaubt man, wie wir erwähnten, daß der Erste aller Erkennenden, der Meister selbst, zum erlösenden Wissen eben durch Versenkung gelangt ist. Aber das bedeutet nicht, daß man diesen Zugang als den einzigen angesehen hätte. Erzählungen genug vom Erwerb der Erkenntnis und Erlösung durch Jünger liegen vor, in denen jede Vorstellung vom Hindurchgehen durch solche Ekstasen, wie Buddha selbst sie in der entscheidenden Stunde erlebt haben soll, deutlich ausgeschlossen ist.

Möchte es hier gelungen sein, von der Rolle yogaartiger Betätigung im Buddhismus ein Bild zu geben, bei dem das Zuviel wie das Zuwenig in gleicher Weise vermieden ist. Bestrebt, alle über das Irdische hinausdrängenden Kräfte zu sammeln, hat man in buddhistischen Kreisen, wie das 
im damaligen Indien absolut selbstverständlich war, dem reinen Glück, der läuternden und erleuchtenden Macht jenes weltentnommenen Schwebens im Unendlichen „dem Nirvāna nahe" sehr hohe Bedeutung zuerkannt. Aber ein bloßer Zweig des Yoga ist der Buddhismus darum doch nicht gewesen. Er war viel mehr.

Im Einzelnen zeigen sich zwischen den Formulierungen des Buddhismus und des Yoga zahlreiche gewichtige Übereinstimmungen. Beständig wird da eine Nähe fühlbar, die sehr bemerklich mit der in den meisten Punkten obwaltenden Entfernung zwischen der buddhistischen Terminologie und der des Sāṃkhya - freilich nicht so zwischen den Grundanschauungen beider Lehren - kontrastiert.

Zunächst auf dem eigensten Gebiet des Yoga, dem der Versenkungen, entsprechen den vier jhāna ("Versenkungen“) des Buddhismus im Yoga ebenso viele Stufen des „bewußten samādhi" ("Konzentration"), und die psychologischen Kategorien, die auf beiden Seiten diese Stufen charakterisieren, stimmen zum nicht geringen Teil überein. Besonders bezeichnend ist Folgendes: an einer Stelle, wo zufällig mit Hilfe eines Mahābhārataverses die betreffende Lehre über das Yogasūtra - hier unsre Hauptquelle - sich in ältere Zeit zurückverfolgen läßt, akzentuiert sich alsbald der Einklang mit dem Buddhismus noch weit schärfer. Das Epos spricht vom ersten dhyāna $(=$ Pāli jhāna):

,Überlegung, Sichabsondern und Erwägung erscheint alsdann,

Wenn der Weise sich tief sammelt in der Versenkung (dhyāna) erstem Grad.“

Das klingt geradezu wie eine versifizierte Abkürzung der Formel des ersten jhāna, die zu unzähligen Malen in den buddhistischen Texten wiederholt wird: „Der Mönch, sich absondernd von Lüsten, sich absondernd von unrechtem Wesen, erreicht das mit Erwägung verbundene, mit Überlegung verbundene, aus Absonderung geborene, Freude und Wohlbefinden enthaltende erste jhāna." "\$10 
Nicht weniger bemerkenswert ist, daß die neben der Hauptreihe der Versenkungen stehenden, ebenfalls eine festgeschlossene Serie bildenden Kontemplationen der „Freundschaft" (mit allen Wesen), des „Mitleids", der „Fröhlichkeit" und des "Gleichmuts" (vgl. oben S. 263) im Yoga und Buddhismus vollständig identisch auftreten: Sodann ist hinzuweisen auf die Übereinstimmung des Yogaausdrucks ,Hingelangen zur Unendlichkeit" mit dem buddhistischen „Hingelangen zur Raumunendlichkeit“, „Hingelangen zur Erkenntnisunendlichkeit".".11 Weiter sei bemerkt, daß der Yoga als Voraussetzungen für Erreichung der Versenkung den Besitz von „Glauben“, „Kraft", „Gedenken“, „Konzentration", „Weisheit" nennt: genau dieselbe Reihe findet sich bei den Buddhisten. So in der Erzählung, wie der werdende Buddha - noch vor Erreichung des höchsten Zieles sich der geistlichen Leitung des Ālāra Kālāma, dann des Uddaka anvertraut. Hier handelt es sich eben um Versenkungszustände, die der "Nichtirgendetwasheit" und des

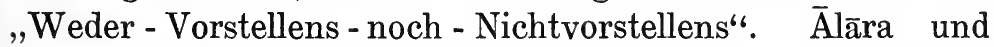
Uddaka wissen diese Zustände zu erreichen; der Schüler traut sich dasselbe $\mathrm{zu}$ und spricht $\mathrm{zu}$ sich: „Nicht allein Ālāra Kālāma (bez. Uddaka) hat Glauben; auch ich habe Glauben. Nicht allein Ālāra Kālāma hat Kraft ... Gedenken ... Konzentration ... Weisheit; auch ich habe Kraft usw.": so will er es denn den Lehrern in jenen Versenkungen gleichtun. Man sieht, wie hier dieselben fünf Tugenden in derselben Reihenfolge erscheinen, in der auch der Yoga sie aufzählt. Und auch hier spielen sie die nämliche Rolle wie dort: sie haben die Eigenschaft, ihren Besitzer zur Erreichung von Versenkungen geschickt zu machen. All dem sei endlich noch hinzugefügt, daß, wenn von Versenkungen und Verwandtem die Rede ist, der Buddhismus mit einer gewiß nicht zufälligen Vorliebe für das dabei funktionierende Seelenorgan denselben Terminus braucht, der speziell auch im Yoga dafür stehend ist: citta. $^{\mathbf{2 1 2}}$

Fragt man, auf welcher Seite diese gemeinsamen Be- 
griffe und Lehren zuerst geformt sind, so spricht offenbar eine Wahrscheinlichkeit, die der Gewißheit nah kommt, für den Yoga. In der buddhistischen Überlieferung wird es deutlich fühlbar, daß3 man hier solche Übungen und Theorien nicht als etwas Selbstgeschaffenes oder als speziellen eignen Besitz für sich in Anspruch nimmt. So wird, vielleicht der Wahrheit entsprechend, jenen beiden Lehrern des Buddha - aus der Zeit als er noch der Buddhaschaft entgegenging - die Kunst bestimmter Versenkungen beigelegt, ihm selbst dagegen keine eigne Produktivität auf diesem Gebiet zugeschrieben oder mindestens solche Produktion nicht betont. ${ }^{218}$ Man spricht von „Samanas und Brahmanen“, welche die Vollendung ("Nirvānaa") durch eins der vier jhāna zu erlangen glauben: diese werden also deutlichermaßen auch als Nichtanhängern des Buddha bekannt und zugänglich angesehen. ${ }^{214}$ Wenn für die Kontemplationen der „Freundchaft (mit allen Wesen)" usw. (S. 325), die übereinstimmend vom Buddhismus und Yoga vorgeschrieben werden, der Buddhismus die Bezeichnung als „Brahman-Zustände“ bewahrt hat, so deutet das, wie längst erkannt ist, ${ }^{216}$ offenbar auf brahmanische Herkunft, vermutlich auf den Yoga als Ursprungsstelle. Überhaupt ist es doch auch das Natürliche, daß die Ausbildung von Versenkungsübungen und Verwandtem - mindestens im Großen und Ganzen - da erfolgt ist, wo man um seines höchsten Heils willen alle Kräfte in dieser Richtung betätigte, nicht aber da, wo neben andern Richtungen des Strebens auch diese nun einmal vom herrschenden Glauben des Zeitalters empfohlene mit aufgenommen wurde.

Vermutlich sind Einflüsse des Yoga auch noch in andern Hinsichten wirksam gewesen, die Struktur und innere Stimmung des buddhistischen geistlichen Lebens gestalten $\mathrm{zu}$ helfen. Vom Yoga konnte man die Kunst lernen, den geistlichen Fortschritt von allen Seiten her planmäßig vorzubereiten und zu fördern, alle Fäden des Seelenlebens in seiner Hand zu sammeln und festzuhalten. Die Stellung- 
nahme des Yoga mag mitgewirkt haben, das Urteil des Buddhismus über die damals allerwärts so schwungvoll betriebenen Selbstquälereien in der Richtung zu fixieren, die ohnehin der seelischen Gesundheit Buddhas entsprach. Der Buddhismus lehnte jene als "leidenreich, unwürdig, nichtig“" ab und lehrte, in innerer Freudigkeit den geistlichen Zielen nachstreben, ihre Erreichung genießen. Ganz die gleiche Stimmung herrscht auch im Yoga, in Äußerlichkeiten und im Innerlichen. Man soll, wie schon oben (S. 262) berührt wurde - allerdings erst spätere Yogatexte schreiben dies ausdrücklich vor - sich nicht mit Fasten abgeben, sondern einfache und ausreichende Nahrung zu sich nehmen. Man soll, sagt die Śvetāśvatara Upanishad (s. oben S. 262), an angenehmer, dem Auge und Geist wohlgefälliger Stätte seine Übungen betreiben. "Gesundheit, Leichtigkeit" wird dem Yogin zuteil (S. 265). Wonnegefühl erfüllt den Versenkten noch auf der dritten Stufe der Versenkung, um erst auf der vierten zu schwinden. Damit vergleiche man, daß der werdende Buddha nach Zeiten fruchtloser Kasteiung, härtesten Fastens erkannt haben soll, daß er mit so entkräftetem Körper die Versenkungen, denen er sich jetzt zuwendet, nicht wird erreichen können; er muß Nahrung zu sich nehmen. Weiter, daß er die Stätte für seine Askese mit den Worten wählt: ,Wahrlich dies ist ein lieblicher Fleck Erde, ein schöner Wald; klar fließt der Fluß ... hier ist gut sein für einen Edlen, der nach dem Heil strebt.،216 Ganz im Ton des Yoga sagt einer der buddhistischen Ältesten:

„O wie leicht ist mein Leib, wie erfüllt ihn

Der Freude, des Wohlseins breites Strömen!

Wie Baumwollflocke im Windeshauch,

Also in Freiheit schwimmt mein Leib." -

Schwieriger als über diese Zusammenhänge ist das Urteil über etwaige Beeinflussung des Buddhismus durch den Yoga auf dem Gebiet der rein theoretischen Weltbetrachtung. 
Zuvörderst ist da zu bemerken, daß der für den Yoga oder doch für Hauptrichtungen des Yoga charakteristische Gottesglaube in den Buddhismus keinen Eingang gefunden hat. Allzu stark wurde hier die Naturnotwendigkeit alles Geschehens betont; allzu stolz fühlte man in sich die Kraft, selbst dieser Naturnotwendigkeit den Erlösungspreis abzugewinnen: da war denn für den in so unklarer Mittelstellung zwischen Diesseits und Jenseits schwebenden Helfer, den İ́vara, kein Raum.

Im Übrigen haben wir gesehen, daß das Weltbild der Buddhalehre in wesentlichen Beziehungen durch das alte Sāṃkhya bestimmt war, aber dieser Zusammenhang schien kein direkter, sondern durch vermittelnde Einflüsse bedingt. War, wie man vermutet hat, eben der Yoga der Vermittler? Hier läßt sich nur in unsicherem Ton sprechen. Wie gerade die Formen des Yoga, die den Buddhismus beeinflußt haben, theoretisch fundamentiert waren, wie sie sich insonderheit zur Sāmkhyalehre verhielten, ist uns ja nicht näher bekannt. Immerhin berührt sich die Weltkonstruktion des klassischen Yoga in einer Reihe von Punkten mit der des Buddhismus so nah, daß ein Zusammenhang der eben bezeichneten Art wohl glaublich scheint. Die allgemein indische Lehre von der Vergänglichkeit und dem Leiden alles Weltdaseins spricht der Yoga mit den Schlagworten „unbeständig, unrein, Leiden, Nichtselbst" aus, in vollkommener Übereinstimmung mit dem Buddhismus, wo oft und nachdrücklich, beispielsweise in jener Rede Buddhas an die ersten fünf Jünger, von allen Elementen des leiblichgeistigen Daseins nach einander gelehrt wird, daß sie ,ein Nichtselbst" und daß sie ,unbeständig, Leiden, dem Wechsel unterworfen" sind. Daß für das Grundúbel des Daseins der Buddhismus den Ausdruck "Nichtwissen“ aufstellt, kann sich gewiß aus der allgemeinen Richtung der indischen Spekulation hinreichend erklären. Es kann doch auch speziell damit zusammenhängen, daß im Yoga als erster der fünf kleśa („Plagen“, „Beschwerden“) das „Nichtwissen“ 
aufgeführt und als „Boden für die übrigen“ hervorgehoben wird, sowie daß man ferner dort als die Ursache der leidbringenden ,Verbindung“ der beiden obersten Weltprinzipien wiederum das Nichtwissen nennt. ${ }^{217}$ Weiter wurde schon oben darauf aufmerksam gemacht (S. 270), daß das Wort Nirvāṇa vielmehr dem vorklassischen Yoga als dem Sāṃkya anzugehören scheint: es erschien uns wenn auch nicht als Gewißheit, so doch als naheliegende Möglichkeit, daß Buddhismus wie Jainatum von dorther dies Wort übernommen hat. Ist Einfluß des Yoga, wie vermutet worden ist, auch dabei im Spiel, daß der Buddhismus die Grundformel seiner Lehre, die heiligen Wahrheiten, in vierfacher Gliederung aufbaut: Leiden, Entstehung des Leidens, Aufhebung des Leidens, Weg zur Aufhebung des Leidens? Für den Yoga ist die entsprechende Anordnung erst bei einem Kommentator des Yogasūtra nachweisbar, der die Lehre als in vier Teile zerfallend erklärt und sich dafür auf die Vierteilung der Heilkunde beruft. Die handelt von der Krankheit, der Ursache der Krankheit, der Genesung und dem Heilverfahren: ebenso habe es der Yoga mit dem Samsāara zu tun, mit der Ursache des Saṃsāra, mit der Erlösung und dem Wege zur Erlösung. So entschieden wir in der Lehre von den Versenkungen den Yoga als Quelle des Buddhismus erkennen, ist es damit doch vereinbar, daß in der eben erwähnten vierfachen Gliederung vielleicht der Buddhismus dem Yoga vorangegangen ist: es ist doch wohl nicht ganz ohne Gewicht, daß dies Motiv dort in der ältesten, grundlegenden Formel begegnet, hier viele Jahrhunderte später, keineswegs tief gewurzelt, allein in der vereinzelten Äußerung eines Kommentators.

Ähnlich unbestimmt muß das Urteil über andre Einzelheiten bleiben, die hier vorzulegen nicht beabsichtigt ist. Ich schließe mit der Erwähnung eines Verses, den ein Yogakommentar zitiert, und seiner Entsprechungen in der Literatur der Buddhisten. An der erstgenannten Stelle liest $\operatorname{man}^{218}$ : 
,Zu der Weisheit Palast steigend schaut leidlos auf die Leidenden

Der Weise, wie von Berghöhen man auf des Tals Bewohner schaut."

Die Buddhisten geben den Vers zunächst, in Pāli statt des Sanskrit, so gut wie wörtlich übereinstimmend. Sodann berichten sie, daß Buddha nach Erlangung der erlösenden Erkenntnis schwankte, ob er sie der Menschheit mitteilen soll; da ermahnte ihn Gott Brahman, der leidenden Welt zu gedenken, und sprach Verse, unter denen sich der folgende findet:

„Wie wer auf Berges Felsengipfel steht, Hinabblickt auf die Menschheit rings umher,

So zu der Wahrheit oberstem Palast

Steigend, du Weiser, Ringsumblickender,

Schau leidlos auf das leidgequälte Volk,

Das alter-tod-bewältigte hinab."

Wir können natürlich nicht feststellen, ob der Poet, dem der Gedanke dieses Verses zuerst aufging, ein Buddhist oder was sonst er gewesen ist. In ähnlicher Form wie in jenem Yogatext liest man den Vers auch im Mahābhārata. Er zeugt eben - und dasselbe gilt von manchen andern solchen poetischen Hervorbringungen - zwar nicht sicher für Übernahme fremden Gutes durch den Buddhismus, aber doch für die große gegenseitige Nähe der verschiedenen Asketenschulen, brahmanischer und nichtbrahmanischer, hinsichtlich ihrer Ausdrucksweise und ihres Vorrats an poetischen Bildern. Ein oft bis ins Kleine und Kleinste gehender Austausch muß da stattgefunden haben, in welcher Richtung im einzelnen Fall sich der auch bewegt haben mag.

Daß im Ganzen doch der Buddhismus überwiegend der entlehnende Teil gewesen ist, haben uns die Vergleichungen, mit denen wir uns beschäftigten, gelehrt. In herrschenden Tendenzen theoretischer Weltbetrachtung erwies sich das Sāmkhya, in vielen Zügen asketischer Praxis der Yoga als die Ursprungsstätte buddhistischer Lehre und geistlicher Übung. 
Erkennt man dies nun an, wie man es anerkennen muß, wird damit dem Buddhismus eigne, im Großen wirkende Schöpferkraft abgesprochen? Wird er zum Nachtreter fremden Vorangehens herabgedrückt?

Unsre Quellen, die Lücken unsres Wissens von so vielen halb, wenn nicht ganz verschollenen Gedankenschöpfungen jenes Zeitalters erlauben uns im Einzelnen Behauptungen darüber, was denn nun dem Buddhismus als selbstgeschaffener Besitz von Lehren oder Institutionen zugehört, meist nur unter aller Reserve aufzustellen. In der Betrachtung des Ganzen wird doch auf die eben gestellte Frage die rechte Antwort nicht verfehlen, wem nicht über dem Aufsuchen von Beziehungen, Einflüssen, Vorbildern der Blick für das Wirken des Genius verloren gegangen ist.

Auf dem Gebiet theoretischer Weltbetrachtung könnte als ein speziell buddhistischer Zug zunächst die frühe, energische Betonung der Herrschaft in Betracht kommen, welche die Kausalität über alles Geschehen übt. $\mathrm{Da} ß$ doch zweifelhaft bleibt, ob jener Fortschritt in der Tat eben in diesen Kreisen erreicht worden ist, wurde schon hervorgehoben.

Weiter die Auflösung alles in der Welt erscheinenden Seins in Geschehen, insonderheit die Auflösung der "Seele" in Reihen seelischer Vorgänge.

Wenn sich da nun auch unter den Reichtümern der Buddhareden manches eindringliche Wort findet, das der knapperen Überlieferung des alten Sāṃkhya und Yoga fehlt. der Gedanke selbst ruht schließlich doch ganz auf der allem Anschein nach dem Sāmkhya gehörenden Herausarbeitung des Gegensatzes von Sein und Werden. Und wir sahen (S. 328), daß der klassische Ausdruck dieses Gedankens in der buddhistischen Formulierung vom „Unbeständigen, Leiden, dem Wechsel Unterworfenen" nicht ohne Wahrscheinlichkeit auf ein Vorbild, das im Yoga erhalten ist, zurückgeführt werden kann. Wenn der Buddhismus speziell immer und immer wieder betonte, da $\beta$ im unbeständigen Fluß des Weltgeschehens - also auch im Fluß der Gefühle, Vorstel- 
lungen usw. - kein Selbst ( $\bar{t} t m a n, a t t \bar{a}$ ) enthalten ist, daß alles jenes Fließen ganz und gar im Bereich des Nichtselbst verläuft, so war das Sāmkhyalehre. Der Unterschied zwischen beiden Systemen war nur der, daß nun weiter das Sāmkhya, evidentermaßen hierin den älteren Standpunkt vertretend, neben dies Reich des Nichtselbst als davon unabhängig ein unwandelbares, absolutes Selbst stellte. Der Buddhismus dagegen - und damit ist nun wohl der Punkt erreicht, wo auf theoretischem Gebiet dessen, soviel wir sehen, durchaus ihm selbst eignes Verhalten vor allem zur Erscheinung kommt - hüllte das Selbst und überhaupt das außerweltliche, überweltliche Sein in jenen Schleier des Geheimnisses: "der Erhabene hat das nicht offenbart." Wer an positivere Sprache gewöhnt war, mochte daraus vor allem die Verneinung heraushören. "Er denkt so": wird von einem solchen einmal gesagt, ",so werde ich denn vernichtet werden; so werde ich zu Grunde gehen; so werde ich nicht mehr sein.' Und er wird bekümmert und elend; er jammert, schlägt sich weinend die Brust und verfällt in Verwirrung." "sı Damit war nun freilich die Absicht des Meisters nicht getroffen. Doch die Texte zeigen, daß es an solchen nicht fehlte, die sie richtiger zu treffen gewußt haben. Sie sahen zwar nicht mehr das jenseitige Wesen das Diesseits beleben und lenken, auch nicht das Diesseits beschauen und genießen. Wenn die Upanishad (oben S. 133) von dem Unerkennbaren gesagt hatte:

„Er ist' spricht man. Wie sonst würd' er als nur durch dieses Wort erfaßt?" -

so fanden sie selbst in einem „Es ist" noch zu viel Erdenrest. Aber sie hielten sich darum doch nicht an ein "Es ist nicht". Aus der Verneinung von Sein und Nichtsein, aus noch unergründlicheren Jenseitstiefen als das Brahman, als der Purusha, blickte die Ahnung des Nirvāna dem Frommen entgegen, der nicht sein Rätsel zu lösen, sondern darin zu verwehen trachtete. Wie das Denken dies Rätsel schweigend ruhen ließ, mag faustischer Begehr nach Er- 
kennen dessen „was die Welt im Innersten zusammenhält", schwächlich und kleinmütig scheinen. Aber wie ganz hatte doch der Buddhismus solches Begehren von sich abgetan. Eine eigne Größe, auch eine eigne Poesie wohnt dem inne, wie man hier vor dem verhüllten Bilde des Jenseits stand ohne das Verlangen, von der Herrlichkeit dessen, was kein Auge gesehen, den Schleier zu heben, und wie man doch eben diese Herrlichkeit still und beseligt in der eigenen Wesenstiefe erlebte.

Auch Sāṃkhya und Yoga haben das Ziel der Erlösung verfolgt. Aber bestimmter, umfassender, klüger abwägend als jene hat der Buddhismus feste Formen eines Lebens geschaffen, in dem Äußerliches und Innerliches auf das eine Ziel hin zusammenwirkt. Gewiß ist all das kein Schaffen aus dem Nichts. Und eine Vollendung, in der es von Unstimmigkeiten, von Unfertigkeiten nichts mehr gäbe, ist hier nicht erreicht worden. Im Ganzen aber, mit welcher souveränen Kraft und Freiheit wird das aus der Vergangenheit Übernommene beherrscht und an seinen Platz gestellt! Welch andre Wucht und alle Lebenstiefen durchdringender Ernst hier als in den geistvollen Betrachtungen, bei denen das Sāmkhya bald anlangte, über den lahmen Geist und die blinde Natur, die sich zweckmäßig verbinden, um dann am Ziel sich freundlich von einander $\mathrm{zu}$ trennen. Wie wird neben den Übungen des Yoga dem unpathologischen Natürlichen, dem rein Ethischen sein Recht gesichert. Wie wird alles Einzelne zu einer großen Lebenskunst zusammengeschlossen, zur Kunst des Lebens, das über das Leben hinausstrebt.

Und diese Kunst wird hier nicht mehr unter einsamen Virtuosen bizarren Asketentums oder in der Enge einer Schule getibt. Die fortschreitende geschichtliche Entwicklung hat dem Buddhismus und überhaupt den Sekten des altbuddhistischen Zeitalters die Aufgabe gestellt und die Kraft verliehen, größere und stärkere soziale Gebilde zu schaffen. Es wurde schon oben (S. 285) beruhrt, wie der 
Aufschwung städtischen Lebens dazu beitrug, den Zusammenhalt Gleichstrebender zu stärken, eine Gesinnung zu entwickeln, die auf die Interessen Vieler hinblickt. Längst haben die Schranken der Kaste gegenüber dem Verlangen nach den neuen geistigen Gütern ihre Macht verloren. Daß die Zahl der Erwählten doch keine große sein kann, weiß der Buddhismus wohl. Aber allen, die zu dieser Zahl gehören, soll und muß die Lehre dargeboten werden. Man fragt nicht mehr, wer sie zu empfangen die mystische Qualifikation besitzt. Sondern man fragt, wer seelisch fähig ist sie zu seinem Heil zu empfangen. „Es sind Wesen, die sind rein vom Staube des Irdischen, aber wenn sie die Predigt der Lehre nicht hören, gehen sie zu Grunde; die werden Erkenner der Lehre sein": so spricht Gott Brahman zu Buddha, um ihn zur Mitteilung des erlösenden Wissens an die Menschheit zu bestimmen; und bald sendet Buddha die ersten Jünger aus: „Zieht hin, ihr Mönche, und wandert, zum Heil für viel Volk, zur Freude für viel Volk, aus Erbarmen für die Welt . . . Predigt, ihr Mönche, die Lehre . . . im Geist und im Buchstaben; verkündet den ganzen und vollen, reinen Wandel der Heiligkeit."

Wo hatten die Denker der Upanishaden, des Sāmkhya und Yoga solche Sprache gesprochen? In ihr liegt der Keim von Wirkungen, die, sobald der Lauf der Geschichte die enge Umgrenzung des Schauplatzes zerbrach, ins Unabsehbare hinausstreben mußten und in der Tat ins Unabsehbare gelangt sind.

So schließen sich also, im Buddhismus wie in den ihm verwandten Gemeinschaften, die Weltentsagenden zusammen. Orden entstehen, in deren Schoß, nach deren Satzungen das ganze Dasein ihrer Glieder verläuft. Da findet der Eine bei den Andern Halt, Hilfe, Stärkung. „Denn also", heißt es in einer Beichtformel, die zu den ältesten Denkmälern des Buddhismus gehört, „ist die Jüngerschar des Erhabenen verbunden, daß einer dem andern zuredet, einer den andern aufrichtet." Daß es in der Tat unter den geistlichen Brüdern 
nicht an solchen gefehlt hat, die des Zuredens und Aufrichtens recht dringend bedurften, ja auch nicht an solchen, bei denen alles Zureden und Aufrichten nur wenig fruchtete, läßt die Literatur der alten Gemeinde deutlich genug erkennen. Sie zeigt auch, daß dem Gefüge der äußeren Ordnungen, in denen sich dies Zusammenleben bewegte, die Schwächen nicht erspart geblieben sind, die aus der unpolitischen, organisatorischer Begabung ermangelnden Natur der Inder sich ergaben. Doch trotz solcher Schwächen, welch' ein Gebilde größten Stiles bleibt sie, diese „Gemeinde der vier Weltgegenden, der Anwesenden und Abwesenden“. Auch über ihre eigenen Grenzen hinaus, durch die Kreise gläubiger Laien läßt sie den Strom, wenn auch nicht den vollen Strom, geläuterten und erhöhten Lebens fluten. Dem weltlichen Dasein jener wird Ordnung und Veredlung gebracht. Man sucht sie zu rüsten für die Erreichung des höchsten Ziels, wenn auch erst in naher oder ferner Wiedergeburt. In solchen Beziehungen der Mönchs- und Nonnengemeinde zu den "Verehrern", den "Verehrerinnen" bereitet sich die Zukunft vor, in den Zeiten König Asoka's und in den nächsten Jahrhunderten das Sicherfüllen Indiens, dann weiter Asiens mit buddhistischem Geist.

Neben dem allen aber, neben der Lehre und der Gemeinde ragt majestätisch das dritte, vielmehr das erste Glied der buddhistischen Trinität, zuerst in leibhaftiger Gegenwart, dann in unauslöschlicher Erinnerung: die menschlich-übermenschliche Gestalt des Buddha.

Das Schema für den Typus der im damaligen Indien ja auch außerhalb des Buddhismus auftretenden größeren oder geringeren Weltheilande hatte die geschichtliche Entwicklung allmählich geschaffen. Von den alten Zeiten des unpersönlichen, in ganzen Familien verkörperten Sängerund Opferertums war die Geltung einzelner, immer höhere Bedeutung beanspruchender geistlicher Persönlichkeiten Stufe für Stufe aufgestiegen. Die Brāhmanatexte fingen an dieses und jenes Wissen als den besonderen Besitz dieses und 
jenes Lehrers zu behandeln; da hoben sich die großen Schulhäupter in eigenartiger Bedeutung hervor. Eine Upanishad häufte, wie wir gesehen haben - zweifellos entgegen der geschichtlichen Wahrheit, doch das macht hier nichts aus - auf einen einzelnen Denker, Yājnavalkya, alle Vollkommenheiten der Erkenntnis und dialektischen Überlegenheit. Auf noch höherer Höhe, wenn auch schattenhaft verschwimmend, erscheint Kapila: vermutlich in Indien der Erste, der als ein Neubegründer weltumfassender Erkenntnis geehrt worden ist.

An solche Gestalten von Wissenden und zugleich Lehrern hat man zu denken - vielmehr an sie als an mythologische Gebilde etwa der Vishnuverehrung -, wenn man nach den Vorstufen des Buddhatypus fragt.

Seine volle Entwicklung wird dieser Typus da erreicht haben, wo der Besitz von Wahrheit und Erlösung nicht mehr als Einzelnen oder als kleinen Gruppen Auserwählter gehörend, sondern als das Universum durchwirkend, mit dessen Leben verwoben zu erscheinen anfing. Da mußte der Enthüller solcher Wahrheit, anders als Yājnavalkya oder Kapila, zu absoluter, über dem Weltganzen ragender Höhe aufsteigen.

$\mathrm{Daß}$ nun neben geringeren Persönlichkeiten, welche das von solchen Gedankengängen gewobene Gewand auf ihre Weise anlegten, ein Größter aufgetreten ist, erfüllt von unvergleichlicher seelischer Wirkenskraft: das war das entscheidende Ereignis.

Aus der unbeholfenen Prosa der alten Buddhisten, mehr noch aus ihren Dichtungen blickt die Erinnerung an die Macht dieses Wirkens schlicht, warm, lebendig hervor. Es richtete sich wohl nicht so sehr auf die Individualität des Einzelnen, der dem Meister begegnete, auf die verschlossene Heimlichkeit der ihm allein eignen Innenwelt. Sondern es war für alle in gleicher Weise, durch Lehre und durch Vorbild, ein unwiderstehliches Hinausheben über das eigne Ich in das Reich der großen Notwendigkeiten, in den Äther des 
Ewigen. Wer das erfahren, der mochte mit dem Dichter sagen:

"Von ihm, das fühl ich, kann ich mich nicht trennen".

Gläubige, in denen solche Liebe und Ehrfurcht lebte, haben das Buddhabild der kanonischen Texte geschaffen. Der geschichtliche Lebenslauf des großen Mannes gab die Grundlinien her. Die Phantasie, welcher die strengen Gedankengänge vom Wirken der Kausalitäten, von der Entstehung und Aufhebung des Weltleidens nur geringen Spielraum gewährten, fand hier freie Bahn, in indischer Überfülle jenes Gegebene auszuschmücken, es in das Zwischenreich von Wahrheit und Dichtung zu versetzen. Zusammenhang mit der Wirklichkeit erhielt sich dabei immer aufrecht. Verglichen etwa mit der Erhebung Krishna's, des listigen Kriegers, des Hirten und Liebeshelden zum Gott oder absoluten Wesen, wie viel enger, natürlicher, fast möchte man sagen glaublicher, schloß sich in der Gestalt des Buddha das Wahre mit den legendarischen und dogmatischen Ausschmückungen zusammen. Da entstanden die tiefsinnigen, eindrucksvollen Erzählungen von seinem Suchen und Finden des ewigen Friedens. Vom Fortziehen aus der Heimat. Von den Zeiten, wo er einer Waldgazelle gleich "von Dickicht zu Dickicht, von Tal zu Tal, von Höhe zu Höhe" umherirrte, um nur von keinem Menschen gesehen zu werden. Von den Kasteiungen, die ihm das Blut austrockneten und sein Fleisch schwinden ließen. Und dann von der Nacht unter dem heiligen Baum, dem Aufleuchten der weltdurchdringenden, erlösenden Erkenntnis, dem Prediger der Lehre vor den fünf Asketen von Benares und weiter vor aller Götter- und Menschenwelt bis zum friedevollen Erlöschen seines großen Lebens im Hain bei Kusinārā. Dies irdisch-zufällige Bild aber mußte sich in einen Rahmen des Ewig-Notwendigen hineinfügen. Durch Erhebung in göttliche oder gottmenschliche Höhe das Erdendasein des Buddha zu adeln konnte der hier herrschenden Denkweise nicht geoldenberg: Upanishaden. 
nügen. Die Götterwürde war etwas Banales, eine Stufe der SSeelenwanderung wie andre Stufen auch. Wohl klingt es nach Göttlichkeit, wenn Buddha von sich sagt: „Die an mich glauben und mich lieben, die alle sind des Himmels gewiß." 220 Aber die entscheidenden Züge seiner Herrlichkeit mußten in höherer Höhe liegen und zugleich bestimmter seinem Wesen eben als Buddha entsprechen. Das Größte mußte hier verwirklicht sein, was in der Welt des Werdens und Vergehens sich verwirklichen konnte: ein ungeheurer, gesetzmäßiger, aus der Weltfinsternis dem Licht zustrebender Daseinszusammenhang. So stellte sich das irdische Leben des Buddha als das Schlußglied einer Kette zahlloser früherer Existenzen dar, in welchen sich dies Wesen unaufhaltsam von Vollkommenheit zu Vollkommenheit erhoben hatte. Und weiter, in andrer Richtung betrachtet, erschien die Buddhagestalt, innerhalb aller absehbaren Zeiträume einzig dastehend, doch als in fernsten Fernen ihre Gegenbilder besitzend in einer unabsehbaren Reihe nach fester Ordnung über die Weltalter sich verteilender Buddhas: eine Einordnung in einen übergroßen Zusammenhang, die von Gleichartigem her dem Ohnegleichen neue geheimnisvolle Erhabenheit zuströmen ließ.

Alle diese Majestät aber, den höchsten Höhepunkt der Bewegung aus dem Diesseits ins Jenseits bezeichnend, drückte sich unvermeidlich immer noch in Formen aus, die selbst dem Diesseits angehören. Mußte nicht das Letzte, Tiefste, das die Gläubigen über das Wesen des Buddha zu sagen hatten, in andrer Sprache ausgesprochen werden? Jenseits des Erdenwandels das Sein im Reich des Transzendenten? Doch von diesem Reich und von Sein in ihm konnte man ja nicht reden. „Der Vollendete ist tief, unermeßlich, unergründlich wie der große Ozean." Es genügte zu wissen, daß er im Nirvāṇa weilt, schon hienieden im Nirvāna geweilt hat. Wird man Anstoß daran nehmen die alte Gemeinde hat das wohl nicht getan - daß eben dieser höchste Zug seines Wesens doch wiederum ihm mit 
andern gemeinsam ist, insonderheit mit seinen eignen heiligen Jüngern? Er hat das Ziel als erster erreicht und ihnen geholfen es nach ihm erreichen. Am Ziel aber sind sie alle. $\mathrm{Ob}$ in dessen Ewigkeitshöhe sein Vorrang als ein nur zeitlicher verschwunden ist? Ferner als fern mußte solche Frage liegen. Es gehörte zum Wesen des Buddha, daß der Gedanke von seiner Glorie nicht zu Ende gedacht werden konnte.

Im Verhältnis der Gläubigen und des Meisters, der Nachfolgenden und des Vorangehenden, erscheint jener alte, das Leben der Religionen beherrschende Gegensatz der Heilserwerbung durch höhere Gnade und durch eigne Kraft in gewisser Weise als überbrückt. Auf der einen Seite wird hier das Heil erlangt, indem man die inneren Kausalitäten, die zur Ablösung von Welt und Leiden führen, selbst in Bewegung setzt:

„Denn das Selbst ist des Selbst Schützer. Wie könnt' ein Andrer Schützer sein?"

So kommt denn in den Formeln, die den Mechanismus der Erlösung beschreiben, das Wort und die Vorstellung "Buddha“ nicht vor. Aber doch andrerseits, die Kenntnis und das Verständnis dieses Mechanismus, die Aufklärung darüber, wo und wie man anzugreifen hat, um das gewollte Ergebnis herbeizuführen: dies hat man als ein Geschenk des Meisters empfangen, der in einem entscheidenden Augenblick seines Lebens es erwählte, die selbsterrungene Erkenntnis nicht in sich zu verschließen, sondern sie der Welt mitzuteilen. Man kann weiter fortfahren: dies Geschenk wiederum verdankt sein Empfänger nicht blindem Zufall oder unergründlicher Gnadenwahl, sondern durch eignes Tun in vergangenen Existenzen hat er den Anspruch darauf und die Fähigkeit des Empfangens erworben. So vereinigen sich hier unauflöslich die Stimmungen des stolzen Vertrauens auf die eigne Kraft und demütigen, dankerfüllten Hinnehmens dessen, was überschwängliche Gnade aus ihrer Lichtwelt darbietet. 
Hier hat Indien den Höhepunkt seines religiösen Gestaltens erreicht, zugleich den Punkt, wo seine Verschlossenheit sich öffnet, fernhin ihre Gaben zu verbreiten. Die Kunst Indiens, dann Asiens, hat in tiefsinniger Schönheit verkörpert, was von dem hier Geschaffenen der Verkörperung fähig war. Griechischer Einfluß half das Buddhabild formen, an das sich die schwachen Kräfte der nationalen altindischen Kunst nicht wagten. Dann hat dies Bild den fremden westlichen Zug abgestreift; es ist in allen Reichen des inneren und des östlichen Asien heimisch geworden. In unendlich erhabener Ferne über der Welt, jenseits von allem Suchen, Wollen, Handeln, steht der Weltüberwinder da oder thront er. Bald ist er in Meditation versunken. Bald deutet der lehrende Gestus der Hände oder das friedeverkündende Sichheben der Rechten leise auf die Segnungen hin, die er Göttern und Menschen spendet. Doch keine Bewegung des Eindringens auf die Geister, kein Ringen darum sie sich zu gewinnen. Sondern allein stilles Ausströmenlassen der eignen tiefen Ruhe über die Ruhesuchenden. Wie die buddhistische Lehre das Jenseitige nur durch Verneinungen des Diesseits auszudrücken wußte, so auch die Kunst. Was dem Werden und Vergehen, dem Sein und Nichtsein gehört, hat sie aus der Buddhagestalt ausgelöscht. Des Nirvana Geheimnis und schweigende Majestät konnte sie nur ahnen lassen. So hat sie dem gehuldigt, der den Weg dorthin, zur Heimat, gefunden zu haben meinte. Den Weg zu jener Ewigkeitshöhe, wo, wie der alte Vers sagt, „den auf die Welt Hinabblickenden der König Tod nicht sieht". 


\section{Anmerkungen.}

1 Vgl. die näheren Ausführungen in meiner Religion des Veda 479f.

2 Durkheim et Mauss, De quelques formes primitives de classification (Année sociologique 1901-02); Léry-Bruhl, Les fonctions mentales dans les sociétés inférieures 31. 198. 428.

${ }^{3}$ Doch glaube ich eher, daß die betreffende Stelle (Śatapatha Br. XII, 9, 3, 11-12) anders zu verstehen ist. Die Parallelität zwischen Tieren und Vätern läbt vermuten, daß die Vorstellung der Befreiung vom Wiedertod einfach von diesen auf jene übergegriffen hat. Für ewig lebende Jenseitsbewohner schien wohl ebenso ewiger, vom Wiedertod unbedrohter Viehbesitz erwünscht.

4 Taitt. Brāhmaṇa III, 10, 11, 3. Auch der Kommentar deutet die Stelle auf den Schatz guter Werke.

5 Śatapatba Br. X, 1, 3, 7.

6 Daselbst XI, 2, 2, $5 \mathrm{f}$.

7 Im Folgenden: Śatapatha Br. XI, 2, 6, 13f.; 5, 6, 9 (in der Anmerkung dort: Kaushitaki Br. XXI, 1); XII, 3, 4, 11; X, 5, 4, 16.

8 Unter den „älteren" Upanishaden stehen in der Mitte, wie wohl allgemein anerkannt ist, die des Bṛhad Äranyaka und die Chāndogya Upanishad; sie sind der folgenden Darstellung vorzugsweise zu Grunde gelegt. Kein Zweifel, daß der älteren Gruppe auch die Aitareya Up. zugehört, vielleicht auch die İsã Up.; dazu -- es scheint in zweiter Linie - die Kena und Kaushītaki Up. (vgl. über die letztere Keith, Ait. Ār. 41 A. 2); hierher auch Taittiriya Up. (Keith 45f.) und Jaiminīya Up. Br.? Natürlich stuft sich vielfach innerhalb derselben Upanishad Älteres und Jüngeres ab. Die Ansicht Deussen's, daß die Yājñavalkyadialoge der Bṛhad Ār. Up. ganz besonders alt seien (Allg. Gesch. der Phil. I, 2, 209, vgl. Transactions of the Third Intern. Congress for the Hist. of. Religions II, 20; doch s. auch Sechzig Upanishad's 426f.), kann ich mir nicht aneignen. Sie hängt mit den, wie mir scheint, bestreitbaren Grundanschauungen dieses Gelehrten über die Richtung zusammen, in der die ganze Gedankenentwicklung verlaufen ist. Eher scheint mir in jenen Dialogen eine literarische Technik sich zu zeigen, die über das älteste Stadium hinaus ist.

${ }^{9}$ Chāndogya Upanishad VII, 23-25 (das vorangehende Zitat über unbegrenztes Wünschen: Aitareya Ār. II, 3,3). 
10 Siehe meine Religion des Veda 403.

1 Vgl. F. Otto Schrader, Über den Stand der indischen Philosophie zur Zeit Mahāvīras und Buddhas, $19 \mathrm{f}$.

12 Die Annahme, der man begegnet, daß brahman geradezu auch bedeute "der heilige Stand, die Brahmanen", trifft m. E., in jedem Fall für die ältere Sprache, nicht genau zu. Wenn wir heute etwa sagen: „der ganze Adel, die ganze Geistlichkeit war versammelt", könnte sich die Vedasprache nicht ebenso über brahman und kshatra ausdrücken. Ist vom Verhältnis zwischen $b r$. und $k s h$. die Rede, so sind natürlich in der Tat Brahmanen und Adlige gemeint. Aber gesprochen wird von den beiden Potenzen, die deren Wesen ausmachen. Bezeichnend sind Stellen wie Aitareya Brāhm. VII, 19, 3: „Deshalb gründet sich auch jetzt das Opfer a uf das Brahman, auf die Brahmanen."

18 Ich verweise auf Tiele-Söderblom, Kompendium der Religionsgesch. ${ }^{4}$ 24 ff., Marett, Arch. für Religionswiss. XII, 186 ff., Preuß ebendas. XIII, $427 \mathrm{ff}$. , Söderblom ebendas. XVII, Iff. und die dort angeführte Literatur. Die Gleichartigkeit dieser Vorstellungen mit der des Brahman wurde schon von Hubert und Mauss bemerkt (Théorie générale de la magie, Année sociologique 1902--3, 108ff.). Vgl. auch O. Strauß, Bṛhaspati im Rgveda 20 A. 4; Söderblom a. a. 0. XVII, 11.

14 Vgl. zum Nachstehenden die Stellen bei Deussen, Allg. Gesch. der Philosophie I, 1, $257 \mathrm{f}$.

15 Deussen a. a. O. 262 f. läßt an dieser Stelle (Taitt. Br. III, 12, 9) schon die Identifizierung des Brahman mit dem Ātman (dem großen "Selbst") vollzogen sein. Beweisbar ist das m. E. nicht. Zwar folgt bald ein Vers, der "den großen, alldurchdringenden Ätman" verherrlicht. Doch scheint der anderweitigen Ursprungs und mit den oben besprochenen Versen rein äußerlich zu einer Litanei zusammengeschweißt zu sein.

16 Sehr klar hat über diese Differenzierung von Prāna und Ātman A. H. Ewing gesprochen (The Hindu Conception of the Functions of Breath II, 16f.).

17 Die beiden Stellen sind : Śatapatha Brāhmaṇa X, 6, 3; Chāndogya Upanishad III, 14.

18 Eggeling's Übersetzung „Let him meditate upon the ,true Brahman" gibt die Struktur der Vorstellung, wie mir scheint, nicht ganz genau wieder.

19 Bṛhad Ār. Up. IV, 4, 5. Dann İsā Up. 5.

20 Stellenangabe bei Deussen a. a. O. I, 2, 134; dort S. 136 Materialien den Eingang der Stelle betreffend.

21 Diese Worte hat neben das "Nein, nein" der Upanishad schon William James gestellt (The Varieties of Religious Experience, 10th Imp., 416 f.). 
22 Bṛhad Ār. Up. III, 8, 8. Dann İsā Up. 13.

28 Satapatha Brāhmaña XI, 2, 3.

24 Im Rgreda. Vgl. meine Noten zu diesem, III, 38, 7 (mit dem Nachtrag); VII, 103, 6; X, 169, 2.

25 Chāndogya Up. VI, 2 f.

26 Wörtlich wäre zu übersetzen "die Schärfe". Doch trifft "Glut" offenbar genauer die Vorstellung, die dem Verfasser vorschwebte. Man vergleiche, wie die betreffende Wesenheit Chānd. Up. VII, 11 geschildert wird.

$27 \mathrm{DaB}$ „Nahrung“ hier an Stelle der Erde steht (Oltramare 87 A. 2), finde ich - sofern damit gemeint sein sollte, daß bei jenem Wort irgendwie an diese Vorstellung zu denken sei - nicht einleuchtend. Man sehe, wie Chānd. Up. VII, 9 die Wirkungen der "Nahrung“ (dort ebenfalls neben Wasser und Glut) beschrieben werden. Die Möglichkeit, daf eine ältere Vorstellungsreihe mit "Erde“ statt „Nahrung“ zu Grunde liegt, soll damit nicht bestritten werden.

${ }^{28}$ vācārambhanam. Sukhtankar (Wiener Zschr. f. Kunde d. Morg. XXII, 144f.) versteht dies Wort anders, mir scheint unrichtig.

${ }^{29}$ Brihad AAr. Up. III, 7, 3ff. Im Folgenden: Ait. Up. I, 3, 13; Ait. Ār. II, 3, 2.

${ }^{30}$ Bṛhad Ār. Up. I, 4, 7. Im Folgenden: Chānd. Up. VI, 13.11. 12; III, 14 (Parallelredaktion zu der oben S. 57f. mitgeteilten Stelle).

${ }^{81}$ Bṛhad Ār. Up. III, 8, 9. Dann Taitt. Up. II, 8.

s2 Atharvaveda XI, 4, 21. Vgl. Mahāohārata V, 45, 14.

${ }^{23}$ Brihad Ār. Up. I, 4.

34 Satapatha Brāhmaṇa X, 4, 2, 2 ff.

35 Taittiriya Up. III, 1.

${ }^{26}$ Chānd. Up. VI, 9. 10. Im Folgenden: Bṛhad Ār. Up. I, 6, 3; II, 4, 6; I, 4, 10. 7. - Überhaupt wäre hier auf die Stellen hinzuweisen, an denen gesagt wird, daß das Brahman "Alles" ist.

${ }^{87}$ Ist es bloßer Zufall, daß nicht, entsprechend der altgewohnten Hervorhebung der sakrifikalen Vorstellungssphäre (oben S. 25), diesen Sätzen etwa auch angereiht wird: „Singt er, heißt er Säman “ und dgl.? -Zeigt sich hier ein Zurücktreten dieser Sphäre?

s8 Man beobachte etwa, in wie verschiedenen Formen in dem Dialog Bṛh. Är. Up. II, $4=$ IV, 5 das Verhältnis des Ātman zur Welt erscheint. Bald ist er die Dinge oder die Wesen. Bald ist er in den Dingen. Bald kommen die Dinge aus ihm. Die Aufmerksamkeit richtet sich eben nicht darauf, wie es geschieht, daß er das All beherrscht. Es kommt darauf an, daB er es beherrscht, allein etwas zu bedeuten hat. Die Auffassung des Übrigen schwankt.

${ }^{39}$ Thibaut, Sacred Books of the East XXXIV, p. CXX.

40 Bṛhad Ār. Up. II, 1, 20. 
41 Ich befinde mich hier im Gegensatz zu Deussen, Allg. Gesch. der Philos. I, 2, $206 \mathrm{ff}$. ("die Mãyālehre in den Upanishads") und zu der m. E. die Forschung kaum fördernden - Schrift von Prabhu Dutt Shāstrī, The Doctrine of Māyā (London 1911). Dagegen stehe ich der sehr umsichtig begründeten Ansicht Thibaut's nah, Sacred Books of the East XXXIV, p. CXVIff. Eine mittlere Stellung nimmt Oltramare ein, L'histoire des idées théosophiques dans l'Inde I, $88 \mathrm{ff}$.

42 Bṛhad Är. Up. II, 4, 14.

43 Man hat aus dem Wortlaut "wo eine Zweiheit gleichsam ist" schließen wollen, daß die Vielheit ausdrücklich als eben nur „gleichsam" seiend, d. h. als in Wahrheit nicht seiend gekennzeichnet werde. Entsprechend, wenn anderswo vom Ātman gesagt wird, , er sinnt gleichsam, er schweift gleichsam" u. a. m. Doch das „gleichsam" (iva) ist den Autoren sehr geläufig, zunächst etwa im Sinn unsres „so zu sagen“. Eine gewisse Unbestimmtheit wird über den Ausdruck gebreitet, allzu wörtliches Verständnis abgewehrt. Schließlich schrumpft dies "gleichsam " zu einer kaum merklichen Nuance der Zurückhaltung von aufdringlichem Ton des Behauptens zusammen. $4,18 \mathrm{f}$.

${ }^{44}$ Bṛhad Ār. Up. IV, 3. Die weiter folgenden Verse: das. IV,

45 Bṛhad Ār. Up. II, 5, 15. Im Folgenden: daselbst II, 4, 5.

46 Deussen, Allg. Gesch. der Philosophie I, 2; s. besonders etwa S. VI. 145 . 149. 205 . 358.

47 Bṛhad Ār. Up. II, 3. Im Folgenden: Taittirīya Up. II, 6 (vgl. auch Maitr. Up. VI, 3); Chāndogya Up. VIII, 3, 4. 5; Bṛ̣. Ầ. Up. V, 1. 48 Siehe meinen "Buddha", 6. Aufl., S. 355.

49 Taittiriya Upanishad II, 5.

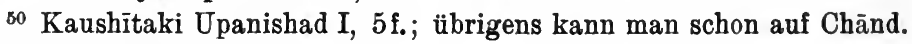
Up. VIII, 5 hinweisen.

${ }^{51}$ Bṛhad Ār. Up. III, 8, 8f. Dann ebendas. IV, 4, 22; Kaush. Up. III, 8.

${ }^{52}$ Bṛhad Ār. Up. IV, 4, 3f. Wo übersetzt ist ,in Bewußtlosigkeit versinken", sagt der Text m. E. wörtlich „zum Nichtwissen gelangen“. Ich glaube eher, daß so zu verstehen ist, als mit Andern: , er läßt das Nichtwissen (fort)gehen. " - Hier sei auf den teilweise an diese Stelle anknüpfenden scharfsinnigen Aufsatz F. O. Schrader's „Zum Ursprung der Lehre vom Samsāra" (ZDMG. LXIV, 333ff.) hingewiesen, dessen Ergebnisse mir doch unannehmbar scheinen.

${ }^{53}$ Chānd. Up. VI, 8 Ende - 10. Schwerlich ist in 9-10 vielmehr von Eingehen in den Tiefschlaf und Erwachen daraus die Rede.

${ }^{54}$ Materialien über Götterweg und Väterweg: Deussen, Allg. Gesch. der Phil. I, 2, 301ff.; vgl. auch Windisch, Buddha's Geburt $63 \mathrm{ff}$. Ein Stück Vorgeschichte dieser Lehre lernen wir aus dem Jaiminìya Brāh- 
mana kennen; vgl. Oertel JAOS. XIX, Second Half, 111ff., Windisch Ber. Sächs. Ges. d. Wiss., Phil.-Hist. Kl., LIX, $111 \mathrm{ff}$. - Die dann weiter im Text übersetzte Stelle: Bṛh. Ār. Up. VI, 2, 16. Zu den hier einschlagenden Vorstellungen des Volksglaubens über den Mond vgl. den inhaltreichen Aufsatz von T. Segerstedt "Själavandringslärans ursprung", Monde Oriental IV, besonders $62 \mathrm{ff}$.

55 Man beachte, wie derselbe Text (S. 107 mit Anm.), der Rückkehr des Menschen zu immer neuem Dasein beschreibt, für die Vergangenheit erstmalige Entstehung, nicht etwa Herkommen von unabsehbaren früheren Wanderungen lehrt. Eine Deutung, die der Konsequenz zu Liebe statt jener Entstehung solche Wanderungen ans dem Text herausliest, scheint mir abzuweisen.

${ }^{56}$ Bṛhad Ār. Up. III, 2, 13.

${ }^{52}$ Ebendas. IV, 4, 5. Im Folgenden: Chānd. Up. V, 10, 7.

${ }^{58}$ Vgl. das schon oben S. 30 Gesagte.

${ }^{50}$ So später Śankara. Siehe Deussen, System des Vedānta $346 \mathrm{f}$. 428. Deussens (Allg. Gesch. der Phil. I, 2, 188f.) eigne kantianisierende Behandlung des Problems für die Upanishaden überzeugt nicht.

${ }^{60}$ Doch s. unten S. 114 Anm. 1.

61 Ja sogar schon in der älteren Periode finden sich Anfänge von derartigem, s. oben S. 32.

${ }^{2}$ Brihad Ār. Up. IV, 3, 33.

${ }^{63}$ Daselbst II, 4 (hier nach dieser Fassung übersetzt) und IV, 5.

64 Daselbst I, 3, 28.

${ }^{65}$ Das. III, 1, 3. Hauptstellen des Folgenden: III, 2, 10; IV, 3, 7; Chānd. Up. VII, 26, 2.

${ }_{66}$ Bṛhad Ār. Up. III, 8, 10. Es folgt Chānd. Up. VIII, 1, 6; 12. „Weltleiden": Kāṭhaka Up. V, 11.

${ }^{67}$ Oben S. 42. Dort ist die Stelle benutzt, die Stimmungen zu veranschaulichen, die zur Schaffung der Idee des All-Einen geführt haben. Man wird verstehen, in welchem Sinn ich kein Bedenken trage, dieselbe Stelle hier in der Schilderung der Entwertung des Weltdaseins durch den Kontrast mit jener Idee wieder anzuführen. Eine Zirkelbewegung: gewisse Stimmungen geben dem Denken die Richtung; das Denken, diese Richtung nehmend, verstärkt jene Stimmungen.

${ }^{68}$ Ich denke hier an das von Simmel, Hauptprobleme der Philosophie 59, Gesagte.

${ }^{69}$ Bṛhad Är. Up. I, 4, 7. Im Folgenden: Chānd. Up. VIII, 1, 3; Bṛ̂ad Ār. Up. IV, 4, 22; III, 4. 5.

${ }^{70}$ Chānd. Up. VI, 9. 10. 13; Bṛh. Ār. Up. II, 1, 20.

${ }^{71}$ Ich verweise vor allem auf die Rolle der Kasteiungen in Taittirīya Upanishad III.

${ }^{72}$ Wenigstens annähernd läuft auf die Dreiheit der hier berührten 
Betätigungen die Aufzählung in Chãnd. Up. II, 23, 1 hinaus. „Es gibt drei Gruppen der Pflicht. Opfer, Vedastudium, Gabenspenden ist die erste. Askese (tapas) ist die zweite. Der Brahmanschüler, der in des Lehrers Haus wohnt, ist die dritte - der sich für immer in des Lehrers Haus festsetzt. Alle diese gewinnen Welten des Glückes. Wer im Brahman feststeht, gelangt zur Unsterblichkeit." Ich übersetze lieber "Gruppen der Pflicht", als mit Oltramare (Théosophie I, 113) "degrés dans le devoir de religion". Eine Abstufung schließt das Wort m. E. nicht ein (übereinstimmend damit Deussen, Allg. Gesch. d. Phil. I, 2, 330).

${ }^{23}$ Bṛh. AAr. Up. III, 8, 10. Im Folgenden: ebendas. IV, 4, 12f.; Chānd. Up. VII, 1, 3; Bṛ̂h. Ār. Up. I, 4, 9 f.

${ }^{74}$ Im Folgenden angeführt: Bṛh. Àr. Up. III, 4, 2; 8, 11; IV, 5, 15.

${ }^{75}$ Kena Up. 11; Kāțhaka Up. VI, 12.

${ }^{76} \mathrm{Zu}$ Brahmasūtra III, 2, 17,

77 Reichen Anfänge des Yoga schon in die hier besprochenen Zeiten zurück? Vgl. S. 141 und unten Anm. 85.

${ }^{78}$ Brịad. Ār. Up. IV, 4, 6.

${ }^{79}$ Deussen, Allg. Geschichte der Philosophie I, 2, 310f. Im FoIgenden Zitat des Gauḍapāda: Mãṇụūkyakārikā IV, 98 (schon von Denssen a. a. 0. angeführt).

80 Eine Stelle wie Chānd. Up. VIII, 3, 2 (Deussen a. a. 0. 311) kann ich für solches Zeugnis nicht halten. Man sieht sehr deutlich, wie der im selben Zusammenhang besprochene Unterschied von Freiheit und Unfreiheit (VIII, 1, 6; genauere Übersetzung wäre: Wandeln nach Wunsch bz. nicht nach Wunsch) durchaus als wirklich vorhanden, nicht als erträumt behandelt wird. Die „Unwahrheit", welche die „wahrhaften Wünsche" zudeckt, ist nicht etwa der Glaube, daß die empirischen Einzelwesen sind, sondern daß sie vom Ātman unabhängig, von ihm aus unerreichbar sind.

${ }^{81}$ Bṛh. Ār. Up. IV, 4, 23. Dann Chānd. Up. III, 11, 3; VIII, 4, 1; IV, 14, 3; Bṛh. Är. Up. V, 2; IV, 4, 21; III, 5, 1; I, 4, 10; III, 5, 1.

${ }^{82}$ Das bemerkt treffend Oltramare I, 135.

${ }^{83}$ Die älteste Belegstelle für śramana findet sich in der Bṛh. Ār. Upanishad; dort steht das Wort ueben tãpasa („Vollzieher von Tapas = Kasteiung "). Im Rigveda (I, 179) spricht das Keuschheit übende Asketenehepaar von seinem „Sichabmühen" (śrāntam, śaśramāñā): da ist offenbar der technische Gebrauch des śram-schon im Werden, wenn auch natürlich die leitenden Gedanken des eigentlichen Śramanatums noch der Zukunft angehören.

${ }^{84}$ Chāndogya Up. VII, 6. Im Folgenden Bṛh. Ār. Up. IV, 3, 19f.; II, 1,19

${ }^{85}$ So ist die Rede von magischer Kraft des Ein- und Ausatmens, vom Zurruhebringen aller Organe im $\bar{A}$ tman (Deussen, Allg. Gesch. der 
Phil. I, 2, 113. 345, vgl. auch oben S. 130; der hier in Betracht kommende Schlußsatz der Chānd. Up. könnte allerdings leicht Zusatz sein). - Die im weiteren Verlauf der obigen Darstellung erwähnten Erscheinungen des „Purusha im rechten Auge“, der die Essenz des Ungestalteten, des „tyam" (oben S. 98 A. 1) sein soll, werden in einer eigentümlichen Stelle der Bṛh. Är. Up. (II, 3, 6) beschrieben. Dafür, daß Gesichtshalluzinationen in der Ekstase gemeint sind, spricht die Vergleichung von Śvetāśv. Up. II, 11. - Die weiter im Folgenden zitierte Stelle von der Geburt der Sonne: Chānd. Up. III, 19.

${ }^{86}$ Oltramare I, 136. - Dann: Chāndogya Up. III, 11.

87 Daselbst VIII, 2.

${ }^{88}$ Das. VIII, 6, 1. Dann Bṛh. Ār. Up. IV, 4, 8; Chānd. Up. VIII, 6,5 ; Bṛh. Ār. Up. VI, 2, 15; IV, 5, 13. - Man beachte die Varianten der Vorstellungen, die sich im Jaiminiya Upanishad Br. III, 28 (Oertel JAOS. XVI, 188) finden: Deutung des Gelangens zur Brahmanwelt als Hin- und Hergehen zwischen Sonne und Mond; Möglichkeit für den Dorthingelangten doch wieder auf Erden in dem Geschlecht, das er sich wünscht, wiedergeboren zu werden und dann von neuem zum Himmel aufzusteigen, worüber freilich ein Lehrer bemerkt: „Wer würde jenes (das jenseitige Dasein) fahren lassen und hierher zurückkehren? Dort würde er bleiben!"

89 An der hier berührten Stelle des Dialogs von Yãjñavalkya und Maitreyī (Bṛh. Ār. Up. IV, 5, 13) kann der Satz überraschen, der anknüpfend an die Vergleichung des im Wasser aufgelösten Salzes besagt, daB der Âtman „aus diesen Wesen sich erhebt und mit ihnen wiederum verschwindet; kein Bewußtsein gibt es nach dem Tode". Daß an ein Untergehen des Ätman in der Tat nicht gedacht sein kann, steht fest. Gemeint ist wohl, dab mit dem Hingehen der vom Ätman beseelten Wesen auch er selbst, sofern er in jenen weilend an begrenztem, bewuBtem Dasein Teil hatte, verschwindet (dem verwandt Kaush. Up. II, 13). An dieser Stelle des Dialogs spricht Yãjñavalkya das nicht in voller Schärfe aus, fügt seinen Worten die an sich unentbehrliche Einschränkung nicht hinzu. Denn jetzt soll in Maitreyī erst eine Furcht erregt werden, die für die dann folgende Verkündigung des höchsten Friedens die Folie abgibt.

${ }^{90}$ Chāndogya Up. VIII, $11 \mathrm{f}$.

91 Mundaka Up. III, 2, 8.

92 Ich sage: den Āranyakas zugerechnet wurden; nicht: als Ār. bezeichnet wurden. Denn neben diesen Waldabschnitten des Brāhmaṇas gab es in den Äranyakasammlungen auch Waldteile der liturgischen Texte selbst (Samhitās), dazu später auch der kurzgefaßten rituellen Leitfäden, der Sūtras.

9s Siehe Macdonell-Keiths Index unter Vamśa (den Zitaten hinzuzu- 
fügen Jaim. Up. Br. III, 40 ff.; IV, 16f.). - Der Zweck dieser Listen war selbstverständlich zunächst, die Bedeutung und Authentizität der betreffenden Lehren zu verbürgen, indem deren göttlicher Ursprung und ununterbrochene Überlieferung aufgezeigt wurde. Von Interesse aber ist, daß einmal (Bṛh. Ār. Up. VI, 3, 6) bei einer zauberartigen Verrichtung das Hersagen der Liste derer, die den betreffenden Zauber früher gelehrt haben, als Bestandteil des Ritus selbst erscheint. Offenbar sollte damit sozusagen die von diesen Vorgängern angesammelte Kraft und Bewährtheit des betreffenden Zaubers in dessen gegenwärtige Ausübung hineingeleitet werden.

94 Sehr deutlich sieht man das in Bṛhad Āranyaka Up. I, 3.

95 Brịad Ār. Up. IV, 3. 4.

96 Ich denke an das Sāmaññaphala Sutta.

92 Über den Wortsinn von Upanishad s. die Literaturangaben in Macdonell-Keith's Vedic Index s. v.; hinzuzufügen ist Senart, Florilegium M. de Vogüé 575ff.; Keith Aitareya Ār. 239. Nicht fördernd K. E. Neumann, Reden Gotamo Buddhos aus der läng. Sammlung II, 497. - Die dann zitierte Stelle über Tārukshya: Ait. Ārr. III, 1, 6. Über den „Lebenssaft des Lebenssaftes": Chānd. Up. III, 5.

98 "Man soll verehren" heißt upāsīta; upās-(upa-ās-) ist synonym mit upa-ni-shad-. Wenn diese Ausdrücke ihrem Wortsinn nach auf (verehrendes) Sitzen ( $\bar{a} s-$, sad-), nicht Stehen (upa-sth $\bar{a}-$, vgl. oben S. 37) hinweisen, wird das damit zusammenhängen, daß für den an mystische Geheimnisse Denkenden das Sitzen die natürliche Stellung ist (vgl. Brahmasūtra IV, 1, 7 und Śankara zu der St.; auch an das Sitzen des Yogin ist zu erinnern). Daß doch auch ein im übrigen entsprechender, aber wörtlich genommen ein Stehen einschließender Ausdruck statthaft war, zeigt Bṛh. Är. Up. V, 14, 7.

${ }_{99}$ So geben auf dem Gebiet des Sāmaveda die beschriebenen liturgischen „Verehrungs"texte (Chānd. Up. I. II) den Ausgangspunkt und die Unterlage für die Ātmanphilosophie der Chānd. Up. ab. Im Yajurveda beobachte man, wie die entsprechenden liturgischen Spekulationen über den Feueraltar im zehnten Buch des Śatapatha Brāhmaṇa (z. B. X, 4, 5, 1: „Nun die Anweisungen der Upanishaden. Vāyu ist der Agni [d. h. der Feneraltar]: so üben die Śăkāyanin ihre Verehrung ${ }^{4}$ usw. $-\mathrm{X}, 5,1,1$ : „Dieses Agni Upanishad fürwahr heißt ,Rede * usw.) schließlich in die Sätze des Śanḍllya über das All-Eine $(\mathrm{X}, 6,3)$ auslaufen und damit das Stadium der Upanishaden im gewöhnlichen Sinne des Worts erreichen. Für die Literatur des Rigveda ist namentlich auf Aitareya Āranyaka III, Śānkhāyana Ār. VII zu verweisen. Daß in Ait Ār. III „the philosophical view is more advanced than that of the Upanishad proper" (d. h. Ait. Ār. II, 4--6), scheint mir Keith (Ait. Âr. p. 17. 44) nicht erwiesen zu haben. 
100 Chānd. Up. III, 11, 3. Im Folgenden: Ebendas. V, 11ff.; Bṛhad Ār. Up. I, 4, 7; IV, 1. 2; II, 1, 20; 3, 6 .

101 Ich kann Senart (Florilegium Melchior de Vogüé $575 \mathrm{ff}$.) nicht folgen, wenn er dem Verb upās- in den Upanishaden direkt die Bedeutung „wissen" zuschreibt. Mir scheint klar, daß durchaus an "verehren" festgehalten werden muß. Aber freilich schließt das Verehren eines mystischen Wesens in der und der Gestalt das Wissen von dieser seiner Gestalt als entscheidendes Hauptmoment in sich, und umgekehrt das Wissen geht, wo es sich um Objekte solcher Art handelt, unvermeidlich alsbald in Verehren über.

102 Chānd. Up. IV, 9, 3. Dann das. VI, 14.

103 Ebendas. V, 11. Im Folgenden: das. IV, 3. 4; Bṛh. Ār. Up. VI, 2; Chānd. Up. VI, 1, 2; Bṛh. Ār. Up. IV, 5; Chānd. Up. I, 10f.; IV, 1. 2; Bṛh. Ār. IV, 1f.; III, 1.

104 Von diesem Opfer (Bṛh. Ār. Up. III, 1) erzählt schon das Śatapatha Brāhmaṇa (XI, 6, 3) und gibt das zugehörige Gespräch, doch so daß dem Yãjñavalkya nur ein Gegner, der letzte der neun in der Upanishad Auftretenden, gegenübersteht und der Redestreit die Sphäre der Brāhmañasymbolik nicht überschreitet. Der enge Anschluß der Upanishad an das ältere Darstellungsschema und zugleich dessen Weiterbildung in ihr tritt deutlich hervor.

105 Bṛh. Är. Up. II, 1.

106 R. Garbe in seinem Aufsatz ${ }_{n}$ Die Weisheit des Brahmanen oder des Kriegers?" (Beiträge zur indischen Kulturgeschichte, S. 23). Hier ist die in Rede stehende Meinung am nachdrücklichsten und eindrucksvollsten vertreten.

${ }_{107}$ Chāndogya Up. VIII, $7 \mathrm{ff}$. Im Folgenden: das. IV, $4 \mathrm{ff}$.

${ }^{108}$ Es genügt auf Chānd. Up, II, 22, Ait. Ār. III zu verweisen.

100 Jaim. Up. Br. III, 8. - Die das Stück Gold betreffenden Parallelstellen Śat. Br. XI, 4, 1, 1 und Gop. Br. I, 3, 6, die im Hinblick auf einander betrachtet werden müssen, scheinen mir wie im Text gesagt zu verstehen. Anders Eggeling SBE. XLIV, 51. Vgl. auch Geldner Ved. Stud. II, 185.

110 Bṛhad Ār. Up. III, 6.

111 Als einer der Fälle, in denen man von weiter gehendem Gelingen sprechen darf, sei Bṛh. Ār. Up. IV, 3, 23 ff. (S. 180) hervorgehoben. Unter den Ansätzen zum Fortschritt in dialogischer und dialektischer Kunst verdienen hier noch die Belehrungen des Prajāpati an Indra hervorgehoben zu werden (Chānd. Up. VIII, 7ff.). Da ist in der Tat, wenn auch eckig genug und am Schlub des Ganzen völlig versagend (S. 146), etwas von unvollkommener und dann immer vollkommener werdender Unterweisung vorhanden, von Zweifeln und Einwänden des Belehrten, die den Lehrer vorwärts treiben.

112 Chānd. Up. V, 12 ff. 
113 Bṛh. Ār. Up. III, 1ff., vgl. oben S. 165.

114 Bṛhad Ār. Up. IV, 3, 23 ff. Zum Inhalt vgl. oben S. 91. Es sei daran erinnert, daß dieselbe Neigung zu Wiederholungen sich unverändert auch noch in der hieratischen Prosa des alten Buddhismus erhalten hat. Vgl. meinen „Buddha“, 6. Aufl., S. $204 \mathrm{ff}$.

115 Eine andre Redaktion derselben Stelle s. oben S. 91. Beide gehören verschiedenen Sammlungen von Textstücken an, die dann zu einer Upanishad vereinigt sind (vgl. oben S. 152).

${ }^{116}$ Nicht tajjalān. Böhtlingk Ber. Sächs. Ges. d. Wiss. 1896, 159f.; 1897, 83 urteilt offenbar zutreffend. Die Gegenbemerkung Deussens, Allg. Gesch. der Phil. I, 2, 164, trifft vorbei. - Den Geheimausdruck tadvanam (Kena Up. 31) versucht Hopkins Journ. Am. Or. Soc. XXII, 362 zu deuten.

${ }^{117}$ Bṛh. Ār. Up. IV, 3, 18f. Dann das. II, 4, 7 f.

${ }^{118}$ Ich verweise auf meine "Literatur des alten Indien" S. $24 \mathrm{f}$.

110 Bṛh. Ār. Up. V, 2; dann das. II, 2.

${ }_{120}$ Wie die Verse von Erzählungen und die belehrenden Verse als etwas Gleichartiges empfunden wurden, sieht man deutlich Aitareya Brāhmaña V, 30, wo ganz in gleicher Linie zuerst zwei Verse über die Bedeutung gewisser Opferriten angeführt werden, dann ein Erzählungsvers aus der bekannten Geschichte vom Lotosdieb (vgl. zu diesem meine Bemerkung, Nachr. Gött. Ges. der Wiss. 1911, 464 A. 2).

${ }^{121}$ Bṛhad Ār. Up. IV, 3, 10 f., dann IV, 4, $7 \mathrm{ff}$.

122 Simmel, Hauptprobleme der Philosophie $13 \mathrm{f}$.

12.3 In diesem Satz und den weiter anschließenden Bemerkungen bezeichne ich meine Stellungnahme zu Auffassungen, für die zu verweïsen ist auf Deussen, Vedānta und Platonismus im Lichte der Kantischen Philosophie S. 11, vgl. denselben, Allg. Gesch. der Phil. I, 2, $208 \mathrm{ff}$., Sechzig Upanishad's 415; Oltramare I, 89 (s. auch 137 A. 1); Prabhu Dutt Shāstrī, The Doctrine of Māyā 63. Von andern Stellen der Upanishaden als der im Text besprochenen (Bṛh. Ār. II, 4, 5) kommt vor allem Kaush. Up. III, 8; Ait. Up. III, 3 in Betracht. Meines Erachtens handelt es sich da einerseits nur um die Behauptung eines Zusammengehörens, man kann etwa sagen eines Ineinanderverwobenseins von Sinnesorganen und $\mathrm{Ob}-$ jekten, Denksubstanz und Gedachtem. („Jene zehn Wesenselemente beziehen sich auf das Erkennen, und die zehn Erkennenselemente beziehen sich auf die Wesen. Denn wenn die Wesenselemente nicht wären, wären die Erkennenselemente nicht, oder wenn die Erkennenselemente nicht wären, wären die Wesenselemente nicht". Kaush. Up.). Man steht da dem Stil des Phantasierens noch nicht sehr fern, der sich z. B. im Schöpfungsbericht der Ait. Up. kundgibt. Der Ātman bebrütet den Mann, den er aus den Wassern herausgeholt hat. Da spalten sich dessen Augen; aus den Augen entspringt das Gesicht, aus dem Gesicht die Sonne. 
Ebenso aus den Ohren das Gehör, aus dem Gehör die Weltgegenden u. s. f. Wenn dann aber an den angeführten Stellen alles weiter auf die Grundmacht, den Ātman, zurückgeführt wird - mag der nun als "Atem“ (prāna), „Erkennen" (prajñāna), „Erkennens-Selbst" (prajñătman), „Brahman" benannt werden -, so ist das nichts andres als die geläufige Behauptung mystischer Zentralität des Ätman: er ist der Erkenner von allem, wie er auch der Wirker ist, der Geher, der Empfinder von Geschlechtslust; ihm ist alles durch mystische Bande verbunden; er lenkt alles; er ist alles; er ist „Wonne, nicht alternd, unsterblich" (Kaush. Up.). Man tut dem altertümlich chaotischen Denken, das etwa in diesen Sätzen wiedergegeben werden kann, zu viel Ehre an, oder auch man tut ihm Gewalt an, wenn man darin die erkenntnistheoretische Einsicht findet, daß, „les phénomènes du monde sensible se résolvent en processus exclusivement intellectuels et subjectifs", „les objets de la connaissance n'existent qu' en tant qu'ils sont connus par l'ātman" (Oltramare). Ich kann mir nicht versagen, hier noch auf die treffenden Bemerkungen hinzuweisen, die vor kurzem ein indischer Forscher gemacht hat: V. A. Sukhtankar, Wiener Zschr. f. d. Kunde des Morgenl. XXII (1908), 134 Anm. 1.

124 Es ist bezeichnend, daß die entscheidenden Ausdrücke der in Rede stehenden Stelle fast wörtlich mit denen eines buddhistischen Dialogs übereinstimmen, wo der König die Königin, die Königin den König fragt: "Ist dir jemand anders lieber als dein eignes Selbst?" Beidemal lautet die Antwort verneinend. Saṃyutta Nikāya vol. I, 75.

125 Über die Stellung Schopenhauers zu den Upanishaden habe ich in meinem Aufsatz "Die indische Philosophie" (Kultur der Gegenwart, 2. Aufl., I, 5, 54f.) gesprochen. Doch war dort von Indischem nicht allein die Upanishadenlehre in Betracht zu ziehen.

126 Über eine einzelne kleine solchc Dichtung, die schon in der älteren Gruppe erscheint, s. oben S. 188.

122 Insonderhejt gilt das vom Grundbestandteil der Upanishad, der als erstes Kapitel (Adhyāya) gezählt wird, während das zweite Zusatz ist. - Ich hebe die altertümlichen Züge der Metrik hervor (s. das von mir ZDMG. XXXVII, 61 beigebrachte), auch die mehrfach (doch nur im ersten Adhyāya) begegnenden zweisilbigen Vokale, den Nom. pl. janāsặ (I, 19). Weiter unten, im Abschnitt über den Buddhismus (S. 298 f.), wird dessen chronologisches Verhältnis zur Kāţhaka Up. wie überhaupt zu den hier besprochenen Upanishaden berührt werden. Anders als ich urteilt über das Alter der Upanishad Garbe, Sāṃkhya-Philosophie 21 A. 1.

128 Siehe den Abschnitt S. 273 ff.

199 Ableitung von samkhyā „die Zahl“. Daß die Benennung dieser Philosophie auf der Vorstellung von Zahl und Zählen beruht, tritt in den Texten deutlich hervor; vgl. Dahlmann, Die Sāṃkhya-Philosophie als 
Naturlehre und Erlösungslehre 39f. An ursprünglich spöttischem Charakter der Benennung (Oltramare I, 223) möchte ich zweifeln. Sāmkhya als „Reflexion" zu erklären, ist verfehlt.

130 Eine Ausnahme würde Āsuri bilden. Doch kann zwischen dem Opferkenner dieses Namens und dem Sāmkhyalehrer zufällige Namengleichheit vorliegen.

181 Śvetāśvatara Upan. V, 2. Daß kapila hier nicht als Name des Lehrers stehe, sondern "rot" bedeute und etwa der Eigenname überhaupt erst nachträglich auf Grund des falsch verstandenen Verses fingiert sei, halte ich für ganz unwahrscheinlich.

${ }_{132}$ Auf brahmanischer Seite erweist sich Asita Devala als ein Mann aus alter vedischer Zeit (s. Macdonell-Keith, Vedic Index I, 48), dessen Beziehung zum Sāmkhya chronologisch undenkbar ist und nur nackt erfunden sein kann. Auf buddhistischer Seite heißt der das gebenedeite Kind besuchende Greis in der ältesten Fassung der Legende und oft auch später nur Asita. Es scheint sich um eine wirkliche Persönlichkeit, den Oheim eines buddhistischen Mönchs zu handeln. Ein zweifellos davon zu unterscheidender Asita Devala, offenbar mit dem vedischen A. D. identisch, wird als Weiser aus ferner Vorzeit genannt (Majjhima Nikāya 93; vgl. auch Jātaka 423. 522). Von ihm hat dann der Besucher des Buddhakindes offenbar den später zu Asita gefügten Namen Devala bezogen. Vgl. noch Jacobi SBE. XLV, 269 A. 1.

${ }^{183}$ Hier sei auf den feinsinnigen Aufsatz von 0 . Strauß verwiesen: Über den Stil der philosophischen Partien des Mahābhārata (ZDMG. LXII, $661 \mathrm{ff}$.$) .$

134 Es ziemt sich hier vor allem der wichtigen Untersuchungen J. Dahlmanns zu gedenken (namentlich „Nirvāna * 1896, in zweiter Linie „Die Sāṃkhya-Philosophie als Naturlehre und Erlösungslehre* 1902), die zwar im Einzelnen zahlreiche, zum Teil schwerste Bedenken erwecken so in der maßlosen Überschätzung des Alters des Epos -, doch im Ganzen vielfach den richtigen Weg gezeigt haben. Daneben ist zu nennen Hopkins, The Great Epic of India (1902, S. 85ff.); Deussen, Allg. Geschichte der Philosophie (I, 3, S. 8 ff.). - Eine durchaus andre Ansicht als die meinige über die Bedeutung der Quellen, von denen die Rede ist, und überhaupt über die Entstehungsgeschichte des Sāmkhya vertreten Garbe (Die Sāṃkhya-Philosophie 1894, vgl. auch Beitr. zur ind. Kulturgesch., 1903, $76 \mathrm{ff}$.) und Jacobi (Gött. Gel. Anz. 1897, 265 ff.). Nach Garbe ergäbe sich, daß die epischen Quellen, „welche der Zeit nach unseren systematischen $\mathrm{S} a \bar{m} \mathrm{kh}$ ya-Schriften vorangehen, der Idee nach denselben Rang nicht beanspruchen können“ (S. Phil. 49). „Das epische, monistische Sāmphya hat sich aus dem dualistischen System, wie es das klassische Sāmkhya bietet, entwickelt und zwar durch Anlehnung an vedāntistische Anschauungen von dem höchsten brahma" (Jacobi a. a. 0. 
273). Der Gegensatz gegenüber diesen Anschauungen der beiden Forscher ist in meiner ganzen Darstellung latent vorhanden und muB sich im wesentlichen aus ihr selbst rechtfertigen. Hier frage ich: hätten Vermischungen des klassischen Systems mit einer anderweitigen Lehre wohl einen, wie man annehmen müBte, so durchaus täuschenden Schein gerade einer Vorstufe jenes Systems hervorbringen können, den Schein eines natürlichen Mittelgliedes zwischen alter Upanishadendoktrin und klassischem Sāmkhya? Müßte das übereinstimmende Auftreten dieses merkwürdigen und so auffallend sich gleich bleibenden Scheins in den teilweise so breit gelagerten Überlieferungsmassen hier der Upanishaden, dort der epischen Abschnitte nicht doppelt und dreifach befremden? Um so mehr, als das Alter der in Frage kommenden Texte der Annahme, daß hier eben kein scheinbares, sondern ein wirkliches Mittelglied vorliegt, stärkste Unterstützung verleiht? Zeigt sich nicht beispielsweise in den auf das Verhältnis von mahãn und buddhi bezüglichen Materialien der älteren Quellen (S. 229f.) der Zustand des klassischen Systems deutlich in seinem Werden aus Ursprünglicherem? $\mathrm{Dab}$ an vereinzelten - ganz vereinzelten - Stellen in dem chronologisch so gemischten, teilweise in recht späte Zeit herabreichenden Wirrwarr des Epos auch klassisches Sāmkhya anzutreffen ist, verträgt sich mit diesen Auffassungen vollkommen. Es wäre geradezu befremdend, wenn derartiges sich nicht fände. Darum aber das klassische $S$. in so ferne Vergangenheit zurückzuverlegen, wie G. und J. wollen, kann ich keinen Grund entdecken.

Bei dieser Gelegenheit möchte ich nicht unterlassen, auch meine Abweichung von der Auffassung Garbes (a. a. 0. 21) zum Ausdruck zu bringen, der von einer in die Zwischenzeit zwischen der älteren und jüngeren Upanishadengruppe fallenden „Beeinflussung des Brahmanismus durch das Sāmkhya-System" spricht. Mir scheint Brahmanismus und Sāmkhya nicht zweierlei, sondern das S. ein wichtigstes, in gradliniger Konsequenz entwickeltes Produkt eben des Brahmanismus. Der obige Satz G.s wäre daher m. E. dahin umzuformen, daß iunerhalb des Brahmanismus die entscheidenden Schritte zur Gestaltung jenes Produkts in der bezeichneten $\mathrm{Zwischenzeit}$ geschehen sind.

${ }_{135}$ Die Grundbedeutung von Guna ist entweder „Faden“ (spezieller der Faden, sofern er mit andern Fäden einen Strick bildet?) oder überhaupt: der Bestandteil eines zusammengesetzten Ganzen, der andern Teilen mehr oder weniger gleichartig ist, sozusagen eine Lage unter andern Lagen bildet. Daher dviguna, triguna "duplex, triplex". Daß aus solchen Zusammensetzungen guna erst nachträglich isoliert sei (Oltramare I, 239 A. 2), glaube ich nicht. Ebenso wenig, dab guna von gunayati „er multipliziert" herkommt (Deussen, Allg. Gesch. der Phil. I, 3, 47f.): nicht viel anders als wollte man "mehr" von "vermehren" ableiten. Der Wiedergabe Dahlmanns (Sāmkhya-Philosophie 50) von G. 
als „bestimmende und gestaltende Eigenschaft” stehen m. E. entscheidende Bedenken entgegen.

${ }^{138}$ Dies hat Oltramare mit Recht bemerkt. Daß mit demselben Forscher (1, 240) Satapatha Br. II, 4, 2, 1 ff. und Atharvaveda VIII, 2, $1 \mathrm{f}$. den Antezedentien der Guṇalehre zuzurechnen sei, scheint mir kaum überzeugend.

${ }^{137}$ Im Epos (XIV, 39, 11) werden ausdrücklich die drei Gunas den „drei Kasten" parallelisiert: und zwar entsprechen die beiden ersten G. den beiden ersten Kasten, der dritte den Ś̉uras. Die Vaiśyas fallen unvermeidlich aus.

138 Maitr. Up. III, 5,

139 Vgl. oben S. 19 ; s. auch die Bemerkungen von Jacobi SBE. XLV, S. XXXIII f.

110 Oltramare I, 244.

141 Maitr. Up. VI, 10.

142 Mahābhārata XIII, 910 ed. Calc.

${ }^{143}$ Daselbst XII, 315, 15 f.; dann XIV, 36, 4 f., wozu Deussen treffend Sāṃkhya-Kārikā 12 vergleicht.

${ }^{144} \mathrm{Ka}$ țh. Up. III, 12. In v. 13 erscheinen allerdings verschiedene als Ätman benannte Wesenheiten, wodurch die Kraft des eben gezogenen Schlusses vermindert würde, kämen nicht andere Bestätigungen hinzu. 145 Anders als in diesem Sinn gelingt es mir nicht, die allerdings schwierige Stelle Maitr. Up. III, 1. 2 zu verstehen, wo meines Erachtens (ebenso nach Deussen, Sechzig Up. 322) gesagt ist, daß der Bhūtātman der Átman (d. h. Purusha) ist, sofern er im Leibe weilend „von den Guṇas der Prakṛti überwältigt ist". Schwerlich darf irre machen, daß dann in $\S 3$ dieser Bhūtātman - allerdings recht befremdlich - vom antahpurusha unterschieden wird. Man sehe weiter, wie IV, 1 die Vereinigung des Bhūtātman mit dem (universellen) Ātman behandelt wird; von einem Geschöpf der Prakṛti könnte so nicht gesprochen werden. So kehrt denn auch, was III, 2 vom Fortgerissenwerden des Bh. durch den Strom der Gunas und von seinem Gebundenwerden gesagt ist, VI, 30 wörtlich auf den Purusha bezogen wieder. Wird nun andererseits VI, 10 als Schöpfer des Bh. ausdrücklich das Pradhāna bezeichnet, so ist das mit der im selben Kapitel belegten Verschiebung auf eine Linie zu stellen, die in Bezug auf den großen Ātman soeben in Rede steht. - Über den Bhūtātman im Epos s. namentlich Deussen Allg. Gesch. I, 3, 63 f.; Hopkins Great Epic 39 ff.

${ }^{146}$ Ich hebe hervor XII, 210, 37; 304, 42; 308, 36. Vgl. auch Deussen, Allg. Gesch. der Phil. I, 3, 55 .

147 So schon Maitr. Up. VI, 10.

${ }^{148}$ In Ühereinstimmung mit dem klassischen System, anders als im Epos (vgl. oben S. 226 Anm. 2) scheinen die Tanmātra den Mahābhūta 
vorangestellt zu werden. Ich schließe das aus Maitr. Up. III, 2; VI, 10. An der letzteren Stelle ist nicht mit Deussen (Sechzig Up. 337 Anm. 2) zu konjizieren. Die Geltung des Terminus visesha hat sich zwischen älterer und jüngerer Zeit geändert (s. Deussen selbst, Allg. Gesch. der Phil. I, 3, 65; Strauß WZKM. XXVII, 265).

149 Mir scheint Deussen (Allg. Gesch. der Phil. I, 2, 219) diesen Zug zu verkennen und zu viel heutige Wohlgeordnetheit vorauszusetzen, wenn er die ursprüngliche Intention des Systems mit den Worten wiederzugeben meint: „Das Eintreten des Ahamkāra oder Ichmacher in die Entwicklungsreihe weist darauf hin und ist nur dann verständlich, wenn in ihm der Übergang liegt von der allgemein-kosmischen zu einer psychischen Evolution."

150 Ein Exemplar einer solchen Kosmogonie ist doch in diese Umgebung geraten (Maitr. Up. V, 2), von der es stark absticht.

151 Maitr. Up. II, 4.

152 das. II, 6; dann Kāțh. Up. V, 9 ff.

${ }^{153}$ Kāth. Up. V, 3 . Im Folgenden: das. II, 22; Maitr. Up. II, 6; Kāțh. Up. VI, 3.

154 Maitr. Up. II, 7. Im Folgenden: das. II, 6; VI, 10.

155 Daselbst II, 5. „Der in jedem Menschen ist": pratipurushah (ebenso V, 2). Man wird hier purusha in unphilosophischem Sinn nehmen und doch vielleicht empfinden, $\mathrm{dab}$ hier ein Anknüpfungspunkt für die Umwandlung des einen universellen Purusha in die Vielheit der Einzel-

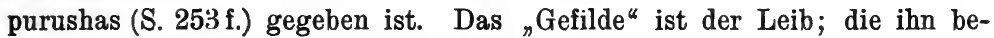
seelende Emanation des Purusha ist „Kenner des Gefildes." - Es folgt das. VI, 10 (die älteste Spur der Vorstellung des Linga finde ich in Brh. Ār. Up. IV, 4, 6); II, 7; Mahābhārata XII, 217, 12; Maitr. Up. VI, 30; III, 2. 3.

156 Maitr. Up. IV, 2. Dann I, 3. 4; Mahābhārata XII, 309.

157 Maitr. Up. IV, 4 (in suyuktah ,wollangespannt" liegt offenbar Beziehung auf Yoga). Dann Kāth. Up. II, 23; Maitr. Up. VI, 30.

158 Maitr. Up. VI, 10.

159 VI, 30. Dann Mahābhārata XII, 307, 28. . Die Kārikāzitate anzugeben scheint unötig.

160 XII, 352.

${ }^{161}$ Dies Motiv hebt Oltramare I, 251 hervor.

162 Yogavāsishţha, zitiert von Vijñānabhikshu zu Sāṃkhyasūtra II, 34.

163 Vgl. Anm. 85 und oben S. $141 \mathrm{f}$.

164 Siehe meine Note zu Rgveda X, 72, 3.

165 Śvetāśvatara Up. VI, 13.

166 Daselbst II.

167 Maitr. Up. VI, 25.

168 Ich verweise auf die vortrefflichen Ausführungen von Oltramare I, $322 \mathrm{ff}$. 
${ }_{180}$ II, 10. Im Folgenden Maitr. Up. VI, 20. 21; Bhag. Gītā VI. 13; Kāth. Up. IV, 1; Maitr. Up. VI, 10; Kāțh. Up. II, 15. 17; Maitr. Up. VI, 22.

170 Kāțh. Up. III, 13. Daß das „Ruheselbst" auf das materielle Prinzip (Avyaktam, Prakṛti) zu deuten sei. bezweifle ich. Wie käme das zu diesem Namen? Der späteren Sāmkhyaanschauung würde jene Deutung freilich entsprechen; das oberste Produkt der Prakrti wird in dieser absorbiert. Aber an der hier in Rede stehenden alten Stelle wird das "Grobe Selbst" noch als Ausfluß des Purusha zu verstehen (S. 229) und eben dieser mit dem "Ruheselbst" gemeint sein. Maitr. Up. V, 1 scheint das zu bestätigen.

171 Śvet. Up. II, 11. Im Folgenden: Kãțh. Up. II, 12; Maitr. Up. VI, 34 ; Śvet. Up. II, 13.

${ }^{172}$ Mahābhārata XIII, 40. 41 ed. Calc.; vgl. dazu Hopkins JAOS. XXII, 359 .

${ }_{178}$ Maitr. Up. VI, 34. Dann Kāṭ. Up. VI, 17; Maitr. Up. VI, 20 21. 22.

174 Edv. Lehmann, der Buddhismus als indische Sekte, als Weltreligion $46 \mathrm{f}$., offenbar unter Einfluß von Jacobi's Aufsatz „der Ursprung des Buddhismus aus Sāmkhya-Yoga". - Über die Kausalitätstheorie des klassischen Yoga s. Tuxen, Yoga $94 \mathrm{f}$.

${ }^{175}$ In der Terminologie des klassischen Yoga betrifft bekanntlich die hauptsächlichste Abweichung vom Sāmkhya die Benennung des Denkorgans, das im Y. citta heißt (vgl. die Materialien bei Deussen, Allg Gesch. der Phil. I, 3 S. 552f.). Gegenüber der komplizierteren Analyse des Sāmphya haben wir hier, scheint es, die einfache, naturwüchsigere Auffassung. Würde sich die im Y. durchgesetzt haben, wenn dies System von Anfang an den Sāṃkhyastandpunkt eingenommen hätte? Man möchte meinen, $\mathrm{da} B$ die Differenz eben hier auftritt, weil gerade an dieser Stelle der Yoga von altersher eine eigene, fest bestimmte Ausdrucksweise besessen haben wird Bezeichnungen dagegen, die ihm fehlten oder bei ihm minder fest gewurzelt waren, konnten leicht früher oder später aus dem Sāmkhya, infolge des diesem zukommenden wissenschaftlichen Prestige, übernommen werden.

126 Hierüber mehr unten im Abschnitt über den Buddhismus.

127 Dies hat schon Senart (Album Kern 104), mir scheint zutreffend, bemerkt. Doch bleibe ich skeptisch, wenn dieser Forscher speziell von "vishnuitischem Yoga" her jenen Ausdruck zum Buddhismus (s. das weiter im Text von mir Gesagte) gelangt sein läßt. Ich habe diesen Punkt im Arch. für Rel. wiss. XIII, $579 \mathrm{f}$. berührt und komme hier nicht darauf zurück. - Dem Gebrauch dets Ausdrucks Nirvāṇa mag im klassischen Sāmkhya und Yoga neben dem Moment, daß die Vorstellung des „Verwehens" diesen Systemen an sich kaum sympathisch gewesen sein kann, eben die Beliebtheit des Worts bei den heterodoxen Sekten entgegengewirkt haben. 
${ }^{178} \mathrm{DaB}$ in der Behandlung dieser Frage J. Dahlmann vorangegangen ist (s. oben Anm. 134), sei hier gebührend hervorgehoben.

${ }^{178}$ Für die Jainaliteratur vgl. namentlich F. Otto Schrader, Über den Stand der indischen Philosophie zur Zeit Mahāvīras und Buddhas. Für das Epos: Deussen, Allg. Gesch. der Philos. I, 3, S. 34 ff., 74 ff.; O. Strauß, Ethische Probleme aus dem Mahābhārata, Giorn. della Soc. Asiatica Ital. XXIV, namentlich S. $226 \mathrm{ff}$.

${ }_{180}$ Die beiden ersten Zeilen sind der Kățaka Up. entlehnt, wo sie vom Ātman stehen.

181 Einstweilen ist hier namentlich auf den lehrreichen Aufsatz von Jacobi zu verweisen: The Metaphysics and Ethics of the Jainas. Transactions of the Third Intern. Congress for the History of Religions II, $59 \mathrm{ff}$. 182 Die direkte Bezugnahme anf mehrere Upanishaden, die Walleser, Philos. Grundlage des älteren Buddhismus 67, in einem altbuddhistischen Text findet, scheint mir in der Tat nicht vorzuliegen.

${ }_{18 s}$ Man erinnere sich an das oben S. 154f. Gesagte.

${ }^{184}$ Vgl. hier und zum Folgenden meinen „Buddha“, 6. Aufl., 194; Sutta Nipāta III, 9.

185 So kann ich - wohl mit Übereinstimmung mit den meisten Beurteilern - mich dem Urteil von Hopkins (Journ. Am. Or. Soc. XXII, 336 A 1; ähnlich in neuester Zeit Rapson, Ancient India 181) schlechterdings nicht anschließen: „I fail to see any reason for believing that even our oldest Upanishads go back of the sixth century".

${ }^{186}$ Man sehe das Gespräch mit dem Prinzen Pāyāsi (Dīgha Nikāya 23).

187 Âcārānga Sūtra I, 7,1 (Sacred Books of the East XXII, 62).

188 Vgl. hier und zum Folgenden die Nachweisungen in meinem „Buddha“, 6. Aufl., 229. 316. 317. 298 Anm.

${ }^{180}$ Vgl. darüber namentlich Garbe, Sāmkhya-Philosophie 6.

190 Anders Jacobi, „Der Ursprung des Buddhismus aus dem SānkhyaYoga", Nachr. der Gött. Ges. der Wiss. 1896, 55. Nach ihm setzte eine Hauptformel der buddhistischen Dogmatik (die Kauisalitätsformel) Bekanntschaft mit Begründung und Deutung der Einzelheiten voraus, die aus dem Sāṃkhya-Yogasystem zu schöpfen war. „Mit andern Worten, die Lehren des S.-Y. waren in denjenigen Kreisen bekannt, an die sich Buddha richtete." Ich kann mir so wenig J.s Beweisführung wie sein Resultat aneignen. Auch scheint es mir schwer, den eben angeführten Satz mit dem andern - mir allerdings ebenso wenig überzeugenden - desselben Forschers zu vereinen: "Brahmans of learning held aloof from the classes of society to which the new religion (der Buddhismus) appealed" (Sacred Books XLV, XXV, A. 1).

191 Siehe Jacobi's in der vorigen Anm. angeführten Aufsatz.

${ }^{192}$ Ich stimme hier mit der Grundrichtung der Dahlmann'schen Unter- 
suchungen (s. Anm. 134) überein, die nur m. E. die Zusammenhänge als viel zu direkt darstellen und unter den Konsequenzen des a. a. 0. hervorgehobenen chronologischen Irrtums leiden.

${ }^{193}$ Siehe zum Folgenden die Nachweisungen im meinem "Buddha", 6. Aufl., 289. 326. 287. 296.

194 Daselbst 314f. Den oben im Text und an dieser Stelle meines "Buddha " herausgehobenen Worten ( ${ }_{n}$ Wenn nun, ihr Jünger ${ }^{*}$, usw.) geht voran: „Wenn ein Selbst ist, ihr Jünger, möchte dann auch etwas meinem Selbst Zugehöriges sein?" „Ja, Herr." „Oder wenn etwas dem Selbst Zugehöriges ist, ihr Jünger, möchte dann auch mein Selbst sein?" „Ja, Herr". Im Zusammenhang mit dem Folgenden scheint das der positiven Leugnung eines Selbst sehr nah zu kommen; ganz genau genommen spricht es die aber doch nicht aus. In der Regel - wie auch eben bier im weiteren Verlauf - wird der Ausdruck gebraucht, daß ein Selbst „sich nicht erfassen läßt" (Buddha ${ }^{6}, 317$ A. 2); im Gespräch mit dem Asketen Vacchagotta (ebendas. 313) schweigt Buddha ebensowohl auf die Frage "Ist das Selbst?" wie auf die Frage "Ist das Selbst nicht?" So scheint es, daß eine kategorische Äußerung über das Problem eines dem Denken unerfaßbaren, einer jenseitigen Ordnung der Dinge angehörigen Selbst vermieden werden sollte. - Hier weise ich schließlich noch auf den Versuch von Senart (Origines bouddhiques 36) hin, die buddhistische „négation de la personnalité ${ }^{4}$ aus Tendenzen des Yoga zu erklären. Ich kann mich nicht überzeugt bekennen.

195 Siehe meinen „Buddha“, 6. Aufl., 254 A. 1; 232. Dann Dhammapada 383 ; „Buddha" 304.

196 Ebendas. 239f. 206.

192 Den hier vertretenen Auffassungen steht das schon von Otto Schrader, Über den Stand der ind. Philosophie zur Zeit Mahāvīas und Buddhas (1902) S. 4 Gesagte nah. Vgl. auch den inhaltreichen Aufsatz desselben Forschers: On the problem of Nirvāna, Journ. of the Pali Text Society 1904-05, $157 \mathrm{ff}$.

198 „Buddha" 6. Aufl. 297.

199 Ebendas. 320f. Zuerst stimmt Khemā weder dem einen noch dem andern zu, denn „der Erhabene (Buddha) hat es nicht offenbart". Nachher lehnt sie beides ausdrücklich ab: "es trifft nicht zu."

$200 \mathrm{Vgl}$. über die Vorstellung vom Nirvāna als einem Ort meine Nachweisungen „Buddha“, 6. Aufl., 303 A. 1. Natürlich ist das bildlich gemeint, wie ich wegen Franke Dīghanikāya 209 A. 1 bemerke. Nicht bildlich bei den Jainas.

${ }^{201}$ Man vergleiche hier Dahlmann, Nirvāṇa $12 \mathrm{ff} .147 \mathrm{ff}$.

202 Die Materialien habe ich in meinem "Buddha" 1. Aufl., $432 \mathrm{ff}$. gesammelt und dort gerechtfertigt, daB ich upadi $=$ upadhi setze.

${ }^{203}$ Mrs. Rhys Davids Buddhism 171. 
204 Ebenso Dahlmann Nirvāna 143.

203 Wie zuerst Garbe bemerkt hat. Die Sämkhyaformel findet sich S. Kārikā 64 ; in zweiteiliger, vermutlich älterer Gestalt Maitr. Up. III, 2; VI, 30. Für die entsprechende buddhistische Formel s. oben S. 30 כ.

${ }^{206}$ Ich verweise besonders auf Kern, Der Buddhismus I, 470ff., Jacobi, Der Ursprung des Buddhismus aus dem Sāmphya-Yoga (Nachr. Gött. Ges. der W'iss. 1896, $43 \mathrm{ff}$.), und auf die sehr wichtigen Aufsätze von Senart, Bouddhisme et Yoga (Kevue de l'hist. des rel. 42, 34う̆ff.) und Origines bouddhiques (Bibl. de vulgarisation du Musée Guimet, t. XXV, 1907). Vgl. auch meinen Buddha, 6. Aufl, 78ff.; Rhys Davids, The Yogāvacara's Manual, XXff. Die Rolle, die der Ausdruck yogãvacara im Milindapañha spielt, ist bezeichnend. Nicht ganz zutreffend m. E. L. de la Vallée Poussin, Bouddhisme 356.

202 Senart, Album Kern 104: „divers indices qui montrent dans le bouddhisme naissant une secte détachée du tronc antique et puissant du Yoga vishnouite." Betreffs der Rolle, die hier dem Vishnuismus zugewiesen wird, s. oben Anm. 177.

${ }^{208}$ Für das Folgende verweise ich insonderheit auf meinen "Buddha", 6. Aufl., 363; Majjłhima Nikāya 79; Sakkapañhasuttanta (Dïghanikāya vol. II p. 265) vgl. Foucher, L'art gréco-bouddhique I, 492 ff.; Theragāthā 119; Dhammapada 372.

${ }_{209}$ Mehr s. bei Rhys Davids a. a. 0. (oben Anm. 206) XXIf.

${ }^{210}$ Mahābhārata XII, 195̃, 15 (Deussen, Vier philosophische Texte 188, wo die Bedeutung der Stelle nicht zur Geltung gebracht ist). Mit „Überlegung, Sichabsondern, Erwägung " gebe ich der Reihe nach vicāra, viveka, vitarka wieder. Über die Stelle vgl. auch Hopkins Journ. Am. Or. Soc. XXII, 357. Betreffend viveka s. unten Anm. 214.

211 Yogasūtra II, 47. Die entsprechenden buddhistischen Ausdrücke finden sich sehr häufig.

212 Vgl. oben Anm. 175; Senart, Revue de l'hist. des religions 42, 353. - Dieser Übereinstimmung von Buddhismus und Yoga sei noch die schon von Andern bemerkte hinzugefügt: die beiderseitige Vorliebe für das Arbeiten mit dem Begriff des nirodha ("Aufhebung").

213 Wäre hier an die Versenkung des saññavedayitanirodha ("Aufhebung von Vorstellung und Empfindung") zu denken? Vgl. meinen "Buddha", 3. Aufl., 452 f., und s. auch Samy. Nik. IV, 228.

214 Brahmajālasutta, Dïgha Nikāya I, 37 f. - Unzutreffend freilich scheint es mir, wenn Senart (Revue de l'hist. des religions 42, 351) den Ausdruck „aus Absonderung geboren" (vivekaja) in der buddhistischen Formel des ersten jhāna (oben S. 324) als direkten Beweis für Entlehnung seitens des Buddhismus aus dem Yoga geltend macht. Viveka ist $\mathrm{m}$. E. hier nicht, wie S. will - wenigstens nicht ursprünglich - die dem Sämkhya bz. Yoga eigene, dem Buddhismus dagegen fremde "Sonderung" von 
Purusha und Prakṛti. Die buddhistische Formel gibt in ihrem Eingang ausdrücklich eine andre, durchaus glaubliche Deutung jenes Worts: "sich absondernd von Lüsten, sich absondernd von unrechtem Wesen". Die höchste, abschließende Erkenntnis der Gesondertheit von Purusha und Prakṛti kann ja auch kaum schon der ersten, niedrigsten Versenkung zugeschrieben worden sein.

${ }_{215}$ Kern, Der Buddhismus I, 472.

216 Vgl. meinen „Buddha“, 6. Aufl., 125. Der dann zitierte Vers: Theragāthā 104 .

${ }^{212}$ Kann man mit Jacobi (Nachr. d. Gött. Ges. d. Wiss. 1896, 48 f.) den ersten Satz der buddhistischen Kausalitätsformel („Aus dem Nichtwissen entstehen die samskāra $a^{\prime}$, d. h. die aus der Vergangenheit stammenden Dispositionen, die zu neuem Dasein führen und dieses gestalten) als Besitz des Yoga in Anspruch nehmen? Ich habe in meinem „Buddha“, 3. Aufl. 448 Bedenken dagegen geltend gemacht. An sich ist der für die buddhistische Dogmatik so wichtige Begriff der samskãra bekanntlich im Yoga, übrigens auch im Sāmkhya, sehr geläufig. Vgl. „Buddha“ 6. Aufl., $278 \mathrm{ff}$., namentlich 284 A. 1.

218 Vyāsa zu Ys. I, 47 (Tuxen, Yoga S. 171). Dazu Mahābhārata XII, 530 ed. Calc. Buddhistische Versionen: Dhammapada 28; Mahāvagga I, 5, 7 und Parallelstellen (s. Franke WZKM. XXIV, 30 f.). Vgl. noch den nördlichen Udānavarga IV, 4 (La Vallée Poussin, Journ. as. 1912, I, $314)$.

210 Majjhima Nikāya vol. I, $136 \mathrm{f}$.

220 Ebendas. 142. 


\section{Register.}

Für die Hauptbegriffe der Spekulation und Ähnliches ergänze man die Angaben des Registers durch die des Inhaltsverzeichnisses.

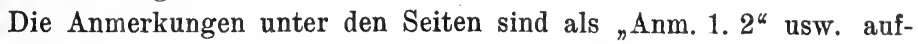

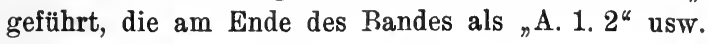

Absolutum: durchweg; hervorzuheben etwa $1.39 \mathrm{ff} .55 \mathrm{ff} .59 \mathrm{ff} .96 \mathrm{ff}$. 114. $115 \mathrm{f} .158 \mathrm{f} .192 \mathrm{ff} .211 \mathrm{f}$. $268276 \mathrm{ff}$. - Im Buddhismus: 303 ff. 332f. - Vgl. Allwesen, Ātman, Brahman, Nirvāṇa, Selbst, Ungestaltetes.

Agni 12f. 23. 66. 75.

ahamkāra 226. 228. 230f. 238. A. 149.

Aitareya Upanishad A. 8.

Ajātaśatru 166.

Ālāra Kālāma vgl. Arāḍa Kālāma. Allwesen vgl. Absolutum, dazu etwa noch 21f. 38. 52. 61f. 131 usw. A. 36.123.

Angelus Silesius 64 .

Arāḍa (Ālāra) Kālāma 220 Anm. 1. 325.

Āranyaka (Waldtexte) 8. 148f. A. 92.

Asita Devala 209. A. 132.

Āsuri A. 130.

Aśvaghosha 220 Anm. 1.

Aśvapati 175.

Atem, Atemkräfte (prāṇa) 18. $52 \mathrm{f}$. 76. 260 f. 321 . A. 16.

Atman: durchweg; hervorzuheben 52ff. 109. 223f. 246. - Der „Große Ātman" 224 Anm. 1. 225f. 228ff. 263. A. 134. 145. 170. - Vgl. Absolutum, Selbst.

Avyakta, vgl. Prakṛti.

Bad 8. 48.

Bāhva 133.

Bakchanten 43.

Begehren 110. 134. 144.

Bettler, religiöse 6. 139. 162.

Beweisführungen 21. 174.

Bhagavad Gìtā 114. 210. 270. 276. 281.

bhakti, Gottesliebe 105. 281. Vgl. 338.

Bhāllaveya 9.

Bhūtātman (Elementenātman) 229. 237 mit Anm. 2. 239. 241. A. 145.

Bindung des Purusha 238 ff. 249. 319.

Brahmacarya, Brahmanwandel $7 \mathrm{f}$. $47 \mathrm{f}$.

Brahman: insonderheit 17. 19. 33. 44 ff. 54 ff. 167. 175 f. 200. 223. 232. 270. 276 ff. 286. A. 12. Vgl. Absolutum, Allwesen, Ātman, Selbst. - Brahman mascul. 103. 106. 126. 143. 192. 286. 330. 334. 
Brāhmaụatexte 15ff. 26. 5̃7.95. 148. 152. 335 .

Brahmanenschüler $6 \mathrm{ff} . \quad 162$. 266 . A. 72 .

Brahmanentum, Brahmanenkaste $4 \mathrm{ff}$. 22. 46. 166 ff. 199 f. 207. 287. 290. A. 134 .

Brahmanopfer 33.

„Brahmanzustände“ 326, vgl. 263. 325.

Bṛhad Āranyaka Upanishad 63. 121. 151. 288. A. 8 usw.

Brihadratha 205.

Bṛhaspati 17. 46 Anm. 1.

Buddha, Buddhismus 2. 114. 117. 120. 131 Anm. 1. 135f. 139 Anm. 1. 143. 150f. 154. 167. 182 Anm. 1. 184 Anm. 2. 190. 209. 222. 259. 264. 268 ff. 273. $282 \mathrm{ff}$. 335 ff. A. 177. 182. 190ff. - Dogma vom Buddha 286. 314. $337 \mathrm{ff}$. - Legenden von seinem Leben 337.

buddhi 225f. 228. 230. 238. 263. budh- 131 Anm. 1. 3.

Chāndogya Upanishad 151. 288. A. 8 usw.

Chronologie Indiens 3f. $284 \mathrm{ff}$. citta 325. A. 175.

da da da 138. 186.

Definitionen 160.

Determinismus 112. 291. 301.

Dialog $160 \mathrm{ff} .210$. 285. A. 111.

Disputationen 9. 165. 172. 291.

Dualismus 60 ff. 192 f. 211 f. 233.246. 294f. $297 \mathrm{ff}$. 304. 315ff. usw. Vgl. Einheit und Vielheit, Sein und Werden.

Durst (in der buddh. Dogmatik) 135. 301 Anm. 2. 302.

Eckhart, Meister 195. 198.

Einheit und Vielheit 60 ff. 84 ff. 92 f. $212 \mathrm{ff}$. 228. $253 \mathrm{ff}$. usw. Vgl.
Dualismus.

Elementenātman vgl. Bhūtātman. Entfaltung der Welt im Sāmphya 213. $225 \mathrm{ff}$.

Epos, episches Sāṃkhya 210f. 224. 226 Anm. 2. 228f. 233 Anm.1. 239. 242. 250. 254. 259. 266. 270. 273. 289. 324. 330. A. 134. 179.

Erkennbarkeit des Absoluten $132 f$. $292 \mathrm{ff} .303 \mathrm{ff}$.

Erlösung 34. 124 ff. 154. 242 ff. 256 ff. 267 ff. 300.304 ff. usw.

"Esser" und „Speise" 237. 247.

Farben 70. 215.

Flammen, Rede von den 306.

Fluida vgl. Kräfte.

Gārgī 64. 75. 121. 130. 132. 172.

Gārgya 166.

Gauḍapāda 89. 136.

Gcdanke, seine magische Wirkung $36 \mathrm{f}$.

Genießer 237. 247. 277.

Geographischer Schauplatz 3f. 165 Anm. 1. $283 \mathrm{f}$.

Gespenster 26.

"Gestaltetes", ${ }_{n}$ Gestaltungen ".296ff. 305 Anm. 1.

Gleichnisse 72. 82f. 8j f. 93. 127. 137. 161. $182 \mathrm{ff}$. 235. 245. $248 \mathrm{f}$. 251 f. 257 f. 330 usw.

Gnadenwahl 245. 339.

Gott 259. 264. 270. 273 ff. 328. 337. - Götter 12 f. 16 f. 37 f. 66.80. - Gottheiten, physische 18.24f. 157.

Götterweg 106. 145. A. 54.

Gottesliebe vgl. bhakti.

Grammatik 171f.

Guna's (Konstituenten), die drei 71. 128. 206. 214 ff. 227 f. 233 . 238 f. 316 f. A. 135.137.

Halluzinationen 147. 264. A. 85. 
Vgl. Visionen.

\section{Hara 278.}

Heiligkeit 46f. $137 \mathrm{ff}$.

Henotheismus 38 .

Himmelswelt, Himmelsseligkeit 26. 32. 143 f. A. 88 .

Hinausziehen 139 Anm. 1. 285.

Höllenstrafen 26. 111.

Hypnose 260f. 262. 264. 266.

Ichprinzip vgl. ahamkāra.

Indien, Volkscharakter 4. 39f. 124.

Indra 12f. 17. 38. 75. 96. 99. $146 \mathrm{f}$. 168f. 175.266.

Iran 4.

iśa, iśvara 275 f. 279.

İsā Upanishad 188. A. 8.

Jahr 18.

Jaiminīya Upanishad Brāhmaṇa A. 8. Jainas 120 Anm. 1. 167. 271. 273. 282. 289f. 293. 329. A. 179. 181. jalān 160. 181.

Janaka 164f.167Anm.1.168 Anm.183. Jātakas 108.

Jenseits, Jenseitiges vgl. Absolutum. jhina 321f. 324. A. 214.

Kāla 18 Anm. 1. 44.

Kant 73 Anm. 2. 195 f.

Kapila 208f. 214. 284. 336.

Kapilavatthu 284.

Karman (Werke) 30. 34. 108 ff. 12 l. $128 \mathrm{ff} .134$. 137 f. 175. 201. 286. 292. 308 .

Kaste 4. 23. 214. 216. 334.

Kāthaka Upanishad 203ff. 210. 220. 228 ff. 242. 269. 288f. usw.

Kausalität, Kausalitätsformel 135. 268. 287. 300 ff. 305. 316. 323. 331. 339. A. 190.

Kaushitaki Upanishad 144 Anm. 1. A. 8.

Kena Upanishad A. 8.

Keśin Dārbhya 10.

Keuschheit 7. 47.
Khemā, Nonne 308. A. 199.

Klassifikation der Weltmächte $22 \mathrm{f}$.

kleśa 328.

Könige $163 \mathrm{ff}$. Vgl. Kshatriyas.

Konzentration vgl. Versenkung.

Kosmogonie vgl. Schöpfung.

Kräfte, unpersönliche; magische Substanzen 11 f. 16 f. 19. 38. 46. $48 \mathrm{ff} .218$.

Krishna 2. 100. 167 Anm. 2. 281. 337.

Kshatra 19. 48. 193. A. 12.

Kshatriyas $166 \mathrm{ff}$., vgl. Könige.

Kshurikā Upanishad 270.

Kunst, buddhistische 140. 340 .

Kuru 16 .

Lehrer 6. 150. 161. 281.

Lehrerlisten 150. A. 93.

Leiden, vgl. Pessimismus.

Linga 238f. 25̆1. 319.

Magadha 283.

Mahābhārata vgl. Epos.

Mahān Ātmā = Großer Ātman, s. unter Ātman.

Maitrāyaṇa Upanishad 205ff. 209 Anm. 1. 240. 247. 249. 253. 269. 289. usw.

Maitreyī 91. 93. 101 Anm. 1. 118. 139 Anm. 1. 146. 163. 197. A. 89. Makkhali 292.

Mana $49 \mathrm{f}$.

manas 225f. 227 Anm. 228. 238. 263. 266.

Māṇụūkyakārikā vgl. Gauḍapāda. Manu 131.

Māra 100. 117. 118 Anm. 3. 289. 314.

Märchen 170.

Materie, materielles Prinzip 68. 78. Vgl. Prakṛti.

Māyā (Schein, Zauberspiel) 85. $88 \mathrm{ff}$. 99 Anm. 1. 136. 279 f. Vgl, auch 90 Anm. 1.

Milindapañha 312. 
Modi des Spinoza 88. 94.

Mokshadharma 210.

Mond 107.

Mrityu vgl. Todesgott.

Mystik 43f. 102. 125. 133.195.198ff. 272 usw.

Naciketas $203 \mathrm{f}$.

Namen und Gestalt 66. 69f. 86 Anm. 1. 98.

Nāłaputta 167. Vgl. 271 Anm. 1. "Nein Nein" 63f. 160. 181.192. 198.

Nichtselbstheit, Rede von ihren Kennzeichen 305 .

Nichtwissen 135. 302. 322f. $328 f$. nirodha 312. A. 212.

Nirvāña 2. 270f. 311f. 318. 321. 324. 326. 329. 332. 338. A. 177. 200.

Nyāya 302 Anm.

Om 37. 142. 156. 192. 262f. 280. Opfer, seine magische Kraft 32.43. 50f. 107 Anm. 1. 138. - Opferwissenschaft $10 \mathrm{ff}$.

Ordensgemeinschaften 285 . $333 \mathrm{ff}$. Orenda $49 \mathrm{f}$.

"Ozeane", die drei 24.

Palidialekt 283.

Pañcāla 165.

Pañcaśikha 209.

Pāyāsi A. 186.

Persönlichkeit des All- Einen? 100 ff. 126. Vgl. Gott. - Elemente der Persönlichkeit 18. 25. - Vgl. Selbst.

Pessimismus, Weltleiden $115 \mathrm{ff} .131$. 199. $239 \mathrm{ff} .247 .248 \mathrm{ff} .268$. 323. 328. A. 66.

Platon 78. 80 Anm. 2. 152.

Plotin 43. 81. 198.

Poesie vgl. Verse.

Pradhāna vgl. Prakṛti.

Prajūpati 24. 44. 49. 51. 83f. 96. 101.116.146.168f.186.274.A.111.
Prakrti (materielles Prinzip, = Avyakta, Pradhāna) 212 und im Flgdn. 279. 316. 319.

Prälogisches Denken $10 \mathrm{f}$.

Prāna vgl. Atem.

pra-vraj 139 Anm. 1.

Prinzipienreihe des Sāmkhya 226f. 296. 302. 316.

Prosa der Upanishaden $178 \mathrm{ff}$.

Purusha 4. 52. 79. 88. 96. 101. 213 und im Flgdn. 223 ff. 233 ff. 278. 318. A. 155 usw. - Purushas pluralisch 219 Anm. 1. 230.253f. 318. A. 155 .

Raikva $163 \mathrm{f}$.

Rajas 214 ff. 239.

Rätsel $186 \mathrm{f}$.

Raum 18. 71 ff. 145.

Rigveda 13. 26. 27 Anm. 2. 29 Anm. 2. 40. 43. 51. 96. 117. 124. 131. 187. 190. 258. 274. $277 \mathrm{f}$. Rudra $278 \mathrm{f}$.

Ruheselbst 263. A. 170 .

Śkvarīgelübde 8 .

samādhi 324.

Sāṃkhya 1f. 128. 193. 206 ff. 258 f. 263. 268 ff. 278. 280 f. 282 . 284. 294 ff. 304.315 ff. 322.324 .328 ff. usw. - Klassisches Sāmpkhya 1f. 128 Anm. 2. 208. 219 Anm. 1. $226 \mathrm{ff}$. 231. 250. $253 \mathrm{ff}$. 312. 318f. A. 134. 177. - Sāmkhya Kārikā 250 f. 254 f. 257 f. 318. samskāra A. 217.

Śāndilya 57f. 62. 126. 181.

Śankara 81. 89. 127 Anm. 2. 133. 184 Anm. 3.

$\Sigma \alpha \varrho \mu \tilde{\nu}{ }^{\prime} \alpha \iota, \Sigma \alpha \mu \alpha \nu \alpha i ̄ \iota 139$.

Sattva 214 ff. 239. 317

Savitar 260

Schaffen, Wesen desselben 82 f.

Schein vgl Māyā.

Schelling 81. 133. 
Schlaf vgl. Tiefschlaf, Traumschlaf.

Schopenhauer 19.. 198. A. 125.

Schöpfung der Welt 66. 68. 69. $78 \mathrm{ff}$. 97103.122.

Schriftgebrauch 179. $289 \mathrm{f}$.

Schüler vgl. Brahmanenschüler.

Scotus Eriugena 64.

Seele, vgl. Ātman, Selbst.

Seelenwanderung 27ff. 105ff. 117.130. 134. 286.

Sein und Werden 60. 194f. 246 f. 297. 331.

Selbst: durchweg; hervorzuheben etwa 24. 33. 35. 42. 44. 54. 91. 294 f. 298f. 304 ff. 331 f. 339. A. 133. Vgl. Absolutum, Ātman, Purusha. Śiva 2. 27õ. 278.

Skepsis 291.

Soma, seine Herabholung 17. Somarausch 43.

Sonne 6 Anm. 1. 66. 99 Anm. 2. 142. 145 Anm. 1.

Sophistik $290 \mathrm{ff}$.

Spinoza 68. 88. 94. 140.

Sramaṇa 139. 200 f. A. 83.

Städte 285. 3:34.

Stoff und Form 61. 68.

Subjekt, Objekt 56. 91 f. 101. 191. 194. A. 123. Vgl. Ātman, Purusha usw.

Substanzen, magische, vgl. Kräfte. Sufismus 198.

Sūrya 66.

svastika 262.

Śvetaketu 162. 182.

Śvetāśvatara Upanishad 205. 269. 273 ff. 289327 usw.

Symbole 20. 24.

Tabu 47. 157.

Tarttirìya Upanishad A. 8.

Tamas $214 \mathrm{ff}$. 239.

tanmátra 226. 232. A. 148.

Tapas (Kasteiungen) und Verwand- tes 6. 43. 49. 129. 205. $259 \mathrm{ff}$. 327. 337. A. 72.83.

Tattva (des Sāmkhya)vgl.Prinzipienreihe.

Tat tvam asi 125. 133. 143. 162. 181. 235. 25 ว́.

Teile des Ātman 127.

Tiefschlaf 91f. 103. 140. 144. 146. 154. 174. 260.

Tiere 10. 30. 71. 110f. 169. A. 3.

Tod und Leben nach dem Tode: hervorzuheben etwa 1.25 . $26 \mathrm{ff}$. 59. 75. 91. 97. $105 \mathrm{ff} .117 \mathrm{ff} .143 \mathrm{ff}$. 154. $203 \mathrm{ff} 211.249 .291$.

Todesgott 203f. 289.

Traumschlaf 140. 147 Anm. 1. 154. 174. 182. 188. 260.

Uddaka 325.

Udgītha $156 \mathrm{f}$.

„Ungestaltetes ' 296, vgl. 303. 313.

Unsterblichkeit vgl. Tod.

Unterscheidung 24j̀f. 317. A. 214. upādi, upadhi, upādhi 312 f. 318.

A. 202.

Upanishaden: durchweg; s. besonders 1. 15 A. 1. 35. 57. 89. $148 \mathrm{ff}$. A. 8. 185. 202 ff. - Vgl. auch unter den einzelnen Upanishaden. upanishad im eigentlichen Sinn 37. $155 \mathrm{ff}$. A. $97 \mathrm{ff}$.

Ushasti 5. 163.

Vacchagotta A. 193.

Varuna 12f. 17. 52.

Vāta 52.

„Väter ${ }^{\star} 26$ ff. 75. 106f. 116. A. 3.

Väterweg 106 f. A. 54.

Vāyu 66.

Vedatexte, ihr Studium, ihre mystische Bedeutung $5 \mathrm{ff} 19.25 .45 \mathrm{ff}$. - Ablehnung durch den Buddhismus 287.

„Verehrung" 37. 41. 57f. 87. 89. 140. $155 \mathrm{ff}$. 164. 173. 175. 184 
Anm. 1. A. 98f. 101.

Verfasser der Upanishaden $149 \mathrm{f}$.

Vernunft vgl. buddhi.

Verse 154. 176. 187 ff. 203. A. 120.

Versenkungen 133. 14l f. 263 ff. 309. 320 ff. Vgl. "Vierter. "

Verstand vgl. manas.

Videha 164f. 283.

Vielheit der Âtmans 128; vgl. Purushas pluralisch.

"Vierter" 260.

Vipula 266.

Virocana 168f.

Vishnu 2. 17. 275. - Vishnuismus A. 177. 207.

Visionen 142. 309. Vgl. Halluzinationen.

viveka 317, vgl.324 („Absonderung"). A. 210. 214.

Wahrheiten, die vier des Buddhismus 120. 135. 305. 323. 329.

„Wahrlieb" 162.

Waldtexte s. Áraṇyaka.

Wasser als Grundelement 45 Anm. 1.

Weltgegenden 18.

Weltleiden vgl, Pessimismus.

Weltzweck 76f. 105. 257. Vgl. 114.

Werden und Sein vgl. Sein und Werden.

Wiedertod $27 \mathrm{ff}$. 34. 108. 117. A.3. Wiedervergeltung vgl. Karman.

Wille 80 Anm. 2. - Willensfreiheit vgl. Determinismus.
Wissen, seine Macht 6f. 31 ff. 265 Anm. 1. - Erlösend 34. 129f. 134f. 244 f. 293. 300 f. 320. Vgl. Nichtwissen, Unterscheidung. Verhältnis des Wissens zum Wissenden $6 \mathrm{f}$. 9.

Wonne, Ātman daraus bestehend 102. - Diesseitige und jenseitige Wonne 116.

Xenophon 152.

Yājūnavalkya 9. 63f. 74. 91. 93. 101 Anm. 1. 103f. 109. 118. 121. 125. 128. 130.132 .134 f. $139.144 \mathrm{ff}$. 154. 163ff. 167 Anm. 1. 168 Anm. 1 170, 174 ff. 188. 197. 204. 209. 283. 336. A. 8. 89. 104. Yajurveda 13.

Yoga, Yogin 114. 129. 133. $141 \mathrm{f}$. 192. 209. 232 Anm. 1. $243 \mathrm{ff}$. 258ff. 275. 278. 280f. 282. 296. 316. 319 ff. A. 85. 98. 157. 175 . 177. 194. 206. 212.

Yogasūtras 269. 324. 329.

Yogāvacara A. 206.

Zahlen in den Brāhmaṇas 23; im Sāṃkhyasystem 208.

Zarathustra 4.

Zaubervorstellungen. Hervorzuheben etwa $10 \mathrm{ff} .14$. 22. 31. 39. 49. 56. 113. i26. 138. 149. 171f. 177. 179 191. 206. 218. 265.

Zeit 18. 44. 73 Anm. 2.

Ziege und Ziegenbock (Wortspiel) 213 Anm. 1. 215. 221. 276. 


\section{Quellen der Religionsgeschichte}

herausgegeben im Auftrage der Religionsgeschichtlichen Kommission bei der Königlichen Gesellschaft der Wissenschaften zu Göttingen.

Der Zweck dieses neuen Unternehmens läßt sich kurz dahin angeben, der religionsgeschichtlichen Forschung ein möglichst umfassendes und zuverlässiges Quellenmaterial zur Verfügung zu stellen und damit zunächst für die deutsche Wissenschaft, der heutigen Erweiterung des Horizonts entsprechend, zu leisten, was einst die Sacred Books of the East für die Forschung bedeuteten.

Ein a usführlicher Prospekt über die Anlage des Ganzen und die erschienenen und bis jetzt geplanten Bände ist durch jede gute Buchhandlung, ein genaues Programm von der Rel.-gesch. Kommission der Kgl. Gesellschaft der Wissenschaften in Göttingen zu beziehen.

Soeben ist erschienen:

Prajna Paramita. sischen Quellen von Dr. Max Walleser, Professor in Heidelberg. 1914. Preis geh. 6,60 Mk.; geb. 7,80 Mk.

Diese für die Kenntnis des Buddhismus so wichtige Gruppe von Texten, die unter dem Titel "Die Vollkommenheit der Erkenntnis" vereinigt sind, präzisiert in aller Schärfe den Negativismus, d h. das Prinzip der allgemeinen Leerheit, die Anschauung, daß unsere Begriffe vom Sein ebenso wie vom Nichtsein bedeutungslos sind, daß die Wahrheit des täglichen Lebens nur einen relativen Wert hat, daß die absolute Wahrheit alle Dinge nur als inhaltlosen Schein erkennen läßt. Diese bedeutungsvollen Lehren, denen verwandte in der griechischen und abendländischen Philosophie auch eine große Rolle spielen, werden nicht systematisch, sondern in Gesprächen des Buddha mit seinen Nachfolgern und mit Heiligen entwickelt.

Prof. Dr. M. Walleser hat das Wagnis durchgeführt, die Texte, in denen selbst in dem bildsamen und als philosophische Sprache unvergleichbaren Sanskrit der Gedanke in einem beständigen Kampfe mit dem Wort und Ausdruck liegt, in eine fremde Sprache zu bannen. Dem Verständnis der Texte hat er durch geschichtliche, kritische und bibliographisclic Einleitungen gedient.

Frühere Bände:

\section{Lieder des Rigveda. Übersetzt v. Prof. Dr. A.Hillebrandt. 1913. Geh. 5 Mk.; geb. 6,20 Mk.}

Joh. Hertel im Liter. Zentralblatt 1914 Nr. 12: . . Daraus ergibt sich schon, daß H.'s Übersetzung kein populärwissenschaftliches Buch ist und sein will. Es ist streng wissenschaftlich in seinem Zweck und in seiner Ausführung und berücksichtigt zugleich Indologen und Nichtindologen. Besonders die letzteren werden es dankbar empfinden, daß die Übersetzung, so sehr sie sich die Treue zur Pflicht macht, in gelenkem Dentsch geschrieben ist."

I. v. Schroeder in d. Dtsch. Lit.-Zeitg. 1914 Nr. 3: „Etwa ein Achtel der Rigvedalieder wird hier von einem der besten Kenner des Gegenstandes in deutscher Übersetzung dem an religions-geschichtlichen Forschungen interessierten Publikum dargeboten. Die Auswahl ist, wie nicht anders zu erwarten war, sehr umsichtig getroffen, und zwar ungefähr in demselben Verhältnis auf die einzelnen Götter und Stoffe verteilt, wie dies in der Rigveda-Sammlung selbst der Fall ist. Nur die philosophischen Lieder und die Zauberlieder sind verhältnismäBig stärker berücksichtigt. Die wichtigsten und wertvollsten Stücke der großen Sammlung findet man hier vereinigt, in sorgiältiger Übersetzung, die als das 


\section{Quellen der Religionsgeschichte}

Resultat langjähriger Forschungen gelten darf. Die reichhaltigen Anmerkungen erhöhen den Wert des Buches nicht nur für das weitere Publikum, sondern auch für die engeren Fachgenossen des Verf. Überall tritt die längst schon rühmlich bekannte Eigenart Alfred Hillebrandts zutage, sich nichts zu ersparen an tiefdringender, gründlichster Durcharbeitung des Stoffes. Das zwingt zum Respekt auch dort, wo wir vielleicht anderer Ansicht sein mögen."

\section{Dighanikaya. Das Buch der langen Texte des buddhistischen}

R. Otto Franke, Kongs Jerg.

Lit. Zentralblatt 1914 Nr. 15: „Für die Religionsyeschichte ist es wohl ausschlaggebend, daB der Buddhismus Dighanikaya als grundlegend ansieht und Buddhas Lehre darin findet. Die Einleitung geht auch auf die vorhandenen Übersetzungen ein und entwickelt die Grundsätze, die bei der vorliegenden neuen Übersetzung beobachtet worden sind. Dem Texte sind unter dem Strich sehr ausführliche Erläuterungen beigegeben, die den schwierigen Stoff mundgerechter machen."

\section{Amida Buddha unsere Zuflucht.}

Urkunden zum

Verständnis des japanischen Sukhāvatī-Buddhismus. Von D. Hans Haas. Mit 12 Abbildungen. 1910. Geh. 6 Mk.; geb. 7,20 Mk.

v. Orelli, Theol. Literaturbl. 1911, 5: „Es sind Schriften der obengenannten Meister und ibrer Jünger vorhanden, aus welchen D Haas eine Auswahl getroffen hat, die ein lebendiges Bild der Gedankenwelt und Sinnesart derselben vor uns entstehen läßt. Die Richtigkeit und Treue der Übersetzung, welche sich flüssig liest und den Leser modern anmutet, kann Ref. nicht beurteilen. Doch spricht dafür im allgemeinen die Sachkenntnis und Sorgfalt des Herausgebers und der Beistand seiner japanischen Mitarbeiter. Der erstere hat auch zahlreiche Anmerkungen zur Verdeutlichung der Texte beigefügt. Von zwei japanischen Gelehrten hat er kurze Skizzen über die Jodo- und die Jodo-ShinSekte vorausgeschickt. So hat D Haas mit diesem formell auch tadellos ausgestatteten Buche dem religionsgeschichtlichen Studium und der Religionsvergleichung wieder einen vorzüglichen Dienst geleistet auf diesem Gebiete, dessen Quellen den europäischen Lesern noch größtenteils verschlossen waren."

\section{Die Religion der Eweer in Süd-Togo. Von D.} Missionar der Norddeutschen Missionsgesellschaft. 1911. Geh. 10 Mk.; geb. 11,20 Mk.

\section{Die Religion der Batak.}

Ein Paradigma für animistische Religionen des indischen Archipels. Von Lic. Joh. Warneck, Missionsinspektor in Barmen. Mit 4 Abbildungen. 1909. Geh. 5 Mk.; geb. 6,20 Mk.

Gemeinsamer Verlag der Firmen: J. C. Hinrichs'sche Buchhandlung, Leipzig und Vandenhoeck \& Ruprecht, Göttingen.

Den Verkehr mit dem Buchhandel besorgen Vandenhoeck \& Ruprecht. 

Idenberg, Hermann

Die Lehre der Upanishaden

nd die Anfange des Buddhismus

PLEASE DO NOT REMOVE

CARDS OR SLIPS FROM THIS POCKET

UNIVERSITY OF TORONTO LIBRARY 
